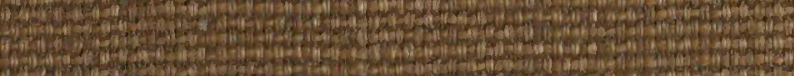

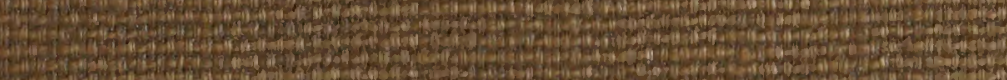

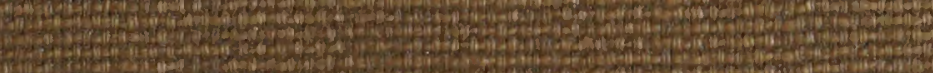
25

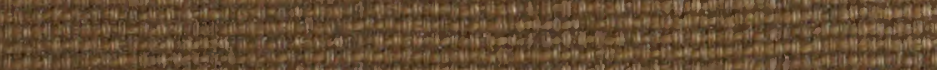
Q5.5.

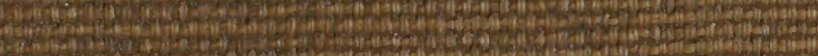
What

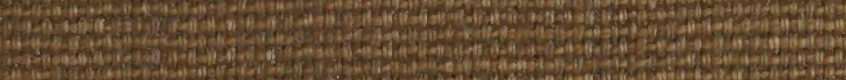
30. 195. - 7 (1) 515 (3) 140 n Wa We

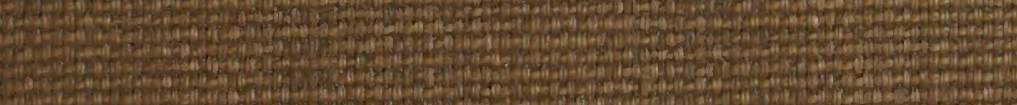
D.

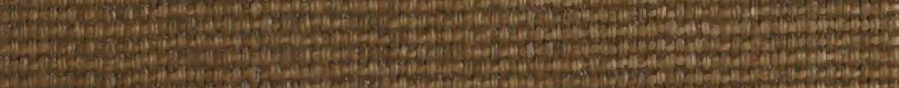

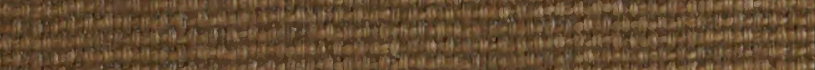

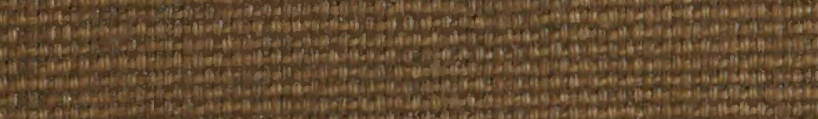
S. 19.45 H. 


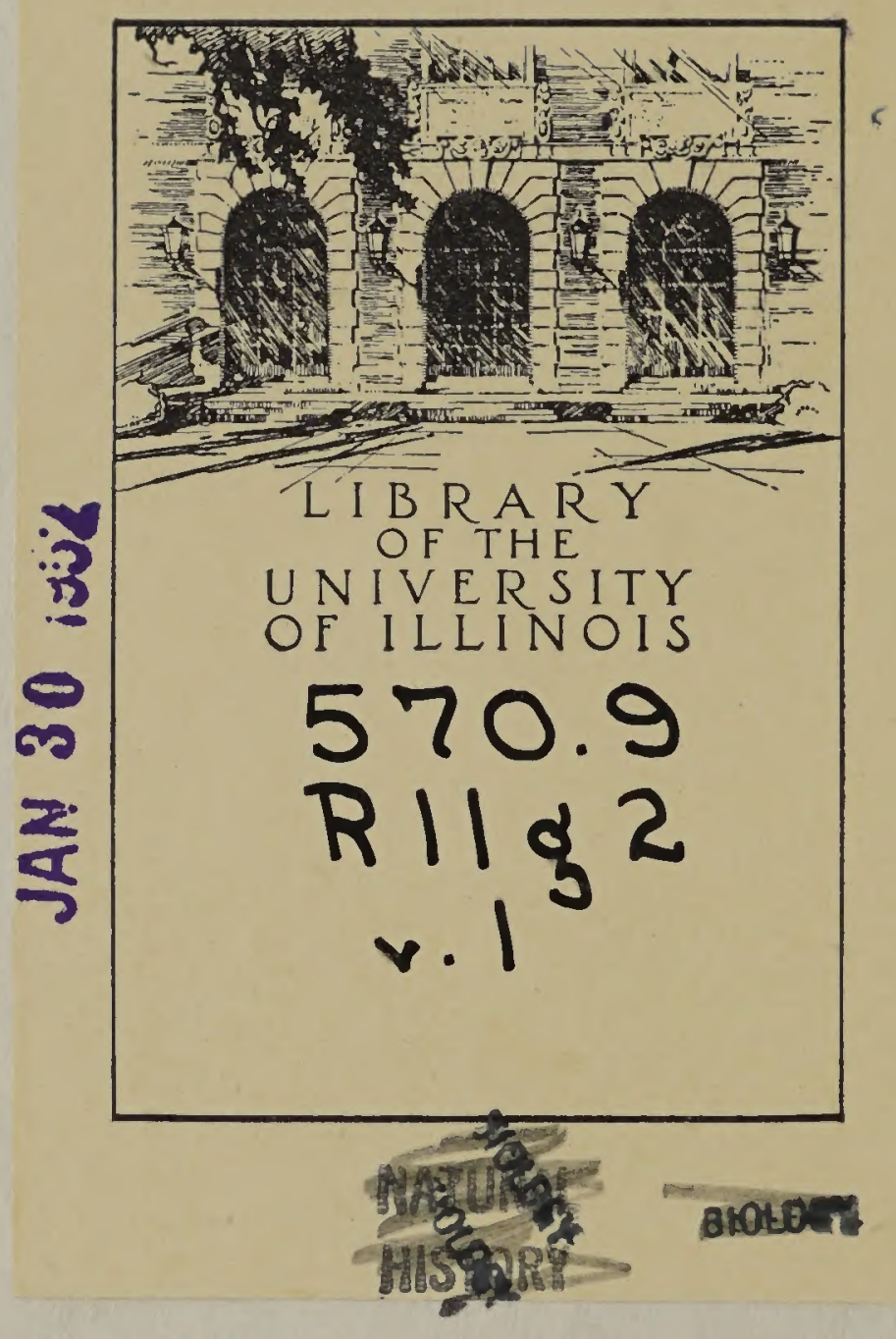


Return this book on or before the Latest Date stamped below.

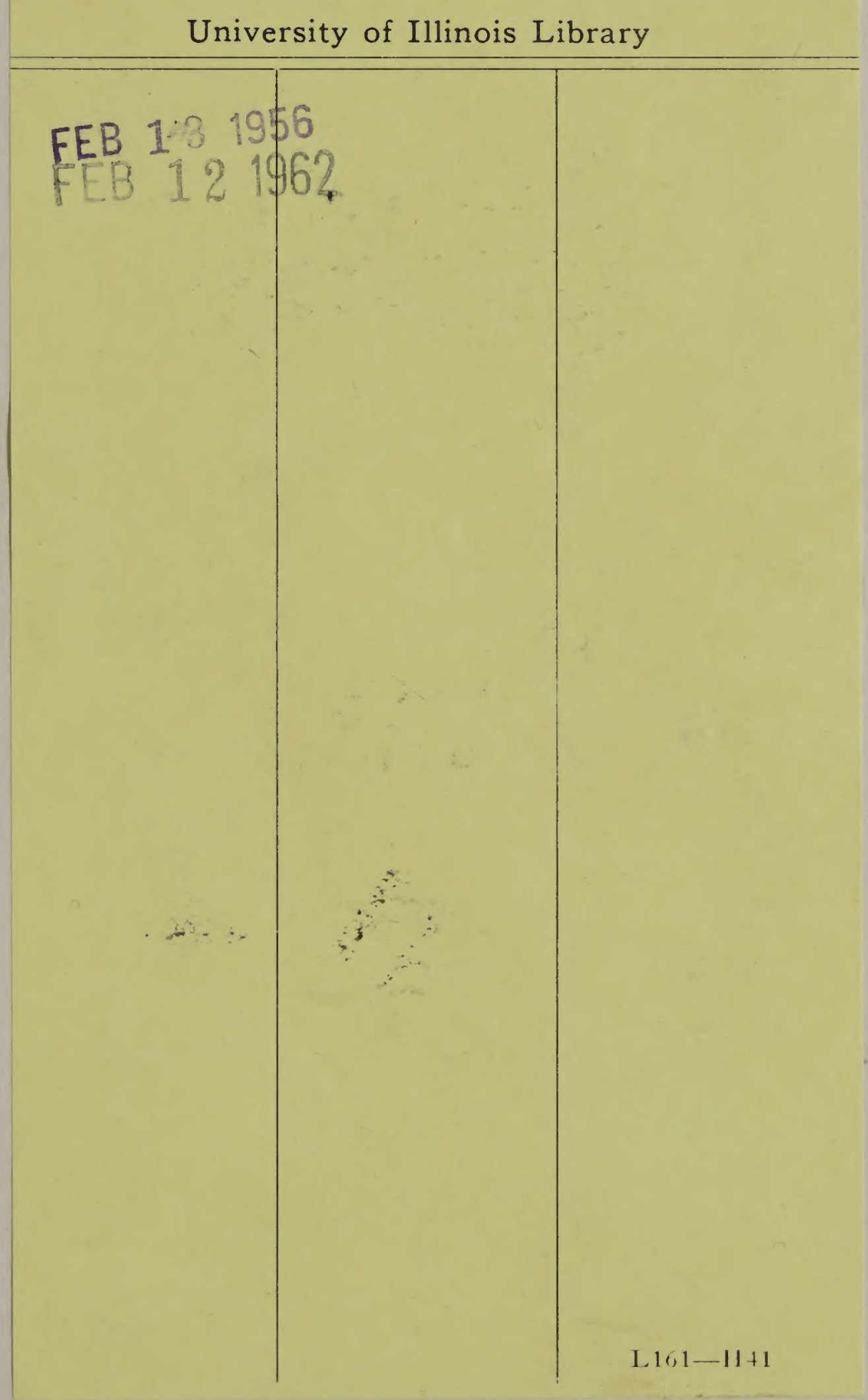





MAR 41935 



\title{
GESCHICHTE
}

DER

\section{BIOLOGISCHEN THEORIEN IN DER NEUZEIT}

VON

\author{
DR. EM. RÁDL
}

I. TEIL

ZWEITE GÄNZLICH UMGEARBEITETE AUFLAGE

LEIPZIG UND BERLIN VERLAG VON WILHELM ENGELMANN 
Alle Rechte, insbesondere das der Übersetzung, vorbehalten. 


$$
\begin{aligned}
& 570.9 \\
& T 11 g 2 \\
& v .1
\end{aligned}
$$

\title{
Prof. WALTHER MAY
}

\author{
IN KARLSRUHE
}

GEWIDMET 



\section{VORWORT.}

Vor 8 Jahren erschien die erste Auflage dieser Schrift, seit der Geschichte der Zoologie von G. CARUS (1876), die übrigens andere Tendenzen verfolgte, der erste umfangreichere Versuch um die historische Erfassung der biologischen Probleme. Die Naturforscher waren der historischen Erforschung der Wissenschaft wenig gewogen; vom Aufbau der positiven Grundlagen der Wissenschaft eingenommen und vom Wahne befangen, daß die eigentliche biologische Forschung erst seit DARWIN zu datieren sei, fanden sie keine Zeit für eine Vertiefung in die wissenschaftliche Vergangenheit. In der letzten Zeit scheint sich eine der historischen Forschung günstigere Stimmung auch unter den Biologen $\mathrm{zu}$ verbreiten; die Tatsache, daß diese Schrift trotz ihrer Unvollkommenheiten in zweiter Auflage erscheinen kann, spricht deutlich dafür.

Durch konkrete Probleme zum Nachschlagen in den Schriften Cuviers, GEOFFroys, Goethes geführt, entdeckte ich zu meiner Überraschung, daß diese Gelehrten andere Lehren vertreten haben, als ihnen von den Darwinisten in den Mund gelegt werden, und, was mir noch wichtiger erschien, daß ihre Entdeckungen und Hypothesen einer geschlossenen, vernünftig begründeten Grundanschauung entstammen, die zwar von der heute gültigen verschieden, sonst aber durchaus möglich und äußerst beachtenswert ist. Es wurde mir klar, daß der Geschichtschreiber eine Reihe von verschiedenen Weltanschauungen in der Vergangenheit der Biologie unterscheiden muß, von denen jede ihren besonderen Inhalt, ihre eigenen Ziele, Wahrheiten und Werturteile besitzt.

Die Erkenntnis, daß die Geschichte der Biologie in einer Abwechselung von verschiedenen Systemen besteht, von denen jedes die Berechtigung in sich selbst enthält, stimmt nicht mit der leitenden Idee der modernen wissenschaftlichen Geschichtschreibung überein. Der Naturforscher von heute erblickt in seiner Wissenschaft, in seinem Tatsachenmaterial, in den jetzt eben anerkannten Theorien den absoluten Maßstab für die Biologie aller Zeiten; er zwingt ferner die vielgestaltigen Begebenheiten der Geschichte der Wissenschaft in das 
Schema vom Fortschritte der Kenntnisse seit dem Anfang des wissenschaftlichen Denkens; die Fülle des wissenschaftlichen Lebens stellt er sich als einen ununterbrochenen, mit der Zeit je weiter desto mehr anschwellenden Strom vor, in dem es keine Ruhe, keine in sich geschlossenen Abteilungen, in dem es nichts gibt, das an und für sich Wert hätte; jedes an sich farb- und formlose Element des Stromes eilt vorbei, und nur die von demselben erlegte Strecke und seine Geschwindigkeit interessieren den Historiker. Jeder wissenschaftlichen Erscheinung wird nach dieser Geschichtsphilosophie nur ein relativer Wert zugeschrieben: die Wahrheit schwebt da über den Köpfen der Einzelnen, schreitet dahin, unbekümmert um das Schicksal der Forscher, die nur als Fortsetzer und Vervollkommner des Früheren oder als Vorläufer und Bahnbrecher des Kommenden, nicht als Eigentümer, vielmehr nur als Träger der unpersönlichen Wahrheit vorgeführt werden. Jede wissenschaftliche Erscheinung besitzt nach dieser Weltanschauung nur eine lineare Dimension; mit einem Ende knüpft sie an die dunkle Vergangenheit an, mit dem anderen prophezeit sie die Morgenröte der Zukunft.

In der ersten Auflage dieser Schrift wurde ein unvollkommener Versuch gemacht, einer anderen Geschichtsphilosophie zu folgen, und im zweiten Teil derselben wurde der Versuch weiter ausgeführt; in dieser zweiten Auflage des ersten Teiles habe ich mich bemüht, meinen Standpunkt noch deutlicher zum Ausdruck zu bringen. Ohne die Tatsache des allgemeinen Fortschrittes der Menschheit und auch der Wissenschaft bestreiten zu wollen, halte ich es für ein Schematisieren der frischen Wirklichkeit, die Aufeinanderfolge der wissenschaftlichen Begebenheiten nur vom Gesichtspunkte einer linearen Entwicklung darzustellen, in der Geschichte der Wissenschaft nur eine hegelianisch, eine bloß nach logischen Gesetzen sich entwickelnde Naturerkenntnis zu erblicken. Die Naturforschung stellt eine menschliche Angelegenheit, die Geschichte der Wissenschaft stellt eine Geschichte der menschlichen Schicksale dar; die Wahrheiten, die Entdeckungen, die wissenschaftlichen Irrtümer entwickeln sich nicht auseinander, abgelöst von den Sorgen und Freuden des täglichen Lebens, sondern sind an konkrete Subjekte gebunden, deren individuelle Färbung sie tragen. Die Grundlagen der Wissenschaftsgeschichte sind nicht wesentlich von denjenigen der Geschichte der Politik, der Religion, oder sagen wir (wohl mit Übertreibung), von der Geschichte des Aberglaubens verschieden. Wie nun das Leben jedes einzelnen Menschen, jeder Gemeinschaft von Menschen, jeder historischen Epoche eine einzigartige Erscheinung darstellt und 
sich von allen anderen analogen Erscheinungen qualitativ unterscheidet, nur durch direkte Erfahrung erkannt und niemals aus gewissen allgemeinen Sätzen deduziert werden kann, so besitzt auch jede wissenschaftliche Begebenheit, d. h. jede wissenschaftliche Persönlichkeit (die eine solche wirklich ist), jede wissenschaftliche Tat einen absoluten Wert; dieselbe kann nur anschaulich erkannt und beschrieben, niemals dagegen auf eine Formel restlos zurückgeführt werden; daher stellt dasjenige, was man vom heutigen Standpunkt der Forschung als Geschichte der Wissenschaft vorführt, im günstigsten Falle nur einen blassen Schatten der Wirklichkeit, meistens sogar nur einen Haufen von teils richtigen, teils unrichtigen und mißverstandenen Angaben.

Die Geschichtschreiber der Wissenschaft und die Naturforscher suchen die (objelstive) Wahrheit am Ende der Entwicklung der Wissenschaft, und das wissenschaftliche Leben der Vergangenheit und der Jetztzeit soll nur in einer Art Vorbereitung für die endgültige Entdeckung bestehen. Praktisch hält sich aber niemand an diese Hypothese, sondern ein jeder ist in seinem Herzen überzeugt, daß seine Lehren die endgültige Wahrheit, die Wahrheit an sich bringen; so haben die Darwinisten, so die Naturphilosophen, so Cuvier, Buffon, Galilei usw. geurteilt. Diese natürliche Überzeugung ist auch berechtigt. Gibt es denn außerhalb der strebenden und handelnden Menschen irgend etwas, das man Wahrheit, Wissenschaft, Erkenntnis, Natur, Gesetz nennen könnte? Die Wissenschaft lebt nur in den Menschen und durch dieselben, ist durch ihre persönlichen Eigenschaften begrenzt, sie stellt sogar ebenso eine Eigenschaft des Menschen dar, wie sein Gesicht oder wie sein Knochenbau; ihre Physiognomie verändert sich je nach dem Charakter des einzelnen Menschen oder der einzelnen Epoche. Diese Arten der Wissenschaft, diese mannigfachen Äußerungen des wissenschaftlichen Triebes, die Weise, wie sich jede einzelne wissenschaftliche Begebenheit vom dunklen Chaos der Unendlichkeit abhebt, zu beachten, ist die Aufgabe des Geschichtschreibers.

Diese Philosophie der Wissenschaft stelle ich der Lehre vom Fortschritte des objektiven Wissens entgegen; dieselbe stützt sich auf die realistische Weltanschauung, die in den Romanen F. DostoJEWSKIs den tiefsten Ausdruck fand und für die bei uns T. G. MASARYK gekämpft hat; dieser Realismus (der mit dem Realismus der französischen Schriftsteller fast nur den Namen gemeinsam hat) ist in mancher Hinsicht auch mit der Philosophie NiETzSCHEs verwandt. Realistisch heißt diese Methode deshalb, weil sie Begebenheiten 
zu schildern sich zur Aufgabe stellt; ein PARACELSUS, ein LEONARDo, ein STAHL bildet für sie ein schlechthin gegebenes Objekt (res) und nicht ein bloßes Durchgangsstadium der wissenschaftlichen Wahrheit; sie stellen ein Objekt dar, das nur aus sich selbst begriffen werden muß.

Auch in der Einschätzung einzelner Epochen unterscheidet sich diese Schrift wesentlich von anderen Darstellungen der biologischen Vergangenheit. Man pflegt die *Renaissance der Wissenschaft, d. h. Galilei, BaCon, Descartes und ihr Zeitalter zu preisen, als ob damals zum erstenmal die wahre Methode der Wissenschaft im allgemeinen, also auch diejenige der Biologie entdeckt worden wäre. Wenn es aber auch unzweifelhaft ist, da $ß$ jene Forscher höchst bedeutsame wissenschaftliche Erscheinungen darstellen, so muß man doch ihre Verdienste um die Mathematik, Astronomie und Physik von denjenigen um die Biologie unterscheiden; man muß in Rechnung nehmen, daß jene Forscher gerade durch die Bekämpfung der biologischen Auffassung der Phänomene sich zu ihrem Standpunkt emporgeschwungen haben und $\mathrm{da} \beta$ folglich ihre Errungenschaften auf Kosten der Biologie erreicht waren. Diese Tatsache, da $\beta$ die Interessen der Biologie sich nicht immer mit denjenigen der mathematisch-physikalischen Wissenschaften decken, hat man bisher unbeachtet gelassen; auch von den Biologen wurde ein GALILEI, ein DESCARTES als Begründer der neuen Auffassung des Lebens gepriesen, obwohl an dieselben keine beachtenswertere biologische Idee anzuknüpfen ist.

In der ersten Auflage dieses ersten Teiles der Biologiegeschichte habe ich die hier skizzierten Grundsätze eher geahnt als bewußt befolgt; überdies war ich noch sehr von der herrschenden objektivistischen Auffassung der Wissenschaft befangen. Ich habe mich bemüht, in dieser zweiten Auflage mich dem realistischen Programm mehr zu nähern. In sachlicher Hinsicht unterscheidet sich diese zweite Auflage von der ersten im folgenden: Die Einleitung wurde weggelassen (der Inhalt derselben wird im Schlußkapitel des zweiten Teiles wiederholt), es wurde eine gedrängte Darstellung der Hauptrepräsentanten der klassischen Biologie hinzugefügt und die Schilderung mit der Renaissance begonnen. Das Kapitel über VAN HELMONT wurde eingeschaltet und die Abschnitte über HARvEY und REDI wesentlich erweitert. Die Darstellung der Naturphilosophie, der Lehre LAMARCKs und E. DARWINs soll dagegen erst im zweiten Teile Platz finden, wo sie ohnehin kurz wiederholt werden mußte. 
Daß die Schrift auch in dieser neuen Form viel zu wünschen übrig läßt, ist zweifellos. Wird man sie aber als den ersten Versuch auf einem bisher in dieser Weise noch unbebauten Gebiet betrachten, so wird man auch die vorhandenen Lücken, die scheinbar schroffen Urteile, Schwankungen und Inkonsequenzen richtig einzuschätzen wissen. Daß die Naturforscher der vergangenen Jahrhunderte lebendige Menschen gewesen sind, daß ihre Probleme neben den modernen noch ungelöst fortbestehen, daß wir uns nicht am Ende der wissenschaftlichen Entwicklung, sondern in einem Urwald von Ideen, von denen jede für sich lebt, befinden und schließlich, daß auch die Geschichte der Biologie, als eine selbständige wissenschaftliche Kategorie, auf direkter Erfahrung erbaut werden muß, dies nachzuweisen war das erste Ziel dieser Schrift.

Prof. J. VLAšímSKx́ bin ich zu vielem Dank für ersprießliche Hilfe bei der Korrektur der Schrift verpflichtet.

Prag, im August I9I3.

Dr. Em. Rádl. 



\section{INHALT.}

I. Kapitel. Das Vermächtnis des Altertums und des Mittelalters . . . . . I

I. Hippokrates . . . . . . . . . . . . . . . 2

2. Plato . . . . . . . . . . . . . . 4

3. Aristoteles. . . . . . . . . . . . 6

4. Plinius . . . . . . . . . . . . . . I4

5. Galen. . . . . . . . . . . . . . . 16

6. Scholastik . . . . . . . . . . . . . I7

7. Universitäten. . . . . . . . . . . . . . . 22

8. Laienwissenschaft. . . . . . . . . . . . . 23

II. Kapitel. Die Renaissance . . . . . . . . . . . . . 26

I. Paracelsus . . . . . . . . . . . . . . 30

Leben des Paracelsus ............ . 30

I. Lehrjahre . . . . . . . . . . . . 30

2. Paracelsus als Professor......... 39

3. Die Doktoren . . . . . . . . . . . 43

4. Abschied ............. . . 52

Lehren des Paracelsus. . . . . . . . . . . 6I

I. Die geheimnisvolle Natur . . . . . . . 6 6 I

2. Erfahrung und Autoriät .......... 65

3. Phantastisches . . . . . . . . . 68

4. Dinge und Wörter . . . . . . . . . . 72

5. Ursache und Korrelation. . . . . . . . . 75

6. Der Arzt und die Krankheit ......... . So

7. Die Natur .............. 83

8. Übersicht . . . . . . . . . . . . 9I

2. Die Dämmerung der modernen Wissenschaft. . . . . . 98

Vesal . . . . . . . . . . . . . . 99

3. Leonardo da Vinci ............. . . ro7

4. Severino. . . . . . . . . . . . . . I Is

Ill. Kapitel. Neue Aristoteliker . . . . . . . . . . . . . . . I20

I. Caesalpin . . . . . . . . . . . . . . I 22

2. Harvey . . . . . . . . . . . . . . I26

a) Blutkreislauf ................ . . I26

b) Vergleichende Forschung Harveys . . . . . . . I32

c) Embryologie . . . . . . . . . . . . . . I34

d) Wesen des Eies................ . . I37

e) Harvey bei der Nachwelt . . . . . . . . . I39

3. Glisson . . . . . . . . . . . . . . . . I I I

4. Die Enzyklopädisten . . . . . . . . . . . . I 43 
- IV. Kapitel. Begründung der neuen wissenschaftlichen Methode. . . . . . I47

I. Der Untergang der biologischen Weltanschauung. . . . . I47

2. Leonardos Mechanismus und Vitalismus ......... I50

3. Die Galenisten . . . . . . . . . . . . I5I

4. Galilei . . . . . . . . . . . . . . I 52

5. Bacon . . . . . . . . . . . . . . . I 153

6. Descartes . . . . . . . . . . . . . . I I54

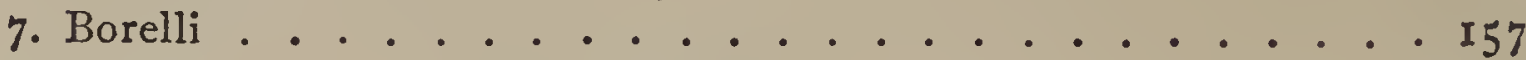

8. Willis. . . . . . . . . . . . . . . 158

V. Kapitel. Epigonenwissenschaft des I7. Jahrhunderts . . . . . . . I6I

I. Redi . . . . . . . . . . . . . . . I I63

2. M. Malpighi . .............. I 65

3. J. Swammerdam . . . . . . . . . . . I 68

4. Leeuwenhoek . . . . . . . . . . . . I73

5. Réaumur . . . . . . . . . . . . . . I73

6. Spallanzani . . . . . . . . . . . . I 76

7. Ovisten und Animalkulisten . . . . . . . . . . I77

VI. Kapitel. Die Paracelsisten . . . . . . . . . . . . . . I 82

I. Die Nachwirkung Hohenheims . . . . . . . . . I 82

2. J. B. van Helmont . . . . . . . . . . . . I 87

I. Pietismus . . . . . . . . . . . . 187

2. Helmont und die Jesuiten . . . . . . . . . I 89

3. Der Charakter der Helmontschen Wissenschaft..... I9I

4. Naturphilosophie . . . . . . . . . . . 202

VII. Kapitel. Die Vitalisten. G. E. v. Stahl . . . . . . . . . . . 204

I. Mechanismus und Organismus ............205

2. Physik, Chemie und Biologie. . . . . . . . . . 207

3. Anatomie . . . . . . . . . . . . . . 208

4. Die Seele . . . . . . . . . . . . . 208

5. Die Ernährung. . . . . . . . . . . . . 2II

6. Die Zeugung und Entwicklung............ 2 I2

7. Bichat . . . . . . . . . . . . . . 213

VIII. Kapitel. Der Aufschwung der Biologie im I8. Jahrhundert . . . . . 2I9

I. Leibniz . . . . . . . . . . . . . . . . . . 220

2. Ch. Bonnet ................. . 228

3. A. v. Haller . . . . . . . . . . . . . . . 235

IX. Kapitel, Die Epigenetiker . . . . . . . . . . . . 24I

I. Der Begriff der wesentlichen Kraft . . . . . . . . . . 244

2. Über die Erstarrung als das zweite Prinzip der Entwicklung • . 244

3. Die Beziehungen des organischen Körpers im allgemeinen oder der Maschine zú dem in Entwicklung begriffenen Körper. . . 246

4. Zellentheorie. . . . . . . . . . . . . . . 247

5. Die Metamorphosenlehre und die Lehre von den Keimblättern . 248

X. Kapitel. Linnés Methode . . . . . . . . . . . . . . 25I

I. Entstehung der Lehre vom Pflanzen- und Tiersystem .. . . . 25I

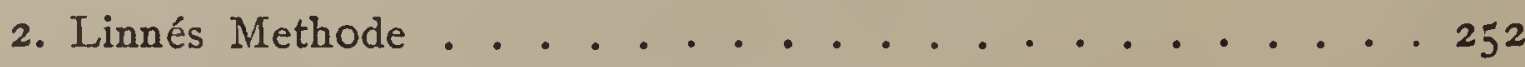

3. Die Ansichten über die Sexualität. . . . . . . . 256

4. Natürliches und künstliches System . . . . . . . . . 260 
5. Begriff der Art. . . . . . . . . . . . 263

6. Binäre Nomenklatur. . . . . . . . . . . 267

XI. Kapitel. Buffon . . . . . . . . . . . . . . . 270

I. Charakteristik . . . . . . . . . . 270

2. Locke und Condillac ............... . . 272

3. Natürliche Methode. . . . . . . . . . . 275

4. Der Bruch mit der Religion . . . . . . . . . . 280

5. Entstehung der Organismen ............ 284

6. Theorie der Erde ................ 286

7. Entstehung und Umwandlung der Arten . . . . . . . . 292

8. Nach Buffon . . . . . . . . . . . . . 298

XII. Kapitel. Französische Morphologie . . . . . . . . . . . : 30 I

I. Entstehung der Morphologie. . . . . . . . . . 30 I

2. Die Entwicklung der botanischen Morphologie... . . . 304

3. Die Morphologie der Tiere vor Cuvier und Geoffroy .. . . 307

4. Georges Cuvier . . . . . . . . . . . 3 II

a) Morphologie............... . . 3II

b) Palaeontologie und Geologie............ 3I7

c) Cuviers Logik . . . . . . . . . . . . 320

5. Geoffroy St. Hilaire. . . . . . . . . . . 325

6. Cuvier und Geoffroy .. . . . . . . . . . 334

7. Die Schule Cuviers . . . . . . . . . . . 338

8. Die Schule Geoffroys............. $33^{8}$

Namenregister . . . . . . . . . . . . . . . . 344

Sachregister . . . . . . . . . . . . . . . . 349 



\section{Kapitel. \\ Das Vermächtnis des Altertums und des Mittelalters.}

Fortwährend sind wir bestrebt, die alten Lehren unter die Schwelle unseres Bewußtseins hinabzudrücken, aber immer und immer leben sie wieder auf. Hippokrates, Aristoteles, Albert 'DER Grosse wurden schon vor Jahrhunderten für vergessen erklärt; noch immer streiten aber Hippokratiker, Aristoteliker, Scholastiker miteinander (obwohl sie unter anderen Namen auftreten), und bis ans Ende der Menschheit werden sie wahrscheinlich bewußte und unbewußte Anhänger finden. Denn dem Geist des Menschen sind gewisse Anlagen a priori verliehen: der eine ist geborener Scholastiker, der andere Platoniker; und wenn wir auch die Frage nach der Zahl solcher möglichen Anlagen der Psychologie der Zukunft überlassen müssen, von der Tatsache, daß es angeborene Geistesrichtungen gibt, spricht die tägliche Erfahrung. Wie dem Jüngling in vager Form die Ideen aufkommen, an deren Realisation das ernste Mannesalter denkt, so hat die klassische Wissenschaft das erste Mal die in der Menschheit schlummernden Anlagen als großartige Gelehrtentypen ins Leben gerufen, die sich im Laufe der Jahrhunderte in mehr prägnanter und differenzierter Form wiederholen sollten. Daher der ungeheuere Einfluß der Alten auf spätere Generationen, die aus den eigenen Idealen fortwährend Nachklänge des Altertums herauszuhören glaubten; weil man geborener Aristoteliker ist und insofern man ein solcher ist, knüpft man an den Vater der Zoologie an.

Kein Historiker der Wissenschaft wird vor der Wiederholung derselben Forschertypen zu verschiedenen Epochen die Augen schließen können; keiner wird aber zugeben, daß die Geschichte der Wissenschaft nur in ewiger Wiederkunft einer bestimmten Anzahl gleicher Ideen bestünde. Kein Theoretiker, keine Epoche entwickeln ihre Lehren nur aus sich selbst heraus, sondern knüpfen jederzeit, bewußt oder unbewußt, bejahend oder verneinend, an die 
Anschauungen der vorangehenden Zeit an. Je tiefer man in die Ge'schichte der Wissenschaft eindringt, desto großartiger erscheint uns der ununterbrochene Nexus zwischen den wissenschaftlichen Problemen der aufeinanderfolgenden Jahrhunderte. Wir sind zu sehr an die Macht der Tradition gewöhnt, um das Unbegreifliche, Überraschende derselben gewahr zu werden: seit ARIST́́t'teles hàt jeder einzelne von den Tausenden und Abertausenden von Forschern das Ziel seiner Forschung in der eigenen Unabhängigkeit, in der Entwicklung seines eigensten Ich und in der Hintanstellung des Überlieferten gesucht; jederzeit waren die Ikonoklasten an der Arbeit; die Arbeiten der Begründer von Wissenschaften waren unzähligen Angriffen des Schicksals preisgegeben und konnten aus der Geschichte verschwinden; immer und immer wieder sind sie für nutzlos, ja für schädlich erklärt worden. Und trotzdem gab es nicht nur jederzeit z. B. Aristoteliker im allgemeinen, sondern der Stagirite hat sich jederzeit seit dem Altertum als historische Persönlichkeit in der Tradition erhalten; seine Formulation der Probleme, seine Nomenklatur, seine persönlichen Anschauungen haben niemals aufgehört zu leben und leben noch immer fort.

So baut sich die historische Kontinuität der wissenschaftlichen Lehren aus zwei Elementarfaktoren auf: aus einer inneren Anlage, die der Mensch aus seinem Wesen entwickelt, und aus der Tradition, die allen Hindernissen zum Spott als eine Art Ansteckung fort und fort von einer Generation auf die andere übertragen wird. Wer nur, einen dieser Faktoren ins Auge faßt, begreift das Wesen der Geschichte nicht; doch wie schwer ist es, beiden gerecht zu werden!

\section{Hippokrates.}

Hippokrates (460-377 v. Chr.) faßte als Biologe die ungesuchte Erkenntnis des Lebens, so wie es ist, ins Auge; unter Leben verstand er nach volkstümlicher Art Tätigsein, Streben, Denken, Vitalität. Die Körpermaschine dagegen hielt der Vater der Arzneikunst nur für das Material, vermittels dessen das Leben in Erscheinung tritt. Es lebte für ihn der Mensch, das Tier, die Pflanze und auch alles dasjenige in der Natur, was sich regt und Kräfte entwickelt so der Wind z. B. Von der wesentlichen Gleichartigkeit des Lebens. überzeugt, hat er ohne weiteres die Entwicklung des Menschen mit der keimenden Pflanze und mit dem Hühnchen im Ei verglichen und die Ähnlichkeiten und Unterschiede zwischen Mensch und Tier hervorgehoben. Auch dort, wo er speziell vom Menschen ge- 
schrieben hat, hat er dessen Leben als Typus für das Leben im allgemeinen aufgefaßt, so in seinen Lehren von der Verdauung, vom Kreislauf der Säfte im Körper und von der Befruchtung.

Aus dèr Art, wie die Anhänger der Koischen Schule, deren hervorragendstes Mitglied Hippokrates war, über die Tiere geschrieben habien, läßt sich entnehmen, daß sie bereits einem Tiersystem folgten, dessen Gruppen sich angenähert durch unsere Namen der Säugetiere, Vögel, Fische, Weichtiere, Schaltiere und Crustaceen ausdrücken lassen. ARISTOTELEs hat später dieses System vertieft und erweitert ${ }^{1}$ ).

Mehrere hippokratische Lehren erreichten ein jahrtausendlanges Leben und sind bis auf den Tag nicht ganz aus der Wissenschaft geschwunden. So die Humoraltheorie, nach der der Organismus aus vier Grundsäften, dem Blut, der gelben und der schwarzen Galle und dem Schleim zusammengesetzt ist, deren klassische Namen sich noch immer in den Wörtern sanguinisch, cholerisch, melancholisch, phlegmatisch erhalten haben. Die Humoraltheorie stellte eine primitive organische Chemie dar; die genannten, in jeder Nahrung vorhandenen organischen Elemente sollen aus derselben durch Verdauung nach den Regeln der Affinität extrahiert werden, wobei der Geschmack des Menschen über die aufzunehmende Menge jedes Saftes entscheidet. HippokRATEs war auch Energetiker, wenn man mit diesem modernen Namen Anschauungen bezeichnen darf, die aus einem von dem unsrigen sehr verschiedenen geistigen Milieu hervorgewachsen sind; er nahm nämlich für die Grundlage des Lebens eine Kraft an, die er sich dem Windstoß analog vorgestellt und Atem (pneuma) genannt hat. Das Pneuma ist etwas Räum liches, denn es durchdringt alles: es strömt zum Feuer, verursacht sein Flackern und ermöglicht das Verbrennen; es dringt aus der Luft in die Lunge, zum Herzen und von da in alle Poren des Körpers (Sauerstoff). Das Pneuma stellt aber gleichzeitig eine Kraft dar, die den Herzschlag und die Bewegung der Glieder verursacht; schließlich bedeutet es ein geistiges Prinzip, das im Gehirn die Quelle des Nachdenkens und des Verstandes bildet.

Hippokrates war ein einflußreicher Arzt; seine Schule überlebte ihn um viele Jahre; der fast um 80 Jahre jüngere ARISTOTELES entnahm ihm manche Idee; auch GaLENus erkannte ihn als seinen Meister an; seit der Renaissance kommen hervorragende Praktiker

1) R. Burckhardt, Das Koische Tiersystem. Verh. Natf. Ges., Basel XV. S. 377 ff. 
immer wieder auf seine Auffassung der Arzneikunst zurück. Er findet Anhänger besonders bei den Praktikern, den Naturärzten, den der schulmäßigen Systemmacherei abholden Individualisten. Seine Abneigung gegen die schematisierenden Theorien, sein Dynamismus, seine Humoral- und Pneumatheorien scheinen direkt der Volksphilosophie entnommen worden zu sein; so steht er der gemeinsamen Quelle nahe, aus der alle großen Männer ihre Ideen geschöpft haben $\mathbf{1}$ ).

\section{Plato.}

Mit den Sophisten, den philosophischen Spezialisten, schließt die ältere Periode der griechischen Philosophie ab; mit Sokrates, einem Mann aus dem Volke und einem Gegner des Fachgelehrtentums, hebt eine neue Periode an. Die Sophisten haben die persönliche Haftung für die von ihnen vertretenen Wahrheiten abgelehnt; sie suchten andere $z u$ überreden - Sokrates war selbst überzeugt; sie stützten sich auf die Tradition, er auf die natürliche Urteilskraft. Für die theoretische Wissenschaft zeigte SokRates nach der Art der praktischen Leute wenig Verständnis; sie sei eine gesuchte, unnatürliche Beschäftigung des Geistes mit Belanglosem.

In Sokrates schlug sich die Reaktion des schlichten Verstandes gegen den Dogmatismus der Kultur nieder; sein Schüler Plato hat aus der sokratischen Schlichtheit, d. h. aus dem ungesuchten und tief erfaßten Verhältnis des Menschen zu den Lebensfragen, eine Philosophie erbaut. Die einzelnen Gegenstände, Steine, Pflanzen, Tiere, Menschen, sofern sie greifbare Erscheinungen darstellen, hat Plato für Dokumente von einem Wesen erklärt, das zu uns durch dieselben zu sprechen sich bemüht. Jenes Haus, das ich betrachte, der Körper dieses hier stehenden Menschen, die Farbe dieses Vogels sind sozusagen nur als geschriebene Wörter aufzufassen; der Sinn, den sie auszudrücken streben, ist das einzig der Erforschung Würdige, während die konkrete Schrift, in der diese Wörter verzeichnet sind, an sich wenig Bedeutung hat. So sind Platos Worte im Timäus zu verstehen.

》Es ist $z \mathfrak{u}$ unterscheiden $z$ wischen dem, was fortwährend ist und keinen Anfang hat, und dem, was fortwährend entsteht und niemals ist.»

1) Üb. Hippokratesvgl. O. SchruTz, Hippokratische Anschauungen iiber den Ursprung, die Zusammensetzung und die Leistungen d. Menschenkörpers, Prag 1895 (tschechisch). Neuburger-Pagel, Handbuch d. Geschichte d. Medizin, Jena I 903. 
In der Tat: wenn man eine Rede betrachtet, so hat ihr Sinn keinen Anfang, sondern er ist vorhanden; einzelne Wörter, d. h. die durch das Ohr vernommenen Lufterschütterungen, entstehen in einem fort, bestehen aber nicht. Demselben Schicksal unterliegt alles in der Natur: der individuelle, der Art-, der Gattungscharakter eines jeden organischen Wesens z. B., besteht, d. h. der vernünftige Beobachter kann ihn erkennen und beschreiben; einzelne Körperteile, einzelne Augenblicke des Lebens kann man zwar mit den Sinnen erfassen, aber nicht behalten, denn sie verändern sich fortwährend, sie entstehen und vergehen. Alle Naturerscheinungen stellen folglich nur Dokumente, nur Zeichen dar: der Körper und das Leben eines Hundes stellen nur den Ausdruck von einer Wirklichkeit dar, die man durch den Namen Canis familiaris bezeichnet; der Lauf der Planeten drückt die Gesetze der Planetenbewegung aus usf. Der Sinn jeder Naturerscheinung heißt ihre Idee, so daß alles, was eine natürliche Bedeutung hat, den Ausdruck einer Idee darstellt; dieses Tier, diese Blume, diese Bewegung eines Tieres, dieses Organ stellen in demselben Sinne Offenbarungen von Naturideen dar, wie Pratos Schriften Darstellungen der Ideen enthalten, die dieser Philosoph uns mitzuteilen sich bemüht hat. Das ist der Grundgedanke der platonischen, nicht nur für die reine Philosophie, sondern auch für die Wissenschaft der nachfolgenden Zeit bedeutungsvollen Weltanschauung.

Plato war kein Biologe, aber auch unter den Biologen haben seine Schriften, namentlich die kühnen Theorien des Timäus, Freunde gefunden. Im Timäus werden Hypothesen entwickelt über die Natur, die Sternenwelt, die Elemente, die Umwandlungen der Metalle, den Bau der Körpers, über die Krankheiten usw., Theorien, deren Auseinandersetzung wir übergehen müssen. Erwähnenswert ist jedoch Platos Tendenz, von den realen Darstellungen der Dinge, wie sie sind, zu Erklärungen abzuschweifen, warum die Dinge so sein müssen. Diese Methode ist so sehr im Wesen des menschlichen Gemüts eingewurzelt, daß der Kampf gegen dieselbe noch immer resultatlos bleibt; kein Wunder, daß sie auch Platos Nachfolger auf falsche Wege verleitet hat. Auf die (sonderbare) Frage, warum der Kopf des Menschen mit Haut bedeckt ist, gibt Plato im Timäus folgende bestimmt lautende Antwort ${ }^{1}$ ):

"Endlich wäre der nur von seiner knöchernen Kapsel bedeckte Kopf zu wenig vor den Extremen der Hitze und der Kälte je nach der Witterung

1) Th. H. MAR'Tin, Etudes sur le Timée de Platon I. II., Taris IS4I, I. S. 203. 
geschützt, und es wäre anderseits nicht möglich, denselben unter einer Schicht Fleisch zu verbergen, denn dadurch würde er dumm und unempfindlich werden. Daher, weil das Fleich nicht austrocknet, entstand auf der Oberfläche des Kopfes eine von demselben abgetrennte Rinde, welche Haut genannt wird. Diese Haut wächst und entwickelt sich unter dem Einfluß der das Gehirn umgebenden Feuchtigkeit, umhüllt die Schädeloberfläche ganz und fließt von allen Seiten zusammen... "

Schließen wir die Augen vor der Primitivität dieser Erklärung und achten wir bloß darauf, wie PLATo die schlichte Beschreibung der Kopfhaut und ihres Verhältnisses zum Kopfe durch eine stilistische Verknüpfung mehrerer heterogener Tatsachen zu ersetzen sucht; er spricht über Hitze und Kälte, Dummheit und Empfindlichkeit, anstatt in concreto anzugeben, wie die Kopfhaut beschaffen ist. In dieser Sucht, Beschreibungen durch aus der Luft ge griffene Erklärungen $z u$ ersetzen wird Plato viele Nachfolger finden. GALENUS ist einer der hervorragendsten, VESAL einer der neueren; noch heute lebt diese Tendenz in den beliebten Erklärungen, warum der Mensch ein Gehirn hat, wozu die geschlechtliche Vermehrung dient u. $\ddot{a}$. - in solchen Theorien, welche durch geistvollen Einfall ein wirkliches Erkennen ersetzen wollen ${ }^{1}$ ).

\section{Aristoteles.}

Vom Grundsatze geleitet, daß die Natur eine vernünftige Sprache redet, hat Plato versucht, ihre Ideen zu verstehen und zu deuten; ARISTOTELES, sein berühmter Schüler, hat es unternommen, die Natur mit Hilfe dieser Ideen wissenschaftlich zu erklären. Von dem großen Laien PLATO unterscheidet sich der Forscher ARISTOTELES dadurch, daß er in seinen Schriften (dem Essaysiten Plato gegenüber) mehr als Monographist auftritt, daß er anstatt des Stiles die systematische Behandlung in den Vordergrund stellt, sich einer festen Terminologie bedient und der seit jeher von den Forschern angewendeten Darstellungsweise folgt. Er formuliert zuerst das Problem, läßt die geschichtliche Diskussion desselben folgen, löst das Thema auf Grund einschlägiger Tatsachen und definiert schließlich das Resultat.

Der anschauliche Plato zielte auf die Vorführung eines plastischen Bildes der Welt, die er aus der Materie (= dem Material), aus der die Erscheinungen geformt werden, und aus dem Grund oder

1) Über Platos naturwissenschaftliche Anschauungen vgl. die (nicht genug übersichtliche) Schrift von J. R. LichtenstäDT: Platos Lehre auf d. Gebiete d. Naturforschung u. d. Heilkunde, Leipzig I 826. 
der Form, oder dem Wesen, die die Art des Geschehens charakterisieren, erbauen wollte. Als typischer Wissenschaftler begnügte sich ARISTOTELES nicht mehr mit der Darstellung von dem, was geschieht, sondern suchte auch nach dem Warum des Geschehens; deshalb unterschied er neben der Materie und dem Grund der Erscheinungen noch die B ewegungs-(Veränderungs)-ursache und den natürlichen Ziveck ${ }^{1}$ ) der Erscheinungen.

Während der Begriff der Natur in der modernen Biologie Natur objekte umfaßt, so z. B. Erdoberfläche, Felsen, Flüsse, Mineralien, Wälder, Tiere, Luft u. ä., bedeutet derselbe bei ARISTOTELES und bei den meisten Naturforschern vor dem 19. Jahrhundert den lebendigen Zusammenhang der Erscheinungen, die fortwährend entstehen und vergehen und doch ein harmonisches Ganzes bilden ${ }^{2}$ ). ARIsroTELES und alle anderen hielten ferner die Naturgesetze für dem Wesen des Menschenverstandes analog; die Logik des gesunden Menschenverstandes soll dem Geschehen der Welt adäquat sein. Deshalb bedeutet die berühmte Logik des ARIsToteles nicht nur die Logik im modernen Sinne des Wortes, sondern lehrt gleichzeitig auch die Grundgesetze des Naturgeschehens kennen.

Aristoteles ist der erste Gelehrte, bei dem einzelne Gebiete der Biologie, Zoologie, Botanik, allgemeine Biologie, Embryologie, Teratologie, Physiologie als selbständige Forschungszweige hervortreten ${ }^{3}$ ). Die Natur schreitet nach ihm durch kleine aufsteigende Schritte von einem Wesen zum anderen; vom Unbeseelten geht sie zu den Tieren durch Pflanzen und Pflanzentiere (Zoophyta, d. h. am Meerboden festgewachsene Tiere) hinüber. Die Grundeigenschaft der Lebewesen ist Psyche, d. h. Vitalität, organisierter Körper und Subjelitivität4). Aristoteles formuliert seine Auffassung der Psyche wie folgt $t^{5}$ :

1) Unter natürlichem Zweck ist der natürliche Sinn des Geschehens zu verstehen, den man in der Natur beobachten kann. So liegt der Zweck der Embryonalentwicklung im entwickelten Organismus. Würde man objektiv konstatieren können, daß die Natur des Menschen wegen da ist, so würde der Mensch der Zweck der Natur sein. Der aristotelische Zweck muß erst induktiv gesucht und nicht a priori in die Erscheinungen hineingedeutet werden.

2) In diesem Sinne sprechen wir noch von der »Natur des Menschen«.

3) Burckhardt, K., Geschichte d. Zoologie (Göschen), S. 20.

4) In der neuen Philosophie gilt nur die Subjektivität (das Bewußtsein) für das Merkmal der Seele. Die Seele im aristotelischen Sinne ist ebenso »objektiv « wie z. B. die sVolksseeler.

5) LEwes, Aristoteles S. 23 I. 
"Da die Vermögen des Wissens, Fühlens, Denkens, Wünschens, Wollens und die Begierden im allgemeinen, ebenso auch Lokomotion, Wachstum, Reife und Verfall, Eigenschaften der Psyche sind ... Einige sagen, das Lebensprinzip sei teilbar, der eine Teil denkt, der andere begehrt; wenn dies aber so wäre, was hält die Teile zusammen? Der Körper gewiß nicht, denn das Lebensprinzip scheint ihn zusammenzuhalten, da er vom Moment, wo jenes ihn verläßt, stirbt und zerfällt... «

Die Seele ist nach ARISTOTELES identisch mit dem natürlichen Sinn jeder Sache: die Seele des Auges ist der innerste und wahrste (unbekannte, aber der Erforschung zugängliche) Sinn des Sehorgans; der letzte Grund einer Pflanze, ihrer Lebensweise, ihrer Organisation, ihrer Entwicklung, also dasjenige, was der Botaniker durch die Beschreibung der Pflanze auszudrücken strebt, ist ihre Seele. Folglich stellt die Seele nicht nur etwas Gedachtes dar; sie existiert und wirkt auf die Umgebung ${ }^{1}$ ).

Die Pflanzen weisen die erste Stufe der Seelentätigkeit auf, die Ernährung; sie nehmen die Nahrung durch die Wurzeln auf, welche den Nabelvenen des Embryos verglichen werden können, indem die Pflanze durch die Erde ernhärt wird, wie der Embryo durch den Uterus. Der Zweck der Blätter ist, die Frucht zu beschützen. Der Same ist eine Art Ausscheidung. Die Pflanzenorgane sind einfach: Holz, Rinde, Blätter und Wurzeln. Die Wurzeln sind dem Munde analog; folglich stecken die Pflanzen mit dem Kopfe in der Erde und ragen mit dem Unterkörper nach oben hervor.

Die Tiere ernähren sich, empfinden und sind wärmer als die Pflanzen; mit der Empfindlichkeit hängt auch Wille und Lokomotion zusammen. Dem Menschen ist die gottähnliche Natur eigen; doch ist er nur der höchste Punkt einer kontinuierlichen Entwicklung der Organismen. Nur der Mensch bildet Begriffe, generalisiert und abstrahiert. Unter den Tieren unterscheidet ARISTOTELES erstens

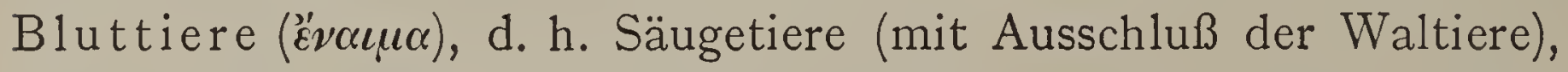
Vögel und eierlegende Vierfüßler (Reptilien und Amphibien), Waltiere, Fische; zweitens blutlose Tiere (a' $\left.\alpha^{\prime} \alpha \mu \mu \alpha\right)$, unseren Wirbellosen analog, die er in Kephalopoden, höhere Krustazeen ( $\mu \alpha \lambda \alpha x o ́ \sigma t \varrho \alpha \varkappa \alpha)$,

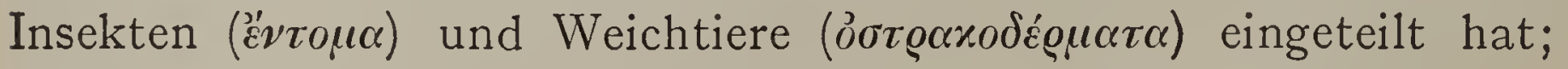
zu den letzten hat er all das Chaos der niederen Tiere gerechnet.

ArIstoteles wußte noch nicht, daß die Tiere und Pflanzen in ihren Formen so beständig sind, daß man Varietäten, Arten, Gattun-

1) ARIstoteles gibt folgende Definition der Seele an: Sie ist die serste vollendete Wirklichkeit eines dem Vermögen nach lebendigen Naturkörpers, und zwar eines solchen, der Organe hat. (DRIESCH, Geschichte d. Vitalismus S. I7.) 
gen usw. unterscheiden kann; nicht einmal die eben angeführte allgemeine Einteilung des Tierreiches wird von ihm als eine logisch geordnete Klassifikation, sondern eher nur als eine selbstverständliche Tatsache angeführt; trotzdem spielen in seiner Philosophie dic

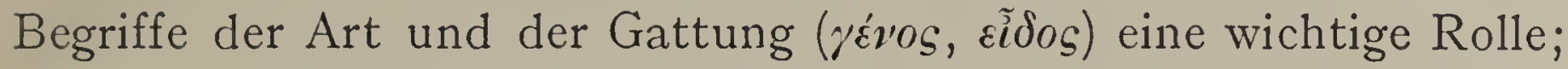
es fehlt ihnen aber noch die moderne konkrete Bedeutung, wo man unter Art z. B. "Hausmaus « oder "Gartentulpe «, unter Gattung "Maus « und »Tulpe "versteht; sie bezeichnen bei ARISTOTELES bloß niedere und höhere Gruppen von ähnlichen Dingen. So zählte Aristoteles beispielsweise die Krustazeen zu einer Gattung und nannte dann einzelne Krustazeen Arten; höheren Gruppen gegenüber ("Gattungen 《) stellte jedoch wiederum der Krustazeenstamm nur eine Art dar. In demselben Sinn sprechen wir noch heute von den Arten der Vorstellungen oder von Getreidegattungen.

ARISTOTELES war der erste vergleichende Anatom, verlegte aber das Wesen des Tieres nebst der Struktur auch in dessen Lebensweise und in dessen geistige Eigenschaften. Deshalb stellte er die Strauße und die Fledermäuse zwischen die Säugetiere und Vögel und zählte die Waltiere unter die Fische, obwohl er nicht übersehen hat, daß z. B. die Waltiere anatomisch Säugetiere sind. Das I9. Jahrhundert warf ihm diese Mißachtung der Struktur und Betonung der Lebensweise vor; heute, wo man gelernt hat, die Lebensweise der Tiere höher einzuschätzen, wird man ARISTOTELEs (im Prinzip) vielleicht recht geben.

Es gibt nach ARISTOTELES drei Arten der Zusammensetzung der Teile bei den Tieren: erstens die aus den Elementen: Feuer, Erde, Luft und Wasser (also unsere chemische Zusammensetzung); zweitens die aus gleichartigen Teilen (unsere Gewebelehre); drittens jene aus ungleichartigen Teilen (Anatomie in unserem Sinne).

Die gleichartigen Teile werden wieder eingeteilt in I) weich und flüssig, wie Fleisch, Fett, Talg, Mark, Lymphe, Blut, Galle, Milch; 2) hart und fest, wie Gefäße, Sehnen, Knochen und Gräten. In den derselben Klasse angehörigen Tieren sind die Teile nur der Größe nach voneinander verschieden; die mehr voneinander entfernten Tiere haben wieder Teile, welche einander nur ähnlich sind und analog genannt werden können:

"so verhält sich der Knochen zur Gräte, der Nagel zur Klaue, die Hand zur Schere und die Feder zur Schuppe; denn was beim Vogel die Feder, das ist beim Fisch die Schuppe «1).

1) LEWES S. 286. 
In der Physiologie hat ARISTOTELEs über geringere Erfahrungen als in der Morphologie verfügt. Die Nahrung wird nach ihm im Magen durch die tierische Wärme gekocht, wird flüssig und kommt als solche in den Darm, wo sie verdampft und durch kleine Gefäße aufgesogen wird und nun zum Herzen, dem Mittelpunkt des Lebens, durch kleine Gefäße gelangt, wo sie aus dem ungekochten Blut (Ichor), zum wahren Blut wird. Aus dem Herzen wird das Blut durch die Adern in den Körper geführt: "Durch die Adern und durch die überall befindlichen Kanäle sickert die Nahrung hindurch, wie das Wasser in rohen Tongefäßen, und wird zu Fleisch oder dem diesem Entsprechenden, indem es durch die Kälte gleichsam gerinnt, und deshalb wird es auch durch Feuer aufgelöst «. Die edleren Organe, Fleisch und Sinne, bekommen den süßesten Teil des Blutes, die Knochen, Haare usw. die bitteren Teile.

Das Herz ist der große Kochapparat, in ihm wird die Wärme erzeugt. Indem das Blut im Herzen gekocht wird, dehnt es das Herz aus; auch die Brust wird dadurch ausgedehnt, und in den so gebildeten Raum dringt von außen die kalte Luft ein und veranlaßt durch die Kälte ein Zusammenschrumpfen der Brust, und diese drückt wieder das Herz zusammen; so läßt sich die Atmung und die Herzbewegung mechanisch erklären. Das Atmen hat also die Aufgabe, das heiße Blut abzukühlen; bei den Fischen geschieht die Abkühlung durch das Wasser.

Das Gehirn kann nicht Sitz der Empfindung sein, da es unempfindlich und kalt ist; es ist dies der kälteste Teil des Körpers und dient dazu, die große Hitze des Herzens zu mäßigen.

Die Bewegung wird aus dem Herzen reguliert: die Seele wirkt nämlich auf das (dem Äther der modernen Theorien einigermaßen analoge) Pneuma, welches im Herzen sitzt; im Herzen liegt auch der Mittelpunkt der Empfindung. Die Bewegung geschieht nicht durch Zusammenziehung der Muskeln, sondern durch Spannung der Sehnen; das Fleisch ist Empfindungsorgan, es ist der Sitz der Sensibilität, das Zeichen der Tierheit.

Den wichtigsten Teil der aristotelischen Biologie bildet die Theorie der Entwicklung. Zur Zeugung sind zwei Wesen, das männliche und das weibliche, nötig; doch sind beide nicht immer voneinander geschieden. Das Männliche ist dasjenige, in dem der Anfang der Bewegung und der Zeugung, das Weibliche jenes, worin der Anfang des Stofflichen liegt. Der Mann produziert den Samen, welcher die Kraft hat, die Zeugung und Entwicklung zu beginnen. 
Auch das Weib produziert eine Art Samen (Menstruum), welcher aber wesentlich Stoff zur Entwicklung liefert. Der weibliche Samen ist nicht tot und roh, sondern er hat nur eine niedrigere Stufe des Lebens als der männliche Samen, er hat nur die Ernährungsseele, während der Same des Mannes auch von der Empfindungsseele durch drungen ist. Dieses Verhältnis gilt in gewissem Sinne auch von Mann und Weib: das Weib erreicht eine niedrigere Stufe der Entwicklung des Menschenwesens als der Mann.

Für die Entwicklung des Organismus aus dem Keime gibt die Entstehung eines Kunstwerkes Vorbild, wo im Geiste des einer neuen Konzeption fähigen Künstlers eine Idee (ein Plan), eben die Seele des neuen Kunstwerkes reift, die dann die Hand des Künstlers führt, da er seine Idee in die Materie verkörpert. Dieselbe Rolle spielen psychische Kräfte in der Embryonalentwicklung; auch in diesem Falle wird der Nachkomme nach dem Bilde der Eltern konzipiert und ins Leben gesetzt; gibt es hier auch keinen bewußten Plan für dessen Erzeugung, so wird doch ein unbewußter Plan durch das männliche Sperma dem Keim eingehaucht, wo er sich in derselben Weise wie die Idee im Marmor verwirklicht. Wie entsteht nun aus dem undifferenzierten Keim das organisierte Lebewesen, und wie werden die Eigenschaften der Eltern auf die Nachkommen übertragen?

"Wenn sich die Organe im Samen voneinander getrennt befinden, auf welche Weise können sie leben? Wenn sie aber zusammenhängen, so hätten wir schon ein kleines Tier. Und wie steht es mit den Geschlechtsteilen? Denn das, was vom Männchen kommt, ist dem vom Weibchen Kommenden nicht ähnlich. Ferner, wenn der Same auf gleiche Weise von allen Teilen beider Eltern kommt, so müssen zwei Tiere werden; denn das Werdende wird alle Teile von jedem der beiden Eltern haben. . «1).

In derselben Weise, wie es ARISTOTELES getan, wird noch heute das Entwicklungs - und Vererbungsproblem formuliert. Bereits ARISTOTELES hat mehrere Versuche um dessen Lösung gelannnt2); er spielt im ersten Satze des angeführten Abschnittes deutlich auf die Präformation an, entscheidet sich dagegen für die Epigenese, die mit seiner allgemeinen Auffassung von der Entstehung der Dinge und von der Entstehung der Erkenntnis zusammenhängt. Das Begreifen der Genese des menschlichen Wissens, wie sie ARIstoteles auffaßt, erleichtert uns das Eindringen in seine Entwicklungstheorie. Nach

1) LEWES S. 350 .

2) Gewiß waren ihm die Theorien der Hippokratiker bekannt. 
den Empiristen gelangt der Mensch zu allgemeinen Begriffen durch Sammlung einzelner Fälle, aus denen er je weiter desto allgemeinere Eigenschaften abstrahiert und diese unter einen Begriff subsumiert. Nach der Aristotelischen Philosophie entwickelt sich die Erkenntnis auf umgekehrtem Wege: zuerst formuliert der Geist allgemeine Begriffe, die sich erst später zur Einzelerkenntnis differenzieren: das Kind nennt zuerst jeden Mann Papa, jede Frau Mama; erst später lernt es, konkrete Individuen $\mathrm{zu}$ unterscheiden. Auf dieselbe Art, vom Allgemeinen zum Besonderen fortschreitend, entwickelt sich nach ARIstoteles auch der Organismus: gegen die Annahme DEMOKRITs, daß aus dem Mutterkörper Elemente einzelner Organe in den Keim wandern, sich dort nebeneinander legen und solcherart den Körper durch Apposition der Teile aufbauen, stellt er die Lehre auf, daß die Organe im Keime selbst neu entstehen; der Organismus ist im Keime anfangs im allgemeinen vorhanden, und später differenziert sich ein Organ nach dem anderen, zuerst das Herz, als der Mittelpunkt des Lebens, und dann reihenweise, je nach ihrer funktionellen Bedeutung, die übrigen Organe.

Höhere Tiere lassen nach ARISTOTELEs Geschlechtsunterschiede erkennen und entstehen durch Zeugung; von den Blutlosen sind einige getrennten Geschlechts, andere nicht, und bei den letzteren sind beide Prinzipien in einem Körper undifferenziert enthalten. Namentlich den Pflanzen fehlt differenziertes Geschlecht. Viele der niederen Tiere, von den höheren Aale und Frösche, entstehen spontan aus faulenden Substanzen. Die spontane Generation hat bei ARISTOTELES einen anderen Sinn als heute; es wäre seiner Philosophie zuwider, anzunehmen, daß zufällig irgendwo günstige Bedingungen zusammentreffen, welche den Organismus hervorbringen; auf sclche Weise könnte nach ARIstoteles niemals etwas Einheitliches entstehen, indem das, was entstehen soll, bereits in den Bedingungen der Anlage nach enthalten sein muß. Aristoteles faßt die spontane Generation folgendermaßen auf $\mathbf{1}$ ):

"Es entstehen aber die Tiere und die Pflanzen in der Erde und im Feuchten, weil in der Erde Wasser vorhanden ist und im Wasser Luft (Pneuma), in aller Luft aber Lebenswärme, so daß gewissermaßen alles von der Psyche erfüllt ist. Daher bilden sich auch Körper, sobald dieselbe in einen Raum eingeschlossen wird; sie wird aber umschlossen, indem sich bei der Erwärmung der körperhaften Flüssigkeit eine Art schaumartiger Blase bildet. Ob nun das, was sich bildet, eine vollkommenere oder minder 
vollkommene Art wird, dieser Unterschied liegt in der Einschließung des Lebenskeimes, und davon ist die Ursache in dem Ort und dem eingeschlossenen Stoffe zu suchen. Im Meerwasser ist eine Menge erdigen Stoffes, daher entspringt aus einer solchen Mischung die Bildung der Schaltiere ... Bei richtiger Betrachtung $m u B$ man aber fragen: was ist es, was bei dieser Art von Bildung dem stofflichen Prinzip (bei den andern Tieren) entspricht? Denn bei den weiblichen Tieren ist dies ein Ausscheidungsstoff des Tieres, der die Anlage zu einem gleichen Tier enthält . . . und durch das vom Männchen stammende Prinzip erregt wird. .. Was soll man aber hier als solches ansprechen, und woher kommt und welches ist das der Kraft des männlichen Tieres entsprechende Erregungsprinzip? ... Was [bei den durch Zeugung entstehenden Tieren] die tierische Wärme aus der Nahrung bereitet, das mischt die Wärme des Sommers in der Atmosphäre aus Meerwasser und Erde durch Kochen zusammen und vereinigt es zu einer Bildung. Und der miteingeschlossene oder in der Luft abgesonderte Teil der Psyche bildet den Keim und legt die Erregung zur Entwicklung hinein. «-

Es genüge dieser gedrängte Auszug aus der aristotelischen Biologie. Ihre Hauptmerkmale sind der Dynamismus und der universelle Vitalismus. Unter dem ersteren ist die Überzeugung zu verstehen, daß das Wesentlichste an der Welt die Kraft, die Energie, der Wille ist, während die Materie einen untergeordneten Begriff bildet. Als universeller Vitalist hat ARISTOTELEs angenommen, daß jedes Geschehen, also z. B. auch der freie Fall, die Bewegung der Sterne am Himmel, der Hauch des Windes, Lebenserscheinungen darstellen. Ist auch der fallende Stein sèlbst tot, so hängt doch seine Bewegung nach ARISTOTELES organisch mit dem Weltgeschehen zusammen, ebenso wie z. B. der Blutkreislauf mit dem Leben des Körpers zusammenhängt; für diesen harmonisch-organischen Zusammenhang hat sich ARISTOTELES an erster Stelle inter. essiert. Der universelle Vitalismus, der Glaube, daß die Biologie (bzw. Psychologie) die höchste Wissenschaft darstellt, während die Physik, die Chemie, die Astronomie nur einzelne Abteilungen der Lehre vom Leben darstellen, war nicht nur ARISTOTELES, sondern auch PLATO, GALEN und der gesamten mittelalterlichen Wissenschaft eigen; erst GALILEI und DEscarTEs haben das Verhältnis jener Gebiete umgeworfen.

In ARISTOTELEs hat die griechische Biologie ihren Kulminationspunkt erreicht und der Nachwelt eine Auffassung des Lebens vermacht, deren philosophische Tiefe und logische Geschlossenheit seitdem niemand überboten hat. Wenn sich spätere Jahrhunderte so oft mit ARISTOTELES beschäftigt haben, so liegt der Grund davon gewiß nicht nur in ihrem blinden Autoritätsglauben - denn auch 
uns Modernen bleibt nur zu oft nichts anderes übrig, als ARISTOTELES ebenfalls als unseren Meister anzuerkennen. Die Tatsache, daß ARISTOTELES einen so großen Einfluß auf die Nachwelt ausgeübt hat, gibt nicht nur ein schwieriges Rätsel dem Historiker der Wissenschaft auf; die Art, wie ARISTOTELES die Natur aufgefaßt hat, muß der natürlichen Wissenschaft besonders nahe stehen, wenn zu allen Epochen der wissenschaftlichen Forschung bedeutende Biologen dieselbe als der ihrigen kongenial haben erklären können ${ }^{1}$ ).

\section{Plinius.}

PliniUs DER ÄLTERE (23-79 n. Chr.), ein reicher Römer, hat teils als Soldat, teils als hoher Staatsbeamter die verschiedensten unter das römische Reich gehörigen Gebiete gesehen und sammelte oder exzerpierte während der Reisen die Schriften, die er auftreiben konnte. Sein aristokratisches Interesse für das Wissenswerte hat aus ihm den größten Dilettanten des Altertums gemacht. Eine Schrift hat er der Kriegsführung, eine andere der Geschichte Germaniens, eine dritte der Biographie seines Freundes Pomponius gewidmet; den größten Umfang, 37 Bücher, erreicht seine Naturgeschichte (Naturae historiarum libri).

Die Natur, wie sie ist, zu beschreiben, lag nicht in Plinius Intentionen; er wollte vielmehr alles Lesenswerte, Interessante aus fremden Schriften zu einer Enzyklopädie sammeln; deshalb rühmt er sich, an 20000 beachtenswerte Angaben aus 2000 Büchern von Ioo Autoren exzerpiert zu haben. Jede Art Methode, bestehe sie auch nur in alphabetischer Zusammenstellung des Dargebrachten, weist ein solcher Antipode des Fachmännertums als eine seiner Freiheit unwürdige Beschränkung zurück; jede Kritik erscheint ihm als Pedanterie: das Interessante als solches (nicht das Wahre, nicht das logisch Geordnete) hat einzig Wert für sein Notizbuch. Deshalb

1) Literatur. Die wichtigsten biologischen Schriften Aristoteles' sind: Über

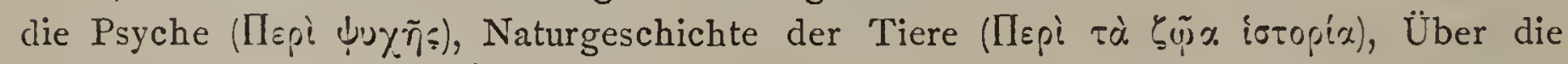

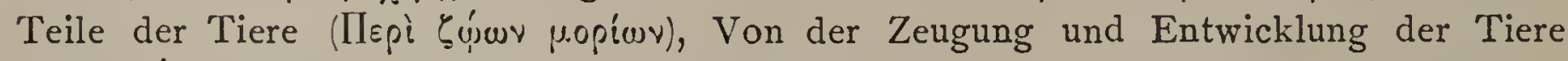

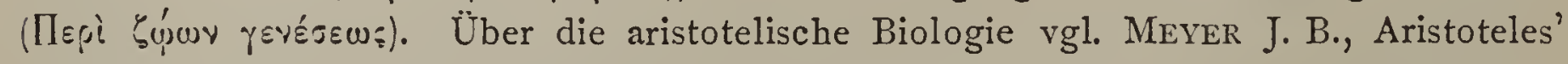
Tierkunde, Berlin 1855. - Lewes, G. H., Aristoteles, Deutsch v. V. Carus, Leipzig 1865. - Rud. Burckhardt, Über antike Biologie, Vortrag, Aarau 1904. - Ders., Geschichte d. Zoologie (Göschen), Leipzig 1907. - H. DrIEsch, Der Vitalismus als Geschichte und als Lehre, Leipzig 1905. - PIAT, Aristoteles, Berlin 1907. - Bruno Bloch, Die geschichtlichen Grundlagen der Embryologie bis auf Harvey, Nova Acta d. k. Leop. Akad. 82. 1904. S. 236-256. - Die ältere Literatur ist angefiihrt im Handbuch d. Altertumswissenschaft, Nördlingen, I 888 Bd. V. I S. Ior. 
kennt PLINiUs nur praktische Rücksichten bei der Zusammenstellung seines Materials; er beginnt seine Naturgeschichte mit einer Art Inhaltsangabe, geht zur Astronomie, Geologie und Physik, zur Geographie über, schreibt weiter über den Menschen, über die Landtiere (die er teilweise geographisch gruppiert), über die Wassertiere, Vögel, Insekten, Pflanzen, über Medizin, über Mineralien. Was wir sonst Naturwissenschaft nennen, Anatomie, Physiologie, Naturphilosophie, hat für Plinius gar keine Bedeutung, weil es zu abstrakt ist. Die Darstellung des Menschen z. B. beginnt er mit einer beredten, pessimistischen Schilderung der Menschenleiden, schreibt dann (nach ARISTOTELES, unter Anführung verschiedener Kuriositäten) über die Fortpflanzung des Menschen, über das Menschenleben von der Geburt an, über den Tod und das Begräbnis und über das Leben nach dem Tode. Dabei kommt er zu sprechen auf Riesen, auf außerordentlich starke, schnellfüßige, scharfsichtige Individuen, auf Persönlichkeiten, die sich durch ihr Gedächtnis, Glück, durch ihren Großmut, ihre Weisheit und Tugend usw. ausgezeichnet haben. Die Tiere erörtert er auf dieselbe Art, unter fortwährender Berücksichtigung des für die Küche, für die Schaulust, für die Medizin usw. Nützlichen. Was geht ihn, den Heerführer, den Freund Vespanians und Titus', den Statthalter von Spanien, solch unnützes Zeug an wie die Anzahl der Knochen beim Menschen oder der Bau der Mundwerkzeuge einer Fliege? Eine witzige Anekdote. schätzt er höher als die ganze Psychologie des ARIstoteles.

Auf die Kritiklosigkeit des Plinius ist Bann gelegt worden. Wer wird auch seine Nachrichten über Elefanten, von denen die Sterne und der Mond als Götter verehrt werden, über giftige Basilisken, über Hyänen, die die Schafhirten mit menschlicher Stimme anrufen, u. dgl. mehr ernst nehmen? Doch die Geschichteder Bücher dieses Märchenschreibers beweist, daß seine Auffassung der Wissenschaft tief im Wesen der Menschennatur begründet ist: warum hat das ganze Mittelalter Plinius verehrt? Etwa des phantastischen Inhalts seiner Schriften wegen? Gewiß. eher aus dem natürlichen Grunde, daß man in der Naturwissenschaft ein Mittel zur Ergötzung des Geistes durch sonderbare Geschichten erblickte. Die Renaissance mit ihrem sonst so gerühmten Natursinn hat Plinius von den gegen den exakten ARISTOTELES geführten Angriffen verschont, weil ihr seine Auffassung der Wissenschaft. praktisch erschien. Die ersten großen biologischen Werke aus der Neuzeit, die Schriften GESNERs und ALDRovandis, zeigen für ARI- 
Stoteles wenig Verständnis; der kompilatorische Geist des Plinius atmet aus denselben. Im I8. Jahrhundert hat kein Geringerer als Buffon Plinius als sein leuchtendes Vorbild gerühmt. Es war kein Irrtum von Buffon, als er Plinius auf dieselbe Höhe wie ARIstoteles gestellt hat; die Methode des Plinius, sich über die Grenzen jeder Methode hinwegzusetzen, ist auch Buffons Methode. Und bis auf den Tag lebt in den Museen und in den Werken à la BrEHMs Tierleben der Geist der in Plinius zum ersten Male aufgeblühten, nach Kuriositäten haschenden Wissenschaft fort.

\section{Galen.}

Mit Galenus aus Pergamon (etwa I3I-200 n. Chr.) findet die Geschichte der Altertumsbiologie den Abschluß. Während HippoKRATES ein großer Praktiker, Plato ein genialer Essayist, ARISToTELES ein wissenschaftlich gebildeter Philosoph, Plinius ein aristokratischer Dilettant war, war. GALEN, der Sprosse der Alexandrinischen (Hoch-) Schule, ein Gelehrter von Standesbewußtsein, der sich bereits über die "unerfahrenen "Philosophen zu erheben gewußt hat. Er hat die hippokratischen, platonischen, aristotelischen Anschauungen im einzelnen mit weitschweifiger Gründlichkeit $\mathrm{zu}$ korrigieren gesucht und $\mathrm{zu}$ dogmatischen Wahrheiten formuliert. Als Ausgangspunkt seiner Theoreme hat er die These von Gottes Weisheit aufgestellt:

"Der Vater der Natur hat seine Güte offenbart durch die weise Sorgfalt für alle seine Kreaturen, indem er jeder das ihr wahrhaft Nützliche verlieh. Laßt uns mit Hymnen und Lobgesängen ihn preisen! - Die wahre Frömmigkeit besteht nicht in Opfern von Hekatomben und kostbaren Spezereien, sondern in der Erkenntnis und dem Lobe der Wahrheit, Allmacht und Güte Gottes «1).

Für Plato und ARISTOTEles war Gott eine sich in allen Naturerscheinungen offenbarende Wirklichkeit; für GALEN ist Gott zu einer Art Hypothese gesunken, durch die dieser Fachmann den Bau des Menschenkörpers zu erklären strebte. Weil die Weisheit Gottes unergründlich ist, hat sie GALEN nach der Art aller Theoretiker dieses Schlages durch seine eigene Weisheit ersetzt; und als ob er alle Zwecke der Natur durchschaut hätte, versuchte er selbst zu er klären, wie zweckmäßig alle Körperteile gebaut sind. Die Seele hat er auf dieselbe dogmatische Art wie Gott begriffen; vom Grundsatze geleitet, daß die Seele zu ihren Lebensäußerungen der Organe

1) E. Schwalbe, Vorles, uib. Gesch. d. Medizin, Jena I909 S. $5^{8 .}$ 
bedarf, suchte er den Nachweis zu führen, daß wir deshalb Hände, Augen, Gehirn usf. besitzen, weil sie der Seele nötig sind. Er hat Tiere seziert und danach über den Bau des Menschenkörpers geschrieben, da er dem Grundsatz huldigte, daß der Tierkörper mit dem Menschenkörper in allen wichtigen Teilen übereinstimmt. Er hat übrigens die Sektionen weniger der Erkenntnis der Körperstruktur wegen ausgeübt, als vielmehr um sich in Erklärungen einlassen zu können, wozu jedes Organ dient. Auf diesem Wege ist GALEN als der erste Fachgelehrte dazu gekommen, Tatsachen und Theorien als zwei voneinander unabhängige Wissensgebiete ab. zusondern. Als Tatsache hat er die Zusammensetzung des Körpers aus Organen, als Theorie die Weisheit Gottes und die allgemeine Zweckmäßigkeit betrachtet; er verknüpft z. B. die Tatsache des Rückenmarks und der Rückenmarksnerven mit der Zweckmäßigkeitstheorie: das Rückenmark sei deshalb vorhanden, um den Rumpfnerven als Ausgangspunkt zu dienen, da diese, müßten sie aus dem Gehirn ihren Ursprung nehmen, wegen allzugroßer Länge leicht hätten zerreißen können ${ }^{1}$ ). Diese Methode ist verführerisch; sie stützt sich auf Erfahrung (erklärt sie doch Tatsachen!), verleiht der Theorie den Schein des Geistreichen und ist sehr leicht zu handhaben; kein Wunder, daß sie für alle Zeiten für gewisse gelehrte Richtungen charakteristisch bleibt und unter immer neuen Namen für alle Ewigkeit leben wird, obwohl sie im Grunde auf diejenige Teleologie herauskommt, über die sich LICHTENBERG mit seiner Bemerkung lustig gemacht hat:

"Er wunderte sich, daß den Katzen gerade an der Stelle zwei Löcher in den Pelz geschnitten wären, wo sie die Augen hätten $\left.«^{2}\right)$.

\section{Die Scholastik.}

Wir übergehen die Wissenschaft des frühen Mittelalters nicht ihrer Bedeutungslosigkeit wegen (die Lehren des hl. Augustin verdienten analysiert zu werden), sondern weil ihre Ideale zu weit von den modernen, die wir zu schildern haben, entfernt sind $\left.{ }^{3}\right)$. Wir

1) Schwalbe, a. a. O., S. 58 .

2) Literatur. Oeuvres anatomiques, physiologiques et médicales de Galien, Paris 1854-57. BRuno Bloch, vgl. S. 14. E. Schwalbe, Vorlesungen ïb. d. Geschichte d. Medizin, Jena 1909. - R. v. Töply, Geschichte d. Anatomie in Neuburger-Pagel, Handbuch d. Geschichte d. Medizin, Jena I903, wo auch die iibrige Lit. zu finden ist.

3) Vgl. W. MAy, Die Naturteleologie und Biogenie der Kirchenväter. Verh. d. natw. Vereins zu Karlsruhe I 906. - Zöckler, O., Geschichte d. Bezieh. zw. Theologie u. Naturwissenschaft, 2 Bde., Gütersloh 1877.

Rádl, Geschichte der biol. Theorien. I. 2. Autl. 
dürfen aber die Scholastik nicht übergehen, diejenige Geistesrichtung, aus der und gegen die sich die neue Wissenschaft entwickelt hat.

Im neunten Jahrhundert erhebt sich die Scholastik, die erste selbstbewußte Wissenschaft der mitteleuropäischen Völker. In einem Teil des westlichen Europas, in Nordafrika und einem Teil des südöstlichen Asiens waren die Kulturträger des frühen Mittelalters konzentriert. Doch auch da lebten die meisten Bewohner als Barbaren; als Kulturideal hat damals in Europa das Christentum gegolten; man blickte zu demselben mit ähnlicher Achtung auf, mit der man heute die Kunst, die Wissenschaft, feine Manieren, die Geistesdisziplin betrachtet. Bücher waren höchst selten; königliche Bibliotheken enthielten nur zehn Bände; die Schriften der klassischen Autoren waren so selten wie heute die Originale der alten Meister, mit deren heutiger Bedeutung sich diejenige der Handschriften im Mittelalter noch am ehesten vergleichen läßt. An die Stelle der Bücher traten ganz notwendig Schulen, an die Stelle der Schriftstellerei mündliches Lehren, statt nachzudenken debattierte man. 》Bene disserere est finis logices «, gut zu debattieren ist das Ziel der Logik hat als Grundsatz gegolten, wobei man unter Logik die Wissenschaft im Allgemeinen verstanden hat.

Die Augen der Menschheit waren nach rückwärts gerichtet. Dort, in der Vergangenheit, ist das Lebensideal verwirklicht, am Anfang sind alle Wahrheiten dem Menschen offenbart worden; auf dem Kalvarienberg ist der Höhepunkt des Lebens der Menschheit überschritten worden und nähert sich seitdem immer mehr dem Untergange. Nichts Neues mehr ist vom Leben zu erwarten; nur darum handelt es sich, die ewigen den Juden offenbarten Wahrheiten $\mathrm{zu}$ verstehen, zu befolgen und auf die gesamte Menschheit $\mathrm{zu}$ verbreiten.

Einmal nach rückwärts gewandt, hat man auch für das heidnische Altertum wohlwollendes Verständnis gezeigt; Plato, ARISTOTELes, GALEN erschienen dem Mittelalter als unerreichbare Genien, die für den Verstand dasselbe, was Christus für den Glauben bedeuten. Gott selbst habe einen ARIstoteles der Menschheit gegeben, steht bei dem seliggesprochenen ALBERT DEM GROSSEN geschrieben ${ }^{1}$ ), und durch dieses Gestirn die Erde beleuchtet. "Wir sind Zwerge «, seufzt ein anderer berühmter Scholastiker, 》 die auf den Schultern der Riesen stehen $\left.«^{2}\right)$.

1) Hervéau, Hist. de la scolastique II. I, S. 225.

2) Bernard de Chartres im 12. Jh. (Hervéau I. S. 61). 
Die Schulmäßigkeit der scholastischen Wissenschaft wurde durch die retrospektive Stimmung ermutigt: liegt es doch im Wesen der Schule, das allgemein Anerkannte, d. h. das Überlieferte zu erhalten und für andere anstatt für sich selbst die Denkoperationen auszuführen. Verurteilen wir nicht blindlings dieses Ideal der Scholastik! Wenn ein Gelehrter von heute die genialen Entdeckungen eines Darwin, Newton, Galilei preist, denen sich alle Menschen der Jetztzeit und der Nachwelt werden unterordnen müssen und die wir nur in Einzelheiten werden verbessern können, so drückt er dieselbe Überzeugung aus, der das verschmähte Mittelalter gefolgt ist; war es diesen Forschern der Neuzeit möglich, sich zur absoluten Wahrheit $\mathrm{zu}$ erschwingen, warum sollten wir diese Möglichkeit einem Hippokrates oder einem ARISTOTELES absprechen?

Im frühen Mittelalter hat sich der Geister Südeuropas eine naiv religiöse, mystische, platonisierende Stimmung bemächtigt; sie fand den besten philosophischen Ausdruck in den Lehren der Neuplatoniker und des hl. AUGUSTIN und hat unter mannigfachen Schicksalen bis in die zweite Hälfte des zwölften Jahrhunderts die Gemüter beherrscht. In dieser Zeit hat der von Spanien aus eingeführte Aristotelismus zum ersten Male in Frankreich und in England die Forscher für den Kultus der abstrakten Wissenschaft gewonnen. Die Anhänger des hl. Augustrin, die Verehrer des schlichten Gemüts, haben mit Mißtrauen die Inthronisierung der skeptischen Vernunft verfolgt; ALBERT DER GRosse und ThOMAs von Aguin, die berühmtesten Aristoteliker und Vertreter der neuen Wissenschaft, waren von ihren Zeitgenossen als kühne Neuerer gehaßt und geliebt; mehrere ihrer Thesen wurden von der Kirche verboten ${ }^{1}$ ). Die Aristoteliker sind aus dem Kampfe siegreich hervorgegangen; die Manuskripte und in späterer Zeit die gedruckten Ausgaben des ARISTOTELES haben sich ungemein vermehrt, so daß man noch vor dem Ende des I 5. Jahrhunderts über I20 Ausgaben seiner Schriften zählt²). Auch die Naturwissenschaft, die einen integrierenden Teil der aristotelischen Philosophie bildet, wurde nicht vergessen. Im Einzelnen haben die scholastischen Naturforscher verschiedene Systeme befolgt; die älteren Scholastiker hielten sich vorwiegend an die Bibel, an die Lehren der heiligen Väter, an den Neuplatonismus; später hat man die naturwissenschaftlichen Teile von Platos Timäus

1) G. v. Hertuing, IViss. Richtungen u. philos. Probleme im I3. Jh. München I9IO. E. Meyer, Geschichte der Botanik. Königsberg I857. IV. Bd., S. 9 sq.

2) HervéAu I. S. 38. 
und noch später ARISTOteles und Galenus zu schätzen gelernt. Im großen und ganzen hat man aber das gleiche Ziel verfolgt: eine "Wissenschaft an sich "auszubauen, ein möglichst exaktes System von logisch aus gewissen Prinzipien abgeleiteten Sätzen zu entwickeln, in dem sich jedes Theorem restlos vernunftmäßig beweisen ließe. Das konkrete Wissen trat dem System und der Beweisführung gegenüber zurück. Alles Subjektive war ausgeschlossen; es wurde eine unpersönliche, abstrakte, rein rationelle, für alle Welt gültige Wissenschaft angestrebt, eine Wissenschaft, die jederzeit das Ideal der professionellen Gelehrten gebildet hat. Der Unterschied zwischen Laien und Fachleuten war scharf gezogen und durch Gesetze bestimmt; nur pflegte man anstatt 》 Wissenschaft " Kirche und anstatt Fachmann » Kleriker « oder » Doktor «zu sagen. Das Konzil von Trient wollte diese von der laienhaften Renaissance gefährdete Auffassung der Wissenschaft durch ein Gesetz bestimmen und hat verordnet:

"Es geziemt dem Laien nicht, öffentlich zu disputieren oder zu lehren, sondern er folge der von Gott bestimmten Ordnung und öffne sein Ohr denjenigen, die den Lehrauftrag erlangt haben, und er lerne von ihnen die Gottesweisheit. Wer sich dagegen versündigen wird, sei auf vierzig Tage exkommuniziert «1).

Die Scholastik bedeutet den Triumph der analytischen Methode über die Mystik, den Sieg der exakten, begrifflichen Wissenschaft, der festen Terminologie und des abstrakten, trockenen Stiles über die das Gefühl und die Subjektivität betonende Intuition, welche letztere ihre Erlebnisse durch Analogien auszumalen sucht; sie bedeutet den Triumph der internationalen ("katholischen «) über die individuelle Wissenschaft, den Sieg der gelehrten Kultur über das natürliche Leben. Die Legende vom seliggesprochenen ALBERT DEM Grossen spielt naiv auf diesen Triumph an. Im Traume ist dem jungen ALBERT die heilige Jungfrau erschienen und hat ihm eine glänzende Zukunft versprochen: er möge zwischen der Berühmtheit in der Gottesgelehrtheit und zwischen der in der weltlichen Philosophie wählen. AlBERT hat sich sofort für die letztere entschieden. Die heilige Jungfrau verlieh ihm also den philosophischen Genius; beleidigt aber in ihrem Herzen, daß er sich den Idealen der Heiligen untreu erwiesen hat, hat sie entschieden, daß er vor dem Tode in die ursprüngliche Unwissenheit verfallen werde. Welches

1) »Non orportet laicum publice disputare vel docere, sed ordini a Domino tradito cedere et aurem is qui docendi gratiam acceperint aperire, et divina ab eis doceri. Qui transgressus fuerit, quadraginta diebus excommunicetur.» HERvÉAU I. 30. 
auch geschah ${ }^{1}$ ). In dieser Legende kommt deutlich die Idee zum Ausdruck, daß die Scholastik zwar eine kirchliche, aber keine göttliche Lehre war. Und wirklich: während der schlichte Christ notwendig jeden Heiden für einen Sohn des Teufels und jedes Wort der heiligen Väter für göttliche Wahrheit nahm, hat ALBERT einen mehr zivilisierten und weniger radikalen Standpunkt vertreten, als er den Grundsatz aufgestellt hat, in religiösen Fragen bleibe wohl der heilige AUGUSTIN Autorität, in der Wissenschaft sei dagegen mehr auf Aristoteles, auf Hippokrates und auf Galen zu achten. Der Grundsatz war nur cum grano salis richtig: die griechische Wissenschaft hängt organisch mit der griechischen Religion zusammen, ebenso wie Augustins Wissenschaft mit dessen Theologie; für einen objektiven Forscher vom Schlage eines ALBERT ist aber jene dogmatische Unterscheidung charakteristisch — und verhängnisvoll: als später die Renaissancestürmer à la GIORDANo BRUno nebst ARISTOTELES auch die heiligen Väter als nicht lebensfrisch genug verwarfen, standen sie dem Gesichtspunkte des schlichten Christen näher als der gelehrte ALBERT - die tote Kultur mußte dem neuen Leben weichen.

Die Scholastik betonte die geistige Kultur, hatte feines Gefühl für die Tradition; das Natürliche, das Urwüchsige war ihr zuwider. Was konnte übrigens damals ein Wissenschaftler unter Natürlichkeit verstehen? Natürlichkeit, Erfahrung, Praxis bedeutete soviel wie Roheit. Die Praktiker waren Hirten, Scharfrichter, Hexen und dergleichen mehr; kein Wunder, daß sich die Scholastiker über diese Wissenschaft erhaben fühlten. In einem solchen Milieu hatte der aristokratische Grundsatz des von den Scholastikern hochgeschätzten arabischen Arztes RHAzES, es sei für einen Arzt wichtiger, tausend Bücher zu lesen als tausend Kranke zu sehen, seinen gesunden Sinn. Bedeutet doch tausend Kranke zu sehen noch nicht etwas Neues an ihnen gewahr zu werden...

Der Spott, mit dem man die Scholastik heute überhäuft, hat mehr historische als sachliche Gründe. Aus den Studien P. Duhems

1) F. A. Pouchet, Hist. des sci. nat. au moyen âge, Paris 1853 , S. 217. In einer modifizierten Form erzählt Gi. Bruno dieselbe Legende yon Aristoteles. Auch diese Verwechslung ist bezeichnend. (Gr. BRuno, V. d. Ursache, dem Prinzip u. d. Einen. Berlin 1872). Damit hängt wahrscheinlich zusammen, was später während der Renaissance mit einem boshaften Akzent erzählt wurde, daß Albert (oder Aristoteles) zuerst Esel, dann ein berühmter Gelehrter und schließlich wiederum Esel war. Bruno spielt a. a. O. darauf an. 
geht hervor, daß die Forscher der Renaissance an die Scholastik anknüpften ${ }^{1}$ ); in der Biologie ist die Kontinuität zwischen der Scholastik und der modernen Wissenschaft niemals ernstlich unterbrochen worden, und sofern dies der Fall war, ist es zum Nachteile der Biologie geschehen, wie wir noch sehen werden. Allein die Stürmer der Renaissance haben das Schulmäßige, Objektivistische jener Wissenschaft dem Gelächter preisgegeben, und wir wiederholen ihren Spott, obwohl wir heute praktisch den abstrakten Scholastikern näher stehen als den Idealen des individualistischen Zeitalters der Renaissance.

\section{Die Universitäten.}

Die europäischen Universitäten sind teils aus Kloster- und Domschulen, teils aus Mediziner- und Juristengilden entstanden. Scholastisch sind ursprünglich nur die ersteren gewesen, als deren Vorbild die um I200 entstandene Pariser Universität galt; bald nach der Sorbonne sind hohe Schulen in Orléans, Bourges, Toulouse entstanden; demselben Zeitalter entstammen die Universitäten in Oxford und in Cambridge; die mitteleuropäischen Universitäten wurden im I4.-I6. Jahrhundert gegründet. An den Hochschulen wurde die Gelehrsamkeit zentralisiert, dogmatisiert und internationalisiert; die Wissenschaft hat durch dieselben offizielle (kirchliche) Anerkennung erreicht. Ihr Ruhm war kein geringer; im I3. Jh. machten die von allen Gegenden Europas herzuströmenden Hörer der Sorbonne fast den dritten Teil der Pariser Bevölkerung aus; ALBerT DER Grosse mußte des großen Andranges der Schüler wegen in Paris im Freien die Vorlesungen halten ${ }^{2}$ ). Aristoteliker, Platoniker, Galenisten ${ }^{3}$ ) stritten da um verschiedene Hypothesen. Die Naturwissenschaften waren auf den Universitäten meistens schwach vertreten; am schwächsten waren die medizinischen Fakultäten besucht, weil nur große Städte einen geprüften Arzt bezahlen konnten ${ }^{4}$; die italienischen Universitäten hatten anfangs nur drei Professuren (für kirchliches und weltliches Recht und für Medizin); die Rhetorik, Mathematik, Astronomie (Astrologie)

1) P. Duhem, Etudes sur Leonardo da Vinci, II, Paris I909, S. 2 sqq.

2) Pouchet, F. A., Hist. d. sci. nat., Paris 1853 , S. 633 sq.

3) Man verstehe diese Namen so, wie wenn man heute von "Darwinisten", "Lamarckisten", „Kantianern" u. ä. spricht.

4) L. Geiger, Renaissance u. Humanismus, Berlin I882, S. 406. 
und Philosophie hat man erst während der Renaissance an den Universitäten eingeführt ${ }^{1}$ ).

Anderen Wurzeln sind die Hochschulen von Salerno (südlich von Neapel) und von Montpellier erwachsen. Dieselben waren von der Kirche unabhängig; die salernitaner Schule ist um 850 aus einer Gilde der städtischen Ärzte entstanden, die die Patienten nach einer gemeinsamen, geheim gehaltenen Methode behandelten; erst später wurde ihr das Öffentlichkeitsrecht und das Recht zu lehren und Schriften herauszugeben erteilt. Im zehnten Jahrhundert hat diese Hochschule den Höhepunkt ihrer Entwicklung erreicht; im I4. Jhrh. wurde ihre Bedeutung durch diejenige der scholastischen Universitäten beeinträchtigt. Die halb französische, halb spanische Schule von Montpellier war nach der Salernitaner die berühmteste in der ganzen Christenwelt; sie ist nach dem Vorbilde der letzteren gegründet und hat vor allem praktische Arzneikunst gepflegt $\left.{ }^{2}\right)$.

Die (scholastischen) Hochschulen sind erst infolge der öffentlichen Anerkennung der Scholastik zu großem Ruhme gelangt; die meisten sind übrigens erst während der Verfallzeit der Scholastik gegründet worden. Die Wissenschaft der Renaissance hat sich unabhängig von den Universitäten entwickelt.

\section{Die Laienwissenschaft,}

Es hat also am Ende des Mittelalters eine sublimierte, äußerst exakte, sich auf eine bewährte Tradition stützende, in allen Einzelheiten durchgearbeitete Wissenschaft bestanden. Ihre Pfleger waren sehr berühmt: der Ruhm eines ALBERT DES GROSSEN reicht bis auf unsere Zeit heran, obwohl uns unsere Auffassung der Wissenschaft kaum begreifen läßt, warum man diesen Mann so sehr verehrt hat.

Neben dieser objektiven Wissenschaft der Hochschulen hat das Mittelalter noch ein mehr subjektives und intimes Verhältnis zur Natur gekannt. Zwar kümmerte sich damals kein Laie nach der Art eines Leonardo, eines Buffon, eines Goethe um die Erkenntnis der Natur, zwar verstand man unter Wissenschaft nur die organisierte Hochschulwissenschaft, d. h. die »lehrende Kirche «; ein halbbewußtes Wissen um die Natur ist aber auch im Mittelalter

1) Burckhardt, J., Kultur der Renaissance, 3. Aufl. I. S. 252.

2) Auch die Universitäten von Bologna und von Padua sind auf analoge Weise wie die Schule von Salerno entstanden (Pouchet a. a. O. S. 93). 
unter den Laien vorhanden gewesen. Man hat Tiere und Pflanzen gezüchtet: neben dem Reitpferd und dem Esel auch Rinder, Schafe, Schweine, Ziegen, verschiedene Hunderassen, Hennen, Enten, Gänse ${ }^{1}$ ) und hat gewiß manche Erfharungen über den Bau, die Lebensweise und die Krankheiten dieser Tiere gesammelt. Niemals ist die Jagd auf Bären, Hirsche, Wildschweine, Wölfe, Auerochsen und auf verschiedene Vögel mehr getrieben worden als im Mittelalter ${ }^{2}$ ). Die Fischerei wurde eifrig gepflegt, und die Bewohner Skandinaviens unterschieden schon damals mehrere Seehundarten und haben die Walfische bereits mit der Harpune gefangen. In einzelnen Städten Südeuropas wurden Löwen und Leoparden im Käfig zur öffentlichen Schau ausgestellt; an Ende des I2. Jahrhunderts war in Palermo ein zoologischer Garten vorhanden ${ }^{3}$ ). KARL DER GROSSE erließ für seine Höfe ein Edikt, »daß allerhand schönes und seltenes Geflügel das Gehöft verziere « $\left.{ }^{4}\right)$, ein sprechender Beweis dafür, daß man an Pfauen, Fasanen, Tauben, Turteltauben, Schwanen u. ä. Gefallen fand.

Die praktischen Kenntnisse über die lebendige Natur würden für die Geschichte der Biologie auch dann nicht bedeutungslos bleiben, wenn sie niemals in einer biologischen Schrift den Ausdruck gefunden hätten, denn es ist nicht nur dasjenige von historischem Wert, das in actis steht. Es gibt aber auch solche Schriften: seit dem dreizehnten Jahrhundert erscheinen Werke über Falkenjagd, und bald folgen auch Schriften über jagdbare Tiere ${ }^{5}$. Man gab populäre medizinische, tierärztliche und gärtnerische Schriften heraus. In den Klöstern wurden solche Werke verfaßt, abgeschrieben und zu Bibliotheken gesammelt; als Pfleger der Kranken legten die Mönche bei den Klöstern Gärten mit Heilpflanzen an; auch Mineralien und Muschelschalenkabinette waren in den Klöstern zu finden ${ }^{6}$ ).

Der Art, in der Plinius die Naturwissenschaften aufgefaßt hat, brachte das Mittelalter großes Verständnis entgegen. Nach seiner

1) Einzelheiten bei V. Carus, Geschichte d. Zoologie, München 1877, S. 180 sq.

2) Vgl. über solche Jagden Pouchet 1. c. S. 7 I sqq.

3) Burckhardt, J., Kultur d. Renaissance, III. Auf. S. ro.

4) CARus, 1. c. S. I 83 .

5) Kaiser Friedrich II. war einer der ersten Schriftsteller ïber die Falknerei; über jagdbare Tiere hat der berühmte Jäger GAston PhoEbus im I4. Jahrhundert geschrieben (Pouchet, S. 7 I sqq.).

6) Pouchet, S. IO8. 
Methode hat der Augustinermönch Thomas DE CAntimpré (etwa I I86-I263) eine große Naturgeschichte, d. h. die Beschreibung der ganzen sichtbaren Welt kompiliert (De naturis rerum). Eine andere Enzyklopädie dieser Art (Speculum malus in 33 Büchern) hat den Dominikanermönch Vincent DE Beauvais ( $\dagger$ I264?) zum Autor. An beide Schriften haben die Enzyklopädisten aus dem Ausgange der Renaissance angeknüpft; der Geist ihrer Naturauffassung lebt noch in Bufrons Naturgeschichte und zum Teil in Brenms Tierleben fort.

Der ungelehrte Mann strebte auch eine ideale Auffassung der Natur an. Als unbedingter Verehrer der Bibel hat er sich vorzugsweise für die in der hl. Schrift erwähnten Tiere und Pflanzen interessiert und die Entstehung und große Verbreitung der sog. "Physiologi " und "Bestiarii ", naturwissenschaftlich moralisierender Bücher, veranlaßt ${ }^{1}$ ). Gegen das Ende des Mittelalters waren auch Reiseschilderungen mit Darstellungen von Tieren fremder Länder beliebt. Die dem schlichten Menschen eigene Vorliebe für Allegorien, für das Mystische, sein naiver Glaube an die Wunder der Natur haben Schilderungen von phantastischen Tieren, Einhörnern, Basilisken, von an Bäumen wachsenden Enten erzeugt. Es gab wenig gelehrte Ärzte; medizinische Praxis wurde von Priestern, alten Weibern, Hirten, Hufschmieden, Barbieren und vagabundierenden Scharlatanen betrieben. Neben der Ärztekunst trieben diese abergläubischen, aber nicht immer unerfahrenen Leute nicht selten auch Magie, Wahrsagerei, Astrologie, Alchemie, eine Beschäftigung, in der der wissenschaftliche Trieb des Menschen mit der volkstümlichen Poesie und Religion zu einem Chaos sich vermengt.

Die mittelalterliche Laienwissenschaft war eine sehr einfache, naive, abergläubische Lehre, ohne jede bewußte Tradition, ohne jede verstandesmäßige Theorie, war aber praktisch, der Kunst verwandt und direkt aus dem Leben geschöpft; sie bildete den Gegensatz zu der trockenen Begriffswissenschaft der Scholastiker.

Die Neuzeit begann: man wurde der Scholastik müde; die italienische Renaissance suchte sie durch die Erhebung der Literatur, PARACElsus durch die Anlehnung an die volkstümliche Wissenschaft zu überwinden.

1) Ausführlich behandelt dieses literarische Genre CARUS in seiner Geschichte d. Zoologie S. Iog sqq. 


\section{Kapitel. \\ Die Renaissance.}

Zur Zeit, als in Paris die Scholastik den Gipfel des Ruhmes erreichte, wurde in Italien das Nationalbewußtsein rege; DANTE (I265-I32I) gab den Idealen der neuen nationalen Kultur Ausdruck in seinen Gedichten. DANTE ist noch voll Ehrfurcdt vor der Scholastik und vor der Wissenschaft überhaupt ${ }^{1}$ ), PETRARCA (I 304 bis I 374) hat das klassische Altertum noch mehr als DANTE verehrt, die Wissenschaft dagegen gehaßt: die Jurisprudenz sei eitler Formalismus und sei keine freie Wissenschaft, und noch verachtenswerter seien die Ärzte, die keinen Sinn für die Natur heilkraft zeigten und den Kranken, ohne die frische Wirklichkeit erfassen zu können, bloß nach schematischen Lehrsätzen beurteilten.

Mit Petrarca beginnt der $\mathrm{Hu}$ man is mus, die philologisch orientierte Vorliebe für das (römische, später auch das griechische) Altertum; bereits bei diesem Dichter kommen die guten und schlimmen Seiten der neuen Richtung zum Vorschein: die Betonung eines eleganten Stiles, das Lob der alten Autoren, Eigendünkel und Wortfechterei. Die Scholastiker setzten die Wissenschaft auf den Thron, der Humanismus betonte wieder die Literatur. Die begriffliche Exaktheit der alten Lehrer, welche es nötig gemacht hat, sich neu gebildeter Technizismen und unnatürlicher Redewendungen zu bedienen, dieser »Pariser Stil $\left.«^{2}\right)$, wurde jetzt für Barbarei erklärt, die aristotelischen Wahrheiten durch CiCERos Redewendungen ersetzt; es wurden korrekte Ausgaben der klassischen Autoren besorgt, wodurch wieder indirekt auch die Naturwissenschaften gefördert wurden, indem man seitdem wortgetreue Ausgaben von ARISTOTELES, Galenus, Plinius, Theophrast u. a. der Forschung zugrunde legen

1) Er hat auch eine scholastisch-geologische Schrift >Über das Meer und das Festland a (Quaestio de aqua et de terra) verfaßt.

2) Nach L. Vives (I492-I540): In pseudodialecticos. 
konnte. Die dem Humanismus geneigten Ärzte waren der Philosophie feindlich gesinnte Galenisten, die sich eine genaue Kenntnis GALENS angelegen sein ließen, während ihre Vorläufer eher die aristotelisch (philosophisch) orientierten arabischen Kommentatoren GaLENs studiert hatten.

Im Humanismus ist nur ein Zweig der Renaissancewissenschaft, und nicht eben der schönste, zur Blüte gelangt; obwohl anfangs gegen die Zunftwissenschaft gerichtet, hat er später alle Gebrechen des gelehrten Standes (die Humanisten haben einen Gelehrtenstand gebildet) gezeitigt. Die Renaissance selbst war inhaltsreicher, lebenskräftiger und war philosophisch begründet. Ihr Vaterland ist Italien, während in Deutschland nur einzelne im neuen Stil zu leben versuchten. Der den romanischen Völkern angeborene Individualismus wurde damals in Italien zum höchsten Ideal in der Politik, in der Kunst, in der Wissenschaft erhoben. Ein jeder wollte auf eigene Faust leben und denken und alles verstehen. Die katholische, d. h. internationale Fachwissenschaft wurde bespöttelt: Laien, Maler, Kardinäle, Fürsten bemühten sich jetzt, Gelehrte und Philosophen zu sein. Das gelehrte Latein wurde durch die Volkssprache, die abstrakten scholastischen Probleme durch konkrete Fragen über den Bau des Menschenkörpers, über das Wesen des Lebens, über den Flug der Vögel u. ä. ersetzt. Die Erfindung der Buchdruckerkunst (um I450) hat die mündlichen Vorträge an den Hochschulen entwertet: jeder Laie konnte von nun an zu Hause Bücher lesen. Populäre Wissenschaften, die Alchemie, die Astrologie und verschiedene geheime Künste wurden jetzt von ungeschulten Laien mit Vorliebe gepflegt. Der offiziellen Religion gegenüber stellte man Skepsis zur Schau. Die Kirche, selbst vom neuen Geist durchdrungen, hat die religiöse Gleichgültigkeit gelitten, solange sie keine demonstrativen Gebärden annahm; waren doch Ciceros und Platos Reden auch von manchen kirchlichen Würdenträgern höher geschätzt als die schlichten Grundsätze der Heiligen Schrift und der heiligen Väter.

Überall greift das Streben nach einer unmittelbaren Beteiligung am Leben um sich; daher kommt in der Politik die Neigung zum Republikanismus, in der Kunst der Realismus, Porträtkunst, Vorliebe für weltliche Bilder, in der Philosophie der Hang zur Mystik, zur Naturphilosophie, zu mathematischen Wissenschaften zum Vorschein.

Aristoteles, als das Vorbild einer indirekten (durch die Vernunftschlüsse vermittelten) Naturerkenntnis, wurde verlassen. Während ARIstoteles die logische Bearbeitung des Wissens betonte, 
sehnte man sich jetzt nach Anschauungen; ARIstoteles galt als Losung der Hochschulen, jetzt verlangte man ein schlichtes Wissen; ARISTOTEles war von den Arabern eingefüht und in barbarischem Latein behandelt worden, jetzt strebte man nach nationaler und formal vollkommener Wissenschaft. GIORDANO BRUNo, obwohl er, der Zeit nach, einer späteren Periode angehört, hat die neue Stimmung zum klaren Ausdruck gebracht. Er nennt einmal ARISTOTELEs einen Esel und an einem anderen Ort einen »sehr seichten Sophist «I $)$; von den Gelehrten schreibt er:

„Und daher kommt es, mein lieber Teofilo, daß die Doktoren so billig herkommen, wie die Sardellen. Wie diese mit wenig Mühe geboren, gefunden, gefangen werden, so billig kauft man auch die Doktoren $\left(^{2}\right)$.

Er lacht die Philosophen aus, die das Wesen der Philosophie in Wortanalysen, Sprachkenntnis und ein wenig Logik suchen ${ }^{3}$ ), er ist fast Heide, bespöttelt die Wunder ${ }^{4}$ ), glaubt an die Astrologie, an die Seele der Erde, der Gestirne und des Weltalls - Platos Geist schwebt über seiner Philosophie.

Plato und Plotin wurden Anführer der Renaissancephilosophen. In Deutschland war diese Weltanschauung vom tiefsinnigen $\mathrm{N}$. CUSANUS (I4OI-I464) und dem kampfeslustigen PARACELSUS (1473 bis I 54I), in Italien vom Kardinal BESSARION (I 403-I472), von MARsilius Ficinus (1433-I499), von PiCo della Mirandola (1462 bis I494) gepredigt. Nach Platos Vorbild haben seine italienischen Anhänger (in Rom, in Florenz, in Mailand) »Akademien «, d. h. Klubs von freien Forschern gegründet, die das Laientum der neuen Wissenschaft den pädagogische Zwecke verfolgenden Universitäten gegenüber charakterisieren. Übrigens waren auch sonst die italienischen Universitäten bei weitem nicht so konservativ und von der Kirche abhängig wie die nordischen.

Obwohl persönliche Freiheit das Ideal der Renaissance bildete, gab es pralktisch, leider, nur wenig wirklich freie Forscher. Die Gesellschaft hat eher nach dem Schein als nach dem Kern der Wissenschaftlichkeit gestrebt, und kein italienischer Forscher dieses Zeitalters hat sich eine Unabhängigkeit erkämpft, die einen SPINOZA, einen SPExcer, einen PARACElsus so sehr ziert. »Künstler, Dichter

1) V. d. Ursache, d. Prinzip u. d. Einen. Übers. v. A. Larsen, Berlin I872, S. I24.

2) V. d. Ursache usw. S. 38 .

3) Ebenda, S. 70, 7 I.

4) Reformation d. Himmels, deutsch von I. Kuhlenbeck, Leipzig i889, S. 3 I3. 
und Gelehrte wurden an den Höfen ,gehalten', etwa wie sich die Fürsten zu anderen Zeiten Hofnarren und deren Frauen Schoßhunde hielten. Auch waren solche Zelebritäten vor allem ein Hauptartikel, mit denen man sich gegenseitig im Renommee den Rang abzulaufen suchte $\left.{ }^{1}\right)$. Der berühmte Leonardo war keineswegs besser als die anderen.

Neben der theoretischen Wissenschaft wurde auch anschauliche Naturkenntnis gepflegt; es wurden botanische Gärten mit aus der ganzen Welt zusammengetragenen Bäumen, Sträuchern und Blumen gegründet, auch zoologische Gärten mit fremden Tieren, mit Löwen, Giraffen, Zebras usf. wurden in Italien bekannt; an den Höfen hielt man fremde Menschenrassen zur Schau ${ }^{2}$ ). Trotzdem wurde die theoretische Biologie während der Renaissance weniger gepflegt als zur Zeit der Scholastik; die Bekämpfung des ARIsToteles lief praktisch auf die Hintansetzung des von ihm gepflegten vergleichenden Studiums der Organismen aus.

Unter die Repräsentanten der Renaissance gehören u. a. LEOnardo, Vesal, Kopernikus, Paracelsus, Kolumbus und die Nachzügler Gi. Bruno, Th. Campanelda, Kepler. Die Renaissancewissenschaft entwickelte sich im I4. Jhrh. und erreichte im I5. den Höhepunkt; die durch Luther ( 5 I 7 ) eingeleitete Reformation versetzte ihr den Todesschlag.

Die sog. moderne, an Galilei, Descartes, Baco anknüpfende Wissenschaft bewegt sich bereits in einem anderen, der Scholastik weniger feindlich gesinnten geistigen Milieu. Weder Paracelsus noch LEONARDO können mit den modernen Fachleuten verglichen werden - am ehesten noch VESAI dem Inhalt seiner Lehren nach; aber auch die Form und die Ideale dieses Forschers stehen den heutigen fremd gegenüber. Die Fragen, die zu jener Zeit die Köpfe der Forscher beschäftigten, werden wir aus der ausführlichen Analyse des PARACELSUs kennen lernen; wir werden diesem Arzt mehr Raum widmen, weil in ihm das Mittelalter mit der Renaissance kämpft, weil er höchst beachtenswert ist und oft mißverstanden wird. LEONARDO und VESAL werden unser Bild der Renaissancewissenschaft vervollständigen.

1) Schemanns Einleitung zu Gobineaus Renaissance (Reclam).

2) Burckhardt, S. Io sq. 


\section{Paracelsus.}

Das Leben des Paracelsus.

\section{Lehrjahre.}

Theophrastus Paracelsus wurde I493 in Maria-Einsiedeln, einem schon damals vielbesuchten Wallfahrtsorte, in der Nähe von Zürich, geboren. Ein Jahr zuvor hat Kolumbus Amerika entdeckt, eine Tat übrigens, deren Bedeutung unserem Helden kaum jemals aufging, wie er überhaupt die Umwälzungen seiner Zeit, von welchen die philosophischen und wissenschaftlichen Historiker uns viel $\mathrm{zu}$ erzählen wissen, mit Ausnahme der religiösen Kämpfe, unberücksichtigt ließ. Sein Vater, Wilhelm Bombast von Hohenheim, der uneheliche Nachkomme eines alten deutschen adligen Geschlechtes, der Bombaste ${ }^{1}$ ) von Hohenheim, lebte der Sage nach in Einsiedeln als Arzt in einem an der Sihlbrücke, der sog. "Teufelsbrücke «, liegenden Haus; erst I 8I 4 wurde dieses Haus eingerissen und an dessen Stelle ein neues Gebäude errichtet, welches noch heute unter dem Namen »Paracelsushaus « bekannt ist. Wilhelm Bombast heiratete eine Gotteshausfrau, ein unfreies, zum Kloster gehöriges Weib, welches ihm ein einziges Kind gebar. Bei der Taufe bekam PARACelsus wahrscheinlich die Namen Philipp Theophrast; der zweite Name, der Name des berühmten Schülers des ARIsToteles, deutet an, daß der Vater auf das Söhnchen von Anfang an große Hoffnungen setzte. I 502, als PARACELSUS neun Jahre alt war, übersiedelte sein Vater nach Villach in Kärnten und ist dort 1534 als geachteter Bürger und Arzt gestorben. PARACELSUs blieb seiner schweizerischen Heimat sein Leben lang treu; doch sprach er gern auch von seinem zweiten Vaterlande.

Neben den angeführten Namen trägt PARACELSUS noch andere; er nennt sich selbst nicht Philipp, desto lieber dagegen THeOPHRAST, oder auch Aureolus Theophrastus, wie behauptet wird, um sich von seinem griechischen Namensbruder zu unterscheiden; doch erzählte man, daß er sich den Namen AurEolus aus mangelhafter Kenntnis der lateinischen Sprache beigelegt hat; er soll irgendwo den Satz »exstant aureoli Theophrasti libri «gelesen ${ }^{2}$ ) und das Epi-

1) Das Wort „,bombastisch" wurde erst später in Zusammenhang mit der Schwärmerei des Paracelsus in Verbindung gebracht; der heutige Sinn dieses Wortes stammt aus dem Englischen, wo man durch sbombast « ursprünglich den zum Ausstopfen dienenden Stoff und dann metaphorisch Redeschwulst bezeichnet.

2) M. B. Lessing, Paracelsus, sein Leben und Denken, Berlin $1 \$_{39}$. 
theton für einen Namen gehalten haben. Jedenfalls war er auf seinen griechischen Namen stolz und rühmte sich, daß er den Namen nicht nur in der Taufe bekommen, sondern daß er auch seinem Wesen nach ein Theophrast sei ${ }^{1}$ ). Den Namen •PARACELSUS «legte er sich wahrscheinlich als Student bei, indem er dem damaligen Brauch folgend seinen Namen HoHenheim latinisiert hat; es ging aber auch ein Gerücht herum, daß er durch diesen Namen seine wissenschaftliche Tüchtigkeit andeuten wollte: er stehe höher als der römische Arzt Celsus; man begründete diese Vermutung damit,

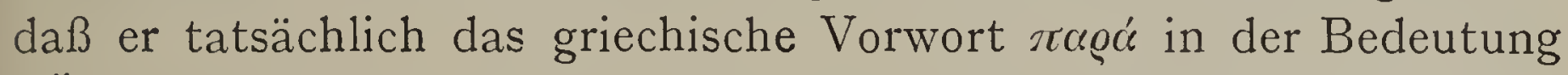
"Über-" angewendet hätte; so in den Titeln seiner Schriften Paramirum, Paragranum. Er unterschrieb sich auch (Helvetius) EREMITA, um seinen Geburtsort anzudeuten, wurde auch GeRmanus und SuEvus genannt, und seine Gegner hießen ihn neben anderen Schimpfnamen gerne Kakophrastus. Die Herausgeber seiner Schriften nennen ihn Philippus Aureolus Theophrastus Paracelsus BomBASTUS AB Hohenheim, utriusque medicinae doctor, mysteriarcha, chemicorum princeps usw.

Paracelsus lebte in seinen Jugendjahren das Leben eines Dorfjungen; er soll Gänse und vielleicht auch Schweine gehütet haben; er selbst gedenkt mehrmals seiner armseligen Jugend:

$" D a ß$ ich in großer Armut erzogen und aufgewachsen bin, daß meines Vermögens nicht gewesen, meinem Gefallen nach zu handeln... mich hat groß gepeiniget der Pflug meiner Nahrung . . der mir ein Kreuz gewesen «2).

Damals soll ihn auch das Unglück getroffen haben - wenn an der Sache überhaupt etwas ist - , welches ihm später von seinen wissenschaftlichen Gegnern vorgeworfen wurde. Man tuschelte von ihm, er wäre Eunuch. Als er als dreijähriger Knabe Gänse gehütet hat, soll ihn - nach einer Version - eine Sau so schlimm gebissen haben $\left.{ }^{3}\right)$; nach einer anderen Erzählung soll ihn ein mutwilliger, vagabundierender Soldat in Kärnten entmannt haben ${ }^{4}$ ); wiederum andere wußten anzugeben, daß PARACELsus (von seinem Vater?).

1) Fr. Bitiscius, Aur. Philippi Theophrasti Paracelsi ... opera omnia, Genevae 1658. Ich zitiere nach dieser lateinischen Übersetzung der Paracelsischen Schriften. weil mir die Husersche Ausgabe nicht zugänglich ist; ich habe aber meine Zitate, wo. es möglich war, mit den deutschen Zitaten anderer Autoren verglichen.

2) C. Sudhorf, De secretis secretorum theologiae. (Kritik d. Echtheit a. Parac. Schriften, Berlin, II, S. 406-407.)

3) Lessing, S. 7 .

4) F. Erastus, Disputationum de medicina Th. Paracelsi p. I. Basileae I57 1, S. 237 - 
kastriert worden wäre, auf daß er sich völlig dem Studium widme ${ }^{1}$ ). Vielleicht ist diese Legende nur zur Erklärung des Äußeren unseres Helden erdacht worden; er war nämlich bartlos (nur an dem angeblich von TintoRetro gemalten Porträt trägt er einen dünnen Kinnbart), stark kahlköpfig, vorzeitig veraltert, sein Schädel soll eher von weiblichem Typus gewesen sein ${ }^{2}$ ), und seiner Umgebung war seine sexuelle Apathie auffallend. Ist es aber denkbar, daß ein Eunuch so temperamentvoll, lebensfrisch, angreifend, so männlich in seinem öffentlichen Auftreten sein könnte, wie es PARAcELsus tatsächlich war $\left.^{3}\right)$ ?

Der Vater pflegte den Knaben gewiß mit zu den Kranken zu führen, lehrte ihn die Kräfte der Pflanzen kennen und weihte ihn in die theoretischen Grundlagen der Arzneikunst ein, sofern sie ihm bekannt waren; in der Bibliothek des Vaters oder in derjenigen des Klosters von Einsiedeln fand der wißbegierige Knabe vielleicht auch einige Bücher, aus welchen er mit Hilfe seines Vaters und der Mönche das Latein erlernen konnte. Wie diese ersten Studien des jungen Adepten der Wissenschaft im einzelnen beschaffen waren, ist unbekannt; wir wissen nur, daß PARACELSUs in späteren Jahren mit Dankbarkeit der väterlichen wissenschaftlichen Leitung gedacht und dabei noch eine Reihe von Geistlichen, Klostervorstehern und Bischöfen aufgezählı hat, bei denen oder aus deren Büchern er die Elemente seiner neuen Wissenschaft geschöpft hatte. Neben der häuslichen Erziehung wurde für seine Denkungsweise der Einfluß

\section{1) L.essing, S. 7 .}

2) LEssing, ebenda.

3) Die Schilderung des Paracelsus als eines Eunuchen wurde nicht nur von seinen Gegnern weitergegeben, um ihn zu verleumden, sondern auch von einigen seiner Anhänger (von van Helmont), um ihn als ein außergewöhnliches Wesen vorzuführen. Einige Autoren weisen auf Paracelsus' geringschätzige Urteile über die Weiber, die nur Halbmenschen sein sollen. Diese Worte lauten aber erstens bei Paracelsus nicht so wegwerfend, um aus ihnen auf einen $\mathrm{Haß}$ gegen die Weiber schließen zu mïssen, und zweitens sprechen sie doch dieselbe Auffassung des Weiblichen aus, welche auch Aristoteles, der gewiß kein Eunuch war, vertreten hatte. In seinem charakteristischen ärtlichen Eide verspricht Paracelsus seine Hilfe auch den Frauen. Es ist ferner auffallend, daß Paracelsus, der mit Vorliebe Schimpfworte gebraucht hat, die nach unserer und auch nach der damaligen Auffassung sehr unanständig waren, keines ausgesprochen hat, das sich auf das Geschlechtsleben beziehen wiirde; auch fehlen unter seinen zahlreichen Metaphern Beispiele aus dem Verhältnis von Weib und Mann; wissenschaftlich wird aber die Befruchtung von ihm analysiert. Ein vielleicht übermäßiges Schamgefühl würde auch zur Erklärung dessen genügen, was die Zeitgenossen auf eine organische Impotenz zurückgeführt hatten. 
zweier scheinbar entgegengesetzte Tendenzen verfolgenden, im Grunde aber geistig verwandten Persönlichkeiten, des Sponheimer Abtes Johann Trithemius und des Inhabers von Silberbergwerken in Schwaz (Tirol) SIEgmund FÜGER, entscheidend. TRITHemius ( I462-I5I6), ein zu seinen Lebzeiten berühmter Schriftsteller, war ein exzentrischer Polyhistor; als leidenschaftlicher Bücherfreund kaufte er in jenen Zeiten, wo eben das erstemal neben Manuskripten auch gedruckte Bücher die Bibliotheken zu füllen begonnen hatten, alle alten Handschriften, deren er habhaft werden konnte; er kannte sich vorzüglich in der klassischen Literatur aus und war, wie andere seiner fortschrittlichen Zeitgenossen, der neuplatonischen Mystik geneigt. Er scheint aber den Neuplatonismus nicht tief genug erfaßt zu haben, erdachte sonderbare Methoden zur leichten und raschen Erlernung fremder Sprachen, konstruierte eine geheime Schrift, verfaßte viele andächtige Bücher und veröffentlichte auch historische Werke, in welchen er sich auf Autoritäten stützte, die er sich, wie heute behauptet wird, selbst erdacht hatte. Auch Medizinisches gab er heraus und veröffentlichte eine große Schrift gegen die Umtriebe der Hexen, welche letzteren er in mehrere Gattungen eingeteilt haben wollte; doch stand auch er selbst im Ruf der Zauberei. Im ganzen ein Mann von seltenem natürlichen Wissensdrang, jedoch ohne schulmäßige, an den Universitäten gepflegte Geistesdisziplin. Seine Abneigung gegen die Scholastik und seine Verachtung der ihre Wissenschaft feilbietenden Gelehrten charakterisieren ihn deutlich als einen Gegner der Schulweisheit ${ }^{1}$ ).

Der »Sponheimer Abt « ist wahrscheinlich für die romantischmystische Denkrichtung des PARACELSUs verantwortlich; von ihm wurde PARACELSUS wahrscheinlich in der Geringschätzung der (damals an den Hochschulen gepflegten) Logik und des systematisch geordneten Wissens bekräftigt, von ihm hat er seine Ehrfurcht vor der heiligen Schrift und sein theoretisches Wissen über die Astrologie, die Magie und andere volkstümliche Grundlagen der Wissenschaft; dort erfuhr er vielleicht den Einfluß des Neuplatonismus, dort wurden ihm die Augen für die Unendlichkeit der Naturgeheimnisse geöffnet, deren Schleier dem menschlichen Verstande unmöglich zu durchdringen sei, weil die Natur von ihren Wahrheiten nur

1) Man vergleiche über Trithemius: Dr. Silbernagel, Joh. Trithemius, Landshut 1868. Von seinen Schriften sind die wichtigsten: Liber de scriptoribus ecclesiasticis. - De luminaribus sive de viris illustribus Germaniae. - Steganographia. - Polygraphia cum clave. - De septem intelligentiis libellus. - Antipalus maleficiorum usw.

Rádl, Geschichte der biol. Theorien. I. 2. Aufl. 
den Eingeweihten erzählt. Mag der Einfluß TRITheims auf PARACELSUS noch. so groß sein, jedenfalls betraf er nur die allgemeine Gemütsstimmung: seine einzigartige Gedankenenergie, die Einheitlichkeit seines Systems und die von keinem anderen Autor vor der Neuzeit so kühn gelehrte Überzeugung von der Natürlichkeit, Menschlichkeit, Diesseitigkeit der Wissenschaft konnte PARACELsUs nirgends sonst als bloß in seinem eigenen Herzen entdecken ${ }^{1}$ ).

Anders waren die Erfahrungen beschaffen, die der aufstrebende Jüngling im Silberbergwerk des SIEGMUND FÜGER gesammelt hat. Welcher Zufall mag ihn in die Bergwerke und in die chemischen Laboratorien, wo das gediegene Metall gewonnen wurde, geführt haben? In den Bergstollen zu arbeiten und Erze zu schmelzen, bedeutete für einen angehenden Doktor kaum etwas anderes, als heute das Hüten der Schafe für einen Naturforscher bedeuten könnte. Den Berg- und Hüttenleuten waren Galen und Avicenna unbekannte Namen; mit ihnen konnte man nur über die tiefen Erdschichten reden, wo die edlen Metalle wachsen, über das komplizierte alchemistische Gerät, mit dessen Hilfe man das Erz im Feuer schmelzte, und über Methoden, Legierungen herzustellen; PARACELsUs' Wißbegierigkeit erlaubte ihm überdies ohne Zweifel, auch manchen alchemistischen Kniff von seinen Genossen zu erlernen, der mehr von medizinischem oder von spekulativem Werte war. Seine Erfahrungen über das Hüttenwesen waren wohl weit von den Lehren des im Kloster unter den Büchern spekulierenden TRITHEIM entfernt; und doch waren beide in einer Hinsicht einander verwandt: beide bildeten den Ausfluß einer volkstümlichen, ungeschulten, natürlichen wissenschaftlichen Bestrebung: auf der einen Seite TRITHEIM, ein phantastischer Dilettant, der mit der Wissenschaft die natürlichen Bedürfnisse seines Geistes gestillt, auf der anderen das Hüttenwesen, das den praktischen, ebenfalls natürlich sich ergebenden Bedürfnissen dient. Die Philosophie der heiligen Schrift, die Mystik, die Astrologie und das Hexenwesen bildeten nur eine Art populäre Theorie zu der harten Praxis in dem Bergwerk; es war wohl eine wilde, undisziplinierte Theorie; gibt es aber im Volke eine andere? TRITHEIMs

1) Ich kenne Tritheim nur aus Silbernagels Schrift; nach der Darstellung dieses. Autors $z \mathfrak{u}$ schließen ist zwischen dem oberflächlichen Tritheim und dem philosophisch ernsten Paracelsus gar kein Vergleich möglich; ïberraschend ist, daß Tritheim keine Stellung zu der Philosophie seines älteren Zeitgenossen, des NIC. Cusanus (I 40I-I 464 ), eingenommen hat. Auch bei Paracelsus suche ich vergeblich nach dem Namen dieses großen, ebenfalls dem Platonismus geneigten Philosophen. 
Wissenschaft und das damalige Hüttenwesen waren beide natür liche Wissenschaften, der künstlichen gegenüber, welche an den hohen Schulen, fern vom Leben und Streben der tatlustigen Menschen, das geduldige Gedächtnis der Schüler mit der pedantisch zurechtgelegten Tradition beschwerte.

Auch dieser hohen Schulen, der deutschen, der italienischen, der französischen, soll übrigens PARACELsus nicht eine kleine Zierde gewesen sein, wie er sich dessen einmal selbst rühmt; es ist aber nicht bekannt, weder an welcher Schule, noch wie lange er die Erklärungen der alten Autoren gehört hat. Irgendwo ist er vielleicht auch zum Doktor promoviert worden. Seine Gegner äußerten später Zweifel, ob er überhaupt den Doktorhut bekommen hätte ${ }^{1}$ ), und es ist sonderbar, daß PARACELSUs seinen Verleumdern nicht den Mund durch die Nennung der Universität, deren Doktorat er erlangt, geschlossen hat. Doch hat er sicherlich fleißig auf den Universitäten studiert, denn nur dort konnte er sein Faustproblem erlebt haben. Er hat es tatsächlich erlebt: wie alle wirklich großen Männer, so weiß auch er von sich mit ungesuchter Natürlichkeit zu erzählen, wie er anfangs an die Schulmedizin wie ans Evangelium geglaubt, wie er sich aber vergeblich bemüht habe, sich in dieselbe hineinzuleben; wie ihm diese Mühe Kummer verursacht, wie er'sich von der Medizin losgesagt und sie wieder aufgenommen; wie er nach Gewißheit, nach lebendiger Wahrheit, nach einer Erkenntnis, der er sich mit seinem vollen Wesen ergeben könnte, gedurstet, und wie man ihm nur tote Gelehrsamkeit geboten ${ }^{2}$ ). Daß er promoviert worden war, das konnte er erdichten; über die inneren Kämpfe um eine neue Wahrheit konnte er nur nach einem tatsächlichen Erlebnis berichten.

Sich ein Urteil über die literarischen Kenntnisse des PARACELsus zu bilden, ist nicht leicht; seine Schriften sind jeder strengeren wissenschaftlichen, an den Schulen gepflegten Methode bar; insbesondere fehlt ihnen die von den Gelehrten geübte Praxis, das eben diskutierte Problem an die bekannte Tradition anzuknüpfen, einschlägige Autoritäten zu zitieren, die Beweise logisch żu entwickeln und seine Anschauungen möglichst den eben herrschenden Vorstellungen anzupassen. PARACELSUS war $\mathrm{zu}$ originell, um

1) Paracelsus nennt sich utriusque medicinae doctor; doch hat er sich einmal auch Doktor der heiligen Schrift genannt, obwohl er keiner war. (SuDHofF-Schuber'T, Paracelsusforschungen II, S. 159 sq.)

2) Bitiscius, III, S. 66. 
das Angelernte eine Rolle in seinen Schriften spielen zu lassen, und so finden sich in seinen Schriften von den älteren medizinischen Berühmtheiten kaum mehr als die Namen einiger hervorragender Autoritäten, Namen wie Hippokrates, Avicenna, Galenus, Rhazes, Mesue u. a.; hie und da tauchen auch Bruchstücke aus ihren Lehren auf, hie und da kann ein ungefährer Eindruck ihrer Denkungsart konstatiert werden. Mit ihren konkreten Behauptungen, Erklärungen und Hypothesen befaßt sich PARACELsus nicht ${ }^{1}$ ), mag er sie schon gekannt haben oder nicht. Übrigens bedeuten ihm solche Namen weniger jene ruhmvollen Ärzte, die einmal gelebt und mächtig auf die Gemüter gewirkt haben, als vielmehr Götzenbilder einer abergläubischen, auf den Hochschulen gepflegten Religion, wobei die Unterschiede zwischen Avicenna, Galenus und ARISTOTELES von ihm kaum beachtet werden.

PARACELSUS selbst schrieb dem gelehrten Residuum, das ihm von den Hochschulen übrig geblieben war, wenig Wichtigkeit $\mathrm{zu}$ : 》was ich von euch gelernt habe, das hat der ferndrige Schnee gefressen "lachte er später ${ }^{2}$ ), und um nachzuweisen, daß er außerhalb des historischen Stromes stand und von der Tradition unbeeinflußt geblieben ist, rühmte er sich in seinen späteren Jahren, daß er bereits zehn Jahre lang nichts gelesen und daß er seine Lehre den Schreibern ex abrupto und ohne literarische Hilfsmittel diktiert ${ }^{3}$ ). Der lateinischen Sprache war er mächtig; griechisch kannte er aber kaum.

Auf den Hochschulen war das wissenschaftliche Ideal nicht zu er. lernen. Wo sollte es PARAcElsus finden? Er begab sich auf Reisen. Und wie er sich für TRITHEIM und für die Bergwerke kaum aus freier, logisch begründeter Wahl, sondern aus innerer Nötigung entschloß, so bewog ihn zu seinen Reisen nicht etwa die Einsicht, daß die Reisen für einen angehenden Arzt notwendig wären, sondern natürlichere, menschlichere, tiefere Gründe: er reiste, weil es sein Schicksal so gewollt hat. Ein angeborener, unüberwindlicher Drang trieb ihn, unstät von Ort zu Ort zu schwärmen, eine den Ärzten bekannte Krankheit, welche ihm viel Böses gebracht hat. Wie lange

1) Nur als Universitätsprofessor ließ er sich anfangs in die Erklärung der Lehren des Hippokrates und des botanischen Gedichtes von Macer Floridus ein. (Macer Floridus ist ein sonst unbekannter Verfasser eines botanisch-medizinischen Gedichts; er gehörte nach E. Meyer der salernitanischen Schule an und lebte gegen das Ende des 9. Jahrhunderts.)

2) Bitiscius, I, I $8_{4}$ (Paragranum, Einleitung).

3) Ebenda. 
er auf Reisen blieb, und wie die Reisen beschaffen waren, darüber schweigt die Geschichte. PARACELsUs bekennt selbst mit seiner wunderbaren Aufrichtigkeit, daß er weniger von seinem Verstand, als von seiner Natur in die weite Welt getrieben wurde und daß für ihn, den Begründer einer neuen Wissenschaft, dieses Schicksal unvermeidlich war. Sein Bekenntnis möge uns gleichzeitig als ein Beispiel dienen für die Art, wie er geschrieben und geurteilt hat ${ }^{1}$ ):

ఎMir ist not, daß ich mich verantworte von wegen meines Landfahrens und von wegen des, daß ich so gar nindert bleiblich bin. Nun, wie kann ich wider das sein, oder das gewaltigen, das mir zu gewaltigen unmöglich ist? Oder was kann ich der Prädestination nehmen oder geben?... Mein Wandern, so ich bisher verbracht habe, hat mir wohl erschlossen: Ursach halber, daß keinem sein Meister im Haus wachset, noch seinen Lehrer hinter dem Ofen hat... die Kunst geht keinem nach, aber ihr muß nachgegangen werden ... Nehmet ein Exempel: Wollen wir zu Gott, so müssen wir zu ihm gehen, denn er spricht, kommt zu mir ... So folgt nun aus dem, will einer eine Person sehen, ein Land sehen, eine Stadt sehen, die Art und Gewohnheit derselben erfahren, des Himmels und der Elemente Wesen erkennen, so muß einer denselben nachgehen. Ich habe etwan gehört von den Erfahrenen der Rechte, wie sie haben in ihren Rechten geschrieben, daß ein Arzt soll ein Landfahrer sein: dieses gefällt mir zum besten wohl. Denn Ursache, die Krankheiten wandern hin und her, so weit die Welt ist, und bleiben nicht an einem Ort. Will einer viel Krankheiten erkennen, so wandere er auch: wandere er weit, so erfährt er viel und lernet viel kennen. Und ob es Sache würde, daß er wieder seiner Mutter in den Schoß kommt, kommt dann ein solcher fremder Gast in sein Vaterland, so kennt er ihn ... Die englischen Humores sind nicht ungarisch, noch die neapolitanischen preußisch. Darum mußt du dahin ziehen, da sie sind ... So nun da ein Zwängnis ist, wie kann man dann einen verachten, oder verspeien, der solches tut? Es ist wohl wahr, die es nicht tun, haben mehr denn die es tun: die hinter dem Ofen sitzen, essen Rebhühner, und die den Künsten nachziehen, essen eine Milchsuppe; die Winkelblaser tragen Ketten und Seide an, die da wandern, vermögen kaum einen $Z$ wilch zu bezahlen; die in der Ringmauer haben Kaltes und Warmes, wie sie wollen, die in Künsten, wenn der Baum nicht wäre, sie hätten nicht einen Schatten ... Der die Natur durchforschen will, der muß mit den Füßen ihre Bücher treten. Die Schrift wird erforscht durch ihre Buchstaben, die Natur aber durch Land zu Land, als oft ein Land, als oft ein Blatt. Also ist Codex Naturae, also muß man ihre Blätter umkehren...."

Diese Schilderung gibt uns gleichzeitig einen etwaigen Vorgeschmack von der Art der wissenschaftlichen Reisen des PARACELsUS. Er führte da wahrscheinlich ein rauhes, ungeordnetes, rauflustiges, ruhmrediges, zerlumptes Gaskognerleben, ein Leben, für das leere

1) Bitiscius, I, 255. - F. Strunz, Th. Paracelsus, Leipzig I903, S. 35 sqq. 
Taschen und ein lebensfrohes Herz am meisten charakteristisch sind; er half sich wahrscheinlich mit der Ausübung der ärztlichen Praxis aus und pilgerte von Dorf zu Dorf, von Stadt zu Stadt; seinesgleichen fand er in den niedersten Schichten der Gesellschaft; da ließ er sich von einer Hexe in ihre geheimen Künste einweihen, dort lernte er bei einem Schmied, der Kurpfuscherei trieb, bei Schafhirten, Badern, vagierenden Juden, bei betrügerischen Alchemisten, bei Scharfrichtern, Zigeunern und bei anderen Leuten, deren rauhe Lebensführung man sich bei den jetzigen geordneten Verhältnissen kaum vorstellen kann. Man suche sich nur lebendig vorzustellen, was die Nachricht eines Zeitgenossen eigentlich behauptet, nach welcher PARACELsus fünf Jahre Zigeuner war ${ }^{1}$ ) - daß er mit den Wölfen heulen mußte, wer wird es leugnen können? Auf diese Weise bereiste Paracelsus fast das ganze Europa; er gibt an, in Spanien, in Portugal, in Siebenbürgen, in Ungarn, in Kroatien, in Neapel gewesen zu sein: » man hat mich aus Litauen, aus Preußen, aus Polen fortgejagt, ich gefiel nicht den Belgen, nicht den Universitäten, nicht den Juden $\left.\ll^{2}\right)$. Welche Erfahrungen — man gebe acht auf das Wort "Erfahrungen " - muß er während dieser Wanderung gesammelt haben! Nur hier und da mit einigen hingeworfenen Worten berührt er die Erinnerungen an jenes Leben. Gewiß gab es manche »lachende Reisezufälle «; gewiß gab es oft » Gelage mit guten Gesellen am Rhein und an der Donau " und auch anderwärts wenn die Mittel dazu waren - nach der überall gleichen Losung der Bohème, für deren König und größten Philosophen PARAcELsus gelten kann: »Ob ich schon das Geld mit guten Gesellen vertummelte, so ist doch meinem Hauptgut nichts abgegangen, denn die Kunst, mein Hauptgut, die verläßt mich mit Gottes Hilfe nimmer $\left.«^{3}\right)$. Was Wunder, daß auch das Kartenspiel und die Würfel auf ihre Rechnung kamen! Es wurde behauptet, daß PARACELsus auch einigemal hinter Schloß und Riegel saß4).

So war das Milieu beschaffen, in dem PARAcelsus seine medizinischen Erfahrungen gesammelt; als er in späteren Jahren gegen die Schulweisheit die Erfahrung betonte, da rief ihm dieses Wort Erinnerungen an die Arzneikunst der Kräuterkenner, der Zigeuner,

1) Vgl. Netzhammer, S. I 20.

2) LESSING, S. 9.

3) Kahlbaum, Th. Paracelsus, Basel i 894, S. 6 r.

4) Erastus, S. 238. Erastus behauptet, daß P. zuerst ein Abstinenzler war und erst später dem Bacchus gehuldigt hat. 
der Scharfrichtergehilfen und anderer in ähnlicher Art erfahrener Leute hervor. Dies war seine berühmte Erfahrung, von der er später viel geschrieben hat, derentwegen er von den Gelehrten ausgelacht wurde, und für welche auch die Jetztwelt wenig Verständnis zeigt. ... Doch davon wird noch die Rede sein. Daß sein Landfahrertum wenig geeignet war, seinen Umgangsformen, seinem Geschmack, seinem Wortschatz, seiner ganzen Gemütsverfassung Schliff und Eleganz zu verleihen, wer würde es auffallend finden?

\section{Paracelsus als Professor.}

Nach langen Reisen und nach einer kurzen und, wie es scheint, wenig rühmlichen Episode in Straßburg (wo PARAcELsus bei Gelegenheit einer Disputation mit einem gewissen Chirurgen VENDELINUS schlecht davongekommen sein soll) ließ er sich 1526 in Basel nieder. Es ist ihm gelungen, dort eine einflußreiche Persönlichkeit, den Buchdrucker Frobenius, zu heilen, durch dessen Verwendung ihm die Professur der Physik, der Medizin und der Chirurgie an der Universität und das Stadtphysikat verliehen wurde. Der damals dreiunddreißigjährige PARACELSUs stand in voller Manneskraft, hatte viele Menschen gesehen, viele Krankheiten behandelt und verfügte auch über gewisse literarische Kenntnisse. Er begann Vorlesungen zu halten. Die Schönheit und Kraft seiner Wissenschaft galt ihm über alles; alles andere Wissen und Tun schien ihm mit dieser verglichen kleinlich; überdies wurde er gewahr, daß er gar manches kannte, das den übrigen Gelehrten unbekannt geblieben war. Die Vorlesungen trug er mit feurigem Temperament vor und wie es sich von einem Menschen mit seiner Vergangenheit erwarten läßt, er sprach über dasjenige, was er kannte und wie er es kannte. Es fehlte ihm jedwedes System; seine Wissenschaft hatte auch keine festen Grenzen; war es eigentlich Medizin? Sie schien bald die Lehre von Krankheiten zu sein, bald Theologie, bald wieder Metaphysik oder Ethik - sie war alles zugleich, alles, was ein erfahrener, übermütiger und ungeschulter junger Mann auf dem Herzen trägt. Manchmal waren seine Vorträge sehr gründlich, indem jeder neue Begriff ausführlich und von mehreren Seiten, unter Anführung populärer Gleichnisse erklärt wurde ${ }^{1}$ ); ein andermal war er wiederum sehr dunkel. Konnte es anders sein? Wenn heutzutage ein Professor der Medizin seinen Hörern die Wissenschaft erklärt, so be-

1) Man lese z. B. die Anfangskapitel von Opus Paramirum. 
achtet er an erster Stelle, daß diese Tatsache in die Anatomie, jene in die Hygiene gehört, daß dieses da die Leber, jenes dort der Magen, daß dieses Bauchfellentzündung, jenes wieder Blattern sind. Darüber wußte aber PARACELsus wenig; oder, sagen wir lieber, er hatte keine Lust und keine Fähigkeiten, solche nach seiner Meinung kleinliche Wortunterschiede mit Nachdruck hervorzuheben. Ihm handelte es sich darum, möglichst nachdrücklich kundzugeben, wie schön, neu und wahr alles dasjenige ist, was er wußte und glaubte; und wenn es einen Unterschied zwischen der Anatomie und Pathologie, zwischen der Medizin und der Theologie, zwischen dem Gehirn und der Leber, zwischen der Bauchfellentzündung und den Blattern gibt, so kümmerte er sich um denselben wenig; höchstens nur insofern, als er durch diese Worte seine Ideen ausdrücken konnte. Weil er die sonst übliche Terminologie (eine sehr präzise Terminologie, in welcher die Begriffe quidditas, potentia, actus und andere ähnliche einen ganz bestimmten Inhalt hatten) außer acht ließ, weil er seine Anschauungen nicht mit denjenigen anderer verglich, weil er kein System hatte, weil er keiner Methode überhaupt folgte, pflegte er so dunkel zu sein; seine Sprache war zu ungesucht, zu unmittelbar, ganz unwissenschaftlich, so daß man meistens nur nach dem Zusammenhange ihren Sinn errät. Er mußte sich für seine neuen Begriffe seine Sprache selbst schaffen, deshalb war sie unbeholfen, malte eher die Begriffe anstatt sie zu definieren und bediente sich mit Vorliebe der Allegorie. Dieselben Wörter (Anatomie, Astronomie, Leben, Tod, Geist u. ä.) bedeuten bei ihm an verschiedenen Stellen Verschiedenes und verschiedene Wörter Gleiches; konventionelle Bezeichnungen, an welche man immer einen und denselben Sinn anzuknüpfen pflegt, bedeuten bei ihm etwas anderes. Fügen wir hinzu, daß er ex abrupto vortrug und diktierte, daß er dem Definieren abhold war und seine Begriffe nur durch Analogien veranschaulichte und last not least, daß sein Deutsch den Wörtern wie dem Stile nach gemein war und daß er in einem schweizerischen Dialekt sprach, den nicht einmal seine Landsleute immer verstanden ${ }^{1}$ ) - was Wunder, daß man seine Lehre dunkel fand!

Seine Vorlesungen wurden mit Beifall aufgenommen. Sein feuriger Vortrag, seine Einzigartigkeit, seine dunkle Vergangenheit und seine Erfolge am Krankenbett lenkten die Aufmerksamkeit

1) $>$ Die Worte sind meistens ex infima fece plebis, die Konstruktionen ganz verworren, die Gedanken oft abgebrochen... bemerkt ein Deutscher ïber ihn (F. Bartscherer, Paracelsus, Paracelsisten und Goethes Faust, Dortmund I9I I, S. 226). 
auf ihn; mit welchen Gefühlen man zu ihm aufblickte, läßt sich aus folgenden Worten eines Zeitgenossen schließen:

' Die Akademie von Basel besa $\beta$ in Theophrastus Paracelsus einen deutsch vortragenden Professor der Medizin, der so tief in das innerste Eingeweide der Natur eingedrungen ist, die Kräfte und Wirksamkeiten der Mietalle und der Pflanzen mit einer so unglaublichen Geistesschärfe erforscht und durchgesehen hat, um auf Grund davon alle, auch die verzweifelten und nach der Überzeugung der Menschen unheilbaren Krankheiten zu heilen, daß erst mit ihm die Arzneikunst geboren zu sein scheint «1).

Die Doktoren und Professoren fanden dagegen viel an dem neuen Stern auzsustellen. Mit seiner ungeordneten Bildung, die er auf eine $z u$ exklusive Art gewonnen, mit seinen Lebenserfahrungen, die er in den schmutzigsten Erdwinkeln gesammelt, mit seinem wilden philosophischen Interesse und nicht $\mathrm{zu}$ allerletzt mit seinem Äußeren und mit seinen groben Umgangsformen wurde dieser Sansculotte plötzlich den Doktoren und Professoren gleichgestellt, der Elite der Gesellschaft, höchst anständigen Personen, die, an Formalitäten im Leben und in der Wissenschaft gewöhnt, voll von systematisch geordneten Wissen waren; ihr allseits anerkanntes Wissen verlieh ihnen ein hohes Sicherheitsgefühl, ein Bewußtsein, daß sie alles wußten, was gelehrte und berühmte Männer zu wissen pflegen. Die Folgen ließen nicht lange auf sich warten.

Später warf man PARACELSUS besonders Scharlatanerie vor, und wer die ewig gleichen Manieren der Gelehrten kennt, der findet diesen Vorwurf leicht begreiflich. PARACELsus kündigte z. B. seine Universitätsvorlesung mit einem herausfordernden Programm an, in dem u. a. zu lesen war:

"Die wenigsten der Doktoren behandeln heutzutage mit Glück die Medizin; ich aber werde diese $z u$ ihrem früheren Glanze zurückführen und von den gröbsten Irrtümern reinigen; ich halte mich nicht an die Vorschriften der Alten, sondern nur an dasjenige, was ich selbst a uf eigene Faust gefunden und durch lange Übung und Erfahrung als bestätigt gesehen habe $\left.\|^{2}\right) \ldots$

Die übermütige Herabsetzung der alten Autoren und die Lob- preisung der individuellen Erfahrung hätte kaum auffallenderes Ärgernis hervorgerufen; eine solche Hypothese, geschickt vorgetragen, hätte man (wohl mit einigen Protesten) hinnehmen können; allein jenes ich - ich - ich, das war gegen alle gute Sitte. PARACELSUS unterließ es, zwischen der Wissenschaft und seiner Person

1) LESSING, S. II.

2) R. Netzhammer, Th. Paracelsus, Einsiedeln-Köln, rgor, S. 40. 
selbst zu unterscheiden; er verlor sein irdisches Wesen so sehr aus den Augen, daß für ihn die Wissenschaft zur ersten Person, zum Subjekt wurde. Die Wissenschaft ist subjektiv — gäbe es keine Menschen, die das Wissen in ihren Köpfen tragen und im Sinne ihrer Erfahrungen, der PARACELsusartigen Erfahrungen, handeln würden, gäbe es eben keine Wissenschaft; die durch individuelle Erfahrung bestimmte Handlungsweise der Menschen, an Subjekte gebunden und durch Subjekte qualitativ bestimmt, macht das Wesen der Wissenschaft aus. In seinem Übermut hat nun PARACELsus, alle Rücksichten und Anstandsregeln beiseite schiebend, diese Wahrheit laut in die Welt hinausgeschrieen: er kenne keine andere Wissenschaft als die seinige, er selbst sei die Wissenschaft. Das "Ich « hat gesprochen; nun mußte auch das »Nicht-Ich» das Wort ergreifen. Denn um PARACELSUs lebten noch Repräsentanten einer anderen Auffassung der Wissenschaft, welche anstatt der subjektiven Überzeugung die objektive Wahrheit für ihre Grundlage erklärten. Für die Gelehrten aller Zeiten, von den Sophisten bis zu den modernsten Vertretern der objektiven Wissenschaft, stellt die letztere ein Objekt, ein von den denkenden und handelnden Menschen trennbares Ding, ein wertvolles » Gemeingut « der Menschheit dar. Und dies war der Grund, warum man PARACELsus Überhebung und Scharlatanerie vorgeworfen hat. Man verübelte ihm keineswegs seine Unbescheidenheit - die Ruhmsucht gehört doch fast zum Wesen des Gelehrten -, sondern die subjektive Art, in der PARACELsus seine Wissenschaft empfohlen hat. Die Gelehrten pflegen bekanntlich auf sich selbst in einer höflicheren Weise aufmerksam zu machen; der letzte Sinn ihres Stolzes liegt weniger in der Tatsache, daß sie entdeckt haben, als darin, daß die Fachleute ihre Entdeckung anerkannt haben; es ist besser zu sagen: »der berühmte $\mathrm{X}$. hat erklärt, daß ich begriffen habe «, anstatt: »ich habe begriffen "; nicht "ich verstehe dies und jenes ", sondern »ich bin berufen, es zu verstehen «. Die Höflichkeit gebietet, sich solcher Umgangsformen zu bedienen; wie nun in der Politik und in der Religion aus den ursprünglichen natürlichen Höflichkeitsformen ein für sich selbst bestehendes Zeremoniell wird, so gehen auch jene wissenschaftlichen Umgangsformen in Mark und Knochen der Gelehrten über und werden zum Wesen der Wissenschaft selbst, d. h. zum Wesen der objektiven Wissenschaft.

PARACELSUS war wahrscheinlich verwundert, daß die Fachleute durch sein vierschrötiges Auftreten beleidigt waren. Aus weiter 
Welt gekommen, voll von lebendiger Glut für die Wahrheit, mit der er sich vollends identifizierte, fühlte er sich natürlich über seine Kollegen, denen die Wissenschaft nur eine Art Amt war, erhaben; hierin war so wenig Eigendünkel, wie wenn sich der Herr über seinen Diener, der freie Mann über einen Sklaven erhaben fühlt; vielleicht erwartete PARACELSUS sogar, daß die Kollegen, von seiner neuen Wahrheit ergriffen, ihm folgen würden. Gewiß dauerte es einige Zeit, ehe er sich bewußt wurde, daß er »nicht nach ihrer Leier komponiert $\left.{ }^{1} 1\right)$ wäre, daß er nicht aus ihren Schulen abstammte und nicht in ihrem Stil schriebe ${ }^{2}$ ). Jedenfalls hat er versucht, sich der Methode der Gelehrten anzupassen, und hat über HrppokRATES, über die Botanik des MACER, über die Untersuchung des Urins und des Pulses - also über recht schulmäßige Themata, Vorlesungen angekündigt.

\section{Die Doktoren.}

Unter den Gegnern des Paracelsus sind diplomierte Ärzte und der gelehrte Stand überhaupt zu verstehen. Die Geschichte schweigt darüber, welche Persönlichkeiten es in concreto waren; es ist aber möglich, sich über ihre Tendenzen eine angenäherte Vorstellung zu machen. Ein Arzt war ein Würdenträger: Seidentalar mit Knöpfen besät, rotes Samtbarett, eine goldene Kette am Halse, Ringe mit Saphiren und Smaragden oder wenigstens mit gefärbtem Glas, Fransen, Spitzen und noch vieles andere der Art bekundete seine Gelehrsamkeit. Der Schein des Exotischen wurde überdies dadurch gefördert, daß man die Medizin seltener daheim, sondern vielmehr in Italien absolvierte, weil den deutschen Universitäten die Professoren der Medizin meistens zu teuer kamen. Die Erklärung der Medizin auf den Hochschulen war pädagogisch und systematisch geordnet. Man stützte sich selbstverständlich nur auf Bewährtes, also auf Galen, auf Avicenna, Rhazes u. ä. alte Autoritäten, die man verschiedentlich korrigierte, für die Lehrpraxis einrichtete und systematisierte. Man überschätze nicht den Glauben jener Gelehrten an diese alten Schriftsteller; sie glaubten an dieselben kaum anders, als ein Lehrer, der den Schülern die Elemente der lateinischen Sprache auf Grund der Lektüre des "De bello gallico « einzuprägen hat, an die Vorzüge von Cäsars Kriegführung »glaubt «. Sie glaubten meinetwegen; doch waren sie nicht überzeugt, da sie ihre "Anschau-

1) Bitiscius, I, I84.

2) Ebenda, I82. 
ungen «nicht geprüft, nicht mit anderen möglichen Lehren verglichen hatten. Man suchte ferner den wissenschaftlichen Geist der Schüler weniger durch die Einprägung von konkretem Wissen, als vielmehr indirekt $\mathrm{zu}$ fördern: wie man heute den philosophischen, ästhetischen und philologischen Geschmack der Gymnasiasten an der Lektüre der griechischen und römischen Autoren heranbildet (ohne sich in erster Reihe um den konkreten Inhalt der Lektüre zu kümmern); so förderte man damals die naturwissenschaftlich-medizinische Bildung durch die Analyse Galens, Avicennas usf., eine Methode, die wohl einseitig übertrieben, aber niemals - in der Schule - ganz entbehrt werden kann. Klarheit der Schlüsse, Exaktheit der Definitionen, überhaupt die formale Seite der Wissenschaft war das Hauptziel der Schulerziehung. Wie sie im einzelnen ausgestaltet war, das müßte erst durch einschlägiges Studium ermittelt werden. Aus der Polemik des PARACElsus und aus der Art, wie man seine Lehren aufgefaßt hat, kann man sich jedoch eine angenäherte Vorstellung von jener Wissenschaft bilden. Als Tatsachen haben a nato mische Fakta gegolten, welche man auf Grund allgemeiner Vorstellungen über das Wesen des Lebens physiologisch zu deuten bestrebt war. Das in anatomischen Lehrbüchern Enthaltene bildete die Grundlage, das allgemein Anerkannte; ein jeder erlaubte sich aber seine Deutungen vorzutragen; und auf diese Art stritten miteinander die Peripatetiker, die Akademiker, die Galenisten, die Scholastiker und andere Richtungen, analog, wie es unter den heutigen Gelehrten Darwinisten, Lamarckisten, Mechanisten, Vitalisten usf. gibt. Die Scholastik hatte zwar ihren Höhepunkt bereits überschritten; untergegangen ist sie jedoch eigentlich nie, sondern trat während der Renaissance nur in den Hintergrund, um nach den Reformationskämpfen von den Jesuiten wieder belebt zu werden. Die scholastische Wissenschaft war internationale, objektive, in gewissem Sinne exakte Wissenschaft (exakt in ihrer Logik); ihre Pfleger arbeiteten wohl mit Ernst und mit größerem oder geringerem Erfolge an der gründlicheren Ausarbeitung der vorhandenen Theorien, standen jedoch in fremdem Dienste, eben im Dienste des angelernten, traditionellen Wissensschatzes; sie waren wohl eifrige Pfleger, erfolgreiche Förderer der Wissenschaft, niemals aber ihre Erzeuger und Herren. PARACELSUS behauptet an einer Stelle, daß jedes Individuum so frei, so absolut, so total a priori gegeben ist, daß sich nichts Wesentliches an ihm verändern würde, auch wenn es keinen Himmel, keine Erde, keine Nahrung, auch wenn es nichts gäbe, wovon sein endliches 
Schicksal abhängig wäre. Die Wissenschaftlichkeit jener Gelehrten war diesem Ideal gerade entgegengesetzt: durch die Zeit, den Raum und die geistige Nahrung wurde das Wesen ihrer Bestrebungen vollends erschöpft.

Es war, wie sich a priori vermuten läßt, nicht nur PARACELSUs, der auf diese Zufälligkeit, Weltlichkeit, Unpersönlichkeit der gelehrten Wissenschaft hingewiesen; die für jene Zeit bezeichnende humanistische Bewegung entsprang ebenfalls dem Kampfe lebensfroher Individualitäten gegen wissenschaftliche Schemata: PeTrarca lachte diese Wissenschaft aus, AEneas Sylvius verurteilte scharf die Universitätslehrer, LEONARDo machte Witze über die Ärzte, und man schrieb damals öffentlich davon, daß akademische Würden um Geld auch den Köchen, Schneidern, Zimmerleuten, ja auch den Räubern verliehen würden ${ }^{1}$ ).

Als PARACElsus seine Wissenschaft zu predigen begann, verbreitete sich der Humanismus aus Italien nach Norden, war aber bereits im Verfall begriffen und artete in einen Formalismus aus, der vor der Scholastik kaum etwas voraus hatte. In Italien fand er wohl einen natürlichen Boden, indem er die Erinnerung an den klassischen Ruhm des Vaterlandes wieder belebte und die Liebe zu Schriftstellern predigte, welche der einheimischen Kultur angehörten; im Norden gab es weder ein entsprechend hohes Kulturniveau, als dessen Index die humanistische Pflege einer eleganten Sprachform hätte gelten können, noch Tradition, an die mit dem Kult Crceros und VERGILs hätte angeknüpft werden können, noch ein geeignetes ethisch-religiöses Milieu. Trotzdem fand aber der Humanismus auch im Norden Freunde und besonders Theoretiker, welche aus gelehrten und pädagogischen Interessen die korrekte lateinische und griechische Sprache pflegten. PARACElsus sah um sich diese schulmäßige Kultur, und ungekünstelt wie er war, sprach er sich über dieselbe sehr anstößig aus:

Was nutzt euch auch, daß ihr euch befleißet viel rhetorischen Geschwätzes, das doch keinen Arzt macht, sondern zerbricht... Was sucht ihr in der Logik und in eurer Dialektik, die all dem Arzt zuwider sind und Hinderung des Lichts der Natur? Verzehret nicht euere edle Zeit mit solchen Büchern. Was ist's weiter, so ihr in bonis litteris übertreffet den Vergilium? Was ist's, so ihr Lucanus selbst seid und seid Ovidius, seid Horatius? Was ist nun in Nöten, wem seid ihr Nutz als euerem Maul? $\mathrm{Ob}$ nicht Vergilium bereut hat seiner geschriebenen Torheit vor seinem

1) L. Geiger, Renaissance und Humanismus, Berlin, 1882, S. 407. 
End, auch den Horatium? Was ist aber, das den Medicum reut? Nichts. Denn er hat seinen Tag vollbracht mit den Arcanis ${ }^{1}$ ) und hat in Gott und in der Natur gelebt als ein gewaltiger Meister des irdischen Lichtes ${ }^{2}$ ).

Hört ihr nicht aus dieser Rede das abfällige Urteil eines Laien, eines Bauern etwa, über die feinen Errungenschaften der aristokratischen Kultur? Über die an Hochschulen erzogenen Doktoren äußerte er sich noch unumwundener:

Im Anfang der Arznei und der Ärzte ist der Arzt seltsam gewesen und wenig und teuer. Denn so viel hat zu dem Arzt gehört, daß wenig gewesen sind, die Ärzte möchten geben. Aber in die Länge ist der Unfleiß eingefallen und sind jetzt 300 Doktores oder 400 und mehr, die zu den ersten Zeiten nicht hätten mögen Köche der Ärzte sein: so gar ist die Arznei in das gemeine Ungeziefer gekommen, und all die, die sonst nirgend zu gut oder Nutz sind, werden Ärzte, werden Meister oder Doktores... Denn die hohen Schulen machen Doktores, die das zu sein nicht wert sind, nicht tauglich, nicht verständig... In Deutschland glaubt man gleichwohl, wenn ein deutscher Esel, verdorbener Schulmeister, Meßner, Henker und dergl. in der Sakristei zu Rom die Krone ${ }^{3}$ ) empfangen, so habe er den heiligen Geist mit sich heraus gebracht. So wird nämlich Deutschland von den Wälschen .....4) Wo sie selber nicht hinkönnen, schicken sie die deutschen Esel hin, nehmen I 4 Dukaten und machen aus einem deutschen Narren einen probierten Esel. . . Was ist uns nutz der Name, der Titel, die hohe Schule, so wir nicht Kunst auch haben? Die Kunst mäht den Arzt, nicht der Name noch die Schule «5).

Ein Muster der Grobheit, des Mangels an Anstand, der Sünde gegen alles, was man damals und jederzeit in den feineren Schichten der Gesellschaft für begehrenswert gehalten hat, waren die Reden dieses Naturmenschen, ganz antikulturell und anarchistisch. Es war, wie wenn im Theater, wo unter lauter fein ausgearbeiteten Redewendungen und delikaten Szenerien eine schöngefärbte Feuersbrunst vorgeführt wird und plötzlich der Schreckensruf Feuer! im Publikum ertönt. Denn der Unterschied zwischen PARAcELsus und den Gelehrten war der Unterschied zwischen Theater und Leben. Die Gelehrten stellten die Wissenschaft dar, eine fein durchgearbeitete, voll bewunderungswürdiger Lehren und Tatsachen, die man in den Schulbänken, daheim im Studierzimmer oder in eleganter Gesellschaft in Ruhe genießen kann; sie waren Schauspieler des Ideals, vielleicht geschickte und gewissenhafte, aber nur Schau-

1) d. h. mit Naturkräften.

2) BArtscherer, S. 3O, 3 I.

3) den Doktorhut.

4) Hier steht ein zu grober Kraftausdruck.

5) Lessing, S. 29-3I. 
spieler, welche von der Darstellung alles wirklich Tatsächliche, alles Natürliche, Eckige abgestreift hatten. Ihnen gegenüber stand PARACELSUS, ein 》mit Käse und Haferbrot in Tannenzapfen " (wie er es von sich erzählt) erzogener derber Mann, kein Schauspieler, sondern das lebendige Ideal selbst: rücksichtslos, kampflustig, Todfeind allem Gezierten.

Die Historiker, welche von den Affären erzählen, die das Auftreten des PARACELsus gegen die Gelehrten zur Folge hatte, pflegen die damaligen Gelehrten als unwissende Stümper darzustellen und geben PARACELsus deshalb recht, weil seine Wissenschaft (die sie für ebenso objektiv wie die der Gelehrten halten) gründlicher war als diejenige seiner Gegner. Wenn wir uns aber die Persönlichkeiten näher ansehen, die damals in Basel wissenschaftlich tätig waren, so rückt der Kampf des PARAcELsus in ein wesentlich anderes Licht. Eben damals (seit I 52I) weilte in Basel der Anführer der Humanisten, ERAsmus von RotTerdam (I467-I536), und gab bei Frobenius, dem Beschützer des PARAcElsus, seine gelehrten lateinischen und griechischen Werke heraus; um ihn sammelte sich eine Anzahl anderer hervorragender Humanisten. In Anbetracht dieser Tatsache gewinnen PARACELsus' Angriffe gegen das rhetorische Geschwätz und gegen den Kult des Vergilius einen lebendigen Sinn; ERAsmus gab in demselben Jahre, als die PARACELsusaffäre zum Ausbruch kam (I528), eine Abhandlung über die korrekte Anwendung der lateinischen Sprache (Ciceronianus sive de optimo dicendi genere), gab Klassiker heraus, verfaßte Anleitungen zu einem schicklichen Briefstil und war der Typus eines ausgesprochen international gesinnten Gelehrten. Dem gegenüber sind folgende Worte des PARACELsus verständlich:

...ob mir die hohen Schulen folgen wollen oder nicht, was kümmert's: mich? Sie werden noch niedrig genug werden, und mehr will ich richten nach meinem Tode gegen sie, als bei meinem Leben, wo sie mich verachten, da $\beta$ ich allein bin, da $\beta$ ich neu bin, da $\beta$ ich deutsch bin!1)

Deutsch sein bedeutet da nicht lateinisch, nicht international sein, bedeutet dem Gemüte nach aus dem Volke, nicht aus der Noblesse abstammen, zu der ERASmus gezählt werden wollte. ERASMus kann auch in anderer Hinsicht als Gegenpol des PARACELSUS betrachtet werden. Er war eine Weltberühmtheit, die weltlichen und kirchlichen Fürsten stritten um die Ehre, ihn unter ihre Freunde

1) Lessing, S. 3 I. 
rechnen zu dürfen. Seine nicht genug orthodoxe Gesinnung und seine Charakteristik der kirchlichen Zustände sollen die Reformationsbewegung gefördert haben. Als aber durch das Auftreten LUTHERs die Sache ernst geworden war, da ergriff eine panische Furcht die Schauspieler des neuen religiösen Ideals: ERASmus veröffentlichte eine Broschüre gegen LUTHER, wurde streng katholisch und starb als reicher Propst, eben als er zum Kardinal ernannt werden sollte. Einem Mann wie Luther gegenüber mußte man Farbe bekennen; auch PARACELSUs hat sie bekannt; man gab ihm den Spottnamen Lutherus medicorum (die Analogie zwischen beiden Reformatoren war keineswegs nur oberflächlich), und er, PARACELSUs, begrüßte öffentlich LuTHERs Offenheit (er sprach wohl das Lob in seiner groben Weise aus) und verurteilte offen das Papsttum, ließ aber beide Kirchen beiseite und predigte seine eigene Religion ${ }^{1}$ ).

Um die Charakteristik der Gelehrten, gegen die PARACELSUS' Angriffe zielten, plastischer zu gestalten, will ich noch THOMAS ERAsTus' kurz Erwähnung tun. Dieser Arzt war jünger als PARACELSUS, und seine Polemik gegen den letzteren erschien erst 30 Jahre nach PARACELSUS' Tode; für die Beurteilung des damaligen wissenschaftlichen Milieus jedoch ist diese Zeitspanne irrelevant. ERAsTUS ( 523 bis 1583) war Philosoph, Theologe und Professor der Medizin; seine ärztliche Praxis soll erfolgreich gewesen sein. Er entschied sich für Zwingli, eiferte für die Unterwerfung der Kirche unter die Macht des Staates und verwarf die kirchlichen Strafen; in England ist später eine Sekte entstanden (Erastianer), welche seine Grundsätze $\mathrm{zu}$ verwirklichen strebte. Als konsequenter Aristoteliker wußte ERASTUS die aristotelischen Theoreme geschickt und nüchtern anzuwenden, wobei er sich das Recht vorbehielt, von ARISTOTELES abzuweichen, wo er selbst eine bessere Einsicht gewonnen hätte ${ }^{2}$ ); die Scholastik verwirft er ausdrücklich. Alle Erscheinungen will er logisch begründen, an alle schreitet er mit scharfer Kritik heran, um das Wahre vom Falschen abzusondern. Mit Entrüstung bekämpft er die Magie, den Glauben an die Macht der Hexen, an die Astrologie, Alchemie, Nekromantie, an die Macht der Geister usw. Er greift auch zu wirklichen Experimenten, um die Unrichtigkeit des Aberglaubens

1) Einmal ließ sich der kranke Erasmus von Paracelsus konsultieren. Der ietztere sandte darauf dem Erasmus eine lateinische Fanfaronade, in der er die Krankheit analysierte und geeignete Medikamente vorschrieb; Erasmus' Dankschreiben war kalt und höflich. Vgl. SudHoff, Paracelsusforschungen, II, S. 99-122.

2) Disputationum de medicina nova Phil. Theophrasti etc., Basileae 157I, S. 69. 
nachzuweisen. Durch literarische Bildung, durch seinen kritischen Geist und durch die Übersichtlichkeit der Darstellung überragt er himmelweit sein Opfer. Unbarmherzig geht er PARACELsus zu Leibe und hebt alle seine Widersprüche, Sinnlosigkeiten, seinen Aberglauben, : sein reaktionäres Wesen, seine Ketzereien hervor und hat in den Einzelheiten seiner Kritik fast überall recht. Von den modernen Verteidigern des PARACELSUs wird ERASTUS ungünstig beurteilt, aber mit Unrecht; seine Polemik ist sehr lesenswert und mutet fast wie ein modernes biologisch-philosophisches Werk an; jedenfalls stehen seine Anschauungen den heute unter den Biologen verbreiteten unvergleichlich näher als diejenigen des PARACELSUs; sie beweisen, daß die damalige Hochschulwissenschaft viel besser, kritischer, logischer, gebildeter war, als heute vielfach behauptet wird. PARACELsUs' Angriffe gegen dieselbe dürfen uns nicht beirren; er beurteilte die Hochschulen zu subjektiv, er schätzte sie nur nach seinem individuellen Maßstabe ein und hatte weder Vorbildung noch guten Willen genug, um denselben gerecht werden zu können. Wohl zeigte es sich, daß all ihre große Vorbildung die Hochschulprofessoren im Stiche ließ, als sie einer Erscheinung, wie PARACELsus eine war, gegenübergestellt wurden. ERASTUS, der gebildetste Gegner des PARACELsus, weiß sehr gut anzugeben, was in dessen. Lehren richtig ist und was falsch, aber für das, was wirklich, wirksam ist, ist er total blind. Aus seinen Beweisen erfährt man absolut nichts über die lebendige Tatsache, welche doch PARACELsus war, nichts darüber, warum er Erfolge gehabt hat, warum er gepriesen wurde; aus seinen Analysen gewinnt man den Eindruck (einen für die gelehrten Diskussionen sehr charakteristischen Eindruck), als ob es vielleicht gar keinen PARACELsus gegeben hätte, sondern nur ein Phantom, das eine Unmasse von Unsinn, Lüge und Betrug zusammengeschrieben. Daß PARACELsus eine Persönlichkeit, eine Erscheinung sui generis war, die man als ein Ganzes nehmen und beschreiben muß, für die das Schulmaß 》richtig-unrichtig " nicht ausreicht, daß er durch sein Stürmen für etwas Großes gekämpft, eine solche Idee, die einem jeden Laien einfallen muß, kam dem gelehrten ERASTUS nicht einmal im Traume bei. Aus einer Reihe von Zitaten aus Paracelsus zieht er z. B. den Schluß, daß dieser "Narr« (insanus), diese "Bestie «, dieser "verfluchteste Dunkelmann « (tenebrio) zu den größten Ketzern gehört und weder an Gott, noch an die Macht Christi, noch an Adam usw. glaubt. Man kann wohl solche Schlußfolgerungen aus gewissen Sätzen des PARACELSUS ziehen; 
ERAstus aber vergaß, wie die Gelehrten auch sonst so gern vergessen, daß für PARACELSUs nicht dasjenige charakteristisch sein konnte, was man durch noch so richtige logische Schlüsse aus einzelnen seiner Behauptungen deduzieren kann, sondern nur was PARACELSUS selbst daraus deduziert hat; ERASTUS hatte gar keinen Sinn für die tatsächliche Religiosität des PARACEĹsus, welche so tief, so aufrichtig, so wirksam war, daß man ihm nur dann gerecht wird, wenn man ihn mit Männern wie der heilige Augustin, der heilige Franziskus von Assisi, LUTHER vergleicht.

Und deshalb übte die Polemik des Erastus gegen Paracelsus keine Wirkung. 'Der Leser wird seines Scharfsinnes bald überdrüssig, und als er von ERAstus erfährt, daß dieser nicht nur PARACELSUS, sondern alle Platoniker, PLATO selbst nicht ausgenommen, verwirft, so ist er zwar bereit, seine Konsequenz anzuerkennen, wird aber suchen, sich über Paracelsus bei einem anderen Autor zu belehren, der für die Tatsachen des Lebens ein angemesseneres Verständnis zeigt.

In ERAsmus von Rótterdam, dem Humanisten, und in ERAstus, dem Arzt, kam das Ideal der Hochschulwissenschaft zum Ausdruck. Und wie war das Ideal beschaffen, das unserem PARACELSUS vor den Augen schwebte? Wer verstehen will, dem ist es leicht, das Ideal des PARACELsús zu begreifen. Weder die Kaiser, noch die Päpste, noch die Fakultäten, noch die Privilegien, noch die Akademien machen den Arzt ${ }^{1}$ ), keine Macht der Welt ist imstande, ihn zu erschaffen, keine Bücher, keine Erfahrungen; diejenigen, die die Medizin erlernen wollen, bleiben nur Kompilatoren und Läusjäger ${ }^{2}$ ), sind den Flechten ähnlich, die, ohne zum Baum zu gehören, seiner Rinde sich anschmiegen ${ }^{3}$ ), sind wie Bettelstudenten, die hier Mehl, dort Weizen, dort Hafer bekommen und alles in einen Sack werfen ${ }^{4}$ ); ihre Wissenschaft ist aus Fragmenten zusammengeflickt: dieser ist Doktor, jener Baccalaureus, jener Chirurg ${ }^{5}$ ) - und keiner ein ganzer Mensch! Gelehrte Ärzte sind gemalte Ärzte, äußerlich geschmückt wie Heilige, innerlich Betrüger, die anders denken und anders handeln und wie Diebe und Mörder nicht durch die rechte

1) Bitiscius, I, S. I85.

2) Bitiscius, I, S. 202.

3) Bitiscius, I, S. I97.

4) Bitiscius, I, S. 135. Vgl. auch Bitiscius, I, S. 204.

5) Bitiscius, I, S. I 82 . 
Tür hereintreten, sie sind Versucher, Probierer ${ }^{\mathbf{1}}$ ); Christus hat auf sie mit dem Finger hingewiesen, als er von den Pharisäern sprach ${ }^{2}$ ). Der echte Arzt kann mit menschlichen Mitteln nicht erschaffen werden; er kommt aus jener geheimnisvollen Gegend, aus welcher der Himmel und die Erde kam, Gott allein ist sein Schöpfer ${ }^{3}$ ); derselbe Gott, der das Gras wachsen gelehrt hat, hat auch PARACELSUS heilen gelehrt ${ }^{4}$ ), und nur Gott legt Schranken seiner Kunst ${ }^{5}$ ). Darum ist das Wahrzeichen des Arztes Ehrlichkeit, Glaube und Keuschheit ${ }^{6}$ ); der Arzt ist den Aposteln ähnlich und ist nicht geringer bei Gott, als sie es waren ${ }^{7}$ ); wie ihre Rede, so muß auch die seinige sein: ja, ja, nein, nein. Der Arzt muß alles, alles wissen; er muß den Lauf der Sterne am Himmel und das Gestein auf der Erde, die Waltiere im Meere wie die Planeten auf dem Firmament kennen.

Ein Arzt ist der, der da öffnet die Wunder Gottes männiglich ... Denn was ist im Meere, das dem Arzt soll verborgen sein? Nichts. Was ist im Meere, das er soll nicht öfnen? Nichts. Er soll's hervorbringen! Und nicht allein im Meer - in der Erde, in der Luft, im Firmament... damit jedem die Werke Gottes offen seien, warum sie sind, was sie bedeuten und besonders insofern sie die Krankheiten betreffen ${ }^{8}$ ).

Der Arzt darf sich nicht nur auf den Augenschein verlassen, an ihrer Wurzel muß er die Dinge erfassen und muß Alchemiker, Astronom und besonders Philosoph sein. Der Verstand genügt nicht; mit den Geheimnissen der Natur muß er in Eins zusammenfließèn und

die Philosophie muß in seinen Ohren brausen und läuten wie der wilde Rheinfall, $m u ß$ in seine Ohren schlagen wie der Sturm im Ozean, seine Zunge muß sie so sü $\beta$ wie den Honig finden und seine Nase muß sie voll einsaugen ${ }^{9}$ ).

Der von Gott vorbestimmte Arzt muß alles wagen; er kennt keine unheilbaren Krankheiten, er kennt keinen Tod, dessen er nicht Herr werden könnte; auch Tote ruft er zum Leben zurück, die von Geburt aus Blinden lehrt er sehen, und das Leben vermag er auf Jahrhunderte $z$ u verlängern ${ }^{10}$ ).

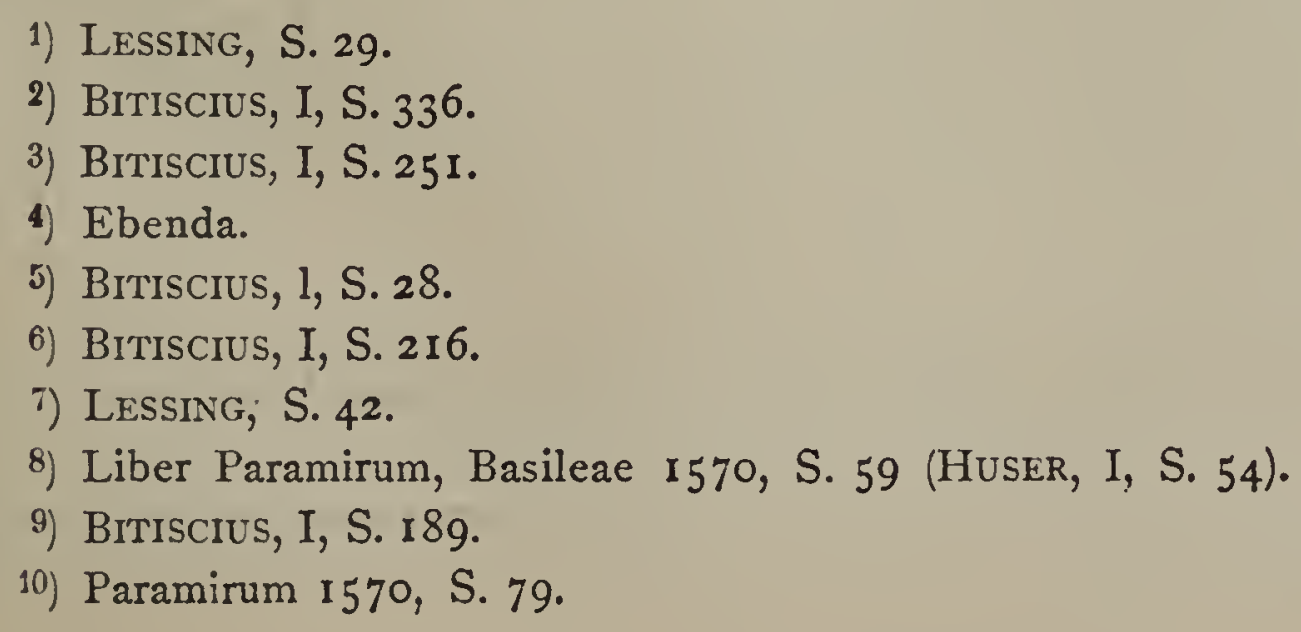


Über solche ganz ungewöhnliche Fähigkeiten muß nach PARACELSUs der wahre Arzt verfügen. . . War es nicht purer Wahnsinn, so etwas der menschlichen Wissenschaft zuzumuten? Eine kurze Antwort ist da schwer zu geben; gewiß aber war PARACELsus nicht der einzige, der in dieser schwärmerischen Weise gepredigt: alle, die an Genialität glauben, haben auf diese unmögliche Art — zu leben versucht.

\section{Absćhied.}

Es ist leicht zu sagen, daß der Arzt alle Krankheiten heilen muß, schwer ist aber das Gelächter der Zuschauer im Zaume zu halten; wenn die Patienten trotzdem sterben. PARACELsus pflegte in solchen Fällen auf die zu lange vernachlässigte Krankheit, auf den Willen Gottes, ohne den kein Haar vom Kopfe herabfällt, und besonders auf die Doktoren hinzuweisen, die die Kranken so verdorben hätten, daß seine Hilfe zu spät käme ${ }^{1}$ ). Es ist leicht zu sagen, daß die wahre Grundlage der Medizin in der Tugend liegt; aber auch PARACELsus hatte einen Magen, und als man ihm das verlangte Honorar verweigerte, klagte er beim Gericht. Es gab übrigens Momente, wegen welcher es auch den objektiv Denkenden schwer kam, PARACElsus zu folgen. Seine Fanfaronaden erweckten Spott, und seine Kritiklosigkeit nährte das Mißtrauen. Gescheitere Leute glaubten nicht mehr an Hexen, an Weissagungen aus der Hand, an Sterndeutungen; PARACELSUs führte aber derartigen Aberglauben fast als das eigentliche Wesen seiner neuen Kunst vor. Auch sein $\ddot{A} u ß e r e s$ war absonderlich. Von einer kleineren Statur, ohne Bart 2), vorzeitig gealtert, soll er neben anderen Professoren "wie ein Fuhrmann " ausgesehen haben; vielleicht ging er schon damals mit seinem langen schweren Schwert herum (er rühmte sich, es von einem Scharfrichter bekommen zu haben); er war zornig wie ein Hahn und grob wie ein Klotz und fand an den saftigsten und gemeinsten Schimpfworten Gefallen. Seine Sonderlingsart sammelte um ihn Zuhörer von sehr verschiedenem Schlage, auch Barbiere und Chirurgen, die nicht einmal auf der Universität immatrikuliert waren; mit seinen Hörern lebte er auf kameradschaftlichem $\mathrm{Fu}^{3} \mathrm{e}^{3}$ ). Gewiß

1) LESSING, S. 36 .

2) Ich schließe so nach den Abbildungen, insbesondere nach derjenigen in Netzhammer, S. 147 .

3) Er tituliert sie in einem Briefe mit Worten, die viel zu erraten geben: » combibones optimi * (Lessing, S. 33). 
wurden von dieser Gesellschaft PARACELSUS' Schimpfreden auf die Doktoren mit besonderer Genugtuung aufgenommen.

Die Doktoren fühlten sich beleidigt. Man warf von ihrer Seite PARACELSUS (nicht mit Unrecht) vor, daß er sich den vorgeschriebenen Prüfungen vor dem Antritt seines Amtes entzogen hätte, daß er unrechtmäßig zwei Ämter, die Professur und das Stadtphysikat, bekleide, daß er die Jugend verderbe, und man wies mit Entrüstung auf seine Verunglimpfung des ärztlichen Standes hin. Es gelang ihnen, PARACELsus den Zutritt zu den Universitätsräumen zu verlegen und seinen Hörern das Doktorat zu verweigern. PARACELSUS wurde wütend und schimpfte, wie nur zur Renaissancezeit geschimpft wurde: 》sie rumpeln im Raimundo (Lullio) wie die Sau im Trog «, Buben, Lügner, Schanddeckel, Requiem-Doktoren, Zahnbrecher, Hodenschneider, lausige Sophisten, Hundschläger, Kälberärzte, Büffel; 》) der heilige Johann in der Apokalypsis hat kein so wunderbares Scheusal gesehen, wie ihr seid «, und noch andere Namen, die heute nicht gedruckt werden können ${ }^{1}$ ). Das war die Stimme des Volkes; aber auch die Doktoren ließen sich in ihrer Weise vernehmen: man erzählte, daß er nur deshalb deutsch vortrüge, weil er des Lateinischen nicht genügend mächtig wäre, daß er seine Wissenschaft abgeschrieben, daß er wer weiß woher gekommen und vielleicht gar kein Doktor wäre, daß er aus Straßburg entfliehen müssen, daß er Atheist wäre und die Kirche nicht besuche, daß er ein Trunkenbold, Eunuch, Landstreicher wäre, daß er nur Syphilis zu heilen verstünde usf. 2). Zwei Welten stritten da miteinander, und wer Ohren zum Hören hat, der kann deutlich aus dem Gebrüll der Schmähreden die beiden Weltanschauungen heraushören. Der Skandal erreichte den Höhepunkt, als sich einmal Sonntags früh an den Pforten der öffentlichen Gebäude ein gedrucktes Pamphlet angeschlagen fand, in dem ein Anonymus (auch das ist bezeichnend) alles, was man gegen PARACELSUS anzuführen pflegte, in gut gebauten lateinischen Distichen und nicht ohne Witz dem öffentlichen Spotte preisgegeben: er verleumde den Galenus, er behandle die Patienten mit Zwiebel und Knoblauch, es sei in seinem Kopfe nicht alles in Ordnung, er

1) Fast jede Schrift des Paracelsus enthält solche Schimpfreden.

2) Auf das Schimpfen verstanden sich Paracelsus' Gegner ebenfalls. Erastus schreitt von ihm, daß er sein gefährlicherer Ketzer ist als die Arianer, Mohammedaner, Türken, ein Narr, eine Bestie, der verfluchteste Dunkelmann, der unverschämteste Betrüger ist «; er versteigt sich sogar zu der kühnen Entrüstung: »solchen Unsinn grunzt dieses Schwein « usw. 
sei Alchimist, er wende mit Vorliebe lächerliche neue Worte an, er sei nicht einmal würdig Säue zu hüten, er sei einmal schon daran gewesen, sich aufzuhängen, habe sich aber im letzten Augenblick für das Leben und für die Begründung einer neuen Wissenschaft entschieden usw. usw. - lauter Dinge, die ein jeder erfahren muß, der sich in den Kampf um eine neue Idee eingelassen hat ${ }^{1}$ ).

»Es möchte eine Turteltaube zornig werden bei solch lausigen Zoten! " rief PARACELSUS aus - wie denn nicht er? Er reichte eine Beschwerde bei dem Magistrat ein. Vielleicht hätte man die Affäre vergessen, wenn nicht unglücklicherwejse der mächtige Fürsprecher des Paracelsus, Frobenius, plötzlich gestorben wäre; man schob die Schuld auf die Heilmethode des ersteren; PARACELSUS soll dem Kranken eine zu starke Opiumdosis verschrieben haben ${ }^{2}$ ). Überdies verlor PARACElsus einen Prozeß, den er gegen einen Patienten um das Honorar angestrengt hatte, und grob, wie er war, sprach er sich (vielleicht in einem gedruckten Pamphlet) sehr unhöflich über den Magistrat aus. Vor der drohenden Verhaftung mußte er nachts aus Basel nach Elsaß entfliehen (I 528). Der Rektor der Universität bemühte sich vielleicht einige Zeit, PARACELSUS die Rückkehr nach Basel zu ermöglichen, aber umsonst. I 529 siegte in Basel die Reformation, und die dem Katholizismus treue Universität wurde geschlossen.

So verlor PARACELsus den Ruhm dieser Welt, nach zwei Jahren Universitätsprofessur. Traurig muß sich sein Abschied von Basel gestaltet haben. Er hatte für die Wissenschaft, für die Wahrheit und Gerechtigkeit geglüht und sah anfangs mit Triumphgefühl, wie er, ein armseliger Landfahrer mit der dunkelsten Vergangenheit, von der Blüte der Intelligenz aufgenommen wurde; er ist Doktor, Professor, Stadtphysikus, ein Kollege der Weltberühmtheiten geworden; und jetzt ist alles vorüber; jetzt muß er da in der Winternacht im Kot und Schnee wie ein Proskribierter fliehen und steht gerade dort, wo er gestanden, als er mit den Zigeunern Brüderschaft getrunken hatte. Und warum dieses bittere Schicksal? Etwa darum, daß er anderen durch seine Schimpfreden Böses antun wollen? Niemals ließ er diese Erklärung zu. Er wußte zwar, daß er es nicht verstanden, sich so anständig zu benehmen wie die anderen, er wähnte jedoch, daß alle verstanden hätten, wie er es gemeint, daß

1) Das Pamphlet wurde von Sudhoff (Paracelsusforschungen II, S. 35) veröffentlicht.

2) Lessing, S. 40. 
sie seinen guten Willen anerkannt hätten. Man lese nur dieses sein Bekenntnis:

... ich sei ein wunderlicher Kopf ... Sie schätzen und achten das eine große Untugend an mir zu sein; ich selbst aber schätze es für eine große Tugend, wollte nicht, daß es anders wäre, wie es ist; mir gefällt meine Weise ganz wohl. Damit ich mich aber verantworte, wie meine wunderliche Weise zu verstehen sei, so merket also: von der Natur bin ich nicht subtil gesponnen, ist auch nicht meines Landes Art, da $B$ man etwas mit Seidespinnen erlange. Wir werden auch nicht mit Feigen erzogen, nicht mit Met, auch nicht mit Weizenbrot, aber mit Käse, Milch und Haferbrot. Es kann nicht subtile Gesellen machen. $Z u$ dem, daß einem alle seine Tage anhängt, was er in der Jugend empfangen hat. Derselbe scheint nun fast grob zu sein gegen die Subtilen, Katzreinen, Superfeinen. Denn dieselbigen, die in weichen Kleidern und bei Frauenzimmern erzogen werden und wir, die in Tannenzapfen erwachsen, verstehen einander nicht wohl. Darum so muß der Grobe grob zu sein beurteilt werden, ob derselbe schon subtil und holdselig zu sein vermeint. Also geschieht mir auch: was ich für Seide achte, heißen die anderen Zwilch und Drillich ${ }^{1}$ ).

PARACELSUS paßte nicht in jene hohe, gelehrte Welt, und es war ein Irrtum von ihm, daß er in dieselbe einzutreten versucht hatte. Der Bruch war unvermeidlich. Jetzt hörte er auch äußerlich auf, Fachmann zu sein, der er innerlich niemals gewesen war, denn niemals hielt er sich im Herzen für ihresgleichen. Jetzt machte er sich von allen Vorurteilen los und ging, wohin ihn seine freie Menschennatur führte: in die weite Welt, unter den Laien Freunde für seine neuen Lehren zu suchen:

$\mathrm{Da}$ ich denn gefunden habe, da $B$ im Laien, in dem gemeinen Mann, im Bauer die Vollkommenheit christlichen seligen Lebens am mehresten wohnet, bei den anderen gar nichts, ihnen denn habe ich angefangen zu schreiben die Wahrheit der christlichen Wohnung...

Neben wissenschaftlichen Arbeiten (die aber sehr weit von den gewöhnlich so genannten Schriften entfernt sind) begann er Flugblätter mit mystischen Prophezeiungen über den Untergang Deutschlands und über die große Macht des künftigen Frankreich, über das Unglück, das die Kometen bringen werden, zu veröffentlichen; er predigte gegen alle Mächtigen dieser Welt und erklärte sich den unterdrückten Armen gleich; er gab metaphysische Traktate heraus über den wahren Sinn des Abendmahls, über die unbefleckte Empfängnis der heiligen Jungfrau, über die Ankunft Christi, und insbesondere über die allgemeine Brüderschaft unter den Menschen; er

1) Lessing, S. 55 . 
stritt mit den Katholiken und Lutheranern und machte keinen Unterschied mehr zwischen den Doktoren und Priestern; auch bei den letzteren machte er sich verhaßt und schonte sie ebensowenig wie die ersteren. Der Leipziger Universität ist es gelungen, den Druck seiner Schrift über die Syphilis in Nürnberg zu vereiteln, und auch sonst stieß PARACELSUS auf ähnliche Schwierigkeiten, so daß viele seiner Vorlesungen, namentlich die theologischen, nur als Manuskripte zirlkulierten. Seitdem er Basel verlassen, hielt er nirgends lange aus; er fuhr auf einem Pferd von Ort zu Ort und bereiste namentlich Süddeutschland und die Schweiz und kam bis nach Mähren. Unterwegs übte er seine Praxis aus und diktierte seine Schriften. Überall wurde er als ein Sonderling aufgenommen, der die Doktoren beschimpft und eine neue Medizin einführt. Die Kranken, immer vom neuesten Arzte Genesung erhoffend und durch die Erzählungen von des PARACELsus Wunderheilungen verblendet, baten ihn zu sich, und PARACELSUs ist es gewiß gelungen, manchem zu helfen. Die meisten waren jedoch sicherlich enttäuscht, und seine Grobheit gegen die Kranken (zu der er sich selbst bekennt), seine fortwährenden Streitigkeiten ums Honorar, seine Kämpfe mit den Priestern und Doktoren waren wenig geeignet, seine Sache zu fördern.

Weder sein Äußeres, noch seine Umgebung vermochten ihn beliebt zu machen. Es war noch immer von Schülern begleitet, die aber kaum imstande waren, ihn zu verstehen. Er hielt seine Vorträge in Ausschänken und in Gasthäusern und nicht nur vor seinen Begleitern, sondern auch vor den Kaufleuten und Fuhrmännern. Unter seine Schüler gehörten gewiß auch sehr anständige Leute; einer derselben, OPORINus, wurde später berühmter Philologe und Buchdrucker; welch eine Bande aber mußte es sonst sein, wenn sich PARACELsus einmal über sie beschweren konnte, daß ihm der Scharfrichter schon einundzwanzig Diener hingerichtet und daß andere nur deshalb in der Welt herumirren, weil der Scharfrichter ihrer noch nicht habhaft werden konnte! Diese Leute sollen ihn nun betrogen haben, indem sie Kranke heimlich, seinen Namen mißbrauchend, zu behandeln pflegten ${ }^{1}$ ). Arme Kranken! Alle stimmen darin überein, daß PARACELSUS schmutzig war, und es scheint richtig zu sein, daß er viel, viel getrunken hat!' Doch hören wir, wie ihn aus dieser Zeit sein Famulus Oporinus schildert:

"So sehr war er während der zwei Jahre, die ich mit ihm zusammen gelebt, ganze Tage und Nächte dem Trunk und Rausch hingegeben, daß

1) Bitiscius, I, S. 26r. 
man kaum die eine oder die andere Stunde ihn nüchtern finden konnte, die ganze Zeit hat er sich nachts nie ausgezogen, was ich der Betrunkenheit zuschreibe. Oft erhob er sich nachts und wütete mit dem Degen so durchs Zimmer, daß ich mehr als einmal für meinen Kopf fürchtete. Item von Geld war er manchmal so entblößt, daß ich wußte, er besaß keinen Pfennig mehr, am Morgen aber zeigte er mir den Beutel wieder voll gespickt, so daß ich mich oft wunderte, woher ihm das Geld käme «1).

Mit solchen Augen haben ihn also die gebildeteren seiner Hörer angesehen; und die anderen? Die haben von seiner Verfeindung mit den Professoren gehört, sie hörten seinen Vorträgen voll unverständlicher und geheimnisvoller Worte $z u$, und abergläubisch, wie die Leute ihres Schlages zu sein pflegen, sahen sie in ihm einen Schwarzkünstler, der mit dem Teufel Beziehungen pflegt - man munkelte, daß PARACELsus in der Kugel am Handgriff seines Schwertes einen Geist eingeschlossen hätte, der ihm dienen müsse, und sie wollten ihm seine geheime Kunst, seine Kenntnis des Steines der Weisen, seine Panazee gegen den Tod und seine Tinktur zur Herstellung des Goldes aus billigem Metall abschauen. Und deshalb folgten die Schüler, oft im Hunger und Elend, dem sonderbaren Prediger. Denn es kamen Zeiten, wo PARACELsus nicht nur auf sein Zwillichkleid hinwies:

"Habe kein Acht meines Elends, du Leser, la $B$ mich mein Übel selbst tragen ... Ich hab' zwei Gebrechen an mir, meine Armut und meine Frommheit. Die Armut ward mir vorgeworfen durch einen Bürgermeister, der etwa die Doktoren nur in seidenen Kleidern gesehen hatte, nicht in zerrissenen Lumpen an der Sonne braten.. «2).

Trotz der zerrissenen Lumpen blieb er aber der selbstbewußte PARACElsus. Er wußte, daß in seiner neuen Lehre eine unzerstörbare Macht lebte, daß er in seinem Kampfe recht hatte und daß er von Gott auserwählt war, jede Unaufrichtigkeit bis auf den Tod zu hassen. Sein Eid, den er (offenbar nach dem Beispiele Galens) geschworen, weist nach, was alles er geliebt und gehaßt:

"Das gelob' ich: meine Arznei zu vollfertigen und nicht von der zu weichen, so lang mein Gott das Amt vergönnt, und zu widerreden aller falschen Arznei und Lehren, keine Hoffnung in die hohen Schulen zu setzen, item dem Barette nicht nachzustellen, item demselbigen nicht Glauben zu geben, denn die

1) Erastus, S. 232. Oporinus soll später bereut haben, diese Charakteristik seines ehemaligen Herrn veröffentlicht $z u$ haben; den Inhalt derselben zog er aber nicht zurück. Vgl. übrigens auch eine analoge Nachricht über Paracelsus bei J. Rütiner (Netzhammer, S. I I9).

2) Bitiscius, I, S. 395. Kahleaum, S. 7o. 
Kranken zu lieben, einen jeglichen mehr, als wenn es mein Leib antreffe . . nicht wähnen, sondern wissen, dergleichen keinen Fürsten arzneien, ich habe denn den Gewinn im Säckel, keinen Edelmann auf seinem Schloß, keinen Mönchen, keine Nonne in ihrem Kloster; in Frankreich und Böhmen nichts arzneien, und wo ein Arzt krank läge, am teuersten zu behandeln, für das, so mich einmal einer ließ nimmer (im Spital) aufnehmen; in der Ehe, wo Untreue bemerkt wird, es sei Frau wider Mann oder er wider sie, mit der Arznei sie nicht zu übernehmen, Geistlichen in ihrer Krankheit nichts verhängen (verordnen), wo Klage ist, alles fahren lassen. Wo die Natur versagt hat, nicht weiter zu versuchen, wer mir den Lohn vorhält, meiner nicht würdig zu sein erkennen, keinen Apostaten aber alle Sekten sonst anzunehmen, bei den Ärzten nichts zu übersehen, Frauen Hilfe selber zu erzeigen, den Martialischen und Saturnischen, Melancholischen Rat zu tun ... Das alles bei dem, so mich beschaffen hat, zu halten gelob’ ich «1).

Die Gelehrten hatten ihn aus ihrem Kreise ausgewiesen, die Schüler fielen von ihm ab und versuchten ihn $\mathrm{zu}$ verleumden, reiche Patienten, darunter auch fürstliche Personen, wollten ihm das vereinbarte Honorar nicht zahlen, die Magistrate verhinderten den Druck seiner Schriften, und die Priester lachten ihn aus und warfen ihm Ketzerei vor, weil ihm die kirchlichen Institutionen nicht heilig waren. Niemand von der offiziellen Welt wollte seine Predigten vom Königreich Gottes auf Erden und von der allgemeinen Bruderschaft ernst nehmen; niemand verstand seine Theorie, daß der Grund der Arznei in der Liebe zum Kranken liegt, daß die Macht der Natur so unermeßlich ist, daß keine Beschreibung, keine Analogie für deren Erfassung ausreicht, niemand von den Repräsentanten der Wissenschaft wollte mit Ernst die sonderbaren, unverständlichen Worte anhören, welche sich PARACELSUS auszudenken pflegte, um seine Wahrheiten vorzuführen. Und doch war die neue Wahrheit, die in ihm lebte, die er erkannt, von der er die kühnsten Bilder schilderte, so überaus schön! Hat er sich ihrer erinnert, so vergaß er die Lumpen, in denen er steckte, den Hunger und seine Umgebung; die berühmten Gelehrtenkoryphäen der vergangenen Jahrhunderte, deren Namen er noch nicht vergessen, und die aufgeputzten Doktoren von den Universitäten der ganzen Welt erblickte er als kleine Pünktchen, tief, tief unter sich, und er selbst war plötzlich ihr König. Und dann, in einer Spelunke, verkommen und betrunken, das Schwert, wie es seine Gewohnheit war, mit beiden Händen festhaltend, schrie er seinen Famulen und anderen wunderlichen Zuhörern, wie von Furien getrieben, zu:

1) Lessing, S. $37,3^{8}$. 
"Mir nach, Avicenna, Galenus, Rhazes, Montagnana, Mesoe und ihr anderen! Mir nach und ich nicht euch nach, ihr von Paris, ihr von Montpellier, ihr von Schwaben, ihr von Meißen, ihr von Köln, ihr von Wien, und was an der Donau und dem Rheinstrom liegt, ihr Inseln im Meer! Du Italia, du Dalmatia, du Sarmatia, du Albanis, du Griech, du Arabs, du Israelita. Mir nach und ich nicht euch nach, mein ist die Monarchie. Euer wird keiner im hintersten Winkel bleiben, an den nicht die Hunde... ich werde Monarcha und mein wird die Monarchie sein .. «1).

Die Gelehrten haßte er auf den Tod und suchte für dieselben die gröbsten Schimpfworte; sie waren nichts als ärztlicher Pöbel ${ }^{2}$ ), der nicht würdig war, seine. Schuhriemen aufzulösen $\left.{ }^{3}\right)$. Er ist Barbar geblieben; mag er aber noch so unanständig geschimpft haben, in doppelter Hinsicht stand er unendlich hoch über seinen wohlerzogenen Gegnern: gegen ihn kämpfte eine anonyme Gesellschaft, eine Gilde, er stand für seine Worte mit seiner Person ein; er griff in der härtesten Weise ihre Lebensauffassung an, aber niemals - es ist dies überraschend bei einem Manne von seiner Lebensart - niemals berührte er mit einem einzigen Worte das Privatleben bestimmter einzelner Persönlichkeiten; umgekehrt kennen wir alle Privatissima über PARACELSUs gerade aus der Polemik seiner distinguierten Gegner. Für seine Privatissima haben sie Verständnis gezeigt; keiner seiner Gegner wurde dagegen gewahr, daß mit PARACELsus eine neue Wirklichkeit in die Welt getreten war, welche zu konstatieren und zu begreifen an erster Stelle den Gelehrten geziemt hätte. Die Theorien der alten Philosophen und Ärzte waren nicht so nichtswürdig, wie sie von PARACELSUs dargestellt wurden; auch die Tradition war keineswegs so belanglos und steril, wie er sie haben wollte; die Institution der Hochschulen und der diplomierten Doktoren war gewiß nicht nur eitler 'Tand, wie sie PARACELsus erschien; bei Lebzeiten des letzteren war aber niemand instande, das wahre Wesen und den Wert jener Schulwissenschaft, von welcher so viele genährt wurden, gegen PARACELsus mit vernünftigen Gründen zu verteidigen. Erst dreißig Jahre nach seinem Tode fand sich ein Gelehrter (ERASTUS), der sich in eine Kritik der PaRACELsIschen Lehren vom Standpunkte des Aristotelismus eingelassen hat. Sein Leben

1) Aus dem Vorwort zu Paragranum. Man vgl. folgende Stelle bei Erastus, S. 236: \Während des Diktierens pflegte er wie von Bremsen gestochen und von Furien verfolgt und wie eine Pythia erglüht $z u$ sein und schreien ... wobei ihm der Teufel jenen Unsinn suggeriert hat, auf den er im gesunden Zustande niemals hätte verfallen können.

2) BrTiscius, III, S. 48 .

3) Bitiscius, III, S. I3. 
lang irrte PARACELSUS einzig und allein durch die Welt, vergeblich nach einem ebenbürtigen Gegner, nach einem vernünftigen Freund sich sehnend.

"So sind in meinen Sachen heimlichen und öffentlichen viel Widerwärtigkeit zugestanden, die allein auf meinem Rücken gelegen sind, und niemand ist da gewesen, der mir hätte Rücken und Schirm gehalten "...1).

Viele haben ihn gehaßt, viele verachtet, einige haben in ihm ein überirdisches Wesen, einen Übermenschen erblickt; wem fiel da ein, daß PARAcElsus ein Unglücklicher war, der unter seinem Schicksal, unter seiner ungeregelten Natur, unter seinem Wissen litt und einen Menschen, einen Bruder suchte, der ihn als Menschen, nur Menschen begriffen hätte; der erraten hätte, daß es sich schließlich nicht um Galen, Aristoteles und Avicenna, um die Doktoren und um die metaphysische Erfassung der Natur handelte, sondern daß hier ein lebendiges Wesen um Hilfe rief, dessen Schicksal wahrscheinlich unvermeidlich war, dem aber desto eher hätte geholfen werden sollen?

Vergessen wir jedoch nicht seine Freunde; wie hätte er auch seinen Kampf auskämpfen können, wenn ihm absolut niemand geglaubt hätte? Der Basler Buchdrucker FroBenius war ihm sehr geneigt; PARACELSUS gedachte seiner als eines "Vaters und Beschützers aller Gelehrten und guten Leute « und als »seines liebsten Freundes $\left.«^{2}\right)$. $\mathrm{Zu}$ seinen Freunden gehörten auch Bonifacius und BASIliUs AmERBACH, der eine Doctor juris, der andere ein berühmter Humanist in Basel. Besonders eine Reihe von Schülern blieb PARACELSUs treu und bewahrte in Ehren die Diktate ihres Meisters auf, um sie nach seinem Tode $\mathrm{zu}$ sammeln und $\mathrm{zu}$ veröffentlichen und so die Grundlage für das Studium seiner Philosophie aufzubauen. PARACELSUs gedenkt selbst seiner (sechs) gelungenen Schüler. Die Bürger der Städte, die er besuchte, haben ihn gern unter sich gesehen; es ist auch eine Nachricht erhalten geblieben, wie er in Preßburg auf Kosten der Gemeinde mit einem Festmahl beehrt worden war $^{3}$ ).

PARACElsus' Anspielung darauf, daß er einmal in ein Krankenhaus nicht aufgenommen worden, beweist, daß er nicht immer gesund war. I 54I kam er nach Salzburg, wo er nach einer kurzen Krankheit verschied. Seine Anhänger ließen nur ungern zu, daß so früh, nicht

1) Strunz, S. 78.

2) Lessing, S. 39 .

3) Strunz, S. 73. 
einmal 50 Jahre alt, der Wunderarzt gestorben wäre, der doch geschrieben hat, daß es der Arzt in seiner Macht haben muß, das Leben auf Jahrhunderte zu verlängern. Auf ihre Verlegenheit ist wahrscheinlich die Sage zurückzuführen, daß PARACELSUS von den Ärzten vergiftet, oder daß er von den Dienern der Doktoren totgeschlagen worden war. Von der Gegenpartei stammt wiederum wahrscheinlich die Erzählung, daß ihn der Teufel geholt hätte. "

Der Erzbischof von Salzburg ließ auf dem Grabe des Paracelsus ein Grabmal errichten, dessen Aufschrift den Ruhm des Paracelsus, seine Arzneikunst und seine Liebe zu den Armen preist.

\section{Paracelsus' Lehre.}

\section{Die geheimnisvolle Natur.}

Woher hat PARAcelsus seine Philosophie geschöpft, wessen Schüler ist er gewesen? Wenn Schüler sein an konkrete Lehren eines Meisters anknüpfen und dieselben fortsetzen bedeutet, so hat PARACELSUS keinem Meister angehört, seinem berühmten Grundsatze gemäß: ne sit alterius qui suus esse potest, es gehöre keinem anderen, der sich selbst gehören kann. Der es kann: im Gegensatze zu der auf den Schultern der Vorläufer stehenden Hochschulwissenschaft wollte er überhistorisch, »neu " und »allein ", ganz anders sein als die übrigen lebenden und verstorbenen Gelehrten, NiETZSCHEs Ideal des unhistorischen Menschen sollte durch ihn verwirklicht werden - ein unmögliches Ideal, denn das Denken und Handeln des Einzelnen hängt notwendig, absolut notwendig mit seinem geistigen Milieu zusammen. Philosophische Robinsons gibt es nicht; bereits als Kind nimmt man mit der Sprache und mit der Erziehung die Keime der Weltanschauung auf, die man später als die ureigenste Schöpfung entwickelt.

PARACELSUS entging dem Einflusse seiner Umgebung nicht: wie könnte er sich sonst zu einem so typischen Repräsentanten der Renaissance entwickelt haben? Wie die übrigen selbständig denkenden Zeitgenossen, so war auch HoHENHEIM jener philosophischen Stimmung gewogen, in der sich der Mensch mit der Natur eins fühlt, sein Nachdenken für Naturgeschehen erklärt, an Intuition und Genialität glaubt, in der sich der Forscher dem Dichter verwandt fühlt. PARACELsus hat sich an der dem Platonismus geneigten Volksphilosophie herangebildet. Die Volksphilosophie aus dem Anfange der Neuzeit zeigte wenig Verständnis für den historischen 
Plato, für den gebildeten Griechen, dessen Geistesdisziplin über jede Phantastik und über alle Extravaganzen erhaben war, für sie bedeutete PLATo einen Übermenschen, einen geheimnisvollen Magus ${ }^{1}$ ) und Theosophen, in dessen Philosophie sie nur eine Art Mysterien der Pythagoreer, der ägyptischen Priester und der Neuplatoniker erblickten, eine dem Okkultismus und der Zauberei verwandte Geheimlehre. Nur die Gemütsstimmung hat PÁracelsus mit Plato gemein: er wendet weder die Platonische Terminologie an, noch beruft er sich auf einzelne seiner Schriften, noch kennt er seine Ideenlehre, seine Anschauungen vom angeborenen Wissen, noch seine religiösen und politischen Theorien. PARACELsus kann nur insofern ein Platoniker heißen, als er ein 》mystischer Realist " (nach der Terminologie einiger russischer Philosophen), ein Intuitivist war, der die Wirklichkeit durch Anschauungsbilder darzustellen sucht, jene Wirklichkeit, die nur durch das schöpferische Gemüt nachempfunden, niemals dagegen durch die Logik analytisch definiert werden kann:

"Im Lichte der Natur befindet sich's, daß alle Dinge nichts sind, dafür wir sie ansehen, sondern unseren Augen die Weise der Corpora alle verborgen ist $\left.\ll^{2}\right)$.

Das Wesen der Dinge ist unnachweisbar, man kann das Verständnis für dasselbe in anderen Menschen nur indirekt erwecken, indem man die Wirklichkeit schildert, auf Analogien hinweist, der Metapher sich bedient. Deshalb geben Allegorien, Analogien und Metaphern das gewöhnlichste Darstellungsmittel HoHEnheims ab; seine berühmte Lehre, der Mensch sei eine kleine Welt für sich, ein Mikrokosmus, ist meistens nur als eine Metapher zu verstehen, die behaupten will, daß die den menschlichen Geist treibenden Kräfte ähnlich sind jenen, welche das Weltall beherrschen. PARAcELsus führt diese Metapher weiter aus: das Fleisch stelle die Erde, die Lebenskraft (balsamus) die Luft, das Blut das Wasser, die Körperwärme das Feuer dar ${ }^{3}$ ). Was sollte es anders als eine kühńe Metapher bedeuten, wenn er die Krankheiten mit den Sternen vergleicht und

1) Man vergleiche die populär naive Art, in welcher Paracelsus, der Verneiner aller Schulautoritäten, über Plato schreibt: 'Wer da viel Werk von der Natur versteht, erkennt und weiß; der ist hoch im Glauben, denn der Schöpfer ist sein Lehrer: als z. B. Plato, in dem wir nicht allein einen natürlichen Philosophus achten, sondern auch einen in Mirakeln bekannt.\& LEssing, S. 91.

2) De cena Domini (Strunz, S. 90).

3) Paramirum Bit. I, S. i8. 
behauptet, daß die Wurzeln der Krankheiten so untrennbar mit dem Wesen des Körpers zusammenhängen wie die Gestirne mit dem Firmament; daß die Krankheit in derselben Weise wie der zunehmende Mond wächst? Seht, mit welchen Bildern er die trockene Wahrheit veranschaulicht, daß der Arzt den Kern des gesunden und kranken Organismus erfassen und dessen Bau, Funktion und physikalische Erscheinungen kennen soll:

"Denn wen èhret der Himmel und die Erde, als den philosophischen Arzt, der sie erkennt? Ihm sind alle Heimlichkeiten der Natur offenbar, er teilt sie erst den übrigen Gelehrten mit. Er umfaßt die Philosophie aller Glieder, Gesundheit und Krankheit, begreift den Puls der Firmamente, die Physiognomie in dem Gestirne, die Chiromantie in den Mineralien, den Atem in den Winden, die Fieber in Erdbeben .. «1).

Überall malt PARACELSUS in dieser bilderreichen Weise seine Wissenschaft aus und bedient sich volkstümlicher Ausdrücke (Chiromantie = Kenntnis der Metalladern in der Erde, Astronomie = Physik, Gestirn = Kraft), um dem Leser eine Ahnung von den geheimnisvollen Naturkräften einzuflößen. Denn seine kühnen, manchmal schwer zu deutenden Analogien verfolgen ein einziges Ziel: zu zeigen, wie tief die Wahrheit verborgen und wie oberflächlich die geläufigen Theorien sind, wie alles um uns in ein großartiges, geheimnisvolles, unaussprechbares Dunkel gehüllt ist.

Die Leser der Paracelsischen Schriften sind geneigt, seine Metaphern für den einfachen Ausdruck der Wahrheit zu nehmen, und sind dann über die Widersprüche und Unmöglichkeiten, in die sich PARACELSUS verwickelt, verwundert. Ganz natürlich; PARACELSUS selbst hat die Metapher für echte Wahrheit ausgegeben: dem astrologischen Aberglauben wurde solcherart Tür und Tor geöffnet. Diese falsche Spur hat ihn zu der (wie es scheint volkstümlichen) phantastischen Lehre verleitet, daß das innere Wesen der Naturobjekte durch ihr Äußeres kundgegeben wird. Die Orchideen verraten durch ihre hodenähnlichen Knollen ihre Kraft, Geschlechtskrankheiten zu heilen; das Schellkraut gibt durch seinen gelben Saft an, daß es die Gelbsucht vertreibt; die Zitrone hilft ihrer Form wegen gegen Herzkrankheiten, die Distel gegen das Seitenstechen usw. ${ }^{2}$ ). Die Paracelsisten arbeiteten diese Verirrung ihres Meisters zu einem System aus, und der Grundsatz »similia similibus "(ähn-

1) Lessing, S. 93 (Basler A. I, S. 207).

2) Lessing, S. I4I (HuSER, I6I8, I, S. 312, 33I, 537, I030, I03 I, 1039. II, S. 306). 
liche Arzneien gegen ähnliche Krankheiten) spielte fortan in der Medizin eine bedeutende Rolle.

Das Problematische und Allumfassende der Naturerscheinungen deutet PARACELSUS durch exotisch klingende Namen an: mit dem biblischen Wort "Limbus " bezeichnet er das Material, aus welchem der Menschenkörper, die ganze Welt, die Krankheiten gebaut $\operatorname{sind}^{\mathbf{1}}$ ); anstatt »Alchimie «sagt er »ars spagyrica «; Yliaster ( bedeutet den Anfang der Dinge, mit "Ares «bezeichnet er den Geist, der jedem Wesen seine spezifische Eigenart gibt; unter "Duelech « ist etwas zu verstehen, das in der Mitte zwischen dem Stein und der steinbildenden Kraft steht; "Leffas " ist der in der Erde enthaltene Sauerteig; "magna Turban «bedeutet die Essenz, welche alles voraussagt; "Euestrum " und »Trarames " stellen eigenartige Geister dar usw. Auch die Titel der Werke und ihrer einzelnen Abschnitte lauten geheimnisvoll:» Liber Paramirum «» Liber Paragranum «» Der Labyrinth der irrenden Ärzte ", "Von der Tinktur der Physiker ", "Der Himmel der Philosophen ", "Das Buch Azoth", "Apokalypsis Hermetis ", "Das Licht der Naturen ", »Bertheonea oder die kleine Chirurgie " usw. Die Mystiker fanden allezeit Gefallen an solchen dunklen Wörtern.

Anstatt der $\mathrm{zu}$ seiner Zeit beliebten komplizierten Pflanzendekokte suchte PARACELSUS einfache chemische Präparate als Arzneien einzuführen; weit entfernt aber, unter denselben Materien zu verstehen, wollte er durch dieselben die Kräfte der Natur an ihren Wurzeln erfassen. Die Namen seiner Medikamente geben ihr tiefes Wesen kund: Arkanum, Lebenselixir, das fünfte Wesen (quinta Essentia, Quintessenz), Mercurius vitae, Prima materia, der Stein der Weisen, die Tinktur der Ärzte, Magisterium, Spezifikum, Balsamus usw. ${ }^{2}$. Welch ein geheimnisvolles Medikament stellt beispielsweise die Quinta essentia dar!

Es ist also das fünfte Wesen eine Materie, aus allen von der Natur erzeugten Dingen und aus jedem belebten Wesen körperlich extrahiert und von allen Unreinlichkeiten und von der Sterblichkeit befreit, am feinsten gereinigt und von allen Elementen abgelöst. Es folgt daraus, daß das fünfte Wesen als wie Natur, Kraft, Tugend und Medizin in den Dingen zwar vormals eingeschlossen liegt, aber auch von jeder Wohnung und äußerer Einschließung befreit sein kann. Dieselbe stellt auch Farbe, Leben und Eigenschaften der Dinge dar. Sie ist ein Geist, dem Lebensgeist ähnlich,

1) De rebus invisibilibus Bir., I, S. I30.

2) Die meisten dieser Namen rühren aus vorparacelsischer Zeit her; doch gibt ihnen Paracelsus einen neuen Sinn. 
mit dem Unterschiede, daß der Lebensgeist der Dinge unsterblich, derjenige des Menschen sterblich ist... (《1).

Wäre eine noch tiefer geholte und mächtigere Arznei vorstellbar? PARACELSUS kennt eine noch mächtigere, das Arkanum:

Arkanum ist das unkörperliche, unsterbliche Wesen des Lebens; es ist über alle Natur und über die menschliche Fassungskraft erhaben ... Es hat die Kraft, unseren Körper umzugestalten, zu verwandeln und zu erneuern ... ${ }^{2}$ )

Auch PARACELsus' Lehren sind geheimnisvoll; deshalb fordert er den Adressaten einer seiner Schriften ${ }^{3}$ ) auf, er möge sie im geheimen halten wie eine Perle, die man nicht den Säuen vorwirft. Um den Leser darin zu stören, mit Muße seine. Ideen zu verfolgen, um ihn mit in die philosophischen Tiefen hinabzureißen, gibt PARACELSUS den gangbaren Wörtern eine neue, ungewöhnliche Bedeutung; die Wörter "Astronomie «, " Medizin «, "Astrum " (Stern), "Anatomie " u. a. haben bei ihm nebst der gewöhnlichen noch eine andere, ganz unerwartete Bedeutung: Astrum bedeutet auch Kraft, unter Anatomie versteht er auch das aus dem $\ddot{u}$ ußeren ermittelbare Wesen der Dinge, mit dem Wort Astronomie bezeichnet er auch den $\mathrm{Zu}$ sammenharig des Himmels mit der Erde usw. Die Spiritisten und die Okkultisten pflegen sich noch heute solcher Darstellungsmethoden $\mathrm{zu}$ einem ähnlichen $Z$ wecke zu bedienen.

\section{Erfahrung und Autorität.}

Von den Geschichtschreibern der Wissenschaft wird unser Held gerühmt, weil er, während seine Mitwelt nur Bücher studierte, sich als der erste für die Erfahrung entschied. Doch wie erklären sie uns HoHENHEIMs Spott über die "Experimentatoren « und * Probierer «, über Ärzte, die sich auf den Zufall verlassen, die unsicher an das Krankenbett herantreten, die die Krankheit nach einzelnen Symptomen analysieren? daß er keine Ahnung von unserer "Induktion " gehabt hạt? daß er nicht geglaubt hat, der Mensch vermöge durch zielbewußte Naturbeobachtung sein Wissen wesentlich zu vertiefen? daß er keinen »Fortschritt der Wissenschaft « gekannt hat?

Wie in so manch anderer Hinsicht, glauben wir auch in diesem Falle, man habe zur Zeit HohenheIms unter Erfahrung dasselbe

1) Archidoxorum lib. II. Biт., II, S. 5.

2) Ebenda lib. V. Bit., II, S. I6.

3) De rerum natura libri 9, Biт., II, S. 84 .

Rádl, Geschichte der biol. Theorien. I. 2. Aufl. 
wie heute verstanden; es fehlt uns eine kritische Geschichte des Erfahrungsbegriffes, wie die Geschichte der meisten anderen in der Wissenschaft angewendeten Begriffe. Die Geschichte würde uns belehren, daß der Erfahrungsbegriff der modernen Wissenschaft sich mit der Zeit verändert. Jedenfalls hat sich PARAcELsus unter Erfahrung etwas anderes vorgestellt als die heutigen Forscher.

Was er unter Erfahrung versteht, ist seiner Definition des wahren Arztes zu entnehmen: die Erfahrung bedeutete für ihn die Abhärtung des Gemüts im Kampfe mit der Natur oder das restlose Sichverlieren des Menschen in den Geheimnissen der Natur. Sein Spott über die alten Autoritäten entstammte anderen Quellen als die moderne Lobpreisung der »Erfahrung «; er bedeutete den Protest eines genialen Menschen gegen die Ketten der Tradition, eine Vorahnung der Lehre Rousseaus von der Degeneration der Menschheit durch die Kultur, das Bestreben, den Einfluß der Vergangenheit abzuschütteln und nur das ureigene Wesen zu entfalten. Deshalb stellt er - wie später auf seinem Gebiete Rousseau - die Forderung auf, daß jeder wahre Arzt seine Kunst so von der Natur erlerne, wie sie der erste Arzt auf der Erde erlernt hat ${ }^{1}$ ). Dasselbe besagen seine Worte, daß die echten Ärzte weder in Leipzig, noch in Wien ${ }^{2}$ ), sondern in der Natur geboren werden, deshalb brüstete er sich, zehn Jahre lang nichts gelesen zu haben ${ }^{3}$ ).

Seine 》Erfahrung " entstammt der Überzeugung, der später ROUSSEAU einen klar formulierten Ausdruck verliehen hat, der Mensch sei von der Natur aus gut (wissend); seine Überzeugung ist dem Glauben der deutschen Naturphilosophen verwandt, daß der Mensch aus seinem Inneren heraus (im Kampfe mit der Natur) die wahre Erkenntnis entwickelt. Konsequenterweise nennt PARACELSUS die Philosophie die 》unsichtbare Natur $\left\langle{ }^{\mathbf{4}}\right)$, als deren Wiederholung der (philosophierende) Arzt erscheint, und er behauptet an derselben Stelle, die Erfahrung sei ein unsichtbares Ding, eine geistige 'Durchdringung dessen, was die Augen sehen und die Hände greifen. So ist die paracelsische Erfahrung "Erfahrung an sich «, gereinigt von jedweder Tradition, von allem Indirekten, Angelernten, Erworbenen; ihren innersten Kern bildet die Überzeugung, daß der Mensch alle äußeren Einwirkungen, alle »erworbenen Eigen.

\footnotetext{
1) Lessing, S. 62 (Huser, I, S. 26).

2) Ebenda (Huser, I, S. 256).

3) BiT., I, S. I65.

4) Biт., I, S. 188.
} 
schaften "von sich abschütteln und aus dem absolut unabhängigen eigenen Gemüt das Wesen der Natur sich entwickeln lassen kann. So ist Hohenheim radikaler als die modernen Erfahrungsphilosophen vorgegangen; die letzteren erkennen die Tradition für unentbehrlich an (aus der gemeinsamen Arbeit vieler Generationen soll sich unser Wissen entwickeln), HoHENHEIM hat sich nur auf sich selbst verlassen wollen.

Der moderne Forscher glaubt an indirekte Erfahrung; seine Hypothesen arbeitet er auf Grund zielbewußter, d. h. verstandes mäßig begründeter Erfahrung aus, er zwingt die Natur zu bestimmten Antworten. Für PARAcelsus bedeutet Erfahrung unvoreingenommene Hingabe an die Eindrücke der Natur, sie bedeutet so viel wie Intuition ${ }^{\mathbf{1}}$ ). Die Natur lehrt uns die Arzneikunst, behauptet er, nicht die Vernunft ${ }^{2}$ ), und an einer anderen Stelle bedient er sich des passenden Bildes, daß das Wissen in uns ebenso wächst wie das Getreide auf dem Felde ${ }^{3}$ ). Er spricht auch davon, daß unser Wissen uns von oben kommt: wie der Erzengel gesandt wurde, Maria die Ankunft Christi zu melden, so sendet Gott gute und böse Geister herab, die in den Menschen wie Licht und Wärme eindringen und ihn mit neuem Wissen durchstrahlen $\left.{ }^{4}\right)$. So stellt die Erfahrung ein kostbares, nur Auserwählten verliehenes, aus transzendenter Welt stammendes Geschenk dar.

Die radikale Ablehnung jeder Nichterfahrung war praktisch nicht durchführbar. Die wahre, realistische Philosophie würde gegenüber dem modernen mechanischen das Postulat eines organischen Verhältnisses zur Tradition aufstellen: ein Realist wird sein Verhältnis zur Vergangenheit $\mathrm{nach}$ innerer Sympathie (nach den Wahlverwandtschaften) seiner Lehre mit denjenigen der Vorläufer ordnen. PARACELSUS hat über diese Konsequenzen nicht nachgedacht; nur durch die Macht der Umstände wurde er zu denselben geführt. Auch PARACELsus kannte nämlich, trotz seiner Proteste, die alten Autoren, auch er mußte sie erwähnen und konnte

1) In Buffon, Rousseau, Goethe kam diese Auffassung der Erfabrung wieder zum Vorschein. Vgl. z. B. Buffons Worte: „Es ist nötig, fast ohne Absicht zu schauen, weil, wenn man sich für eine bestimmte, an sich noch so gute Methode entscheidet, man niemals $z u$ einer genügend umfassenden Einsicht gelangt.... (Hist. naturelle, I. Discours.)

2) BiT., III, S. 5 I.

3) BiT., I, S. I43.

4) Ebenda. 
nicht vor ihren Vorzügen die Augen schließen. Sie werden von ihm gerühmt, insofern sie das Wesen der Krankheiten kurz beschrieben hatten und in der Aufzeichnung neuer Arzneimittel fleißig gewesen waren; erst die scholastischen Kommentatoren sollen sie verdunkelt haben ${ }^{1}$ ). Namentlich Hippokrates wird von PARAcElsus lobend erwähnt ${ }^{2}$ ); doch auch einem Galenus, ja auch einem AviCENnA ${ }^{3}$ ) wird gelegentlich Anerkennung erteilt; PLATO wird hoch gepriesen ${ }^{4}$ ). Doch was nützt uns all ihre Weisheit?

Welch ein Nutzen aus dem Regen, der vor tausend Jahren gefallen war? Der Regen nützt, der jetzt fällt5 5$) !$

\section{Phantastisches.}

Unser großer Prediger der Erfahrung kennt die Skepsis nicht einmal der Möglichkeit nach; unkritisch wie ein Kind, das noch aufrichtige Freude an Märchen hat, glaubt er alles schlechthin; man denke sich welchen Unsinn immer, bei PARACELSUS wird man einen noch größeren mit einer Sicherheit angeführt finden, als ob es gar keine Zweifel auf der Welt gäbe. Ihr wähnt, der Mensch nehme durch den Mund Nahrung auf; o nein! er nimmt sie nach PARACELSUS durch die ganze Körperoberfläche auf, denn beim Baden fühlt man keinen Durst, und die in der feuchten Luft der Alpen lebenden Kühe trinken niemals; würde man die Füße des Menschen in den Boden einpflanzen, so brauchte er nicht zu essen; ein gewisser Mann habe sich sogar ein halbes Jahr ohne jede Nahrung am Leben erhalten, indem er sich bloß feuchte Erdschollen auf den Magen gelegt habe $\left.{ }^{6}\right)$. Durch passende Heilmethoden soll sich der Mensch sein Leben auf tausend, auf neunhundert oder "wenigstens " auf sechshundert Jahre verlängern können ${ }^{7}$ ). PARACELSUS gibt ein ausführliches Rezept für die Auferweckung getöteter Vögel und für die künstliche Erzeugung der Menschen in einer Phiole ${ }^{8}$ ). Er gibt ein anderes Rezept für die Zubereitung der Tinctura physicorum, durch die das Leben auf I50 und mehr Jahre verlängert werden kann; es soll einmal einer auf die Tinktur nicht achtgegeben haben,

\footnotetext{
1) BIT., III, S. I 76.

2) Lessing, S. 64 .

3) Bit., II, S. 28.

4) Lessing, S. 9I (Huser, II, S. IO7).

5) BiT., I, S. 249.

6) Archidoxorum lib. I. BiT., II, S. 5 .

7) Ebenda, S. 68.

8) De natura rerum BiT., II, S. 85 .
} 
die Hennen haben sie gefressen, und siehe da! ihr Gefieder ist verkehrt gewachsen; PARACELsus selbst habe eine solche Henne gesehen ${ }^{1}$ ). Er glaubt an Prophezeiungen aus dem Vogelflug und an alle Arten der Hexenkunst. Durch Wärme und Feuchtigkeit wird das Wachstum aller Dinge gefördert - die Nägel und Haare wachsen im feuchten Boden auf dem Leichnam noch zwei Jahre nach dem Tode; auch das Gold wächst, wenn man es befeuchtet, bis es baumgroß wird. Er kennt eine vorzügliche Arznei für die Verjüngung des Körpers; ihre Wirkung ist so mächtig, daß sogar ein ausgestopfter Eisvogel infolge derselben gemausert hat ${ }^{2}$ ).

Vergeblich wird man PARACELsus' Aberglauben durch seine wenig fortgeschrittene Zeit zu entschuldigen suchen. Es gab damals Denker, die viel, viel kritischer waren. ALBERT DER GROSSE, der 300 Jahre vor PARACELsus gelebt, glaubte zwar auch an viele Sachen, an die er hätte nicht glauben sollen, immerhin war er viel behutsamer als PARACElsus. ERASTUS, ein Aristoteliker, war nur um 30 Jahre jünger als PARACElsus; in seiner Polemik gegen den letzteren ist er höchst entrüstet über dessen Kritiklosigkeit und nennt PARACELSUS wegen solcher Lehren, die wir beispielsweise angeführt haben, einen unverschämten Lügner. Vergleichen wir den Standpunkt dieser beiden Forscher zu dem Hexenproblem. PARACELsus glaubte

1) BIT., II, S. I 19.

2) Erastus, S. 46. - Hier noch eine Auswahl anderer Beispiele seiner Leichtgläubigkeit. Er hat eine Arznei gesehen, die auf das Auge mit einer so starken magnetischen Kraft eingewirkt hat, daß sie dasselbe aus der Augenhöhle bis zur Nasenspitze herausgezogen hat (LEssing, S. 80). Wer eines natürlichen Todes gestorben ist, ist auf immer tot; man soll aber imstande sein, getötete Menschen zum Leben zurückzurufen (BiT., II, S. 96). Von der Möglichkeit der Transmutation von Metallen ist er fest iiberzeugt; doch soll die Herstellung edler Metalle schwer sein; man brauche dazu den Stein der Weisen (BIT., II, S. IOo). An einer anderen Stelle bestreitet er jedoch eine solche Möglichkeit (BIT., I, S. 213). Er glaubt an Succubus und Incubus und behauptet, daß aus dem dabei verstreuten Sperma Würmer und Schlangen entstehen (De orig. morb. invis. BiT., I, S. I24). Die Pest soll auf dieselbe Weise entstehen, und darum sollen Klöster und Hurenhäuser am meisten an der Verbreitung der Pest schuld sein (Lessing, S. I66). Er glaubt an die Verzauberung der Menschen und der Kühe, an die Macht der Verfluchung (BIT., I, S. 25). Er führt zwei verschiedene Rezepte zur Herstellung des Homunculus an (BIT., II, S. 86); derselbe soll uibrigens auch im Magen nach einem Koitus per os entstehen; aus dem Homunculus sollen sich Pygmäen, Riesen und andere Wundergeschöpfe entwickeln (ebenda). Die Geister (z. B. die Nymphen) können mit den Menschen menschliche Kinder zeugen (BiT., I, S. I89). Paracelsus schreibt den Kranken auch verschiedene Amulette vor (BrT., II, S. 695.sq.) und glaubt, daß man im Kristall den Einfluß eines Sterns konzentrieren und auf beliebige Zeit einschließen kann (BARTSCHerer, S. r99) usw. usw. 
aufs Wort, daß man mit Hilfe der guten und bösen Geister zaubern könne, er warnt wiederholt den Leser, sich bei der Zauberei ja nicht dem Einflusse des Teufels preiszugeben, sondern dem Beispiele Gottes zu folgen, der sich auch der bösen Geister zur Bestimmung der Menschenschicksale bedient. ERASTUS verwirft energisch diesen Aberglauben und weist klar und ausführlich nach, daß der Glaube an die übernatürliche Macht der Hexen purer Wahn (fabulae superstitiosae) sei, daß solche Weiber nicht auf Besen fliegen könnten usw., und daß sie an den ihnen zugeschriebenen bösen Taten unschuldig seien. Trotzdem stimmt er der Verbrennung derselben bei ${ }^{1}$ ); ihre Schuld liege in dem bösen (obwohl ohnmächtigen) Willen, sich zum Verderben des Nächsten mit dem Teufel zu vereinigen ${ }^{2}$ ).

PARACELSUS' platonisch gestimmter Geist schwelgte in lauter Ideen und hatte wenig Verständnis für die vergänglichen Tatsachen. Er wollte seiner Überzeugung Ausdruck geben, daß in der Erde dieselben Elementarbestandteile enthalten sind wie im Menschenkörper; ob sich aber der Mensch tatsächlich mit den Erdschollen, sogar durch die Haut hindurch ernähren kann, das war für ihn Nebensache und galt ihm nur als eine Art Ausschmückung oder Bekräftigung jener Idee. Er war bestrebt, seinen Zeitgenossen die große Macht seiner Arzneimittel darzulegen; ob sie wirklich das Leben auf Jahrhunderte zu verlängern vermöchten, ob sie wirklich imstande wären, das Mausern eines ausgestopften Vogels hervorzurufen, darnach fragte er nicht. Er nahm die Lehre von Gottes Allmacht wörtlich; warum sollten aber dann Gottes Kinder, die Natur und der Arzt, nicht ebenfalls allmächtig sein?

Würde sich Gott zur Erde wenden und befehlen: Übertrage dich, du Berg, in die Mitte des Meeres, dann wird der Berg glauben, daß er sich über seine natürlichen Kräfte davonzubewegen und sich ins Meer zu werfen ver-

1) ... tametsi facto nullum laeserint. Erastus, I, S. 97.

2) Der gute Wille, Paracelsus gegen die Angriffe des Erastus zu beschützen, verleitete einige Autoren $z u$ einem sonderbaren Mißverständnis. Indem sie PARACELsus als einen für seine Zeit sehr fortgeschrittenen Mann ausgeben, suchen sie seine Umgebung als weniger gescheit darzustellen; R. NETZHAMMER bemerkt infolgedessen über ERASTUS: „Er huldigte auch einem ganz unbegreiflichen Aberglauben; so z. B. war er uberzeugt von dem Bunde der Hexen mit dem Teufel, ihrer Gewalt, Gewitter zu erregen, durch Zauberei Menschen und Vieh Schaden zuzufïgen, und ermahnte deshalb die Obrigkeit, die Welt von solchen Ungeheuern zu befreien (S. 8I). Wahr ist indessen, daß Erastus schreibt, Paracelsus sollte verbrannt werden, weil er an die Hexerei glaubt. Paracelsus selbst stimmte, wohlgemerkt, auch ausdrücklich dem bei, daß die Hexen durch den Scheiterhaufen bestraft werden sollten! 
mag. Denn der Natur wohnt ein innerer Glaube inne, und sie verläßt sich auf Gott, ihren Schöpfer...1)

Wer in PARACELsus einen gelehrten Professor, einen trockenen Verfasser von Handbüchern sieht, der wird wohl nicht begreifen können, wie er nur an die Ungeheuerlichkeiten, die er gelehrt, hat glauben können. Allein PARACELSUs war kein Nachkomme der kritischen Scholastiker; seine Wissenschaft erwuchs jenem Gebiete des menschlichen Schaffens, dem auch die Wissenschaft der Schafhirten, der Hexen und der Alchimisten entstammt, der Menschen, denen der Unterschied zwischen den Märchen und dem kritisch gesichteten Wissen unbekannt bleibt, für welche Dichtung zur Wahrheit und Wahrheit zur Dichtung wird. In der Tat sind PARAcelsus' phantastische Angaben volkstümlichen Erzählungen und nicht wissenschaftlichen Irrtümern zuzuzählen, Erzählungen, welche noch heute unter Dorfkindern leben. Erinnerungen aus eigener Jugend werden in uns wachgerufen, wenn wir in PARACELSUS vom hohen Alter Methusalems lesen, von dem Gold, das, fleißig begossen, zum Goldbaume heranwächst, von wunderbaren Bildnissen und Figuren in alten Kapellen, in Gräbern, in Höhlen, in heimlichen Gängen, in Felsen, in Steinklüften, auf Inseln und an wilden, unbewohnten Örtern, auf die große Achtung zu geben sei, da sie oft wunderbare Bedeutung haben...2). Mit solchen halb andächtigen, halb furchtsamen Blicken betrachten noch heute die Dorfkinder auffallend gestaltete Ruinen, alleinstehende Bäume, alte Kapellen und öde Örter; in Erzählungen über deren Bedeutung besteht ihre erste naive Wissenschaft.

Trotzdem war PARACELsus keineswegs abergläubisch im wahren Sinne des Wortes. Denn Aberglaube bedeutet an erster Stelle Furcht, Furcht vor dem Teufel, vor den Gespenstern, und es steckt in demselben etwas Boshaftes, das Licht und Menschen fürchtet.

Das verwerfliche Hauptmerkmal des Aberglaubens liegt, wie PARACELSUS und ERASTUS richtig erkannt haben, in der auf Schleichwegen wandelnden Niederträchtigkeit und nicht im Inhalt des Geglaubten. Es mögen nun die Behauptungen PARACELSUs' noch so ungeheuerlich klingen, er glaubt von natürlich en Erscheinungen, von Offenbarungen mächtiger, der Natur innewohnender Kräfte zu reden. Überall sucht er die von ihm besprochenen Erscheinungen

1) Astronomia magna BIT., II, S. 605.

2) Bartscherer, S. 196 (Huser 1616, II, S. 302). 
als natürliche Tatsachen darzustellen; er behauptet z. B., daß der Leichnam große und wunderbare Heilkraft besitze, beteuert aber in einer langen Auseinandersetzung, daß die Heilkraft nicht in der Materie desselben zu suchen sei, so daß die Körper der Heiligen wirksamer wären als diejenigen der Missetäter, sondern dieselbe wohne allen Menschenkörpern als Bestandteilen des allmächtigen Weltalls, als eine natürliche Eigenschaft inne ${ }^{\mathbf{1}}$ ). Der Teufel soll eine große Macht besitzen; warum sollten wir auf seine Mithilfe verzichten, wenn Gott selbst durch den Teufel auf die Welt einwirkt? ${ }^{2}$ ) Deshalb bekämpft PARACELSUS immer und immer wieder die schwarze Kunst, welche auf unehrlichen Wegen die Natur zu vergewaltigen strebt; die Menschen, welche die Magie »den Menschen zum Verderben und Schaden «mißbrauchen, sind nichtswürdig; deshalb ist es onicht unbillig noch unrecht, daß man sie und alle Zauberer mit dem Feuer hinrichtet. Denn diese sind die schädlichsten Leute und die bösesten Feinde, so wir auf Erden haben, so sie je mand Übel wollen « 3 ).

\section{Dinge und Wörter.}

Unklare Sprache und barbarische Terminologie bilden einen nicht wegzuleugnenden Fehler der paracelsischen Schriften. ERASTUS ereifert sich aber darüber, daß HoHENHEIM sogar an einen natürlichen, innerlich mit dem Wesen der Dinge zusammenhängenden Sinn der Wörter geglaubt hat; auch andere Platoniker, Plotinus, Marsilius Ficinus, Pomponatius, beschuldigt er desselben Vergehens. Welch ein Aberglauben! ruft er aus; wer sieht nicht ein, daß die Wörter und die Sprache nur etwas Künstliches, nur konventionelle Zeichen der Dinge bedeuten $\left.{ }^{4}\right)$ ?

Die Jetztwelt gibt ERASTus recht, und nur die Philosophie-Historiker erinnern sich, daß auch PLATO selbst vom natürlichen Sinn der Wörter überzeugt war; höchstens werden gewisse, übrigens auch für überwunden gehaltene Theorien erwähnt, nach denen die Wortwurzeln (zum Teil) Nachahmungen von Naturlauten sein sollen und wenigstens ihrem Ursprunge nach »natürlich « sind. Sonst gibt man den Wörtern nur den Wert von konventionellen Zeichen für Begriffe, für Anschauungen und für Vorstellungen der Dinge; in den Sätzen 》die Rose ist rot «, 》der Löwe ist ein Raubtier «, »Herr X. ist Melancho-

\footnotetext{
1) De morb. invis. BiT., I, S. 25.

2) BiT., I, S. 135 .

3) Bartscherer, S. 46 (Huser, II, S. 298).

4) Erastus, S. I69 sq.
} 
liker « bedeuten die Worte " rot ", »Raubtier ", "Melancholiker « nur mehr oder weniger willkürlich festgesetzte Symbole, nicht einmal für Dinge, sondern für Abstraktionen. Denn (so werden wir belehrt) die rote Farbe der Rose ist nichts an sich selbst, sondern nur eine Folge der Netzhautreizung durch Ätherschwingungen; der Begriff 》Raubtier《 ist nur eine kurzgefaßte Sammelbezeichnung für verschiedene Katzen, Hunde usw.; unter "Melancholie « ist bloß eine Folge von gewissen Organveränderungen zu verstehen.

Dieser (nominalistische) Standpunkt der modernen Wissenschaft ist auch derjenige des Aristotelikers ERASTus gewesen; PARACELsus war anderer Meinung über das Verhältnis der Wörter zu den Dingen. Mit Plato, mit Buffon, mit Goethe, mit Schopenhauer und mit SCHELIING ruft er unserem nominalistischen, logisierenden Standpunkt gegenüber fortwährend aus: nur Sachen, keine Wörter! fort mit solchen Wörtern, die jeden realen Inhaltes bar, bloße Zeichen wären! Die rote Farbe der Rose gilt diesen Realisten als etwas Ansichseiendes (dies ist der Inhalt der GoETHEschen und der ScHoPENHAUERschen Farbenlehre), das Raubtier ist ein Wesen, nicht nur ein Wort, die Melancholie ist ein Ding, das den Menschen wie ein lebendiger Feind überfallen kann.

Meine Philosophie, sagt Paracelsus, ist weit von der Schulphilosophie entfernt, denn diese schwelgt bloß in den Phantasien und definiert und erklärt die Wörter, wie es einem jeden einfällt. Daher die leeren Namen [d. h. Abstraktionen] Cholera, Melancholia, Phlegma, Sanguis, deren Grund nichts anderes ist als eine leere und vergängliche Spekulation. Auf solchen Meinungen und Träumen bauen die Ärzte ihre Lehren. Der wahre Arzt geht jedoch von der Natur und nicht von der Spekulation aus. Denn die Natur ist sichtbar, die Spekulation unsichtbar. Deshalb müßt ihr sagen: dieses ist Cholera, dieses ist Melancholia, wie man zu sagen pflegt, dieses ist Arsenik ${ }^{1}$ ).

Ein cholerisches, melancholisches usw. Temperament sind also als konkrete Dinge (Kräfte), nicht als Definitionen aufzufassen; sie sind so wirklich wie ein chemisches Präparat. In demselben Sinne führt PARACELSUs die Medizin als ein Wesen, als eine Naturkraft vor; in demselben Sinne ist seine Frage zu verstehen:

Was ist die Philosophie anders als eine unsichtbare Natur, was anders ist die Natur als eine sichtbare Philosophie?2)

Dasselbe haben die deutschen Naturphilosophen in ihren Lehren gepredigt, die Natur sei ein sichtbar gewordener Geist, die Geschichte

1) Paragranum BIT., I, S. I98.

2) Ebenda, S. 189. 
séi die Entwicklung des absoluten Geistes, die Naturgesetze seien dem Menschen angeboren. In dieser Weltanschauung ist PARACELSUS' Ehrfurcht vor der Erfahrung und seine Abneigung gegen die logisierende Schulwissenschaft begründet; er rühmt die Erfahrung als Natürlichkeit, Ungesuchtheit, als das schlichte Bewußtwerden des Seienden.

Indem PARACELSUS die Ideen des Menschen für einen Teil der organischen Natur gehalten hat (hatte er damit nicht recht?), suchte er den Wörtern und Sätzen einen tieferen, wirklicheren Sinn zu geben, als sie zu haben scheinen; nicht über die Natur zu spekulieren, sondern die Natur selbst in der Philosophie leben zu lassen, war sein Ideal; das Wort »Baum "sollte sich zur lebendigen Vorstellung des Baumes wie der Same desselben zum entwickelten Baum verhalten. Deshalb gibt er der Anschauung Vorzug vor der Definition, deshalb setzt er an Stelle der Lehrsätze die Erfahrung, an Stelle der Pädagogik die Praxis, deshalb stellt er Wirklichkeit an Stelle des Formelnkennens. Daher die bilderreiche Sprache, die Neigung zur Mystik, die Vorliebe für neue, sonderbar klingende Wörter.

Von diesem Standpunkte aus sucht PARACELSUs in den Wörtern mehr als der moderne Forscher; in einer anderen Hinsicht achtet er sie wieder geringer. Die analytische Wissenschaft ist bestrebt, jedem Begriffe, jedem Ding einen Namen zu geben, der als konventionelles Zeichen für eben dieses Ding dienen soll. In diesem Sinne hat LiNNÉ alle Organismen mit Namen belegt; in der neuesten Zeit hat die künstliche Schaffung von neuen Namen für jede wissenschaftliche Kleinigkeit unmögliche Dimensionen erreicht. Diese künstliche Wortbildung und die mit derselben im inneren Zusammenhange stehende Bildung einer besonderen wissenschaftlichen Sprache (die für die Scholastik und mutatis mutandis für die moderne Wissenschaft charakteristisch ist) widerstrebt dem die Natürlichkeit betonenden Geiste des Realisten. Deshalb verachtete PARAcELsus die lateinische Sprache der Doktoren, deshalb hielt er sich an keine festgesetzte Terminologie, deshalb unterschätzte er den Wert von Wörtern und wendete die Sprache nur als plastisches Werkzeug zur Mitteilung seiner Ideen an. Keiner seiner Zeitgenossen hat dieses sein Streben begriffen; erst das Aufklärungszeitalter hat in seinen besten Repräsentanten, in BuffoN und Goethe, den Wert der nat ü rlich en gegenüber der in der Wissenschaft herrschenden kü nst. lichen Sprache wieder hervorgehoben. 


\section{Ursache und Korrelation.}

Die Dinge entstehen nach PARACELsus nicht durch gegenseitige Einwirkungen, sie sind überhaupt keine Folge irgendwelcher Ursachen, sondern alle sind a priori, und die äußeren Faktoren machen nur ihre gebundenen Eigenschaften frei. Der Mensch, die Erde, der Himmel, der Stein, das Licht und jede andere Naturerscheinung besitzt nach PARACELsus ihre eigen en Wurzeln, durch welche sie direkt, ohne Vermittlung der sekundären Ursachen, mit dem Urwesen der Dinge zusammenhängt; einzelne Eigenschaften des Menschen, des Himmels, des Lichtes sind wieder ansichseiende Wesen, Typen, Ideen; es gibt so viel Ideen (»Samenwesen «nach PARAcElsus) als einheitliche Erscheinungen. Es gibt so viel selbständige, wesentlich verschiedene Menschentypen als verschiedene Menschenindividuen $^{1}$ ); auch der melancholische und jeder andere Charakter des Menschen gilt ihm als ein besonderes Wesen ${ }^{2}$ ). Die Sinne, das Gesicht, das Gehör usw. faßt er als Tiere auf, welche in den Sinnesorganen und durch dieselben ebenso leben, wie die Seele im Körper ${ }^{3}$ ); auch solche Eigenschaften, wie den süßen oder bittern Geschmack der Früchte, hält PARACElsus für besondere in den Früchten eingeschlossene Wesen; seine Medizin ist ganz auf der Idee aufgebaut, daß die Krankheit als ein besonderes (vom Anfang der Welt daseiendes) Wesen lebt, das sich im Körper aus präexistierenden Anlagen als eine Art Parasit entwickelt. Dasselbe Element (z. B. Sulphur) ist anders im Holz, anders im Menschenkörper, anders in den Metallen, anders im Gestein vertreten; ja in jeder Quelle kommt ein besonderes, von jedem anderen qualitativ verschiedenes Wasser an die Erdoberfläche. Auch jeder Traum stellt ein besonderes Wesen dar, das durch die Seele des Träumenden hindurchgegangen ist; jeder Gedanke ist ein Geist für sich, der unabhängig

1) PARACELSUS glaubt nicht nur an die Konstanz der Arten und Gattungen, sondern an die Unsterblichkeit jedes Individuums (wohl hatte er noch keine Ahnung von unserem Begriffe der Art und Gattung). Er stellt sich die Unsterblichkeit der Individuen so vor, daß er eine endliche Zahl der möglichen Menschenvariationen annimmt, welche nach einer gewissen, sehr langen Zeit alle auf der Welt erscheinen werden, worauf sich dieselben Gesichter und dieselben Charaktere wiederholen werden; als Arten und Gattungen des Menschen faßt er Riesen, Nymphen, Idioten, Wolfmenschen, Schafmenschen usw. auf (BIT., I, S. 350).

2) Paracelsus führt diese Lehre an vielen Orten an; ausführlich z. B. in Paramirum BIT., I, S. 5 sqq.

3) BIT., II, S. 4 . 
vom Menschen lebt und ihn zufällig besucht. So ist jede Naturerscheinung, jede ihre Eigenschaft, jede Gemütsbewegung und jeder natürliche Begriff der Ausdruck eines besonderen, für sich selbst existierenden Samenwesens. In der Mehrzahl der Naturwesen sind jedoch viele Einzelwesen organisch aneinander gebunden; so stecken im Kind die Eigenschaften seiner Vorfahren.

Auch andere Platoniker erweisen sich einer substanziellen Auffassung aller Erscheinungen geneigt; der Platonismus des PARACELSUS ist jedoch so aufrichtig, daß er die Ideen für ebenso existierend hält wie die Steine, die Menschen, die Tiere: der tolle Hund beißt sich in den Fuß des Menschen ein; sein ganzes Gemüt konzentriert sich in seinen Zähnen, und der erschrockene Mensch wendet seine Aufmerksamkeit ganz der Verwundung zu; so stoßen in der Wunde die Tollwut und die Furcht des Menschen zusammen; aus ihrer Vereinigung entsteht die Ansteckung,

"denn sind auch jene Vorstellungen nicht materiell, so sind sie trotzdem körperlich, d. h. luftig, wie der Wind «1).

Die Phantasiebilder der Menschen vergiften die Himmelssphären, das Gift steigt hinab und verbreitet die Pest unter den Menschen ${ }^{2}$ ). Die Ähnlichkeit der Kinder mit den Eltern kommt daher, daß der Himmel (d. h. unser Milieu) seine Ideen der Einbildungskraft der Eltern einprägt, woher sie in den Embryo eintreten; auf demselben Wege gelangen auch die Krankheiten vom Himmel in die Eltern und ihre Kinder ${ }^{3}$ ). Deshalb betrachtet es PARACELsus als selbstverständlich, daß die Welt voll Engel und guter und böser Geister ist; daß im Wasser Nymphen, in der Luft Sylphen, unter der Erde Pygmäen, im Feuer Salamander, in den Wäldern Riesen wohnen, daß in der Luft die Geister der Verstorbenen umherirren und daß diese Wesen in das Naturgeschehen ebenso eingreifen wie die Men$\left.\operatorname{schen}^{4}\right)$.

Jedes der unendlich zahlreichen die Welt zusammensetzenden Wesen ist nach PARACELSUs so absolut, so für sich selbst, daß es

1) BiT., III, S. 3 I.

2) Erastus, S. 55 .

3) BiT., III, S. 180 .

4) De Nymphis etc. BrT., II, S. 388 sqq. Der Glaube an Geister (= von der Materie isolierte Kräfte) war im Mittelalter allgemein verbreitet; den Sehvorgang stellte man sich z. B. in der Weise vor, daß vom Objekt ein Bild ausgeht, sich durch die Luft fortpflanzt und durch das Auge und den Sehnerven ins Gehirn eindringt. wo es zur bewußten Vorstellung wird. Noch im I7. Jahrhundert wurden solche Hypothesen verteidigt. 
von jedweder äußeren Einwirkung ganz unabhängig dasteht. So konsequent folgt PARACELsus diesem Individualismus, daß er die kühne Behauptung aufzustellen wagt, daß die Menschen ganz so, wie sie sind, bleiben würden, auch wenn es keine Sonne, keine Planeten, keine Nahrung gäbe, denn die Menschenwesen (ihre Ideen, ihre "Samen ") kommen von Gott; durch die Sonne und durch die Natur sei nur das materielle Leben realisiert, keineswegs aber das ideelle ${ }^{1}$ ). Weil nun jedes Wesen nur durch sich selbst bestimmt wird, kennt PARACELSUS keine mechanische Kausalverknüpfung zwischen dem Vorangehenden und dem Nachfolgenden, er nimmt vielmehr nur einen organischen Zusammenhang, eine Sympathie der Vorgänge an; wie im Organismus jedes Organ eine Einheit für sich bildet und wie sich die Organe $\mathrm{zu}$ höheren Individualitäten verbinden, so soll es im ganzen Weltall sein; die Sonne, die. Planeten, die Erde, die Pflanzen, die Steine, das Wasser, die Geister sind einerseits aus Elementen niederer Ordnung aufgebaut, stellen aber andererseits selbst Teile eines höheren Ganzen dar und treten zu höheren Individuen zusammen, um endlich das höchste organische Wesen, das Weltall, den Makrokosmos zu bilden. Wie nun im Körper jedes Organ für sich selbst und dadurch für den gesamten Körper lebt, so auch im Makrokosmos: der Mensch, das Tier, die Pflanzen folgen ihrem Lebensschicksal frei und von der Umgebung unabhängig, erfüllen aber gerade dadurch kraft der inneren Korrelation (Sympathie) aller Erscheinungen das Schicksal des Makrokosmos selbst; keine Ursachen, nur kosmische Korrelationen verknüpfen das Weltgeschehen zu einer Einheit ${ }^{2}$ ). Zufolge des organischen Zusammenhanges aller Erscheinungen im Makrokosmos gibt es in demselben kein isoliertes Geschehen: erkrankt ein Organ, so ist der ganze Körper, so ist die ganze Welt erkrankt, und die ganze Welt kämpft gegen diese Störung. Auch zwischen den Planeten und den Menschenschicksalen herrscht diese Sympathie; die Konstellation am Himmel verursacht wohl nicht die Schicksale der Menschen, und die Astrologen, die dies gelehrt haben, haben sich völlig getäuscht; richtig ist aber, daß zu jeder bestimmten Konstellation der Planeten bestimmte Begebenheiten auf der Erde passen, daß zwischen dem Leben und

1) Paracelsus führt diesen Gedanken ausführlich in Paramirum, BrT., I, S. 7 sq. aus; die Nahrung vergleicht er da mit dem Dünger, durch welchen das Wachstum der Pflanzen gefördert, nicht aber in seinem Wesen bestimmt wird.

2) Paramirum I570, S. 105. 
dem Lauf der Gestirne eine heimliche Sympathie besteht; richtig ist, daß unser Schicksal in den Sternen geschrieben steht ${ }^{1}$ ).

Die Lehre von inneren Sympathien oder Korrelationen des Geschehens ist PLATo und den Neuplatonikern eigen; alle Vertreter derselben folgen der Annahme unendlich vieler Substanzen, der Ideen Platos, der Samenwesen Paracelsus', der Monaden LeibNizens, und alle verwerfen die Kausalverbindung der Naturvorgänge. Am liebsten möchten sie die Möglichkeit der Beeinflussung einer Erscheinung durch eine andere verneinen (LEIBNIz hat diese Konsequenz gezogen), doch zeigen sie dadurch nur die wunde Seite ihrer Philosophie: sehen wir doch fort und fort, wie hart die Dinge aufeinanderstoßen, wir wirken selbst auf unsere Umgebung und erleiden Einwirkungen von seiten derselben. PARACELSUS war sich wahrscheinlich dieser Schwierigkeit bewußt und er ahnte, daß man sie vielleicht durch den Begriff der Auslösung überwinden kann; so ist er zu seiner, wenn nicht ganz befriedigenden, so doch die einzu: schlagende Richtung anzeigenden Theorie gelangt, daß jedes Wesen bestrebt ist, seine Anlagen zu entwickeln, wodurch es die Entwicklung anderer Wesen stört; ein jedes Wesen ist für die anderen ein todbringendes Gift, und daraus erfolgt in der Natur ein fortwährender Kampf aller gegen alle.

"Der Arzt soll die tödliche Art erkennen, wie die Natur wider die Natur strebt, wie je eins in der Natur wider das andere ist, in gleicher Weise wie die Tiere, die sich zusammenrottieren wider einander... Darauf merket, da $\beta$ alle Dinge, die geschaffen sind, wider den Menschen sind und der Mensch wider sie ... «2)

Die Außenwelt vermag also im Menschen nichts hervorzurufen, wovon die Anlagen nicht im voraus in ihm enthalten wären; da

1) Die Paracelsische Unterscheidung zwischen dem Kausalzusammenhang und der Korrelation auf die Astrologie angewandt, hat die Erklärer der Anschauungen dieses Philosophen in Verwirrung gesetzt. Die einen (SUDHOFF) begrïnden durch seine Negation der Verursachung des Lebensschicksals durch die Gestirne die Meinung, daß Paracelsus ein Gegner der Astrologie war; andere (Proksch) bestreiten dies, indem sie auf seine astrologische Praxis hinweisen. Paracelsus hat zweifellos an die Astrologie geglaubt, doch muß man dabei seinen Vorstellungen darüber, was »Astra « und was \Astrologie ist, Rechnung tragen.

2) Lessing, S. I 3. - Vergleichen wir mit der Paracelsischen Lehre von den absoluten Wesenheiten die »modern* lautende Polemik seines Gegners, des Erastus (S. 23): salle irren, die annehmen, daß die Formen etwas Ansichseiendes darstellen und sich aus eigenen inneren Kräften entwickeln, oder daß sie aus einem anderen Prinzip als aus der Fähigkeit der Materie (mit Ausnahme der vernünftigen Seele) entstehen. Jeder Mechanist könnte diesen Grundsatz unterschreiben. 
nun der Mensch die ganze Welt mit seiner Vernunft aufzufassen imstande ist, so muß die ganze Welt in ihm in nuce eingeschlossen sein: wie das Ei den vollkommenen Organismus einschließt, so auch der Mensch den Makrokosmos. Folglich gleicht der Mensch selbst einem in sich geschlossenen Weltall, er ist Mikrokosmos:

"Und das ist ein Großes, das ihr bedenken sollt: nichts ist im Himmel und auf Erden, das nicht sei im Menschen. Und Gott, der im Himmel ist, der ist im Menschen «1).

Der Puls regiert auch das Firmament, den physiologischen Gesetzen des Menschenkörpers untersteht auch der Lauf des Planeten, das Gebirge ist nach anatomischen Grundsätzen gebaut, der Atem weht in dem Winde, und während des Erdbebens ist die Erde am Fieber $\mathrm{krank}^{2}$ ). Ein anderes Mal drückt PARACELSUs denselben Gedanken anders aus: Gott hat den Menschen erschaffen aus der Materie und aus der Quintessenz aller anderen Geschöpfe, aus dem Wesen aller Elemente, aus dem Kern der Fixsterne, der Planeten, des Himmels, der Erde, aus allen Eigenschaften, Essenzien, Naturen und aus dem ganzen Firmament ${ }^{3}$ ). Der Mensch ist die Quintessenz aller erschaffenen Dinge; in ihm liegt die Milchstraße, in ihm liegen beide Erdpole, der Zodiakus, in ihm schlafen alle Krankheiten ${ }^{4}$ ). So ist der Mensch ¿̌v $x \alpha i \pi \tilde{\alpha} \nu$, wie bei den alten griechischen Philosophen; und wie im Menschen, so breitet sich im Innern eines jeden Wesens das ganze unendliche Weltall aus ${ }^{5}$ ).

Ist der Mensch dem Weltall gleich, warum gibt es viele und wesentlich verschiedene Leute, wenn es nur einen Makrokosmos gibt? Es gibt keineswegs einen einzigen Makrokosmos, antwortet PARACELsus; mit der fortwährend sich verändernden Lage der Gestirne am Himmel geht das Weltall durch eine ununterbrochene Reihe von verschiedenen Zuständen hindurch, und jedem derselben entspricht ein anderer Mensch $^{6}$ ).

1) Lessing, S. 100.

2) Paragranum BIT., I, S. I9I.

3) BiT., II, S. 664 .

4) BiT., I, S. I97, 20 I.

5) Paracelsus schließt $z$ war hier und da andere Wesen als den Menschen aus dem Begriffe des Makrokosmos aus; an anderen Stellen erklärt er jedoch alle für makrokosmisch. Eine eingehendere Durcharbeitung seiner Philosophie müßte zu der Konsequenz führen, daß jedes Wesen das Weltall auf eine andere Art einschließt.

6) BrT., I, S. 20I. Paracelsus erklärt da also die Verschiedenheit der Menschen astrologisch. 
In der Lehre vom Makrokosmos und Mikrokosmos kulminiert die Philosophie Hohenheims. Ideen von ehrwürdigem Alter wurden durch dieselbe zu neuem Leben hervorgerufen: die mystische Lehre der Pythagoreer von der Harmonie der Sphären, Platos Deutungen der Gestirne als vollkommener, lebender Wesen, die Hypothesen Plotins, daß die Erde ein tierisches Wesen darstellt, die Lehren des Cusanus vom inneren Zusammenhange aller Erscheinungen und vom Menschen als einer kleinen Welt (parvus mundus); dieselbe Idee wurde später von GI. BRUNo verteidigt und liegt auch der LEIBNIZschen Philosophie zugrunde; das letzte Mal kam sie in den Lehren der deutschen Naturphilosophen zur Geltung, als OkEN die Behauptung aufgestellt hat, die ganze Natur stelle nur einen auseinandergelegten Menschen dar. Für eine wissenschaftliche Theorie lautet die Lehre vom Makrokosmos und vom Mikrokosmos zu allgemein, zu metaphysisch; da sie aber wiederholt auf dem Plan des philosophischen Denkens aufgetreten ist und gewiß noch oftmals auftreten wird, entspricht sie gewiß einer Grundtendenz des menschlichen Gemüts. Wo sind ihre Grundlagen zu suchen?

\section{Der Arzt und die Krankheit.}

Dem Zeitalter des PARACELSUs war der Unterschied zwischen dem praktischen Arzt und dem theoretischen Biologen noch unbekannt. Der Arzt war eo ipso Biologe, weil man unter Leben vorzugsweise Menschenleben verstand, und noch mehr aus dem Grunde, weil man die Theorie nicht von der Praxis schied. In der im Dienste der Menschenliebe geleisteten biologischen Praxis mußte sich der philosophisch begabte Mann bewähren.

Für PARACElsus bedeutete der Arzt so viel wie eine Natur. kraft, die gegen die Krankheiten aus einem ihr innewohnenden Drange kämpft, eine Kraft, die für ihn ebenso wirklich war, wie für uns die Elektrizität. Wie er Gott, die Wahrheit, die Moralität für etwas Reales (obwohl Unsichtbares) gehalten hat, so hat er auch die heilende Naturkraft realistisch aufgefaßt; und wie Gott, Moralität, Krankheiten an gewissen Symptomen erkannt werden, so wird auch der »Arzt « erkannt; er ist in den Metallen, in den Pflanzen, im Menschen als Möglichkeit verborgen und kommt zu seiner deutlichsten Ausprägung, zu seinem Bewußtwerden, wird verwirklicht in einem Mann, der aus innerem Instinkt, durch göttliche Vorsehung vorherbestimmt, die Kranken heilt, indem er mit Bewußtsein tut, was die Natur automatisch zu leisten vermag. 
In jeder Krankheit kommt ebenfalls eine besondere Naturkraft zum Vorschein; jede Krankheit entsteht aus einem besonderen Keim, jede Krankheit entwickelt sich und stirbt ab wie ein Organismus:

" Und so wisset denn am ersten, daß eine jegliche Krankheit einen unsichtigen Leib hat, und ist ein Glied desMakrokosmos und Mikrokosmos, und ist auch selbst Mikrokosmos und ein ganzer Mensch. Die Krankheiten werden geschmiedet und gemacht wie der Mensch; darum so ist eine jegliche Krankheit ein ganzer Mensch. Also ist der Mensch selbander in solcher Krankheit und hat zwei Leiber in solcher Weise und hat zwei Leiber zu gleicher Weise in einander verschlossen und ist ein Mensch «1).

Der Körper kennt instinktmäßig die Mittel gegen die Krankheit; deshalb muß sich der Arzt an erster Stelle auf die natürliche Heilkraft des Organismus verlassen. Weil ferner die Krankheit ein Naturwesen darstellt, das organisch mit allen anderen Naturobjekten zusammenhängt, müssen in der Natur andere Wesen vorhanden sein, die ein natürliches Gift gegen die Krankheit darstellen; ${ }^{2}$ ) die spezifische Heilkraft bildet eine so wesentliche Eigenschaft der Naturobjekte wie die Farbe, das Gewicht usf. Zu jeder Krankheit gehört ein bestimmtes in der Natur vorhandenes Heilmittel, wie zu dem Mann das Weib, zum Puls das Herz gehört. So gebiert die Natur nicht nur die Krankheiten, sondern bereitet auch gleichzeitig die Arzneien gegen dieselben zu. Der Arzt schließt - als Mikrokosmos - alle Krankheiten und alle Heilmittel ein; seine Pflicht ist, durch Erfahrung die in der Natur zerstreuten und verborgenen Heilmittel und die gesetzmäßigen Beziehungen zwischen den Arzneien und den Krankheiten zu entdecken.

"Es liegt die Erkenntnis nicht im Arzt, sondern in der Natur.... Darum so allein die Natur dieselbige weiß, so muß sie auch dieselbige sein, die das Rezept komponiert. Denn aus der Natur kommt die Krankheit, aus der Natur die Arznei und aus dem Arzt nicht. So muß nun der Arzt der sein, der aus beiden kennen lernen muß, und was sie ihm lernen, das $\mathrm{mu} \beta$ er $\left.\operatorname{tun} \ll^{3}\right)$.

So ist die Arzneikunst selbst ein Organismus, ebenso unfaßbar, ethisch und geheiligt wie alles, was Gott erschaffen. Der Glaube an Gott und die Liebe zum Kranken sind folglich die einzig wahren Grundlagen der Medizin — man verstehe diese Worte nicht im mora-

1) Lessing, S. II8. Daß eine jede Krankheit ein selbständiges Wesen darstellt, sollen auch Plato, Harvey und Sydenham angenommen haben.

2) LESSING, S. I23.

3) Lessing, S. 94 (Huser, I, S. 234).

Rádl, Geschichte der biol. Theorien. I. 2. Auff. 
lisierenden, sondern im metaphysischen Sinne. Denselben philosophischen Sinn sprechen folgende Worte aus:

"Wisset, daß ein Kranker Tag und Nacht seinem Arzt soll eingebildet sein und er ihn täglich vor Augen trage: all seinen Sinn und Gedanken soll der Arzt in des Kranken Gesundheit stellen mit wohlbedachter Handlung . . , Der höchste Grund der Arznei ist die Liebe «1).

Niemand vor PARAcElsus und niemand nach ihm hat es gewagt, ein so kühnes, strenges und schwer erreichbares Ideal der Arzneikunst aufzustellen. Sollten wir seinen Maßstab auf die wirklich vorhandene Medizin anwenden, wohin würde der größte Teil derselben geraten? Niemand hat aber versucht, die Wahrheit der paracelsischen Auffassung vom Arzt als von einem durch die Natur selbst erschaffenen, vorherbestimmten Wesen, der seine Kunst als ein unvermeidliches Schicksal nehmen muß, zurückzuweisen; nur in der Unvollkommenheit der menschlichen Natur scheint ein triftiger Einwand gegen jenes Ideal zu liegen.

Die Konsequenzen der paracelsischen Philosophie der Medizin ergeben sich leicht: der Arzt ist ein genialer Mann. Wie Hohenheim auch sonst die Originalität und Genialität der Gelehrsamkeit gegenüber gepriesen hat, so hat er auch innerhalb der ärztlichen Praxis alles, was zur eigentlichen Wissenschaft, zur Kenntnis (im Gegensatz zur Praxis) gehört, verworfen; er verschmähte die Beschreibung der Krankheit, die kritische Analyse derselben nach festgesetzten Regeln, er verwarf jedes System, jede feste Methode, jede Logik; er verschmähte alles, was zur.Mitteilung der individuellen Erfahrung an andere unumgänglich nötig ist. Indem er die Praxis und die Erfahrung hervorhob, hat er das Erlernen nach bestimmten Regeln auf die radikalste Art bekämpft: jeder Arzt solle in jedem einzelnen Falle instinktiv die wahre Methode erraten. Zweifellos eignet sich eine solche » Methode «wenig für die Schule und für einen Durchschnittsarzt und ist ganz unpraktisch; es folgen ihr aber alle großen Praktiker wenigstens in ihrem Herzen. Der geniale Mensch würde nicht genial sein, wenn er sich an hergebrachte Vorschriften halten sollte.

Über die konkreten medizinischen Theorien des PARACELsus ist hier nicht der Ort zu sprechen. Nur noch eine Konsequenz seiner

1) Kahlbaum, G., Th. Paracelsus, Basel I894, S. II. - In derselben Weise sind folgende scheinbar sinnlose Worte des Paracelsus zu verstehen: Der Kranke, der seine Hoffnung in die Arznei setzt, ist kein Christ (BIT., I, S. 28). Denn, fuigt Paracelsus hinzu, nur Gott kann die Krankheiten vertreiben. 
Naturphilosophie sei hier erwähnt. PARACELSUS war so sehr von der Überzeugung über die Natürlichkeit der Arzneikunst und über die Heilkraft der Natur durchdrungen, daß er kein künstliches Eingreifen des Arztes in den Verlauf der Krankheit zuließ. Es fiel ihm nicht ein, daß eine Verwundung ( $z$. B. eine Schußwunde) eine künstliche, äußerlich bedingte Störung des Lebens darstellt, die folglich auf künstlichem Wege, durch eine chirurgische Operation geheilt werden muß, sondern er verwarf die Chirurgie überhaupt und erlaubte nicht einmal Fremdkörper aus den Wunden zu entfernen, wenn man sie nicht einfach mit den Fingern wegnehmen konnte. Er verbot, die Wunden zuzunähen, er verwarf alle schneidenden Apparate (mit Ausnahme der Aderlaßlanzette) und alle ätzenden Substanzen; er erwartete die Heilung nur von der eigenen Lebenskraft des Kranken, deren Kampf gegen die Krankheit er mit seinen Arzneien unterstützen wollte. Sein Widerwille gegen die Chirurgie entblößt am deutlichsten die wunde Stelle seiner Naturphilosophie und läßt uns auch die Quelle anderer seiner Irrtümer erraten: wenn wir einmal anerkennen, daß im organischen Leben zufällige Störungen (Verwundungen) vorkommen, welche den Organismus rein von außen her überfallen, und wenn wir zugeben, daß solche Störungen durch künstliche Eingriffe in den Lebenslauf des Organismus, durch eine Art Gewalt am Leben geheilt werden müssen, so müssen wir auch die Wahrscheinlichkeit zugeben, daß solche äußerliche (mechanische) Störungen des Geschehens auch sonst vorkommen und daß vielleicht überall in der Natur neben den Ideen auch die Materie, neben der Vernunft auch der Zufall herrscht. Die moderne Wissenschaft hat mit der Betonung dieser Folgerung ihr Leben begonnen und hat sich schroff gegen die Philosophie des PARAcelsus gestellt; sie hat in den mechanischen Theorien den geraden Gegensatz zum Paracelsismus aufgestellt und hat behauptet, daß alles Geschehen nur äußerlich, nur zufällig bedingt ist. Sie hat sich dadurch in entgegengesetzte Unmöglichkeiten verwickelt. Wie ist also die Formel zu finden, welche den paracelsischen absoluten Vitalismus mit dem modernen absoluten Mechanismus versöhnen könnte?

\section{Die Natur.}

Als Idealist fühlte sich PARACELSUs frei, nur solange er über Ideen, über die Macht der Phantasie, über Geister und Kräfte sprechen durfte; nur mit Unwillen erkannte er auch die Materie, den Körper und den Tod an, die nach seiner Meinung eigentlich 
nicht zum wahren Gegenstand der Forschung gehören. Zwar spricht er eine dualistische Sprache: er unterscheidet Materie und Kraft, Körper und Geist, Tod und Leben, Urmaterie (Limbus) und Urkraft (Astrum), körperliche und geistige Nahrung; zuletzt aber sucht er auch im materiellen Bestandteil des Weltalls wesentlich geistige, jedoch noch nicht entwickelte oder verworrene Kräfte. Die Natur objekte, die heute den Hauptgegenstand der Forschung bilden, beachtet er nicht; er sieht in der Natur nur Bewegung und nur Streben nach der Realisation von Anlagen, nach im voraus gegebenen Möglichkeiten; er sieht lauter Entwicklung aus inneren Kräften, doch keine Entwicklung der greifbaren Formen, sondern eine Differenzierung der Kräfte, eine Individualisierung der Fähigkeiten, die der Natur von Gott eingehaucht worden sind. Diese Fähigkeiten personifiziert er und führt sie als selbständige geistige Wesen vor.

Gott hat die Welt durch das Wort »Fiat! " erschaffen (als ob durch einen Hauch ein Haus entstanden wäre); damals hat sich die Einheit der Kraft und der Materie, Yliaster $\left(w^{\prime} \lambda \eta=\right.$ Materie, astrum $=\mathrm{Kraft}$ ) zum Ideos oder Chaos (auch Mysterium magnum, Ilyades, Limbus maior genannt) entwickelt, das aus einer unsichtbaren und ungreifbaren Lebenskraft und aus der organischen Materie besteht $^{1}$ ). Die im Ideos schlafende Urkraft teilt sich in drei, allen Naturobjekten zugrunde liegende Grundkräfte: das flüssige Wesen, Mercurius (= Quecksilber), auch gotaronium oder liquor genannt; das brennbare Wesen, Sulphur (= Schwefel) oder Resina; das feste in Flüssigkeiten lösliche Wesen, Sal (= Salz) oder Balsamus. Die Urmaterie des Ideos zerfällt in vier Elemente, in Erde, Wasser, Luft und Feuer, aus denen die einzelnen Naturobjekte auf eine ähnliche Art entstanden sind, wie sich aus dem Samen die Wurzeln, der Stamm, die Blätter, Blumen und Früchte entwickeln. Unter Wasser, Luft usf. verstehe man nicht die uns bekannten Materien, sondern wiederum eine Art Kräfte:

jede Flüssigkeit, die durch den Durst angezogen wird, ist Element des Wassers. Dann wieder, was durch den Hunger angezogen wird, ist Element der Erde 2 ).

PARACELSUS kennt praktisch den Unterschied zwischen Leben und Nichtleben, doch schließt er vor dem letzteren die Augen und

1) saus dem Leben und dem Körper der Geschöpfe a.

2) De morbis tartareis BIT., I, S. 295 . 
sieht nur das Leben als Naturwirklichkeit an; das Nichtleben gilt ihm nur für eine Täuschung. Was uns als Tod erscheint, ist tatsächlich nur der Übergang von einem Leben zum anderen: der Mensch stirbt, und durch Fäulnis entstehen aus seinem Körper Würmer und Substanzen, die die Keime zu einem neuen Leben enthalten. Auch das Weltall ist belebt; die Luft ist die Trägerin der Weltseele. Jeder natürliche Bestandteil der Welt ist wieder lebendig:

"Es ist nichts korporalisch, es hätte und führete nicht einen Spiritus in ihm verborgen; es ist nichts, es hätte nicht auch ein Leben in ihm verborgen und lebete. Es hat auch nicht nur das Leben, was sich regt und bewegt, als die Menschen, die Tiere, die Würmer der Erde, die Vögel im Himmel und die Fische im Wasser, sondern auch alle korporalischen und wesentlichen Dinge $\ll \mathbf{1})$.

Beachten wir jedoch den paracelsischen Sinn des Lebensbegriffes. Seit Linnés Zeiten verstehen wir unter "Leben " oder unter »Organismus "vor allem einen aus Organen zusammengesetzten Körper; das Wort "Pflanze "ruft uns die Vorstellung vom Komplex der an einer getrockneten oder gemalten Pflanze sichtbaren Eigenschaften hervor, als "Löwe " gilt uns ein Tier von bestimmter Größe, Farbe, mit bestimmt gebauten Zähnen, Krallen, Knochen usw.; der Unterschied zwischen dem Menschen und dem Affen besteht für uns im Unterschied der Statur, der Gehirngröße, der Hände, des Schädels usf. PARACELSUS dagegen achtet, nach volkstümlicher Art, auf die körperlichen Merkmale gar nicht; der Löwe bedeutet für ihn ein mutiges Tier; wenn er von einer Pflanze spricht, so denkt er an ihre spezifischen Heilkräfte, unter dẹm Menschen versteht er den Menschengeist. Unter Herz versteht er z. B. nicht das Herz der heutigen Anatomie, sondern die spezifische Kraft des Herzens:

$\leadsto \mathrm{Da}$ alles Herz ein Herz sei, den Augen sichtbar, ist nichts, sondern es ist eine Kraft und eine Tugend dem Herzen gleich « $\left.{ }^{2}\right)$.

Deshalb hat sich PARACELsus abfällig über die den Körper analysierenden Galenisten ausgesprochen:

... ich halte dagegen jenes Studium der auseinandergelegten Menschen für bloße Kinderpossen, wenn man dadurch die höheren Geheimnisse der Arzneikunst aufhellen will, obwohl es nicht wenige gibt, die dieses Studium hochachten und glauben, daß es sehr die Unterscheidung der Krankheiten unterstützt... Deshalb unterscheiden wir eine zweifache Anatomie, eine deskriptive (localis) und eine, die auf die Bedeutung der wesentlichen (physiologischen) Elemente zielt (anatomia essentialis seu essata)... Deshalb

1) LESSING, S. 95 .

2) LESSING, S. IO2. 
müßt ihr auf die Anatomie achten, welche die gegenseitigen Beziehungen der Krankheiten im Körper und die für bestimmte Krankheiten spezifischen Örter im Körper untersucht...1)

Deshalb definiert Paracelsus das Leben als das den Körper erhaltende Streben:

Nichts anderes stellt wahrlich das Leben dar als einen gewissen lebendigen Saft, der den sterblichen Körper vor den tödlichen Würmern und vor der Fäulnis beschützt, und der eine flüssige Mischung der Salze enthält 2 ). Der Körper ist ein Kunstprodukt (creatura) und kein Leben ${ }^{3}$ ).

Der lebendige Saft (»Mumie «) soll über den ganzen Körper verbreitet und je nach dem Organ verschieden sein; eine andere Mumie ist den Knochen, eine andere den Blutgefäßen, eine andere den Sehnen eigen ${ }^{4}$ ).

Das Leben ist also überall verbreitet; seine niedrigste Stufe äußert sich durch die Fäulnis (putrefactio), d. h. durch chemische Veränderungen; doch offenbart sich in den chemischen Prozessen nur das Leben im allgemeinen, ohne jedwede Individualisation; durch »Fäulnis « kristallisieren aus der Erde einzelne Tiere und Pflanzen; durch »Fäulnis «wird im erwachsenen Körper die Nahrung assimiliert; dieselben chemischen Prozesse liegen der Entwicklung des Samens zur Pflanze und der Embryonalentwicklung des Menschen zugrunde. Die embryonale Entwicklung geht unter fortwährender chemischer Differenziation vor sich: aus dem Körpersaft, der potentiell den ganzen Menschen enthält, entsteht, durch die Geschlechtslust angeregt, durch einen Gärungsprozeß zuerst der Same, d. h. eine Spannung (kein Ding!), die zur Entwicklung führen kann. Jeder besondere Teil des Organismus bildet seinen eigenen Samen; der Same der höheren Tiere (der Menschen- und "Vieh«same) soll jedoch nicht auf dieselbe Art wie derjenige der niederen Wesen entstehen. Im Gestein (auch dieses entsteht aus Samen), in den Pflanzen und in den einfacheren Tieren ist der Same an die Materie gebunden, so daß die genetische Aufeinanderfolge dieser Wesen im Zusammenhang der Materie besteht, der Menschensame dagegen ist bloß ein Geist, eine Kraft, und verkörpert sich erst ex post in ein materielles, für jeden Körperteil spezifisches Sperma, das durch den Lebenssaft von allen Körperteilen in die Hoden

1) Chirurgia magna. BIT., III, S. 109. Vgl. auch J. K. Proksch, S. 56 sq.

2) De vita longa. Bit., I, S. 63.

3) Ebenda, S. 54 .

4) Chirurgia minor BiT., III, S. 7 . 
geleitet ${ }^{1}$ ) und während der Paarung in den Uterus analog wie das Getreide auf das Feld gesät wird. Die weiblichen Geschlechtsorgane betrachtet PARACELSUS einmal nur als einen geeigneten Nährboden für die Spermateilchen, an einer anderen Stelle schreibt er dagegen auch den Weibern die Fähigkeit Sperma zu bilden zu; in den Keim soll nach dieser zweiten Version das männliche und das weibliche Sperma von jedem Organ gelangen; es entwickelt sich aber nur das kräftigere, obwohl auch das andere einigen Einfluß ausübt ${ }^{2}$ ). Bekanntlich geht G. MENDEL von einer ähnlichen Vorstellung über das Wesen der Erblichkeit aus; PARACELsus steht ihm so nahe, daß er für die tatsächlich zur Entwicklung gelangenden Eigenschaften (die dominierenden Eigenschaften nach MENDEL) ein ähnliches Wort (praedominatio) anwendet und daraus auch die Übertragung der erblichen Krankheiten und die Bestimmung des Geschlechts der Nachkommen ableitet, wie man es heute zu tun pflegt. Aus demselben Prinzip leitet er vernünftig genug die Entstehung der Zwillinge und der Monstrositäten $\mathrm{ab}^{3}$ ).

Auch an anderen Stellen spricht PARACElsus von der Erblich. keit beachtenswerte, den modernen analoge Hypothesen aus. Er führt aus, daß in den ersten Menschen die Urelemente des Menschenorganismus so spezifiziert waren, daß Adam den Mann an sich, Eva das Weib an sich verkörperte, indem jener nur männliche, diese nur weibliche Elemente enthielt4). In ihren Nachkommen sollen sich dagegen ihre Eigenschaften kombiniert haben, so daß jeder Mann auch weibliche Charaktere und umgekehrt jedes Weib männliche entwickelt,

"und dies ist die einzige Ursache, warum niemals ein Mensch mit dem anderen identisch geboren wird «.

An einer anderen Stelle lehrt Paracelsus, daß die Anlage der 》tartarischen " Krankheiten (z. B. Gallenstein) entweder durch die Nahrung in den Keim eindringt, oder sie wird von den Eltern geerbt. Es wird aber nicht jede Tartaruskrankheit auf die Kinder übertragen; diejenige, die nur den entwickelten Körper der Eltern

1) Bekanntlich hat Darwin eine ähnliche Theorie der Vererbung ausgesprochen.

2) Fast identisch damit lautet die Vererbungstheorie in der hippokratischen Schrift "Über die Natur der Ursachen*. (Vgl. über dieselbe B. BLoch, Die geschichtl. Grundlagen d. Embryologie bis auf Harvey. Nova Acta Ac. Leopold 1904, S. 228.)

3) De generatione BrT., I, S. I54, und Lessing, S. I07.

4) Deshalb soll Adam der traurigste Mann, Eva die lustigste Frau auf der Erde gewesen sein. De generatione BIT., I, S. I64. 
(das »Soma ", würde WEISMANN sagen) überfällt, ist nicht erblich, wohl aber jene, die in der prima materia (im » Keimplasma «) wurzelt. Denn diese prima materia schließt. in nuce alle Eigenschaften des erwachsenen Menschen ein, seine Organe, seinen Intellekt, seine Krankheiten; im Kind kombinieren sich die Eigenschaften der Eltern, hemmen oder fördern einander und lassen neue und unerwartete Merkmale entstehen. Die im Keime wurzelnden Krankheiten sollen unheilbar sein.

Durch diese Auffassung der Erblichkeit wurde PARACELSUS auch zu Betrachtungen über die Entstehung der Mannigfaltigkeit der Tiere und Pflanzen geführt, die einigermaßen an diejenigen modernen Phylogenien erinnern, welche die Entstehung der Arten durch Kreuzung erklären. Die Natur soll ursprünglich alles nach einem Plan, wie aus einem Samen hervorgebracht haben, und es sei unwahrscheinlich, daß gleich von Anfang an die heutige ungeheuere Mannigfaltigkeit der Pflanzen und Tiere bestanden hätte. Neue Formen sollen durch »Transplantation «, d. h. durch Kombination ungleicher, aber verwandter Wesen entstanden sein; durch Kreuzung von zwei, drei und mehr Formen sei die jetzige Mannigfaltigkeit hervorgebracht worden. Auch neue Typen der Krankheiten sollen durch Mischungen der Keime von alten Krankheiten entstehen ${ }^{1}$ ).

Die Embryonalentwicklung faßt PARACELsus epigenetisch und vitalistisch auf. Der Mann und das Weib sind je ein Mikrokosmos; weil im weiblichen Uterus potentiell das ganze Weib konzentriert ist (tota mulier in utero), ist auch der Uterus dem Weltall gleich, stellt den kleinsten Mikrokosmos dar. Das Kind soll im Uterus auf dieselbe Art wie ein Plan im Kopfe des Baumeisters entstehen; wie der Baumeister mit der Idee des Hauses zugleich auch den Willen es aufzubauen entwickelt, so entsteht auch in der Gebärmutter ein energisches Verlangen nach der Hervorbringung des Kindes, der Idee gemäß, die sich über dasselbe die Gebärmutter bildet ${ }^{2}$. Diese vitalistische Auffassung erlaubt PARAcELsus nach volkstümlicher Art anzunehmen, daß der Wille und die Vorstellungen der Mutter die Entwicklungsweise des Kindes beeinflussen können. Er glaubt z. B., daß, wonach die Frau im sichtbaren Leben verlangt, sich im Keime entwickelt ${ }^{3}$ ), und begrenzt dies nur durch die Bedingung, daß der Wille der Frau organisch (natürlich) sein muß;

1) Chirurgia magna Bit., III, S. $x_{5}$.

2) De reb. invis. BIT., I, S. ז2 I.

3) Bit., I, S. I 24. 
er lacht die Eltern aus, die sich intensiv ARISTOTELES vorzustellen bemühen, um einen weisen Nachkommen zu erzeugen ${ }^{1}$ ). In jedem Entwicklungsprozeß unterscheidet PARACELsus den Anfang, der eine Einheit der Idee und des Willens darstellt und in einer undifferenzierten Materie wirksam ist (dieser Zustand heißt prima materia), und das Ende, wo das fertige Ding dasteht (ultima materia).

Die Fäulnis stellt also die niedrigste noch undifferenzierte Stufe des Lebens dar; als eine höhere organische Kraft faßt PARAcELsus den "Archeus «auf. Der Name wie der Begriff ist in diesem Sinne von PARACELsus geprägt worden und bedeutet fast soviel wie Lebenskraft. Archeus ist der Erzeuger der Körpermaschine, er baut die Organe aus dem Keime, er dirigiert die Assimilation der Nahrung (er ist der Alchimist, d. h. der Chemiker des Körpers, sagt PARACELSUS); in jedem Organ und in jedem Organismus waltet ein besonderer, von den anderen spezifisch verschiedener Archeus $\left.{ }^{2}\right)$. Auch die in unserem Sinne leblosen Naturobjekte werden von einem Archeus beherrscht. So besitzt die Erde einen besonderen Archeus, den Paracelsus "Vulcanus « nennt:

") dieser Vulcanus ist kein Geist, ist auch nicht ein Person ... Sondern er ist ein Arbeiter, der gar nichts mehr tut, denn der Natur warten um das aus ihr zu bringen, das in ihr ist, und, das Gott in sie getan hat, zu bringen in ultimam materiam $\left.\ll^{3}\right)$.

Vom Archeus unterscheidet Paracelsus nur undeutlich den "balsamus naturalis ", d. h. die natürliche Heilkraft des Körpers, und die »Mumie «, einen hypothetischen Saft, der jener Heilkraft zugrunde liegt $\left.{ }^{4}\right)$. Noch höher stehen Geister verschiedener Art. Beim Wort 》Geist " (spiritus) kamen jedoch PARACELsus andere Vorstellungen auf als uns. Er verstand unter Geist erstens etwas Luftähnliches, d. h. etwas Unsichtbares, das aber trotzdem wirkt (wie z. B. der Wind); zweitens den menschlichen Atem, den er für eng mit dem Leben zusammenhängend hielt, drittens das Leben

1) Bire, I, S. 165.

2) Es ist schwer, den Begriff des Archeus durch die moderne Terminologie auszudriicken; dem Begriffe des Instinktes steht er nicht fern. Der Archeus ist eine qualitative Kraft, die die Organe ihren Anlagen gemäß baut, sie wirkt unbewußt, aber zweckmäßig. Übrigens hat Paracelsus den Begriff des Archeus nicht näher definiert. Paracelsus polemisiert zwar gegen Aristoteles, sein Begriff des Archeus ist aber dem

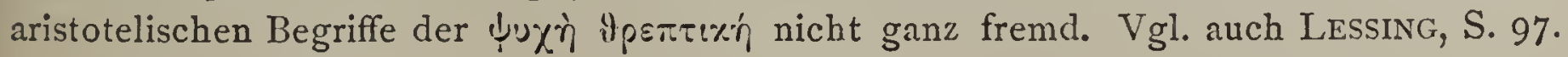

3) Bartscherer, S. 83 (Huser, II, S. 79).

4) Chirurgia minor BIT., III, S. 7 . 
selbst $\left.{ }^{1}\right)$, viertens die nach dem orthodoxen Christentum aufgefaßte Menschenseele, d. h. ein unsterbliches, lebenslang im Körper eingekerkertes Wesen ${ }^{2}$ ); sonst bedeutet bei Paracelsus der Geist auch so viel wie selbstbewußter Wille ${ }^{3}$ ), oder wieder Quintessenz oder das Wesen des Individuums ${ }^{4}$ ).

Auch die physikalischen Kräfte, durch welche die Planeten am Himmel bewegt werden und durch welche der Wind die Objekte bewegt, werden Geister genannt:

Der Geist (spiritus)... nötigt das Feuer zu brennen, treibt die Erde Frucht zu bringen, befiehlt dem Wasser Fische zu zeugen, treibt den Wind über die ganze Erde und führt die Sonne und den Mond und alle Sterne nach den Gesetzen ihres Umlaufes ${ }^{5}$ ).

Vorzüglich bedeuten jedoch bei ihm die Spiritus verschiedene Geister der volkstümlichen Mythologie, Engel, Seelen der Verstorbenen usf. ${ }^{6}$ ).

PARACELSUS hegte nur vage Vorstellungen über das konkrete Tier- und Pflanzenleben. Es fällt ihm niemals ein, daß die anatomischen Unterschiede zwischen einzelnen Tieren der Beachtung wert wären, und er begnügt sich mit der geläufigen Unterscheidung der allgemein bekannten organischen Wesen. Seine Bemerkung von den Pflanzenblättern, sie dienten den Pflanzen zum Schmuck, wie dem Menschen das Gesichts- und das Gehörorgan, zeigt, was er von einzelnen Organen etwa gewußt hat. Von der Konstanz der organischen Formen hat er keine Ahnung; er glaubt (wie man es noch lange nach ihm geglaubt hat), daß das Unkraut im Getreide aus verdorbenem Getreidekorn entsteht, welches dann zum Lolch oder zur Ackerschnalle erwächst $\left.{ }^{7}\right)$; in ähnlicher Weise nennt er die Pilze "abortus naturae $\left.«^{8}\right)$.

1) $\gg$ Das Leben und der Geist sind ein Ding und nicht zwei ... \& LESsing, S. 88 (Huser, I, S. 791).

2) De gener. rer. nat. BrT., II, S. 9 I.

3) Die Kinder, die noch keinen Willen haben, haben keinen Geist. BrT., I, S. 23.

4) Der Geist des Auges, des Ohres ist soviel wie das Wesen dieser Sinne. Archidoxorum lib. I. BiT., II, S. 4.

5) Astronomia magna BIT., II, S. 525.

6) Der Begriff der »Spiritus war den Gelehrten der älteren Zeiten unklar, weil ihnen noch der Begriff der Gase gefehlt hat und weil sie zwischen der Materie und der Kraft keine klaren Grenzen gezogen hatten. Bei Erastus bedeutet Spiritus etwa soviel wie jetzt Gas.

7) Anat. Fragmente. Bir., II, S. 268.

8) Ebenda, S. 276. 
So betrachtete PARACELSUS die organische Welt mit wesentlich anderen Augen als wir. Er sah nur Kräfte, nur Ideen und Seelen, nur Allgemeines; den modernen Leser überrascht am meisten der gänzliche Mangel jeder konkreten Naturbeobachtung; bei PARACELSUs trifft man keine Beschreibung irgendeiner Pflanze, ihrer Blätter, Blumen, Früchte, ihres Duftes, ihres Habitus usf. an, nirgends gibt er kund, daß er mit Interesse ein Tier, seinen Bau oder seine Lebensweise beobachtet hätte; PARACELsus sieht die Natur mit den Augen eines schlichten Landmanns, der sich wohl der Begriffe Tier, Pflanze, Löwe, Blut, Krankheit bedient, über die materielle Beschaffenheit dieser Objekte aber nur halbbewußte Vorstellungen hegt. Und trotzdem hat er viel Wahres über dieselben auszusagen vermocht.

\section{8. Übersicht.}

PARACELSUS war ein ungewöhnlicher Mann; es gab keinen ihm ähnlichen weder zuvor noch später. Nur ein voreingenommener und geistloser Doktrinär wird sein »Paramirum " oder "Paragranum " mit dem verachtenden Gedanken wegwerfen, es sei nichts als Schimpfreden, maßlose Überhebungen und lauter Unsinn darin zu finden. Aus jedem der oben angeführten Zitate spricht die Natur selbst zu uns, eine wilde und ungezügelte, aber auch eine mächtige und lebendige Natur.

PARACElsus war ein biologischer Philosoph. Seine Philosophie lag in seinem Leben und Wirken, im Wirken durch Wort und Tat. $\mathrm{Daß}$ er seine Anschauungen nicht deutlich genug gegen seine Tätigkeit abzugrenzen wußte, ist die Folge von der Unvollkommenheit seines Systems: seine Lehren sind meistens nur Erlebnisse, nur Sachkenntnis, ohne die Stufe eines logisch geordneten Wissens $\mathrm{zu}$ erreichen. Er war ein biologischer Philosoph: sein ceterum autem censeo war die praktische und theoretische Erfassung des Lebens, die »Arzneikunst «, wie er zu sagen pflegte, die Biologie, wie wir heute sagen, und zwar eine ethisch aufgefaßte Biologie. Er war ein großer Arzt, Pharmakologe, Chemiker ${ }^{1}$ ). Es gab wohl größere, gebildetere, gewandtere Ärzte und Forscher vor und nach ihm; doch gibt es in der geschriebenen Geschichte der Wissenschaft keinen Arzt, keinen Biologen, der die Lehre vom Leben so menschlich tief, so sub specie aeterni begriffen hätte wie Paracelsus. Er

1) Die Auseinandersetzung seiner chemischen, astrologischen und religiösen Anschauungen habe ich beiseite gelassen. 
wurde nicht deshalb ein Philosoph der Biologie, daß er Theorien über den Mikrokosmos, über den Archeus, über das Wesen der Erblichkeit veröffentlicht hat, sondern weil er bis an den Kern des Lebens zu greifen gewagt hat, bis dorthin, wo die Medizin mit der Biologie, mit der Theologie, mit der Ethik, mit allem, was dem Menschen heilig ist, zusammenfließt, bis dorthin, wo der Arzt aufhört, eine durch die äußerlich bedingte Organisation der Menschheit gegebene Institution zu sein, und wo er Mensch, nur Mensch zu sein beginnt. $\mathrm{Zu}$ jenen Tiefen, wohin andere kaum den Blick zu werfen wagen, stieg* PARAcelsus hinab und war nicht müde nachzuweisen, daß sein Weg allein direkt zum natürlichen Wissen führt.

PARACElsus war kein Titan, kein Übermensch. Man weist darauf hin, daß Goethe seinen Faust nach dem Vorbilde HoHenHEIMs konzipiert hat, man weist auf das Phantastische in PARACELSUs, auf sein Suchen nach dem Stein der Weisen und dem Lebenselixir, auf seine Verbindung mit dem Teufel, auf sein Schimpfen auf die nüchterne Wissenschaft. Neuerdings suchte A. BARTscherER durch vergleichendes Studium des Faust und der Schriften des Paracelsus den Nachweis zu führen, daß bei Goethe Reminiszenzen an PARACELSUS vorkommen. Obwohl viele Belege der Autorin überzeugend sind, so scheint sie doch den Grundunterschied zwischen PARAcELsus und Faust verkannt zu haben, der bestehen bliebe, wenn auch GoETHE noch so viel aus PARACELSUs geschöpft hätte. Daß Goethe in PARACELSUs eine kongeniale Natur erkannt hat, ist nur natürlich; sein Faust ${ }^{1}$ ) aber ist ein moderner Mensch, ein Skeptiker, mit sich entzweit; in Faust ringt die Sinnlichkeit mit dem Ideal, der Teufel mit dem Engel; Faust ist subjektiv, und sein Kampf spielt sich vorzugsweise nur in seinem Inneren ab. PARACELsus dagegen war nur in den Jugendjahren Skeptiker - damals, als ihm zuerst die Nichtigkeit der Schulwissenschaft klar wurde; sein Kampf gegen die Gelehrten zeigt jedoch keine Skepsis mehr, sondern ist die Folge einer besseren Erkenntnis. Bei ihm war kein Zwiespalt zwischen Wissen, Glauben und Handeln; er kannte nur ein Wissen, das zugleich Glauben war und das sich in Taten äußern mußte. Niemals hätte er zugegeben, daß zwei Seelen in seinem Inneren wohnten; eine solche Unnatürlichkeit würde er höchstens seinen Feinden, den

1) Der historische Faust, ein Zeitgenosse des Trithemius, des Lehrers Hohenheims, war ein wirklicher Fanfaron. Tritheim, selbst ein Phantast, soll ihn für einen Schwätzer erklärt haben, der irgendwo wegen Päderastie verfolgt wurde. (Silbernagel, T'rithemius, S. I I 3.) 
Professoren vorgeworfen haben, denen Gott das echte Vertrauen zu sich selbst vorenthalten hat. Die Reden des Mephistopheles wären für ihn so unverständlich wie für ein unschuldiges Kind; er kannte nur ein Verhältnis zum Teufel: denselben nach dem Beispiel der Heiligen zu überwinden und sich dienstbar zu machen. Und last not least: Faust ohne Gretchen ist kein Faust; für PARACELsus existiert dagegen die Frauenfrage nicht.

Das Titanentum ist Unnatürlichkeit, ist ohnmächtige Wut gegen die Götter, d. h. gegen das Unumgängliche, gegen sich selbst. PARACELSUS stellte gerade seine Natürlichkeit der Affektiertheit der anderen entgegen; daß er an Magie, an Zauberei und an den Teufel geglaubt hat, ist nebensächlich; entscheidend ist, daß er mit voller Kraft an Gott und an die Natur geglaubt; hielt er doch die Magie für ein natürliches, gottesfürchtiges Handeln. In all den Punkten weicht Paracelsus von Goethes Faust $\mathrm{ab}^{\mathbf{1}}$ ); Faust ist eine moderne, PARACELSUS eine ganz mittelalterliche Natur. Wohl finden wir im letzteren auch moderne Ideale verkörpert; eher aber als GoETHEs Faust ruft uns sein Lebenskampf einen anderen welthistorischen Mann, Rousseau, ins Gedächtnis. Rousseau war ein Naturmensch (oder er wollte es sein), war antiwissenschaftlich, antikulturell (sofern man unter Kultur den Gegensatz zur Natur versteht), er hat den "Menschen an sich "gesucht, hat die natürlichen Anlagen des Kindes zu entwickeln angestrebt. Wie Rousseau, hat auch PARACElsus den Kampf gegen die Gesuchtheit und die Rückkehr zur Natur gepredigt. Doch ist auch Rousseau zu modern, zu blaß, zu subjektiv und weiblich gegen den robusten, objektiven PARACELSUS, der auch philosophisch ungesuchter und gründlicher ist ${ }^{2}$ ).

Die Tatsache, daß PARAcELsus die Schulen bekämpft und auf Reisen Erfahrungen zu sammeln gesucht hat, bedeutet an und für sich wenig; ist doch während der Renaissance und des Verfalls

1) Auch in Brownings bekanntem Gedicht »Paracelsus s wird dieser als Titan vorgeführt und ist folglich unhistorisch. Paracelsus würde sich niemals als eine Art Prometheus aufgeführt haben; er hätte sich niemals der Worte bedient, die ihm Brownrng in den Mund legt:

- - I seemed to long

At once to trample on - yet save mankind -

To make some unexampled sacrifice

In their behalf - to wring some woundrous good

From heaven or earth for them - to perish, winning

Eternal weal in the act...

2) Auch das unruhige Leben ist Paracelsus und Rousseau gemeinsam. 
der Hochschulen (der Scholastik) die Herabsetzung der Gelehrsamkeit zur Mode geworden. Sogar ein ERASMUS von RotTerdam, ein typischer Gelehrter, hat eine Schrift verfaßt, in der er eine quasi Verachtung des wissenschaftlichen Getriebes zur Schau trägt ${ }^{1}$ ). Wer gedenkt aber heute der wissenschaftlichen Skepsis des ERASMUS? Man kann sie nicht ernster nehmen, als sie dieser Forscher selbst genommen hat. Auch kein anderer von den Zeitgenossen des PARACELSUS vermochte die wissenschaftliche Skepsis nur annähernd so tief zu begründen wie er. Wir finden unter den besseren Skeptikern CORNELIUS AGRIPPA (I 486-I 535), einen in ähnlicher Weise unruhigen Geist, wie es PARACElsus war. Dieser sehr belesene Philosoph gab I527 eine Schrift heraus mit dem bezeichnenden Titel:

"Über die Unsicherheit und Eitelkeit der Wissenschaften und Künste; eine polemische oder zynische Rede, in der gelehrt wird, daß nirgends etwas Beständiges, Sicheres, Göttliches vorhanden ist, außer in soliden Lobpreisungen Gottes und in der Vorzüglichkeit der Worte Gottes « ${ }^{2}$ ).

Wie unendlich tief stehen die Ideen dieser Schrift unter den Lehren des PARAcelsus! Es scheint, als ob es sich dem Autor um nichts anderes gehandelt hätte, als alle seine literarischen Kenntnisse dem Leser vorlegen zu können; auf die oberflächlichste Art beweist er z. B. die Eitelkeit der Geschichtschreibung daraus, daß die Autoren im Datieren einer historischen Begebenheit nicht übereinstimmen, die Wertlosigkeit der Philologie soll u. a. daraus erhellen, daß die Tschechen allein um des Wörtchens 》nisi " willen gegen die ganze Welt Krieg geführt haben; durch solche geistreich sein wollende

1) Encomium moriae (Lob der Narrheit) I5II und später. Aus historischem Interesse ist es wert, dieses seinerzeit weltberühmte, in zahlreiche Sprachen übersetzte Schriftchen durchzulesen, um eine lebendige Vorstellung von der Gedankenvorsicht und der seichten Spitzfindigkeit des Erasmus dem brutal geraden Paracelsus gegenüber zu gewinnen. Erasmus schreibt u. a. auch über die Wissenschaft und wirft den Gedanken auf, daß die Unkenntnis der Wissenschaft den Urmenschen glücklich gemacht hat, und fährt fort: »die Künste hat Teutus im Zorn gegen das Menschengeschlecht zum größten Schaden der Menschheit erfunden; denn sie sind sehr nutzlos und außerstande, die Seligkeit zu fördern ... Jene schlichte Menschen der goldenen Zeit, durch keine Künste beschränkt, lebten durch den reinen Naturtrieb und durch die Leitung der Natur... Die Arzneikunst ferner ist nichts anderes (wenn wir Plato glauben) als ein gewisser fünfter Teil der Schmeichelei... Seht ihr nicht an anderen Lebewesen, daß diejenigen am glücklichsten sind, die den Künsten am fernsten stehen . . .? " Man muß Erasmus lesen, um anschaulich zu sehen, wie verklausuliert alles dargeboten ist, so daß man nicht weiß, was im Ernst und was im Scherze gemeint ist.

2) De incertitudine scientiarum etc. Agrippa wird auch unter denen angeführt, die den jungen Goethe beeinfluft haben sollen. 
Gründe wird von AGRIPPA die Notwendigkeit der Wissenschaften bestritten ${ }^{1}$ ).

Die Bekämpfung der Wissenschaft (des Gelehrtenwesens) gehörte während der Renaissance zum guten Ton; nicht dadurch ist also PARACELSUS groß geworden, daß er gegen die Gelehrten auftrat, sondern in dem, wie er sein Verhältnis zur Wissenschaft begründet hat. Der Skeptiker, der Alchimisten, der Astrologen, der Magiker, der Naturärzte und der landfahrenden Wissenschaftler gab es mehr als genug, und es werden solcher Leute unter verschiedenem Gewande jederzeit genug bereit sein, ihre Ansprüche gegen die traditionelle Wissenschaft geltend $\mathrm{zu}$ machen; niemals hat aber jemand den Gegensatz zwischen natürlichem Wissen und den Institutionen so lebendig dargestellt, so über jede Zeit und über jeden Raum erhoben, wie Paracelsus. Von Zeit zu Zeit verkörpert sich der fortwährende Kampf zwischen der Tradition und dem lebendigen Wissen in einer welthistorischen Persönlichkeit, welche immer alle Institutionen hinunterzureißen und eine neue Welt aufzubauen sich bemüht. Eine Sisyphusarbeit! Denn jede Vernichtung der früheren bedeutet immer nur den Anfang für neue Traditionen. So hat SokRates, der schlichte Bildhauer, die gelehrten Sophisten zu stürzen gesucht, so Nietzsche und namentlich Schopenhauer. Besonders an des letzteren Angriffe gegen die Professoren erinnert die Polemik des PARACELSUs; sehr oft stimmen sie fast bis aufs Wort überein, so daß man fast für jeden Satz aus Schopenhauers Diatribe »Über Gelehrsamkeit und Gelehrte « eine analoge Stelle bei PARACELSUS finden könnte. Beide werfen den Gelehrten vor, daß sie die Wissenschaft nur aus nebensächlichen Ursachen, nur um des Ruhms und um des Amtes willen pflegen, daß ihrer Wissenschaft eigene Ideen fehlen, daß sie andere zu Doktoren nur aus Gewinnsucht promovieren, daß sie die Genialität hassen usf. Mit Schopenhauer hat ParaCELSUS auch die maßlosen Beschimpfungen der Professoren gemein. Schopenhauer wie PARAcelsus haben sich mit der Schulwissenschaft entzweit, und beide haben unter den Laien Anhänger gesucht. Immerhin ist PARACELSUS radikaler vorgegangen als der boshafte Pessimist. Dieser ist auf Hegel, Schelling, Fichre erzürnt, aber

1) Agrippa nimmt eine Wissenschaft nach der anderen durch; es ist interessant zu sehen, welche wissenschaftlichen Gebiete damals die Lehre vom Leben umfaßt hatte; Agrippa unterscheidet in dieser Hinsicht: Medizin, Chirurgie, Pharmakologie, Anatomie (des Menschen), Veterinärkunst. Von der Botanik und Zoologie (in ihrem weitesten L'mfange) weiß er noch gar nichts. 
KANT wird von ihm hochgepriesen, obwohl auch dieser nicht nur dem Amte, sondern auch seinem System nach Professor war; ScHOpenHAUER beschimpft ferner die Professoren sozusagen nur pro praeterito, freut sich aber, daß er von der Zukunft wird anerkannt werden - von wem denn anders als von den Professoren? Paracelsus gab dagegen niemand Pardon; so genial konsequent war er in seinem Hasse gegen die Hochschulen, daß er auch von den künftigen nur Böses erwartet. Als er sich (im Vorwort zum Paragranum) in wilder Wut zum Könige aller vergangenen und zeitgenössischen Gelehrten erklärt; wendet er sich zu den zukünftigen und konstatiert bei diesen denselben Haß gegen sich. Sie werden ihn, sagt er, zwar anerkennen, sie werden einmal selbst Plinius und ARISTOTELES bespötteln, aber erst wenn sie mit Gewalt dazu geführt sein werden, und sie werden sich verstellen:

"Wie werdet, ihr Kornuten, es ansehen, wenn euer Kakophrastus ein Fürst der Monarchie sein wird? Und ihr Calefactores werdet Schlotfeger. Wie dünkt es euch, wenn die secta Teophrasti triumphieren wird? Und ihr werdet in meine Philosophie müssen und euern Plinium Kakoplinium heißen und euern Aristotelem Kakoaristotelem heißen und ich werde sie und eueren Porphyrium in meinem ... taufen mitsamt euerer Gevatterschaft «1).

Da sind alle Brücken verbrannt und allen Schulen der künftigen Zeiten, sie mögen wie immer heißen, die Feindschaft proklamiert. Welch eine Konsequenz! Und dabei stellen die Angriffe gegen die Gelehrten einen ganz notwendigen Bestandteil der paracelsischen Philosophie dar, indem durch dieselben sein Glaube an die natürliche, angeborene Wissenschaft nach der negativen Seite hin ausgedrückt wird. PARACELSUS war vom Schicksal vorherbestinmt, durch seine ganze Lebensführung das Wesen der natürlichen Wissenschaft darzulegen; er wuchs aus dem Volke, aus dem wirklichen rauhen Lebenskampfe hervor, und er konstruierte sich seine wissenschaftlichen Anschauungen auf Grund der volkstümlichen Traditionen, aus seinem eigenen Kopfe und ohne Mithilfe der Gelehrten; so sind in ihm die im Volke schlafenden Kräfte wach geworden und haben sich zu einer phantastischen, mystischen, aber höchst beachtenswerten Wissenschaft entwickelt. In PARACELSUS' Lehre von der Wissenschaft als einer Naturkraft, die das Weltall erfüllt und im Menschen sich über die Schwelle des Bewußtseins erhebt, vom Arzt als einem Naturwesen, von den Krankheiten und Arzneien als Entitäten, die die Welt um uns bevölkern und vom Menschen nur be-

1) BiT., I, S. 183 (Huser, 4. Ausg., VI, S. 399). 
obachtet werden wollen, in dieser großartigen Lehre liegt die eigenste Theorie jener natürlichen, ungelehrten, nichttraditionellen Wissenschaft. Für sie kämpfte PARACELsus mit seinen positiven Lehren, für sie kämpfte er auch negativ, indem er mit unerhörter Rücksichtslosigkeit alles Falsche, Gekünstelte, Tote der institutionellen Wissenschaft, der Wissenschaft der Hochschulen - nicht nur der damaligen, sondern aller, die je die Tendenz der Menschheit Institutionen zu schaffen gebären wird, bekämpft hat. PARACELsus wies auf den ewigen Streit hin zwischen der Genialität und dem Gelehrtenwesen, zwischen dem Leben und der Schule, zwischen der Idee und der Institution. Diese Bedeutung des Paracelsus ist um nichts geringer als die seiner speziellen Theorien: es werden noch mehrmals Zeiten kommen, wo man über PARAcElsus mit Achselzucken urteilen wird; wer aber wirklich zu erkennen strebt, aus welchen dunklen Tiefen die Liebe zum Wissen hervorwächst, der wird jederzeit zu PARAcelsus als $\mathrm{zu}$ dem wunderbarsten Beispiel eines Forschers von Gottes Gnaden aufblicken.

Man nannte PARACELSUs Lutherus medicorum. $\mathrm{Zu}$ seiner $\mathrm{Zeit}$ mag dies ein Schimpfwort gewesen sein; heute hat diese Bezeichnung einen tiefen Sinn. PARACELSUS ist ein Repräsentant der nordischen Renaissance: während jenseits der Alpen diese Richtung hochgebildete, aristokratische Geister traf und in den Werken eines LEONARDO, eines VESAL ihren Ausdruck fand, traf sie in der Schweiz und in Deutschland weniger fein gebildete, mehr demokratische, aber dafür wieder gläubigere Geister an, die die neue Überzeugung als eine ernste, für sich und für alle Welt gültige Lebensfrage nahmen und an die Gründung neuer Kirchen zu treten wagten. Luther ist sein Versuch gelungen; PARACELsus blieb dagegen zu sehr Individualist, um eine größere Anhängerschaft finden zu können; in seinem Bestreben stand er aber LUTHER nicht fremd gegenüber. Der Unterschied zwischen LEONARDO und zwischen PARACELSUS ist der Unterschied zwischen dem Papsttum und Luther, zwischen der italienischen und der deutschen Renaissance.

Literatur über Paracelsus: Gesammelte Schriften des P.: Joh. Huser, ${ }_{5} 59$ bis I59I, Basel, I I Bde. $4^{0}$; 2. Auf. I603 in Frankfurt in Io Bd. und in demselben Jahre eine neue Ausg. in Straßburg in 2 Bd. Folio. Die Basler Ausgabe wird für die beste erklärt. Mir war es leider nicht möglich, dieselbe $z u$ benutzen; ich habe die lateinische Übersetzung der parac. Schriften, herausg. 1658 von Bitiscius in Genf in 3 Bd., gelesen. Neuerdings gab F. Strunz das Pamphlet des P. $\gg$ Das Buch Paragranum r heraus (Leipzig I903), aus welchem sich der Leser eine lebendige Vorstellung von der Vortragsweise des -P. bilden kann. - Eine kritische Übersicht der unter dem 
Namen des P. vorkommenden Schriften wurde von K. SudHoff herausgegeben: Versuch einer Kritik d. Echtheit d. paracelsischen Schriften, I, II, Berlin I894, 1898. Über Paracelsus wurde sehr viel geschrieben; von neueren Publikationen sind die wichtigsten: M. B. Lessing, Paracelsus, sein Leben und Denken, Berlin I 839 (allseitige und gute Charakteristik des P., obwohl in Einzelheiten veraltet). - Schubert, E., u. K. Sudhoff, Paracelsus-Forschungen, Frankfurt a. M. I889 (Bibliographisches über P.' Schriften; nebstdem eine Reihe von Arbeiten SudHoffs über einzelne Schriften Hohenheims). - R. Netzhammer, Theophrastus Paracelsus. Das Wissenswerteste iiber dessen Leben, Lehre und Schriften. Einsiedeln, Waldshut, Köln I90I. Populär, aber sachlich und gut. - F. Strunz, Theophrastus Paracelsus, sein Leben und seine Persönlichkeit, Leipzig 1903. Interessiert sich für die Philosophie und religiöse Seite der paracelsischen Lehren. Agnes Bartscherer, Paracelsus, Paracelsisten und Goethes Faust. Eine Quellenstudie. Dortmund I9II. Weist den Einfluß des P. auf Goethe nach. J. K. Proksch, Paracelsus als medizinischer Schriftsteller. Polemik gegen SudHoff und gegen die Überschätzung der paracelsischen Lehren. - H. A. PREU, Das System der Medizin des Theophr. Paracelsus aus dessen Schriften ausgezogen und dargestellt. Berlin. - H. Magnus, Paracelsus der Überarzt. Eine kritische Studie, Breslau I906. (Wertlos.) - Rixner, TH. A. und Siber, Th., Leben und Lehrmeinungen berühmter Physiker, Sulzbach I8I9.

\section{Die Dämmerung der modernen Wissenschaft.}

Nur mit Vorbehalt kann PARAcElsus ein Vorläufer der modernen Wissenschaft, jener Wissenschaft, für die Descartes, Bacon, GalileI die Grundlagen festgelegt haben, ein Ahne der objektiven, internationalen Erfahrungswissenschaft, auf die das 19. Jahrhundert stolz war, genannt werden — denn er hat fast alles dasjenige bekämpft, was diese für unumgängliche Bedingung einer erfolgreichen Forschung hält. PARACELSUS' Ideale sind von den Gelehrten der nachfolgenden Zeiten mißverstanden worden, während man einen GALILEI oder einen BACON ohne weiteres zu begreifen und anzuerkennen wußte; PARACELSUS wurde von der Wissenschaft fast vergessen, ein GaLILEI wird in allen Schulen gepriesen. PARACELsus bildet viel eher einen Abschluß der mittelalterlichen als den Anfang der neuen Wissenschaft. Er lebt in der Gedankensphäre der Religiosität; Gott und eine ethische Lebensführung stellen seine höchsten Ideale dar, als deren bloße Folge ihm die Wissenschaft erscheint. PARACElsus' Geistesverwandte sind in der älteren, der Mystik ergebenen Periode der Scholastik zu suchen; die heute sogenannte Renaissancewissenschaft hat sich aus anderen Quellen entwickelt und hat andere Ideale als der Prediger der allgemeinen Verbrüderung aller Menschen verfolgt. Paracelsus suchte die Schulphilosophie durch eine praktische Weltanschauung zu ersetzen; die eigentlichen Begründer der.modernen Wissenschaft verwarfen die Scholastik als 
Philosophie und erhoben eine Art aphilosophischer Wissenschaft auf den Schild. VESAL und LEONARDo haben diesen letzteren Weg verfolgt.

\section{Vesal.}

Praktisches Bedürfnis hat die Ärzte des späten Mittelalters zur gelegentlichen Sektion des Menschen und der Tiere geführt, ohne daß sich aber die aus den Büchern gelehrte und durch derartige Sektionen vervollständigte Anatomie eines besonderen Ansehens erfreut hätte. Weil die Gesundheit und die Krankheit, die wichtig. sten Objekte der ärztlichen Untersuchung, in dy na m is chen Lebensvorgängen bestehen, und weil man gewohnt war, dieselben auf den Zustand der Körpersäfte zurückzuführen und folglich chemisch zu deuten, hatte man keinen Grund, der materiellen Hülle, innerhalb deren sich das eigentliche Leben abspielt, besondere Aufmerksamkeit zu widmen. Wenn man trotzdem in den Schulen Anatomie nach GALEN vorgetragen hat, so geschah dies mehr der theoretischen (philosophischen) als der praktischen Zwecke wegen. Versuchen wir den Standpunkt Galens zum Problem der Körperstruktur zu begreifen. Ein vorurteilsloser Beobachter wird die Frage, warum der Mensch einen Kopf, warum er einen Schädel hat, ob es auch intelligente Wesen geben könnte, deren Körper ganz anders gebaut wäre als der unserige, für sehr schwierig, vielleicht über die Kräfte der Wissenschaft reichend erklären. Es ist die reale Anschauung, die uns überzeugt, daß unser Kopf so beschaffen sein muß, wie er es ist; er $\mathrm{mu} \beta$ es sein, wie die Planeten um die Sonne sich drehen müssen, und wie der Mensch sterben $m u ß$, wie im Dreieck die Summe der inneren Winkel $180^{\circ}$ sein $\mathrm{mu}$ B. Den praktischen Menschen überzeugt die direkte Anschauung, daß die Tatsachen so sein müssen, wie sie sind. GALEN dagegen hat im Geiste aller Dogmatiker die Tatsachen als Folgerungen aus gewissen Prinzipien erklären wollen: der Menschenkopf sei da, so behauptet er, der Augen wegen. Denn die Augen müssen eine solche Körperstelle einnehmen - so hat er geurteilt -, von wo aus eine ungehinderte Umsicht möglich ist, daher tragen niedere in einen harten Panzer eingeschlossene Krebse gestielt te Augen. Für den Menschen würden gestielte, aus seinemweichen Hals herausragende Augen kaum vorteilhaft sein. Deshalb hat die Natur den harten Kopf als Schutzapparat für die Augen erschaffen.

Obwohl die Unrichtigkeit dieser teleologischen Erklärungsweise auf der Hand liegt, muß es ungemein leicht sein, in dieselbe zu verfallen, denn sie ist uns (leicht modifiziert) bei PLATo begegnet; VESAL, 
der große Bekämpfer GALENs, nimmt sie ohne Bedenken auf, und bis auf den Tag bildet sie die Schablone, nach der die Gelehrten anatomische Tatsachen zu erklären pflegen. Ihr Fehler liegt in der Voraussetzung, daß die Augen (oder irgendein anderer Körperteil) vor allen anderen Organen gegeben sind, welch letztere logische (durch Verstandesoperationen ermittelbare) Folgen der Augen darstellen; tatsächlich bilden die Augen und der Kopf und die übrigen Organe für die Erfahrung Erscheinungen gleicher Ordnung, die wir alle zuerst erfahren und erst nachher in ihrer gegenseitigen $\mathrm{Ab}$ hängigkeit erforschen können.

Lassen sich einzelne Körperteile aus gewissen allgemeinen Annahmen durch Syllogismen ableiten, wie es die Galenisten praktiziert haben, dann dienen die anatomischen Tatsachen nur als Bestätigungen der Schlüsse. Die Entdeckung neuer Körperelemente verliert den Wert einer neuen, ungeahnten lebendigen Erfahrung und bedeutet nur eine Hinzufügung einer neuen Einzelheit zu dem vorhandenen Wissensschatz; wenn auch der Menschenkörper in allen Einzelheiten ganz anders gebaut wäre, als es in GaLENs Schriften steht, würde es für seine Erklärungen ohne wesentliche Folgen bleiben: der Galenist erklärt das Vorhandensein von drei, fünf, zehn, hundert Schädelknochen ebenso leicht und auf dieselbe Weise.

Die Gelegenheit eine menschliche Leiche zu sezieren war im Mittelalter viel seltener als heute; immerhin gelang es zuweilen den Ärzten, die Einsicht in das Eingeweide zu gewinnen: manchmal mußte man die Toten einbalsamieren, es gibt auch Nachrichten über Obduktionen; an den Hochschulen wurden Sektionen zu pädagogischen Zwecken ausgeführt ${ }^{1}$ ). Die Ärzte von Salerno häben vor der Hörerschaft anstatt des Menschen Schweine seziert²), später mußten Verbrecherleichen zu anatomischen Demonstrationen dienen ${ }^{3}$ ). $\mathrm{Zu}$ diesem $\mathrm{Z}$ wecke wurde einmal im Jahre (oder in längeren Perioden) von der Regierung der Körper eines Verbrechers bewilligt, den man hier und da zuvor auf eine für anatomische Zwecke geeignete Art hingerichtet hatte ${ }^{4}$ ). In einer geräumigen, bis auf mehrere

1) Private Sektionen wurden vom Papst Sixtus IV. verboten.

2) Daher die älteste anatomische Schrift dieses Stils: Anatomia porci ex traditione Cophonis aus dem II. Jh.

3) In Montpellier z. B. seit dem I4, in Paris seit dem I6. Jh. (Pouchet, S. 573).

4) In Wien hat sich die Nachricht über die Unterhandlungen der Universität mit dem Scharfrichter erhalten; von sechs zum Tode verurteilten Frauen haben sich die Professoren drei erwählt, von denen die eine, als die geeignetste (sie sollte offenbar weder $z \mathfrak{u}$ dick noch $z \mathfrak{u}$ mager sein), ertränkt wurde. 
hundert Personen berechneten Halle, im sog. "Theatrum anatomicum «saß auf dem erhöhten Katheder vor einem offenen Buch, gewöhnlich vor der Anatomie des Mundinus oder, namentlich wenn es ein Humanist war, vor der Anatomie Galens der Professor und las laut vor. Unten sezierte ein Chirurg, der Darstellung des Professors folgend, den Leichnam. Die Hörer, unter denen es manchmal zahlreiche Laien gab $^{1}$ ), sahen der Sektion $z u$, hörten die Darstellung des Professors an und besichtigten die Körperteile, die vor ihnen von den Dienern herumgetragen wurden. Als ein anschauliches Hilfsmittel haben dabei Sektionen an Tieren gedient, auch Vivisektionen. Die der Sektion beiwohnenden Doktoren ließen sich in Debatten über die Prinzipien der galenischen, aristotelischen, platonischen Naturphilosophie ein. Die Anatomie hat einige Tage, manchmal bis drei Wochen gedauert; deshalb hat man zuerst die der raschen Fäulnis unterliegenden Teile durchgenommen.

Meistens hat man bei der Anatomie die Schrift des Bologneser Arztes Mundinus, des "Restaurators der Anatomie " aus dem Anfange des I4. Jahrhunderts, ein Gemisch aus des Autors eigenen Beobachtungen und aus den nach arabischen Quellen dargestellten Lehren GaLENs, vorgelesen. Aus der nachfolgenden Beschreibung des Schädels kann man sich eine Anschauung vom Inhalt und vom pädagogischen Charakter dieser Schrift machen:

"Der Schädel ist ein großer Knochen, der das Gehirn nach außen umgibt. Das Gehirn liegt in seinem Hohlraum und deshalb ist dieser Knochen beim Menschen groß, da auch das Gehirn groß ist. Er nimmt seine Lage [deshalb] ein, weil er von den oben erwähnten Teilen aus angeführten Gründen umschlossen ist und weil er selbst aus demselben Grunde das Gehirn umgibt. Dieser Schädel war nicht [wie sie bemerkt haben] einheitlich und zusammenhängend, sondern war aus Teilen zusammengesetzt und zwar aus vielen Gründen. Erstens, auf daß sich die Beschädigung eines Teiles nicht auf die übrigen und auf den ganzen Schädel verbreite. Z Weitens, auf daß die Ausdünstungen durch die Schädelnähte aus dem Schädel ausgetrieben werden könnten. Drittens, auf da $\beta$ die Kraft der Arzneien, falls sie nötig sein würden, in die Gehirnsubstanz eindringen könnte... Und daraus folgt, daß es allgemein fünf Schädelknochen gibt ... die sie eben sehen ... $\ll^{2}$ )

Der pädagogische Wert dieser Vortragsweise bleibe dahingestellt; jedenfalls war die Ausführung der Demonstration nicht so sinnlos,

1) An einigen Universitäten wurden zu der Anatomie nur die Hörer der Medizin und die Chirurgen zugelassen; an anderen war dieselbe auch vom besseren Laienpublikum besucht. Es wurden auch Einladungen zur Anatomie versandt.

2) Anatomia Mundini aus der Sammlung der mediz. Schriften, die in Venedig 500 erschienen sind (ohne Seitenangaben). 
wie man sie darzustellen pflegt; zweifellos war aber diese Anatomie außer stande, die organische Strukturlehre zu vertiefen, denn MunDINUS' eben zitierte Theorie bleibt unerschüttert feststehen, auch wenn es am Schädel eine andere Anzahl ganz anders gruppierter Knochen gäbe, als Mundinus angibt. Mundrusus hat die Methode GALENs befolgt; nichtsdestoweniger fühlte er sich, wie eine Reihe anderer ihm gleichstehender Autoren, GALEN gegenüber als einen unabhängigen Forscher; jeder wies mit Gelehrtenstolz auf ein Stück Fleisch oder auf ein Knöchelchen hin, von denen bei Galen nichts geschrieben steht und die erst er entdeckt hatte ${ }^{1}$ ).

Neben dieser medizinisch-pädagogischen, auf GALEN und seinen arabischen Erklärern fußenden Anatomie wurden im Mittelalter theoretische Betrachtungen über den Bau und die Verrichtungen des organischen Körpers im Stile der aristotelischen Lehren, als Bestandteil der Scholastik gepflegt. Man spekulierte über die Prinzipien der Embryonalentwicklung, über das Wesen der organischen Formen, über die Seele der Tiere und der Pflanzen usf. Obwohl diese scholastische Biologie an unverkennbaren Mängeln litt, hat sie immerhin einen höheren Standpunkt eingenommen, als der allein den Menschen und zwar ausschließlich praktischer $Z$ wecke wegen berücksichtigende und jeder originellen Einsicht in das Wesen des Lebens bare Galenismus. Die Renaissance hat die Scholastik dem öffentlichen Spotte preisgegeben; es war nur natürlich, daß mit der letzteren auch die biologisch orientierte Anatomie in den Hintergrund gedrängt und dadurch indirekt dem Galenismus Vorschub geleistet wurde, indem sich nun die Mediziner angelegen sein ließen, die Arabisten und die Aristoteliker zu überwinden und nach korrekten Ausgaben Galens Vorlesungen zu halten. Während der Renaissance herrschten also drei Auffassungen der Anatomie. Die Aristo-

1) A. Achillini $(1463-15 \mathrm{I} 2)$ hat die Einmuindung des Gallenganges in d. Zwölffingerdarm, G. Gerbi (Ende d. I5. Jh.) die Tränendrüse entdeckt, Berengar DA CARPI (1470-I530) hat Galens Ansicht iiber den Wurmfortsatz berichtigt, A. BenEdeTTI (t 1525) hat die Einmiindung der Bartholinschen Driisen beschrieben; auch andere Entdecker haben sich berühmt gemacht: A. MASSA (t I569), G. FERRARI (t I 472), J. Dubois (Sylvius, tr555), Ch. Estienne (t I564), Guy de Chauliac (* I3Oo) u. a.

Es wird oft gegen die Galenisten der Vorwurf erhoben, daß sie ihren Meister für unfehlbar erklärten. Gegen die Zitate, die dies dartun sollen (z. B. Vesals Fabrica, Einleitung), lassen sich dagegen Zitate aus den Schriften anderer, nicht weniger berühmter Galenisten anführen, die ausdrücklich die direkte Erfahrung höher als jede Autorität, Galen nicht ausgenommen, stellen. Aber diese wie jene Forscher folgten Galens Methode blind nach, auch wenn sie ihn in Einzelheiten korrigiert haben. 
teliker oder Philosophen (wie man sie auch genannt hat), die sich noch am ehesten den Biologen (Zoologen, Botanikern) von heute vergleichen lassen, wurden als Scholastiker bekämpft; die Arabisten waren halb aristotelisch, halb galenisch orientiert; die Galenisten, als die modernsten, waren humanistisch gebildet. Alle drei Richtungen waren wesentlich akademisch, indem sie nur für die Hörsäle bestimmt waren und der Streit zwischen denselben innerhalb der Hörsäle ausgefochten wurde; relativ am höchsten standen immerhin die Aristoteliker; die Niederlage derselben bedeutete den Sieg der aphilosophischen Schuldogmatik über die philosophische. Die Folgen davon waren verhängnisvoll.

In dieses wissenschaftliche Milieu fällt die Arbeit Vesals. ANDREAS VESAL(IUS) aus Brüssel (I I 4-I 564) hat seit seiner Jugend, als Hörer an der Universität in Löwen, aus eigenem Anlaß Mäuse, Maulwürfe, Ratten, Hunde und Katzen zergliedert. Später studierte er Medizin in Paris unter Jаков. Sylvius, einem damals berühmten humanistischen Anatomen. Bei Sylvius und durch Privatstudium war er in der Sezierkunst so weit fortgeschritten, daß er, nach Hause zurückgekehrt, eine öffentliche Anatomie vorführen konnte. Er war 23 Jahre alt, als er zum Professor der Anatomie in Padua ernannt wurde. Dort hat er anatomische Vorlesungen im üblichen Stil gehalten, jedoch mit dem Unterschied, daß er selbst, von den Hörern unterstützt, die Sektion und die Demonstrationen auszuführen pflegte. Aus derartigen öffentlichen, mit Begeisterung aufgenommenen Anatomien (VESAL pflegte an 500 Hörern vorzulesen) ist seine große Schrift über den Bau des Menschenkörpers (I543) entstanden $\left.{ }^{1}\right)$.

Im Vorwort erklärt VESAL den Sinn seiner Unternehmung: es genüge nicht, daß der Arzt nur die wichtigeren Teile des Menschenkörpers, etwa nur das Eingeweide, kenne, und das Studium der Knochen, Muskeln, Nerven, Gefäße den Chirurgen überlasse, denn der Körper ist viel komplizierter gebaut, als die Gelehrten glauben; er besteht nicht nur aus IO-I $2^{2}$ ), sondern aus einigen Tausend Teilen. Mag diese Begründung der Notwendigkeit einer eingehenden anatomischen Forschung vom praktischen Gesichtspunkte (als eine Art Entschuldigung, daß eine so große Arbeit unternommen wird, oder

1) Andr. Vesalii de humani corporis fabrica libri 7. Ich habe die Ausg. aus d. J. I568 benutzt.

2) Mit welchen einige Anatomen auszureichen strebten. 
als eine Art Empfehlung an den Leser) berechtigt sein, theoretisch ist sie ungenügend. VESAL hätte dartun müssen, daß die Kenntnis einer ins einzelne eingehenden Anatomie für die Heilung der Krankheiten nötig ist; und hätte er diesen Versuch unternommen, würde er auf die Maschinentheorie des Lebens gekommen sein. Ihm hat es sich jedoch nicht darum gehandelt, die Notwendigkeit der Anatomie zu begründen oder das Wesen dieser Wissenschaft dem Leser zu veranschaulichen; er war praktischer Anatom, er wollte vor dem Leser sein Wissen aufrollen und hat die oben erwähnte Begründung seiner Arbeit nur als eine Art Einleitung vorangeschickt, der er gleich die Beschreibung des Menschenkörpers folgen läßt. Er beschreibt die Zusammensetzung des Körpers an der Hand zahlreicher größerer und kleinerer Abbildungen, wobei er sich fortwährend nachzuweisen bemüht, daß Galenus falsche Angaben gemacht hat, indem er Tierkörper anstatt der Menschenkörper seziert und nach denselben den Menschen beschrieben hätte ${ }^{1}$ ).

Vesals Fabrica ist eine topographische Anatomie im Stile der anatomischen für die Hochschüler bestimmten Handbücher, wendet sich aber an die Intelligenz im allgemeinen. Jeder philosophischen Tendenz steht das Werk fern; es ist aber frisch, bündig und anschaulich geschrieben und legt als solches ein klassisches Zeugnis ab für die von den Männern der Renaissance vielfach betonte Vorliebe für reine Wirklichkeit, für nackte Tatsachen. Nur das unmittelbar Sichtbare und Greifbare wird da für wahr gehalten, während die »Erklärungen « (deren eine Menge in der Schrift zu finden ist) zu bloßem stilistischen Schmuck der Beschreibung degradiert sind. Deshalb spielen auch die künstlerichen, von Tizians Schüler J. Stephan v. Calcar gezeichneten Abbildungen der Fąbrica eine große Rolle.

VESAL ist ein Reformator der anatomischen Lehre. Als der erste hat er die Sektion mit dem Vortrag verknüpft und (wenn man LEONARDO nicht berücksichtigt) sich in ausgedehntem Maße der künstlerisch ausgeführten Abbildungen bedient. In REMBRANDTs "Anatomie " aus dem Jahre 1632 besitzen wir ein Dokument, wie sich seit VESAL der Vortrag gestaltet hat. An der der Anatomie Mundinus' beigefügten Abbildung zeugt noch alles vom Mittelalter: die Kleriker umgeben den Leichnam, den ein Chirurg zu öffnen sich vorbereitet; im Hintergrund sitzt auf dem Katheder der Professor.

1) Doch gibt Vesal selbst einzelne Darstellungen der tierischen Organe für Darstellungen der menschlichen; vgl. B. BLoch a. a. O., S. 295; M. HoLl, Vesals Darstellung des Baues der Niere. Arch. f. Gesch. d. Med. I9I3, S. 6. 
Bei Rembrandt atmet bereits alles den Laiengeist: der Professor (Tulp) mit einem breiten Hut demonstriert selbst die fein präparierte Hand eines Leichnams ehrwürdigen Bürgern, den Mitgliedern der Chirurgengilde.

Wie groß man diese pädagogische Leistung VESALs einschätzen mag, bleibe dahingestellt; jedenfalls blieb die Reformation an die Hörsäle der Universitäten gebunden ${ }^{1}$ ). Für die allgemeine Biologie dagegen ist VESALs Fabrica von einem viel geringeren Werte, als man glauben würde. VESAL ist nämlich nur so lange selbständig, als er die Körperteile demonstriert und den GALEN korrigiert; in der Auffassung der Körperteile bleibt er Galenist. Vesal hat mit seiner Schrift nur den Zweck verfolgt, anzugeben, daß hier das so und so große, so und so geformte Stirnbein liegt, hier der Dünndarm, dort der Dickdarm usw. Überall befolgt er dieselbe schematische Ordnung in der Beschreibung (wie die Galenisten), indem er die Anzahl, die Lage, die geometrische Figur, die Größe, die Zusammensetzung, die Verbindung, den Nutzen, die Funktionen der einzelnen Organe anzugeben sucht. Um diese pedantische, nichts weniger als philosophische Aufzählung der Körperteile dem Leser angenehmer zu machen, bedient er sich verschiedener stilistischer Kniffe: er vergleicht die äußere Form der einzelnen Organe mit der Form bekannter Objekte (z. B. mit derjenigen eines Hammers, einer Hostie, eines Votivbildes; er schreibt z. B. ${ }^{2}$ ), daß das Gehirn wie ein König oben auf dem Throne sitzt und von den Knochen wie von Mauern umgeben ist) oder er konstruiert sich Funktionen oder eine ästhetische Bedeutung für einzelne Teile - ganz im Stile Galens. Wir haben oben ein Beispiel der Art angeführt, wie GALEN über den Schädel geschrieben hat; VESAL nimmt dieses Beispiel ohne weiteres in seine Schrift auf. Er weist ferner auf das gegliederte Rückgrat hin. Woher die Gliederung, fragt er, und antwortet:

»... Denn die Knochen sind nicht nur der Bewegung, sondern auch der Sicherheit wegen gegliedert, oder auch deshalb, daß sich die Beschädigung leichter ertrage, oder auch der Mannigfaltigkeit der Teile wegen «3).

Auf diesem Wege des flachen Dogmatismus ist keine allgemeine Einsicht in das Wesen der organischen Struktur zu finden. VESAL hat keine Ahnung von der morphologischen (vergleichend anatomischen) Wissenschaft, die sich durch das Studium einzelner Körper-

1) Eine ausführliche Analyse der Fabrica gibt Roth a. a. O.

2) S. I 9 .

3) S. 9 . 
teile zu allgemeinen Strukturgesetzen hindurcharbeitet, VESAL kennt auch die aristotelischen Prinzipien der anatomischen Forschung nicht. Als Theoretiker ist VESAL Galenist. Zwar hat er Tiere seziert, aber nur um der Einzelheiten, nicht allgemeiner Gesetze wegen. Der Titel seiner Schrift »Fabrica humani corporis " deutet an, daß er den Menschenkörper nur als eine zur Vollführung bestimmter, a priori gegebener Leistungen konstruierte Maschine aufgefaßt hat. Deshalb ist VESAL nur cum grano salis als der "Begründer der Anatomie «zu nennen; er war Begründer der medizinischen, der deskriptiven Anatomie, der Anatomie als eines Vorstudiums für den ärztlichen Beruf, aber kein Begründer der Anatomie als einer selbständigen Wissenschaft. Deshalb ist auch seine Bedeutung in der Geschichte der Biologie weniger groß, als sie geschildert wird. Schon Vesals Zeitgenossen haben ihm vorgeworfen, daß er — selbst ein Galenist — sich mit Unrecht über GALEN erhebt; kein späterer Anatom ist zu den Anschauungen VESALs zurückgekehrt (weil es keine gibt); mit Recht wurden zwar seine Beschreibungen und Abbildungen gerühmt, es gibt aber keine allgemeinere "Idee "VESALs, es gibt keinen Vesalismus. Jedenfalls steht in seiner Schrift nichts, worin die tiefer angelegten Naturen während des Verfalls der Biologie im I7. Jahrhundert einen Stützpunkt zu neuen Anschauungen erblicken konnten; es steht dagegen in seinen Schriften manches, das den geistlosen Glauben an den Mechanismus zu fördern imstande war. Nichtsdestoweniger stellen Vesals Sinn für die anatomische Wirklichkeit und seine Darstellungskunst ein Beispiel von großartiger wissenschaftlicher Potenz dar.

Neben der "Fabrica " hat VESAL noch andere Schriften anatomischen und medizinischen Inhalts herausgegeben; im dreißigsten Lebensjahre hat er jedoch das wissenschaftliche Studium aufgegeben und wurde Leibarzt der spanischen Herrscher KARL V. und PHILIPP II. Mit PhilipP, dem blutigen Unterdrücker des niederländischen, gegen die spanische Herrschaft und gegen die Inquisition gerichteten Aufstandes, ist unser Reformator der Anatomie (der selbst ein Niederländer war) nach Madrid übergesiedelt, wo er die Forschung nicht betreiben konnte, denn in Madrid war es schwer, wie VESAL selbst bekennt, auch nur einen Schädel zu bekommen. I564 hat VESAL eine Reise nach Jerusalem unternommen; auf der Rückkehr starb er im selben Jahre in einer nicht sicher zu bestimmenden griechischen Stadt. Über die Beweggründe seiner Reise nach dem heiligen Lande kursieren unkontrollierbare Gerüchte, nach denen er zu der Pilger- 
fahrt wegen eines wissenschaftlichen Verbrechens von der Inquisition verurteilt worden sei. Es werden aber auch andere, ebensowenig verbürgte Gründe der Reise angegeben.

Nach Vesal folgte die Anatomie den Spuren Galens weiter. G. Rondellet (I 507-i 566), M. R. Colombo († I 559), Fabricius ab Aquapendente (I 537-I6I3), Gabr. Fallopio (I523-I562), Bart. Eustachi ( $\dagger$ I 574), V. Coiter (I 534-i600), Th. Bartholin (I6I6-I680) und eine Reihe anderer haben diese Richtung gepflegt ${ }^{1}$ ).

\section{Leonardo da Vinci.}

LEONARDO (I452-I5I9), der vielbewunderte Künstler, Ingenieur, Mathematiker und Biologe 2 ), in Vinci bei Empoli geboren, lebte seit i 494 am Hofe der Galeazzo und Ludevico SForza, der Fürsten von Mailand, worauf er sich auf Reisen begeben haben soll (nach Ägypten?); dann weilte er in Florenz, in Venedig, später am Hofe des Cesare Borgia in Romagna, dann wieder in Florenz und in anderen Städten Italiens, auch am Hofe des Papstes LEO X.' in Rom; zuletzt übersiedelte er an den Hof Franz I. nach Amboise in Frankreich, wo er, von allen verehrt, I5I9 gestorben ist.

Wer mit den gangbaren Vorstellungen über den Tiefstand der Wissenschaften am Ende des Mittelalters an Leonardos Schriften herantritt und seine naturgetreuen anatomischen Zeichnungen, physiologischen Bemerkungen, mechanischen Untersuchungen, seine allgemein wissenschaftlichen Grundsätze betrachtet, glaubt vor einem Wunder zu stehen. Wie ist der feinfühlige Maler dazu gekommen, so Bedeutendes, Wahres und Neues aus sich selbst, ohne sich auf Vorläufer zu stützen, geleistet zu haben? Aber auch ein LEONARDO ist nicht gelehrt vom Himmel herabgefallen.

LEONARDO ist bei dem berühmten, dem Realismus geneigten Florentiner Maler Verocchio (I435-I488) in Lehre gestanden. Verocchio empfahl seinen Schülern, neben dem vergeistigten Ge-

1) Über Vesal vgl. die Monographie M. Rotrs, Andreas Vesalius Bruxellensis, Berlin 1892, eine sehr gründliche (enthusiastische) Schrift. Ferner: M. Holl in Arch. f. Gesch. d. Medizin I910, I9rr, 1912. RorH, Arch. f. Anat. (u. Phys.) r905, 1906, 1907. - Die Beschuldigung JackschaHTs, Vesals Anatomie wäre ein Plagiat an Leonardo, wurde einstimmig verworfen (vgl. M. Holl, Leonardo da V. u. Vesal, Arch. f. Anat. [u. Phys.] r905).

2) Leonardo ist älter als Vesal; aus sachlichen Gründen habe ich den mehr schulmäßigen Vesal im Zusammenhange mit der schulmäßigen Anatomie durchgenommen und widme Leonardo ein besonderes Kapitel. 
sichtsausdruck auch auf die Einzelheiten des Körperbaues, auf die Lichtverteilung in der Natur zu achten und auch Blumen und Tiere auf das Bild zu übertragen. Er fand Vergnügen an der Darstellung von phantastischen Geschöpfen, und sein Juwelierladen soll "voll von Tieren, Pflanzenblättern und anderen Bizarrerien " gewesen sein $^{1}$ ). VASARI, der dies berichtet, schreibt ihm auch Interesse für die Wissenschaft und besonders für die Geometrie $\mathrm{zu}^{2}$ ). Ob VerocCHIO auch Anatomie gepflegt hat? Obwohl es an einschlägigen Nachrichten über VEROCCHIOs anatomische Forschungen fehlt, so wird man an denselben kaum zweifeln dürfen; denn Leichen zu sezieren gehörte zur Mode unter den Malern der damaligen Zeit, wie es Vasari von Anr. Pollajuolo (I429-I 498), dem Zeitgenossen VERocchios, berichtet und wie es auch von dem etwas jüngeren Michelangelo bekannt ist.

Es war nur natürlich, daß der empfängliche Schüler Verocchios ein gleiches Interesse für geometrische Wissenschaften, für die Anatomie des Menschen und der Tiere gezeigt hat. Er wollte kein Fachmann im modernen Sinne des Worts, d. h. kein Scholastiker nach der Terminologie seiner Zeit sein, denn diese waren des früheren Glanzes beraubt; er studierte die Wissenschaft als Laie und hat sich zu einem der größten Dilettanten herangebildet. Das Interesse für die Wissenschaft ließ ihn einen regen Umgang mit den Gelehrten seiner Umgebung pflegen; VASARI führt vor allem den Professor der Anatomie in Pavia Marc Antonio della Torre als Leonardos Freund an. Als bekannter Maler fand LEonaRdo Zutritt zu den Bibliotheken an den Fürstenhöfen, wo er die scholastischen Autoren und die philosophischen Schriften der Begründer der Renaissancebewegung ruhig exzerpieren konnte. Namentiich der Neuplatoniker der Frührenaissance, Nikolaus Cusanus, dessen Schriften damals schon gedruckt vorlagen, hat ihn stark beeinflußt; nebstdem auch ALBERT DER GROSSE und einige andere Scholastiker $\left.{ }^{3}\right)$; in der Anatomie folgte er Mundinus, Galen, Alex. Benedetto und anderen berühmten Gelehrten; er bediente sich der damals üblichen arabischen Nomenklatur ${ }^{4}$ ) und kannte auch Avicenna, Aristoteles, Plinius u. a. LEONARDO war also nichts weniger als von der zeitgenössischen Wissenschaft unabhängig; vielmehr hat er sie gründlicher beherrscht

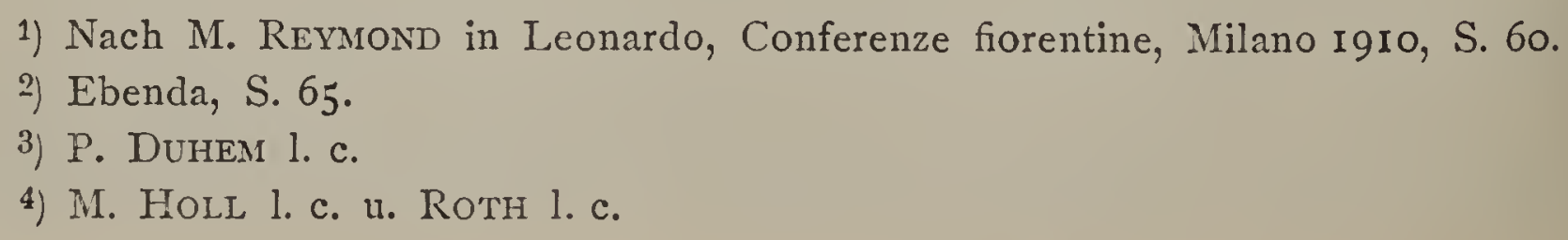


als mancher seiner gelehrten Zeitgenossen, - eine vom historischen Standpunkte bedeutungsvolle Tatsache.

Ein klares Bild von LEONARdos Biologie zu entwerfen, wird durch den Umstand erschwert, daß der Leser, voll Begeisterung für die Genialität dieses einzigartigen Mannes, geneigt ist, jede einschränkende Bemerkung als einen Angriff gegen diese Begeisterung zu nehmen. LEONARDO ist auch als Biologe ein genialer Forscher; man legt seine kurzen Bemerkungen über biologische Probleme und die Pläne, die er für die Zukunft aufwirft, mit Bewunderung für seinen durchdringenden Geist aus der Hand; sein Stil, seine Abbildungen, seine Probleme sind äußerst klar, seine wissenschaftliche Unabhängigkeit ist großartig. Trotzdem erwehrt man sich beim Durchblättern seiner Aphorismen (seine Biologie besteht fast nur aus solchen) kaum des unangenehmen Gefühles, daß die Ideen dieses Denkers an einem empfindlichen Mangel leiden. Es ist desto wichtiger, denselben hervorzuheben, als er sich historisch als verhängnisvoll erwiesen hat.

Die scholastische Biologie bestand in der systematisch geordneten und philosophisch gedeuteten Lehre von den Tieren und Pflanzen; eine solche Lehre findet man bei LEONARDo nicht, und es scheint, daß eher der Mediziner Galen als der Biologe ARISTOTELes für seine Auffassung der Lebenserscheinungen bestimmend war. LEONARDO hat eine Reihe Aphorismen über einzelne Tiere hinterlassen, die das beste Zeugnis davon ablegen, daß die aristotelische (= philosophisch biologische) Naturauffassung außerhalb seines Gesichtskreises gelegen war. Was versteht ein Biologe unter einem Wolf, einem Rebhuhn, einem Basilisken? Eine Organisation, ein Stück Leben, ein Naturobjekt. LEONARDO faßte sie als moralische Wesen, als Charaktere auf. Offenbar hat er bei der Abfassung seiner Bemerkungen einen "Physiologus " als Vorlage benutzt und dessen andächtige Allegorien mit einer künstlerischen Form bekleidet; und so tritt bei ihm die Taube als Repräsentantin der Undankbarkeit, der Adler als Repräsentant der Großmut auf, der Wolf zeigt Sinn für Disziplin, das Rebhuhn verändert plötzlich sein Geschlecht usw. Auch der giftige Basilisk kommt in einem Aphorismus auf seine Rechnung:

"Der Basilisk ist von einer solchen Grausamkeit, daß er, wenn er mit seinem giftigen Blick keine Tiere töten kann, sich gegen die Gräser und Pflanzen wendet und mit seinem Blick dieselben fixierend sie zum Welken bringt. "

Als Biologe hat sich LEONARDo vor allem für die Anatomie des Menschen interessiert. Wie es zu seiner Zeit Mode war, hat er in 
seiner Privatwohnung (in den Jahren I489-I5I0) Leichname seziert und die Knochen, Muskeln usw. abgebildet; die Abbildungen z. B. des Schädels, der Muskulatur, der inneren Struktur des Herzens gelten für naturgetreuer und für künstlerischer als diejenigen in VESALs Fabrica. Seine ganz unsystematisch ausgeführten Bilder sind mit kurzen Anmerkungen versehen, die die Grundlage für ein anatomisches Werk bilden sollten, das LEONARDO vielleicht in Gemeinschaft mit MARC ANTONIO DELLA TORRE herauszugeben gedachte. So war LEONARDo der erste (40 Jahre vor VESAL), der sich der anatomischen Abbildungen zur Erläuterung der inneren Körperbeschaffenheit bedient hat, denn die früheren Anatomen hatten den Bau des Körpers nur abstrakt dargestellt. Der Mangel an einer einheitlichen, die Einzelheiten beherrschenden Idee war offenbar der Grund, warum LEONARDos Anatomie ein Stückwerk geblieben ist. LEONARDO gab sich den schlichten Eindrücken der unendlich mannigfaltigen Natur hin und suchte sie in ihrem Nebeneinander bildlich darzustellen und mit Randglossen zu begleiten; er wählte sich nicht besondere vom anatomischen oder physiologischen Gesichtspunkte theoretisch interessante Objekte zum Studium; er zeichnete vielmehr bloß die fein präparierten Teile des Menschenkörpers, wollte auch diejenigen des Tierkörpers zeichnen, und da die Natur grenzenlos mannigfaltige organische Formen darbietet, verlor sich LEONARDOs anatomische Arbeit schier ins Unendliche. Weil seine Anatomie weder sachlich noch begrifflich begrenzt und zum großen Teil nur aphoristisch ist, ist es nicht leicht, dieselbe scharf zu charakterisieren; sie überschreitet durch das bearbeitete Material die Grenzen des Galenismus, indem sie nebst dem Menschenkörper auch die Tiere anatomisch untersucht, ist aber nicht aristotelisch, da LEONARDo das Studium der Tiere de facto nur als Anhang an dasjenige des Menschen aufgefaßt hat.

P. Duhem hat durch eingehendes Studium die Abhängigkeit LEONARDOS mathematischer, mechanischer und geologischer Untersuchungen von der Scholastik nachgewiesen. Eine bedeutende Zahl von LEONARDOs Sentenzen sind als Anmerkungen während der Lektüre Alberts des Grossen, Alberts De SaXe, des Nikolaus Cusanus usw. entstanden ${ }^{1}$ ). Auch Leonardos Anatomie ist von seinen geschriebenen und gedruckten Vorlagen mehr abhängig, als man glauben würde. Alle, die sich mit den anatomischen Zeich-

1) P. Duhem, Etudes sur Léonard de Vinci, Paris 1909. 
nungen LEONARDOs befaßt haben, erklären sie für äußerst wahrheitsgetreu und für bewundernswürdig künstlerisch ausgeführt; dort aber, wo das sinnliche Sehen aufhört und die begriffliche Arbeit beginnt, hört seine Selbständigkeit auf: LEONARDOS anatomische Ideen gehen nicht über den Galenismus hinaus. Den Bau des Herzens und den Klappenapparat desselben, der sich an anatomischen Präparaten direkt sehen läßt (man verstehe die Worte nicht so, daß dieses "Sehen " eine leichte Aufgabe wäre), wußte LEONARDo bewunderungswürdig gut zu beschreiben (wie BORUTTAU berichtet); den Blutkreislauf dagegen, dessen Erfassen von einer scharfen Analyse der Tatsachen abhängig ist, hat er ganz im Sinne des damals herrschenden Galenismus ${ }^{1}$ ) dargestellt, trotzdem diese Theorie zu seinen anatomischen Befunden am Herzen gar nicht paßt. Die oberflächlichen Nützlichkeitsdeutungen, die galenistisch-physiologische Methode leiten ihn bei seiner anatomischen Forschung. Man kann sich den Geist der Anatomie vorstellen, auf die LEONARDo hingearbeitet hat, wenn er sich z. B. folgendes charakteristische Problem. stellen konnte:

»Sieh, wozu der Höcker des Oberarmes dient. Und so alle ähnlichen. Höcker jedes Knochens... I Ich erinnere mich daran, sämtliche besonderen. Nützlichkeiten jedes Höckers, jedes Knochens aufzusuchen ...«²)

Auf diesem Wege ist niemals eine wissenschaftlich begründete Strukturlehre des organischen Körpers, sind niemals allgemeine physiologische Begriffe zu finden; am Ende dieses Weges steht nur die deskriptive Anatomie, auch wenn man den Menschenkörper noch so eingehend beschreiben, alle Tierkörper sezieren und die Funktionen aller Körperteile angeben würde. Die Begriffe der »Extremität «, des »Segmentes «, der Homologie, der Atmung, des Blutkreislaufs, überhaupt die allgemeinen morphologischen und physiologischen Begriffe liegen ganz abseits von dieser Richtung, die nur Einzelheiten zu sammeln vermag. LEONARDo war so sehr im Banne des Galenismus befangen, daß ihn nicht einmal sein Künstlergenius. auf die diesem doch so nahe liegende Idee geführt hat, daß im Menschenkörper eine Form sui generis verwirklicht ist und daß diese als eine solche in Formelemente und nicht in materielle Bestand-

1) Vasari erzählt, daß Leonardo seine anatomischen Untersuchungen in Gemeinschaft mit M. A. della Torre ausgeführt hat, >der die Medizin nach Galens Lehre. $z$ u erklären und die Anatomie in die wahre Beleuchtung zu stellen begonnen hat... (Conferenze fiorentine, S. 23).

2) Zitiert nach Roth. 
teile analysiert werden soll. Wie unkünstlerisch, unwissenschaftlich, lautet seine Angabe der Folge, in welcher der Menschenkörper zu beschreiben sei:

»Beginne die Anatomie mit dem Kopfe und beschließe sie mit der Fußsohle «1).

Kaum tiefer ist dieses ausführlichere Programm seiner Anatomie ${ }^{2}$ ) gefaßt:

»Dies Werk muß beginnen mit der Empfängnis im Mutterleibe. $\mathrm{Zu}$ beschreiben ist die Natur der Gebärmutter und in welcher Weise der Fötus sich in ihr befindet und in welchem Grade der Entwicklung er sich von ihr lostrennt und wie er lebt und wie er sich ernährt. $\mathrm{Zu}$ untersuchen ist sein Wachstum in den verschiedenen Intervallen, die Ursache, warum er sich aus dem Körper der Mutter begibt und aus welcher Ursache er öfters zu früh geboren wird. Dann beschreibe, welche Teile, nachdem das Kind geboren ist, mehr wachsen als andere, und gib die Maße eines einjährigen Kindes an. Dann beschreibe den erwachsenen Mann und die erwachsene Frau und gib ihre Maße an; ferner die Natur der inneren Leibesbeschaffenheit, der Farben und der Physiognomien. Dann beschreibe, wie er zusammengesetzt ist aus Venen, Nerven, Muskeln und Knochen. Dies wirst du im letzten Buche machen... Dann beschreibe die Attribute und die Bewegungen. Dann die Perspektive, die Funktion des Auges und des Gehirns und beschreibe alle anderen Sinne. Dann beschreibe die Natur der Sinne.«

Der Unterschied dieser Problemstellung von der aristotelischen fällt in die Augen. ARISTOTELEs hat mit Hilfe der embryologischen Tatsachen Proble me zu lösen gesucht, wie z. B.: Besteht Evolution oder Epigenese zu Recht? Worin liegt das Wesen der Geschlechtlichleit? Welches Organ ist für die Entwicklung das allerwichtigste? Worin besteht die Erblichkeit? Welcher Unterschied ist zwischen der Entwicklung der höheren und der niederen Tiere zu finden? usw. Für LEONARDo dagegen existieren die Begriffe Evolution, Epigenese, Geschlechtlichkeit, relative Bedeutung des Organs, Erblichkeit, höhere und niedere Tiere usf. nicht; er sucht nur die Entwicklung des Kindes Schritt für Schritt zu verfolgen und sozusagen kinematographisch vorzuführen. Und wie er den Menschen in allen seinen materiell gegebenen Erscheinungsformen beschreiben will, so versucht er auch die Tiere bloß als gegebene Naturobjekte zu beschreiben: nebst dem Menschen will er auch die ihm ähnlichen Affen und ferner auch die Löwen- und Pferdearten ebenso eingehend beschreiben

1) Richter, II, S. II2. Analog lautet ein anderer Grundsatz: »Definiere alle Teile, aus denen der Körper zusammengesetzt ist, indem du mit der Haut und ihrer Oberbaut beginnst. (RICHTER, II, S. I I 7.)

2) Richter, II, S. 108 u. Io9. 
und die Unterschiede zwischen den einzelnen Arten hervorheben. Er will auch den Unterschied zwischen dem Menschen und dem Pferd an jedem einzelnen Knochen dieser beiden Organismen studieren ${ }^{1}$ ). LEONARDO fällt es nicht ein, anatomisch zu untersuchen, warum der Affe dem Menschen ähnlicher ist als das Pferd, oder wie sich die Pferdeform von der Menschenstatur unterscheidet, sondern er geht auch hier rein deskriptiv, ohne Probleme aufzustellen, vor. Auch dort, wo er Ähnlichkeiten unter den Organismen bemerkt, stellen sie für ihn etwas Selbstverständliches und nicht weiter log is ch Analysierbares dar: er will z. B. die Vorderextremität und deren Variationen bei verschiedenen Tieren beschreiben (nicht analysieren!). Seine Bemerkung:

\Zeichne hier den Fuß des Bären und des Affen und anderer Tiere, worin sie sich vom Fuße des Menschen unterscheiden; und füge auch die Füße eines Vogels hinzu « -

sprechen wohl dafür, daß er die Ähnlichkeit zwischen diesen Extremitäten bemerkt hat; vergessen wir aber über dieser Tatsache nicht, daß erstens die Ähnlichkeit jener Organe auf der Hand liegt, daß das Aufsuchen solcher "Analogien " bei den Aristotelikern nichts Unbekanntes war, und, last not least, daß LEONARDo nicht den Begriff der Analogie zu vertiefen suchte ${ }^{2}$ ), sondern nur Einzelheiten über die Ähnlichkeit und Unähnlichkeit aufzuzeichnen sich vorgenommen hat $^{3}$ ).

LEONARDO verlangt vom Anatomen die Kenntnis der Mathematik und der Mechanik - etwa um aus bekannten Körperteilen die un. bekannten $\mathrm{zu}$ berechnen und auf diese Art die Morphologie zu pflegen? Mit nichten, sondern nur um die Funktion einzelner Organe (Muskeln, Sehnen) mechanisch deuten zu können. Deshalb besteht

1) Richter, S. I20. Die ganze Stelle bei Leonardo spricht noch deutlicher: iHier will ich den Unterschied zwischen dem Menschen und dem Pferde darstellen, und in ähnlicher Weise denjenigen zwischen anderen Tieren; und zuerst werde ich mit den Knochen beginnen und werde alle Muskeln verfolgen, die ohne Sehnen an den Knochen beginnen und endigen, und dann jene, die mit der Sehne beginnen und endigen an den Knochen ....

2) M. A. Severino ( $1580-1656)$, von dem unten die Rede sein wird, hat viel feinere Strukturähnlichkeiten bemerkt und begrifflich gedeutet.

3) Auch die Physiologie Leonardos bleibt am Einzelnen haften. Er stellt sich z. B. die vergleichend physiologische Aufgabe, zu untersuchen, wie sich Fisch, Aal, Schlange, Blutegel mittels ihres Schwanzes vorwärts bewegen; die Lokomotion als solche interessiert ihn nicht, sondern nur einzelne Fälle derselben.

Rádl, Geschichte der biol. Theorien. I. 2. Aufl. 
LeONARDos Physiologie 》durchaus in teleologisch-scholastischen Erörterungen mit Hinweisen auf Galen und AvICENNA «1).

Die aphilosophische Methode LEONARDOs macht es verständlich, daß sich in seinen biologischen Aufzeichnungen so wenig Keime der späteren Entdeckungen finden. Er hat keine Ahnung von der Möglichkeit eines Tiersystems, von der Gleichheit des Organisationsplanes, von der beschränkten Zahl der Grundfunktionen des Lebens, von dem Gegensatze zwischen der Präformation und der Epigenese, von dem Gegensatze zwischen dem Vitalismus und Mechanismus; dagegen beschreibt er vollkommen richtig Querschnitte durch den Schädel, die Krümmungen der Pflanzen nach dem Licht, oder das Wesen der Versteinerungen (das letztere im Anschlusse an die Scholastiker).

B. CROCE hat in einem lesenswerten Aufsatze den Nachweis zu führen gesucht, daß LEONARDo kein Philosoph im wahren Sinne des Wortes gewesen ist, kein Philosoph im Sinne eines Plato, eines ARIstoteles, eines Thomas von AQuin: Leonardo läßt die Erscheinungen resigniert über sich gehen und zeichnet sie nur, ohne sich mit festem Willen in den Strom des Geschehens zu stellen und der Natur Antworten auf selbstgeschaffene Fragen abzulauschen. Daher das Unzusammenhängende seiner Lebensarbeit, daher seine eigentümliche Passivität und das Traurig-Melancholische seines Wesens; daher kommt es, daß Probleme, die einen energischen, tatlustigen Mann interessieren, ethische, religiöse, politische, metaphysische Probleme, für ihn höchstens nur einen theoretischen Wert haben ${ }^{2}$ ). Es gibt wohl Leser, denen sein gelegentlicher Spott über die Mönche, über den Syllogismus, über die heilige Schrift imponiert; Witze zu machen pflegt aber eine billige Methode zu sein, den Mangel an festem Willen und an heißem Glauben zu beschönigen. Es sind nicht alle frei, die ihrer Ketten spotten! Der zynische, LEONARDo zugeschriebene Grundsatz: io servo chi mi paga, ich diene dem, der mich be-

1) Leonardo da V.s Verhältnis zur Anatomie und Physiologie d. Kreislaufsorgane v. H. Boruttau, Arch. f. Gesch. d. Med. 6. I912, S. 233. Auszunehmen sind seine konkreten physiologischen Beobachtungen, wie diejenige über den Gang des Menschen, über die Stimme der Fliege, über den Rückenmarksfrosch, über den Flug der Vögel. Ähnlich wie Boruttau urteilt auch Roth, Die Anat. des L. da V., Arch. f. Anat. (u. Phys.), Suppl. 1907.

2) Die Kritiker finden auch an seinen Bildern den Mangel an Instinkt, an Leidenschaftlichkeit. Leonardo ist der Maler der Intelligenz, Michelangelo der Herr der Instinkte und Leidenschaften (J. PÉLADAN in Conferenze fiorentine, S. 308). 
zahlt, mag unhistorisch und vielleicht auch zu grob für den delikaten Maler sein - allein, die von jeder konkreten Begebenheit losgelösten schriftlichen Bemerkungen LEONARDOs ausgenommen, zeugt nichts dafür, daß dieser Mann von genialem Intellekt auch die ethische Genialität, die sich in der Kraft äußert, das Böse als Böses zu bezeichnen und sich gegen dasselbe aufzulehnen, besonders hoch geschätzt hätte.

Lassen wir jedoch diese Beschuldigungen, bei denen sich viel durch den amoralischen Geist der italienischen Renaissance erklären läßt, beiseite; die wesentlichste Eigenschaft der biologischen Beobachtungen LEONARDOs ist, daß sie nirgends über das bloß Richtige hinausgehen. LEONARDO weiß die Dinge richtig zu sehen; nirgends fühlt man aber, daß er ahnend den Spuren einer tiefen Wahrheit folgte, daß er mehr wüßte, als er auszusprechen vermag. Er hat (als Biologe) keine Hypothesen konstruiert, kein System erbaut, seine Schriften zeigen auch keine Vorarbeiten zu einer geistigen Bewältigung der organischen Natur. Wie ganz anders war in dieser Hinsicht PARACELSUs beschaffen! Bei diesem ist fast in jedem Wort die ganze Welt in nuce eingeschlossen; die Schriften des LEONARDO sind dagegen kaum disjecta membra, denn es fehlt das sie zur Einheit verknüpfende organische Band.

Diese schwachen Seiten der Physiognomie des LEONARDo nußßen hervorgehoben werden, um die Genialität dieses einzigartigen Mannes ins wahre Licht zu stellen. Was ist leichter als einen LEONARDO zu bewundern? Unsere Aufgabe ist, ihn historisch und psychologisch $\mathrm{zu}$ verstehen, das Typische in demselben darzustellen; erst die Erkenntnis der Grenzen seiner Leistungskraft belehrt uns über die Qualität derselben ${ }^{1}$ ). Das Ideal der Frührenaissance war der Neuplatonismus, das Sichverlieren in der Natur, selbst eine »zweite Natur « zu werden, wie sich einmal LEONARDo — ähnlich wie PARACELsus - ausdrückt. Dieser an sich bedeutungsvolle Grundsatz ist verführerisch: asketische Ideale bedrohen seine Befolger. Denn sich mit der Natur eins zu fühlen, heißt sie nicht vergewaltigen $\mathrm{zu}$ wollen; leicht verfällt man in die falsche Konsequenz, die Gewalt mit der Herrschaft zu verwechseln und auf das Beherrschen der Natur durch den menschlichen Verstand zu verzichten. Daher

1) Leonardo wurde Universalgenius genannt: Ein Universalgenius ist wahrscheinlich eine psychologische Unmöglichkeit; jedenfalls war Leonardo keiner; es genügt daran zu erinnern, daß er kein Verständnis für die Politik, die Religion, die Geschichtschreibung, die Philologie, das Recht, die Psychologie usw. usw. nachgewiesen hat. 
hat es LEONARDo vorgezogen, zu schauen, anstatt zielbewußt zu handeln:

-mit Hilfe der Gedanken sind wir universell und weilen auf allen Orten gleichzeitig, der Wille siedelt und überträgt uns auf einen einzigen Ort $\left.{ }^{1}\right) . \ll$

Unter den Mystikern werden solche Reden geführt; nur pflegen diese neben dem Willen auch noch den Verstand des Menschen preiszugeben und sich nur auf den Instinkt zu verlassen. In der letzteren Hinsicht war LEONARDo dagegen kein Mystiker, sondern ein Scholastiker, ein Verstandesmensch. PARACELSUS nahm einen entgegengesetzten Standpunkt ein: ein starker Wille und das urwüchsig Instinktmäßige war bei ihm mit einer Geringschätzung des Verstandes gepaart. In der eigenartigen Verknüpfung des Mystizismus mit der Scholastik, des Realismus mit dem Rationalismus ist LEONARDO ein Vorläufer der besten Repräsentanten der modernen Wissenschaft; GALILEI und BACON scheinen von einer analogen Gemütsverfassung gewesen zu sein.

Ist es wahr, was LEONARDo in jenem für die abstrakten Denker aller Zeiten charakteristischen Satze ausspricht, daß die Gedanken universell, der Wille räumlich begrenzt ist? Kein tatkräftiger Mensch wird den Primat der Gedanken über den Willen zugeben: erstens gibt es keine echten Gedanken, die sich unabhängig vom Willen, dieselben zu realisieren, entwickeln würden, zweitens wirkt zwar der Wille in den Raum hinein, ist aber selbst ebensowenig räumlich wie der Gedanke, und drittens sind die Gedanken (in dem Sinne, an den LEONARDo an jener Stelle denkt) bloße Reproduktionen, Spiegelbilder der Wirklichkeit, während der Wille, als schaffende, neue Werte in die Welt setzende Macht, die Wirklichkeit selbst darstellt. Es ist nicht überflüssig, auf dieses Verhältnis von Gedanken und Taten hinzuweisen: die nachherige Biologie wird mit LEONARDO die »Gedanken «betonen und wird infolgedessen bald die praktische Fühlung mit dem Leben verlieren.

Durch die geniale Durchführung seines Grundsatzes »sapere vedere " (sich aufs Sehen zu verstehen) erwies sich LEONARdo als Erfahrungsmann, als Ultrarealist; so war sein Standpunkt dem der Scholastik entgegengesetzt; diese suchte auf analytischem Wege von den höchsten absoluten Wahrheiten allgemeine abstrakte Normen des Geschehens abzuleiten, LEONARDo verachtete die Wissenschaft

1) Conferenze, S. 46 . 
von den Prinzipien; er war so außer stande, sich zu konzentrieren und mit der Macht seines Geistes die Flucht der Erscheinungen zu überwinden, daß er nur Aphorismen schrieb, in denen er sich nur über Konkretes auszusprechen pflegte.

Sapere vedere war sein Grundsatz; machen wir uns klar, daß noch ein anderes "Sehen " möglich ist. Auch für die Entdeckung der Planetenbewegungen durch den Mystiker KEPLER war ein 》sapere vedere« nötig, jedoch ein Sehen, mit dem viel geistige Arbeit, viel Suchen und Probieren verbunden war, ein Sehen ferner mit geistigen Augen: LEONARDO dagegen war ein Sinnenmensch.

LEONARDO war also kein vollkommener Realist; er war auch kein durchgehender Antipode der Scholastik: den Syllogismus hat er verworfen, gleichzeitig aber mathematische Deduktionen für die einzig mögliche Methode der Wissenschaft erklärt. Was stellen mathematische Deduktionen anders dar als Syllogismen, durch welche nur klarer formuliert wird, was man bereits vordem gewußt hat? Sein Lob der Mathematik und der Mechanik $\mathbf{1}$ ) bedeutet im Grunde nur die Negation des auf die Erforschung der Metaphysik gerichteten Teiles der Scholastik; innerhalb der $\mathrm{Na}$ turwissenschaft läßt LEONARDO die scholastische Methode in voller Geltung.

LEONARDOs Abhängigkeit von der Scholastik erhellt aus seinen ziemlich ausführlichen Auseinandersetzungen über den "Sitz « und über das Wesen der Seele. Dieselbe soll in dem Orte siedeln, "wohin alle Sinne zusammenlaufen und der das Sensorium commune (,senso commune') heißt, und sie ist nicht über den ganzen Körper verbreitet, wie viele angenommen haben $\left.\|^{2}\right)$. An einer anderen Stelle erklärt LEONARDO den Geist für ein dem Körper beigemischtes Element ${ }^{3}$ ). Das war im Geiste der Scholastik gedacht. Historisch bedeutungsvoll ist, daß DESCARTES später analoge Grundsätze verteidigt hat: Doch auch BACONs Lehren klingen aus LEONARDOs Unterscheidung der "Erfahrung " und der Verstandesoperationen, mit deren Hilfe die Erfahrung bearbeitet wird. In diesen Forschern und in deren Anhängerschaft sind die Fortsetzer der Wissenschaft LEONARDos zu suchen.

1) Die Mechanik nennt er $>$ das Paradies der mathematischen Wissenschafter $<$ und will dẹrselben auch die Anatomie unterordnen.

2) Richter, II, S. I 27.

3) Duhem, II, S. 180 . 
Literatur über Leonardo: Richter, The Literary Works of Leonardo, London I883, 2 vols. Solmi, Studi sulla filos. naturale di L. da V., Modena I898. Ders., Nuovi studi etc., Mantova 1905. - Les manuscrits de Léonardo da V. de la bibl. roy. de Windsor, Paris I888 u. Turin-Rome I901. - Léonardo da V., Notes et dessins ... Feuillets inédits etc., Paris 190I. - Les manuscrits de Léonardo da V. par M. Ch. Ravaisson Mollien I.-IV., I88I-I891. - Il codice Atlantico., Milano. - Leonardo da V., Conferenze fiorentine, Milano I910. - Leonardo da V., Quaderni d'anatomia I. II., Christiania I9II, I9I2. - P. Duhem, Etudes sur Léonardo de Vinci I. 2., Paris 1909. - H. Boruttau, L. da V.s Verhältnis zur Anatomie u. Physiologie d. Kreislaufsorgane, Arch. f. Gesch. d. Medizin 6, I9I2. - M. Holl, Leonardo da V. u. Vesal, Arch. f. Anat. (u. Physiol.) 1905. Ders., Unters. üb. d. Inhalt d. Abhandlung Roths, Die Anatomie des Leonardo da V. Ebenda rgro. - M. Roth, Die Anatomie des L. da V. Ebenda. Supplbd. 1907 (dazu Holl, ebenda 19ro). - A. Foster, Einiges üb. d. Beziehungen Vesals zu L. da V. usw. Ebenda 1904. - E. Jackschaht, Die Begriindung der modernen Anatomie durch L. da V. usw. Mediz. Blätter I902, S. 25, u. Verhandlungen d. Ges. deutsch. Natf. u. Ärzte in Karlsbad, 74. Vers., 1902, II. M. Duval, Un biologiste du I5. siècle, Leonardo da V. Revue scientifique I885. J. RAAB, Leonardo da V. als Naturforscher, Berlin I880. - C. LANGER, Leonardo da V., Sitzber. d. Wiener Akad. I867, Bd. 55 .

\section{A. Severino.}

Aus der Schule der neuplatonischen Philosophen TELEsio und CAmpanella hervorgegangen, hat MARCo Aurelio Severino (1580-1656), Professor der Anatomie und Chirurgie in Neapel, ein Nachzügler der Renaissance, die Notwendigkeit einer Anatomie der Tiere zu begründen versucht. Er teilt mit seinen Meistern die Abneigung gegen ARISTOTELES, er betont mit denselben die Notwendigkeit direkter Naturbeobachtung und die Eitelkeit des Autoritätsglaubens; sonst aber ist es bei ihm fast nur bei dem guten Willen geblieben. Der Galenismus kommt in seinen Schriften viel deutlicher zur Geltung als die Ideen Platos. Es fehlt ihm die Einsicht in die elementare Voraussetzung jeder vergleichenden Biologie, daß das Leben (der Pflanzen, der Tiere, des Menschen) eine Naturerscheinung ist, die für sich selbst studiert und verstanden werden muß; er seziert vielmehr, nach GaLENs Vorbild, die Tiere nur deshalb, um die Heilkunde zu fördern. An Plato erinnert jedoch seine Lehre, daß die Tiere nach dem Abbild des Menschen geschaffen sind:

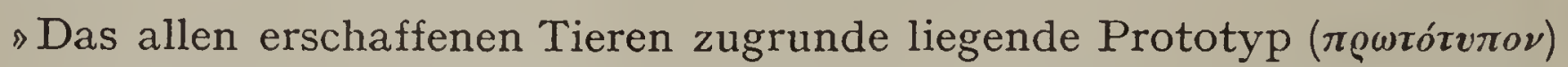
ist so deutlich, daß der Anatom dasselbe auch gegen den eigenen Willen bemerkt. «

Praktisch sucht er aber das Prototyp der Tiere weniger in der Struktur, als in der Psyche: der Fuchs ist das Prototyp der Tücke, der Esel das der Dummheit usf., und da jede Psyche einen adäquaten 
Körper beherrscht, sind auch die Tierkörper dem Menschenkörper ähnlich.

Die konkrete Ausführung der anatomischen Lehren ist SEvErino mißlungen. Seine Schrift scheint ohne Widerhall ausgeklungen zu haben ${ }^{1}$ ).

1) Zootomia Democritaea (I645). - Über Severino vgl.: O. Schmidt, Die Entwicklung der vergl. Anatomie, Jena 1855. Carus, Gesch. d. Zool., r866. - BurckHARDT, Gesch. d. Zoologie, 1907. 


\section{Kapitel.}

\section{Neue Aristoteliker.}

Die Laienwissenschaft, das Ideal der Renaissance, erhielt sich auf die Dauer nicht. Es liegt im Wesen derselben, keine Schule begründen zu wollen, um sich anderen nicht aufzudrängen. Der Individualist sucht nur verständnisvolle Gesinnungsgenossen, unter denen er sich als Gleicher unter Gleichen fühlt; deshalb steht er immer abseits von dem Lärm der Meinungen, den man in den Schulen Geschichte der Wissenschaft nennt: dieses Schicksal hat im vorigen Jahrhundert die Wissenschaft GoErhes und die Philosophie SCHOPENHAUERS getroffen, es war auch den Repräsentanten der Renaissancebiologie beschieden. Man bewundert LEONARDO, geht aber an ihm kalt vorüber; wohl haben sich die größten Dichter für PARACELSUS erklärt, in der Wissenschaft weiß man aber kaum, was mit ihm anzufangen ${ }^{1}$ ). Man datiert das Wiederaufleben der Wissenschaft nicht von ihnen, sondern erst mit der darauffolgenden Epoche beginnend, von Harvey, Galilei, Descartes usf., einer Epoche, wo sich bereits andere wissenschaftliche Ideale geltend gemacht haben.

Der dem ARIsTOTELEs und dem Hochschulwesen feindliche Neuplatonismus erhielt sich noch durch das ganze I6. Jahrhundert hindurch. GIORdANO BRUNO (I548-I600) war ein typischer Repräsentant dieser Denkungsart in der Philosophie, der phantastische J. Kepler (I57I-I630) in der Astronomie, Bernh. Telesio (I 508-I 588) und Thomas Campanella (I 568-I639) in der Naturphilosophie; auch an Galilei (I 564-I642) ist die platonisierende Stimmung nicht spurlos vorübergegangen. Neben PLATo erscheinen

1) Die Schrift J. K. Prokschs, Paracelsus als medizinischer Schriftsteller, Wien u. Leipzig I9r r, gibt davon ein beredtes Zeugnis. Oder man vergleiche H. MAGNus' Schriftchen: Paracelsus als Überarzt, Breslau 1906, das für die Stellungnahme gewisser Forscher Paracelsus gegenibber charakteristisch ist. 
nun aber zwei neue Richtungen: ARISTOTELES kommt wieder zu Ehren, und eine mechanistische Weltanschauung beginnt Wurzel zu fassen. Die Entwicklung der letzteren wollen wir später verfolgen; wer hat aber den verschmähten Gesetzgeber der Scholastik rehabilitiert? Mehrere Ursachen sind für die Erklärung dieser Wendung anzuführen. Es erhob sich erstens eine Reaktion gegen die führenden Geister der Renaissance, eine Reaktion, die jede bedeutsame historische Bewegung im Gefolge hat; der Humanismus wußte ferner mit dem kritisch gesichteten ARISTOTELES den scholastischen Aristotelismus $\mathrm{zu}$ bekämpfen und fand auf den Hochschulen eher Anklang als die radikalen Bekämpfer des Aristotelismus schlechthin. Die neuen kirchlich-politischen Zustände unterstützten ebenfälls den neuen Aufschwung der aristotelischen Philosophie. I5I7 begann LUTHERs Reformation. Die Renaissanceaufklärer, die sich über die Religionsfragen mit einem Witz hinwegzusetzen pflegten, sind jetzt unmöglich geworden, denn die durch die protestantische Gefahr bedrohte und durch den Kongreß von Trient (seit I 545) gestärkte Kirche begann jetzt ernst und streng zu walten. Von großer historischer Bedeutung war ferner die Bestätigung des Jesuitenordens (I 540), der, aus einer Hochschülervereinigung entstanden, sich zur Aufgabe gemacht hat, die Leitung der Schulwissenschaft fortan in eigene Hände zu nehmen, und der den orthodox gebliebenen Aristotelismus gefördert hat. Die Zeit hat sich geändert: KopERnIKus konnte noch ruhig seine Schrift dem Papste widmen, PARACELsus konnte ungehindert seine Angriffe gegen die Theologen predigen, LEONARDO wurde von niemandem nach der Innigkeit seines Gottesglaubens gefragt. Bereits VESAL aber ließ es sich angelegen sein, den Verdacht einer Sympathie mit den Reformierten von sich abzuschütteln $;^{1}$ ) B. Telesios grundlegende Schrift »De natura rerum «(I565), auf die sich GaLILEI und andere Begründer der neuen Wissenschaft gern beriefen, kam auf den Index; der unglückliche GI. BRUno kam mit seiner Renaissancephilosophie zu spät und wurde verbrannt (I600). GalILEI, eine weltbekannte Autorität, mußte viel gegen einflußreiche Aristoteliker kämpfen und wurde schließlich genötigt, seine neue Lehre abzuschwören (I633). Diese beiden Affären haben in Europa viel Aufsehen erregt und haben gewiß manchen Leuten die Lust am freien Spekulieren genommen; an DESCARTES' und an LEIBNIZENs vorsichtigem Herumgehen um heikle theologische Probleme 
sind die Folgen der Verurteilung Brunos und GalileIs fühlbar. Desto schlimmer war es, daß sich die Protestanten um kein Haar liberaler als die Katholiken erwiesen haben.

Diese neue, der realistischen Laienwissenschaft feindliche Stimmung förderte den amtlich anerkannten Aristotelismus, der während der Renaissance zwar die führende Rolle verloren, aber auf den Hochschulen auch weiterhin gewaltet hatte; wie wäre es sonst möglich, daß jetzt plötzlich so zahlreiche dem Aristotelismus geneigte Gegner gegen GalileI aufgestanden wären? Mag nun diese Wiederbelebung der aristotelischen Philosophie den physikalischen Wissenschaften hinderlich gewesen sein, der Biologie ist diese Reaktion zugute gekommen. Denn die Begründung der neuen Physik geschah auf Kosten der Biologie; gegen GaLILEI waren die biologisch gestimmten Gelehrten eingenommen; wir finden unter denselben auch den berühmten Botaniker CaEsalpinus.

Demzufolge hat gegen das Ende des I6. und in der ersten Hälfte des I7. Jahrhunderts eine rege biologische Forschung eingesetzt: erstens eine vergleichend physiologische Untersuchung des Tierund Pflanzenkörpers, zweitens eine enzyklopädische Darstellung des Tier- und Pflanzenreichs. Etwas später greift eine an GalILEI anknüpfende mechanische Richtung der Biologie ein, und der Aristotelismus wird allmählich vergessen, um erst im I8. Jahrhundert unter veränderten Bedingungen zu einem neuen Leben erweckt $\mathrm{zu}$ werden.

\section{A. Caesalpin.}

Andreas Caesalpinus (I519-I603), Professor in Pisa und später Leibarzt des Papstes Clemens VIII., hat über die Medizin und über Mineralien geschrieben (I 596) und ein philosophisches System nach den Grundsätzen des ARISTOTELES entwickelt (I603). Sein wichtigstes Werk handelt über die Pflanzen; namentlich die Einleitung zu demselben gibt eine Übersicht seiner Vorstellungen von dem Wesen der Pflanzenwelt.

CAESAlPIN folgt treu den Fußstapfen seines klassischen Meisters und wendet dessen Grundsätze mit bedeutendem Erfolg auf die Analyse der Pflanzenwelt an. Wie ARIstoteles, sucht auch CAesALPIN alle Thesen folgerichtig aus allgemeinen Prinzipien abzuleiten, interessiert sich vor allem für die Probleme der Entwicklung, der Organisation, des Systems, der Psyche; mit ARISTOTELES teilt er auch die Auffassung, daß das Leben bei allen Organismen, bei 
Pflanzen, Tieren und Menschen dieselben Gesetze befolgt, sowie die daraus sich ergebende Folgerung, daß man die Formen und Funktionen auch der heterogensten Organismen miteinander vergleichen $\operatorname{kann} \mathbf{1}^{\mathbf{1}}$.

Beim Keimen der Pflanze entsteht nach CAEsalpin zuerst die Wurzel, die entweder aus dem Samen wächst oder direkt aus faulenden Substanzen entsteht. Wohl können sich manche Pflanzen auch durch Sprosse, Pfropfen u. ä. fortpflanzen, doch ist das eine unvollkommenere Fortpflanzungsart, denn der Zweck der Pflanze, der Same, wird dadurch umgangen. Der Same entsteht wie das Ei der Tiere, welches das Produkt der Ernährung durch die feinsten Nährstoffe ist und durch die vom Herzen geschaffene Lebenswärme befruchtet wird; ähnlich entwickelt sich bei den Pflanzen der Same aus der dem Herzen analogen Substanz, aus dem Mark im Holz. Nur braucht der Pflanzensame keine Befruchtung, da bei den einfach organisierten Pflanzen die befruchtende Lebenswärme und der Stoff, der durch dieselbe befruchtet wird, noch nicht voneinander differenziert sind.

Die Entwicklung fängt an, indem durch die Feuchtigkeit der Erde die im Samen gebundene Wärme befreit wird, etwa wie der Kalk durch Wasser heiß wird; daraufhin mischt sich die zuströmende Feuchtigkeit mit dem milchigen Inhalt des Samens und vermehrt die Nahrung, das Material für die wachsende Wurzel und für den Stengel mit seinen zwei Blättern.

Die Seele, d. h. das den Organismus realisierende Prinzip, welche bei den Tieren im Herzen siedelt, ist bei den Pflanzen im Mark enthalten; namentlich ist sie konzentriert an der Grenze zwischen Wurzel und Stamm, wo am Anfange der Entwicklung die ersten zwei Blätter hervorsprossen. An jener Stelle befindet sich die Seele im wirksamen Zustande (actu); es soll aber keineswegs geleugnet werden, daß sie auch in anderen Teilen der Pflanze sich befindet: das

1) Caesalpins Standpunkt zu den politisch-wissenschaftlichen Zeitfragen ist durch die Widmung seiner Schrift De Metallicis an den Papst Clemens VIII. charakterisiert, in der er ausdruicklich der Kirche das Recht zuschreibt, in wissenschaftliche Diskussionen mit ihrem Machtspruch einzugreifen. Dies geschah 1596; zehn Jahre darauf wurde Kopernikus' Lehre von der Inquisition für verboten erklärt. Historisch interessant ist auch, daß Caesalpin in der schärfsten Weise B. Telesio, den Neuplatoniker und den Schwärmer für die neue, von der Tradition unabhängige Wissenschaft, als kirchenfeindlich verurteilt. (L. C. MialL, The early naturalists, London 1912, S. 37.) An Telesio knüpft GalrleI und die auf diesen sich stïtzende Wissenschaft an. 
Wachstum des Weidenzweiges zur ganzen Pflanze beweist, daß auch in ihm die Seele der Anlage nach (potentia) enthalten sein muß; überhaupt ist sie der Möglichkeit, der Anlage nach in allen solchen Teilen enthalten, welche der Regeneration fähig sind.

Die Samen (= Früchte) haben verschiedene Hüllen, wie: die Blüte, die Hülse, die Schote usf. Die Bedeutung der Blüte ist zweierlei: einmal kommt sie »ex necessitate « der Pflanze $z u$, d. h. sie ist aus der Ausscheidung eines notwendig die Befruchtung (die Empfängnis) begleitenden Spiritus entstanden; etwas Analoges ist auch bei den Tieren vorhanden, wo der Same (nicht der materielle Same, sondern die Kraft in demselben) nicht ohne eine Ausscheidung und ohne Erregung herauskommt; etwas dieser Ausscheidung und der damit verbundenen geistigen Erregung Ähnliches ist auch bei den Pflanzen vorhanden, und daher kommt es, daß die Blüten so fein und duftig sind und daß sie Honig enthalten - denn sie sind aus einem Spiritus entstanden. Zweitens sind die Blüten »alicuius gratia ", und zwar zum Schutze des Samens ${ }^{1}$ ).

Den größten Teil der Schrift hat CAESALPIN dem Pflanzensystem gewidmet, und zwar einem natürlichen System, wie es sich bei einem Aristoteliker von selbst versteht. Den Ausgangspunkt des Systems findet er in dem Grundsatze:

"Jede Wissenschaft besteht in der Zusammenfassung des Ähnlichen und in der Unterscheidung des Unähnlichen « 2 ).

Das System der Pflanzen soll nicht nach ihren zufälligen Eigenschaften (quae accidunt ipsis), wie z. B. nach ihren medizinischen und anderen nützlichen Kräften eingeteilt werden, sondern nach Merkmalen, welche dem Wesen (substantia) der Pflanzen angehören. Als solche sind die greifbaren Eigenschaften aufzufassen, durch welche sich die Seele der Pflanze offenbart. Da nun das Wesen der Pflanzenseele in der Ernährung, im Wachstum und in der Fortpflanzung besteht, so dienen die Organe (die materiellen Äußerungen dieser Tätigkeiten) zur Unterscheidung der Pflanzensippen: nach den Ernährungsorganen werden die Pflanzen in Holzpflanzen und Kräuter geschieden; die Unterabteilungen der Pflanzen klassifiziert CAEsALPIN nach den Fruktifikationsteilen; es werden daher die Pflanzen

1) Der Gegensatz zwischen sex necessitate und salicuius gratia ist etwa derart, wie der zwischen den sog. homologen und den analogen Organen in der heutigen Terminologie.

2) De Plantis, Vorwort. 
in Bäume, Sträucher und Kräuter eingeteilt, und jede dieser Klassen nach der Beschaffenheit der Frucht in kleinere Gruppen geschieden.

Unter den Namen »species " und "genus « versteht CAESALPIN mit ARISTOTELEs nur den logischen Begriff, noch nicht eine natürlich gegebene Einheit. Er spricht z. B. von vier Gattungen (genera) der Pflanzen: Bäume, Sträucher, Halbsträucher, Kräuter; aber die verschiedenen Arten von Nießwurz bilden auch ein "genus «. Die Behauptung, daß die Klassifikation das Wesen der Pflanzen, nicht die Akzidentien betreffen muß, erläutert er durch folgendes Beispiel: wenn der Verstand (intellectus) des Menschen zu seiner Tätigkeit Organe benutzen würde (so wie z. B. zur Bewegung Beine, Hände usf. dienen), so würde man die Menschen je nach diesen Organen in viele Spezies einteilen; da aber der Intellekt, welcher das Wesen des Menschen ausmacht (per quem homo est), sich keiner Organe bedient, »daher hat die Natur nur eine menschliche Spezies gegründet«, und wenn es Riesen und ähnliche Leute gibt, so sind es nur Akzidenzien, keine Arten $^{1}$ ).

Während den Pflanzen nur die Kraft der Ernährung (eine anima altrix) eignet, haben die Tiere auch die der Empfindung und Bewegung. Die Ernährung als Verähnlichung (gignere quale ipsum) zielt einmal auf die Erhaltung des Individuums (Nahrungsaufnahme), zweitens auf die Erhaltung der Art (Samenbildung). Daher besitzen die Pflanzen zwei wesentliche Organe: die Wurzel, welche die Nahrung aufsaugt, und den Stengel, welcher die Frucht hervorbringt.

Der Ernährungsvorgang geschieht bei den Pflanzen analog, wie ihn ARISTOTEles bei den Tieren schildert: Der Darmkanal ist durch den nährenden Humus vertreten, aus dem durch die Gefäße die flüssige Nahrung aufgesogen und zum Zentrum der Pflanze (zum Analogon des Herzens), d. h. zum Wurzelhals geführt wird, wo sie von einer schwachen Lebenswärme durchtränkt wird und dadurch an Beschleunigung gewinnt, durch die sie als Nahrungssaft in alle Pflanzenteile strömt.

CaEsalpin ist der erste Botaniker der Neuzeit, der das Pflanzenstudium auf wissenschaftlichen Grundlagen erbaut hat. Wir drücken heute unser Wissen von den Pflanzen in anderen Worten, als es CAESALPIN getan hat, aus; wer es aber versteht, sich von den Worten zu dem Sinne der Rede zu erheben, der wird eine tiefe Er-

1) De Plantis I. Kap. XIII. 
kenntnis der Wahrheit CAESALPIN nicht absprechen. Und dieser Mann erweist sich als ein hartnäckiger Aristoteliker, sogar als ein Anhänger der Feinde GalileIs! Wer diese Tatsache zu schätzen lernt, der wird die Bedeutung der sog. Renaissance für die Biologie der späteren Epochen mit einem anderen Maßtsab messen, als es derjenige ist, an den uns die bisherigen Historiker gewöhnt haben, die nur die Entwicklung der Physik beachten. CAESALPIN verlor den Streit, GalileIs Wissenschaft hat triumphiert; zugleich aber ist die Biologie verfallen, CAESALPIN wurde fast vergessen. Erst als sich die Biologie zu neuem Leben aufzuraffen anschickte, hat LINNÉ auf CAESALPIN zurückgegriffen, LINNÉ, der die neue botanische Wissenschaft begründet hat ${ }^{1}$ ).

Unter die Schüler CAESALPINs gehört JoAchim Jungius (I 587 bis I607), Mathematiker, Philosoph und Naturforscher, zuletzt Schuldirektor in Hamburg. In seiner "Isagoge phytoscopica " trägt er in Form von streng logisch formulierten Lehrsätzen ein System der theoretischen Botanik vor, formuliert die wichtigsten morphologischen Verhältnisse der äußeren Gliederung des Pflanzenkörpers, gibt den verschiedenen Formen des Stammes, dessen Verzweigungsarten, den Blattypen Namen, die noch zum großen Teile gelten, strebt überhaupt die Gestaltverhältnisse der Pflanzen als solche zu studieren. RAY hat sich in seiner Pflanzengeschichte auf JUNGIUS gestützt und als Vermittler zwischen diesem und LinNé gedient²).

\section{William Harvey.}

\section{a) Der Blutkreislauf.}

Die Biologen des klassischen Altertums betrachteten das Herz als den weitaus wichtigsten Körperteil, als die Quelle der Lebenskraft, als den Erzeuger der Lebenswärme und als den Sitz des Geistes - das Herz bedeutete für den Körper dasselbe, was die Sonne für die Erde. Die Astrologen pflegten mit dem Namen der Sonne zugleich

1) Literatur. Caesalpinus: Quaestionum peripateticarum libri 5 (I57I; gegen die Galenisten). De Plantis libri 16 (1583). De Metallicis (1596). - Über Caesalpin vergl. die Schriften ïber die Geschichte des Blutumlaufes und ferner J. SACHS, Gesch. d. Botanik, München 1875 .

2) Nach J. SACHS, Geschichte d. Botanik, München I875, S. 63 sq. - Jungius' Schriften wurden erst nach dessen Tode von seinen Schülern herausgegeben; die wichtigsten sind Doxoscopiae Physicae minores und Isagoge phytoscopica. - Vgl. auch WoHlwll, Joach. Jungius u. die Erneuerung atomistischer Lehren im I7. Jh., Hamburg I $887 .-$ S. Guhrauer, J. Jungius und sein Zeitalter, Stuttgart I 85 I. 
auch das Herz zu bezeichnen; noch HARVEY nennt in seiner epochalen Schrift das Herz "die Sonne des Mikrokosmos ". Auch in dem Blut erblickte man eine kostbare im Eingeweide aus der Nahrung gebildete Flüssigkeit, aus der sich alle Organe aufbauen. Weil aber die Körpermaschine, die greifbare und in unzählige Organe differenzierte Materie, an der sich das Leben äußert, für das Altertum (und das Mittelalter) weniger Bedeutung gehabt hat als heute (unter Leben verstand man Lebensweise und Vitalität, nicht Bewegung einer komplizierten Maschine), erschien den Gelehrten die anatomische und physiologische Organisation des Lebewesens einfacher als uns. Von den feinen Strukturen in den Muskeln, in den Nerven, von den Kapillaren, von den Funktionen der Drüsen wußte man fast gar nichts und achtete auch kaum darauf; kannte man ja nicht einmal die Bedeutung der Muskeln und wurde sich nicht über den Unterschied zwischen den Sehnen und den Nerven klar. Wie noch heute ein Laie, ja auch mancher Biologe praktisch überzeugt ist, daß ein Regenwurm oder irgend eine Insektenlarve sozusagen nur einen Klumpen lebendiger Substanz ohne beachtenswerte innere Differenziation darstellt, so faßte man damals auch den Menschen auf. Die Gelehrten dachten so, als ob sie nicht gewahr würden, daß der Mensch Lungen besitzt, daß sein Herz kompliziert gebaut ist, daß die Blutgefäße in bestimmter Weise aus dem Herzen heraustreten; d. h. ihre Augen sahen diese Tatsachen, ihre Theorien wußten aber nicht, was mit denselben anzufangen: Gott selbst weiß, warum der Körper so kompliziert ist, war das heimliche und nicht selten auch offen ausgesprochene Ende ihres Philosophierens ${ }^{1}$ ). Indem man einzelne Lebensfunktionen (Verdauung, Wärmeerzeugung, Atmung usf.) nicht tief genug zu unterscheiden und dieselben auf eine Funktion zurückzuführen strebte, pflegte man nur vom "Leben " zu handeln, als ob dieses Wort schon an sich genügen könnte, die Fülle der organischen Erscheinungen plastisch zu beschreiben.

Weil man den Unterschied der Lebensfunktionen mißachtete, hegte man auch unklare Vorstellungen über die Bedeutung des Herzschlages und der Blutbewegung. Daß das Blut in den Gefäßen

1) Dieser Standpunkt von der unübersehbaren Kompliziertheit der Erscheinungen kommt immer wieder bei der Geburt einer neuen Idee zum Vorschein. Daß man wirklich so geurteilt hat, folgt aus der Polemik des Parisanus gegen Harvey; jener Galeniker behauptet nämlich, daß die wahre Bedeutung des Herzens zu begreifen äußerst schwer sei; FraCASTORIUs habe nicht ohne Grund gesagt, daß der Bau und die Bewegungen des Herzens nur Gott bekannt sind (Harvey, S. 66). 
strömt, daß diese Strömung mit dem Herzschlag zusammenhängt, daß vom Blut der Körper ernährt wird, wußte man wohl; sonst aber hat man sich diese Erscheinungen im allgemeinen als $\mathrm{zu}$ einfach, als $\mathrm{zu}$ leicht begreiflich und im besonderen als zu kompliziert und jeder allgemeineren Deutung unzugänglich vorgestellt. Nach den Vorstellungen der Alten saugt das Herz das Blut auf und verteilt es auf einzelne Körperteile, die sich mit dem Blut nähren, und erzeugt Lebensgeister (pneuma, spiritus), die in den Gliedern Bewegung und im Kopfe Gedanken ermöglichen. Ist diese Theorie durchaus falsch zu nennen? Es wird durch dieselbe in ungeschickter Form dieselbe Wahrheit ausgedrückt, an die auch wir glauben; die alten Biologen schematisierten sie leider und kamen so zum Schluß, daß die ernährende und die lebenspendende Tätigkeit des Herzens mechanisch voneinander getrennt sind, so daß die linke Herzkammer in den Körper Lebensgeister aussendet, die rechte das Blut. Aus diesem Gedanken ${ }^{1}$ ) entstand die von Hippokrates und ARISTOTELES verteidigte Lehre, daß nur in den Venen das Blut (aus dem Herzen zu den Körperteilen) strömt, während die Arterien nur die Lebensgeister (ebenfalls aus dem Herzen) führen sollten.

Unter den »Lebensgeistern « ist da ein ganz eigenartiges, in unserer Terminologie kaum auszudrückendes Wesen zu verstehen; sie stellen eine greifbare Lebenskraft dar, etwas, das in der Mitte zwischen Kraft und Stoff steht und dem Atem, d. h. der eingeatmeten Luft, den ausgeatmeten Gasen und der Atmung selbst verwandt ist, eine Art feiner, energiehaltiger, geistvoller Nahrung. Durch jene Theorie drückte man also die Tatsache aus, die man heute als Oxydation des Blutes und der Gewebe nennt. Tatsächlich verteidigte zu Harveys Lebzeiten der Aristoteliker A. CaEsalpinus gegen die Galeniker jene Deutung der Arterien als Bahnen für die Lebensgeister durch die richtige Bemerkung, daß das Blut vom Herzen in die Lunge strömt, dort eine helle Farbe bekommt und zum Herzen zurückkehrt. Er hat auch die Tatsache der Oxydation gestreift, konnte sie aber nicht begreifen, weil man noch nicht Mischungen von chemischen Verbindungen begrifflich zu trennen gewußt hat.

GALEN und seine Anhänger haben eine andere Theorie vom Wesen des Herzens verteidigt, welche von ihren Anschauungen über die Ontogenese beeinflußt war. Nach ARISTOTELES entsteht nämlich im Embryo zuerst das Herz als der wichtigste Körperteil;

1) und aus der Tatsache, daB die Arterien am Leichnam blutlos sind. 
nach GALEN soll sich zuerst die Leber bilden, aus der dann die Venen hervorsprossen; darauf legt sich die Aorta an, aus welcher das Herz entsteht; zuletzt werden das Gehirn und die übrigen Organe angelegt ${ }^{1}$ ). Infolgedessen spielt die Leber nach GALEN auch im entwickelten Organismus eine große Rolle: das Blut entsteht im Verdauungsrohr aus der Nahrung, gelangt durch die Pfortader zur Leber, wo es zum zweitenmal verdaut wird, strömt durch die Venen, die sämtlich von der Leber entspringen, in die rechte Herzkammer. Im Herzen wird das Blut von neuem gereinigt; die Ausdünstungen werden von da in die Lunge geleitet und dort ausgeatmet; das gereinigte Blut dringt durch feine in der Ventrikelscheidewand vorhandene Poren in das linke Herz und von da in den Körper. Die Bedeutung der Vorhöfe des Herzens blieb unklar; man stritt auch darüber; ob das ganze Herz als eine Einheit sich zusammenzieht, oder ob vielmehr der Rhythmus der rechten und der linken Herzkammer verschieden ist 2 ).

Das Herz soll Lebenswärme erzeugen, durch welche das Blut ins Sieden gerät und durch die heißen Dämpfe erweitert wird; die aus der Lunge ankommende Luft soll wieder die übergroße Hitze des Herzens mäßigen ${ }^{3}$ ). Eine natürliche Folge dieser Auffassung ist, die Atmung und den Herzschlag für zwei Äußerungen einer und derselben Tätigkeit, der Wärmeregulierung, zu halten; daß der Rhythmus der Atmung und des Herzschlages verschieden ist, haben die Galeniker für nebensächlich gehalten. Über die Blutbewegung im Körper hegten sie unklare Vorstellungen; sie hielten jedoch den Herzschlag für wesentlich den Atembewegungen ähnlich, so daß das Herz während der Erweiterung (der Diastole) das Blut einsaugen sollte, worauf das Herz wieder zusammensinkt und das Blut wegfließt, daß sich also das Herz während der Diastole aktiv, während der Systole passiv verhält (während das Umgekehrte richtig ist) ${ }^{4}$ ). Auch rief den Alten die Pulsbewegung das Bild der Meeresbrandung

1) Noch zu Lebzeiten Harveys fanden beide Auffassungen der Entwicklung Vertreter: CAESALPINUS vertrat die aristotelische, REALDo Colombo (der bekannte Anatom) die galenische Lehre.

2) CAsp. Bauhin u. J. Riolan haben (nach Harvey) am Herzen vier dem Ort und der Zeit nach verschiedene Bewegungen unterschieden. Vgl. Harvey, S. 60.

3) Deshalb sollen nur die Warmblüter eine Lunge besitzen; die Fische besitzen keine, da ihre Hitze durch das Wasser gemäßigt wird.

4) Doch weisen einige moderne Forscher nach, daß das Herz auch während der Diastole aktiv ist; überhaupt scheint das Problem komplizierter zu sein, als Harvey geglaubt hat.

Rádl, Geschichte der biol. Theorien. I. 2. Aufl. 
ins Gedächtnis; das Blut soll rhythmisch an die Enden der Blutgefäße pochen, welche direkt mit dem Fleisch kommunizieren. Der für uns auffallendste Grundzug der alten Theorie bestand in der Meinung, daß die Blutbewegung einen Anfang und ein Ende hat, daß sie im Verdauungsrohr beginnt und im Fleisch endigt. Nach unseren Anschauungen zirkuliert das Blut im Organismus, so daß jeder Teil desselben nach einer gewissen Periode in das Herz zurückkehrt; nach ARISTOTELES und GALEN ging die im Verdauungsrohr erzeugte Blutmasse nur einmal durch das Herz hindurch und koagulierte am Ende der Blutgefäße zum Fleisch, so daß fortwährend neues Blut gebildet werden müßte.

So etwa hat man die Herz- und die Blutbewegung beurteilt; es ist aus dieser gedrängten Darstellung zu sehen, daß die diesbezüglichen Anschauungen unklar und widersprechend waren. Man faßte den ganzen Erscheinungskomplex nicht als einheitliches Problem auf, sondern hob verschiedene Einzelheiten hervor, betonte, vor allem die Frage, ob das Herz oder die Leber wichtiger sind und wo die Venen beginnen. Einzelne Autoren haben die neue Wahrheit gestreift, so A. CAESALPINUs, der bereits den kleinen Blutkreislauf (vom Herzen zur Lunge und zurück) angedeutet hat; von Mich. Servetus und REAldo Colombo wurde derselbe Blutkreislauf schon früher beschrieben ${ }^{1}$ ); keiner dieser Gelehrten wußte aber was mit der Tatsache anzufangen, keiner hat den Hauptgedanken betont, daß das Blut im Körper zirkuliert; sie stellten vielmehr ihre Deutungen nur als Verbesserungen oder Vertiefungen der Lehren GaLENs und ARISTOTELES' hin.

W. Harvey (I 578-I657), der Schüler des berühmten Anatomen und Embryologen Fabricius ab Aquapendente, der die Venenklappen entdeckt hat (diese Klappen unterstützen den nach dem Herzen gerichteten Blutstrom in den Venen), war seit I6I 5 Professor der Anatomie und der Physiologie in London und später Leibarzt

1) Caesalpin, Quaestiones peripateticae 1571. - Mich. Servetus, Christianismi restitutio 1553. - Servetus war ein exzentrischer spanischer Arzt; die angeführte Schrift ist äußerst selten, weil sie heimlich gedruckt wurde und alle Exemplare, die in die Hand der Ämter gelangt sind, vernichtet wurden; sie ist wesentlich religiösen Inhalts, und der Blutkreislauf soll in derselben nur ganz vorübergehend erwähnt sein. Servetus wurde wegen Gotteslästerung (die aber in keinem inneren Zusammenhange mit seiner Arzneikunst stand) von CaLviN verbrannt. Über Einzelheiten vgl. A. DIE, Mich. Servet et Calvin, Paris I910. - Realdus Columbus, De re anatomica libri XV. Venetiae I559 (Columbus war Vesals Nachfolger in Padua). - Über andere Entdecker des Blutkreislaufs vgl. Luciani, Physiologie des Menschen I, Jena Igo4. 
der Könige JaKob I. und KARL I. Den Blutkreislauf hat er früh entdeckt, hat aber seine Beboachtungen erst I6I 8 veröffentlicht. Es war nicht leicht, die eingebürgerten Anschauungen zu überwinden; es handelte sich nämlich nicht nur um die Tatsache, daß das Blut im Körper eine in sich geschlossene Bahn beschreibt - war doch der kleine Blutkreislauf, der auch eine fast geschlossene Bahn bildet, bereits bekannt, und niemand fand daran auffallenden Anstoß. Zur Überwindung der herrschenden Anschauungen war es nötig, das Verhältnis zwischen der Atmung und dem Herzschlag auf eine neue Art darzustellen, die Ernährung des Körpers durch das Blut von einem ganz neuen Standpunkte zu erklären, den Bau und die Bewegungen des Herzens und seiner Teile, das ganze vegetative Leben überhaupt auf eine neue Art aufzufassen. HARvey wies auf die Tatsache hin, daß der Rhythmus der Atmung von dem des Herzschlages verschieden ist; daß die Lebensgeister dem Blut keineswegs mechanisch beigemischt sind, sondern - chemisch, würden wir sagen; HARVEY, dem dieser Begriff noch unbekannt war, bediente sich der (nicht ganz passenden) Analogie: die Lebensgeister stecken im Blut wie die Butter in der Milch oder wie die Wärme in einem warmen Körper. Er suchte den Beweis zu führen, daß das Herz bei der Systole und nicht bei der Diastole aktiv ist, daß sich zuerst beide Vorhöfe und dann beide Kammern zusammenziehen, und suchte die heute bekannte Richtung des Blutkreislaufes als die einzig richtige $\mathrm{zu}$ verteidigen, indem er einerseits auf die Undurchlässigkeit der Herzscheidewand und andererseits auf die große Blutmenge hingewiesen hat, die fortwährend durch das Herz strömt und die die Annahme unglaubwürdig macht, daß alles Blut am Ende der Blutgefäße zum Fleisch gerinnen sollte. Deshalb hat HARveY den Schluß gezogen, daß das Blut durch die Arterien aus dem Herzen strömt, den Körper durchtränkt (die Kapillaren kannte er nicht) und durch die Venen zum Herzen zurückkehrt. Warum das Blut überdies noch in der Lunge zirkuliert, war ihm nicht klar; er behauptete jedoch, daß das arterielle Blut "wärmer ", "vollkommener ", "voll von Dämpfen « ist und daß ihm diese Vorzüge im Herzen verliehen werden ${ }^{1}$ ). Während seine Vorgänger beim Herzschlag an die Meeresbrandung gedacht hatten, vergleicht er die Blutzirkulation mit dem Kreislauf des Wassers in der Atmosphäre: wie das Wasser durch die Erdkruste zu den Quellen durch-

1) HARvey, W. Exercitatio anatomica de motu cordis et sanguinis in animalibus. Frankf. a. M. 1628 . S. 138 . 
sickert, so soll auch das Blut durch die schwammigen Gewebe des Körpers filtriert werden.

Die Vitalisten des Altertums kannten noch nicht das Problem der Kraft, die den Organismus bewegt; ihnen galt die Lokomotion, die Muskelkontraktion und die Bewegungen der Säfte innerhalb des Organismus als selbstverständlich und als von keiner sekundären Ursache abhängig; höchstens dachten sie an die Lebensgeister als an die wahren Motoren. Das Blut war nach ihnen nicht durch eine maschinelle Einrichtung in der Bewegung erhalten, sondern es strömte von selbst, ebenso wie sich der Organismus "von selbst " bewegt. HARVEY, obwohl er sonst ARISTOTELES folgt und obwohl er auch in diesem Falle die alten Lehren nicht bekämpft, arbeitet doch, auffallenderweise, unter dem Einfluß der modernen Anschauungen: er vergleicht nämlich den Blutkreislauf mit einer komplizierten Maschine, wo ein Teil die Bewegung verursacht, die anderen dagegen bloß passiv folgen, obwohl es scheinen mag, daß sich jeder Teil selbständig bewegt; so ruft - bemerkt er - das Abdrücken des Hahns an einem Gewehr den Stoß auf das Feuereisen, ruft Funken und die Pulverexplosion hervor. Im Blutkreislauf soll das Herz den alleinigen aktiven Motor bilden, der das Blut in Strömung erhält. Die mechanische Lebensauffassung wird durch diese Behauptung gestreift, obwohl noch keine Konsequenzen aus derselben gezogen werden ${ }^{1}$ ).

\section{b) Vergleichende Forschung Harveys.}

Von den Untersuchungen der galenischen Ärzte, auch eines Vesal und Leonardo, die nur das Studium des Menschen (der gelegentlichen Erwähnungen der Tiere nicht zu gedenken) im Auge gehabt hatten, unterscheidet sich der Aristoteliker HARveY durch seinen allgemeinen, biologischen Standpunkt. Bereits die Entdeckung des Blutkreislaufs hat in die Wissenschaft eine allgemeine biologische Tatsache eingeführt, diejenige nämlich, daß ein Bestandteil des Organismus im Körper zirkuliert, ohne irgendwo absorbiert zu werden. Noch heute bleibt die wahre Bedeutung dieser

1) Harvey, S. Ior. Fügen wir hinzu, daß der Mechanismus des Blutkreislaufs nach modernen Anschauungen viel komplizierter ist, als Harvey angenommen hat; es sind verschiedene Regulationen desselben bekannt, das Herz soll auch als Saugpumpe für das venöse Blut wirken, und einzelne Körperteile sollen direkt die Blutbewegung beeinflusssen. (Vgl. W. NAGEL, Handbuch der Physiologie des Menschen, Braunschweig 1909, I, 2, S. 857.) 
Tatsache unaufgeklärt. HARveY hat überdies sein Problem von Anfang an als ein Problem der allgemeinen Biologie zu lösen gesucht. Die Spekulationen über die Ähnlichkeit des Menschen und der Tiere beiseite schiebend, studiert er den Blutkreislauf von Anfang an bei allen ihm zugänglichen Tieren, bei den Säugern, Fischen, Fröschen, Schlangen, Eidechsen, bei den Krustazeen, Weichtieren, Wespen, Fliegen ${ }^{1}$ ). Er glaubt gefunden zu haben, daß die einfachsten Tiere, wie die Insektenlarven, die Regenwürmer und die am Meeresgrunde festsitzenden Tiere ("Plantanimalia «, 》Zoophyta «, wie er sie nennt), wie z. B. die Austern, die Miesmuscheln, die Seeschwämme, kein Herz besitzen und die Körpersäfte durch die Konvulsionen des Körpers in Bewegung erhalten. Bei den Insekten bemerkte HARveY bereits einen (noch undeutlichen) Puls; die Weichtiere und die Krustazeen sollen bereits ein pulsierendes Körperchen, als wie einen Vorhof (ohne die Kammer), besitzen. Der Vergleich der höheren Wirbeltiere mit den niederen führt ihn zum Schluß, daß bei den Fischen der kleine Kreislauf fehlt und daß mit dem doppelten Kreislauf der höheren Wirbeltiere auch die Teilung des Herzens in die rechte und linke Hälfte zusammenhängt ${ }^{2}$ ).

Sein Gegner PaRISANus, ein Galeniker, zuckt die Achseln über diese vergleichende Methode: HARver soll den Leser über lauter Vivarien und Aquarien, unter Schildkröten, Blindschleichen, Muscheln, Fröschen, Kröten, Schlangen ${ }^{2}$ ) und ähnlichem Ungeziefer herumführen, und zu welchem Zweck? Ist nicht der Mensch der König der Natur, sind nicht »alle Eigenschaften, die über verschiedene Tiere zerstreut und in rudimentärem Zustande vorkommen, bei jenem vollkommen und in vollendeter Ausbildung "vorhanden? Sie sind es, und folglich ist es überflüssig, »die unsicheren, unvollständig bekannten, unvollkommenen, nicht gehörig angepaßten, zu kleinen, obskuren Wesen «zu beachten; durch das Studium des Tierkörpers sollen wir um kein Haar mehr erfahren als durch das Studium des Menschenkörpers ${ }^{3}$ ).

Noch heute trifft man diesen Standpunkt, wenn nicht theoretisch so scharf ausgedrückt, so doch praktisch befolgt, nicht selten an; wie schwierig es ist, die Methode HaRveYs zu befolgen, erhellt am besten daraus, daß trotz des Lobes, das man ihm zollte, der Blut-

1) Harvey, S. II 2.

2) HARVEY, S. I I 2, 243.

3) Harvey, S. II 6. 
kreislauf bis in die neueste Zeit als eine fast ausschließlich den Menschen (und die Wirbeltiere) betreffende Angelegenheit behandelt wird.

HARVEYs Schrift, bündig, klar und übersichtlich geschrieben, wurde in England günstig aufgenommen, stieß jedoch auf dem Festlande auf Einwände, deren Wesen eben angedeutet wurde ${ }^{1}$ ). Bald wurde die neue Entdeckung durch weitere Beobachtungen bekräftigt: Gasp. Aselli entdeckte 1622 und Th. BARTholin 1652 die Lymphgefäße (HARVEY erkannte jedoch diese neue Tatsache nicht an); M. MALPIGHI beschrieb I66I den kapillaren Blutkreislauf. Nach neueren Anschauungen gestaltet' sich der Blutkreislauf komplizierter, als sich HARVEY vorgestellt hat; es ist nicht unmöglich, daß die Zukunft einen neuen HARVEY hervorbringen wird, der das Problem der Blutzirkulation von einem ganz anderen Standpunkte beleuchten wird.

\section{c) Embryologie.}

Wenn HARvey in der Lehre vom Blutkreislauf als unverkennbarer Aristoteliker erscheint, so entwickelt er seine embryologischen Anschauungen so sehr mit "aristotelischem Harnisch «bekleidet und "die Lehre des Fabricius wiederkäuend" (wie es ihm RoB. Willis vorwirft), daß er begrifflich kaum über den Stagiriten hinausreicht. Die Embryologen der Renaissance teilten sich in Aristoteliker, Galenisten und Arabisten. Nach den weniger exakten Galenikern entsteht im Embryo zuerst die Leber; die Aristoteliker verteidigten eine theoretisch mehr durchgearbeitete Lehre, nach der das Herz, als der Mittelpunkt des Lebens, die Entwicklung der embryonalen Organe einleitet; die Arabisten schließlich verteidigten die sog. Dreiblasentheorie, nach der alle Organe aus drei Urbläschen des Embryo hervorwachsen. Seit der Scholastik haben fortwährend diese drei Hypothesen um die Vorherrschaft gestritten; am Ausgange der Renaissance gewann die aristotelische Auffassung die Oberhand. Der berühmte Zoologe Ulysses ALDROvand suchte durch neues Studium der Hühnchenentwicklung im Ei dieselbe zu bekräftigen und die Galenisten zum Schweigen zu bringen; wohl hat er wesentlich nur das von Hippokrates, Aristoteles und ALBERT' DEM Grossen Ermittelte wiederholt ${ }^{2}$ ). Bei ULysses, der an der Universität in

1) Zu Harveys Gegnern gehörte nebst Parisanus der berïhmte Pariser Professor J. Riolan jun. (1577-1657).

2) Br. BLOCH, Die gesch. Grundl. usw., S. 306. - Ulysses' embryologische Beobachtungen sind in seinem großen Werke über die Vögel enthalten (Ornithologiae libri XII. Frankfurt 16ro). 
Bologna Logik und Pharmakologie gelesen hatte, hat die Embryologie der Holländer Volcher CoITER (KOYTER, I 534-I600) studiert, der auch die Entwicklung des Hühnchens beschrieben hat (I573). Der Zeitgenosse des letzteren FABRICIUS AB AQUAPENDENTE (I 537 bis I6I9), Professor in Padua, hat nicht nur die Embryonalentwicklung mancher Tiere beschrieben, sondern spekulierte auch weit und breit über dieselbe ganz im Geiste des ARIstoteles. Der beste seiner Schüler war HARVEY.

Wie kommt es, daß Harvey zwei so heterogene Fragen wie die Embryonalentwicklung und den Blutkreislauf studiert hat? Nur im Stile der heutigen Biologie stehen diese Probleme weit voneinander; im I6. Jahrhundert wurden beide als ein Problem diskutiert. Die Frage, was im Embryo zuerst entsteht, ob die Leber (und die Venen) oder das Herz (und die Arterien), verknüpfte das konkrete Studium der Embryonalentwicklung mit dem Studium des (embryonalen) Blutkreislaufs und erwuchs im Geiste eines weitblickenden Mannes natürlich zur Frage über den Blutkreislauf im allgemeinen. Die aristotelische Lehre war es, welche HARvey auf die Entdeckung des Blutkreislaufs geführt hatte, dieselbe Lehre, der er seine vergleichende Methode und seine ontogenetischen Anschauungen verdankt.

HARVEY hat nach dem Vorbilde seines Lehrers FABRICIUS die Bildung des Eies bis in den Eierstock der Henne und anderer Vögel verfolgt und richtig erkannt, daß sich der Embryo aus einem Teil des Dotters bildet, und hat auch die ersten Stadien der Entwicklung, soweit dies ohne Vergrößerung möglich war, beschrieben. Auch den Anfang der Entwicklung der Säugetiere hat HARveY an den Rehen untersucht, welche ihm in großer Anzahl vom König KARL I. zur Verfügung gestellt wurden, und er ist zu dem Resultat gekommen, daß die Säugetiere, wie alle anderen Tiere, ihre Entwicklung mit einer Form beginnen, welche er Ei, d. h. den organischen Anfang der Entwicklung in der Form einer noch nicht differenzierten Masse, benannt hat. Das wahre Ei der Säugetiere sah er nicht nur nicht, sondern er erkannte auch nicht die GraAFschen Follikel; sein Säugetierei war bereits ein Embryo.

Seine Entwicklungstheorie besteht wesentlich in folgendem. Es gibt zwei mögliche Arten der Entwicklung ${ }^{1}$ ): entweder ist zuerst das gesamte Material vorhanden und aus demselben wird daraufhin

1) Exercitatio. XLV. S. I54. 
das neue Ding geformt, wie etwa wenn der Bildhauer eine Statue aus Stein bildet; oder die Masse entsteht und wird gleich bei ihrer Entstehung geformt (cum materia simul et formatur et fit). Die Entstehung der ersteren Art will er Metamorphosis nennen, die andere Epigenesis. Beide Entstehungsarten kommen bei den Tieren vor; einige Tiere entstehen aus einer bereits vorbereiteten Masse (ex materia prius cocta et aucta formantur et transfigurantur), indem ihre Organe durch die Metamorphose jener Masse entstehen; andere Tiere jedoch entwickeln sich so, daß ein Teil nach dem andern entsteht, wobei das Organ gleichzeitig wächst und eine bestimmte Form annimmt; diese Entstehungsart, die Epigenesis, ist die eigentliche Zeugung (generatio).

Durch Metamorphose entstehen nach Harvey die Insekten, d. h. die niederen Tiere, wobei der Wurm (die Larve) aus dem Ei oder aus faulenden Substanzen, und aus dem Wurm durch wiederholte Metamorphose das entwickelte Insekt entsteht. Bei diesen niederen Tieren ist es am meisten der Zufall, welcher die Entwicklung fördert (casus seu fortuna videtur maxime generationem promovere), indem die wahre Ursache der Entstehung hier eher die Kraft der bestehenden Materie ist (potentia materiae praeexistantis), als die Wirkung der Außenwelt; daher sind diese Tiere auch weniger vollkommen und in ihren Gattungseigenschaften weniger beständig (genus suum minus servantia), als die höheren, blutführenden Tiere, welche niemals durch Zufall, sondern immer durch Zeugung aus einer und derselben Tierart entstehen.

So geschieht, sagt HARvEy an einem Ort, in der Entstehung der Tiere dasselbe, was auch in den mechanischen Erzeugnissen des Menschen: unter diesen entstehen ebenfalls einige zufällig von sich selbst, wie z. B. die Gesundheit (man beachte an diesem Beispiel, daß HARveY unter "zufällig " und "spontan " nicht Zufall in unserem Sinn versteht), andere aber niemals ohne die Kunst, wie ein Haus.

Höhere Tiere (perfectiora animalia sanguinea) entwickeln sich epigenetisch und wachsen nach ihrer Geburt. Beim Hühnchen entsteht aus dem Ei, welches das Leben potentia enthält, zuerst ein Blutfleck (punctum sanguineum), der dann die anderen Körperteile, einen nach dem anderen, gebiert. Das Ei enthält nicht nur die Masse, sondern auch das Lebensprinzip in sich, welches die spezielle Struktur des künftigen Tieres bestimmt und dem Organismus die Ernährungskraft und alles andere, welches das Wesen 
des Lebens ausmacht, gibt. HARvey drückt sich folgendermaßen $\left.\operatorname{aus}^{1}\right)$ :

"Und erstens weil es feststeht, daß das Hühnchen durch Epigenesis oder durch den Zuwachs der neu entstehenden Teile (partium exorientium additamentum) gebildet wird, sollen wir zusehen, welcher Teil vor allen anderen gebildet wird, und was über denselben und dessen Entstehungsart zu beobachten ist. Es ist gewiß ausgemacht, und es erscheint klar im Ei, was ARIstoteles über die Zeugung der vollkommenen Tiere aussagt: nämlich, daß nicht alle Teile auf einmal entstehen, sondern der Ordnung nach der eine nach dem anderen; und da $\$$ zuerst das zeugende Teilchen entsteht, durch dessen Kraft (virtus) als wie aus einem Anfang alle übrigen Teile hervorkommen. So erkennen wir auch bei den Samen der Pflanzen (in den Bohnen, vielleicht auch in den Eicheln), daß zuerst die Knospe oder der Gipfel hervorbricht, als der Anfang des ganzen künftigen Baumes. Und dieses Teilchen ist wie der selbständig gemachte und ins Freie gesetzte Sohn (velut filius emancipatus seorsumque collocatus), und als der selbständig lebende Anfang, aus welchem dann die Ordnung der Teile bestimmt wird und alles, was zum vollständigen Aufbau des Tieres gehört, verteilt wird.*

Zur Erzeugung der höheren Tiere ist die Befruchtung durch das Männchen nötig; der Same desselben wirkt auf das Ei nach der Art der Ansteckung, oder wie der Magnet, der dem Eisen seine magnetische Kraft überbringt; und diese Wirkungsart des Samens läßt auch die Tatsache der Vererbung von väterlicher Seite verständlich erscheinen. HARVEY veranschaulicht dies durch folgenden Vergleich: wie das Gehirn des Weibes die Fähigkeit hat, die Welt zu begreifen, also den Gegenständen ähnliche Vorstellungen zu erzeugen, so hat ihr Uterus, dessen Ideen die Eier sind, die Kraft, diese Eier dem sie befruchtenden Mann ähnlich zu bilden; ein Vergleich, welcher ebenso kühn als originell ist und sehr gut die Richtung veranschaulicht, in welcher sich HARvEYs Gedanken bewegt haben.

\section{d) Das Ei.}

In seinen entwicklungsgeschichtlichen Spekulationen schreibt HARVEY viel über die Eier, aus denen die Tiere entstehen, über die Eicr der Säuger, der Vögel, der Insekten. Unsere Vorstellung des Eies als eines bestimmten Dinges (das sich von anderen Dingen sachlich unterscheidet) ist uns so geläufig geworden, daß wir unwillkürlich auch dem Eibegriff HARvEYs dieselbe Bedeutung unterlegen. HARVEY hat jedoch unter einem Ei nicht ein konkretes Ding, sondern nur einen abstrakten Begriff verstanden. Die Sache ver-

1) De gen. lib. II. cap. 4 . 
dient ausführlicher erklärt zu werden. Es wird HARvey oft der Satz zugeschrieben, daß alles Lebendige aus den Eiern entsteht, und der Satz wird als eine Negation der spontanen Generation gedeutet. In dem Wortlaut »omne vivum ex ovo "befindet sich der Satz bei HARVEY nicht; man findet jedoch Stellen genug, welche sich mehr oder weniger dem Inhalt nach mit ihm decken ${ }^{1}$ ). Alle allgemeinen Erörterungen HARVEYs beweisen, daß er gewiß überzeugt war, daß alle Tiere aus Eiern entstehen. HARvey stellt sich vor, daß alle Tiere, auch die spontan entstehenden, einen Zustand während ihrer Entwicklung durchmachen, welcher als undifferenzierte lebendige Masse erscheint, und diesen Zustand nennt er Ei. Unter Ei versteht er also nicht nur die Eier der Vögel, sondern auch die Larven und Puppen der Insekten und den (gemutmaßten) Anfang der Embryonalentwicklung des Menschen. Er sagt z. B. von den Insektenlarven:

So sind auch die Samen der Insekten beschaffen, welche ARISTOTELES Würmer nennt, welche, anfangs unvollständig erzeugt, sich die Nahrung suchen, dadurch genährt werden, und aus der Larve zur Puppe, a us einem unvollständigen Ei $z u$ einem vollständigen Ei und Samen wachsen 2 ).

In dem Kapitel »über das Ei als Anfang aller Tiere « sagt er:

... Welche [Tiere] gleich ein Tier gebären [actu animal pariunt], heißen lebendig gebärend; welche nur der Möglichkeit nach, eierlegend. Jeden Anfang nämlich, welcher der Möglichkeit nach lebt, wollen wir (mit FabRICIUS) ein Ei nennen; dasjenige ferner, was ARISTOTELES Wurm [i. e. Larve] nennt, unterscheiden wir keineswegs vom Ei: sowohl weil es dem Auge so erscheint, als weil es auch mit dem Verstand übereinstimmt.

Mit dem »Ei " HARvEYs verhält es sich nicht anders als mit den »Arten " und "Gattungen " des ARISTOTELES. Ursprünglich künstlich konstruiert, wurden diese Begriffe anfangs auf heterogene Erscheinungen angewendet; späterhin erst kristallisierten sie zu Namen für bestimmte Dinge. Im zweiten Falle war ein LiNNé nötig, um die »Arten « in der Natur zu entdecken, d. h. um dem seit langem bekannten Namen der »Art " eine konkrete Bedeutung zu verleihen; der abstrakte Begriff des Eies als des theoretisch konstruierten Anfanges der Entwicklung verwandelte sich dagegen in den heutigen Namen »Ei « allmählich ${ }^{3}$ ), so daß wir keinen Entdecker der Eier

1) scuncta animalia quodammodo ex ovo nasci affirmavimus... Harvey, Exercitationes, S. 292.

2) Exercitatio. XI.

3) Während der evolutionistischen Spekulationen der nachfolgenden Epoche. 
feiern können. Solche "unbewußte Entdeckungen « sind keineswegs vereinzelt in der Geschichte der Wissenschaft; der "Same "im modernen Sinne des Wortes bildet auch eine solche. Heute versteht man unter Samen nur Pflanzensamen, bestimmte Dinge von charakteristischen Eigenschaften. Vergeblich wird man in der Vergangenheit nach einem Forscher suchen, der diese Auffassung des Samens in die Wissenschaft eingeführt hätte. Und doch bedeutete der "Same " noch zu HaRveys Zeit etwas anderes als heute; sprach man doch von Samen (sperma) der Dinge im allgemeinen, vom Samen der Steine, der Tiere, der Krankheiten usw. Die moderne Bezeichnung der männlichen Geschlechtszellen als Spermatozoiden (Samentierchen) stellt das letzte Rudiment jener altertümlichen Auffassung des Samenbegriffes dar.

\section{e) Harvey bei der Nachwelt.}

Bei HARvey erreichte der wiedererweckte Aristotelismus seinen Höhepunkt, um späterhin im leeren Dogmatisieren auszuklingen. HARVEY ging den Fußstapfen seines griechischen Meisters treu nach. Mit diesem teilt er die Organismen in Bluttiere und in Blutlose und sucht diese Einteilung auch embryologisch zu begründen, indem er den Bluttieren (d. h. den Wirbeltieren) eine epigenetische Entwicklung, den Wirbellosen eine Entwicklung mit Metamorphose zuschreibt. Der HARVEYsche Begriff der Metamorphose ist leider nicht klar genug von der Epigenesis abgegrenzt, was desto schlimmere Folgen nach sich gezogen hat, als sich die Embryologen der nachfolgenden Zeiten gerade auf diesen Begriff gestützt und die Epigenesis zur Seite geschoben haben. HARvey selbst gab dazu Anlaß. Die »Evolutionisten «, wie sich die späteren Gegner der Epigenese nannten, stützten sich auf die mechanische Weltanschauung und suchten nachzuweisen, daß die Organe im Embryo nicht sukzessive gebildet werden, sondern von Anfang an vorhanden sind und nur heranwachsen. Indem HARVEY die Schmetterlingspuppe für ein Ei erklärt hat, gab er unwillkürlich zu einer solchen Auffassung Anlaß, denn die Gelehrten fingen an, ihm gegenüber den Beweis zu führen, daß bereits das Ei eine Struktur hat und daß im » Schmetterlingsei « bereits der Schmetterling enthalten ist, und daß dieser folglich nicht entsteht, sondern nur wächst.

HARvey hat die Tiere in blutführende und blutlose eingeteilt. Den Anschauungen ARISTOTELES' folgend, die sich in dieser Hinsicht an die Lebensauffassung des schlichten, ungelehrten Mannes an- 
lehnen, hat er nur die blutführenden Tiere, d. h. die Wirbeltiere, eingehender untersucht und den Wirbellosen nur vorübergehend seine Aufmerksamkeit gewidmet. Hat er mit seiner Geringschätzung der Wirbellosen recht gehabt? Die Natur spricht zu uns durch die einfachsten wie durch die kompliziertesten Erscheinungen; auch durch das Studium der einfachsten Tiere können wir Bedeutendes über das Wesen des Lebens erfahren; je weiter wir uns jedoch in der Stufenleiter der Organismen vom Menschen, dem lebendigen Wesen par excellence, entfernen, mit desto blasseren Formen bekleidet sich der Lebensinhalt. Der Mensch führt ein Leben, für das die Leistungen eines Alexander des Grossen, eines Plato, eines Cäsar, eines Dante, eines Mohammed den Maßtsab bilden, ein Leben, das sich in der Politik, Religion, Kunst, Wissenschaft offenbart, ein Leben, an welches praktische Menschen denken, wenn vom Leben die Rede ist. Bei einem Infusor dagegen wird das Zittern von ein paar Zilien, die Bewegung eines mikroskopisch kleinen Stückes Schleim Leben genannt. Gewiß reicht das wahre Leben auch der einfachsten Organismen tiefer, als die landläufigen Hypothesen der Schulen vermuten lassen; es besteht aber die Gefahr, daß man die an diesen Wesen in den Laboratorien ermittelten Lebensäußerungen für das Maß des Lebens an sich nimmt. Der Begriff des tatsächlich zwischen Himmel und Hölle in unendlicher Weite sich entwickelnden Lebens wird dann zu einem Schuldogma verengt, nach dem als Leben etwa nur Eiweiß, Säftebewegung, Schaumstrukturen oder irgend eine andere am grünen Tisch konstruierte gelehrte Tatsache hingestellt wird. Die einseitige Betonung des Studiums niederer Tiere hat immer auf eine solche Verflachung der wissenschaftlichen Lebensauffassung geführt, das erste Mal bei HARVEYs unmittelbaren Nachfolgern. Diese haben an HARVEYs Geringschätzung der niederen Tiere Anstoß gefunden und waren nicht müde nachzuweisen, daß auch die Raupen, die Spermatozoiden, die Eier wissenschaftlich eingehend studiert werden müssen. Natura in minimis maxima! wurde zur Losung jener Epoche - und der größte Verfall der biologischen Forschung begleitete die Befolgung jenes Grundsatzes.

An HaRveys konkrete Beobachtungen haben MALPIGHI, DE GRAAF und SWAMmERDAM angeknüpft. MALPIGHI verfolgte eingehender die Entwicklung des Hühnchens, DE GRAAF diejenige des Kaninchens und Swammerdam die Insektenentwicklung. Auch die Anschauungen über das Wesen der Geschlechtsunterschiede hat Harvey beeinflußt. ARIStoteles stellte die Grundthese auf, daß 
sich das Weib nicht nur seinem Wesen, sondern auch seiner Rolle bei der Fortpflanzung nach vom Manne qualitativ unterscheidet; die weiblichen und die männlichen Reproduktionsorgane sollen funktionell verschieden sein. GALEN, der auch sonst einen Rückschritt gegenüber ARISTOTELES bildet, bekämpfte diese Lehre und erklärte die Funktion der weiblichen Geschlechtsteile für wesentlich identisch mit derjenigen der männlichen; oder wie man es $\mathrm{zu}$ formulieren pflegte: er hat gelehrt, daß das Weib ebenso wie der Mann Samen erzeuge. Diese letztere Auffassung blieb bei den Anatomen der Renaissance vorherrschend ${ }^{1}$ ) und hatte zur Folge, daß man die weiblichen Ovarien allgemein als »Hoden «(testes muliebres) beschrieben hat. Als nach dem Verfall der Renaissance ARISTOTELEs zu neuer Ehŕe kam, erhielt der Unterschied zwischen dem Mann, der dem Keime die Entwicklungskraft einhaucht, und dem Weib, das das Material für den Nachkommen liefert, neuen Wert. HARvey spekulierte über dieses Thema und kam zu dem Schluß, daß die Ovarien sich wesentlich von den Hoden unterscheiden. REGNIER DE GRAAF (I64I-I673) verfolgte diese Idee weiter, und in der Überzeugung, in den Ovarien der Säuger "Eier « gesehen zu haben ${ }^{2}$ ), nannte er als der erste diese Organe "Ovarien«. Doch hat man zu seiner Zeit fast vergessen, daß es ARIstoteles war, der diese Entdeckung angebahnt hatte. So sehen wir, daß auch das Vorhandensein eines wesentlichen Unterschiedes zwischen den weiblichen und den männlichen Geschlechtsorganen zuerst theoretisch formuliert und erst nachher bestätigt wurde.

\section{F. Glisson.}

Francis Glisson (I 597-I677), Professor in Cambridge, später Arzt in London, befolgt treu die peripatetische Methode. Sein bestes Werk, Die Anatomie der Leber (I654), beginnt mit strengen Definitionen, welche nach aristotelischer Art als logische und sachliche auseinandergehalten werden; es wird an den Körpern Materie und Form unterschieden und diese Unterscheidung ähnlich wie bei

1) Über Einzelheiten vgl. G. H. Lewes, Aristoteles. Leipzig 1865. S. 34 I.

2) R. DE GraAF, De mulierum organis generationi inservientibus. Opera Leyden I678. Was Graaf gefunden hat, waren keine Eier, sondern sog. Graafsche Follikel, in denen erst das wahre Ei eingeschlossen ist. Auch an diesem Beispiele ist zu sehen, wie die Theorie vom Wesen des Eies auf seine Entdeckung geführt hat; das wahre Säugetierei wurde erst im 19. Jahrhundert von K. L. v. BAER entdeckt. 
ARIstoteles begründet, die Möglichkeit einer vergleichenden Aṇatomie wird wenigstens gestreift $\mathbf{1}$ ).

GLISSON stellt folgende allgemeine Vorstellungen über die Anatomie, d.h. die (anatomische, physiologische, pathologische, chemische) Analyse des Körpers auf. Als das nächste Objekt der Anatomie gilt der menschliche Körper; zwar darf auch die Sektion der Tiere nicht vernachlässigt werden, aber nur insofern, als sie der Anatomie des Menschen verschiedentlich dienen kann. Gemäß dem Unterschied zwischen Materie und Form werden auch die Teile des Körpers (wie bei ARISTOTELES) in ähnliche und organische (unähnliche bei ARISTOTELES) eingeteilt; die ersteren sind durch das Material bestimmt, aus welchem sie aufgebaut sind, die anderen durch die Form, welche sie annehmen. Auch die weitere Einteilung erinnert an Aristoteles; Glisson unterscheidet:

Ähnliche Teile

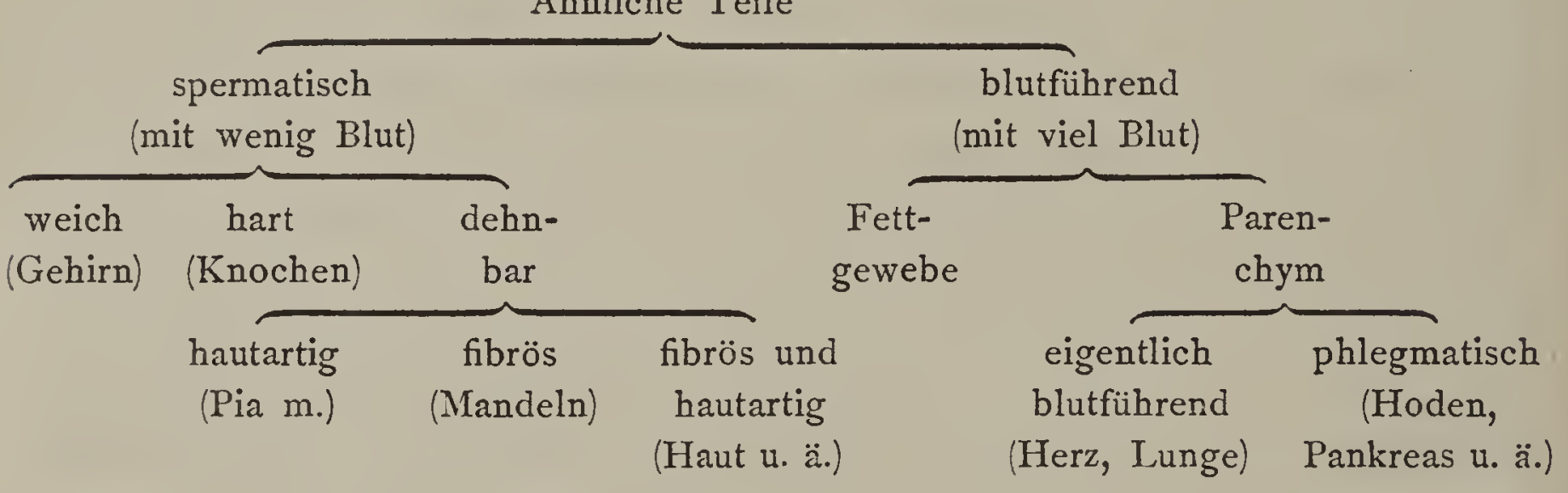

In dem naturphilosophischen Traktat » Über die energetische Natur der Substanz« (I672) hat GLISSON zu zeigen versucht, daß alle Erscheinungen der lebendigen Wesen, der Tiere wie Pflanzen, sowie auch der toten Körper sukzessive Entwicklungen der Fundamentalenergie der Natur sind; aus einer allgemeinen Naturkraft entwickelt sich dieselbe zu der Pflanzen- und der tierischen Energie; die materielle, vegetative und sensitive Seele sind verschiedene Stufen ihrer Entwicklung.

1) S. 2: Es sei nicht nur die Struktur des Körpers, sondern setiam generales communitates et differentiae cum aliis animalibus zu beachten. S. 61, 62 steht folgende vergl. anat. Betrachtung: Die Leber liegt auf der rechten Körperseite, I. weil sie diese Lage beim ersten Menschen eingenommen hat und weil die Vererbung nachwirkt (= causa efficiens); 2. auf daß die Anatomie einen Sinn hätte (!); 3. die Tiere sind nach menschlichem Vorbilde gebaut, damit der Mensch durch das anat. Studium derselben sich selbst erkenne; 4. damit es einen erkennbaren Unterschied zwischen der rechten und linken Körperseite gebe. 
Indem er in der Abhandlung über die Leber (1654) die Frage löst, wie es kommt, daß die Galle sich nur zu bestimmten Momenten in den Darmkanal ergießt, zeigt GLISSon, daß die Gallenblase mehr Galle gibt, wenn sie gereizt ist, daß sie die Fähigkeit, gereizt zu werden, besitzen muß; diese Fähigkeit nennt er "irritabilitas". Auch der Name »Protoplast(um) « kommt hier zum ersten Mal vor.

Obwohl GLIssons anatomisches Werk auf die Aufstellung der logischen Prinzipien der Strukturlehre abzielt, bietet es inhaltlich kaum mehr als eine bloß deskriptive Anatomie. Seine Definition dieser Wissenschaft verrät deutlich GLIssons Ziele:

Die Anatomie ist die Wissenschaft, in der durch künstliche Sektionen, durch Messen, Wägen, Aufblasen, Injektionen mittels einer Röhre, durch Ligaturen und durch andere passende Operationen der Bau des menschlichen Körpers und seiner Teile, die Proportionen, Komplemente, Defekte, Elemente, Verbindungen, Verschiedenheiten, Sympathien, Antipathien, Kräfte, Tätigkeiten und Zwecke gründlich erklärt werden, sofern eine derartige Erklärung wenigstens dem menschlichen Geiste zugänglich ist11).

Danach ist es kein Wunder, daß GLIsson mehr für die Physiologie als für die Morphologie von historischer Bedeutung ist 2 ).

\section{Die Enzyklopädisten.}

Gegen das Ende der scholastischen Naturwissenschaft waren Kompendien über die Natur geschätzt, in denen im Stile der Wissenschaft eines Plinius ohne jeden philosophischen Apparat Erzählungen über die verschiedensten wirklichen und phantastischen Naturobjekte nach verschiedenen Quellen vorgeführt wurden. „Das Buch der Natur " (De naturis rerum) vom Dominikaner Thomas DE CANTIMPRÉ und 》Das Buch von den Eigenschaften der Dinge "vom Franziskaner Bartholomaeus ANGlicus, beide aus dem I3. Jh., gehörten zu den beliebtesten. Nach der Erfindung der Buchdruckerkunst wurden sie oft aufgelegt; BARTHOLOMAEUs' Schrift hat (bis zum. I6. Jh.) gegen 20 Auflagen erlebt, und die deutsche Bearbeitung des Buches von der Natur (von Conrad v. Meggenberg) ist in 5 Auflagen erschienen.

1) S. 5 .

2) Literatur: GLIsson, Anatomia hepatis Londini 1654. Tractatus de natura substantiae energetica Lond. I672. - Über Glisson vgl. Foster, M., History of Physiology in the $16^{\text {th }}, 17^{\text {th }}$ and $18^{\text {th }}$ centuries Cambridge 1901 . - MARION, H., Glissonius quid de natura substantiae senserit et utrum Leibnizio de natura substantiae cogitanti quidquam contulerit. Paris 1880. 
Diese in der Mitte zwischen der exakten Scholastik und den allzu schlichten Bestiarien und Physiologen stehenden Schriften sind von dem gegen die Scholastik geführten Ansturm der Renaissance verschont geblieben und dienten am Anfange der Neuzeit als Grundlagen für die Entstehung der Zoologie und der Botanik, sofern diese beiden Gebiete neben den theoretisch und experimentell begründeten Lehren über das Wesen des Lebens als selbständige Zweige der Wissenschaft bestehen. Der Londoner Arzt EDUARD WoTTON (I 492 bis I 555) gab I 552 eine Schrift in Io Büchern »Über die Unterschiede der Tiere " (De differentiis animalium, Paris) heraus, in der er, unter direktem Anschlusse an ARISTOTELES, den Bau der Tiere behandelt und die Tierformen nach dem aristotelischen System beschreibt. Der Züricher Arzt CoNRAD GESNER (I 5I6-I 565) hat sich zum Ziele gesetzt, die Aristotelische Naturgeschichte durch die literarischen Angaben anderer, klassischer sowie späterer Autoren zu vervollständigen, und hat eine große "Naturgeschichte der Tiere " (Historia animalium) in vier Bänden verfaßt (denen nach seinem Tode noch ein Band beigefügt wurde). Ulysses Aldrovandi (I 522-I605), der philosophisch gebildete Direktor des botanischen Gartens in Bologna, schrieb ein großes Werk über die Vögel, über die Insekten und über "andere blutlose Tiere".

Gesners und Ulysses' mammutgroße Schriften sind nach PliNIUs' Vorbilde verfaßte Kompilationen, die die aristotelischen, galenischen und humanistischen Tendenzen zu einem undifferenzierten Gemisch von schwerfälliger Gelehrsamkeit vereinigen. Den Wurzeln einer Idee nachzugehen, waren diese Autoren nicht imstande; auch in der Auswahl ihrer Autoritäten gingen sie wenig selbständig vor; sie schrieben über die Tiere nach eigenen Erfahrungen, nach den Berichten der Zeitgenossen, nach Plinius, Aristoteles, Albert dem Grossen, Thomas de Cantimpré usw. Die Tiere zu beschreiben war nicht ihr Ziel, sie suchten vielmehr dasjenige zu kompilieren, was man über die Tiere Wahres, Interessantes, Wichtiges ausgesagt hatte $^{1}$ ).

Eine kurze Analyse des Gesnerschen Werkes wird uns dessen

1) Ulysses begriindet z. B. das Studium der Ornithologie durch folgende Argumente: Die Vögelabbildungen dienten den Ägyptern als Buchstaben, die Vögel werden von den Dichtern besungen, geben uns ein Beispiel des Fleißes, der Tapferkeit im Kampfe und der Moralität, sind dem Bauer nützlich, geben uns Gefieder, bauen Nester (primitive Architektur), werden in der Küche und in der Arzneikunst verwendet, geben das Wetter an. (S. $1-6$. De utilitate operis.) 
Tendenz veranschaulichen. Im Vorwort sucht er die Ersprießlichkeit der Tierkunde zu begründen: dem Arzt, dem Jäger, dem Koch ist diese Wissenschaft nötig; das Studium der Tiere, des Vogelsanges, des Bienen- und Ameisenstaates ergötzt uns; viele berühmte Männer haben sich der Naturforschung gewidmet. GESNER nimmt einzelne Säugetiere nach alphabetischer Reihenfolge durch und gibt bei jedem einzelnen folgendes an: Name, Vorkommen, Habitus, Ortsbewegung, Krankheiten, Geistesleben, Nutzen und Haltung, Symbolik, Fabeln, Sprichwörter ${ }^{\mathbf{1}}$ ). Die Körperbeschaffenheit einzelner Tiere betrachtet GESNER noch als nebensächlich, oder wenigstens als den physiologischen, psychischen und für den Menschen bedeutungsvollen Eigenschaften gleichwertig. Folgende Excerpta aus seinem Kapitel über den Bären geben einen Vorgeschmack von seiner Darstellungsweise ${ }^{2}$ ).

Viele Bären werden von kalten Gegenden geboren und zwar graue oder schwarze, deren es zwei Gattungen, große und kleine, gibt... die kleine Gattung der Bären wird von unseren Schweizern »Steinbären «... die größere in gewissen Gegenden Deutschlands » Hauptbären " genannt. . . Es gibt einen gemeinen Bär und einen anderen im Wasser lebenden, von weißer Farbe, der unter dem Wasser fischt wie die Fischotter und der Biber, Albert (d. h. nach Albert D. G. zitiert). Es gibt gewisse Bären, Hunde, Wölfe und gewisse andere ähnliche Tiere, die amphibisch, wie im Wasser, so auf der Erde leben. Derselbe (d. i. AlberT) ... Der Bär ist ein sehr feuchtes (= fettiges) und formloses Tier. Albert. Vergilius nennt die Bären formlos, Ovidius elend. ,Quid nisi pondus iners, stolidaeque ferocia mentis?" Ovidius... Während der Ortsbewegung stellen sie zuerst die Fußspitze leicht auf den Boden und folgen dann mit der Ferse . . Die stärkste Kraft besitzt der Bär in den Schultern und Hüften: daher greifen sie manchmal mit den Hinterfüßen an. Solınus ... Das Bärenfleisch ist kalt, schleimig, schwer zu kochen, nicht gelobt. Rhazes...

Die Ornithologie des ULYSSES ist nicht wesentlich anders geschrieben. Auch die Pflanzensammler haben zu dieser Zeit begonnen, große Herbarien, d. h. meistens alphabetisch geordnete Beschreibungen und Abbildungen der medizinisch wichtigen Pflanzen im Anschlusse an die Botaniker der klassischen Zeit herauszugeben. Hierher sind die Herbarien des OtTo BRUnfels (I530), Lobelius (I576), Caspar Bauhin (i623), Leonhard Fuchs (I542), Rembrandtus Dodonaeus (i6i6), Pierandrea Mattioli (I562) zu

1) Diese einzelnen Schlagwörter sind bei Gesner durch mehrere Bezeichnungen umschrieben; ich gebe sie nach der Kürzung Burckhardts (Geschichte S. 52) wieder.

2) S. $1065 \mathrm{sq}$.

Rádl, Geschichte der biol. Theorien. I. 2. Aufl. 
zählen. Auch Gesner hat ein Kräuterbuch verfaßt. Der wissenschaftlichen Tendenz nach stehen die Kräuterbücher auf derselben Höhe wie die zoologischen Schriften der Enzyklopädisten ${ }^{1}$ ).

1) Literatur. C. GESNER, Historia animalium Lib. I-V. Opus philosophis, medicis, grammaticis, philologis, poëtis et omnibus rerum linguarumque variarum studiosis utilissimum simul iucundissimumque futurum Tiguri I55I-I587. - U. ALDRovand, Ornithologia, hoc est de avibus historiae, libri XII. Bononiae I599-r606. - Über Gesner und Aldrovandi vgl. Carus a. a. O. Über die oben angefuihrten Botaniker schreibt ausfiihrlich E. H. F. MEYER, Geschichte d. Botanik. Königsberg 1857. Bd. IV. und J. SAchs, Geschichte d. Botanik. München I 875 . 


\section{Kapitel.}

\section{Begründung der neuen wissenschaftlichen Methode.}

\section{Der Untergang der biologischen Weltanschauung.}

Der Mensch hat seit jeher die Natur auf zwei Arten aufgefaßt. Entweder fühlte er sich als ihr Sohn und erkannte durch eine Art Solidaritätsgefühl, von innen aus, die wesentliche Ähnlichkeit seiner Lebensäußerungen mit denen der Natur; er erblickte die Natur in sich selbst und sich in der Natur widerspiegelnd. Oder es steht der Mensch der Natur als einem fremdartigen, unbegreiflichen Objekt gegenüber, das in ihm Neugierde erweckt und in dessen Gesetze er schrittweise, durch Erforschung von Einzelheiten einzudringen sich bemüht. Einem Naturforscher, der zu der Natur wie ein Kind zu seiner Mutter aufblickt und von einer unbewußten Sympathie zu derselben durchdrungen ist, kommen die Naturerscheinungen nicht fremdartig vor, sondern er faßt dieselben als natürlich, vom Leben und von der Seele erfüllt auf: der Blitz und das Säuseln des Laubes sind für ihn ebenso selbstverständliche Lebensäußerungen der Natur wie seine eigene Stimme und Bewegung. Ein solcher Mann ist von Grund aus Vitalist, oder eher Universalvitalist, indem er mit biologischem Maßstabe alle Naturerscheinungen mißt. Plato, ARistoteles, Galen, das ganze Mittelalter und zum großen Teil auch die Renaissance waren in diesem Sinne Vitalisten. Das Weltall faßten sie als einen Organismus auf; sie nannten ihn "Kosmos ", welcher Name fast dasselbe bedeutet, wie ein gesetzmäßig, zweckmäßig, harmonisch, also organisch geordnetes Geschehen. Sie fühlten sich selbst als einen organischen Bestandteil des Weltalls, sozusagen als eine Zelle des Weltorganismus, die durch innere Sympathien mit dem letzteren zusammenhängt, so daß die 
heimlichsten Gedanken jedes Individuums in ihrer Wirkung bis nach den Himmelssphären reichen, von dort zurückprallen und die gesamte Menschheit beeinflussen - in derselben Weise wie nach den Modernen die kaum merkliche Ausscheidung einer geringfügigen Drüse für die Gestaltung des Lebens des gesamten Organismus maßgebend sein kann. Daher der astrologische Wahn, daher der Glaube an Geister und an heimliche Sympathien der Dinge. In der Überzeugung, daß der Mensch das Maß der Dinge bildet, erblickten jene Vitalisten nicht nur in den Tieren und Pflanzen, sondern auch in der Erde und im Weltall handelnde, Zwecke setzende und erfüllende Wesen. "Göttliche Tiere " hat Plato die Sterne genannt, und alle Platoniker, KEPPLER inklusive, sind ihm darin gefolgt, so daß Spekulationen über die Weltseele, über die »Intelligenzen «, die die Himmelssphären in Bewegung erhalten, über den Weltgeist, der sich zum Pflanzen-, Tier- und Menschenorganismus verdichtet, zu den üblichsten Thesen dieser Weltanschauung gehört haben. Die aristotelische Physik ist als eine organische Wissenschaft, als ein Teil der Biologie aufzufassen: daher der Nachdruck, den ARISTOTELES auf das Qualitative in der (anorganischen) Natur gelegt hat, daher seine Unterscheidung von natürlichen und unnatürlichen Bewegungen, seine Lehre vom natürlichen Ort eines jeden Dinges (der Luft, des Wassers, der Steine), daher auch die Identifizierung der logischen mit den Naturgesetzen, die Zweckmäßigkeitslehre usw. ARISTOTELES hat jede physikalische Erscheinung, den freien Fall, den Blitz, die Planetenbewegung usw. als eine Äußerung des Lebens betrachtet;

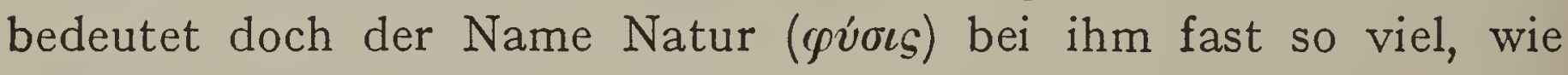
heute der Name "Menschennatur «.

Die Neuzeit bricht mit diesem Solidaritätsgefühl mit der Natur ab; je weiter desto deutlicher bringt sie die Überzeugung zum Ausdruck, daß der denkende Mensch der Natur wesensfremd ist, daß nur er im eigentlichsten Sinne lebt und denkt, während die Natur, die Pflanzen und Tiere keineswegs ausgenommen, eigentlich tot sind, oder wenigstens ein Leben führen, dessen innere Regungen uns auf immer verschlossen sind. Der Mensch ist dieser mechanistischen und empiristischen Auffassung nach nur imstande, Einzelheiten gewahr zu werden, die er nach den Prinzipien seiner Vernunft zu allgemeinen Gesetzen zusammenfaßt, Gesetzen, die wohl Naturgesetze heißen, im Grunde aber nur von den Menschen über die Natur aufgestellte subjektive Regeln bedeuten. Diese Naturauffassung entsteht nicht auf einmal; niemals wird sie von allen Forschern 
anerkannt; sie kann jedoch für die Neuzeit als ebenso bezeichnend gelten, wie die naiv vitalistische es für das Altertum war.

Auch die neuplatonischen Wortführer der Renaissance, CusAnus, Telesius, Paraceilsus, Cardanus, Giordano Bruno, Leonardo waren noch vitalistisch gestimmt, obwohl man aus den Hypothesen einiger derselben bereits Anklänge an eine mechanische Weltanschauung heraushören kann. Folgende Darstellung G. BRunos zeigt, wie sich diese Denker den Universalvitalismus zurechtgelegt haben:

Die universelle Vernunft ist das innerste, wirklichste und eigenste Vermögen und ein potentieller Teil der Weltseele ... sie verhält sich demnach zur Hervorbringung der Dinge in der Natur, wie unsere Vernunft sich zur entsprechenden Hervorbringung der Gattungsbegriffeim Verstande verhält ... sie ist es, welche die Materie mit allen Formen erfüllt ${ }^{1}$ ).

Noch tritt hier das Universum als ein beseeltes und deshalb lebendes Wesen auf; einzelne Neuplatoniker wissen jedoch bereits diesen universellen Vitalismus durch die Lehre einzuschränken, daß die Welt wohl vom Geist beherrscht wird, der aber ausschließlich mathematischen und mechanischen Prinzipien gemäß waltet. Diese neue Auffassung wird namentlich vom Naturphilosoph BERNARDINUS TELESIUS (I 508-I I88) gepredigt ${ }^{2}$ ) und findet bald lebhaften Anklang; LEONARDO hat derselben bereits früher einen günstigen Boden vorbereitet. Die Anhänger der neuen Philosophie stellen ihre Lehren in bewußten Gegensatz zum Aristotelismus, d. h. gegen die biologische Auffassung der Naturvorgänge. Die Scholastiker waren vorzugsweise Biologen; die meisten Neuplatoniker fördern dagegen die Mathematik, Mechanik und die Astronomie (Cardanus, Campanella, Telesius, Bruno, Keppler); mit Ausnahme des wenig bedeutenden und einflußlosen SEvERINO is t kein er von ihnen Biologe; von der biologischen Weltanschauung behalten sie nur einen vagen Begriff der Allbeseeltheit und der Weltvernunft.

So bereitet der Neuplatonismus den Sieg der mechanischen Weltanschauung über die vitalistische und gleichzeitig auch den Sieg der Mechanik über die Biologie.

1) V. d. Ursache, d. Prinzip u. dem Einen. Übers. von A. Lasson, Berlin 1872. S. 51,52 .

2) De rerum natura iuxta propria principia. $15^{6} 5$. 


\section{Leonardos Mechanismus und Vitalismus.}

Weder der Platonismus an sich noch die Betonung der Erfahrungswissenschaft hätten zu einer mechanischen Weltanschauung geführt, denn auch die Aristoteliker (HARvEY) waren für die Erfahrung, und ausgesprochene Platoniker (PARACELSUS) gehören $\mathrm{zu}$ typischen Vitalisten. Es scheint, daß eine Verbindung des auf Anschauungen bauenden Platonismus mit dem die Logik betonenden Aristotelismus die neue rationalistische Erfahrungswissenschaft gezeitigt haben. Der Platoniker betont direkte Erfahrung, das unmittelbare Erleben der Naturerscheinungen; der Aristoteliker dagegen beachtet in erster Reihe die logische Bearbeitung (die Analyse, Diskussion, Erklärung) der Tatsachen; und es ist gerade die Verknüpfung dieser beiden Methoden, die für die neue Wissenschaft charakteristisch ist, denn fortwährend predigt diese die Notwendigkeit der Erfahrung und fortwährend übt sie praktisch analytische Methoden als ihre wichtigste Aufgabe. LEONARDo mit seiner Methode, die Erscheinungen realistisch aufzufassen und rationalistisch $\mathrm{zu}$ deuten, LEONARDO, der an den Scholastikern erzogene Neuplatoniker, ist ein Vorläufer dieser neuen Wissenschaft. Im Sinne der Platoniker (und der Pythagoräer) lehrt er, daß unsere Seele und unsere Gesundheit in der Harmonie der Teile bestehe ${ }^{\mathbf{1}}$ ); im Geiste derselben Philosophie vergleicht er den Organismus mit dem Weltall, nennt den Menschen mit Vorliebe einen Mikrokosmos (mondo minore) und sucht diese Analogie bis in die Einzelheiten durchzuführen ${ }^{2}$ ); folgerichtig wohnt nach ihm auch im Erdboden eine Seele, aus der die Pflanzen ihr Leben schöpfen. LEONARDO ist dem Vitalismus noch so sehr unterworfen, daß er auch die physikalische Kraft vitalistisch auffaßt:

Die Kraft ist eine geistige, unkörperliche, unsichtbare Macht, die auf kurze Dauer in Körpern entsteht, die durch eine zufällige Gewalt in ihrem Wesen gestört und aus ihrem natürlichen Sitz entrückt sind. Ich habe die Kraft geistig genannt, weil in dieser Kraft ein aktives unkörperliches Leben steckt, und ich nenne sie unsichtbar, weil sie den Körper, in dem sie entsteht, weder der Masse noch der Form nach verändert; sie hat wenig Leben, weil sie immer ihre Ursache überwinden will, und wenn dies geschehen, stirbt sie $\left.a b^{3}\right)$.

Beachten wir die Vitalität dieser Kraft! Sie entsteht nur auf kurze Dauer und vergeht - um dem Tode, dem Anorganischen zu

1) Conferenze fiorentine, S. 2 II. - DUHem, II, S. I80.

2) Conferenze, S. 213 .

3) Duhem, S. 226. 
weichen; dieser regiert also neben der Kraft; sagt doch LEONARDo an einer anderen Stelle ausdrücklich ${ }^{1}$ ), daß der der Kraft verwandte Geist dem Körper wie ein Element beigemischt ist, und er lehrt von der Kraft, daß sie aus der vitalen Bewegung entsteht, welche letztere er sich grob mechanisch vorstellt:

die Bewegung der Lebensgeister, die durch die Glieder der empfindenden Tiere strömen, erweitert ihre Muskeln, die sich dadurch verkürzen und ziehen die Sehnen, mit denen sie verbunden sind, und von den Sehnen ist die Kraft in den Gliedern der Menschen hervorgebracht2).

LEONARDO unterscheidet also bei den Lebensvorgängen die etwas Vitales darstellende Kraft und die Körpermaschine, die er bereits als solche nennt und nach rein mechanischen Prinzipien zu erklären strebt. Während ARISTOTELES die Seele für die Form (das Wesen) des Organismus erklärt hat, spielt sie bei LEONARdo die Rolle einer im Gehirn festgesetzten Substanz, und ihre physiologische Bedeutung tritt in den Hintergrund; die "Lebensgeister ", d. h. eine Art feinster Materie, die einen Übergang zwischen der Seele (der Kraft) und der Materie bilden, sind von nun an bestimmt, als Antrieb der Lebensmaschine tätig zu sein.

Das Bedürfnis der Anschaulichkeit hat offenbar LEONARDo zu seiner Konstruktion der Lebensgeister (der "Ätherschwingungen ", würden wir heute sagen), zu seiner oben erwähnten Theorie der Muskelzuckung, zu seiner Auffassung des Körpers als einer Maschine geleitet. Diese Anschaulichkeit ist aber keine platonische mehr, da sie keine Beschreibung des unmittelbar Geschauten und Erlebten, sondern eine zur Erklärung gewisser Tatsachen erdachte Hypothese darstellt. Erst durch Abstraktion und durch Analyse der Tatsachen, also auf logischem Wege, kommt man auf solche auch für die moderne Wissenschaft charakteristischen Hypothesen.

\section{Die Galenisten.}

Der Kampf der Renaissance gegen den Aristotelismus gestaltete sich z. T. zum »Streit der Fakultäten «; die Mediziner als aphilosophische Erfahrungsmänner griffen die Professoren der Philosophie an: der Fachmann GALEN wurde über den spekulierenden ARISTOTELES erhoben. Der dogmatische Geist der galenischen Wissenschaft war dem Aufschwung der mechanistischen Weltanschauung insofern

1) DuHEM, S. I80.

2) DuHem, S. 237 . 
förderlich, als GALEN den Bau der Körpermaschine für die schlechthin gegebene Grundlage der Biologie genommen hat, auf deren Grund er seine physiologischen Schlußfolgerungen entwickelt hatte. Die Galenisten folgten dieser Methode und konnten sich deshalb u. a. nicht in HARVEYs Denkungsart einleben, nach der die Leistung des Organismus, der Blutkreislauf, eine ebenso primäre Tatsache darstellt wie die Struktur ${ }^{1}$ ). Wie mechanistisch bereits die Anatomen der Renaissance die Lebenserscheinungen gedeutet haben, ist nebst LEONARDO auch an VESAL zu sehen, der die Medizin dadurch zu reformieren gesucht hat, daß er die $\mathrm{K}$ örpermas ch in e in eingehendster Weise erforschte und aus ihr die Leistungen abzuleiten suchte. VESAL lehrt, daß sich die Muskeln infolge der Spannkraft der denselben durch die Nerven zugeführten feinsten Materie (Spiritus) und infolge ihrer inneren Struktur zusammenziehen und dehnen. Das Sehen, Hören, Schmecken stellen nach ihm keine wesentlich verschiedene Leistungen dar, sondern ein und dasselbe Nervenfluidum (Spiritus) soll von dem Gehirn aus zu einzelnen Sinnesorganen strömen und Sinnesfunktionen zur Folge haben, deren Qualität nur von der Konstruktion einzelner Sinnesorgane abhängig ist2). VESALs theoretische Anschauungen sind galenistisch; als sein Werk als eine Reformation der Anatomie auf den Thron gesetzt wurde, wurde zugleich dem Galenismus zu einem neuen Triumph verholfen und dadurch die mechanistische Weltanschauung angebahnt.

\section{Galilei.}

Es bleibe unentschieden, ob LEONARDOs mechanische Lehren auf die Biologen der nachfolgenden Epoche von Einfluß gewesen sind oder ob sie nur die Stimmung der Zeit ausdrücken, die später in anderen Geistern unabhängig von ihm ähnliche Früchte gezeitigt hat. Jedenfalls steht GALILEIs (I 564-I64I) mechanische Weltanschauung derjenigen LEONARDOs nahe; auch dieser Begründer der modernen Wissenschaft ist überzeugt, daß die Mathematik das Wesen der physikalischen Erscheinungen erschöpfend darstellen kann, daß die Qualitäten in der Natur auf Quantitäten reduziert werden müssen, und daß die mechanistische Weltanschauung die einzig richtige ist. Er glaubt, daß das Buch des Weltsystems mit mathematischen Buch-

1) Wir haben gesehen, daß Harvey diese Idee nicht konsequent durchgeführt und dem Mechanismus Konzessionen gemacht hat.

2) Fabrica, S. I 72. 
staben geschrieben ist, daß unsere Erkenntnis nur so weit, als die Möglichkeit, die Erscheinungen zu messen, reicht; das Qualitative, das Wesen der Sachen soll der Wissenschaft unzugänglich bleiben.

GALILEIs Lebenskampf hat sich zu einem Ringen um die Anerkennung der mechanischen Weltanschauung und $\mathrm{zu}$ einem Vernichtungskampf gegen die Biologie gestaltet: sollen wir deshalb GALILEI tadeln? Mit nichten: GaliLEI war an dem Verfall der Biologie ebensowenig persönlich schuldig, wie seine kirchlichen Gegner für die indirekte Verteidigung der Biologie und für die Verurteilung Galileis zu loben sind. Tatsache bleibt jedoch, daß GALILEI dadurch, daß er vor der wissenschaftlichen Welt Recht behalten hatte, die Biologie der nachfolgenden Epoche auf sehr falsche Bahnen geführt hat.

\section{Bacon.}

Auch die Erfahrungsphilosophie FRANCIS BACONs (I56I-I626) war geeignet, das Verständnis der Zeitgenossen für das Wesen der Biologie zu hemmen, denn auch dieser Wortführer der Ideale der modernen Wissenschaft hat die Physik der Biologie gegenüber begünstigt. Auch BACON vereinigt den Aristotelismus mit dem Realismus der Renaissancephilosophen. Mit GIORDANo BRUno und seinen Gesinnungsgenossen teilt er den Glauben an die Allbeseeltheit der Natur, mit PARACELSUs glaubt er an natürliche Sympathien und Antipathien der Dinge, an die Erfahrung, an die Wertlosigkeit der scholastischen Metaphysik und der offiziellen Wissenschaft; mit den Scholastikern hält er am Wert der Qualitäten in der Natur, an den vier aristotelischen Ursachen und namentlich an der methodologischen Bearbeitung der Wissenschaft fest.

Anstatt jedoch nach realistischer Art sich mit der Natur eins zu fühlen, sie mit Worten zu malen, zu begreifen, direkt zu erfahren, stellt sich BACON als ein typischer Scholastiker über dieselbe, sucht sie mit dem Verstande zu meistern - wohlbemerkt, nicht die Natur, sondern die aus sekundären Quellen gesammelten Angaben über die Natur. Von den Scholastikern unterscheidet er sich dadurch, daß er kein Biologe mehr ist, sondern am ehesten noch ein Arzt und Physiker. In seiner Klassifikation der Wissenschaften hat die Biologie (Zoologie, Botanik, Physiologie, Anatomie der Tiere u. ä.) unter den sehr zahlreichen von ihm aufgezählten Wissenschaftsgebieten keinen Platz; sie verschwindet in der "Naturgeschichte der Generationen " (der natürlichen Vorgänge) und der Monstrositäten. Die Physik dagegen 
wird ausführlich behandelt und noch ausführlicher die Anthropopologie, in der sogar eine Kosmetik und eine Athletik als besondere Disziplinen auftreten. Zwar spricht BACON auch von der Notwendigkeit einer "vergleichenden Anatomie ", aber, was er darunter versteht, veranschaulicht am besten seine Unwissenheit in biologicis: während die beschreibende Anatomie (A. simplex) einzelne Körperteile anführt, soll jene "die Verschiedenheit der Formen und $\mathrm{Zu}$ stände jener Teile bei verschiedenen Menschen beachten ( $\mathbf{I}$ ).

Mögen die Grundsätze der Philosophie BAcons an sich noch so beachtenswert und für die Physik noch so förderlich sein, für die Biologie konnten sie nur verhängnisvoll sein, indem sie für die Lebenserscheinungen kein echtes Verständnis zeigen.

\section{Descartes.}

RENÉ DESCARTES (I 596-I650), der vielgepriesene Bahnbrecher der modernen Philosophie, war sehr beflissen, die scholastische Syllogistik bloßzustellen und die Erfahrung zu preisen; die »Erfahrung " bietet ihm jedoch nur eine Reihe von meistens aus zweiter Hand geschöpften Tatsachen, auf welchen er seine Denkoperationen (mathematische, mechanische, logische Schlüsse) bauen kann. Er wirft z. B. GALILEI vor, daß dieser keine allgemeinen Ursachen (d. h. Erklärungsprinzipien) der von ihm entdeckten Tatsachen anführt; er hält die Anatomie für eine bereits vollkommene Wissenschaft $^{2}$ ), in der nur noch die Erklärungen der Teile auseinandergehen (eine These, die kein auf Anschauungen bauender Denker vertreten könnte, die dagegen gut in die Scholastik paßt); in seinen embryologischen Spekulationen stützt er sich auf die Aristoteliker FABRICIUS und HARVEY und sucht die Körperteile auf logischem Wege aus gewissen allgemeinen Hypothesen zu entwickeln ${ }^{3}$ ).

DESCARTES ist in demselben Sinne anschaulich wie LEONARDO: er ersinnt leichtbegreifliche Mechanismen, um mit deren Hilfe die (sonst bekannten) Tatsachen des organischen Lebens zu erklären.

Ich nehme an, sagt er, daß der Körper nichts anderes ist als eine Statue oder Maschine aus Erde, die Gott ganz so bildet, daß sie uns möglichst ähnlich erscheint, so daß er derselben nicht nur in ihrem Äußeren die Farbe

1) De dignitate et augmentis scientiarum libri IX. Parisiis 1624, S. 219.

2) K. Jungmann, R. Descartes. Leipzig I908, S. I79. - Descartes folgt in der Physiologie Galen (Jungmann, S. I 82).

3) Tractatus de homine Amsterodami 1686. S. I90. - (Biologischen Problemen ist teilweise gewidmet auch: Traité des passions de l'âme 1650.) 
und die Form aller unserer Glieder gibt, sondern auch, daß er in ihr Inneres alle die Teile legt, welche nötig sind, auf daß sie schreitet, ißt, atmet und schließlich sie alle diejenigen Funktionen den unsrigen ähnlich ausübt, von denen man sich vorstellen kann, daß sie aus [den Eigenschaften] der Materie folgen und nur von den Lagebeziehungen der Organe abhängig sind1).

Aus dem Blut scheiden sich die beweglichen Elemente, die Lebensgeister (spiritus animales), welche dann in die Poren des Gehirns und von da in die Nerven eindringen; und je nachdem sie in den einen mehr, in den andren weniger eintreten, oder auch nur einzutreten suchen, haben sie die Kraft, die Gestalt des Muskels, in den die Nervenröhren einmünden, zu verändern und dadurch alle Glieder in Bewegung zu setzen.

So ist z. B., meint Descartes, an den Grotten und Springbrunnen, die in königlichen Gärten zu sehen sind, die Kraft, mit welcher das Wasser seinem Behälter entströmt, hinreichend, um verschiedene Maschinen zu bewegen und diese sogar Instrumente spielen und Worte aussprechen zu lassen, je nach der verschiedenen Lage und Stellung der Wasserröhren. Und wirklich können die Nerven der tierischen Maschine, die ich beschreibe, sehr gut mit den Röhren dieser Wasserkünste verglichen werden; ihre Muskeln und Sehnen den andern verschiedenen Maschinen und Brunnen, die sie in Bewegung zu setzen scheinen; ihre Lebensgeister dem Wasser, das sie in Bewegung setzt und dessen Quelle das Herz ist, während die Höhlen des Gehirns das Hauptreservoir bilden ...

Durch grob mechanistische Hypothesen, in denen Molekularwirbel, Hebel und Lebensgeister (= feine Materie) die erste Rolle spielen, hat Descartes versucht, auch die psychischen Regungen, die Embryonalentwicklung und andere organische Erscheinungen $\mathrm{zu}$ erklären. Übrigens hat er sich für die Biologie nur wenig interessiert: seine Lehre, daß die Tiere geistlose Maschinen sind, die er allen Ernstes gegen die Aristoteliker verteidigt, legt nicht nur von seiner mechanischen Weltanschauung, sondern auch von seiner Unerfahrenheit auf dem Gebiete der Biologie Zeugnis ab. Man muß jedoch mit eigenen Augen lesen, wie unbekümmert um die vorhandenen Tatsachen sich die Kartesianer die Maschinentheorie des Lebens zurechtgelegt haben. MALEBRANCHE glaubt behaupten $z u$ dürfen ${ }^{2}$ ):

So gibt es in den Tieren weder Verstand noch Bewußtsein in dem Sinne, in dem man es gewöhnlich versteht. Sie essen ohne Lust, sie schreien ohne Schmerz, sie wachsen, ohne es zu wissen: sie begehren nichts, sie fürch-

1) T. 3. S. 27 .

2) Recherche de la vérité VI. 2e Ptie. Kap. 7. (Nach E. Cassierer, Leibnitzens Werke, Einleitung zum 2. Bd.) 
ten nichts, sie erkennen nichts; und wenn sie in einer Weise handeln, die Verstand bekundet, so kommt dies daher, daß Gott zum Zwecke der Selbsterhaltung ihren Körper so eingerichtet hat, daß sie rein maschinenmäßig und ohne Furcht alles meiden, was sie zu vernichten droht.

Die peripatetischen Gegner DESCARTES' müssen besonders ungeschickte Naturforscher und der Glaube an den Mechanismus muß besonders stark gewesen sein, wenn die aristotelische Lehre von den Organismen Anschauungen unterliegen konnte, die in den zitierten Sätzen vertreten werden ${ }^{1}$ ).

Die wissenschaftliche Methode Leonardos, Bacons, Descartes' 2 ), d. h. die Methode der Begründer der modernen Wissenschaft, ist diescholastische, auf die im Gegensatze zur biologisch orientierten Scholastik antibiologisch gedeutete Natur angewendete $\mathrm{Me}$ thode, welche darin besteht, aus einer Reihe von (meistens aus zweiter Hand genommenen) Tatsachen gewisse allgemeine Schlüsse zu ziehen. Die Tatsachen bilden nur den Ausgangspunkt dieser Forschung; der größte und wichtigste Teil derselben besteht dagegen in Folgerungen, die auf logischem Wege gewonnen werden. Diese Methode war besonders geeignet, die Aufmerksamkeit der Forscher auf sich zu lenken; denn sie betonte - im Gegensatze zu der scholastischen Metaphysik - die Notwendigkeit der Erfahrung; sie war modern; sie fand endlich einen mittleren Weg zwischen der konservativen Scholastik und dem radikalen Neuplatonismus. Die letztere Philosophie, die Weltanschauung der Frührenaissance, wie sie namentlich in PARACELSUs' Schriften zutage tritt, befolgte eine andere Methode als diejenige der modernen Wissenschaft; als radikale Feindin der Scholastik stellte sie Erfahrung, d. h. Erlebnisse dem Schlußverfahren gegenüber, anstatt des theoretischen Erklärens der Naturerscheinungen betonte sie das Erfassen derselben; die Neuplatoniker waren der instinktiven Intuition, die neue Wissenschaft der Verstandestätigkeit geneigt.

Wenn man Bacon, Descartes, Galilei als die Gesetzgeber der neuen Wissenschaft rühmt, so denkt man an ihre Leistungen in der Mechanik, Mathematik, Astronomie; der Biologie ist unter ihrer Herrschaft niemals ganz wohl gewesen, und wiederholt haben die

1) Literatur. Garnier, Oeuvres philosophiques de Descartes. 3 Vols. Paris 1835. - Heussler, H., Der Rationalismus des I7. Jahrhunderts in seinen Beziehungen zur Entwicklungslehre. Breslau 1885.

2) Über Galileis Methode wage ich kein Urteil zu fällen, da ich sie eingehender nicht studiert habe. 
Biologen Versuche gemacht, sich von der Vormundschaft der Mechanik zu emanzipieren. Zu konsequenten Mechanisten, zu den Anhängern Galileis und Descartes' gehören unter den Biologen des I7. Jahrhunderts BORELLI und WILLIS nebst den wenigbedeutenden Iatromechanikern.

\section{Borelli.}

Giovanni Alphonso Borelli (i608-i679), Arzt, Mathematiker, Physiker, Astronom und Physiologe, sagt ausdrücklich, daß die Physiologie einen Teil der Physik ausmacht. Sein wichtigstes Werk handelt über die Bewegung der Tiere (I680), in dem er die von dem Holländer N. StEno ( I 664) begründeten Anschauungen über die Muskelzusammenziehung physikalisch zu analysieren sucht. Während nämlich ARISTOTELES die Ursache der Muskelkraft in die Sehnen verlegte, hat $\mathrm{N}$. STENo mit Hilfe des Mikroskops gefunden, daß das Fleisch des Muskels aus parallelen Fasern zusammengesetzt ist, welche wieder aus Bündeln von feinen Fibrillen bestehen; die einzelnen Muskelfasern sollen miteinander durch [bindegewebige] Querfasern verbunden sein, und in dieser Struktur des Fleisches sei die Ursache der Muskelbewegung zu suchen. Auf Grund dieser Befunde stellte BoRELLI die Theorie auf, daß die Muskelfasern aus reihenweise angeordneten Rhomben bestehen, und daß während der Zusammenziehung keilartige Elemente zwischen einzelne Rhomben eingeschoben werden, welche dadurch entstehen, daß beim Impuls zur Bewegung eine feine Substanz durch die Nerven in den Muskel strömt und in demselben eine andere Substanz antrifft, die mit der ersteren gemischt in eine plötzliche Fermentation gerät, deren Produkt die Lücken im Muskel ausfüllt und so die Turgeszenz und $\mathrm{Zu}$ sammenziehung verursacht.

Mechanisch will BORELLI auch die Tätigkeit der Drüsen erklären. Die Flüssigkeiten stellt er sich als aus elementaren, freibeweglichen Partikelchen zusammengesetzt vor; die Mannigfaltigkeit der Flüssigkeiten besteht in den Verschiedenheiten der Konsistenz, Form und Bewegungsart der sie zusammensetzenden Teilchen. Die Sekretion in den Drüsen geschieht auf die Art, daß die einen Flüssigkeitsteilchen durch die porösen Drüsenwände durchdringen können, die anderen nicht. So z. B. wird man nach Borelli in der Niere Poren von zweierlei Größe annehmen müssen: durch die einen wird das venöse Blut hindurchgelassen, durch die anderen die Urinflüssigkeit.

In dieser handgreiflichen aber erfahrungswidrigen Weise entwickelte BORELLI, der Begründer der »iatromechanischen« 
Richtung, seine Theorien und fand in einer durch GaLILEI, DescaRTES und den nunmehr ganz mechanistisch gedeuteten HARVEY beeinflußten Zeit viele Anhänger, von denen GIoRgIo BAGLIvi (I668i707), Antonio Pacchioni (I665-I726) und Fr. Hoffmann (I660 bis I742) als die bedeutendsten angeführt seien. Ein Abschnitt aus Hoffmann mag zur Charakteristik der Denkweise der Iatromechaniker dienen.

Nur die Mechanik, mit der Anatomie und Chemie verbunden, führt die Naturwissenschaft und Medizin von dem niedrigen zu einem erhabenen Standpunkte: wer mit einer solchen Wissenschaft gehörig bewaffnet ist, wird am leichtesten die Ursachen der dunkeln Vorgänge ermitťln, die zweifelhaften Kontroversen und Meinungen der Ärzte lösen, kräftige Medikamente auch in den hoffnungslosen Krankheiten glücklichst erfinden können; diese Wissenschaft verwendet die geringste Anzahl der Prinzipien, welche eben Prinzipien der künstlichen wie der natürlichen Dinge sind, nämlich die Materie und die Bewegung ${ }^{1}$ ).

Historisch bemerkenswert ist, daß derartige Anschauungen zu jener (religiös sehr empfindlichen) Zeit keinen Anstoß bei der Kirche hervorgerufen haben ${ }^{2}$ ).

\section{Willis.}

Thomas Willis(IUS) (I62I-I675), ein berühmter Londoner Arzt, hat nebst Untersuchungen über verschiedene Krankheiten auch über den Bau der Tiere und besonders über Tiergehirne geschrieben. Er beschrieb eingehend das Menschengehirn, analysierte auch das Gehirn der Säuger und der Vögel. In diesen Untersuchungen macht sich das Bestreben geltend (wahrscheinlich unter HARVEYs Einflusse) auch eine »vergleichende Anatomie « zu begründen. Von der Idee geleitet, daß alle Tiere wesentlich dieselben Organe besitzen, vergleicht er z. B. den Organismus des Krebses mit demjenigen des Menschen: wie der Krebs nach rückwärts schreitet und schwimmt, so besitzt er auch invers gelagerte Organe, die Knochen nach außen, die Muskeln nach innen, die Aorta und das Herz oben, die Eingeweide und das Rückenmark unten. Mag dieser Vergleich naiv senn: eine Ahnung der Grundwahrheit jeder vergleichenden

1) Hoffmann, F., Fundamenta Medicinae ex principiis naturae mechanicis in usum Philiatrorum succincte proposita. Halae 1695. S. 4.

2) Literatur. Borelir, A. G., De motu animalium. Leyden 1680-8r. Steno, N., De musculis et glandulis observationum specimen. Kopenhagen I664. Elementorum myologiae specimen. Ibid. 1667. PACCHIONI, A., De durae matris fabrica et usu. Ranae I 7or. 
Anatomie, der Einheit des Organisationsplanes im Tierreich, liegt ihm zu Grunde. Sonst hat WiLlis das Wesen der vergleichenden Anatomie kaum besser zu charakterisieren vermocht als sein Volksgenosse GLISSON ${ }^{1}$ ):

Um Kenntnis vom Gehirn und seinen Teilen $z u$ erlangen, wird es nötig sein, nicht nur die menschlichen Köpfe, sondern auch die Köpfe anderer Tiere jedweder Gattung anatomisch $z u$ untersuchen, denn erstens sind die menschlichen Leichen schwer zu erlangen, ferner ist das Gehirn des Menschen sehr groß und deshalb nicht leicht übersichtlich ... Und wenn ich bei dieser Untersuchung einige Ähnlichkeiten und Verschiedenheiten nachweisen werde, welche bei verschiedenen Tieren, wenn untereinander und mit dem Menschen verglichen, bestehen, so werden gewiß von einer solchen vergleichenden Anatomie nicht nur die Fähigkeiten und Funktionen jedes Organs, sondern auch die Spuren, die Einflüsse und die verborgenen Wirkungsarten der sensitiven Seele entdeckt werden können.

Der Beschreibung der (makroskopisch sichtbaren) Teile des Gehirns fügt WILlis Auseinandersetzungen über die Seele hinzu, die gut die Verwandtschaft seiner Anschauungsweise (mit DEscartes und) mit der Scholastik veranschaulichen. Im Gehirn werden nach seiner Lehre alle Begriffe (conceptus) der rationalen wie der sensitiven Seele, so die Ideen, der Wille, die Fähigkeiten, gebildet, und nachdem sie dort ihre Form erlangt haben, werden sie verwirklicht. Nur der Mensch hat eine unsterbliche Seele, welche nach dem Himmel zielt, und deshalb ist sein Großhirn an der höchsten Stelle, nämlich über dem Kleinhirn, ausgebreitet. Die tierische und die niedrigere menschliche Seele (anima sensitiva) ist materiell und läßt sich mit dem Feuer vergleichen; sie besteht aus feinen und sehr beweglichen Partikelchen, welche im Gehirn aus dem Blut durch die porösen Wände der Blutgefäße filtriert werden. Alle seelischen Funktionen sind Folgen dieser feinen Substanz, dieser Lebensgeister; so ist die Vorstellungskraft 》eine gewisse Undulation der tierischen Spiritus «, welche in das Gehirn gerichtet ist und von dort wieder gegen die Peripherie zielt; ähnlich kann auch das Gedächtnis und das Streben (appetitus) erklärt werden; die Empfindlichkeit und Beweglichkeit, die Affekte und Instinkte hängen nur mittelbar vom Gehirn ab und haben ihren wahren Sitz im Kleinhirn und im verlängerten Mark. Die Dura mater zieht sich an verschiedenen Stellen des Gehirns zusammen und reguliert auf diese Art den Zufluß des Blutes zu verschiedenen Gehirnteilen und dadurch auch die Produk-

1) Cerebri anatome, S. 2. 
tion der Lebensgeister, die in der grauen Substanz des Großhirns gebildet, durch die weiße Substanz und die Nervenröhren in die Muskeln und andere innervierte Körperteile geleitet werden.

Diese Ansichten hat WILlis auch auf die niederen Tiere angewendet (1672). Die tierische Seele soll je nach der Struktur des organischen Körpers verschieden sein, und um die Mannigfaltigkeit der Tierseelen darzustellen, muß man zuerst die Geschichte der Tiere, ihre Anatomie und Einteilung schreiben. Die Tiere können entweder nach ihren Atmungsorganen in solche, welche durch Kiemen, und solche, die durch die Lunge atmen, eingeteilt werden, oder nach der Beschaffenheit des Lebenssaftes (nach dem Beispiele des ARISTOTELES) in blutlose und blutführende; die letzteren sind teils weniger vollkommen und kalt (z. B. Regenwurm), teils vollkommen und warm. Die blutlosen sind entweder Landtiere, wie viele Insekten, oder Wassertiere, unter die andere Insekten und verschiedene Fische gehören; die Fische sind teils weich, wie Sepia, teils mit einer Schale versehen, wie die Auster und die Krustentiere (Krebs) ${ }^{1}$ ).

1) Literatur. Th. WILlrs, Cerebri anatome nervorumque descriptio atque usus. Londini 1659. De anima brutorum, quae hominis vitalis ac sensitiva est, exercitationes duae. Oxonii 1672. - Opera omnia. 2 Vol. Genevae 1680. 


\section{Kapitel.}

\section{Epigonenwissenschaft des 17. Jahrhunderts.}

Wir haben uns in der Schilderung des biologischen Denkens schon weit von der Sturm- und Drangperiode der Wissenschaft entfernt, in der die Menschheit, vor dem Schauer der unendlich tiefen Wirklichkeit ergriffen, derselben die verwegenen Entdeckungen eines KolUMBUS, eines VASCO DE GAMA, eines KOPERNIKUS entrungen hat, in der ein Paracelsus, ein Leonardo, ein Vesal die neuen Grundlagen für die Erforschung des Lebens gelegt hatten; auch die Periode Galileis, Harveys, Descartes', Bacons lebt bereits nur als Erinnerung an kühne Leistungen der vergangenen Zeit im Gemüt einer neuen Generation von Biologen. Die altertümliche Tradition, GALEN, ARISTOTELES, Plato, ist jetzt für auf ewige Zeit überwunden erklärt - und eine neue, an die Begründer der modernen Wissenschaft anknüpfende Tradition, mit allen dunklen Seiten, die der pedantischen Verehrung der Vergangenheit anhaften, hat den Thron bestiegen.

Die Wissenschaft hörte auf, eine in klaren Begriffen konstruierte Erfahrung, d. h. ein auf die Höhe der Logik erhobenes Bewußtwerden der Erlebnisse zu sein; der Schauer vor der unmittelbaren Wirklichkeit verschwindet vor einem ruhmredigen Vernünfteln über künstlich konstruierte Probleme. Man fühlte sich der Pflicht überhoben, die Vergangenheit verstehen zu lernen; alles was hinter HARVEY lag, war vergessen oder mißverstanden, denn die »moderne Wissenschaft «mit ihren epochalen Entdeckungen der Fliegenmaden, die aus Eiern entstehen, und der in der Samenflüssigkeit des Menschen schwimmenden, mit Kopf, Füßen und sogar mit einer Art Kleid versehenen Spermatozoen, die Betonung der mathematischen Exaktheit, die Herrschaft der mathematisch und mechanistisch begründet sein sollenden Medizin, der Iatromathematik, Iatrophysik, Iatrochemie erlaubte es den neuen Berühmtheiten nicht, sich um die unaufgeklärte griechische Wissenschaft, um das dunkle Mittelalter oder um die Renaissance zu kümmern. 
Es wäre Schande für einen Philosophen, für einen Arzt, in einem so aufgeklärten Jahrhundert wie dieses ist, wo die Erfahrung und die soliden Lehren der Mathematiker so viel Licht auf die Entdeckung der Ursachen geworfen haben,... es wäre Schande »den falschen Galenisten « zu glauben und nicht anzunehmen, daß die parasitischen Würmer aus Eiern entstehen, die von Gott bei der Erschaffung des Menschen in denselben eingepflanzt worden sind...

so brüstet sich der berühmte Iatrophysiker BAGLIVI in einem Schreiben an N. ANDRY ${ }^{1}$ ). Solche Stimmung hat damals geherrscht. Man hatte den Mund voll von Mathematik und berechnete, wieviel Menschenkeime in Eva eingeschachtelt waren; der Grundsatz »hypotheses non fingo « war allerorten zu hören, gleichzeitig hat man aber im Ernst über Spermatozoen debattiert, die kleinen Männlein ähnlich und bereits mit Händen und Füßen und mit einer Mütze auf dem Kopf versehen sein sollten. Hören wir denselben BAGLIVI:

... ich würde nicht leicht von der Meinung des Hippokrates abweichen oder wenn ich abweichen sollte, würde ich es nicht wegen frivolen syllogistischen Subtilitäten tun, noch wegen leerer Fiktionen von Hypothesen, die zu verachten ich mir zum Ruhme anrechne; ich würde es tun, um mich an eine konstante Erfahrung anzuschmiegen, von.deren Gewißheit noch eine lange Reihe von Beobachtungen überzeugen würde. Die Quelle von mehreren Krankheiten wird im Schoß der Mutter gesucht, so diejenige der sogenannten erblichen Krankheiten, warum sollten wir zu denselben nicht den Plattwurm zählen, namentlich da wir für uns die Autorität eines so klaren Mannes haben, wie Hippokrates einer war? 2)

Der Galenismus, d. h. ein leichtfertiges Rationalisieren über die Tatsachen, kam in dieser Epoche zu neuer Blüte. Von dieser Zeit haben wir die falschen Vorstellungen von der Renaissance der Wissenschaft geerbt, nach welchen Galilei, Harvey, Descartes, NewtoN an der Wiege der modernen Wissenschaft gestanden haben sollen, während die eigentlichen Führer der Renaissance, Cusanus, PARACELSUS, LEONARDO, TELESIUS, unbekannt und unverstanden bleiben; von dieser gedankenlosen Zeit übernehmen wir auch den unberechtigten Spott über die Scholastik, einen Spott, der ein zur leeren Floskel gewordener Kampf der individualistischen Renaissancewissenschaft gegen die objektivistische Scholastik war.

Es entstand eine Epigonenbiologie, deren Ideale, je weiter sie sich von ihrer Quelle, von DEscarTes und von Harvey entfernte, desto flacher wurden ${ }^{3}$ ). Theologische Deutungen der organischen

1) Andry, N., De la génération des vers etc. Amsterdam i jor.

2) Ibid., S. 267 .

3) Niemals waren die Gelehrten eifersüchtiger aufeinander, niemals verschwiegen sie mehr die Verdienste anderer, niemals war die Ruhmsucht größer. 
Erscheinungen rücken wieder vor. Der Jesuit Athanasius KIRCHER, ein bekannter Physiker und zu seiner Zeit ein berühmter Mann, hat in seiner 》Arca Noe《 (1675), einer ausführlichen Aufzählung der von Noe vor der Sintflut geretteten Tiere, ein Beispiel dieser Literaturart hinterlassen. Die Physiko-, Astro-, Hydro-, Ichthyo-, Insektotheologien wurden beliebt. Der berühmte Zoologe und Botaniker RAY gab eine Schrift unter dem Titel »Die in der Schöpfung geoffenbarte Weisheit Gottes «(I69I) heraus; der Botaniker N. GREW verfaßte eine "Cosmologia sacra «(I7Or); auch der Chemiker Boyle hat mehrere solche wissenschaftliche Werke hinterlassen; ("Der christliche Virtuos «). Der oft genannte Geologe J. J. Scheuchzer verfaßte eine »Kupferbibel, in welcher die Physica sacra oder geheiligte Naturwissenschaft derer in heil. Schrift vorkommenden natürlichen Sachen deutlich erklärt und bewährt «wird (I73I). Bis in den Anfang des I9. Jahrhunderts hat sich diese Art der Naturwissenschaft hingezogen und fand namentlich in England Anhänger. Noch $\mathrm{CH}$. DaRWin fand es nötig, gegen dieselbe zu polemisieren ${ }^{1}$ ). $\mathrm{Zu}$ dieser Zeit haben auch die sonderbaren Streitigkeiten der Ovisten und Animalkulisten die Aufmerksamkeit der Forscher gefesselt. Die Biologie als selbständige Wissenschaft hat sich noch nicht herauskristallisiert; immerhin ist $\mathrm{zu}$ ihrer Grundlegung Bedeutendes geleistet worden. Redi, Malpighi, Swammerdam, Réaumur, RöSei, von Rosenhof, Spallanzani bezeichnen den je weiter desto mehr sinkenden Wellenschlag dieser Forschungsrichtung.

\section{Redi.}

FRANCESCO REDI (I626-r694) war ein sehr berühmter italienischer Gelehrter. Seine stilistisch ausgearbeiteten und mit Zitaten aus klassischen Autoren (ARistoteles, Plinius, Ovid, Cicero u. ä.) durchspickten wissenschaftlichen Abhandlungen wechseln mit Gedichten $\mathrm{ab}$, die von den Literaturhistorikern nicht geringgeschätzt werden; namentlich der Dithyrambus auf den Wein wird gelobt, und REDI soll sogar diese Art der Poesie begründet haben. In einer ausführlichen Arbeit hat REDI die Entstehung der niederen Tiere (der Insekten) studiert und die Lehre HARvers, daß alle Organismen aus Eiern entstehen, weiter ausgeführt. HARVEY hat als treuer Schüler des ARISTOTELES angenommen, daß bei den Insekten und den ihnen ähnlichen niederen Tieren aus faulenden Substanzen

1) Ausführlicheres über diese Literaturgattung bei O. ZöCKLER, Geschichte d. Beziehungen zw. Theologie u. Naturwissenschaft. Gütersloh I789. II. S. 74 sq. 
"Eier « entstehen, die sich zum vollkommenen Tier entwickeln. REDI führt nun auf Grund zahlreicher Beobachtungen den Nachweis, daß (entgegen der peripatetischen Lehre) auch bei den Insekten die Geschlechter differenziert sind, daß befruchtete Weibchen Eier legen, aus denen sich die Insekten entwickeln. REDI entwickelt auch die Konsequenzen dieser Lehre: alle alten Schriftsteller, die Mechanisten wie die Vitalisten, haben angenommen, daß die Organismen (den Menschen mit einbegriffen). der Erde wesensverwandt sind: diese Lehre ist nun als unrichtig erwiesen; das Reich der Organismen ist radikal von der toten Erdkruste getrennt, das Leben von heute entsteht nur aus dem Leben von gestern, und alle je auf der Erde erschienenen Organismen hängen in einer kontinuierlichen genetischen Reihe zusammen. Seitdem Gott am Anfang den Menschen, die Tiere und die Pflanzenformen durch ein Wunder auf die Welt gestellt hat, entwickelt sich das Leben nur durch Zeugung von lebenden Eltern.

Klingt diese Lehre nicht wie ein verpuppter Darwinismus? Auch in diesem wird eine ununterbrochene Kontinuität des Lebens auf der Erde gepredigt. REDI hat noch nichts von der Formenbeständigkeit der Tiere gewußt und konnte deshalb kein Darwinist sein; er erblickt nichts Unmögliches in der Annahme, daß parasitische Würmer aus den lebendigen Säften ihres Wirtes und daß die Gallinsekten direkt aus dem Pflanzensafte (durch die Einwirkung der Ernährungs- und Wachstumsseele) geboren werden - denn auch in diesem Falle entsteht Leben aus Leben. In einer Kritik der REDIschen Anschauungen korrigiert ein Zeitgenosse REDIs, VALLISNIERI, diese Hypothese und behauptet, daß auch die Gallinsekten und die parasitischen Würmer aus Eiern entstehen. Auf welche sonderbaren Konsequenzen diese Beobachtungen geführt haben, werden wir später sehen ${ }^{1}$ ).

Alle späteren Berichterstatter rühmen REDIs Entdeckung der geschlechtlichen Vermehrung der niederen Tiere und lachen ARISTOTELES, der an die Entstehung der Frösche aus dem Schlamme geglaubt hat, aus; keiner hat bemerkt, daß REDIs Entdeckung um einen so hohen Preis erkauft wurde, daß es Jahrhunderte hat dauern müssen, bevor ihn die Arbeit der Forscher zu tilgen vermochte. Man nahm mit REDIs tatsächlichen Beobachtungen auch seine Lehre mit in Kauf, daß die Natur ohnmächtig ist, Leben zu erschaffen: Gott allein habe am Anfang die Organismen ins Leben gesetzt, und

1) REDr, Esperienze intorno alle generatione degli Insetti. Firenze 1668. 
seitdem pflanzen sie sich unveränderlich auf der toten Erde fort. Die Grundlage für die Präformationstheorien wurde durch diese These gelegt. Und zweitens: ARISTOTELES hat die »niederen Tiere « wenig geachtet; REDI hat das Interesse für die Insekten erweckt, hat nachgewiesen, daß sie sich analog wie die höheren Tiere vermehren. Diese Entdeckung hat in Verbindung mit Malpighis Arbeiten zur Folge gehabt, daß man sich bald auf das Studium der Insekten konzentrierte und die Probleme der Biologie dieser in Einzelheiten mannigfachen, im Großen jedoch faden Tiergruppe anpaßte ${ }^{1}$ ).

\section{M. Malpighi.}

Marcello Malpighi (I628-I694), Professor "der Medizin in Bologna und später an anderen italienischen Universitäten, ein Freund des Mechanisten BoRELLI, hat als erster das im letzten Dezennium des I6. Jahrhunderts entdeckte Mikroskop zu wissenschaftlichen Untersuchungen mit Glück angewendet. Man fand Vergnügen an der Untersuchung der heterogensten Objekte mit den unvollkommenen Vergrößerungsgläsern; der wissenschaftliche Geist jedoch, der die Tatsachen beherrscht und sich derselben als Mittel zur Aufstellung von Naturgesetzen bedient, war lahmgelegt; und so führte man das unter dem Mikroskop Gesehene meistens nur mehr als Beweis für die Vergrößerungskraft des Mikroskops an. In dieser Weise haben sich des Mikroskops die Physiker R. Hooke und Huyghens, der Biologe Leeuwenhoek und viele andere bedient und zu den im I7. und I8. Jahrhundert in der Philosophie herrschenden Spekulationen über die unendlich kleinen Bestandteile und Keime der Dinge beigetragen; wenn auch MALPIGHIs Forschung höher als diejenige dieser Biologen steht, so hat auch dieser Gelehrte den Empirismus seiner Zeit nicht zu überwinden vermocht.

MALPIGHI entdeckte die Kapillaren und den kapillaren Blutkreislauf (I66I) und vervollständigte dadurch bedeutend die HARVEYsche Lehre (nach der sich das Blut aus den Gefäßen in das Körperparenchym ergießen sollte); eingehender als HARveY hat er die erste Entwicklung des Hühnchens beschrieben; einer gründlichen Untersuchung hat er den Bau der Drüsen unterzogen (1665); von ihm rührt eine ausführliche mikroskopische Untersuchung des Pflanzengewebes (I675) und eine monographisch bearbeitete Anatomie des Seidenwurmes (I669) her.

1) REDI, Esperienze intorno alle generatione degli Insetti. Firenze r668. 
Das eingehende Studium der feinen Tier- und Pflanzenorganisation führte zum Ergebnis, daß der organische Körper viel komplizierter gebaut sei, als sich HARVEY und die Peripatetiker vorgestellt hatten. Als MALPIGHI die Kapillaren entdeckte, hat er in HaRveys physiologische Lehre eine anatomische Tatsache eingeführt, die man aus derselben nicht deduktiv gewinnen konnte. Durch die Anatomie des Seidenwurms hat er nachgewiesen, daß auch die niederen Tiere, welche die Peripatetiker für Klumpen undifferenzierter Masse gehalten hatten, sehr verwickelte und ungeahnte Strukturen besitzen, und zu einem ähnlichen Resultat kam er durch die Untersuchung des pflanzlichen Körpers, in dem er eine Reihe von Gewebselementen zu entdecken wußte.

Eine Vertiefung der Lebensauffassung war auf Grund von MaLPIGHIs Entdeckungen möglich, trat aber nicht ein; der fortschreitende Verfall der biologischen Forschung bildete eine Ursache; die andere lag in MalPighi selbst. MalPighi bemerkte nicht, daß seine Entdeckungen mit dem gangbaren Mechanismus unvereinbar waren, und hat neuen Wein in alte Gefäße gegossen: er suchte seine Entdeckungen als Folgerungen der bekannten Tatsachen darzustellen. Er hat z. B. als erster die Tracheen der Insekten und die Spiralgefäße der Pflanzen beobachtet; anstatt vor diesen auffallenden Sćrukturen überrascht stehen $\mathrm{zu}$ bleiben und durch gründliches Studium ihr Wesen zu erforschen, erklärt sie MALPIGHI nach einigen oberflächlichen Experimenten für der Atemröhre des Menschen funktionell analog, behauptet, auch bei den Pflanzen rhythmische Atembewegungen beobachtet $\mathrm{zu}$ haben, und erniedrigt seine qualitativ neue Beobachtung zu einer bloß quantitativen Erweiterung des bereits Bekannten. MALPIGHI trägt selbst Schuld daran, daß seine Anatomie keine neuen Untersuchungen, keine neuen Ideen angeregt hat; im I9. Jahrhundert mußte die Pflanzenanatomie fast neu entdeckt werden.

Desto nachhaltiger hat MALPIGHI durch seine embryologische Theorie gewirkt; er war der erste, welcher sich, von mechanistischen Vorurteilen verleitet, für die Theorie der Präformation und gegen die Epigenesis aussprach. Wie HARvey sucht auch MALPIGHI sich den Vorgang der Entwicklung durch eine Analogie zu verdeutlichen, kennt aber den aristotelischen, von HARvEY noch klar vertretenen Vitalismus nicht mehr, sondern die Maschinen bilden sein einziges Vergleichsobjekt. Die künstlich erzeugten Maschinen, sagt er, werden so gebaut, daß aus einzelnen für sich konstruierten Teilen 
die Maschine zusammengesetzt wird. So entsteht jedoch der Organismus nicht; folglich ist bereits im $\mathrm{Ei}$ das ganze künftige Tier eingeschlossen, und anstatt des ersten Anfangs desselben sehen wir allmähliche Entfaltung der Organe. Wie der Tod weder des lebendigen noch des bereits gestorbenen Körpers Eigenschaft ist, so soll etwas Ähnliches auch bei der Entstehung des Organismus statthaben ${ }^{\mathbf{1}}$. Da Malpighi die erste Entstehung des Embryos nicht gesehen hat, ist er zu der nicht ganz deutlich ausgesprochenen Meinung verführt worden, daß der Embryo überhaupt nicht (als etwas Neues) entsteht, sondern sich nur a uswickelt 2 ). Und in diesem Glauben wurde er noch mehr durch die Beobachtung bestärkt, daß die Furchung des Hühnereies oft bereits vor der Befruchtung beginnen kann. Die Analogie zwischen dem Ei der Tiere und dem Samen der Pflanzen hat ihn in seiner Hypothese bekräftigt; er findet auch im Samen die bereits vollständige künftige Pflanze eingeschlossen.

Durch diese unglücklichen Gedanken von der Präexistenz der definitiven Organe im Keime hat MALPIGHI viel Schaden angerichtet; alle Biologen und alle mechanistischen Philosophen der nachfolgenden Zeit beriefen sich auf ihn als auf eine bewährte Autorität, als sie den Nachweis führten, daß die Natur außerstande ist, qualitativ Neues hervorzubringen.

Eine der MalPighischen Arbeit über die Pflanzenanatomie ähnliche Untersuchung hat der Engländer NEHEMIAH GREw (I628-I7 I I) veröffentlicht; der beschreibende Teil seiner Anatomie ist vielfach noch gründlicher als derjenige der Schrift MALPIGHIs, theoretisch erreicht er MALPIGHI nicht.

MalPIGHi hat die Pflanzenzellen bemerkt, ohne sie jedoch richtig verstanden zu haben. Vor ihm hat den zelligen Bau der Pflanzen ROBERT Hooke (1635-r703) beobachtet (1667). Hooke war ein sehr vielseitiger Mann; außer dem Problem der Flugmaschine hat er eine Reihe von physikalischen und astronomischen Aufgaben gelöst, mit Huyghens stritt er um die Priorität in der Anwendung des Pendels zur Zeitmessung, er hat chemische Experimente gemacht und war daneben noch ein geschickter Architekt. Auch das Mikroskop verbesserte er wesentlich und bemühte sich, die Kraft desselben

1) De form. pulli. Einleitung.

2) $>$ Quare pulli stamina in ovo praeexistere, altioremque originem nacta esse fateri convenit, haud dispari ritu ac in plantarum ovis. « Ibid., S. 2. 
$\mathrm{zu}$ beweisen und die Vollkommenheit der Werke Gottes zu preisen. Die Zellen sah er an einem dünnen Schnitt des Flaschenkorkes; der Name Zelle rührt von ihm her. Hooke hielt die Zellen für Poren in der Pflanzensubstanz und war erfreut, durch seine Entdeckung die Porosität der Materie bewiesen zu haben ${ }^{1}$ ).

\section{J. Swammerdam.}

Das Leben von Jan JaKob Swammerdam (I637-I680) fällt in die religiös erregte Zeit, in der Helmont, PAScal, Comenius, SpINOZA ihren Lebenskampf gegen den herrschenden, sich auf die weltliche Macht stützenden Jesuitismus führen mußten. An SwammerDAM ist jene Erregung nicht wirkungslos vorübergegangen. Der reiche Vater Swammerdams hatte sich in Amsterdam große Sammlungen von Kuriositäten angelegt, und der junge Sohn hatte bei dem Ordnen derselben, womit er vom Vater betraut worden war, bereits in der frühesten Jugend Gelegenheit gehabt, sich bedeutende naturwissenschaftliche Kenntnisse zu erwerben. Swammerdam studierte Medizin in Leiden, wo er mit den Naturforschern N. STENo und REGNIER DE GRAAF befreundet wurde; mit dem letzteren geriet er später in eine Polemik, welche ihm das Leben verbitterte. Die innigste Freundschaft schloß er während einer Reise nach Frankreich mit dem französischen Gesandten in Genua, Melchior Thevenot; dieser wurde ihm, wie SWAMmERDAM vor seinem Tode schrieb, der einzige »certus, fidus, verus amicus, cui neminem parem usquam inter mortales reperisset «. I668. wurde er auf den Toskanischen Hof unter ehrenvollen Bedingungen eingeladen; sein Freund, der Geologe und Anatom N. STEno, folgte einer analogen Einladung, wurde Leibarzt des mediceischen Fürsten, trat zum Katholizismus über und erreichte bald die Würde eines Bischofs. Swammerdam lehnte den Vorschlag ab, da ihm das Leben am Hofe nicht gefiel, und da er seine Selbständigkeit in Sachen der Religion nicht opfern wollte.

1) Liter a tur. Malpighi, M., De pulmonibus epistolae duo ad Borellium. Bonon. I66I. - De viscerum structura exercitatio anatomica. Londini I669. - De structura glandularum conglobatarum epistola. Londini 1697. - Anatome Plantarum cum appendice observationes de ovo incubato continente. Londini 1672. - Opera omnia, zuerst Londini 1686 und später mehrmals (ich habe diese Gesamtausgabe benutzt). Die * Anatome Plantarume erschien stark verkürzt und mit Anmerkungen versehen in OsTWALDS Klassikern der exakten Wissenschaften. Nr. I20. Leipzig 1901. - HookE, Roв., Micrographia or some physiological descriptions of minute bodies made by magnifying glasses. London 1667. - GREw, NEH., The anatomy of vegetables begun with a general account of vegetation founded thereupon. London 1672 . 
$\mathrm{Zu}$ Hause erwarteten ihn jedoch Mißverständnis und Not. Er war stets nur in seine wissenschaftlichen Arbeiten vertieft und übte keine ärztliche Praxis, und die Wissenschaft kostete nur zu viel Geld; sein praktischer Vater hörte auf, ihn zu unterstützen. Große Anstrengungen und das äußere Mißgeschick zogen eine Krankheit nach sich, welche deprimierend auf das empfindliche Gemüt SwAMMERDAMS wirkte. Er fing an, sich vorzuwerfen, daß er in seinen wissenschaftlichen Bestrebungen nur dem Ehrgeiz gefolgt wäre, und suchte in den Gedanken an Gott Ruhe zu finden. Es kamen ihm die Schriften einer durch religiöse Schwärmerei berüchtigten Jungfrau, Antolnette De Bourrignon, in die Hand, welche eben in Holstein predigte. In seinem zerrütteten Gemütszustand wandte sich Swammerdam an diese Person um Rat, trat mit ihr 1673 in Briefwechsel, folgte ihr I675 nach Schleswig und, als sie von dort ausgewiesen wurde, nach Kopenhagen. Das Leben in der Gnade Gottes war seitdem sein einziger Gedanke. Durch Vermittlung Stenos kam an SwAmmerdam eine neue Einladung aus Florenz, doch war sie an die Bedingung, zum Katholizismus überzutreten, gebunden ${ }^{1}$ ); SwAMmerdam lehnte mit den Worten ab, daß seine Seele nicht feil sei.

In den letzten Jahren seines Lebens entsagte SwAmmerdam der Wissenschaft; die unter großen körperlichen Leiden verfaßte Abhandlung über die Biene hat er seinem Freunde im Manuskript gegeben, ohne sich um ihr Schicksal weiter zu kümmern. Endlich erlöste ihn I680 der Tod von den körperlichen wie geistigen Leiden. Seine Sammlungen und Handschriften (über die Insekten) vermachte er Thevenot, dem es aber nicht gelang, aller seiner Arbeiten habhaft zu werden; erst $\mathrm{H}$. BOERHAAVE, der berühmte Mediziner, hat die Arbeiten Swammerdams gesammelt und 1737 unter dem Titel "Biblia naturae « veröffentlicht.

PASCAL war um I4 Jahre älter als SwAMmERDAM; auch er hat mit der Wissenschaft begonnen, wurde dann infolge eines ununterbrochenen körperlichen Leidens pessimistisch; er fing an, in dem wissenschaftlichen Streben etwas Kleinliches zu sehen, und der Gedanke an Gott erfüllte seitdem sein ganzes Gemüt. Doch war PASCAL insofern glücklicher als SWAmmeRDAM, als ihm sein durch tiefe philosophische Bildung unterstützter Glaube die Kraft verlieh, das körper-

1) STENo hat versucht, auch LEIBNiz zum Katholizismus zu bekehren, und hat eine Streitschrift gegen Spinozas Politischen Traktat veröffentlicht. (L. STEIN, Leibniz und Spinoza. Berlin I89o. S. 77.) 
liche Leiden ruhig zu tragen, währ̉end Swammerdam, dem die philosophische Bildung fehlte, in seinem Gemüt vergeblich nach der Ruhe suchte, die ihm in der äußeren Welt versagt war.

SWAMmERDAM bekämpft in seinen Schriften in der heftigsten Weise die vitalistisch epigenetischen Theorien HARVEYs - ohne ihren philosophischen Kern begriffen zu haben. HARvey hielt noch an der Überzeugung fest, daß in der Erde (wenigstens ein potentielles) Leben schlummert, das unter gewissen (»zufälligen «) Bedingungen zu einem sichtbaren Organismus in der Form eines »Eies «sich herauskristallisiert, das sich sprungweise zur vollendeten Lebensform umwandelt. Swammerdam hat richtig erkannt, daß der Kern dieser "Metamorphosenlehre", wie sie HARveY nannte, dem Glauben an die Transmutation der Metalle nicht fremd war: wie die Metallle aus dem Erdinneren (aus dem Wasser) entstehen und sich $\mathrm{zu}$ Quecksilber umwandeln sollen, das unter den Händen eines geschickten Alchymisten zum echten Silber oder Gold plötzlich geschmiedet wird, so sollen nach HARvEY auch einzelne Lebensstufen in einander transmutiert und anfangs aus der Erde geboren werden. Der Glaube an die Transmutation der Metalle, obwohl falsch, enthielt trotzdem ein Körnchen Wahrheit: SwAmmerdam hatte kein Verständnis für das Tertium comparationis dieses Bildes, nämlich dafür, daß Leben so viel wie fortwährendes Erschaffen von Neuem, Unvorhergesehenem bedeutet, daß in der »Metamorphose« das eigentlichste Wesen des Lebens zu Tage tritt. Im Banne des Mechanismus befangen knüpft er an REDIs Lehre von der Kontinuität des Lebens an und stellt HARVEY gegenüber die These auf, daß es vielleicht keine Entstehung eines neuen, sondern nur ein kontinuierliches Wachstum des ewig sich gleichbleibenden Lebens auf der Welt gibt.

Wie es bei der Bekämpfung der an sich richtigen Lehren zu sein pflegt, hat Swammerdam auf eine Reihe von tatsächlichen Irrtümern und scheinbaren Inkonsequenzen HaRveYs hinweisen können. HaRVEY hat die Wirbellosen nur vorübergehend beachtet; schon REDI und Malpighi haben das Interesse für die Insekten erweckt; SwammerDAM geht weiter und spricht als erster den Satz aus ${ }^{1}$ ), daß große und kleine Tiere gleichen Wert haben, ja daß die kleinen, als einfacher organisiert, für den Forscher wichtiger sind. Aus diesem Grund erklärt er HARVEYs Ansicht für unrichtig, daß kleine Tiere nur zufällig oder aus faulenden Substanzen entstehen sollen; sie gehören ebenso

1) Biblia naturae Kap. I. 
zum Wesen der Natur wie die großen Tiere; übrigens entstehen die großen wie die kleinen Organismen aus kleinen Anfängen. An einem anderen Orte $^{1}$ ) sagt er:

Und nun lasse ich alle verständigen Leute urteilen, ob ein Geschöpf (die Fliegenmade), an dem sich so viel Kunst, Ordnung, Weisheit und der allmächtige Arm Gottes sehen läßt, wohl aus Fäulnis oder zufälligerweise entstanden sei. Muß die Vernunft selbst hierzu nicht nein sprechen? Ich sollte es wahrlich meinen.

$\mathrm{Zu}$ einer solchen Überzeugung kam SwAMmERDAw durch sein eingehendes Studium der Insekten; es sind dies Beobachtungen eines fleißigen Forschers, welcher, von der verwickelten Organisation seiner kleinen Objekte überzeugt, die einzelnen Organe mit dem Messer herauspräpariert, mit dem Mikroskop untersucht, ihre Funktion zu erraten sucht und sie endlich abbildet, Arbeiten eines gewissenhaften und das Innere des Tieres erforschenden Entomologen, also deskriptive Anatomie und spekulative Physiologie. Eingehend hat Swammerdam die Anatomie der Biene untersucht; er lieferte eine Untersuchung des Baues der Schnecken, der Urogenitalorgane des Frosches u. a.

Die ausgedehntesten Bemühungen widmete Swammerdam den Untersuchungen über die Entwicklung der Insekten. Er rühmt sich wiederholt dessen, daß er die Präformationstheorie durch Erfahrung stützen könne, und daß die Epigenesis ein Hirngespinst sei. Nach der Art der Stubengelehrten verwechselt er Erfahrung mit einer nicht eingehend genug analysierten gelehrten Beobachtung und verachtet theoretische Analysen. Die Erfahrung zeigt ihm, daß die Raupe eine komplizierte Organisation hat und daß sie nicht, wie viele Autoren (HARVEY) behauptet haben, eine strukturlose, halbflüssige Masse ist. Er hat die Schmetterlingspuppen anatomisch untersucht und unter der Haut der Puppe bereits den fertigen Schmetterling gefunden. Sprechen diese Tatsachen nicht für die Evolution und gegen die Epigenesis? SwAmmerdam und seine Zeitgenossen waren davon überzeugt.

Auch allgemeinere Gründe sollen gegen die Aristotelische Lehre sprechen. SwAmmerdam weist die Konsequenz dieser Lehre, die Metamorphose der Steine, d. h. die vermeintliche Verwandlung derselben in Fossilien zurück, weist nach, daß sich die Lehre von der Verwandlung der Insekten nicht mit der christlichen Lehre von der

1) Biblia naturae. S. 2 So. 
Auferstehung analogisieren läßt, da sich die Puppe in den Schmetterling durch Wachstum, nicht durch Tod verwandelt; er weist die spontane Generation zurück. Alle diese tatsächlich unrichtigen Ansichten bildeten einen Teil der epigenetischen Theorien; was ist natürlicher, als daß SwAmmERDAM in deren Zurückweisung zugleich auch den Beweis der Evolution sah?

Aus diesen Gründen folgert Swammerdam: Die Verwandlung der Puppe in das entwickelte Tier ist dem Wachstum der Wirbeltiere und der Entstehung und Sprossung der Pflanzen und ihrer Blüten wesentlich analog. Die Raupe verwandelt sich nicht, sondern wächst sich bloß zur Puppe aus, und in dieser ist bereits das fertige Insekt enthalten. In den früheren Stadien der Puppe findet man wohl nicht den Schmetterling, weil sein Körper noch sehr weich und durchsichtig ist, so daß er kaum herauszupräparieren und wegen seiner Durchsichtigkeit nicht $\mathrm{zu}$ sehen ist.

Auch die Entwicklung des Frosches aus der Kaulquappe geschieht nur durch Wachstum dieser letzteren, und ebenso ist das Keimen der Pflanzen aufzufassen, da die ganze Pflanze bereits im Samen enthalten ist.

Von Swammerdam rührt der erste Versuch einer Klassifikation der Insekten nach der Art ihrer Entwicklung her. Er unterscheidet:

I. Insekten, welche das Ei ziemlich in derselben Form verlassen, die sie als fertige Insekten haben sollen (Spinnen, Schnecken, Regenwürmer, Blutegel usf.);

2. Insekten, welche mit 6 Füßen auf die Welt kommen und die Flügel zuerst unter der Haut verborgen haben (Heuschrecken, Libellen usw.);

3. Insekten, welche nach der letzten Häutung lange bewegungslos ruhen (Schmetterlinge u. ä.).

Die 4. Klasse bilden die Insekten, welche nach der letzten Häutung den Eiern ähnlich sind; später öffnet sich ein Deckel an diesem "Ei «, und das erwachsene Tier kriecht heraus (Fliegen).

SWAMmERDAM wurde in seinen auf einzelne Entdeckungen abzielenden, theoretisch dagegen flachen Untersuchungen von einer Reihe Nachahmer befolgt, unter denen RÉAUMUR, LyONET, MERIAN, Spallanzani, Trembley, Bonnet sich ausgezeichnet haben ${ }^{\mathbf{1}}$ ).

1) Literatur. Biblia naturae sive historia Insectorum, in classes certas redacta, nec non exemplis et anatomico variorum animalculorum examine, aeneisque tabulis illustrata, insertis numeris naturae observationibus. (Latein. u. holländ.; mit der Lebensgeschichte Swammerdams.) Leydae 1737. 


\section{Leeuwenhoek.}

Anton van LeEUWEnhoek ( I632-I723), der berühmte Dilettant von Delft, untersuchte in den Mußestunden die verschiedensten Objekte mit Hilfe der von ihm selbst verfertigten Vergrößerungsgläser - ohne daß er sich bemüht hätte, in das Wesen des Beobachteten einzudringen; seine holländisch verfaßten Berichte sandte er den englischen Freunden von der Royal Society, bei denen sie in jener ideenarmen Zeit die günstigste Aufnahme fanden. Die "entdeckten Geheimnisse der Natur " (Arcana naturae detecta) hat er seine Schriften betitelt; es ist ihm oft gelungen, Neues zu finden, das Neue aber als geheimnisvoll zu behandeln und die Geisteskräfte zur Bewältigung desselben anzuspannen, scheint ihm überflüssig vorgekommen $\mathrm{zu}$ sein. LEEUWENHOEK hat als erster die roten Blutkörperchen bemerkt und die Spermatozoen beschrieben, die er als kleine Männlein mit Kopf, Rumpf, Händen und Füßen zeichnet, hat die parthenogenetische Vermehrung der Aphiden beschrieben, die Ameisenpuppen als Puppen gedeutet (sie wurden für Eier gehalten), hat als erster die Rotatorien und die Bakterien entdeckt; seine Arbeiten trugen zur Unterstützung der Präformationstheorien und der LEIBNIZschen Ideen von unendlich kleinen Organismen bei. In seinen Schriften sind die sinnlosen Berechnungen der Anzahl der Spermatozoiden im 'Hoden eines Mannes zu finden, denen gegenüber die Anzahl aller Menschen auf der Erde verschwinden soll, Berechnungen, aus welchen große theoretische Folgerungen gezogen wurden. (LEEUWENHOEK berechnet, daß die Erde von I3385 Millionen Menschen bewohnt wird, während im Samen eines Mannes I 50000 Millionen Spermatozoen herumschwimmen, deren jedes ein kleines Männlein darstellt ${ }^{1}$ ).

\section{Réaumur.}

Réné Ant. Ferchault, Seigneur de Réaumur des Alpes et de la BeRmendik̀re (I683-I757), war ein Mathematiker und Physiker; auch praktische, industrielle Probleme haben ihn beschäftigt. Seine biologischen Arbeiten haben viel zu seinem Ruhm beigetragen - er wurde der Plinius des I8. Jahrhunderts genannt, und aus der Literatur jener Zeiten sieht man, wie oft und wie respektvoll er zitiert wurde.

1) Opera I. 2, S. II. - Leeuwenhoeks Schriften sind enthalten in A. van L., -Opera omnia, seu Arcana naturae. IV Vols. Lugduni Batavorum 1722. 
Eine imposante Reihe von biologischen Beobachtungen knüpft sich an seinen Namen. Er hat die künstliche Bebrütung der Eier (I749) ausgeführt, die Bewegung der Muscheln, der Seeigel und der Seesterne (I7 I2), die Füßchen der beiden letzteren beschrieben und die letzteren als Haftorgane erklärt, die Regeneration der Beine beim Flußkrebs (I7I2) beobachtet, die praktische Anwendbarkeit des Spinngewebes (I7IO) behauptet und viele kleinere Beobachtungen über die Insekten (I734-I742) gemacht.

Obwohl also das von RfAUmuR wissenschaftlich bearbeitete Gebiet sehr ausgedehnt ist und die Probleme, die er sich aufstellt, nicht uninteressant sind, begreift man doch beim Durchblättern seiner Arbeiten kaum, wie RÉAUMUR seinerzeit in so hoher Achtung stehen konnte: kein einziger origineller Gedanke, keine einzige neue Auffassung ist zu finden, sondern nur eine verflachte Fortsetzung desjenigen, was MalpighI und Swammerdam geleistet haben.

In seiner Geschichte der Insekten stellt sich RÉAUmuR die Aufgabe, die wichtigeren Gattungen der Insekten, ihre Lebensweise, Verwandlungen, Fortpflanzung und ihre Fertigkeiten zu erforschen. Er spricht über die Versuche, ein System in die Kenntnis der Insekten einzuführen, und entscheidet sich, wenigstens theoretisch, für dasjenige von Swammerdam. Er schildert die Lebensweise der Raupen, berührt ihren Körperbau und untersucht auch Probleme, wie dasjenige über die Seele der Tiere und über das Wesen der Metamorphose; in ersterer Hinsicht weist er zwar die Lehre von der maschinellen Natur der Insekten zurück, ohne sie aber durch etwas Passenderes ersetzen zu können. Inbetreff der Metamorphose beruft er sich auf die "moderne Wissenschaft und moderne Philosophie", welche nicht erlauben, die Epigenesis anzunehmen - ein bewährter Kunstgriff aller derjenigen, welche nichts Sachliches für ihre Ansicht anzuführen wissen.

Origineller waren RḱaumuRs Versuche über die Verdauung. Er war der erste, der die künstliche Verdauung durchgeführt hat: er ließ die Vögel einen Schwamm verschlingen, welcher bald darauf, mit Magensaft durchtränkt, vom Tier wieder ausgeworfen wurde; die auf diese Art gewonnene Flüssigkeit ließ er auf zerriebene Samen einwirken. Um sich zu überzeugen, ob der Magen nebst der mechanischen Zerkleinerung der Nahrung dieselbe auch chemisch angreift, ließ er die Vögel in offene Metallröhren eingebrachte Samenpäckchen verschlingen; die teilweise Zersetzung derselben überzeugte ihn, daß der Magen nicht nur die Nahrung zerreibt (trituratio), sondern che- 
misch verändert (putrefactio). Auch diese wichtigen Versuche RÉAUMURs haben fast keine Wirkung auf seine Zeitgenossen ausgeübt; Spallanzani hat sie gegen das Ende des Jahrhunderts wiederholt und von neuem bekannt gemacht.

RÉAUMur hat auch die Regeneration der Beine beim Flußlyrebs untersucht und im Sinne der mechanistischen Philosophie gedeutet. Er stellte sich vor (I712), daß im Körper des Krebses unsichtbare Keime für jeden Fuß vorhanden seien, die in höchst verkleinertem Maßstabe den ganzen Fuß wiedergeben; wenn nun der Krebs eine Extremität verliert, so reizen die sonst für diese bestimmten Säfte jene Keime und bringen sie zum Wachstum. Er weist auf die Analogie mit der Regeneration der Zähne beim Menschen hin und spricht die Ansicht aus, daß es nur eine beschränkte Zahl Keime gebe, wovon man sich durch wiederholtes Abschneiden der Füße überzeugen könne. Diese Theorie hat BonNET später aufgenommen und im 19. Jahrhundert WEISMANN verteidigt.

Kein fruchtbarer philosophischer Gedanke ist an die biologischen Arbeiten des fleißigen und geschickten RÉAUmuR anzuknüpfen.

In ähnlich ethologisierender Art hat noch eine Reihe anderer Biologen die Naturgeschichte behandelt: CHARLES Butler ( $†$ I647), der in seiner "Feminine Monarchy « eine vielgelesene Abhandlung über die Bienen herausgab, OLIVER DE SERRES (I539-I6I9), der sich um die Seidenindustrie in Frankreich verdient gemacht hat, JoH. LEONH. FRISCH (I666-I743), der Verfasser der »Beschreibung von allerlei Insekten in Deutschland (I720-38), ABRAham Trembley (I700-I784), dessen Monographie der Hydra (I744) gerühmt wurde, in welcher er unter anderem die Regeneration der Teile dieses Tieres (und auch diejenige von Nais) beschreibt. Ein anderer, ebenfalls noch heute oft dem Namen nach angeführter Biologe dieser Richtung war Pierre Lyonet (I707-I789), welcher Zeit und Geduld genug gefunden hat, 404I Muskeln an der Raupe des Weidenspinners zu beschreiben. In Deutschland hat in ähnlicher Weise RöSEL vON ROSENHOF (I705-I759) die biologischen Beobachtungen gepflegt; namentlich hat er die Lebensweise der Frösche monographisch bearbeitet (I758); eine Zeitlang gab er auch monatlich erscheinende Berichte über das Leben der Insekten ${ }^{1}$ ) heraus (I746-I76I).

1) Literatur. RösEL v. RosenHof, Historia naturalis ranarum nostratium etc. Nurinbergi $175^{8}$. Monatlich herausgegebene Insektenbelustigungen. Nürnberg 1746 bis I761. 4 Bde. - RÉAumur, Mémoires pour servir à l'histoire des Insectes. Paris I734 bis 1742. 6 Bde. - Die übrigen biologischen Arbeiten RÉAUMURs sind in den 


\section{Spallanzani.}

Die von diesen Forschern gepflegte, tändelhafte Auffassung der Biologie, welche so gut in die salonmäßige, von der damaligen Damenwelt geförderte Wissenschaft hineinpaßte, hatte vielfach bis zum Ende des I8. Jahrhunderts Bestand. Als einer der letzten Forscher dieser Art kann der italienische Abbé Lazaro Spallanzani (I729 bis I799) angeführt werden, ebenfalls eine Berühmtheit seines Jahrhunderts. Spaldanzani war Geologe, Mineraloge und Biologe; in der letzteren Wissenschaft hat er sich durch die Versuche über die spontane Generation, über die embryonale Entwicklung, über die Befruchtung der Tiere und Pflanzen und über die künstliche Verdauung bekannt gemacht. Seine Versuche und Beobachtungen sind, wie diejenigen von RÉAUMUR, originell und sehr heterogen; doch bleiben sie an der Oberfläche der Erscheinungen haften; eine allgemeinere und tiefere Auffassung der Naturerscheinungen würde man vergeblich in seinen Schriften suchen.

In seinen Versuchen über die Erzeugung der Tiere (I768) beschreibt Spallanzani gründlich die Befruchtung der Frösche und die Entwicklung der Kaulquappe aus dem Ei. Gleich am Anfange der Entwicklung findet er im Froschei die Larve und folgert daraus, daß der (befruchtete oder unbefruchtete) Froschlaich keine Eier sind, sondern kleine Tierchen oder Fötus,

denn sie haben keine häutigen oder schalenartigen Hüllen an sich, wie die Jungen der eierlegenden Tiere, sondern sie erscheinen bloß und ohne Hüllen, wie man bei den Tieren, die ihre Jungen lebendig zur Welt bringen, wahrnimmt, nur das Schafhäutchen (amnion) ausgenommen, das sie umgibt1).

Folglich sind die Frösche lebendiggebärend. Die Kaulquappe und der Frosch sind ein und dasselbe Tier wie die Raupe und ihr Schmetterling, denn sie haben denselben Darmkanal, dasselbe Nervensystem, Herz usf. - wie es die evolutionistische Philosophie verlangt.

SpallanZani ist es gelungen, die Befruchtung bei den Fröschen und bei den Hunden künstlich durchzuführen, indem er im letzteren Fall einer Hündin frisches Sperma in die Geschlechtsteile eingespritzt

Mémoires de l'Acad. des sciences (Paris) mit den Jahreszahlen, welche im Text angeführt sind, enthalten. - A. Trembley, Mémoires pour servir à l'histoire d'un genre de polypes d'eau douce à bras en terme de cornes. Paris I 744, 2 Bde. - P. Lyonet, Traite anatomique de la chenille qui ronge le bois de saule. La Haye 1762.

1) Versuche üb. die Erzeug. d. Tiere. Deutsch von Ch. F. Michelis. I786. S. 8 I. 
hat. Dabei wies er auch die Unrichtigkeit der alten Lehre von der Wirkung eines Samenduftes, der »Aura seminalis « bei der Befruchtung nach; indem er die Froscheier in ein Uhrgläschen legte und mit einem andren bedeckte, welches mit Sperma bestrichen war: selbstverständlich trat keine Befruchtung ein. Eigentümlich und sehr charakteristisch für die theoretische Oberflächlichkeit SPALLAN. ZANIs ist, daß er auch an die Befruchtung durch die damals bereits gut bekannten Spermatozoen nicht glaubte, obwohl er selbst gefunden hat, daß gehörig filtriertes Sperma seine Befruchtungskraft einbüßt. Er stellte sich vor, daß die Befruchtung durch in das Ei eindringende Säfte geschieht, die den im Ei eingewickelten Fötus zum Wachstum erwecken und die Evolution beschleunigen.

Über die Befruchtung der Pflanzen hat Spallanzani ungenau durchgeführte Versuche angestellt, die ihn zu dem Schlusse geführt haben, daß der Pollen zur Befruchtung nicht unumgänglich nötig ist; vielmehr soll der Pollen dem Samen nur eine gewisse Feuchtigkeit erteilen, die zur ferneren Fortpflanzung erforderlich sei.

In einer andren Reihe von Versuchen hat SPALLANZANI sich bemüht, die Unrichtigkeit der Versuche T. NeEDHAMs über die spontane Generation nachzuweisen. Letzterer behauptete nämlich, daß in verschiedenen Aufgüssen kleine Organismen von selbst und namentlich durch Zerfallen faulender Pflanzenteile entstehen. Eine solche Tatsache müßte die evolutionistischen Theorien stürzen; SPALLANZANI hat jedoch nachgewiesen, daß im ausgekochten Wasser keine solchen Organismen mehr entstehen, und glaubte so die Evolution gegen NEEDHAM gerettet zu haben ${ }^{\mathbf{1}}$ ).

\section{Ovisten und Animalkulisten.}

Die biologische Forschung aus dem I7. und aus der ersten Hälfte des I8. Jahrhunderts bietet ein unerfreuliches Bild. Die von der Renaissance mit jugendlicher Frische diskutierten Probleme sind vergessen; keine neue biologische Disziplin wird geschaffen ${ }^{2}$ ), und

1) Literatur. L. Spallanzani, Saggio di osservationi microscopiche concernenti il sistema della generazione de Signori di Needham e Buffon. Modena I766. (Gegen die. spontane Generation.) - Opuscoli di fisica animale e vegetabile. Modena 1776. (Verdauung und andere Versuche.) Auch gesammelte Arbeiten (Opere scelte). Milano I $825-1826$. I2 Bde.

2) Man wußte nichts vom System, von der geogr. Verbreitung der Tiere, von der Embryologie, Morphologie, Physiologie (als von selbständigen Wissenschaften). Die Insekten haben, wie wir gesehen haben, zum Hauptthema der wissenschaftlichen Diskussionen gehört, und man sollte folglich glauben, daß die Gelehrten schon etwas über 
die Theorien, um die die wissenschaftlichen Berühmtheiten jener öden Epoche untereinander gestritten haben, sind so abgeschmackt, daß einem alle Lust vergeht, darüber zu referieren. Man lernte die organische Welt als eine Welt der Maschinen kennen - nicht der modernen Maschinen, die ideenreiche Konstrukteure fortwährend erfinden, sondern als von Gott allein am Anfang der Welt erschaffenen Maschinen; seit dem siebenten Tage der Erschaffung der Welt könne keine Maschine, keine neue Wirklichkeit auf der Welt entstehen; die am Anfange der Welt ins Leben gesetzten Keime können nur wachsen. REDI, MALPIGHI, SwAmMERDAM und eine Menge anderer haben diese Lehre je weiter desto unumwundener gepredigt. Daß die Theorie ohne Vergewaltigung der handgreiflichsten Tatsachen über das Leben undurchführbar ist, liegt an der Hand: der Mensch schafft fortwährend Neues, und auch das Wachstum jedes Organismus besteht in fortgesetzter Erschaffung neuer. Wirklichkeiten. Was geht dies aber einen Naturforscher an, dem es sich nicht um lebendige Ideen, sondern um eine möglichst sensationelle Ausschmückung seiner sogenannten Entdecliungen handelt?

Redi, Malpighi und Swammerdam haben evolutionistische Gedanken ausgesprochen; konsequent hat dieselben zuerst A. VALIISNIERI durchgeführt. ANTONIo VAllisnieri (I66I-I730), Professor der Medizin an der Universität in Padua, hat in seinen Untersuchungen an die Arbeiten seiner unmittelbaren Vorgänger REDI und MALPIGHI angeknüpft. Wie MALPIGHI, hat er eine Anatomie des Seidenwurms veröffentlicht und in seinen Untersuchungen über die Entstehung der Insekten die Versuche REDIs wiederholt und die Nichtigkeit der gegen sie erhobenen Einwände nachgewiesen. Auch über die Entstehung der Fossilien hat er geschrieben.

VALLISNIERI hat sich sehr bemüht, das Ei der Säugetiere aufzufinden; denn er war überzeugt, daß das, was DE GRAAF beobachtet hatte, kein Säugetierei, sondern ein bereits fortgeschrittenes Entwicklungsstadium ist. Trotz vieler Mühe, mit welcher er die Ovarien durchforscht hat, fand er das Ei nicht; desto mehr hat er, wie es in solchen Fällen zu geschehen pflegt, über dasselbe spekuliert. Im Ei soll das künftige Wesen materiell bereits ganz enthalten sein;

die Insekten gewußt haben; noch RÉAUMUR erklärt jedoch auch das Krokodil für ein Insekt; ANDRY unterscheidet sgroßer und skleine Insekten und rechnet zu den großen u. a.: Schlangen, Frösche, Skorpione, zu den kleinen Fliegen, Raupen, Schnecken' Regenwürmer, Spermatozoen. 
dieses winzige Wesen hat wieder ein Ovarium mit äußerst kleinen Eiern, in denen wieder ein ganzes Tier enthalten ist, usf.; konsequenterweise war in Evas Ovarium bereits das ganze menschliche Geschlecht materiell enthalten. Da eine Generation in der andren wie in einer Schachtel, eingeschlossen sein sollte, bekam die Lehre den Namen der Einschachtelungstheorie (Präformations- oder Evolutionstheorie). Der Ungeheuerlichkeit seiner Annahme war sich VALLISNIERI bewußt, doch half er sich durch den Hinweis auf die engen Grenzen der Fassungskraft der menschlichen Vernunft.

Die zur Evolutionstheorie führende Überzeugung, daß nichts Neues auf der Welt entstehen kann, hat VALLISNIERI auch dazu geführt, die Herkunft der parasitischen Würmer im Menschenkörper durch eine sehr sonderbare Hypothese zu erklären. Bereits REDI bemühte sich vergeblich, den Ursprung jener Würmer zu erklären; denn wenn sie früher da waren als der Mensch, wie haben sie sich erhalten können, und wenn sie erst nach dem Menschen entstanden sind, woraus und wie sind sie entstanden? REDI hat sich noch mit dem aristotelischen Begriff der sensitiven Seele helfen dürfen, durch deren Hilfe die Würmer im Körper aus dessen Säften gebildet werden sollten; doch diese vitalistische Erklärung war dem "modernen « VALLISNIERI nicht mehr erlaubt. Es blieb ihm kein anderer Ausweg übrig, als anzunehmen, daß die parasitischen Würmer gleichzeitig mit und in dem ersten Menschen erschaffen worden sind. Ein gefährlicher Einwand gegen diese Hypothese war wohl, daß doch der vernünftige Gott solches Ungeziefer in Adams unschuldigen Körper nicht hätte hineinpflanzen dürfen. Doch kann man sich immer helfen, wenn man nur guten Willen hat: VALLISNIERI weist diesen Einwand dadurch zurück, daß die parasitischen Würmer vor dem Sündenfall dem Menschen nicht schadeten, sie beseitigten im Gegenteil die überflüssigen Säfte aus dem Körper. Schlimmer war es jedoch zu erklären, wie der Wurm aus Adam in Eva gelangt ist. Ein gewisser LE CLERK soll geglaubt haben, daß vor dem Sündenfall diese Würmer im Körper als Eier enthalten waren, und daß erst die Sünde sie zur Entwicklung gebracht hat; daß die Eier auf das Weib leicht übertragbar sind, das schien LE CLERK ganz annehmbar; VALLISNIERI fand eine bessere Hypothese: er nimmt an, daß der liebe Gott schon gewußt habe, auf irgendeine Art den Wurm in die Rippe Adams und so in das Weib zu bringen.

Der Theorie von der Entwicklung des Menschen aus dem Ei und von der Einschachtelung aller Menschen in Eva widersprach 
jedoch LeEuWenHoeks Entdeckung der Samentierchen, die, nach LeEuWenhoeks Darstellung winzigen Männlein ähnlich sind.

Die Entdeckung der Spermatozoen wurde von andren Zeitgenossen bestätigt, und zugleich fing man an, in diesen Elementen den Schlüssel zu allen Problemen zu sehen. Besonders haben sich in dieser Hinsicht N. Andry, N. Hartsoeker, Bourguet u. a. ausgezeichnet. Der Franzose Nicolaus ANDRY (I658-I73I), thomo vermiculosus ", wie ihn VALLISNIERI nannte, sah in allen Dingen die neuentdeckten Spermatierchen ("Würmchen «); sie sollen nach ihm auch Ursache der Krankheiten sein. Nicolaus Hartsoeker (I656 bis I725), Mathematiker, Physiker und Geometer aus Holland, hat sich seine Mikroskope wie LEEUWENHOEK selbst verfertigt, und diese standen den Apparaten jenes Forschers nicht nach; später hat er auch Teleskope konstruiert. HARTSOEKER wollte gegen LEEUWENHOEK die Priorität der Entdeckung der Spermatozoen für sich erkämpfen; beobachtet hat er sie ganz gewiß; N. ANDRY hat überdies gefunden, daß die Spermatozoen nur bei den Männern, nicht bei Kindern und weder bei Greisen noch bei geschlechtlich kranken Personen vorkommen. Auf Grund solcher Befunde haben nun LEEUwENHOEK und ANDRY die Theorie von VALLISNIERI verworfen und eine neue aufgestellt: der künftige Organismus ist nicht im Ei enthalten, sondern das Spermatozoon ist der Keim, aus welchem der Organismus sich durch Wachstum entwickelt. Sie stützen ihre Ansicht besonders darauf, daß das Spermatierchen lebendig und rege ist, während das Ei wie eine tote Masse liegt; gegen den Einwand, wozu denn die übermäßige Produktion dieser Tierchen, wenn nur so wenige zur Entwicklung kommen, wehrten sie sich durch den Hinweis auf die Pflanzen, bei denen auch sehr viele Blüten zugrunde gehen.

Eine "Bestätigung " dieser Theorie ließ nicht lange auf sich warten. LEEUWENHOEK und ANDRY haben beobachtet, daß jene Würmchen beim Menschen vorn eine Erweiterung mit einem Kopf besitzen, was nach ANDRY offenbar damit im Zusammenhange steht, daß auch der menschliche Embryo einen viel größeren Kopf hat als bei den Tieren ${ }^{1}$ ). Die Krone hat der Theorie jedoch ein gewisser DALENPATIUS aufgesetzt (I699), dem es gelungen sein soll, mit dem Mikroskop die Spermatierchen des Menschen in ihrer Entwicklung zu verfolgen, wobei er sah, wie sie, ursprünglich einer Kaulquappe ähnlich, später ihre Haut abzogen, und was darunter erschien, war nicht

1) De la génération des vers. Amsterdam r 7or. S. Igr. 
mehr ein Tier, sondern ein kleiner Mensch, an welchem Dalenpatius mit seinem Mikroskop zwei Hände, zwei Füße, die Brust und den Kopf gut unterscheiden konnte; an dem Kopfe sah er sogar eine zusammengerollte Kappe aus den Exuvien dieses Männleins. Auch andere (J. Gautier, I750) haben die Spermatozoen mit Menschengesichtern abgebildet.

Wahre Triumphe hat die Phantasie der Evolutionisten auch in der Erklärung der Mißbildungen gefeiert, zu der schon SwAmmerdam Anlaß gegeben hat. Jedes Ei hat nach ANDRY eine mit einer Klappe verschlossene Öffnung; während der Befruchtung öfnet sie das Spermatierchen und kriecht in das Ei hinein, schließt dann die Klappe mit seinem Schwanze, damit kein anderer Gast hinein kann. Es kommt aber vor, daß mehrere Spermatierchen gleichzeitig an einer und derselben Klappe ankommen; der Leser kann sich schon vorstellen, wie in ihnen ihre Menschennatur vorzeitig erwacht, wie ein Kampf entsteht, und kein Wunder, daß der Glückliche, der das Ei schließlich siegreich besetzt, ein Bein oder sogar dẹ Kopf auf dem Kampfplatze zurückläßt und darum später als einbeinig oder als kopfloses Monstrum geboren wird ${ }^{\mathbf{1}}$ )!

Bis zum Ende des I8. Jahrhunderts haben solche Spekulationen geblüht; noch CUVIER konnte sich nicht von denselben freimachen 2 ).

1) De la génération des vers. Amsterdam I 70r. S. I97.

2) Literatur. VALLISNiERI, ANT., Istoria della generatione dell' uomo, e degli animali, se sia da vermicelli spermatici o dalle uovi. Venezia 172I. - Considerazioni ed esperienze intorno alle generazioni dei Vermi ordinari del corpo umano. Padova I 7ro. - ANDRy, Nic., De la génération des Vers dans le corps de l'homme. Paris i7or. - Gautier D'Agoti, JACQ., Zoogénésie ou génération de l'homme et des animaux. Paris I750. - Hartsoeker, N., Essai de dioptrique r694 und Principes de physique 1696 . 


\section{Kapitel. \\ Die Paracelsisten.}

\section{Die Nachwirkung Hohenheims.}

Als I54I der jähe Tod dem Umherirren HoHenheims ein Ende gemacht hatte, glaubte kaum jemand im Ernst, daß seinen verworrenen Lehren eine Zukunft beschieden wäre. Kein ernster Gelehrter hielt PARACELSUs für des Studiums wert; die meisten Diktate des Begründers der chemischen Wissenschaft irrten als Manuskripte unter den Hörern des PARACELsus herum, die sie nicht verstanden, verstümmelt wiedergegeben und vielleicht auch verschiedentlich nach eigenem Ermessen korrigiert haben. Immerhin erhielt sich unter den Schülern des PARACELSUS (von denen sechs als besonders treu vom Meister erwähnt ${ }^{1}$ ) werden) die Überzeugung, daß Hohenheim ein außergewöhnlicher Mann gewesen ist; unter den Autodidakten, die vom natürlichen $\mathrm{Ha} \beta$ gegen Fachgelehrten erfüllt sind, und im Volke, das ebenfalls wenig Vertrauen zur hohen Wissenschaft zeigt, hat sich die Erinnerung an den großen Monarchen der Arzneikunst erhalten, der sich getraut hat, alle Krankheiten zu heilen, der mit den Armen gelebt und gefühlt und die Reichen, den Papst, Luther und die Doktoren gehaßt hat, der selbst arm und tief religiös war. Einzelne Schriften des Paracelsus erschienen noch zu seinen Lebzeiten im Drucke und erlebten mehrere Auflagen; bald nach dem Tode des Meisters wurden andere herausgegeben und rasch vergriffen. Erst jetzt haben auch Gelehrte begonnen sich mit PARACELSUS zu befassen. I57I, dreißig Jahre nach dem Tode des letzteren, fühlte sich TH. ERASTUS, ein beachtenswerter Arzt und Philosoph, veranlaßt, eine gründliche und ausführliche Polemik gegen das Paracelsische System herauszugeben, um, wie er im Vorwort schreibt, das sichtliche Zunehmen des Ansehens jenes Schweizer Arztes zu hemmen; denn es begönnen bereits viele und auch ernste Menschen

1) Bitiscius, III, S. I 59. 
Paracelsus zu preisen. Sein Kampf gegen Paracelsus war aber vergeblich; das Volk ließ sich seinen Helden nicht mehr nehmen: etwa aus dem Jahre 1600 stammt ein primitiver Lobgesang auf PARACELsus, nach dem sich urteilen läßt, daß unser Arzt damals bereits unter dem Volke einer der berühmtesten Männer war:

... Wie Durer (Dürer) in der Malerei,

So dieser in der Arzenei .. . ${ }^{1}$ )

hat man von ihm gesungen. I 589 erschien die erste (und die letzte) Gesamtausgabe der paracelsischen Schriften durch J. Huser; einzelne Bände derselben erlebten bald neue Auflagen, I603 wurde das ganze Werk zweimal gedruckt (in Frankfurt und in Straßburg); I658 wurde es durch Brtiscius ins Lateinische überführt. Die Einleitungen zu diesen Ausgaben preisen den Autor als den größten Naturforscher.

Die paracelsische Stimmung war zu jener Zeit viel verbreitet. Der Neuplatonismus, durch Cusanus, durch C. AgRIPPA und durch die italienischen Philosophen gefördert, fand besonders bei den Dilettanten ein williges Ohr; die durch Luther und durch die religiösen Streitigkeiten wachgerufene Mystik war jener Philosophie ebenfalls geneigt; die Mystiker haben PARAcelsus eifrig gelesen. Die Alchemie, bereits früher eifrig gepflegt, kam jetzt in Blüte und erblickte in PARACELSUs ihren kühnsten Heros. Die aristotelische Universitätswissenschaft war im Verfall begriffen, und insofern sie sich in die "moderne " an Galilei, an Descartes und an Harvey anknüpfende rationalistisch-mechanistische Wissenschaft umgewandelt hat, war sie in den Händen von Aristokraten oder von aristokratisch gesinnten Forschern gelegen, die zu hassen ein natürliches Schicksal der an PARACELsus anknüpfenden Radikalen war.

Bedeutende Philosophen äußerten sich günstig über PARACELSUS. Giordano BRUNo, eine mit PARACELsus in mancher Hinsicht verwandte literarische Erscheinung, schrieb über denselben:

Paracelsus hat augenscheinlich eine tiefere Kenntnis der Heilkunst und Heilmittel inne gehabt, als Galenus, Avicenna und alle Doktoren. Sein höchstes Lob ist, daß er zuerst wiederum die Medizin als Philosophie behandelte - und magische Mittel anwendete, wo die gemeinen physischen und chemischen nicht hinreichten ${ }^{2}$ ).

1) BARtscherer, S. 307 .

2) Nach Lessing, Paracelsus. Berlin 1839 . S. 247 . 
F. BACO hat ihn auch gekannt:

Paracelsus ist kühn und wagt allerlei Mieinungen, gleichsam aufs Geratewohl. Seine Dreiheit der Prinzipien ist jedoch kein unnützer Einfall und grenzt z. T. nahe an die Wirklichkeit der Dinge ... ${ }^{1}$ )

Wenn so aufgeklärte Männer PARACELSUS ernst genommen haben, dann waren die zornigen Ausfälle der Aristoteliker ohnmächtig, ja sie lenkten auf den wunderbaren Mann noch mehr die Aufmerksamkeit hin. Das Unregelmäßige und Geheimnisvolle des PARACEIsus beleidigte zwar logisch disziplinierte Geister, wurde dagegen für viele $\mathrm{zu}$ einem besonderen Reiz, und man achtete seine Geheimmittel desto eher, als es Gegner gab, die die Macht des PARACELsus nicht unterschätzten, sie aber dem bösen Geiste zuschrieben und PARACELSUS für dem Teufel verschrieben, für einen Nekromanten und Schwarzkünstler proklamierten.

Bald erheben sich aus der namenlosen Volksüberzeugung, daß die Natur in PARACELsus einen großartigen Geist erschaffen hat, einzelne Persönlichkeiten, die ihn nachzuahmen sich zum Lebenszweck gemacht haben. Einer der ersten Paracelsisten, der die Aufmerksamkeit auf sich gelenkt hat, war der Däne PETER SEVERIN²) (I 540 bis I602); einflußreicher als dieser Alchymist war der englische Kabbalist und Neuplatoniker ROBERT FLUDD (I574-I637), Arzt in London, und der Mystiker JAKoв BöHme (I 575-I624), der bekannte Schuhmacher aus Görlitz; alle drei suchten ihre Systeme im Anschlusse an PARAcelsus zu entwickeln. Am Anfange des 17. Jhs. begann die durch PARACELSUS hervorgerufene Bewegung konkretere Formen anzunehmen. Die freisinnige Renaissancebewegung trat zu dieser Zeit vor dem Gegensatz zwischen dem Katholizismus und den Reformierten zurück. Der Katholizismus schlug sich zum religiösen Liberalismus der Jesuiten nieder, mit dem auch die neue, von DESCARTES abhängige Wissenschaft, die Naturforschung eines REDI, eines Steno, eines RÉAumur, Kompromisse einzugehen sich beeilte. Diese rationalistische, empirische, "moderne « Richtung zog die besten Geister an und wurde offiziell gefördert; als ihr Gegensatz hat sich eine die aufrichtige Überzeugung betonende und den Ruhm dieser Welt verachtende Gemütsstimmung entwickelt, die die Verbreitung verschiedener religiöser Gesellschaften (wie z. B. der Böhmischen

1) Opera omnia. Amster. I7I2. Fol. 74. (Lessing, Paracelsus S. 247.)

2) Idea medicinae philosophicae, fundamenta continens totius doctrinae Paracelsicae, Hippocraticae et Galenicae I 570 . 
Brüder), wissenschaftlicher Geheimbünde, wie der sog. Rosenkreuzer, und namentlich die Gründung der Freimaurerei gefördert hat.

Die Gemütsstimmung dieser theosophischen und kirchenfeindlichen Richtungen war eine gedrückte. Die Lebenslust der Renaissance und die polemische Kühnheit eines PARACELSUS sind zum Pessimismus und zur Resignation herabgesunken. Wohl hatte man Schlimmes zu ertragen, wohl wurde man hart verfolgt; anstatt aber den Kampf mit den Jesuiten unerschrocken aufzunehmen, ergab man sich vielfach einem kleinmütigen Verfolgungswahn; man klagte in unbestimmten Worten anstatt konkrete Persönlichkeiten anzugreifen; man zog sich ins Geheime zurück, anstatt offen die Wahrheit zu predigen. Solche Stimmung spricht zu uns in verschiedenen Abstufungen aus den Schriften der genialsten Sprecher dieser Richtung, Pascals, Helmonts, Comenius'.

PARACELSUS am nächsten standen die sog. Rosenkreuzer. Am Anfang des I7. Jhs. in Deutschland entstanden, hat sich dieser Geheimbund bald über ganz Deutschland und über England verbreitet. Die Rosenkreuzer waren landfahrende Alchemisten, die ihrem Meister durch Armut, durch Herstellung von Panazeen und anderen Geheimmitteln gegen Krankheiten und durch den $\mathrm{Haß}$ gegen die offizielle Wissenschaft nachzuahmen strebten. Ein ungeordnetes Äußeres, vorne abgeschorene Haare, ein schwarzes Bändchen im Knopfloch, gelegentlich auch eine kleine grüne Fahne, galt als Abzeichen der Rosenkreuzer, die sich für geistige Nachkommen des Johanniterordens ausgaben ${ }^{1}$ ). Aus den Briefen des deutschen Philosophen JoH. Jungius (I587-I657) ist $\mathrm{zu}$ sehen, daß die alchemistische Bewegung auch bessere Kreise ergriffen hat; auch LEIBNIZ gehörte eine Zeit lang der Gesellschaft der Rosenkreuzer an. Man mag über diese sonderbare Frucht der Paracelsischen Wissenschaft die Achsel zucken; der Historiker wird in derselben eine natürliche Folge der Bestrebungen HoHENHEIMs nach einer nichtoffiziellen, aus dem Geiste des Volkes hervorwachsenden Wissenschaft erblicken und wird sich erinnern, daß aus derselben die für

1) Ein tschechisches, von einem Paracelsisten (Rodovský) verfaßtes Gedicht spielt auf die äußere Erscheinung der Rosenkreuzer an:

»... sie laufen wie Wölfe im Lande herum, man erkennt sie an dem Kleide, denn sie sind zerlumpt wie Vagabunden ...«

Über die Rosenkreuzer vgl. OtTo Henne AM Rhyn, Das Buch der Mysterien. Leipzig I 890. S. 2 I I sq. 
die Entwicklung der modernen Wissenschaft nicht unbedeutende Freimaurerei sich entwickelt hat. FINDEL weist in seiner "Geschichte der Freimaurerei "auf PARACELSUs als auf einen der Vorfahren dieses Geheimbundes hin 1 ). Der berühmte Chemiker und Schüler des PARACElsus, van Helmont, war Rosenkreuzer; der bekannte Pädagoge und Bischof der Böhmischen Brüder, J. A. Comenius, ebenfalls ein Anhänger HoHenHeIms, hat einen mächtigen Einfluß auf die I7I7 entstandene Londoner Großloge ausgeübt2). Durch die Vermittlung der Rosenkreuzer, des Comenius, des VAN Helmont und seines Sohnes, durch die Freimaurer haben PARACELsUS' Ideen auch auf fein gebildete Geister eingewirkt: LEIBNIZ ließ sich von PARACELSUS in dieser Hinsicht beeinflussen; GoETHE studierte eifrig Hohonheims Schriften, und seine größte Dichtung, Faust, ist durch PARACELSUS (entweder direkt oder durch die Vermittlung VAN HELMONTs) inspiriert worden; die deutsche Naturphilosophie endlich hat in PARACELSUs ihren Mann gefunden.

"Vielleicht grünet, das jetzt herfürkeimet, mit der Zeit " hat PARACELSUS hoffnungsvoll versprochen - und es ist, trotz der Mißgunst der Menschen ergrünt ... nur die exakte Wissenschaft hat noch kein warmes Verhältnis zu diesem freien Manne finden können. Die Hochschulmedizin streitet darüber, ob PARACELsus für dieselbe einen Wert hat; die Biologie nennt seinen Namen kaum, und die Chemie behauptet, daß PARACELsus erst durch VAN HELMONT für diese Wissenschaft bedeutungsvoll geworden ist. Es wird dies kaum richtig sein; ERAstus hätte kaum den Paracelsismus bekämpft, hätte derselbe in besseren Kreisen keine Anhänger gehabt; VAN HELMONT erwähnt einen Universitätsprofessor, der sich bemüht hat, einen handgreiflichen, von PARACELSUS gepredigten Unsinn zu verteidigen. An einer anderen Stelle polemisiert HELMONT gegen PARACELSUs' Erklärung der Krankheiten durch den sog. Tartarus und behauptet, daß diese Theorie (hundert Jahre nach HoHENHEIM) "dermaßen angenommen worden und nunmehr so tief und fest eingewurzelt, daß schier niemand mehr zu finden, der nicht seine $\mathrm{Zu}$ flucht nehme zu dem Tartar des PARACELSI ${ }^{3}$ ) «. Daß sich nach dem Inhalt der Schriften, die Lehrbuchweisheiten vorführen, kein Einfluß des PARACELsus auf die Schicksale der Wissenschaft verzeichnen

1) Findel, Gesch. d. Freimaurerei. Leipzig r87r. S. I30 sq.

2) Findel, S. 135. - Über Comenius' Abhängigkeit von Paracelsus vgl. F. Strunz, Die Mineralienkunde des J. A. Comenius. Janus, Amsterdam I902.

3) Helmont, Aufgang der Arzneikunst. S. 404. 
läßt, ist wohl möglich; die wirkliche Wissenschaft, die in den Seelen der aus innerem Trieb der Forschung ergebenen Männer lebt, hat jederzeit aus PARACELSUS die fruchtbarsten Anregungen geschöpft. Ein Denker, von dessen Ideen Comenius, Helmont, Goethe, BROWNING mit tiefster Ehrbezeugung sprechen, kann unmöglich für die Wissenschaft bedeutungslos sein, es sei denn für eine Wissenschaft, die seiner nicht würdig wäre.

\section{J. B. van Helmont.}

\section{Pietismus.}

Joh. Baptista van Helmont (I 577-I644), aus Brüssel, hat die stürmischen Zeiten erlebt, da Tausende seiner Volksgenossen wegen der Bekämpfung der spanisch-jesuitischen durch den berüchtigten AlBA geleiteten Herrschaft den Tod auf dem Schaffot fanden. Auch die katholischen, dem Pietismus geneigten Niederländer (HELMONT war Katholik) waren von Widerwillen gegen die zu weltlich gesinnten Jesuiten erfüllt. Die ernste, moralisierende, verdrießliche, das praktische Leben mit Verdacht verfolgende Stimmung der Landesgenossen war auch HELmoNT eigen und äußert sich in seinen Schriften durch eine pessimistische, negativistische Umdeutung der paracelsischen Ideale. PARACELSUS hat ein vielbewegtes Leben geführt, Helmont, dessen Leben kaum wesentlich gestört dahinfloß, hat über seine inneren Seelenkämpfe geschrieben. Er erzählt, wie er an der Universität in Löwen Philosophie und Medizin studiert habe, später aber von Zweifeln über den Wert der Wissenschaft ergriffen, sich nacheinander der Astronomie, der Theologie, der Magie, der stoischen Ethik, der Pharmakologie und der Rechtswissenschaft gewidmet habe. Nachdem er noch den Gedanken an das Klosterleben überwunden, hat sich HELmont für ein von Grund aus neues Leben entschieden; sein Vermögen hat er seiner Schwester überwiesen und ging in die weite Welt, um niemals mehr heimzukehren. Auf den Reisen lernte er von einem landfahrenden Alchemisten, einem gemeinen Kerl, dessen geheime Kunst. Nach Hause zurückgekehrt, hat er sich einzig seiner Wissenschaft gewidmet, ohne auf Frauen, Freunde und Gesellschaften zu achten. Trotzdem hat er geheiratet und mit der Frau einiges Vermögen bekommen. HELMONT erzählt ferner, wie er besonders die Armen nach seiner Methode umsonst behandelt und "mehreren Millionen Menschen " das Leben gerettet habe. 
Ein interessantes Leben, gewiß. Es wäre noch interessanter, wenn es von jemand anderem als von vAN HELMONT selbst erzählt wäre, oder wenn wir aus den Taten HELMONTs seine Opferwilligkeit, seine Erfolge in der Heilkunst, seine auf den Reisen gesammelten Erfahrungen, seine Seelenkämpfe erraten könnten. Aus Helmonts Erzählung gewinnt man jedoch den Eindruck, daß er zwar nicht gerade Unwahrheit sagt, immerhin aber übertreibt; daß das Leben Hohenheims Helmont als Vorbild bei seiner Autobiographie vor den Augen geschwebt hat ${ }^{\mathbf{1}}$ ), ist kaum zu verkennen.

Die skeptischen Gedanken HELMONTs charakterisieren die Stimmung des pietistischen Milieus, in dem er gelebt. Seine wissenschaftlichen Abhandlungen sind von Exkursen über die Allmacht Gottes, über die Sündhaftigkeit der Menschen, über den Unglauben der Zeitgenossen, über die gottlosen Türken und Heiden, von Bekenntnissen über den verwerflichen Ehrgeiz des Autors selbst u. ä. übervoll. So verlangte es die Stimmung der Zeit: man ergab sich der religiösen Mystik, man las Thomas a Kempis (Helmont beruft sich auf denselben). Anstatt der selbstbewußten Angriffe, die PARACELsus im souveränen Bewußtsein der eigenen Erhabenheit über die Brotjägerei dieser Welt gegen die Gelehrten und Priester geschleudert, hören wir jetzt nur allgemeine Rekriminationen, Schmerztuerei, einen ungesunden Subjektivismus.

Die nimmer aufhörenden Seufzer HeLmonts fordern die Frage heraus, inwiefern sein Pessimismus berechtigt war. Er war ein Adeliger, ein reicher, unabhängiger Mann, ist Katholik (nur seine pietistisch-mystische Stimmung ist nicht ganz orthodox) und politisch passiv geblieben. In seinen Schriften greift er (indirekt) in der heftigsten Weise die Professoren (Jesuiten) an. Welch' Wunder, daß sie sich gerächt haben? Desto mehr, als sie sich in mancher Hinsicht als überlegen gezeigt haben. Das schlimmste Übel, das HELmont traf, war, daß er zum Hausarrest verurteilt war, weil er dem Geheimbund der Rosenkreuzer angehört hat. Eine solche Verfolgung mußte wahrlich viel aufgebauscht werden, auf daß sie den Schicksalen des PARACElsus ähnlich scheine! Die Methode der HELMONTschen wissenschaftlichen Skepsis mag folgendes Beispiel veranschaulichen. Er erzählt, wie er sich auf die Exaktheit der

1) HeLmont erzählt von sich selbst, daß er von den Gelehrten und Geistlichen verfolgt wurde und daß ihn die Jesuiten haben vergiften wollen - ebenso, wie es von Paracelsus erzählt worden war. 
(nach PtolomäUs erklärten) Astronomic verlassen hat; da bekam er die Schrift Copernikus' zu lesen, in der erwiesen wird, daß diese Lehre ein eitles Nichts sei. Und der Schluß?

Darüber fing die Sternkunst bei mir an, gewaltig in Verachtung zu kommen, weil ich sahe, daß so wenig Gewißheit und Wahrheit drinnen wäre, und ihr meistes Wesen ein leeres Vorgehen sei ${ }^{1}$ ).

Dieser unechte, innerlich unwahre Pessimismus, diese Vanitasvanitatum-Philosophie fand jederzeit, von den Stoikern bis zu den modernsten Skeptikern, Vertreter; wenn die schlimmen politischen Zustände des I7. Jahrhunderts sie erklären, entschuldigen dürfen sie dieselbe nicht ${ }^{2}$ ).

\section{Helmont und die Jesuiten.}

HeLmont wird niemals müde, die Repräsentanten der zeitgenössischen Wissenschaft, die Universitäten und die Jesuiten zu bekämpfen. Die offizielle Wissenschaft ist für ihn nur die »Lehre des Schwindels und der Faulheit ${ }^{3}$ ) ", sie ist nur auf Gewinnsucht berechnet, auf den hohen Schulen habe der Teufel seine Patronen ${ }^{4}$, die Professoren müssen ihrer groben Unwissenheit wegen direkt in die Hölle kommen ${ }^{5}$ ); sie sind Fledermäuse, die die tief unter der Erde begrabene Wahrheit beschützen und jedem den Zutritt zu derselben verhindern, indem sie nur sich selbst für berechtigte Eigentümer derselben halten. Diese Allegorie geht HeLmont so von Herzen, daß er sie sogar auf dem Titelbild seiner gesammelten Schriften veranschaulichen ließ. Mit dieser Auffassung hängt auch HELmonts Philosophie der Geschichte zusammen: neue Erkenntnisse sind aus Wahrheitsliebe der genialen Menschen entstanden, werden aber im Laufe der Zeit von den ehrgeizigen Nachahmern verdunkelt. Fast jedes Traktat beginnt HeLmont mit dem Verurteilen der Prahl-

1) S. I5.

2) Pascals Pessimismus steht höher als derjenige Helmonts, ist dem letzteren aber innerlich verwandt. Historisch interessant ist, daß Pascals Gemütsstimmung ebenso durch den Gegensatz zum Jesuitismus bestimmt war; Pascal (1623-1662) war bekanntlich Jansenit; C. JANSEN (1585-1638) war ein Zeit- und Stammgenosse Helmonts. Comenius gehört demselben Zeitalter an (I592-I677); seine berïhmte Schrift >Labyrinth der Welt uud Paradies des Herzense ist in derselben pessimistischen Stimmung geschrieben.

3) S. 5 .

4) S. 979 .

5) S. 939 . 
sucht, der Weltlichkeit, der Gottlosigkeit der Professoren. Leider greift HELmont keine lebendigen, konkreten Persönlichkeiten an, analysiert keine ihrer konkreten, in einer bestimmten Schrift formulierten Lehren, sondern er schreibt »insgemein gegen die Unwissenheit aller Schulen «. So bleibt nichts anderes übrig, als indirekt Wege zu suchen, um sich über die Gegner Helmonts zu informieren.

HeLmonTs wirkliche und vermeintliche Gegner waren Hochschulgelehrte. Die gesellschaftliche Stellung der Professoren hat sich seit dem Anfang der Neuzeit wesentlich geändert. Als die Scholastik auf dem Gipfel des Ruhmes war, hat man die Professoren (man nannte sie damals Scholastiker oder Doktoren) für die einzigen Repräsentanten der Wissenschaft gehalten, denn Schulwissenschaft (= Scholastik) hat für identisch mit der Wissenschaft gegolten. Zur Zeit der Renaissance in den Hintergrund gedrängt, begannen die Professoren seit der Reformation allmählich, jetzt meistens unter dem Namen der Jesuiten, an Bedeutung wieder zu gewinnen; denn die Jesuiten haben bekanntlich in den katholischen Gebieten das Schulwesen in die Hände bekommen. Die protestantischen Hochschulen vermochten nicht die geistige Selbständigkeit neben den katholischen zu behaupten. Die jesuitische Wissenschaft hat in der Biologie nichts Erwähnenswertes geleistet, hat aber ohne Zweifel durch die Macht ihrer Pädagogik die rationalistisch orientierte Wissenschaft eines REDI ${ }^{1}$ ), eines STENO, eines RÉAUMUR, eines DesCARTEs indirekt beeinflußt, eine Wissenschaft, die ihr Hauptziel in der Klarheit der logischen Methode, in der Experimentierkunst, in der Analyse gesucht und unter »Natur « die von den Gelehrten vorgeführten Lehren über die Natur verstanden hat.

Wir gehen kaum irre, wenn wir für HELmonTs Gegner, oder sagen wir lieber Antipoden, gelehrte Jesuiten betrachten. Über deren allgemeine Grundsätze ist nur ein Urteil möglich; als konkrete Persönlichkeiten haben sie aber kaum immer so schlimm ausgesehen, wie sie uns ihre Bekämpfer vorzuführen pflegen. Aus HELmonTs Polemik gewinnt man den Eindruck, daß die Jesuiten wissenschaftlich und gesellschaftlich geschulter und jedenfalls liberaler (auch in Sachen der Religion) waren, als Helmont selbst. HeLmont erzählt z. B. ${ }^{2}$ ), daß die Jesuiten in Löwen Philosophie vorzutragen begonnen haben, obwohl die Vorlesungen vom (spanischen) König

1) Der die Schriften des Jesuiten A. Kircher zitiert.

2) S. I5. 
wie auch von den Ständen ungünstig aufgenommen worden waren. Endlich hat der Papst (CLEmens VIII.) die Vorlesungen eingestellt; die Schüler gingen auseinander, allein die Jesuiten lockten »die anderen und die reichsten mit der annehmlichen Lehre von der Weltbeschreibung an sich». Daß die »Weltbeschreibung « nur einen anderen Namen für die Philosophie bedeutet hat, geht daraus hervor, daß einer der Professoren, MARTIN DEL RIo, in diesen Vorträgen über die Magie gelesen hat ${ }^{1}$ ). In diesem Falle haben sich also die Jesuiten des berüchtigten Probabilismus gegen die Obrigkeit und im Interesse einer guten Sache bedient. Wenn HELmont an einer anderen Stelle die Professoren Atheisten nennt, die an die Hexen und an sympathische Heilungen nicht glauben wollen ${ }^{2}$ ), so ist es schwer, sie deshalb zu verurteilen. In einer zwischen HELMONT und den Jesuiten geführten ${ }^{3}$ ) Polemik (über sympathische Kuren) haben sich die Jesuiten als vernünftiger, geschickter und liberaler als der allzu rechtgläubige HELmont erwiesen. Daß HeLmont trotz. dem höher stand als die Jesuiten, verdankte er nicht seiner Bildung oder Geschicklichkeit, sondern der Innigkeit seiner Überzeugung, die den Professoren gefehlt hat.

\section{Der Charakter der Helmontschen Wissenschaft.}

Als HeLmont die neue Wissenschaft aufzubauen unternommen hat, war die Schrift des COPERNIKus längst erschienen; GALILEI war

1) S. 15 .

2) S. 979 .

3) Der Fall sei kurz geschildert. Paracelsus gibt folgende Vorschrift für die sympathische Heilung frischer Wunden an. Man bereite eine Wundsalbe aus dem Moos, das man von den unter dem Galgen liegenden Schädeln abgeschabt hat, aus Menschenblut, Bärenschmalz, Rosenöl, Regenwürmern und noch anderen Bestandteilen; befeuchte ferner ein Stiick Holz mit dem Blut der Wunde und stecke dasselbe in die Salbe, die also meilenweit von der Wunde stehen kann. >Auf solche Weise kannst du auch diejenigen heilen, die wohl 20 Meilen weit von dir sind; wenn du nur Blut von dem Verwundeten zur Hand bekommen kannst. Eben dieses Mittel ist auch gut ... wider das Zahnweh ... Wenn auch ein Pferd vernagelt worden, kann man gleichfalls ein blutiges Hölzlein davon in die Salbe stecken; so wird dem Pferde kein Leid geschehen ... « usw. Ein deutscher Universitätsprofessor hat diese Sympathiekur empfohlen (nur in überaus pikanten Einzelheiten verbessert, so z. B., daß das Moos vom Schädel der Erhängten das beste ist und nur, wenn der Mond zunimmt, gesammelt werden darf), und der Jesuit JoH. ROBERTI hat eine Broschüre veröffentlicht, in der er diese Art Medizin abfällig kritisierte. Helmont fühlte sich als Paracelsist getroffen und verteidigte in einer ausführlichen Abhandlung die Kraft der erwähnten Wundsalbe. (Von der magnetischen Kur der Wunden. Eine Disputation. Aufgang der Arzneikunst. S. I003 sq.) 
weltberühmt, KEPPLER hat seine Entdeckungen veröffentlicht, F. Bacon wurde gelesen, Descartes arbeitete eben an seinem System, HARveYs Schriften erregten allgemeines Aufsehen. Dieses neue wissenschaftliche Leben existierte für HELmont nicht. Die Namen der genannten Forscher fehlen unter den von ihm zitierten Autoren; er kennt ebensowenig Fallopia, Caesalpinus, Fabricius, Gesner. Galenus, Aristoteles und Hippokrates sind ihm (neben ParaCELSUS) noch immer die Autoren, nach deren Lehren er seine Gedanken orientiert. Auch die Ideale der neuen »Experimentalwissenschaft «, der Induktion, der exakten Methode sind HeLmont fremd geblieben. Zwar ist sein Glaube nicht mehr so naiv wie derjenige Hohenheims, immerhin glaubt er aber an die Astrologie, an die Macht des Teufels, an die Hexen ${ }^{1}$ ), an den Gold- und Silbermachenden Stein $^{2}$ ) und an andere Ungeheuerlichkeiten. Die Macht des Mondes ist groß, erklärt er. Suche einen Frosch während des Vollmonds in einer kalten Winternacht auf, wascheihn rein und steckeihn an einen Stock im Freien; in der Früh wirst du anstatt des Frosches einen durchsichtigen Schleim finden, denn der Mond hat den Frosch in den Urzustand, in die erste Materie überführt. Dieser Schleim heilt den $\mathrm{Krebs}^{3}$ ).

HELMONT war nicht ganz im Unrecht, wenn er - entgegen der herrschenden Überzeugung unserer Zeit - die experimentelle, auf Vernunft und Beweisführung gegründete Wissenschaft als Jesuitismus und als ein Werk des Teufels bekämpft hat. Er hat richtig herausgefühlt, daß die Experimentalwissenschaft auf indirekten Wegen die Natur zu beschleichen, ihr heimlich und durch peinliches Prozeßverfahren, durch Inquisition ihre Wahrheiten zu erpressen bestrebt war, eine Methode, die seinen Realismus beleidigte. Auf logischem Wege gelange man nur zu Meinungen (Hypothesen), denn jeder Beweis hängt mit innern Zweifeln, daß auch das Gegenteil wahr sein könnte, zusammen ${ }^{4}$ ). Die logisch (experimentell, induktiv) gewonnene Erkenntnis bedeute nur ein Umgehen des direkten und wahren Wissens. Die durch die logische Bearbeitung der Sinneseindrücke gewonnene Wissenschaft bietet nur »ein äußerliches Merken und Spüren «, keine inwendige Erkenntnis; sie führt zu dem von den Aristotelikern vertretenen Wahne, daß es eine all-

1) S. 932.

2) S. 1262 .

3) S. 184 .

4) S. 45 . 
gemeine, objektive, für alle Menschen in gleichem Maße verbindliche Wissenschaft gebe, während sich die Dinge in der Tat nach der Art dessen, der sie aufnimmt, verändern ${ }^{1}$ ). Die Wahrheit ist Realität, ist undenkbar ohne Subjekte, die ihr Leben und Qualität verleihen; die Wahrheit muß man früher haben, ehe man sich aufs Beweisen einläßt; die Wahrheit existiert, die Meinung ist dagegen nur Schein.

Denn die Wahrheit ist ein wirkliches Ding, welches wahr ist, die Vernunft aber ist ein eingebildetes, in Worten bestehendes und nur dem Schein nach also genanntes Ding2).

Diese wirkliche Wahrheit, die die Sache der Überzeugung, ein Stück Leben bedeutet, sucht HeLmont. Sie kommt uns auf, wenn wir mit dem erkannten Objekte eins werden:

wenn die Seele Gedanken hat von sich selbst oder von etwas andrem, als werin sie es selbst wäre, ohne habenden Unterschied zwischen dem gedenkenden und dem gedachten Dinge, wie auch ohne Verknüpfung, Abkehrung oder Abscheu auf Zeit, Ort und andere Umstände... ${ }^{3}$ )

Wenn Wahrheit und Erkenntnis reale Reaktionen eines bestimmten Individuums auf die Umgebung darstellen, dann muß man auch die Ideen (sachgemäße Vorstellungen) als Realitäten auffassen. Solange man z. B. an die Krankheit nur oberflächlich denkt, bedeutet sie ein Hirngespinnst; eine lebendige Vorstellung der Krankheit wird dagegen zur wirksamen Idee, die wirkliche Erkrankung nach sich zieht $\left.{ }^{4}\right)$. Die Wahrheit erkennen heißt also soviel wie an der Wahrheit krank werden, von der Wahrheit infiziert werden. Diese realistische, organische Auffassung der Wahrheit, die im radikalen Widerspruch gegen die Auffassung der Wahrheit seitens der modernen Wissenschaft steht, führte HELMONT zum Entschluß, sich von der Herrschaft des Verstandes zu emanzipieren und auf Eingebungen und auf Träume mehr als auf Schlußfolgerungen zu achten; es sei doch die Erkenntnis der Wahrheit immer eine geniale Tat, der der Mensch nur durch besondere Gnade Gottes teilhaftig werden kann; die Wahrheit durchfährt den Menschen wie ein Blitz ${ }^{5}$ ), sie ist weder diskursiv noch aus Worten zusammengesetzt, sondern einheitlich. Deshalb ist die echte Arzneikunst

1) S. 75 .

2) S. 45 .

3) S. 26 .

4) S. 964 .

5) S. 26.

Rádl, Geschichte der biol. Theorien. I. 2. Aufl. 
eine lautere Gabe und bloßes Geschenk des allerhöchsten Gottes, und sei hierbei von einem scharfen und subtilen Geiste sehr wenig zu hoffen ... Denn der Herr hat den Arzt erschaffen und machen ihn nicht die Schulen ${ }^{1}$ ).

Denselben mystisch realistischen Sinn haben auch die Lehren des PARACElsus gehabt; auch Platos Lehre von der Wahrheit als einer wirklich existierenden Idee geht auf eine ähnliche Konsequenz heraus; VAN HELMONT hat sie nur erneuert und in neuen Worten formuliert.

\section{Naturphilosophie.}

Die Lehre vom Makrokosmos feiert bei HELMont ihre Wiedergeburt: das Weltall erklärt er für ein lebendiges Wesen, dessen Teile (wie die Glieder des Organismus) in durchgängiger Wechselwirkung stehen; die Bewegungen der Planeten hängen mit dem Menschenschicksal, die Bodenbeschaffenheit mit dem Charakter der Pflanzenwelt, die Tätigkeit des Magens mit derjenigen des Gehirns, die Begebenheiten in einem Lande mit den jenigen eines anderen zusammen ${ }^{2}$ ); es gibt eine allgemeine Sympathie ${ }^{3}$ ) der Erscheinungen. Alle erschaffenen Dinge sind einander ähnlich, jedes verwirklicht in seiner Art dasselbe Weltall.

Nach der mechanischen Anschauung der Antipoden HeLmonTs, der Kartesianer, gibt es objektive Dinge außer uns, die aufeinander stoßend das Weltgeschehen verursachen. Alle Kräfte sind da in letzter Instanz mechanische Kräfte (Druck- und Stoßkräfte), die von einem Ding auf das andere übertragen werden. Diese Philosophie kennt nur verschiedene Modalitäten einer Kraft und einer Materie. VAN HELMONT geht vom entgegengesetzten Standpunkt aus; jedem Ding ist eine eigene spezifische Kraft, eine besondere für dieses Ding charakteristische Art Streben inne, "Blas " nach HELMoNT genannt. In der Entwicklung jedes Menschen, in der Bewegung eines jeden Planeten, im Wachstum eines jeden Kristalls äußert sich eine besondere Kraft, deren es also eine unendliche Menge gibt; ihr gemeinsames Merkmal ist das Vorwärtsstreben, welches "Blas « heißt" ${ }^{4}$ ).

An jedem Naturobjekt unterscheidet Helmont Materie, Form und Kraft. Alle Materie läßt sich auf das Wasser als auf das Ur-

1) S. 7 .

2) S. 826

3) Helmont nennt diese Sympathie sactio regiminis«.

4) Nach Descartes erleiden die Körper die Wirkung der Kraft; nach Helmont entwickeln sie Kraft. Leibniz steht mit seiner Monadologie in der Mitte zwischen Descartes und Helmont. (HelmonT, S. 8I5 sq.) 
element zurückführen; HeLmoNT führt eine Hierarchie der Formen und der Kräfte (die er nicht deutlich genug von einander unter. scheidet) an und zwar unterscheidet er insbesondere die folgenden: den Samen der Dinge, das Ferment (Urheb), das individualisierte Bewegungsprinzip (Archeus) und die Ideen. Mit Hilfe dieser und anderer untergeordneter Begriffe baut HeLmont die Welt auf.

\section{Biologie.}

Als Paracelsist erblickt van Helmont im Leben einen dynamischchemischen Prozeß und versteht unter Leben jeden Naturvorgang. Anstatt der althergebrachten vier Elemente (Erde, Wasser, Luft und Feuer) führt HeLmont als, einziges Urelement das Wasser ein, neben dem nur die Luft noch einige Unabhängigkeit behält. Aus dem Wasser entsteht der materielle, aus der Luft der geistige Teil der Dinge. Daß z. B. die Erde aus Wasser entstehen kann, weist HELMONT durch folgendes Experiment nach. In einen mit Erde gefüllten Blumentopf hat er einen Weidenstock gepflanzt, nachdem er zuerst die Topferde und den Stock gewogen hat. Daraufhin begoß er den Weidenstock fünf Jahre hindurch regelmäßig mit Regenwasser oder mit destilliertem Wasser und schützte die Topferde vor Staub. Nach fünf Jahren hat er die Erde und die Weide von neuem gewogen; das Gewicht der Erde hat nur um ein Geringfügiges abgenommen (HELMONT glaubte diesen kleinen Verlust übersehen zu dürfen), während die Weide um mehrere Pfund zugenommen hat, ein Beweis, daß das Holz (= die Erde) aus dem Wasser entstanden sein muß. So leben - führt HeLmont weiter aus - auch die Fische bloß vom Wasser - dem Stör fehlt sogar der Mund - und legen doch viel Fleisch und Knochen an. In ähnlicher Weise entstehen auch das Gestein, der Sand, die Metalle, der Dampf, die Gase aus Wasser und können sich wieder in Wasser zurückverwandeln 1 ).

Den Begriff einer blinden Ursache kannte HeLmont nicht, er individualisierte vielmehr das Geschehen; jeden Vorgang faßt er als Entwicklung einer konkreten, in sich geschlossenen Erscheinung auf, und es gibt folglich in seinem System soviel Kräfte, als es einheitliche Begebenheiten gibt, und alle Kräfte sind organische Kräfte.

1) Das Experiment mit dem Weidenstock wird als das erste moderne Experiment aus der Pflanzenphysiologie gerühmt. Die Betrachtungen über das Wasser als das Urelement haben Helmont ferner auf die Entdeckung des Luftthermometers, des ersten Thermometers überhaupt, geführt. 
Die allgemeinste Eigenschaft der Kräfte ist »Blas «1 $)$, 》ein Trieb sowohl zu Bewegungs- als zu Änderungsfällen «²), der sich in der Wirkung des Gewichts, in den Erscheinungen der Härte, beim Händedruck, beim Stiche der $\mathrm{Nadel}^{3}$ ), im Wehen der Winde ${ }^{4}$ ) offenbart. Konkreter ist das "Ferment "(fermentum, Urheb, natürlicher Sauerteig), ein Geschehen, das die heute sogenannten chemischen Veränderungen charakterisiert, zu denen HELMONT auch das Wachstum der Pflanze, die Embryonalentwicklung der Tiere, die Verdauung ${ }^{5}$ ), die Entstehung der Mineralien ${ }^{6}$ ) und Kristalle ${ }^{7}$ ) rechnet. Das Ferment ist im Boden, im Wasser, in der Luft enthalten; jedes Naturobjekt besitzt ein spezifisches Ferment, so daß es soviel Fermente gibt, »als Früchte aus ihr (der Erde) zu erwarten sind ॥ $\left.^{8}\right)$. In jedem Ding liegen wieder soviel Fermente, als es verschiedene Veränderungen erleben kann. Das Ferment stellt also eine Art Impuls für ein konkretes Geschehen dar, durch das z. B. direkt aus der Erde Pflanzen und Tiere kristallisieren können.

Auf diese spontane Art entstehen die konkreten Formen nur ausnahmsweise; den regelmäßigen Anfang der Entwicklung jeder Natureinheit bildet der Same, d. h. ein an ein Stück Materie gebundenes Bild des zukünftigen Wesens; der "Same " des Roggens liegt im Korn, derjenige des Vogels im Ei, der Same der Krankheit stellt die Inkubationsperiode derselben dar $^{9}$ ), die Samen der Mineralien sind deren Keime oder deren in der Erde eingeschlossene Möglichkeiten $\left.{ }^{10}\right)$. Die Samen der Menschen und der höheren Tiere 'existieren seit der Weltschöpfung, andere Samen entstehen durch die Einwirkung des Fermentes auf die Materie. HELmont will sich durch ein Experiment überzeugt haben, daß Frösche auf die letztere Art aus Schleim in Felsenspalten entstehen ${ }^{11}$ ).

1) Den Namen hat Helmont analog zu dem von ihm geschaffenen Worte $\rtimes$ Gas geprägt; er erinnert an das Wort sblasen..

2) S. 970 .

3) S. 876 .

4) S. II2.

5) S. 1220 .

6) S. 304 .

7) S. 194 .

8) S. 34 .

9) S. 966 .

10) S. 204.

11) S. $65 \mathrm{I}$. 
Wie die Elemente das Substrat des materiellen Geschehens bilden, so bilden die Samen die Grundlage der individualisierten Erscheinungen; denn alle Naturvorgänge streben danach, Konkretes hervorzubringen: so einzelne Mineralien, Pflanzen, Tiere, die sich aus formlosem Anfang durch Überwindung einer Reihe von inneren Widerständen zu vollkommenem Naturobjekt entwickeln, auf diesem Höhepunkt einige Zeit beharren und dann untergehen. Ihre Entwicklung und ihr Kampf ums Leben wird von einer Lebenskraft, dem sog. A r che u s ${ }^{1}$ ) beherrscht, der die Lebensäußerungen der Körper dirigiert und dieselben vor Unfällen und Krankheiten beschützt. Der Archeus beherrscht den Körper wie der Feldherr die Armee; er bestimmt den Plan der Handlungen, er dirigiert die Antriebe des Blas, er ist der »inwendige Werkmeister der Samen $\left.\|^{2}\right)$; der Archeus des Menschen ist "ein Schatten oder Schemen des Menschen mit voller Wissenschaft von allen Dingen, die vonnöten sein zu seinem Trieb und Regiment $\left.\ll^{3}\right)$.

In jedem Körper gibt es eine ganze Hierarchie von Archeen; deren Anzahl derjenigen der qualitativ verschiedenen Funktionen gleicht; ein Archeus beherrscht die Lokomotion, ein anderer den Bau der Knochen, ein anderer die Herztätigkeit, ein anderer die Verdauung, und auch jede Krankheit hat ihren eigenen Archeus; jeder Sinn stellt ein besonderes lebendiges Wesen dar: das Auge besitzt seinen spezifischen Archeus, das Ohr besitzt einen usf. ${ }^{4}$ ). Einzelne Archei arbeiten harmonisch miteinander, mit Ausnahme der Archeen der Krankheiten, die die Harmonie des Körpers stören. Über diesen Archei insiti herrscht der die Einheitlichkeit des Lebens bestim. mende oberste Befehlshaber des Körpers, der Archeus influus. Die Anlegung von Fett an einer unrichtigen Körperstelle bedeutet z. B. einen Irrtum des Archeus influus, der den fettbildenden Archeus bestimmt hat, an jener falschen Stelle zu funktionieren ${ }^{5}$ ).

1) Den Namen $\triangleright$ Archeus c hat Helmont von Paracelsus übernommen, hat aber den ihm untergeordneten Begriff gründlicher und konsequenter ausgefïhrt.

2) S. 40 .

3) S. 4 I.

4) S. 826 .

5) S. 42. - Helmont vergleicht den Archeus an einer Stelle mit einer Art snatürlichen Lichtes « (Lichtmaterie), das den Körper durchleuchtet, an einer anderen Stelle mit dem natürlichen Geruch der Körper, der für jedes Einzelding verschieden sein soll; die Ähnlichkeit der Gerïche bedingt Sympathie, die Unähnlichkeit Antipathie (S. I54. G. J ÄGER ist bekanntlich vom Materialismus aus auf dieselbe Schlußfolgerung gekommen.) 
Da sich die Krankheiten trotz mannigfacher Symptome als individualisierte Vorgänge entwickeln, besitzt jede Krankheit ihren Archeus; denn jede Krankheit stellt »ein natürliches Wesen, so von einem Wesen herkommt «1) und sitzt im Körper entweder als natürliche Disposition (non materialiter sed characteraliter) von der Geburt an, oder sie wird dem Körper während des Lebens imprägniert.

Einen höheren Rang als die Beherrscher der Dinge, die Archei, nehmen nach HeLmont die Ideen ein, die den Plan, den Stil, das Wesen eines jeden Dinges bedeuten, entweder unbewußt oder bewußt sind, in der Seele der Dinge entstehen ${ }^{2}$ ), den Anfang der durch den Blas hervorgerufenen Bewegungen bilden ${ }^{3}$ ) und die Kenntnis aller zur Entwicklung nötigen Dinge enthalten. Die Ideen entstehen, wenn eine Vorstellung dem Körper imprägniert wird: solange man nur oberflächlich an etwas denkt, ist die Vorstellung nur »ein bloßes eingebildetes Wesen und ein Unding ( $\left.^{4}\right)$, nur eine Art Gehirnausdunstung, und ist außerstande eine Bewegung auszuführen; lebt man sich jedoch in die Vorstellung hinein, wird sie zu unserem Bestandteil und führt zu konkreten Taten: die Vorstellung ist zur Idee geworden. Gott hat zuerst eine Vorstellung der Welt gehabt; durch sein Wort Fiat! wurde die Vorstellung zur Idee; durch ein analoges Fiat! entstehen die Samen aller Dinge ${ }^{5}$ ). Von der übersinnlichen Welt (Helmont beruft sich auf dieser Stelle auf Plato) treten Vorstellungen herab, die von den Steinen, Pflanzen, Organen, Tieren, Menschen erfaßt und zu wirksamen Ideen umgewandelt werden.

Und ist also aus diesem allem klar $z u$ sehen, nicht nur da $\beta$ in diesen Gedankenbildern (idea) eine überaus starke Kraft zu wirken stecke: sondern auch, weil sie sämlich sind, daß sie natürlicherweise alles durchdringen und wirken ...6)

Am ausführlichsten erörtert HELMONT die Ideen der Krankheiten. Von außen kommt die Erregung der Krankheit, welch letztere aus dem Wesen jedes Individuums, aus der Idee hervorkommt. Im Menschen oder in einem Organ seines Körpers entsteht eine (unbewußte) Vorstellung der Krankheit, die sich dem Lebensgeist einprägt und zur »Idea sigillaris «wird; der Lebensgeist wird gereizt,
1) S. 676 .
2) S. 593 .
3) S. 976 .
4) S. 662 .
5) S. 594 .
6) S. 964 . 
beginnt zu rasen (= Fieber), scheidet Gift aus, durch das der Körper infiziert wird. Namentlich auf die ansteckenden Krankheiten sucht HELMONT diese Theorie anzuwenden. Wenn auch die Ideen meistens an bestimmte Körper gebunden zu sein pflegen, so können sie sich von denselben auch losmachen und sich im Raume frei bewegen: die Ideen der Sterne können auf die Erde hinabsteigen und die Menschen beeinflussen ${ }^{1}$ ).

VAN HELMONT hat die Gase entdeckt; der moderne materialistische Begriff derselben, als vollkommen elastischer Materien, die den größtmöglichen Umfang einzunehmen streben, ist ihm jedoch unbekannt; die Luft und das Gas bedeutet für ihn eine Zwischenstufe zwischen Materie und Geist; sie sind materiell, weil sie im Raume ausgebreitet sind, sie sind geistig, weil sie unsichtbar $\operatorname{sind}^{2}$ ); aus der Luft entsteht ja auch der Archeus und die Seele.

Die Gase gehören zu den Elementarbestandteilen der Dinge $\left.{ }^{3}\right)$; und es gibt deren nach HeLmont mehrere Arten: die Luft, "Windgas oder Winddunst, welcher nichts anderes ist als eine lautere Luft $\left.\ll^{4}\right)$, Fettgas (leuchtende Gase?), »trockener Gas, den man Sublimat nennet ", "Rußgas " (Rauch und Dampf), "Gas fuliginosum sive endemicum " und Wildgas (Gas silvestre), "der sich in keinen sichtbaren Körper zusammenzwingen läßt «, in gärenden Substanzen entsteht und unserer Kohlensäure entspricht ${ }^{5}$ ). Eine besondere Art der Gase bilden die Lebensgeister (Gas vitale, 》ein gesalzenes, scharfes, subtiles Wesen «6)), die während der Ohnmacht den Körper verlassen und durch reine Luft ersetzt werden, eine Art natürlichen Lichtes bilden und den Körper vor Verwesung beschützen ${ }^{7}$ ). Die Lebensgeister entstehen durch Oxydation des Blutes; in ihnen wohnt die Seele ${ }^{8}$ ). Sie steigen zum Gehirn hinauf und erwecken in demselben die Vorstellungskraft und das Gedächtnis, in den Sinnesorganen verwandeln sie sich zu spezifischen Sinnestätigkeiten, zum Gesicht, Gehör usw. Die Lebensgeister stellen die

\section{1) S. 975 .}

2) Für Helmont wie für die älteren Philosophen überhaupt stellen übrigens auch die Seele, der Archeus, die Idee etwas halbmaterielles dar.

3) Den Namen \Gas hat Helmont geprägt; die philologische Bedeutung des Wortes ist noch strittig.
4) S. $72 \mathrm{r}$.
5) S. $109 \mathrm{sq} ., 727 \mathrm{sq}$.
6) S. 149 u. 1220.
7) S. 150.
8, S. 232 . 
Materie dar, in der die Krankheiten wohnen; durch die Lebensgeister wirkt der Archeus mit Hilfe des Blas.

Das eingehende anatomische Studium der Körpermaschine verwirft HELMONT ${ }^{1}$ ), denn nur die in Veränderungen vor sich gehende Dynamik des Lebens hat für ihn Interesse. Er bekämpft die Lehren, nach denen der Körper eine durch Hebel und Röhren getriebene Maschinerie darstellen sollte, und als das. Wichtigste stellt er die gegenseitige harmonische Abhängigkeit der Leistungen des Organismus auf.

Im normalen, gesunden Leben entwickeln sich keineswegs alle im Organismus latenten Möglichkeiten; das Leben besteht vielmehr nur in monarchischer Herrschaft des obersten Archeus über die unterjochten Lebenskräfte. Auch die Knochen, Muskeln, der Magen usw. sind eines freien, vollkommenen Lebens fähig, das aber im Organismus nur insofern seine Kräfte entwickelt, als es der Archeus influus erlaubt ${ }^{2}$ ); sie führen ein »Mittelleben ", eine Art unfreies, gedämpftes Leben ${ }^{3}$ ), während der Archeus influus die Stufe des »letzten Lebens " erreicht, indem er alle seine Kräfte in voller Freiheit entwickelt. Jedes vollentwickelte Ding lebt als solches sein letztes. Leben, so z. B. auch die Tiere und die Pflanzen. Die Vorbereitung derselben in der Küche und die Verdauung ihrer Körper im Magen (auch die Herstellung der Drogen) zielt auf die Herabdrückung ihres letzten Lebens auf die Stufe des Mittellebens, auf der sie fähig sind Untertanen und Bestandteile unseres Körpers zu werden $\left.{ }^{4}\right)$. Durch Verdauung verändert also z. B. das Schweinefleisch keineswegs seine Natur, es bleibt auch, da es zum Körperbestandteil des Menschen wird, wesentlich (im latenten Zustande). Schweinefleisch. Daher kommt es z. B., sagt Helmont, daß Schweine, die mit Fischen ernährt werden, Fischgeruch bekommen.

Folglich besteht das Leben in lauter Unterjochung und Erhebung einer Macht über die andere, wobei aber die Wesenheiten unverändert bleiben.

Auf der Stufe des Mittellebens stehen auch erbliche Krankheiten; dieselben werden auf die Kinder nicht materialiter übertragen, sondern "durch eine gewisse Zeichnung im Mittelleben «,

1) S. 824 .

2) S. 708 .

3) S. 200.

4) S. 205. - Im 19. Jh. hat eine analoge Theorie (Vererbungstheorie) Sam. Butler entwickelt. (Vgl. Bd. II dieser Schrift. S. 449 sq.) 
als Dispositionen, die lange Zeit schlafen können, bis sich einmal ihr Archeus erweckt und sich zum letzten Leben, zur wirklichen Krankheit entwickelt.

Als erstes Leben sind die undifferenzierten Anfänge der Dinge zu verstehen.

Die embryonale Entwicklung soll epigenetisch vor sich gehen, indem der Archeus den Körper allmählich baut:

Weil aber eine jede körperliche Handlung ihr Absehen auf einen Körper hat und sich darinnen endiget; so geschieht es dahero, daß der sämliche Geist (= Archeus), der Werkmeister und Regent der Zeugung, sich alsobald mit einem körperlichen Kleide und Wesen bekleidet. Denn in den Arten der Tiere und des Menschen durchwandelt er alle Winkel und verborgene Löcher seines Samens und fängt an, daraus eines Menschen Leib zu machen. $\mathrm{Da}$ verwandelt er die Materie, darinnen er ist, nach dem Inhalt und der formenden Wirkung seines Bildes. Denn hier macht und setzt er das Herz hin, dorthin zeichnet er das Gehirne ab; und weil er das allgemeine Regiment hat, so setzet er überall und in jedes Glied einen gewissen Verwalter hin, der unbeweglich alldorten wohnen muß, nachdem es nämlich die Teile und deren Zweck erfordert ${ }^{1}$ ).

HELMONTs Schriften enthalten lauter biologische (physiologischchemische) Betrachtungen; über einzelne Tiere und Pflanzen äußert er sich aber kaum. Die Biologie als selbständige Wissenschaft ist ihm unbekannt geblieben; von einzelnen Wissenschaften führt er nur Medizin, Geschichte, Mathematik, Logik an, und nur vorübergehend erwähnt er die Organismen. Er glaubt, daß sich der Mensch von den Tieren durch die unsterbliche Seele unterscheidet, die sozusagen in die Lebensgeister eingewickelt ist und durch dieselben auf den Körper einwirkt. Sonst führt Helmont folgende Lebensstufen an: I) Das erste Leben ist stumm und kaum spürbar (Mineralien); bereits auf dieser Stufe kommen jedoch Empfindungen und eine Art der der magnetischen Wirkung analogen Phantasie vor ${ }^{2}$ ). 2) Die Samen der Dinge. 3) Die Pflanzen, die wachsen und sich vermehren; auch sie haben Empfindungen, denn sie drehen sich nach der Sonne. In konkreto schreibt HeLmont über die Pflanzen nur vom pharmakologischen Standpunkte aus. 4) Die Tiere sind beweglich, haben Sinnesorgane, Willen, Einbildungskraft, Verstand (Schlußvermögen). Tiere als anatomische Erscheinungen sind HELMONT (wie den übrigen seiner Zeitgenossen) noch unbekannt;

1) S. 4 I.

2) S. 588 . 
er sieht in denselben nur geistige Wesen; so z. B. beschreibt er den Hund wie folgt:

Ein Hund ist ein fressiges, bissiges, neidisches, wachsames, bellendes, jagendes Tier, das um eines einigen Bissens willen aller Wohltaten uneingedenk, undankbar, schmeichelhaftig und dergleichen ist ${ }^{1}$ ).

5) Der Mensch allein hat das Gemüt (die Seele).

So lautet der gedrängte Auszug aus HELMONTs zwar weitschweifigen aber ideenreichen Erörterungen; HELMONTS Spekulationen über einzelne Krankheiten, über das Fieber, über Heilquellen, über das Wesen der Zeit und viele andere müssen wir unberücksichtigt lassen. Der Einfluß des PARACELsus auf sein Gedankensystem ist desto leichter zu konstatieren, als sich HELmont wiederholt für den Fortsetzer dieses Philosophen ausgibt, den er nur in Einzelheiten berichtigen ${ }^{2}$ ), in der Hauptsache aber nur billigen kann. HeLmonTs Verhältnis zur zeitgenössischen Wissenschaft ist dasselbe wie dasjenige HoHENhEIms zu der offiziellen Wissenschaft der Renaissance; daß er weniger freimütig ist, ist dem Geist der Zeit zuzuschreiben. Mag auch Helmonts Naturphilosophie an vielen Mängeln leiden, immerhin ragt sie turmhoch über die schöngeistigen Spekulationen der sogenannten Erfahrungswissenschaft der RÉaUmuR, VALlisNIERI und Consortes.

VAN Helmont bildet ein Bindeglied zwischen PaRAcelsus und den Vitalisten; für die nachfolgende Periode hat er wohl an erster Stelle als Chemiker Bedeutung gehabt; zweifellos haben ihn aber auch Biologen verstanden, so StahL, Leibniz, Goethe.

Einzelne Ideen vaN HELMONTs erinnern auffallend an den etwas jüngeren Leibniz, der den Sohn Helmonts, Franz Mercurius vaN HELmont, sogar persönlich gekannt hat. Helmont des Jüngeren philosophische Schriften enthalten verflachte Ideen des Vaters mit den mechanischen Lehren der Kartesianer kombiniert; vielfach erinnern sie an die Phantastereien der deutschen Naturphilosophie. Insbesondere hat er über die Seelenwanderung spekuliert: jeder Organismus und jeder einheitliche Teil desselben wird von einer Seele beherrscht, so daß der Körper einer Armee von Seelen gleicht, die alle unsterblich sind und als Keime vom Körper zum Körper wandern, sich eventuell zu höheren Stufen erschwingen können und auf diese Art sich durch eine Reihe von »Revolution en « einmal den höchsten

1) S. 166 .

2) Nichtsdestoweniger polemisiert Helmont oft und heftig gegen seinen Meister. 
Rang des Lebens erreichen. Ein undeutlicher Keim der Phylogenie und der modernen Vererbungstheorien ist in dieser Seelenwanderungslehre verborgen $\mathbf{1}$ ). LEIBNIZ polemisierte später gegen F. M. HELMONT; anfangs aber hat er ihn als eine "machtvolle, eigenartige Persönlichkeit «gepriesen; von ihm hat er manches Brauchbare über den Mikrokosmos, über Monaden, über die Unzerstörbarkeit des Lebens lernen können, lauter Ideen, die sicht leicht auf HELmont den Älteren zurückführen lassen ${ }^{2}$ ). An HELmont den Älteren schließt ferner E. STAHL an; er polemisiert zwar viel gegen seinen vitalistischen Vorläufer, man sieht aber aus seinen Diskussionen leicht, wie ihm HELMONTs Ideen zu schaffen gaben.

1) Helmonts Schriftchen $\gg$ Paradoxal Discourse wird, ist nach der Art eines Katechismus verfaßt; von den >Revolutionen , d. h. von stufenweiser Entwicklung, wird darin viel geschrieben.

2) Literatur. Über den Einfluß des Paracelsus vgl. Lessing, M. B., Paracelsus, sein Leben und Denken. Berlin 1839. - Neuburger-PAGel, Handbuch d. Geschichte der Medizin. Jena 1903. I. Bd. - J. K. Proksch, Paracelsus als medizinischer Schriftsteller. Wien u. Leipzig I9Ir. - J. B. HeLmonts gesammelte Schriften wurden unter dem Titel: Aufgang der Arzneikunst, das ist noch nie erhörte Grundlehren von der Natur usw., von dessen Sohne in Sulzbach 1683 herausgegeben. - Über van Helmont als Chemiker vgl. F. Strunz, Joh. Bapt. van Helmont. Leipzig und Wien 1907. Über Helmonts Theologie vgl.: F. GreSECke, Die Mystik J. B. van Helmonts. Leitmeritz 1908. - Der Titel der im Texte zitierten Schrift des F. Mercurius Helmont lautet: Paradoxal Discourse oder Ungemeine Meinungen von dem Makrokosmus und Mikrokosmus d. i. v. d. großen und kleinen Welt u. derselben Vereinigung. Hamburg 1691. - Über des jüngeren Helmonts Verhältnis zu Leibniz vgl. L. STEIN, Leibniz u. Spinoza. Berlin I89o. 


\section{Kapitel. \\ Die Vitalisten.}

\section{G. E. Stahl.}

Der Kartesianismus, der in der Biologie die Präfornationstheorien gezeitigt hat, hat die theoretische Medizin auf die bereits erwähnte "Iatrophysik " und auf die "Iatrochemie " geführt; die letztere, durch Franz de LA BOE (Sylvius, I614-1672), Professor in Leyden, begründet, war eine Schullehre, welche die Errungenschaften der zeitgenössischen Physik und Chemie (soweit von einer solchen die Rede sein konnte) zu einem mechanistisch gedeuteten System der Medizin auszubauen suchte. Die "Lebensgeister " (kleine Partikelchen, die den Äther der modernen Theorien vertreten und eine große treibende Kraft besitzen), die "Fermentation ", saure und alkalische "Salze" spielten in diesem im I7. Jahrhundert weltberühmten, heute vergessenen System die Hauptrolle.

Daß diese Theorien falsch sind, mußte ein jeder erkennen, der Ernst genug besaß, nicht für die Schulen und für die Öffentlichkeit, sondern für sich selbst die Erscheinungen des Lebens durchzudenken. GEORG ERNST STAHL (I660-I734), zunächst Hofarzt in Weimar, seit 1694 Professor der Medizin in Halle, seit I7I6 der Leibarzt des Königs von Preußen, ein Mann von ernster und religiöser Lebensführung, hat diese Aufgabe unternommen. STAHL ist kein echter Biologe mehr, wie HELMONT noch einer war, sondern er spekuliert nur als medizinischer Fachmann: im I7. Jahrhundert begannen sich die Wege der Biologie und der Medizin zu trennen; Réaumur, LEEUWENHOEK waren keine Ärzte mehr, STAHL kümmert sich nicht um die Tiere und Pflanzen; auch für die Philosophie zeigt er kein Interesse. Immerhin sind seine Lehren von allgemein biologischem Standpunkt beachtenswert.

StAHL hat offenbar viel in HeLmont gelesen; als Spezialist findet er 
jedoch diesen vitalistischen Chemiker zu kühn, sucht seine Lehren mit dem mechanistischen System zu versöhnen, und so erbaut er in seinen, im schwerfälligen Stil geschriebenen Abhandlungen einen Vitalismus, der sich von dem aristotelischen und paracelsischen durch bedeutende Konzessionen an den Rationalismus der Zeit unterscheidet. Der Vitalismus als eine besondere Doktrin tritt in dem System STAHLS zum ersten Mal in der Geschichte auf, indem er sich da in Gegensatz zu dem Mechanismus als einer anderen anerkannten Lehre stellt und nach ihren Grundsätzen die seinigen orientiert.

\section{Mechanismus und Organismus.}

Worin besteht, wovon ist abhängig, auf welche Verhältnisse und Bedingungen stützt sich dasjenige, was man Leben nennt; warum und auf Grund welcher Einsichten wird der Körper als lebendig bezeichnet $\left.{ }^{1}\right)$ ?

Zwar haben sich viele, behauptet STAHL, mit diesem Problem befaßt, doch haben sie zu keinem rechten Ergebnis kommen können, da sie keinen Unterschied zwischen Organis mus und Mechanismus machen.

Die Worte Mechanismus, mechanisch, Maschine, mechanische Kräfte (potestates) werden heute sehr oft angewendet, und man versteht darunter gewöhnlich die Figur, Größe, Lage und Beweglichkeit; einige nehmen auch die tatsächlich am Mechanismus bestehende Bewegung oder die Tendenz zur Bewegung (nisus motorius) als zum Wesen des Mechanismus gehörig an. Die Mechanisten spekulieren über die Lebensgeister, über mechanisch-physikalische Reizungen, Fermentationen, spezifische Anlagen der Säfte, über kleine Partikelchen, Poren im Gewebe, über die Struktur der Organe, über die Lage der Fasern in den Muskeln usw ${ }^{2}$ ). Sie bestreiten aber insgesamt, daß die Bewegungen oder die Tendenzen zu denselben untereinander in einem Verhältnis stünden, das durch ein gemeinsames Streben charakterisiert wäre.

Die heutige Anschauung ist, daß jeder Körper an sich mechanisch ist, und nicht nur an sich, sondern daß er sich nur in bezug auf sich selbst bewegt, ohne irgendein anderes $Z$ iel zu erreichen, weder warum er sich überhaupt, noch warum es eben auf diese Weise, noch wie oder warum er sich in bezug auf einen anderen Körper bewegen sollte ${ }^{3}$ ).

1) Theoria medica vera. Halae I jo8. S. 63.

2) S. 200.

3) S. I4. 
Zwar haben solche Bewegungen auch eine Resultante, doch soll diese niemals a priori (d. h. aus dem $Z$ weck), sondern immer nur a posteriori (nach dem Effekt) zu erraten sein.

Der Organismus ist von dem auf diese Art aufgefaßten Mechanismus grundverschieden: am Mechanismus geschehen die $\mathrm{Be}-$ wegungen, am Organismus werden sie hervorgebracht (facere: efficere); d.h. einzelne Vorgänge des Geschehens erfolgen nicht für sich selbst, sondern bekommen erst durch den Zweck, um dessentwillen sie geschehen, einen vernünftigen Sinn; und ebenso haben die einzelnen Teile des den Zweck Hervorbringenden eben in diesem Zweckihre raison d'être. Solche für einen $\mathrm{Z}$ weck konstruierten Apparate müssen Organismen im allgemeinen genannt werden. Die vom Menschen konstruierten Instrumente sind solche Organismen.

Das Eigentümliche an dem Organismus ist immer und muß ihm notwendig angehören, da $B$ er eine mechanische Disposition hat; und zwar nicht nur im Allgemeinen, insofern in jedem Körper die mechanische Disposition absolut notwendig vorhanden ist, sondern auch im Besonderen, so da $\beta$ dem Ding, welchem er angepaßt ist, der Organismus in seiner mechanischen Beschaffenheit entsprechen $m u B^{1}$ ).

Wohl behaupten die Mechanisten, daß man nicht ängstlich nach den Zwecken der Dinge suchen soll, und dies hat seine Richtigkeit, wenn von Problemen die Rede ist, welche weit vom Verständnis des Menschen entfernt sind, so daß keine Hoffnung ist, in das Wesen dieser Probleme einzudringen, wie z. B. in das Problem, zu welchem Zwecke die so vielen Himmelskörper so angeordnet sind, wie sie es sind, oder zu welchem Zwecke nicht nur so unzählige Individuen, sondern auch einzelne Arten der Insekten geschaffen worden sind und sich täglich vermehren. Anderseits wieder gibt es Probleme, wo niemand auf den Gedanken kommen wird, von der Erscheinung den Zweck abzusondern, so z. B. den Nutzen der organischen Teile, daß nämlich die sensorischen Teile für die Sinne, die Muskeln für die Bewegung, die Zunge für die Sprache usw. bestimmt sind. Diese Zwecke sind also der wissenschaftlichen Erforschung zugänglich.

\section{Das Verhältnis der Physik und Chemie zur Biologie (Medizin).}

Durch die Bemühungen vieler Forscher sind in die Medizin Lehren eingeführt worden, welche das wahre Wesen derselben ver- 
schleiern. So die Physik, welche seit den ältesten Zeiten mit ihren nackten und abstrakten Sprach- und Begriffsformeln die Geister von der wahren Erkenntnis des Körpers und der Vorgänge im Körper irregeleitet hat; heute ist sie (als Kartesianismus) wieder in allgemeine Begriffe von der Materie verflüchtigt, die höchstens auf sehr wenige tatsächliche Erscheinungen passen; die wahren und tätigen Ursachen und die Gründe des Geschehens, sowie die Energien läßt sie unberücksichtigt oder erfaßt sie nur unvollkommen. Die heutige Physik betont außerdem nur die Materie, die gröbere Struktur (conformatio) und die gegenseitigen Proportionen der Körper. Die Bewegungen, die Kraft und die Wirkung auf die Materie, ihre Zeitverhältnisse, ihre Intensität und ihre Veränderungen beachtet sie nicht. Richtig haben die Alten gesagt, daß der Medicus dort anfängt, wo der Physiker aufhört; dies zieht man heutzutage nicht in Betracht. Die Physiker können uns höchstens lehren, auf welche Art der Körper beschädigt werden könnte - doch dies zu erkennen ist keineswegs die Aufgabe des Mediziners; ihm liegt es ob, zu wissen, auf welche Art der Körper beschädigt $z u$ werden pflegt, und wie der Beschädigung vorzubeugen ist.

Aus ähnlichen Gründen ist auch die Chemie ohnmächtig, dem Arzte dic Erklärung des Lebens zu bieten. Die einfachen chemischen Verbindungen haben in ihrer inneren Beschaffenheit keinen Grund dafür, wie lange sie bestehen sollen; die lebendigen Körper dagegen können sich niemals ununterbrochen lange als solche erhalten. Der Grund der Auflösung der chemischen Verbindungen liegt in ihrem Verhältnis zu anderen chemischen Substanzen, welche auf sie einwirken. Nicht so bei den lebendigen Körpern, welche, obwohl ihre chemischen Bestandteile an sich sehr leicht zerfallen, trotzdem viel länger aushalten, als es ihrer bloßen chemischen Beschaffenheit entsprechen würde. Die ganze Art der Wirkung und des Geschehens, welche auf die Erhaltung der chemischen Bestandteile des lebendigen Körpers abzielt, ist weit verschieden von den einfachen Wirkungen der toten Mischungen, indem das Bestehen der lebendigen Substanzen durch eine formale, unkörperliche und der ganzen materiellen Mischung fremde Wirkung ermöglicht wird. Auch die Assimilationsund die ihr verwandte Fortpflanzungsfähigkeit ist nur den lebendigen Körpern im Unterschied von den toten gegeben, nämlich die Fähigkeit, daß die Teile der lebendigen Körper, auch wenn sie ihre chemischen Bestandteile durch Zufall verlieren, diese durch Assimilation der sie umgebenden Substanz wieder neu hervorbringen; 
und dies geschieht ununterbrochen. Den toten Körpern ist diese "Regeneration « und "Restitution der Individualität « fremd, und wenn etwas Analoges dann und wann bei ihnen geschieht, so ist dies bloß Zufall, während die Tiere sogar Instinkte, Appetite, den Willen, die Sehnsucht haben, welche sie zur Vermehrung der Nachkommenschaft antreibt.

\section{Biologie und Anatomie.}

Jeder konsequente Vitalist muß die eben vorgeführten Grundsätze STAHLs unterschreiben; von früheren Vitalisten wurden sie deshalb nicht formuliert, weil keiner der früheren Biologen den Mechanismus als eine konsequente, öffentlich anerkannte Lehre gekannt hat; der bewußte Gegensatz zu dem Mechanismus verleiht STAHLs Ausführungen ihre Bestimmtheit. Der konseqente Vitalismus führt unseren Autor zur Bekämpfung der Anatomie wir haben gesehen, daß weder PARACELsus noch vaN HELMONT vom großen Wert der Anatomie überzeugt waren. Die Kenntnis der Anatomie, führt Stahl aus, ist nicht nötig, um die Funktionen des Körpers erkennen zu können. Die Anatomie führt uns bloß auf die Kenntnis des ruhenden Körpers, welche Kenntnis wesentlich physikalisch bleibt. Ebenso wie es unmöglich wäre, durch die Einsicht oder sogar Beschreibung eines Uhrwerkleins, sei sie noch so vollkommen, die mathematisch-physikalischen Gesetze desselben zu erkennen, oder die Beziehungen der miteinander zusammenarbeitenden Teile, der Zahlen, Zähne und Räder, sowie die Folge der durch die Uhr gemessenen Zeiten zu begreifen, wie es ferner unmöglich wäre, durch jene Einsicht zu erkennen, wie die Uhr zu machen oder zu reparieren ist, so kann man aus jenen nackten physischen Beschreibungen des menschlichen Körpers nicht erkennen, auf welche Art er beschädigt werden könnte, besonders auch nicht, auf welche Art er gewöhnlich beschädigt wird.

\section{Die Seele und das Wesen des Lebens.}

Die Lehre von der Seele (anima) bildet den Kern der Stahlschen Naturphilosophie. Auch in der aristotelischen Biologie spielt der Begriff der Seele, der Psyche, die allerwichtigste Rolle; doch hat es STAHL nicht vermocht, sich zu dem kühnen Seelenbegriff des ARISTOTELES aufzuschwingen; während bei dem letzteren die Seele den Kern des Organismus, seiner Form und seiner Kräfte bedeutet, ließ sich STAHL bei der Aufstellung des Seelenbegriffes von der christ- 
lichen und von der Kartesianischen Auffassung der Seele als eines immateriellen, selbstbewußten, über die Körpermaschine waltenden Prinzips beeinflussen. Deshalb nennt man seine Theorie auch "Animismus «. Der kartesianische Dualismus von Geist und Körper wird von STAHL beibehalten. Er lehrt, daß die Seele nichts ohne den Körper kann: sie kann nichts perzipieren und daher auch nichts erkennen ohne die körperlichen Sensoria; sie kann ihren Willen nicht realisieren ohne den Dienst der körperlichen Organe. Daher ist der Körper notwendig: er ist notwendig als Mittel, welches die Intentionen der Seele ermöglicht ${ }^{1}$ ).

Weil der gesamte Körper in seiner ganzen Konstitution auf jene zwei Ziele (effectus) hinarbeitet und ihnen dient, erstens, daß er überhaupt erhalten bleibt durch die vitalen Vorgänge; zweitens, daß er den Sinnesempfindungen, den lokomotorischen Bewegungen und endlich dem Nachdenken selbst dient: desto klarer kann daraus eingesehen werden, daß dies eigentlich der $Z$ weck ist, dessentwegen der Körper so konstruiert ist.

Wie kann die Seele, als ein immaterielles Prinzip, auf den materiellen Körper wirken? Für einen Aristoteliker oder Platoniker hat dieses Problem keinen Sinn, da nach denselben die Seele und der Körper ein und dasselbe sind. Dem Vitalisten STAHL verursacht jedoch die Frage nicht weniger Schwierigkeiten als den Mechanisten. Er verwirft die Lehre der Mechanisten ${ }^{2}$ ), nach der feine Substanzen (Lebensgeister) von der Seele beeinflußt werden, denn wenn die Seele auf feine Substanzen wirken kann, so müßte sie auch auf die groben wirken können. Andere (LEIBNIZ) sollen etwas richtiger angenommen haben, daß zwischen den Handlungen der Seele und des Körpers ein festes, unveränderliches Verhältnis besteht; doch spricht die Möglichkeit der Erfahrung und die Wirkung der Phantasie der Mutter auf die Frucht gegen ein solches festes Verhältnis. STAHL verwirft auch die aristotelischen Lehren von der vegetativen und der sensitiven Seele, und auch van Helmonts Lehre von den Archei, denn es sei unnötig, mehrere Prinzipien der Tätigkeit des Körpers anzunehmen.

STAHL kennt also nur eine Seele im Körper, an der er zwei wichtigste Tätigkeiten, den intuitiven Intellekt (intellectus) und das diskursive Urteil (rationatio) unterscheidet. Das Urteil (und das Gedächtnis) arbeitet nur mit dem Material, welches irgendwie vor-

1) S. 258 .

2) S. $261 \mathrm{sq}$.

Rádl, Geschichte der biol. Theorien. I. 2. Aufl. 
stellbar (figuralis) ist, der Intellekt dagegen hat einen viel größeren Inhalt. So z. B. unterscheidet der Intellekt verschiedene Gerüche, Farben, Töne, Tastempfindungen u. ä.; durch kein Urteil wird man dazu kommen, den Grund dafür anzugeben, warum wir diese Farbe von jener unterscheiden, einer dritten dagegen gleichstellen; auch das Gedächtnis hilft uns dabei nicht. Auch in dem Urteil selbst gibt es solche durch das Urteil oder das Gedächtnis nicht aufzufassende Elemente: wenn wir einen Schluß ziehen, haben wir kein Bewußtsein von dem, was den Schluß bildet, keine Erinnerung daran, wie das gewirkt hat, was den Schluß hervorbrachte. Ähnlich ist es bei den Erscheinungen des Willens, oder wenn wir der Bewegung eine bestimmte Kraft geben, wenn wir die Füße einer Stiege angemessen emporheben wollen usf. Jener Intellekt nun, welcher unmittelbar mit der Umgebung zusammenhängt, ist die Folge der Seelentätigkeit; die Urteilskraft ist sekundär und erst auf dem Intellekt aufgebaut.

Die Seele wirkt und vollendet ihre Ziele durch die Bewegung. Die Bewegung ist die Eigenschaft des lebendigen Körpers; nichts kann der Körper weniger als Materien bilden; doch kann er aus den von allen Seiten hergebrachten Materien durch seine Energie das Nötige sammeln und den Bedürfnissen anpassen. Dies ist die wahre Naturmedizin, durch welche ohne ärztlichen Rat und äußere Hilfe viele Menschen genesen, wie schon längst Hippokrates erwähnt hat. Das Leben wird erhalten durch die Vermittelung des Säftekreislaufs, doch ist dieser Kreislauf kein Leben, sondern nur ein Werkzeug des Lebens, und zwar ein ziemlich entferntes. Als Bewegung erscheint das Leben in den Exkretionen und Sekretionen, aber auch diese sind kein Leben, sondern nur das unmittelbarste Instrument des Lebens. So wird das Leben hervorgebracht, nämlich die Erhaltung des Körpers und seiner Mischung und der Schutz vor jeder Beschädigung, der sonst der Körper durch seine materielle Beschaffenheit preisgegeben ist.

So enthält ${ }^{1}$ ) der allgemeine Begriff des Lebens und des Lebendigen immer den Begriff einer Aktivität, oder eher der Handlung innerhalb der körperlichen Dinge, welche Handlung ihnen immanent ist (nicht von außen erteilt), nicht vorübergehend.

... Weil der $\left(\mathrm{Mensch}^{2}\right)$ eigentlich Seele ist, der gesamte Körper aber 
nichts als die Offizin derselben: indessen beruht diese Seele nicht nur in der körperlichen Beschaffenheit dieser Offizin, sondern auch in den Zuständen der Materie, in ihren Zielen, welche an diese Materien gebunden sind; überhaupt besteht das Leben des Menschen, d. h. der menschlichen Seele, nicht einfach in einer Wirkung überhaupt, sondern spezifisch in der Wirkung im Körper, durch den Körper, innerhalb der und über die körperlichen Dinge hinaus und auch in der Wirkung auf den eigenen Körper.

Die Bewegung wird also von innen aus veranlaßt, die Seele bewegt den Körper. HELmONT ist derselben Ansicht gewesen, und auch HELmont hat gelehrt, daß man die Bewegungen konkret nehmen muß, d. h. als Streben nach einem bestimmten Zweck, wie es hier STAHI verlangt. Die Seele realisiert also ihre Zwecke durch den Körper und durch die Bewegung innerhalb desselben. Die menschliche Seele hat andere Zwecke als die irgendeines Tieres; um ihre Zwecke zu erreichen, muß die Seele dafür sorgen, daß der Körper unversehrt bleibe, und so wird durch die Seele der Vorgang der Sekretion und Exkretion, durch den unnütze und schädliche Bestandteile aus dem Körper vermittelst des Säftekreislaufs entfernt werden, erhalten.

\section{Die Ernährung.}

STAHL weist auf den Hunger und auf die Fähigkeit des Menschen hin, sich angemessene Nahrung zu wählen. Der Appetit ist der Wille der Seele, einen bestimmten und notwendigen Zweck zu erreichen. Der Hunger und der Appetit sind nicht an das Vorhandensein, an die Wirkung der Nahrung gebunden, sondern sie entstehen auch, wenn die Nahrung nicht gesehen oder irgendwie empfunden wird. Der Appetit ist die Handlung desjenigen Prinzips, welches nicht nur des organischen Körpers, sondern auch der Erhaltung desselben um seiner Zwecke willen bedarf.

Der letzte, elementarste Vorgang der Ernährung ist die Assimilation ${ }^{1}$ ). Die komplizierten Vorgänge der Ernährung, z. B. die Herbeischaffung der Nahrung, ihre Zerstückelung, Verdauung u. ä. bedürfen spezieller Organe; der Assimilation jedoch dient kein spezifisches Organ, sie geschieht unvermittelt durch eine ganz besondere Art der organischen Bewegung, durch die Abzählung, Zusammenstellung und Anordnung der elementaren Nahrungspartikelchen, nicht nach der Menge der herbeigeschafften Nahrung, sondern danach,

1) S. 484 . 
wieviel von derselben von Tag zu Tag, von Jahr zu Jahr, im Verlaufe der Jahre in einem stetig richtigen Verhältnis nötig ist.

\section{Die Zeugung und Entwicklung.}

Als Vitalist sollte StahL Epigenetiker sein; er kennt aber die epigenetischen Theorien eines HARVEY oder eines ARISTOTELES nicht oder versteht sie nicht, und so weiß er kaum, wie er die Entwicklung deuten sollte. Die Seele soll Entwicklungskraft besitzen und baut den Körper ihren Zwecken gemäß; es sei schwierig, die Art anzugeben, wie die Seele den Körper bilden kann; trotzdem muß zugegeben werden, daß die rationelle Seele, welche den fertigen Körper beherrschen kann, auch die Kraft haben muß, denselben, sofern er unvollständig ist, zu bilden. Die Tatsache der Phantasie zeigt uns, daß so etwas möglich ist: denn wie in der Phantasie der unvollständige Körperteil $\mathrm{zu}$ einem vollständigen gemacht werden kann, so kann dies die Seele in der Wirklichkeit. Das Beispiel ist gut gewählt: die Phantasie (eines Dichters, eines Forschers) kann wirklich neues schaffen - daß aber das Tertium comparationis eben in der Erschaffung von Neuem liegt, scheint StahL nicht eingesehen zu haben; er neigt in seinen Ausführungen eher zum Evolutionismus.

Schwierig sei es, die Vermehrung der Seelen zu begreifen, doch kann man sich da auf folgende Art helfen. Das Wesen der Seele liegt in der Tätigkeit durch die Bewegung; die Bewegung besteht wieder in beständiger numerischer Teilung, indem sich nämlich die Bewegung mit der Zeitfolge verändert, also in verschiedenen Zeitpunkten verschieden ist, und diese Verschiedenheit kann auch auf die bewegende Ursache, auf die Seele übertragen werden.

Stammt die Seele des Nachkommen von dem Vater, von der Mutter, oder kann sie von beiden herkommen, oder entsteht sie aus der Verbindung des männlichen und des weiblichen Prinzips? STAHL will die Frage nicht entscheiden, neigt aber zu der althergebrachten Ansicht, daß der Mann die Seele gibt, das Weib den Körper. -

Ausgedehntere Auseinandersetzungen über Pflanzen und Tiere fehlen in der Schrift STAHLs; hätte er versucht seine Theorie auf dieselben anzuwenden, müßte er manche seiner Ansichten modifizieren.

STAHLs Theorie hat namentlich die medizinischen Theoretiker nachhaltig beeinflußt; es läßt sich eine direkte Linie von ihm bis 
zu dem Vitalismus der deutschen Naturphilosophie über die MonTPELIIERsche Schule und über Bichat ziehen. Erst zu Zeiten der Naturphilosophie wurde jedoch der Stahlsche Animismus zu einer allgemeinen vitalistischen Theorie umgedeutet.

\section{Bichat.}

In derselben Zeit wie STAHL hat auch der Holländer M. HARTSOEKER (I656-I725) eine plastische oder formbildende Seele angenommen, welche $z$. B. dem Krebs den abgebrochenen Fuß regenerieren soll; dieselbe Seele soll im Menschenkörper die Spermatozoen bilden. Diese Seele ist intelligent, intelligenter als die verständige Seele; sie beherrscht und vollführt alle Körperveränderungen, die Lokomotion, den Blutkreislauf, die Ernährung, das Wachstum usf. Auch die Tiere und Pflanzen haben eine solche Seele, und die Him. melskörper werden durch solche Seelen bewegt. Ähnliche Ansichten über die Bedeutung der Seele hat auch der Engländer Cudworth zur selben Zeit ausgesprochen.

In England hat für STAHL Robert WhytT (I7I4-I766) gearbeitet, welcher insbesondere die Reflextätigkeiten des Körpers untersuchte und sie vitalistisch deutete; namentlich hat er den Begriff der spezifischen Reizbarkeit verschiedener Gewebe entwickelt. In Deutschland schloß sich an StahL JoH. Aug. Unzer (I727-I799) aus Halle an, bei dem sich ebenfalls die Andeutung der reflexartigen Bewegungen findet; er behauptet nämlich gegen STAHL, dạß viele Bewegungen der Tiere ohne Mitwirkung der Seele geschehen, und zwar windem derartige Reize gegen das Gehirn emporstreben, abwärts geleitet und gleichsam reflektiert, nämlich durch die Nervenknoten aufgehalten und abgeleitet werden «. In Frankreich wurde der Vitalismus von der Universität in Montpellier aus verbreitet, wo THEOPHILE DE BORDEU (I722-I776) wirkte, welcher der tierischen Substanz - gegenüber den physikalischen und chemischen Kräften - eine »Sensibilität « zuschrieb, die in jedem Organ spezifisch modifiziert ist, wodurch der Organismus wie zu einer Hierarchie lebendiger Wesen wird. Insbesondere von den Drüsen hat er behauptet (I 752), daß die Sekretion in ihnen nicht mechanisch geschieht, daß also etwa die Speicheldrüsen im Munde nicht durch den mechanischen Druck beim Kauen zur Abgabe des Speichels genötigt werden, sondern daß sie den Speichel nach einer ihnen inhärenten Sensibilität sezernieren.

Ebenfalls zu Montpellier wirkte PAUl JosePh BARTheZ (I734 bis 
I806), welcher die Lebensfunktionen teils auf die konkrete Seele (âme pensante), teils auf das "vitale Prinzip "(principe de la vie) zurückführte. Ebendort hat PhilipP PiNel (I755-I826) für den Vitalismus gewirkt, und von ihm hat FRANZ XAVER BICHAT (I77I bis I 802) ihn übernommen, der ihm neue Kraft verlieh.

MARIE FRANçoIS XAVIER BICHAT (I77I-I802), ein origineller und fleißiger Forscher, hat den Vitalismus STAHLs histologisch umzudeuten versucht. Seine physiologischen »Untersuchungen über Leben und Tod " ( 1800 ) gelten der Unterscheidung der animalischen und der vegetativen Teile des Körpers. Der größte Teil der Schrift ist der speziellen Physiologie des (menschlichen) Todes gewidmet; wir wollen nur auf die allgemeinen Gesichtspunkte, unter denen der Gegensatz $z$ wischen organischem und animalischem Leben darin behandelt wird, kurz eingehen.

Bichat behauptet, daß die animalischen Organe (Muskeln, Sinnesorgane, Haut) immer symmetrisch angeordnet sind, während die vegetativen Körperteile (er nennt sie die organischen), zu denen Herz, Magen, Sympathikus usw. gezählt werden, unsymmetrisch zu sein pflegen. Diese Symmetrie und Asymmetrie greift nach BICHAT tief in das Leben des Individuums ein: das rechte und das linke Auge arbeiten als symmetrische Teile gleichmäßig; die Abnahme der Sehkraft eines Auges hat eine Herabsetzung der Sehkraft des anderen zur Folge. Bei den organischen Teilen hat es dagegen keine üblen Folgen, wenn die rechtsliegenden Speicheldrüsen stärker sezernieren als die linksliegenden. Ein anderer Unterschied zwischen organischem und animalischem Leben soll darin bestehen, daß ersteres ohne Unterbrechung andauert, während letzteres periodisch auf und nieder geht. So muß der Mensch fortwährend atmen, auch der Kreislauf darf nicht unterbrochen werden; die Sinnesorgane dagegen und die Muskeln müssen ausruhen. Der dritte Unterschied besteht darin, daß die Gewöhnung nur auf das animalische, nicht aber auf das vegetative Leben wirken soll: so wird der Eindruck durch längere Einwirkung auf ein Sinnesorgan geschwächt, durch Wiederholung das Urteil geschärft; der Kreislauf des Blutes aber, das Ein- und Ausatmen, die Aufsaugung usw. werden durch die Gewohnheit nicht alteriert, das Leben würde sogar bedroht werden, wenn das geschähe.

Auch die Lebenskräfte, deren Bichat im Gegensatz zu Stahl eine Reihe unterscheidet, teilt er nach dem Unterschiede des animalischen und vegetativen Lebens ein, und zwar führt er folgende an: 

Klassen
Gattungen
Arten
Varietäten
I. Lebenskräfte $\left\{\begin{array}{cl}\text { I. Empfindlichkeit } & \left\{\begin{array}{l}\text { I. Animalisch } \\ \text { 2. Organisch }\end{array}\right. \\ \text { II. Kontraktilität } & \left\{\begin{array}{l}\text { I. Animalisch } \\ \text { 2. Organisch }\end{array}\right.\end{array}\right.$
$\left\{\begin{array}{l}\text { a) In die Sinne fallend } \\ \text { b) Unmerklich. }\end{array}\right.$

II. Eig enschaften $\{$ Extensibilität

des Gewebes Kontraktilität.

In der systematischen Einteilung der Lebenskräfte macht sich der Einfluß der Klassifikationen LINNés fühlbar; die französische Medizin aus dem Ausgange des I8. Jahrhunderts war nämlich bestrebt, sich $\mathrm{zu}$ einer exakten philosophischen und biologisch begründeten Lehre auszuarbeiten. PINEL (I745-I826), ebenfalls ein Anhänger STAHLs, hat z. B. behauptet, daß die Krankheiten »eine natürliche Kette der Ideen bilden und sich nach äußeren Merkmalen wie alle anderen Naturobjekte klassifizieren und wissenschaftlich benennen lassen $\left.\ll^{1}\right)$.

Die Lebensvorgänge sind nach BICHAT von den Vorgängen der anorganischen Natur grundsätzlich verschieden; denn die Lebenskräfte können in einem Teile des Körpers zunehmen, in anderen Teilen abnehmen, während die physikalischen Kräfte konstant sind. Unter der Lebenskraft stellt sich Bichat die Fähigkeit der Körperteile vor, die ihnen gebührenden Funktionen auszuüben; wenn z. B. die Speicheldrüsen einseitig exstirpiert werden, und die der anderen Seite ihre Funktion übernehmen und stärker als früher sezernieren, so ist dies ein Zeichen der Zunahme ihrer Lebenskraft. Diese ist nichts vom Körper Isolierbares, sie ist Eigenschaft der lebenden Körperelemente, ebenso wie die chemischen Reaktionen Eigenschaften der chemischen Substanzen sind. Demgemäß sagt Bichat:

Das Verhältnis der Eigenschaften als Ursachen zu den Erscheinungen als Folgen ist heute ein fast feststehendes Axiom in der Physik, in der Chemie, in der Astronomie usw. Wenn dieses Werk ein analoges Axiom in den physiologischen Wissenschaften aufstellt, so wird es sein Ziel erreichen ${ }^{2}$ ).

Die durch diesen Satz ausgedrückte Betrachtungsweise läßt sich leicht durch eine Analogie veranschaulichen. Es ist die Eigenschaft des Wasserstoffes, sich mit dem Sauerstoff zu verbinden; man nennt sie Affinität. Die Affinität kann man selbstverständlich nicht

1) Blainville, Histoire des sci. de l'organisation III. S. 158 .

2) Vorwort $z u$ »Traité des membranes«. - Der Ideengang des späteren Poritinismus ist aus diesem Satze deutlich $z u$ vernehmen. 
am Wasserstoff als solchem sehen, man muß sie vielmehr experimentell ermitteln; durch Experimente gewinnt man eine Reihe von Affinitäten, welche dann dem Wasserstoff als dessen Eigenschaften zuerkannt werden. Ein Analogon der Affinität bildet für Bichat die Lebenskraft. Sie ist demnach die Art, wie die lebendige Substanz auf die Einwirkung der Umgebung reagiert. BICHAT hat sich die Denkweise des damals berühmten LAvoISIER und des analytischen PINEL (eines berühmten Vitalisten) angeeignet. Wie LAvoisIER die chemischen Substanzen zu zerlegen versuchte und jeder ihre besonderen Affinitäten zuwies, so ging Bichat darauf aus, die lebendigen Substanzen $\mathrm{zu}$ zerlegen. In seiner »Allgemeinen Anatomie« bemüht er sich, den lebendigen Körper (des Menschen) in seine Elemente zu analysieren und Physiologie, Pathologie und Therapie auf die Kenntnis der Eigenschaften jener Elemente oder - »einfachen Systeme « zurückzuführen. Als organische Elemente bezeichnet er folgende Gewebeformen:

I) Zellgewebesystem

2). Animales (zerebrospinales) Nervensystem.

3) Organisches Nervensystem (Sympathikus).

4) Arterien.

5) Venen.

6) Exhalierende Gefäße.

7) Absorbierende Gefäße.

8) Knochensystem.

9) Knochenmark.

Io) Knorpel.
II) Fasersystem.

I2) Faserknorpel.

I3) Animales Muskelsystem.

I4) Organisches Muskelsystem.

I 5) Schleimhäute.

I6) Seröse Häute.

I 7) Synovialhäute.

I8) Drüsen.

I9) Lederhaut.

20) Epidermis.

2I) Haar- und Horngewebe.

Wie die chemischen Elemente behalten diese Elemente überall, wo sie vorhanden sind, ihre Natur bei.

Seien die Partien, in denen sie vorkommen, wie immer beschaffen, ihre Natur ist konstant dieselbe, wie in der Chemie die einfachen Körper nicht variieren, mögen auch die Verbindungen, die durch sie gebildet werden, wie immer beschaffen sein.

Jedes dieser organischen Elemente hat seine bestimmte Reaktionsart, seine bestimmte Lebenskraft. Auf diese Weise hat Bichat die Grundlagen zur empirischen Histologie gelegt und die aristotelische Einteilung der Gewebearten verdrängt. BicHAT machte den kühnen Versuch, die Gewebeformen als Elemente im histologischen und physiologischen Sinne zu betrachten, denen ebensoviel verschiedene Lebenskräfte eigen sind. Die Lebenskraft war nun nicht 
mehr die den ganzen Körper belebende Seele, sondern sie konnte an den Reaktionen bestimmter, greifbarer Gewebeformen studiert werden, und das Leben war nur die Einheit dieser empirischen Reaktionen. Den Nachfolgern Bichats verblieb die Aufgabe zu prüfen, $\mathrm{ob}$ und inwiefern die histologischen Elemente wirklich als Einheiten aufzufassen seien, und inwiefern die ihnen zugeschriebene Reaktionsweise wirklich konstant ist. Aber dazu verstand man sich nicht. Unter dem Einfluß der deutschen Naturphilosophie änderte man die Anzahl der von BichAT angenommenen Lebenskräfte ganz willkürlich, ohne sich an bestimmte Begriffsbestimmungen und an deren empirische Prüfung zu halten.

Der Vitalismus erhielt sich auf die Dauer in Frankreich nicht und verlor sich in dem je weiter desto mehr um sich greifenden Materialismus, zu dem das »Système de la Nature «, DE LA MetTrie, Cabanis und Pinel die Grundlagen gelegt hatten. Namentlich Pinels Ausführungen sind historisch bedeutungsvoll, da man aus denselben die Grundsätze des späteren Positivis mus heraushören kann. PInEL (I745-I826) war zwar Stahlianer, suchte aber die Medizin auf den Grundlagen der exakten Wissenschaften aufzubauen. PInEL suchte ein System der Krankheiten aufzustellen, denn

... die Krankheiten auf diese Weise nach ihren Affinitäten studiert, bilden eine natürliche Kette von Ideen, sind wie alle anderen Objekte der Naturwissenschaft nach ihren äußeren Merkmalen klassifiziert und werden schließlich einer exakten und unveränderlichen Terminologie unterworfen ... .

Pinels Arbeiten über die Geistesstörungen sollen ebenfalls dem Positivismus vorgearbeitet haben. Sein jüngerer Genosse BrousSAIS (I772-I838), BICHATs Schüler, bekämpfte schon offen den Vitalismus und jedwede »Ontologie«, namentlich die Philosophie KANTs, und empfahl nur die Erfahrung. Er verspottete den Glauben an eine Seele, folgte der Gallschen Phrenologie und suchte (nach der Analogie dieser Wissenschaft) einzelne Krankheiten in bestimmte Körperorgane zu lokalisieren: die Organe sollen eine Republik bilden und von keinem einheitlichen Prinzip beherrscht sein ${ }^{2}$ ). Der bekannte Begründer des Positivismus, A. Comte, stellt eine Fortsetzung der Ideen Pinels, Broussais', Bichats dar.

1) Blainville, Histoire III. S. I5S. - Linnés Einfluß auf diese Problemstellung ist offenbar.

2) Blainville, Histoire III. S. 224. - Virchow hat später diese Ideen spezialisiert. 
In Deutschland erfreute sich der an BICHAT anknüpfende Vitalismus eines längeren Lebens; von der Naturphilosophie unterstützt, bildete er die offizielle Lehre der Universitäten bis zum Verfalle der $\operatorname{ersteren}^{1}$ ).

1) Literatur. G. E. STAHL, Theoria medica vera, physiologiam et pathologiam tamquam doctrinae medicae partes vere contemplativas e naturae et artis veris fundamentis intaminata ratione et inconcussa experientia sistens. Halae r708. (Im Text ist diese Ausgabe zitiert). - Ders., De autocratia naturae sive spontanea morborum excursione et convalescentia. Halae 1696. - Disquisitio de mechanismi et organismi diversitate. Halae I706. - De vera diversitate corporis mixti et vivi. Halae I707. Die vitalistische Schule von Montpellier hat die gesammelten Schriften von STAHL (französisch) herausgegeben: G. E. STAHL, Oeuvres médico-philosophiques et pratiques, traduites et commentées par T. BLondin, revues par M. L. Boyer etc., Montpellier 1858-r864. - R. WhytT, An essay on the vital and other involuntary motions of animals. London I75I. - T. BORDEU, Recherches sur les différentes positions des glandes et sur leur action. Paris $\mathbf{7 5 2}$. - P. J. BARThez, Oratio de principio vitali hominis. Montpellier I773. - Nouveaux éléments de la science de l'homme. Paris I 806. - Rов. WhyтTs sämtliche zur theoretischen Arzneikunst gehörige Schriften. Aus dem Englischen von J. E. Lietzau. Berlin u. Stralsund I 790. - Bichat, X., Traité des membranes. Paris I 800 . - Recherches physiologiques sur la vie et la mort. Paris 1800. - Anatomie générale. Paris I80I.

Über den deutschen Vitalismus (Blumenbach usf.) wird im 2. Teile dieser Schrift berichtet werden. 
VIII. Kapitel.

\section{Der Aufschwung der Biologie im 18. Jahrhundert.}

Die Entomologen-Biologie des 17. Jahrhunderts, die auf ihre Exaktheit ungemein stolz war, aber um keinen einzigen Gedanken die Wissenschaft vom Leben zu bereichern vermocht hatte, ist durch keine Revolution vernichtet worden, sondern lebte ruhig bis gegen das Ende des I'8. Jahrhunderts weiter; gegen das Ende des 17. Jahrhunderts raffte sie sich zu einem regeren Leben auf, weniger dadurch, $\mathrm{da} ß$ sie die Minderwertigkeit der Insektenforschung und des planlosen Mikroskopierens eingesehen hätte, als vielmehr dadurch, daß sie höhere Gesichtspunkte zu schätzen lernte. Die neuen, von LeIBNIZ inspirierten Denker vermochten zwar nicht die durch DESCARTES und GaliLei geschmiedeten Fesseln des Rationalismus und Mechanismus abzuschütteln, führten. aber nichtsdestoweniger dadurch, daß sie die Notwendigkeit der Kompromisse mit vitalistischen Systemen anerkannten, einen relativen Fortschritt herbei.

Nur Schritt für Schritt befreien sich die Forscher aus dem Sumpfe der überwundenen Epoche; noch immer leben sie in der Furcht vor freien Gedanken, noch immer wagen die Biologen nicht der Vormundschaft der mathematisch-physikalischen Wissenschaften zu entsagen; von LEIBNiz zu BoNNET und zu LiNNé ist aber ein stetiger Fortschritt bemerkbar, der in BUfFon und in den Denkern aus dem Ausgange des I8. Jahrhunderts seinen Höhepunkt erreicht, ein Fortschritt, der die Biologie je weiter desto höher (den mathematischen Wissenschaften gegenüber) zu schätzen lehrt. Die Grundlagen für die Emanzipation der Biologie von der Medizin, für die Differenziation einzelner Gebiete der Biologie, so der Systematik, der Morphologie, der Embryologie werden gelegt; die Paläontologie und die Geographie der Tiere werden wenigstens als Wissenschaften der Zukunft geahnt. Die Ideen, an deren Ausbau das 19. Jahrhundert arbeiten soll, werden zu dieser Zeit das erste Mal formuliert. 


\section{Leibniz.}

GotTFRIED WilHelm LeibNiz (I646-I7I6) hat sich $\mathrm{zu}$ einem typischen Repräsentanten des nach Vielseitigkeit und Genialität strebenden, aber an Kleinlichkeiten haftenden Zeitalters entwickelt, des Zeitalters der langen Perücken, der Jesuiten, der adeligen Wissenschaft, der Blütezeit der Mathematik und Mechanik, des Zeitalters, wo NEwTon das einfachste Gesetz für das Sonnensystem entdeckt und wo die Völker Europas dreißig Jahre lang das Gesetz des gegenseitigen anständigen Benehmens im eigenen Blute gesucht haben. Anfangs Aristoteliker (Scholastiker), hat sich LEIBNIZ später »dem Leeren und den Atomen "zugewendet, wie er von sich selbst erzählt; endlich hat er eine eigene Philosophie aus den Elementen der verschiedensten Systeme erbaut. Während DEscarTes den lebenden Korper als einen Spezialfall der mechanisch sich entfaltenden toten Natur betrachtete, wählte LEIBNIZ das Leben als den Ausgangspunkt seiner Naturphilosophie und griff in diesem Punkte wissentlich auf ARISTOTELES zurück. Das nach der Art eines Künstlers neue Formen schaffende, nach der Verwirklichung von eingeborenen Zielen vorwärtsstrebende tatkräftige Leben, über das ARISTOTELES philosophiert hatte, kannte jedoch der dem Rationalismus ergebene LEIBNIZ nicht; er betonte vielmehr am Leben nur den inneren Impuls, der sich in der embryonalen Entwicklung, im Wachstum, in den Willensäußerungen offenbart, den Impuls, der zwar mechanische Bewegung verursacht, nichts Neues aber in der Weltmaschine hervorzubringen vermag. Nach seiner Lehre entwickelt der Organismus eine von innen aus wirkende Kraft, einen Antrieb, der die Lebensmaschine in Bewegung setzt. So gibt LEIBNIZ teils den Vitalisten, teils den Mechanisten recht; auch sonst sucht er nach einem Kompromiß zwischen den beiden Weltanschauungen: er behauptet mit REDI und mit den Kartesianern, daß das Leben niemals aus toten Substanzen entstehe; doch auch die Lehre der Aristoteliker, die tote Materie schließe die Möglichkeit des Lebens ein, sei nicht ganz abzuweisen, sondern muß nur mechanistisch umgedeutet werden: wenn auch die leblose Materie als solche des Lebens unfähig ist, so ist sie doch von unzähligen materiellen Lebenskeimen durchdrungen;

denn die Lebensprinzipien gehören nur den organisierten Körpern an. Allerdings gibt es (nach meinem System) kein Stück des Stoffes, in dem sich nicht eine unendliche Menge organischer und belebter Körper befinden, worunter ich nicht bloß die Pflanzen und die belebten Wesen ver- 
stehe, sondern möglicherweise noch andere Arten von Wesen, die uns ganz unbekannt sind ${ }^{1}$ ).

Die richtige Auffassung der Entwicklungsvorgänge hat LEIBNIZ viel Sorge gemacht; hat er doch selbst die Losung "le présent est gros de l'avenir « als den seine Lebensanschauung am prägnan. testen bezeichnenden Grundsatz genannt, eine Losung, die dem Entwicklungsgeschehèn entnommen ist. Doch hat er angenommen, daß die in der Gegenwart im embryonalen Zustande enthaltene $\mathrm{Zu}$ kunft da bereits materiell mit allen ihren Merkmalen fertig eingeschlossen liegt. Den Standpunkt der Evolutionisten vermochte er in nichts Wesentlichem zu vertiefen. Die Entwicklung (evolutio) bedeutet bei LEIBNIZ erstens den Gegensatz zur "Entstehung " (aus etwas anderem) und zweitens die Entwicklung einer Kraft (weniger die Veränderung der Form). Das Wort darf nicht historisch aufgefaßt werden (d.h. daß nach einem früheren Stadium ein späteres folgt), sondern es ist rationalistisch zu nehmen. Entwicklung heißt so viel wie Differenziation (Entwicklung von etwas, was bereits da war, jedoch eingewickelt).

Die Philosophen, sagt er in der Monadologie2), haben sich viele Schwierigkeiten gemacht mit dem Ursprung der Formen, Entelechien oder Seelen. Indessen haben gegenwärtig genaue Untersuchungen, angestellt mit Pflanzen, Insekten und Tieren, zu dem Resultat geführt, daß die organischen Körper der Natur niemals aus einem Chaos oder einer Fäulnis hervorgehen, sondern allemal aus Samen (semences), worin ohne $Z$ weifel schon eine Präformation vorhanden war; so hat man geurteilt, daß in dieser Anlage nicht bloß der organische Körper vor der Zeugung existiere, sondern auch eine Seele in diesem Körper, mit einem Worte, das Individuum nur zu einer großen Formumwandlung fähig gemacht werde, um ein Individuum einer anderen Art zu werden. Man sieht selbst etwas Ähnliches außerhalb der Zeugung, wie wenn die Würmer Fliegen und die Raupen Schmetterlinge werden.

Diese Theorie führte folgerichtig zur Einschachtelungshypothese $:^{3}$ )

So sollte ich meinen, daß die Seelen, welche eines Tages menschliche Seelen sein werden, wie jene der andern Gattungen dagewesen sind in den Samen, in den Voreltern bis auf Adam, also seit dem Anfang der Dinge immer in der Form organisierter Körper existiert haben; eine Ansicht, worin, wie es scheint, Swammerdam, Malebranche, Bayle, Pitcarne, HartSOEKER und viele andere gelehrte Männer mit mir übereinstimmen. Und diese Ansicht ist zur Genüge bestätigt durch die mikroskopischen Beobachtungen von LEEUWENHOEK und andern tüchtigen Naturforschern.

1) Sur les principes de la vie I705. - Kirchm. S. 145.

2) Monadologie Nr. 74. Kirchm. S. I 86.

3) Theodizee I. S. 9 I. 
Es gibt aber doch ganz radikale Veränderungen innerhalb der Entwicklung des Lebens, die Geburt und den Tod. LeIBNiZ erklärt sie nicht, er bestreitet sie: es gibt nach ihm keinen Anfang des Lebens und kein Ende. Die Geburt besteht vielmehr in der Ausdehnung und Auswickelung (evolutio) des bereits früher bestehenden Individuums; der Tod in der Zusammenziehung, Einwickelung (involutio) der Individualität, in einer Art von Verpuppung.

Aber die bedeutendste Frage war noch übrig; die, was aus diesen Seelen oder Formen durch den Tod des Geschöpfes oder durch die Zerstörung des Individuums der organisierten Substanz wird ... Dies hat mich endlich zu der Ansicht geführt, ... nämlich, daß nicht bloß die Seele, sondern auch das Geschöpf selbst und seine organische Maschine erhalten bleiben, wenn auch die Zerstörung seiner gröberen Teile es zu einer Kleinheit herabbringt, welche ebenso unseren Sinnen entgeht, wie die, in welcher es sich vor seiner Geburt befunden hat 1 ).

Seine Evolutionstheorie erweitert LEIBNIZ über die Grenzen des Individuums und gelangt so $\mathrm{zu}$ einer Art phylogenetischer Theorie. Er nimmt an, daß einige der Spermatozoen, welche eben damals LEEUWENHOEK beschrieben und für Anfänge des neuen Organismus erklärt hat, nicht bloß $\mathrm{zu}$ weiterer, sondern zugleich $\mathrm{zu}$ höherer Lebensentwicklung bestimmt sind und auf diesem Wege in eine höhere Ordnung der lebenden Wesen eingeführt werden:

Die Tiere ${ }^{2}$ ), von denen einige zur Stufe größerer Tiere vermöge der Zeugung erhoben werden, können Samentiere genannt werden, aber diejenigen unter ihnen, welche in ihrer Art bleiben, und das ist der größte Teil, werden geboren, vervielfältigt und aufgelöst, wie die großen Tiere, und es ist nur eine kleine Zahl auserwählter, die einen höheren Schauplatz betreten.

An einem anderen Orte ${ }^{3}$ ) sagt er wieder: Es ist möglich, daß in irgendeiner Zeit oder in irgendeinem Orte des Universums die Arten der Tiere dem Wechsel mehr unterworfen sind oder sein werden, als sie es jetzt bei uns sind, und mehrere Tiere, welche etwas von der Katze haben, wie der Löwe, der Tiger und der Luchs, dürften von einer gleichen Rasse gewesen sein und werden jetzt gleichsam als neue Unterabteilungen der alten Spezies der Katze gelten können. So komme ich immer wieder auf das zurück, was ich mehr als einmal gesagt habe, daß unsere Bestimmungen der natürlichen Arten provisorisch und unseren Kenntnissen entsprechend sind.

LEIBNiZ hat auch der Geologie und Paläontologie eine Abhandlung gewidmet. In seiner Schrift »Protogaea « (I693) entwickelt er

1) VAN HELmont der jüngere hat eine analoge Lehre vertreten. Brief an Arnauld. Cassierer, II. Bd., S. 228.

2) Syst. nouv. I695. Kirchmann, S. 50. Vgl. auch ebenda S. I39, wo ausdrücklich die Unsterblichkeit der Tiere behauptet wird.

3) Zitiert nach HEUSSLER. 
seine Gedanken darüber, wie unsere Erde entstand, wie sich auf ihr die Felsen bildeten, und wie ihre Oberfläche mehrmals verändert wurde, spekuliert über den Ursprung der Edelsteine und Metalle, über das Feuer im Innern der Erde und auch über die Fossilien. Auf elf Tafeln führt er dem Leser eine Reihe von - für jene Zeit ziemlich gelungenen - Abbildungen der vorweltlichen Fische, Brachiopoden, Zephalopoden, Zähne der Haie u. ä. vor, beschreibt dieselben und bringt einen ausführlichen Nachweis, daß diese Petrefakten keine 》lusus naturae " sind, sondern Versteinerungen von wirklich einmal lebenden Tieren. Sie sind Denkmäler der neptunischen Urzeit, die uns lehren, daß einst Meer war, wo heute Gebirge sind, daß ursprünglich alle Tiere als Wassertiere gelebt haben, daß später aus ihnen Amphibien und Landtiere entstanden sind ${ }^{1}$ ). An einigen derselben glaubte er erkannt zu haben, daß sie zu Arten gehören, die noch heute bei uns leben; andere leben ebenfalls noch, jedoch in entfernten Gegenden.

Einige wundern sich, fährt er fort 2 ), daß manchmal in den Felsen Arten zu sehen sind, welche man entweder überhaupt auf der bekannten Welt, oder wenigstens in den benachbarten Gegenden umsonst suchen würde. So sollen die Ammonshörner, die für den Nautilen verwandt gehalten werden, manchmal wie durch ihre Form so durch ihre Größe (denn es wurden auch solche gefunden, die einen Fuß im Durchmesser haben) von all den Formen verschieden sein, welche das Meer hervorbringt. Doch wer hat seine versteckten Winkel oder die unterirdischen Höhlen durchforscht? Wie viele früher unbekannte Tiere bringt uns nicht die Neue Welt? Und es ist glaubwürdig, daß durch jene großen Umwälzungen (der Erde) auch die Arten der Tiere sich verändert haben.

Die Spekulationen über unveränderliche, seit der Welterschaffung daseiende Strukturen der Organismen waren danach angetan, die altertümliche Auffassung der Lebewesen als physiologischer und psychischer Charaktere in den Hintergrund zu stellen und auf die Organismen als Organkomplexe zu führen. Doch hat sich diese heute allgemein übliche Vorstellung vom Wesen der Organismen nur allmählich entwickelt. Bei LEIBNIz sind die ersten Anläufe dazu zu spüren.

Die Monaden, die den lebendigen Wesen entsprechen, bilden

1) Leibniz gibt diese Ansicht als eine fremde, die geologisch wohl berechtigt, aber mit der Bibel unverträglich sei. Vgl. K. Fischers Geschichte d. Philosophie.

2) Protogaea § 26. Opera II. S. 220. 
eine kontinuierliche aufsteigende Reihe von der Ieblosen Welt bis zu dem höchsten Wesen.

Die Menschen sind mit den Tieren verknüpft, diese mit den Pflanzen und diese mit den Mineralien (fossiles)... Das Gesetz der Kontinuität verlangt, da $\beta$ alle natürlichen Wesen eine einzige Kette bilden, in welcher die verschiedenen Klassen, wie ebensoviele Ringe, so eng aneinander angeschlossen sind, daß es unmöglich ist, bestimmt den Punkt anzugeben, wo die eine (Klasse) beginnt oder aufhört, da alle Arten, welche die Stellen der Biegung und Verbindung (d. h. an jener Kette) einnehmen, mehrdeutig (équivoque) sind und Eigenschaften haben, welche sich gleichartig auf die benachbarten Arten beziehen. So z. B. enthält die Existenz der Zoophyten, der Tierpflanzen, nicht nur nichts Monströses in sich, sondern es folgt vielmehr aus der Anordnung der Natur, daß es solche gibt.

Tout se tient, war der berühmte Grundsatz Leibnizens. Die alte Platonische Lehre vom Stufengang der Ideen wurde durch diese Lehre erneuert und das Verständnis für den Individualismus angebahnt. (Wem wird nicht einfallen, daß das für die Biologie so fruchtbringende Kontinuitätsprinzip, dessen Einfluß bis in die darwinischen Spekulationen zu verfolgen ist, demselben Ideenkreis entstammt, aus dem sich LEIBNizens Differenzial- und Integralrechnung entwickelt hat?) Besteht das Wesen eines jeden Organismus in einer ewigen, unzerstörbaren einzigartigen Monade, so erwächst für die Biologen die Aufgabe, einzelne Monaden, d. h. einzelne Organismen (als Typen betrachtet) zu analysieren und $\mathrm{zu}$ beschreiben; nur durch Beschreibung und Vergleichung kommt man dann auf den Kern der organischen Einheiten. Der rationalistische Standpunkt erlaubte LEIBNIZ nicht, dieser auf die vergleichende Anatomie führenden Konsequenz sich klar zu werden; er streift nur dieselbe, wenn er weiterhin in dem Sinne schreibt, daß je näher einander die Organismen (die Monaden) in der aufsteigenden Reihe stehen, desto ähnlicher sie einander sind; die niederen Organismen sind - ihrem Wesen nach - in den höheren enthalten, d. h. die höheren Organismen sind ein Spezialfall der niederen, wie die Ellipse der Spezialfall einer Kurve zweiten Grades ist. Diesen Gedanken drückt LEIBNIZ philosophisch durch das Bild aus, daß ein jeder Organismus (eine jede Monade) die ganze Welt verworren vorstellt; die einander nahestehenden Organismen haben eine deutlichere Vorstellung voneinander als die entfernteren; die niederen Formen werden von den höheren deutlich, die höheren von den niederen nur undeutlich vorgestellt. "Alles in der Natur ist analog ", lautet eine andere Formulation dieser Lehre bei LEIBNIZ, der durch diese Worte deut- 
lich zu erkennen gibt, daß der Gedanke von der Analogie der Formen auf das vergleichende Studium der Organismen zielt, ein Studium, das tatsächlich unter dem Einfluß seiner Ideen die höchste Entwicklung erfuhr.

Trotz der vitalistischen Anläufe ist LEIBNIZ ein überzeugter Mechanist geblieben. Er will keine speziellen organischen Kräfte zulassen, er weist zwar die vitale Kraft nicht zurück, versetzt sie aber an den metaphysischen Anfang des Lebens; die wirklichen Lebenserscheinungen geschehen nach ihm nur nach mechanischen Gesetzen. Er schreibt z. B. $\left.{ }^{1}\right)$ :

Auch ich habe immer angenommen, daß alles in (den lebenden) Körpern mechanisch vor sich geht, obwohl wir nicht immer die einzelnen Mechanismen bestimmt erklären können, daß aber die eigentlichen allgemeinen Prinzipien des Mechanismus aus einer höheren Quelle stammen...

Immer wieder kommt er auf die Behauptung zurück, daß DEsCARTES mit seiner Behauptung im Unrecht war, die Tiere und der Menschenkörper seien Analoga der künstlichen Maschinen. Denn die lebendigen Körper unterscheiden sich nach LEIBNIZ von den Maschinen wesentlich dadurch, daß jeder einzelne ihrer Teile wieder aus kleineren Maschinen besteht; die Lebewesen sind unendlich zusammengesetzte Maschinen. Trotzdem bleiben die lebendigen Körper nur Maschinen, sie sind keine schaffenden, autonomen Wesen. Gott verfügt über die Natur, sagt LEIBNIZ an einer Stelle, "wie ein Ingenieur seine Maschinen dirigiert «; Gott beherrscht sie; sie selbst kann keinen tatkräftigen Willen entwickeln. Und an einer andern Stelle behauptet er ${ }^{2}$ ): "Die Tiere halte ich für vollkommene Automaten, sie haben jedoch zugleich die Empfindlichkeit (perceptio).«

Am deutlichsten tritt die mechanistische Anschauungsweise Leibnizens aus seiner Polemik mit dem Vitalisten StahL hervor. In einem Briefe ${ }^{3}$ ) macht er Witze über STAhls Behauptung, daß der kranke Organismus sich oft selbst helfen kann: STAHL wolle die Krankheiten durch Erwartung, d. h. durch Nichtstun heilen, und, gegen STAHL selbst sich wendend, hebt er unter anderem folgende angeblich falsche Punkte aus seiner »Theoria medica « hervor: STAHL ist im Unrecht, wenn er behauptet, es bestehe ein radikaler Unterschied zwischen der Maschine und dem Organismus; dieser ist nur

1) Epistola ad F. Hoffmannum. Opera II. S. 260.

2) Epistola ad P. Des Bosses. Opera II, I. S. 272.

3) Epistola III. ad Schellhammerum. Opera II, 2, S. 73.

Rádl, Geschichte der biol. Theorien. I. 2. Aufl. 
eine höhere, sozusagen göttliche Maschine ${ }^{1}$ ). Unrichtig sei die Annahme STAHLs, in den Organismen geschehe etwas, was andern als mechanischen Gesetzen unterworfen ist. Von der embryonalen Entwicklung des lebendigen Körpers, seiner Ernährung, Regeneration, Fortpflanzung glaubt LEIBNIZ, daß sie sich aus der Struktur des lebendigen Körpers erklären lassen, und daß die Flamme eine Analogie dieser Erscheinungen bilde. Er bemüht sich, die Undenkbarkeit des STAHLschen Begriffes der Seele nachzuweisen. Nach STAHL soll der Kern der Seele die Bewegungskraft sein; diesem Begriffe wirft LEIBNiz Materialismus vor, da man sich die Bewegung ohne den sich bewegenden Körper nicht denken könne; ganz besonders schüttelt er den Kopf über die Behauptung Stahls, daß es eine Bewegung an sich, ohne den sich bewegenden Körper, gebe.

In der LEIBNizschen Philosophie meldet sich - zunächst nur schüchtern - die Erkenntnis zum Wort, daß die Biologie des I7. Jahrhunderts auf falsche Wege geraten ist; die ersten Ansätze zum Aufschwung, den die Biologie im nachfolgenden Zeitalter, demjenigen eines Buffon, eines Linné, eines Goethe, eines Cuvier nahm, ist in LEIBNIzens Ausführungen das erstemal zu spüren. Dem Hauptinhalte und der unangenehm kompromißartigen, alles Echte, Radikale, wahrhaft Tiefe und Gesunde beiseite schiebenden Tendenz seiner Philosophie nach gehört LEIBNIZ dem älteren Zeitalter an; er ist Mechanist und zeigt kein warmes Verständnis für die konkreten Lebenserscheinungen; anstatt in seiner Philosophie die Ungereimtheiten der zeitgenössischen Biologen zu überwinden, anstatt sich zur Rolle des Propheten von neuen Wahrheiten und des Anführers der Unzufriedenen und nach vorne Strebenden zu erheben, stellt er sich in den Dienst der philosophisch ungebildeten Biologen. Er hat aber von neuem auf Aristoteles und Plato, auf Paracelsus, auf die englischen ebenfalls vitalistisch gesinnten Mystiker MORE und Cudworth, auf Helmont und Giordano Bruno hingewiesen und hat sich wenigstens zum Teil klar gemacht, daß der Kartesianismus für die Biologie unzureichend ist. Und es war eben diese leider schüchterne - Anknüpfung an die Vorkämpfer der biologischen Weltanschauung, die sich für die Biologie fruchtbringend erweisen sollte. In seiner Lehre vom Stufengang der Wesen und von der einheitlichen Form der Tiere kommen die ersten Vorstufen zum

1) Animadversiones etc. Opera II, 2. S. 136. 
vergleichenden Studium der Organismen zu Tage. Im Anschlusse an seine Lehren sind die Theorien von der Einheit des Bauplanes der Tiere, von der Korrelation der Formen, der Streit über das Wesen der Art entstanden.

C. F. WolfF, der Begründer der modernen epigenetischen Theorie der Entwicklung, hat dieselbe als Schüler des Leibnizianers CHRIsTIAN WolfFs entwickelt. Die Ideen LEIBNIZens kann man noch aus den Lehren der deutschen Naturphilosophie heraushören, die Quellen der letzteren, die Morphologie, Kielmeyers und Herders Ansichten über die Entwicklung, sind LEIBNIZens Kinder.

Auch zum Aufblühen der phylogenetischen Theorien hat LEIBNIZ beigetragen: die embryologischen Vorstellungen wurden, wie oben erwähnt, bereits durch LEIBNIZ selbst, aber noch viel mehr durch die Leibnizianer Bonnet und RoBInet auf die Phylogenie übertragen.

Die Philosophen rühmen an LEIBNIZens Lehre von den angeborenen Ideen, daß sie dem KANTschen System der apriorischen Begriffe vorgearbeitet hat. Analog kann man vom biologischen Standpunkte behaupten, daß dieselbe Betrachtungsweise innerhalb der Biologie angewandt die Lehre von den spezifischen Sinnesenergien vorbereitet hat. Tatsächlich erscheinen Gedanken, welche an diese Theorie erinnern, zuerst bei dem Leibnizianer Bonnet und dann wieder in den Zeiten der deutschen Naturphilosophie ${ }^{\mathbf{1}}$ ).

1) Literatur. Unter den Schriften Leibnizens sind vom biologischen Standpunkte am wichtigsten die folgenden: Discours de la métaphysique. I689. Considérations sur les Principes de la vie et sur les Natures plastiques. I 705. - Système nouveau de la nature et de la communication des substances, aussi bien que de l'union qu'il y a entre l'âme et le corps. I695. - Dazu: Éclaircissement I, 2, 3. I695. - De vi activa corporis, de anima, de anima brutorum. (Brief an R. CH. WAGNER.) - Animadversiones circa assertiones aliquas Theoriae medicae verae Cl. Stahlii cum eiusdem Leibnitzii ad Stahlianas observationes responsionibus. 1737. - Protogaea, sive de prima facie telluris et antiquissimae historiae vestigiis in ipsis naturae monumentis, dissertatio I749. (Posthum.) - Die Zitate im Text beziehen sich auf: G. Gu. Leibnitzii Opera omnia studio Lud. Dutens, Genevae I768; J. H. v. Krrchmann, Die kleineren wichtigeren Schriften von G. W. Leibniz. Philos. Bibliothek, Bd. 8I. Über Leibniz vgl. Geschichte der Philosophie von KUno Frscher, ferner die bei Descartes zitierte Schrift von H. Heusser und: Jul. Schaller, Geschichte der Naturphilosophie von Baco v. Verulam bis auf unsere Zeit. 2 Bde. Leipzig I89I; Ed. Cassierer, Leibnizens Hauptschriften zur Grundlegung der Philosophie. Übers. v. A. Buchenau, Leipzig I904. - J. TH. Merz, Leibniz. Aus dem Engl. Heidelberg r886. - Ludw. Stern, Leibniz und Spinoza. Berlin I89o. 


\section{Charles Bonnet.}

Charles Bonnet (I720-I793), ein Epigone Swammerdams und LEIBNIZens, war Zoologe, Botaniker und Philosoph. Als er sich durch mikroskopisches Studium der Insekten die Augen verdorben hatte, beobachtete er die Pflanzen und spekulierte über das Leben im allgemeinen. Seine entomologischen Arbeiten sind die besten; was er sonst geliefert hat, sind kaum mehr als Reminiszenzen eines alten Herrn an die Zeiten, wo er auch wissenschaftlich gekämpft hat. Immer und immer von neuem wiederholt er denselben nichts weniger als tiefen Gedanken, immer führt er dieselbe Tatsache als Beweis für seine Behauptung an, und durch solches Hin- und Herreden hat er Io dicke Bände auszufüllen gewußt. SAcHs wundert sich, wie sich seine botanischen Arbeiten seinerzeit einer so großen Achtung erfreuen konnten; aber auch die große Verehrung, mit der seine philosophischen Ansichten von den Biologen aufgenommen wurden, sind nur aus dem damaligen Verfall des wissenschaftlichen Geschmackes erklärlich. Immerhin sind bei BONNET Ahnungen von lebensfähigen Ideen nicht zu verkennen.

In seiner ersten Arbeit (I745) hat BoNNET im Anschlusse an LEEUWENHOEK nachgewiesen, daß sich die Blattläuse geschlechtlich und ungeschlechtlich fortpflanzen können; an die Versuche TREMBLEYS anknüpfend, beschrieb er die Regeneration einiger Süßwasserwürmer, die Vermehrung des Wurmes Nais durch Teilung und teilte verschiedene kleinere Beobachtungen aus dem Leben der Raupen mit, die über das von MalPighi, Swammerdam und RéauMUR Gebotene niemals hinausreichen. In seinen botanischen Arbeiten aus dem Jahre I745 versuchte er den Gedanken durchzuführen, daß die Laubblätter die Aufgabe haben, Wasserdampf aufzunehmen, und beschrieb verschiedene Bewegungen der Pflanzen. Später hat er sich ausschließlich der Naturphilosophie gewidmet.

Als den höchsten naturphilosophischen Gedanken erklärt BONNET, 》daß es eine Gradation in allen Teilen dieses Weltalls gibt $\left.{ }^{1} \mathbf{1}\right)$, und führt folgenden Stufengang der Wesen an ${ }^{2}$ ):

1) Traités d'Insectologie. Euvres I. p. I.

2) Der Stufengang schließt nicht mit dem Menschen ab, sondern wird in den Engeln fortgesetzt. Alle Wesen sind ferner in gegenseitiger Abhängigkeit, jede Erscheinung ist Ursache aller andern Erscheinungen. 


$\begin{array}{ll}\text { Mensch, } & \text { Pflanzen, } \\ \text { Orang-Utan, } & \text { Flechte, } \\ \text { Affe, } & \text { Schimmel, } \\ \text { Vierfüßer, } & \text { Pilze, } \\ \text { Fliegendes Eichhörnchen, } & \text { Trüffel, } \\ \text { Fledermaus, } & \text { Korallen, } \\ \text { Strauß, } & \text { Steinkorallen, } \\ \text { Vögel, } & \text { Asbest, } \\ \text { Wasservögel, } & \text { Talk, Gips, Selenit, } \\ \text { Amphibische Vögel, } & \text { Schieferstein, } \\ \text { Fliegende Fische, } & \text { Steine, } \\ \text { Fische, } & \text { Geformte (figuré) Steine, } \\ \text { Kletternde Fische, } & \text { Kristalle, } \\ \text { Aal, } & \text { Salze, } \\ \text { Wasserschlangen, } & \text { Vitriol, } \\ \text { Schlangen, } & \text { Metalle, } \\ \text { Nackte Schnecken, } & \text { Halbmetalle, } \\ \text { Schnecken mit Schale, } & \text { Schw efel, } \\ \text { Muscheln, } & \text { Erdharz, } \\ \text { Röhrenwürmer, } & \text { Erden, } \\ \text { Gallinsekten, } & \text { Reine Erde (terre pure), } \\ \text { Bandwurm, } & \text { Wasser, } \\ \text { Polypen, } & \text { Luft, } \\ \text { Aktinien, } & \text { Feinere Materien. } \\ \text { Sinnpflanze, } & \end{array}$

Aus dem Grundsatze, daß es in der Natur lauter Übergänge gibt, folgert BonNET, daß unsere Klassifikation, die notwendig feste $\mathrm{Ab}$ grenzungen setzen muß, nicht natürlich begründet ist und nur subjektiven Wert hat. Eingehender den Stufengang zu begründen, nachzuweisen, warum die Naturobjekte eine aufsteigende Reihe (und nicht etwa eine baumartig verzweigte Hierarchie) bilden, wie sich diese Lehre zum System des ARISTOTEles und Plato verhält (die Ideen des letzteren sind einander auch hierarchisch überordnet), hat BONNET nicht versucht.

Viel Raum hat er evolutionistischen Spekulationen gewidmet. Keine andere als die mechanistische Weltanschauung ist ihm bekannt; als "epigenetische "Theorie der Entwicklung faßt er die Lehre von der Entstehung des Organismus durch Apposition einzelner Körperteile auf; an der Unwahrscheinlichkeit einer solchen Hypothese zweifelt er nicht:

Man braucht kein Morgagn, kein Haller, kein Albinus zu sein, um zu begreifen, da $\beta$ alle Teile des Tieres so direkt, so verschiedenartig, so vielfach miteinander in Beziehung stehen, daß ihr Zusammenhang so eng, so unlösbar ist, da $B$ sie immer miteinander haben bestehen müssen, Die 
Arterien setzen die Venen voraus, die einen wie die andern setzen wieder die Nerven voraus, diese das Gehirn, dieses das Herz, und alle bedingen eine Menge anderer Organe $^{1}$ ).

Die Möglichkeit, daß die materiellen Organe nur Verwirklichungen bestimmter immaterieller Prinzipien darstellen könnten, hat BoNNET übersehen und schloß folgerichtig, daß der Organismus qualitativ unveränderlich ist und nur an Größe zunehmen kann. Der Keim ist von Anfang an organisiert und erscheint anfangs nur als ein winziges Netz; durch die Befruchtung wird sein Herz belebt und treibt nun die Blutflüssigkeit in die Gefäße; durch den Druck dieser Flüssigkeit erweitern sich die Maschen jenes Netzes, in die Lücken dringen die Nahrungspartikelchen, und so wächst der Keim zum fertigen Organismus. Wäre es möglich, aus diesem alle Nahrung wieder zu extrahieren, so würde der Körper wieder zu dem ursprünglichen, unsichtbaren Keime zusammenschrumpfen.

Die Keime sind von Gott geschaffen worden; sie gleichen aber nicht völlig den erwachsenen Formen; wenn wir die unsichtbaren Keime so stark vergrößern könnten, daß ihr Äußeres erkennbar wäre, so würden wir in denselben Säugetiere, Vögel, Reptilien, Insekten usw. nicht einmal erkennen können,

und wir würden an Stelle derselben nur bizarr zugeschnittene Figuren sehen, deren unregelmäßige und formlose Umrisse uns in Ungewißheit lassen würden, ob das, was wir unter den Augen haben, ein Vierfüßler ist oder ein Vogel. Es würde sich mit diesen Figuren so verhalten wie mit den optischen, deren wahre Natur man nicht erkennt, bis man sie durch einen Spiegel umkehrt. Der Befruchtung fällt hier die Rolle des Spiegels zu, sie ist das Prinzip der Entwicklung, welches die Formen herstellt und bemerkbar macht2).

Auf diese durchsichtige Weise sucht Bonnex die Tatsache zu verschleiern, daß die Organismen während der Entwicklung durchgreifende Veränderungen ihrer Konstitution erleben. Auch die unmögliche Konsequenz des Evolutionismus, daß die aufeinanderfolgenden Generationen alle in der Urmutter bereits als winzige materielle Keime eingeschlossen liegen müssen, bemüht er sich zu umgehen; einmal behauptet er, daß man die Einschachtelungen nicht wörtlich nehmen darf und (wenn ich richtig verstehe) daß man sich darunter mehr die Einheit der die Entwicklung treibenden Kräfte vorstellen soll ${ }^{3}$ ), ein andermal erklärt er wieder die Sache

1) Consid. corp. org. p. $26 \mathrm{I}$.

2) Contemplations de la nature. S. 268.

3) Consid. corp. org. S. $48_{3}$. 
ganz wörtlich so, daß das Verhältnis der Keime zueinander wie das des Samens zur Pflanze ist: der Same ist ein Teil der Pflanze und schließt bereits eine neue Pflanze ein, welche bereits wieder Samen hat usw., und verteidigt diesen Unsinn dadurch, daß hier der Verstand die Unfähigkeit der Sinne, sich die Sache vorzustellen, ersetzen muß1).

Die Tatsachen der Regeneration und der Kreuzung, an denen die Präformationstheorien des 19. Jahrhunderts gescheitert sind, bilden auch für BONNET eine unüberwindliche Schwierigkeit. Regeneration erklärt er ähnlich ${ }^{2}$ ) wie WEISmann. Er glaubt nämlich (und folgt darin einer Idee RÉAumuRs), daß in dem Körper kleine Keime zerstreut sind, welche zur Entwicklung gelangen, wenn der Körper verwundet wird. Zur Erklärung der Kreuzung nimmt er an, daß durch die Befruchtung von dem Männchen nur eine Art Nahrung dem Keime geliefert wird, durch die auch das Männchen die Form des künftigen Organismus beeinflussen kann. An einer andern Stelle ${ }^{3}$ ) nimmt er wieder an, daß im Samen so viele Elemente des Körpers für den künftigen Embryo enthalten sind, wie im Ei des Weibchens; bei der Kreuzung des Esels mit der Stute gelangt in den Keim des Pferdes eine größere Anzahl der Elemente des Ohres aus dem Esel, daher die langen Ohren des Maulesels. Die Monstrositäten sollen durch äußere Einflüsse auf den Keim verursacht werden.

Die evolutionistischen Gedanken überträgt BonneT auf die Entwicklung der ganzen organischen Welt (1769) und gelangt auf diese Weise zu einem kleinen Rudiment der historischen Auffassung der Organismen. Die Welt entstand seiner Ansicht nach viel früher, als Moses lehrt; seit ihrem Bestehen hat sie mehrere Revolution en erlebt. Da nun alle Wesen der Welt untereinander in Beziehung stehen, so muß auch jeder Organismus zu den Revolutionen, welche unsere Erde noch erleben soll, in bestimmtem Verhältnis stehen; so wie das Hühnchen bei seiner Entwicklung verschiedene Formzustände durchläuft, so haben auch die organischen Körper bei jeder Erdrevolution eine neue Form angenommen:

Alles das hilft uns die neuen Formen zu begreifen, welche die Tiere annehmen werden in jenem künftigen Zustande, zu dem sie, wie ich schließe, berufen sind. Dieser kleine organische Körper [der Keim], durch welchen ihre Seele jetzt mit dem sichtbaren Körper verbunden ist, schließt bereits

1) Consid. corp. org. S. 269.

2) Ebenda, S. II.

3) Ebenda, S. 24I. 
in sich wie im unendlich Kleinen die Elemente aller Teile, welche jenen neuen Körper bilden werden, unter dem sich nur das Tier in seinem künftigen $Z$ ustande zeigen wird ${ }^{1}$ ).

So hat sich auch die Geschichte der Organismen als eine Evolution von präformierten Keimen entwickelt. Nichts Neues wird in der ganzen Weltgeschichte produziert; alles, was kommen wird, war bereits am Anfange der Welt im Keime (materiell, nicht nur potentiell) vorhanden. BONNET führt auch philosophische Gründe dafür an, daß nichts Neues entstehen kann:

Alle Kombinationen, sagt er, welche sich aus denselben Partikelchen der Materie bilden konnten, sind gebildet worden und haben ebensoviele verschiedene Spezies hervorgebracht. Andere Partikelchen, mit diesen verbunden, haben neue Kombinationen und infolgedessen neue Spezies gebildet. Dadurch sind alle Lücken ausgefüllt, alle Stellen eingenommen worden ${ }^{2}$ ).

Ausdrücklich bemerkt BonNET, man dürfe nicht annehmen, daß in den nachfolgenden Perioden etwa die Spinne vollkommener sein werde als der Esel, da beide gleichzeitig ein höheres geistiges Leben erlangen werden ${ }^{3}$ ).

Dann wird der Tiger aufhören, ein Raubtier zu sein, und wird zu einem denkenden Wesen werden; unter den Affen und Elefanten wird ein NEwToN und LEIBNiz erscheinen.

Diese naive Form haben die Spekulationen über die Geschichte der Organismenwelt angenommen, als sie zum ersten Male die Gemüter der Biologen zu beschäftigen begannen. LEIBnizens Philosophie spricht zu uns aus dieser Theorie, doch ist ein kleiner Fortschritt zur historischen Auffassung der Vorgänge nicht zu verkennen. Bei LeibniZ entwickelt sich alles, jedoch nicht in der Zeit, wenigstens ist die Zeit dabei Nebensache, nur das, was sich entwickelt, wird betont. In BonneTs Palingénésie herrscht dieser Gedanke noch stark vor; zugleich sehen wir aber, wie durch die Theorie von den Erdrevolutionen der Gedanke von der Entwicklung als von etwas, das in der Zeit.geschehen ist, eingeführt wird; so wird LEIBNIzens ideelle Fassung der Entwicklung von BONNET durch eine mehr empirische ersetzt.

Wie schwach jedoch dieser Anlauf zu einer empirischen Richtung bei Bonnet war, ist z. B. aus seiner Behauptung zu ersehen, daß, wenn wir in das wahre Wesen, d. h. in den Keim eines Tieres eindringen

1) Paling. philos. S. 227 .

2) Principes philos. sur la cause première. p. 227 .

3) Paling. philos. p. I49. 
könnten, wir darin alle seine Beziehungen zur Vergangenheit und Zukunft finden könnten. Denn trotz der Jahrtausende dauernden "Entwicklung « gibt es nach BonNET keine wesentliche Veränderung, gibt es sogar kein wahres Nacheinander der Erscheinungen:

Alle Bestandteile des Weltalls sind also gleichzeitig. Der schaffende Wille hat mit einer einzigen Tat alles realisiert, was je möglich war. Er schafft nicht mehr; aber er konserviert, und diese Konservation wird, wenn man es will, zu einer kontinuierlichen Schöpfung ${ }^{1}$ ).

Welch eine sonderbare Geschichte, diese Evolution BonNETs! Keine Begebenheiten, keine Taten, kein schaffender Wille, kein Leben; nur ein blindes Dahinsausen einer einmal aufgezogenen Maschine! Wie ohnmächtig mußte sich der Mensch in einer Natur vorkommen, in der selbst Gott nichts anderes tun kann, als das Vorhandene zu erhalten!

In den siebziger und achtziger Jahren des I8. Jahrhunderts gehörte BONNET zu den berühmtesten Biologen; seine philosophischen Schriften waren ins Deutsche, Italienische und Englische übersetzt und vielfach diskutiert; er konnte noch selbst die Gesamtausgabe seiner Schriften besorgen. Von bedeutenderen Biologen haben ihn namentlich Haller und SPALlanZani sehr geehrt. In Deutschland haben übrigens auch seine psychologischen Anschauungen Schule gemacht; unter anderm soll JACOBI von ihm beeinflußt worden sein ${ }^{2}$ ).

1) Palingénésie S. I8r.

2) Literatur. CH. Bonner, Traité d'Insectologie ou observations sur les pucerons et sur quelques espèces des vers d'eau douce, qui coupés par morceaux, deviennent autant d'animaux complets. 2 Parties. Paris I745. - Recherches sur l'usage des Feuilles dans les plantes et sur quelques autres sujets relatifs à l'histoire de la végétation. Gottingue et Leyde r754. - Essai de Psychologie, ou considérations sur les opérations de l'âme, sur l'habitude et sur l'éducation, auxquels on a ajouté des principes philosophiques sur la cause première et sur son effet. Londres I754 (1755). Essai analytique sur les facultés de l'âme. Coppenhague I760. - Considérations sur les corps organisés, où l'on traite de leur origine, de leur développement, de leur réproduction etc. où l'on a rassemblé en raccourci tout ce que l'histoire naturelle offre de plus certain et de plus intéressant sur ce sujet. 2 Vol. Amsterod. I762. - Contemplation de la nature. 2 Vol. Amsterod. I764. - La palingénésie philosophique ou idées sur l'état passé et sur l'état futur des êtres vivants, ouvrage destiné à servir de supplément aux derniers écrits de l'auteur et qui contient principalement les précis de ses recherches sur le christianisme. 2 Vol. Genève 1769. - Recherches philosophiques sur les preuves du christianisme. Genève I770. - Die im Text angeführten Zitate beziehen sich auf: CH. BonNer, Euvies d'histoire naturelle et de Philosophie Vol. I. -X. Neuchâtel I779-I783. - Über BonNETs naturwissenschaftliche Theorien vgl. E. PERrier (La philosophie zoologique avant Darwin, Paris I886) und C. O. Whitmann, Evolution and epigenesis. Boston I\$95. 
Auch der Philosoph Jean Baptiste Réné Robinet (I735-I820) ist im Anschluß an LEIBNIZ auf den Gedanken der historischen Entstehung der Organismen geführt worden (I76I). Er lehrt in Ưbereinstimmung mit LEIBNIZ, daß alle Naturdinge einen kontinuierlichen Stufengang bilden, und behauptet, daß alles belebt ist. Es gebe nur ein Naturreich, das Tierreich - auch die Sterne, die Sonne, die Erde und die Planeten sind Tiere; die Natur kennt keine Gruppen, wie die Klassen, Ordnungen, Gattungen und Arten, sondern nur Individuen in kontinuierlich aufsteigender Reihe. Es findet nicht nur eine embryonale Entwicklung - Evolution natürlich, nicht Epigenese - statt, sondern auch eine phylogenetische, und es hat Zeiten gegeben, in denen ganz andere Organismen als unvollkommenere Ahnen der jetzigen die Erde bevölkerten. Die Entwicklung kommt durch einen inneren Drang der Natur zustande; die Organismen sind mehr oder weniger mißlungene Versuche der Natur, ihr Ideal - einen vollkommenen Menschen - zu bilden; in dem jetzigen Menschen hat die Natur ihr Ideal noch nicht erreicht; es werden Zeiten kommen, wo die Schönheit der Venus mit derjenigen des Apollo in einem Individuum vereinigt sein wird $^{1}$ ).

Betrachtungen über den Stufengang der Wesen und über »Übergangsformen "gehörten in der 2. Hälfte des I7. und im I8. Jahrhundert zu den allergewöhnlichsten. Die meisten lehrten einen einreihigen Stufengang; P. S. PALLAS, der erste wissenschaftliche Erforscher Sibiriens, nimmt als erster eine baumartige Verzweigung des Tiersystems an ${ }^{2}$ ); LAMARCK hat später dieselbe Methode befolgt. Andere, mit Linné an der Spitze, haben den Zusammenhang der Wesen mit dem flächenhaften Zusammenhange der Städte einer Landkarte verglichen. Noch in der deutschen Naturphilosophie, bei OKEN und HERDER hat die Idee des Stufenganges der Wesen eine Rolle gespielt. In den darwinistischen Spekulationen wurde die Lehre, historisch umgedeutet, zu neuem Leben erweckt $\left.^{3}\right)$.

1) Robinet, JeAn BAptiste RÉNé, De la nature. 2 Vols. Amsterdam I 76I-I 763. - Considérations philosophiques de la gradation naturelle des formes de l'être, ou les essais de la nature qui apprend à faire l'homme. Paris I767.

2) Elenchus zoophytorum I766. S. $23-24$.

3) Über die Geschichte der Lehre von der Stufenfolge der Dinge vgl.: Aug. Thientmann, Die Stufenfolge der Dinge, der Versuch eines natürl. Systems der Naturkörper aus d. IS. Jh. Würzburg I909. 


\section{A. v. Haller.}

Die Physiologie als ein einheitliches, selbstbewußtes, eigene Probleme mit eigenen Methoden lösendes Glied der Wissenschaft vom Leben gab es vor dem I8. Jahrhundert nicht. Wohl gab es physiologisch denkende Biologen, ja der physiologische Gesichtspunkt galt von HippoKrates bis zu StaHL für fast einzig möglich; es wurden auch große physiologische Entdeckungen, wie diejenige HARVEYs gemacht; doch eben darum, daß man sich nicht bewußt war, es gäbe noch andere Auffassungen des Lebens als die physiologische, konnte sich keine Physiologie differenzieren. Nachdem sich durch den Aufschwung der Mechanik in der nachgalileischen Periode zuerst die Biologie im allgemeinen von den physikalischen Wissenschaften abzusondern begonnen hatte, hat man im Laufe des I7. Jahrhunderts allmählich auch zwischen der Medizin und der Biologie im engeren Sinne zu unterscheiden gelernt. Einen halbbewußten Versuch, die Gebiete der Anatomie und der Physiologie innerhalb der Biologie zu unterscheiden, hat der vielseitige HALLER unternommen.

Die aphilosophische Wissenschaft des I7. Jahrhunderts erwuchs zu einem die Gebärden der Genialität annehmenden Enzyklopädismus. Man suchte sich möglichst vielseitig zu bewähren: RÉaumur hat das Thermometer konstruiert, hat sich um die Industrie interessiert und über Insekten geschrieben; Rов. Hooke war ein Mann von ähnlichem Schlage; Buffon war Mathematiker und Biologe. Keine einheitliche Idee verknüpfte jedoch diese heterogenen Forschungsgebiete, so daß die Vielseitigkeit mehr von mangelhafter Konzentration des Geistes als von wirklicher Genialität jener Forscher zeugt. $\mathrm{Zu}$ einer lebensfrischen Auffassung der Wissenschaft gehört auch ein kritisch begründetes, selbstbewußtes Verhältnis zu den Theorien der Vorgänger; auch als Historiker blieben nun die Forscher des I7. Jahrhunderts nur pedantische Dogmatiker. Sie gaben gesammelte Schriften von manchem berühmten Manne heraus; BoERHAAVE veröffentlichte diejenigen SwammerdaMs, Albinus veranstaltete den Neudruck VeSALs, Haller gab eine ausführliche Bibliographie der physiologischen Wissenschaft heraus - nach einem Verständnis der älteren Autoren wird man aber bei diesen Enzyklopädisten umsonst suchen. Man konnte sich für keine konsequente wissenschaftliche Richtung entscheiden; praktisch förderte man die mechanistische Philosophie, fand aber keine Kraft, dem Vitalismus 
definitiv zu entsagen, und suchte durch Kompromisse und durch Häufung von Einzelheiten den Mangel an Tiefe zu verdecken. Der berühmte eklektische Mediziner HERRMANN BOERHAAVE (I668 bis I738) hat dieser Richtung angehört; A. HALLER, sein Schüler und intimer Freund, hat sie zum Höhepunkt gebracht.

ALBRECHT VON HALLER (I708-I777) stritt mit seinen Zeitgenossen Linné und BUfFon um die Weltberühmtheit. Schon der Knabe HALLER galt als Wunderkind. In Bern als Sohn eines reichen Vaters geboren, hat er in seinem achten Jahre aus den gelehrten Wörterbüchern MORELLIs und BAYLEs über 2000 biographische Abschnitte ausgezogen; im zehnten Jahre konnte er lateinisch und griechisch schreiben und war auch in der chaldäischen und hebräischen Sprache bewandert. In seinem I 5. Jahre verfaßte er mehrere Lust- und Trauerspiele und ein Heldengedicht von 4000 Versen; später hat er es verbrannt. I 723 ging er nach Tübingen, um Arzneikunde zu erlernen, I 725 reiste er nach Leiden zu BoERHAAVE. I 727 wurde er Doktor, reiste nach England und Paris, wo er, bereits ein guter Botaniker, Bernard Jussieu als Freund gewann. Dann studierte er in Basel Mathematik unter JoHANN BERNouILLI, worauf er I730 als Bibliothekar in Bern angestellt wurde. Nachdem er sich dort durch mehrere Gedichte berühmt gemacht hatte, wurde er Professor der Anatomie und Botanik in Göttingen. Hier entwickelte er eine beispiellose literarische Tätigkeit. 1753 kehrte er nach Bern zurück und war' (als Anhänger der Aristokratie) politisch tätig. Nachdem er dort noch mehrere Gedichte religiösen Inhalts verfaßt, auch eine Herausgabe der Bibel veranstaltet und schließlich noch zwei politische Romane veröffentlicht hatte, starb er I777 fast 70 Jahre alt, den umstehenden Freunden den Augenblick andeutend, wo sein Puls nicht mehr schlagen werde. HALLER war dreimal verheiratet und hinterließ elf Kinder $^{1}$ ).

Aus dieser Lebensgeschichte ist zu ersehen, daß HALLER ein ganz ungewöhnlicher Mensch war. Seine Gedichte haben literarischen Wert wenigstens gehabt. Seine botanischen Arbeiten verschafften ihm ebenfalls große Anerkennung, und in der Physiologie bedeutet er den Anfang einer neuen Epoche. Die Kehrseite dieser Genialität besteht darin, daß ScHILlER nur sehr höflich von seiner Poesie spricht - er sagt:

1) Diese Daten habe ich WHEwell entnommen. 
Kraft und Tiefe und ein pathetischer Ernst charakterisieren den Dichter; nur überwiegt überall zu sehr der Begriff in seinen Gemälden, sowie in ihm selbst der Verstand über die Empfindung den Meister spielt. Daher lehrt er durchgängig mehr, als er darstellt; er ist groß, kühn, feurig, erhaben, zur Schönheit hat er sich selten oder niemals erhoben ${ }^{1}$ ).

SACHS weiß in seiner ausgezeichneten Geschichte der Botanik über HALLERs botanische Verdienste gar nichts zu sagen, und so sollten ihn eigentlich seine physiologischen Entdeckungen retten; doch wird auch von den Physiologen HALLERs Irritabilitätslehre kühl behandelt.

In der Botanik wetteiferte HALLER mit LinNé im Streben nach einem künstlichen System der Pflanzen, jedoch ohne Erfolg ${ }^{2}$ ). Als Anatom gab er im Stile seiner Epoche genaue anatomische Zeichnungen mit erklärendem Text heraus. Auch mehrere embryologische Untersuchungen hat er in großem Stil durchgeführt, jedoch nichts wesentlich Neues, dagegen viel Unrichtiges gefunden.

Hallers Bedeutung liegt nicht in seinen Entdeckungen, sondern in dem Systematisieren der biologischen Wissenschaft. In dieser Hinsicht hat man im I 8. Jahrhundert sehr viel getan, doch hat HALLER nur in LiNNÉ einen würdigen Nebenbuhler gefunden. Es ist überhaupt wunderbar, wie in der Mitte des I8. Jahrhunderts die Forscher von einem wahren Fieber nach möglichst breitem Wissen, nach dicken Büchern befallen waren: LinNÉ als Anführer in der Botanik und Zoologie, Haller in der Physiologie, BoerhaAve in der Medizin. Sie alle waren nach besten Kräften bemüht, das große Gebiet ihrer Wissenschaften möglichst breit aufzufassen. Was Wunder, wenn dann wenig Originelles dabei herauskam? In seiner großen Physiologie hat HALLER versucht, alles wissenschaftlich Beachtenswerte über den Menschenkörper und die ganze einschlägige Literatur von den ältesten Zeiten an zu sammeln und überdies noch eigene Beobachtungen hinzuzufügen. Seine Elemente der Physiologie des Menschen bildeten für lange Zeit nachher ein Nachschlagebuch voll von Einzelheiten, lesenswert für die Spezialisten; frische Ideen und allgemeine Gesichtspunkte sind dort nicht zu finden. HALLER erwies sich so wenig selbständig, daß er nicht einmal dazu kam, die von ihm be-

1) Über naive und sentimentale Dichtung. Ich habe dieses Zitat HETtNer, Gesch. des XVIII. Jahrhunderts, II. T., 5. Aufl., entnommen.

2) HALLER wollte die Gattungen mit einem Namen, die Spezies jeder Gattung mit Nummern 1, 2, 3 usw. bezeichnen; vgl. seine Enumeratio plantarum horti gottingensis I743; De methodo studii botanici, Göttingen I736; Opuscula botanica I 749 . 
gründete Physiologie als eine selbständige Wissenschaft vorzuführen; er erklärt die Physiologie für eine beseelte Anatomie ("physiologia est animata anatome «); die Anatomie von der Physiologie zu trennen wäre soviel - behauptet er -, als wenn ein Mathematiker die Gesetze einer Maschine ohne die Kenntnis der Räder und Dimensionen ermitteln könnte. Alle Mechanisten waren dieser der wahren Physiologie feindlichen Überzeugung und sind es bis auf den Tag.

Theoretisch Neues hat HALLER in der Lehre von der Irritabilität geliefert. Zwar war die Lehre nicht ganz neu. Der Begriff wie das Wort stammt von dem englischen Arzt GLISSON, welcher unter der Irritabilität diejenige natürliche Reaktion des lebendigen Gewebes auf Reize verstand, die einerseits von keiner Empfindung begleitet ist und andererseits nicht eine mechanische Bewegung, sondern den unmittelbaren Ausdruck des Lebens darstellt. Vielleicht hat BoerhaAve die Lehre von Gissson übernommen, und von BoerhaAve kam sie auf seinen Schüler Haller.

Irritabe1 ${ }^{1}$ ) nennt HaLleR (I753) einen solchen Teil des menschlichen Körpers, welcher sich verkürzt, wenn ein fremder Körper ihn berührt; je stärker die Verkürzung, desto größer ist die Irritabilität; sensibel dagegen ist diejenige Faser des menschlichen Körpers, die nach erfolgter Berührung der Seele den subjektiv empfundenen Eindruck der Berührung zuführt; bei den Tieren, bei denen wir die Seele nicht kennen, ist diejenige Faser als sensibel zu betrachten, deren Berührung objektive Zeichen von Schmerz und Unbehagen zur Folge hat $^{2}$ ). Durch viele in grober Art ausgeführte Versuche (das untersuchte Organ wurde entblößt und dann durch Berühren, Kneifen, Stechen oder durch chemische Agenzien gereizt) weist Haller die Behauptung seines Lehrers BoERHAAve, daß alle festen Teile des Körpers innerviert und infolgedessen alle sensibel und irritabel sind, als unzutreffend nach. Er stellt fest, daß die Irritabilität nur in den muskulösen, die Sensiblität nur in den nervösen Elementen des Körpers anzutreffen ist. Die reizbarsten Teile, wie z. B. das Herz, sollen wenig sensibel, und umgekehrt soll der Nerv, der sensibelste Teil des Körpers, gar nicht irritabel sein.

Gegen die Vermutung der Stahlianer (WHYTT), daß durch den Reiz die Seele affiziert und erst von letzterer die Verkürzung des

1) Mir liegt die französische Ausgabe vor: Mémoires sur la nature sensible et irritable des parties du corps animal. Lausanne 1756 .

2) Mémoires I 756. S. 8, 9. 
Muskels verursacht wird, nimmt HALLER an, daß die Irritabilität direkt an die Muskelsubstanz gebunden, ihr inhärent ist, und behauptet, daß sie nichts mit der (kartesianisch aufgefaßten) Seele gemein hat, da sie doch noch einige Zeit nach dem Tode andauert.

Die Irritabilität soll eine Grundeigenschaft des tierischen Körpers sein, sie darf nicht mit der Elastizität verwechselt werden. Die Elastizität ist nämlich besonders an trocknen, harten und alten Fasern zu finden, während die Irritabilität an feuchten, gallertigen und jungen Elementen am stärksten ausgeprägt ist. Sie darf auch nicht der Seele gleichgestellt werden, wie DE LAMETTRIE, der bekannte Materialist, es zu tun versucht hat; denn die Irritabilität dauert nach HALLER noch einige Zeit nach dem Tode des Tieres fort.

Die Muskelsubstanz ist nach HALLER aus zwei Substanzen, einer erdigen und einer gelatinösen, zusammengesetzt; es soll sehr wahrscheinlich sein, daß die Irritabilität an diese gelatinöse Substanz gebunden ist und deren wesentliche Eigenschaft ausmacht, etwa so, wie die Gravitation die Eigenschaft aller Körper darstellt1).

HALLERs Irritabilitätslehre ist nur auf vitalistischer Grundlage möglich; HALLER wehrte sich inzwischen gegen den für ihn zu ernsten Vitalismus und verursachte die Irrtümer, auf die seine Lehre geführt hat. Seine Schrift über die Irritabilität ist überaus flach; kein tieferer Gedanke, keine originelle Auffassung irgendeines Autors oder einer Erscheinung, kein wesentlich neues Experiment ist in ihr zu finden; die darin mitgeteilten Versuche dienen nicht zur Vertiefung der Lehre, sondern nur zur Prüfung der Frage, ob der am Anfange aufgestellte Begriff der Irritabilität für jeden speziellen Fall paßt oder nicht, keineswegs aber, wie er paßt. So erscheinen die Versuche sehr trocken und inhaltsleer, und ihre große Anzahl ist eher eine schwache als eine starke Seite der Abhandlung.

Die Irritabilitätslehre wurde bald berühmt. Tissot, der Übersetzer der Schrift ins Französische, vergleicht den Hallerschen Gedanken mit der Entdeckung der Gravitation; was diese für die Physik, das soll jener für die Physiologie bedeuten ${ }^{1}$ ). Tatsächlich haben die Schulen bald aus der Irritabilität ein Prinzip gemacht, auf Grund dessen man die ganze tierische Ökonomie, die Tätigkeit der Blutgefäße, diejenige der Nerven, der Muskeln erklären zu können glaubte; in der Pathologie machte sich die Ansicht geltend, daß alle Krankheiten aus der Vermehrung oder Verminderung der Irritabilität der

1) Mémoires S. XIV. 
Gefäße herrühren. So ist die Lehre von der Irritabilität nur an die Stelle der Iatromechanik getreten und für das große wissenschaftliche Publikum zu einer moderneren Nahrung geworden. Die Unklarheit in der ursprünglichen Auffassung der Irritabilität ist auch von den Nachfolgern übernommen worden und hat namentlich auf die deutsche Naturphilosophie ihren Einfluß nicht verfehlt.

Als Histologe stellte sich HaLler vor, daß der tierische Körper (chemisch) aus Gallerte (eiweißartiger Flüssigkeit) und erdiger Substanz zusammengesetzt sei. Je höher ein Tier organisiert ist, desto mehr erdige Bestandteile soll es enthalten. Aus der (chemischen) Mischung von Gallerte und Erde entsteht das organische Element des Körpers, die Faser; aus den unsichtbaren Elementarfasern, an die die Biologen seit MALPIGHI glaubten, setzen sich die sichtbaren Fasern zusammen, die (theoretisch) etwa unseren Zellen analog sind.

Als Embryologe vertrat HALler die Evolutionstheorie. Er fand, daß der Dotter nicht außerhalb des sich entwickelnden Hühnchens liegt, sondern daß er einen Teil des Hühnchens selbst bildet, indem er von den Häuten des Embryos ungeben und später in dessen Darmkanal aufgenommen wird. Diese Tatsache führt HALLER als exakten Beweis der Evolution an: sie zeige, daß das Hühnchen nicht aus dem von außen kommenden Baumaterial zusammengestellt werde, sondern von innen aus wachse. Er hebt ferner hervor ${ }^{1}$ ), daß es zwar schwierig sei, zu sagen, wie der neue Embryo entsteht, doch weise der zweckmäßige Bau des menschlichen Körpers darauf hin,

daß der Mensch, wie er ist, das Werk Gottes ist, und daß folglich dasjenige, was in der vollkommenen Frucht zugegen ist, schon in dem zarteren Keime vorhanden war, wenngleich Lage, Gestalt und Bindung der ersten Periode gänzlich von derjenigen verschieden scheint, die sich in der letzteren zeigt: eine unermüdete Geduld im Beobachten entdeckt uns, wie nun Lage, Gestalt und Ebenmaß so nach und nach verbessert werden.

Den Nachkommen galt HALLER immer mehr als eine Berühmtheit, eine Kuriosität in seinem umfassenden Wissen, denn als origineller Denker, an den mit neuen Theorien anzuknüpfen wäre ${ }^{2}$ ).

1) Grundriß der Physiologie, deutsche Übersetzung, S. 657 .

2) Literatur. HAller, A. von, Icones anatomicae. Gotting. 1745-r754. Primae lineae Physiologiae. Gotting. I747. - Opuscula botanica. Gotting. I749. Elementa Physiologiae corporis humani. 8 Vols. Lausanne et Bern I759-1766. De partibus corporis humani sentientibus et irritabilibus. Gotting. 1853. - De formatione pulli in ovo. Gotting. I757, I758. - Über Haller vgl. G. ImHoF, Alb. Haller als Physiologe. Arch. f. Gesch. d. Med., Bd. VI, I9r2. - H. Boruttau, Gesch. d. Physiologie in ihrer Anwendung auf die Medizin (Handb. d. Gesch. d. Medizin, Jena 1903). 


\section{Kapitel.}

\section{Die Epigenetiker.}

Im I7. Jahrhundert herrschten die Präformationstheorien fast ohne Widerspruch, und noch gegen das Ende des I8. Jahrhunderts gab es zahlreiche Biologen, die - wohl mit einiger Zurückhaltung die Evolution als die einzig mögliche Art der embryonalen Entwicklung betrachteten. Noch Cuvier und GEOFFroy wußten von nichts, was dem Evolutionismus gegenübergestellt werden konnte.

Seit der Hälfte des i8. Jahrhunderts erschienen schüchterne und wenig Anklang findende Versuche, die epigenetische Theorie von neuem in die Biologie einzuführen. BuFFon war einer der ersten, der der epigenetischen Theorie der Entwicklung bedeutende Zugeständnisse gemacht hat, und sein Schritt sowie seine allgemeine Auffassung der Biologie war der Einführung der neuen Theorie jedenfalls förderlich. Der berühmte MAUPERTUIS hegte analoge Vorstellungen vom Bau der Organismen aus Elementarkörperchen. In der anonym herausgegebenen Schrift »Venus physique « (I745) wies MAUPERTUIS auf die von HARVEY vertretene epigenetisch-vitalistische Theorie; MAupertuis selbst stellt sich die Entwicklung (wie BuffoN) als eine Art Kristallisation vor ${ }^{1}$ ). Bonnet und Buffon loben die Schrift (BonNeT wirft ihr die Sucht nach Sinnlichkeit vor), ohne auf ihren Inhalt näher einzugehen. Jedenfalls war MAUPERTUIS ein viel gelesener Autor.

Ein Epigenetiker, dessen Ansichten sich BUFFON ebenfalls teilweise anschloß, war Turbervill Needham ${ }^{2}$ ) (I745). Seine »Be-

1) Hans Driesch, Der Vitalismus als Geschichte u. als Lehre. S. 40. Vgl. insb. die italienische Übersetzung dieser Schrift durch M. Stenta, Milano I9I I, der zahlreiche lit. Nachweise hinzugefügt sind.

2) Mir lag die französische Ausgabe der Schrift vor: Nouvelles découvertes faites avec le microscope par T. Neediam. Leyde I744. Dieser T. Needham ist nicht mit C. NeEdhaM, dem Verfasser von $\$$ De formato foetu $1667 \ll$, einer beschreibend embryologischen Schrift, zu verwechseln. 
obachtungen « sind zwar oberflächlich, aber zur Zeit BonNETs und Buffons wurden sie ziemlich beachtet, und Bonnet und SPALLANZANI kämpften ebenso gegen sie, wie sich BUFFON ihrer annahm.

NEEDHAM erklärte, daß die mikroskopischen Tierchen, welche in einem Wassertropfen leben (z. B. Daphnia), den großen Tieren im Meere analog sind. Es sei möglich, meint er, daß es noch kleinere Tierchen gebe, so kleine, daß sich die mikroskopischen Tiere zu denselben so verhalten, wie der Walfisch zu einem Wasserfloh; so verbreite sich die Stufenleiter der Tiere nach beiden Richtungen ins Unendliche.

Diese Vorstellung von den Analogien der Tiere, von ihrer Stufenleiter und TRembleys Arbeit über die Hydra hat NeEdham ermutigt, Meerfische zu suchen, welche Polypen en gros wären, und er behauptet, solche Fische in den »bernacles « gefunden zu haben; leider hat er diese so oberflächlich beschrieben, daß es unmöglich ist, $\mathrm{zu}$ erraten, was er denn eigentlich vor sich hatte (Cirripedien?). Noch eine solche Analogie fand er: ein kleines Fischlein mit Schalen, so groß wie ein Sandkorn (wahrscheinlich Daphnia oder Cypris), das einem mikroskopischen Infusor analog sein soll. Nach seiner Meinung können uns solche Analogien das Studium der mikroskopischen Tiere erleichtern, indem wir die an großen Tieren gemachten Beobachtungen auf kleine übertragen.

In seiner Theorie der Entwicklung geht NEEDHAM von LEIBNIZ aus. Während die Evolutionisten LEIBNIZ nur den oberflächlichen Gedanken entnahmen, daß der Organismus sich aus einer vorhandenen Form durch bloßes Wachstum entwickelt, haben NEEDHAM und später WolfF den Begriff der Monade, die sich durch eine ihr inhärente Kraft entwickelt, tiefer erfaßt. Sind die Evolutionisten auf ihre Theorie durch die Überzeugung von der Unmöglichkeit der Formbildung nach den Regeln der Mechanik gekommen - sie folgerten daraus, daß die Form überhaupt nicht entsteht, sondern nur wächst -, so richteten NEEDHAM und WOLFF ihr Augenmerk auf die die Entwicklung treibende Kraft. Diese Kraft zogen die Evolutionisten nicht in Betracht; sie halfen sich mit der oberflächlichen und physikalisch unmöglichen Annahme, daß die beschleunigte Tätigkeit des Herzens die Blutgefäße erweitere, wodurch das Wachstum des Keimes gefördert werde.

NeEDHAM stellt sich vor, daß der Materie das Streben innewohnt, sich im Raume ins Unendliche zu verbreiten. In den orga- 
nischen Wesen wird dieses Streben durch eine besondere vegetative Kraft überwunden, und so wird die Materie zusammengehalten. Die richtig im Körper verteilte, je nach der Tierart verschiedene vegeta. tive Kraft (dem »moule intérieur "BUFFons analog) bildet den Körper, sobald sie darin zu wirken beginnt, zu einer spezifischen Form aus, etwa so, wie die Kraft eines Wurfgeschosses in Verbindung mit der Attraktionskraft das Geschoß nötigt, eine parabolische Bahn zu beschreiben und an einem mathematisch definierbaren Orte zu Boden zu fallen, - oder wie ein Feuerwerk, dessen Kräfte durch das Anzünden sich nach außen entwickeln und eine bestimmte Figur bilden, die vom Feuerwerker zuvor bestimmt war.

Denselben Gedanken wie NEEDhaM hat WolfF, aber viel konsequenter und wissenschaftlicher, entwickelt. CASPAR FrIEDRICH WOLFF (I733-I794), ein Deutscher, Professor in Petersburg, wurde durch den Philosophen Christian WolfF beeinflußt. Seine wichtigste Schrift "Theoria generationis ", die Arbeit eines 26jährigen Jünglings, ist eine aus formalen wie sachlichen Gründen nicht leicht zu lesende Abhandlung. WOLFF hat sich nämlich bemüht, seinem philosophischen Lehrer in der logisch korrekten Formulierung der Probleme zu folgen; darum ist seine Abhandlung den ins Unendliche ausgedehnten französischen Publikationen jener Zeit so unähnlich: eine neue Terminologie wird eingeführt, alles wird definiert, Prämissen werden formuliert und aus ihnen bündige Schlüsse gezogen, und das alles in ungewöhnlich gedrängtem Stil. Der Lehrer unseres Embryologen, CHRISTIAN WOLFF (I679-I754), war Leibnizianer, der die zerstreuten philosophischen Ansichten LeIBNizens systematisiert und, wie ihm die heutigen Historiker vorwerfen, verflacht hat. Er hat auch botanische Untersuchungen angestellt, doch blieb er in der Biologie nur Dilettant.

Die historischen Quellen der epigenetischen Theorie C. F. WolfFs sind an erster Stelle LEIBNIZ mit seiner Theorie der Monade, die sich zu einem Organismus entwickelt, zweitens NEEDHAM, der diesen Gedanken auf die embryonale Entwicklung anzuwenden versuchte, sodann CHR. WolfF, der die Ausbildung der Theorie nach ihrer formalen Seite beeinflußt hat ${ }^{\mathbf{1}}$ ).

1) Ich habe in der I. Aufl. angenommen, daß Wolff seinen Vitalismus aus den Schriften StaHLs geschöpft hat; nach den Ausführungen M. Stentas (a. a. O. S. 779) werde ich vorsichtiger sagen, daß er Stahls Vitalismus gekannt hat. Zweifellos ist Wolff Vitalismus ni ht animistisch wie derjenige Stahls. 
Im folgenden werden wir WolfFs Ansichten erklären; es sei im voraus bemerkt, daß es nicht leicht ist, in dieselben einzudringen $\mathbf{1}$ ).

\section{Der Begriff der wesentlichen Kraft.}

Wesentliche Kraft (vis essentialis) ist die Kraft, »durch welche Flüssigkeiten, aus der umgebenden Erde gesammelt, in die Wurzeln einzutreten gezwungen, durch die ganze Pflanze verteilt, z.T. an verschiedenen Stellen aufgespeichert, $z$. T. auch wieder ausgeschieden werden $\left.\ll^{2}\right)$. Auch bei den Tieren ist die wesentliche Kraft vorhanden; denn am Anfange der Entwicklung nährt sich das Hühnchen aus der Substanz des Eies; es folgt daraus,

daß eine Kraft vorhanden ist, durch die dies erfolgt, und daß diese Kraft nicht die Kontraktion des Herzens und der Arterien, ebensowenig der dadurch erzeugte Druck in den benachbarten Venen, noch auch die Kompression derselben durch Muskelbewegung sein kann; ferner daß sie nicht durch bestimmte Kanäle, die den Weg vorzeichnen, wirkt, daß sie also analog der im $\S$ I [im obigen Zitat] definierten Kraft ist. Ich werde sie daher ebenso als wesentliche Kraft bezeichnen ${ }^{3}$ ).

Die wesentliche Kraft ist je nach der Pflanzenart quantitativ und qualitativ verschieden. WOLFF meint, es sei möglich, diese Kraft für jede Pflanze zu ermitteln; die Kenntnis derselben und der spezifischen Erstarrungsfähigkeit (s. weiter unten) werde einen Mathematiker in den Stand setzen, die Gestalt der Pflanze und ihre charakteristische Zusammensetzung zu berechnen ${ }^{4}$ ).

\section{2. Über die Erstarrung als das zweite Prinzip der Entwicklung.}

Im Beginn der Entwicklung besteht die pflanzliche und die tierische Substanz aus einer gallertigen Masse; auch die Blätter und neuen Sprosse sind anfangs ähnlich beschaffen. Diese Masse enthält auf verschiedene Art miteinander in Verbindung stehende Löchelchen, deren Wände die Neigung haben zu erstarren; doch ist die Erstarrungsfähigkeit bei verschiedenen Pflanzen verschieden ${ }^{5}$ ); der tierische

1) Ich zitiere nach der deutschen Ausgabe in OsTwALDs Klassikern der exakten Wissenschaften.

2) I. S. I I.

3) II. S. 4 .

4) I. S. 56 .

5) I. S. I6. 
Körper besitzt eine viel geringere Erstarrungsfähigkeit als der Pflanzenkörper.

Durch das Zusammenwirken der wesentlichen Kraft und der Erstarrungsfähigkeit entsteht der organische Körper: die aufgesaugten Substanzen dringen durch die Wirkung der wesentlichen Kraft in die Poren, drängen die Wände derselben auseinander, in den so entstandenen Lücken bilden sich neue Wände und Poren, neue Bläschen. An der Stelle, wo der die Pflanze durchströmende Saft die Wände berührt, erstarrt er; dadurch werden die Wände dicker. Auf diese Art läßt sich die Entstehung verschiedener Gebilde bei Pflanzen und Tieren begreifen; so zuerst die Bildung der Blätter: die wesentliche Kraft treibt den Saft in junge, weiche Pflanzenteile; in der Nähe des Vegetationspunktes der Pflanze durchbricht der Saft leicht die Haut, fließt heraus und bildet, an der Luft erstarrend, Bläschen, die durch fortgesetzte Wirkung der Kraft länger und breiter werden. An ihrem Rande bleiben die neuen Gebilde weich und wachsen deshalb fort. So entstehen die Blätter. Ganz analog wird auch die Blüte hervorgebracht: der Kelch wächst den Blättern ähnlich heraus, die Krone wird aus Säften gebildet, die, nach oben strebend, weder im Kelch, noch im Vegetationspunkt Platz haben und daher zwischen beiden im Kreise hervordringen; analog entstehen auch die übrigen Teile der Blüte.

Die Richtung und die Geschwindigkeit der Säfteströmung verursacht auch die Form der Gewebeteile: bei langsamer Strömung entstehen Bläschen, bei schneller Strömung in einer Richtung Gefäße.

Auf dieselbe Art bilden sich durch den Druck der vis essentialis bei den Tieren Gefäße, und die vorhandenen dehnen sich aus; so werden auch die Urin führenden Gänge und die Ureteren durch den Druck der Urinflüssigkeit, die durch sie hindurchging, gebildet.

Es ist daher die wesentliche Kraft mit der Erstarrungsfähigkeit des Nährsaftes ein hinreichendes Prinzip jeder Entwicklung sowohl bei Pflanzen als auch bei Tieren 1 ).

Die Erstarrungsfähigkeit der organischen Säfte ist gewiß keine glückliche Erfindung WolfFs; sie zeigt jedenfalls, wie sehr ihm ein Prinzip gefehlt hat, auf Grund dessen er die sichtbare Form des Organismus hätte erklären können. Ebenso wie NEEDHAM, der aus dem Zusammenwirken der Repulsivkraft und der Vegetationskraft

1) II. S. 60. 
die Entstehung der Form abzuleiten suchte, ist er bemüht, aus dem Gegeneinanderwirken der Essentialkraft und der Erstarrungsfähigkeit (von der er selbst sagt, daß sie sich nicht von der allgemeinen Kraft der Kohäsion unterscheidet) dasselbe Resultat zu entwickeln. Eigentümlicherweise ist bei NEEDHAM die vitale Kraft zusammenziehend, bei WOLFF auseinandertreibend.

\section{Die Beziehungen des organischen Körpers im all- gemeinen oder der Maschine zu dem in Entwicklung be- griffenen Körper.}

Unter diesem Titel stellt WoLfF seine Theorie in Gegensatz zu der Lehre DescaRTEs', nach welcher der Körper nur eine Maschine sein soll. Die sich entwickelnden Körper sollen anfangs strukturlos sein; ihre Struktur (Maschine) sei die Folge der Entwicklung. Diese Auffassung kommt in dem Satze zum Ausdruck,

daß in Entwicklung begriffene Körper nicht Maschinen sind, sondern bloß aus unorganischer (= nicht organisierter) Substanz bestehen. Und diese sich entwickelnde Substanz ist von der Maschine, in die sie eingehüllt ist, wohl zu unterscheiden. Die Maschine ist als das Erzeugnis derselben anzusehen.

WolfF folgert daraus, daß diejenigen Vorgänge im Organismus, welche von seiner Struktur abhängig sind, eine nur akzessorische Bedeutung für die Entwicklung haben, und wendet diese Schlußfolgerung, dem Beispiel STAHLs folgend, auf die praktische Medizin an. So bezeichnet er die Theorien, welche die Lebensvorgänge aus der Struktur (Anatomie) erklären und den kranken Körper durch die Beeinflussung der Materie am Körper heilen wollen, als falsch, da die Krankheit nicht in der Struktur, sondern in der Kraft ihre primäre Ursache habe.

Die epigenetische Theorie WolfFs steht und fällt mit dem Begriffe der wesentlichen Kraft. Was bleibt vom Leben der Pflanze übrig, wenn man ihr WolfFs Essentialkraft abspricht? Wie wird dann die Pflanze die Nahrung schöpfen, die Säfte in ihr bewegen, die Blätter hervortreiben? Die Entwicklung der Pflanze wird ohne die wesentliche Kraft nicht einmal beginnen können, ganz abgesehen davon, daß auch keine Differenzierung entstehen würde.

WolfF hat den Fehler der Evolutionstheorien richtig erkannt, daß diese die treibende Kraft der Entwicklung anzugeben unter- 
lassen und die Struktur als das einzig Beachtenswerte ansehen, und hat richtig die Notwendigkeit einer die Entwicklung treibenden Kraft betont; dadurch ist er jedoch ins andere Extrem verfallen: er sah sich zu der unmöglichen Annahme gezwungen, die Form sei die bloße Folge davon, daß die Säfte durch ihre Erstarrung an weiterer Ausdehnung gehindert werden. In diesem Punkt ist WolfF in die Scylla aller Vitalisten geraten: die Kraft hat er wohl in sein System eingeführt, die Form fiel ihm aber aus dem System heraus.

Ein anderer Mangel liegt darin, daß WolfF die wesentliche Kraft zu schematisch genommen und keinen Versuch gemacht hat, ihre Erscheinungsformen konkret darzustellen; es hätte sich dann auch herausgestellt, daß die periodische Ruhe und Bewegung des Lebens nicht nur aus sekundären Einflüssen zu begreifen ist; daß die vitale Kraft etwas in sich haben muß, was sie dazu bringt, hier energischer als dort, in der Jugend frischer als im Alter zu wirken, usw.

\section{Zellentheorie.}

Daß das Pflanzengewebe aus kleinen, von festen Wänden begrenzten Hohlräumen besteht, erkannten schon MALPIGHI, HookE und GREw. Über hundert Jahre ist diese Beobachtung unberührt geblieben; erst C. F. WolfF hat den Versuch gemacht, sie zu vertiefen. Er hat die Zellen wahrgenommen und für Schaumgebilde gehalten: sie erschienen ihm als mit Saft gefüllte Bläschen, die durch einfache Wände voneinander abgesondert sind; er suchte sie aus der Einwirkung der expansiven vis essentialis auf die hyaline Pflanzenmaterie zu erklären. In diesem Punkt hat sich die Geringschätzung der Morphologie an ihm gerächt: es fiel ihm nicht auf, daß die Bläschen des pflanzlichen und des tierischen Gewebes qualitative morphologische Elemente sind, die nicht aus dem Begriff seiner Kraft a priori entwickelt, sondern nur beobachtet werden können.

WoLfF suchte sich auch eine Vorstellung von dem Wesen der Befruchtung zu bilden. Wenn das Pflanzengewebe älter wird, wird es zu dick und zu fest, und die Säfte können nicht mehr so schnell wie vordem strömen. In dieser Zeit werden Samen gebildet. Die Pollenkörner sind für den im Pistill enthaltenen Keim nichts anderes als ein überaus vollkommenes Nahrungsmittel, welches dem Keim ermöglicht, mit dem Wachstum von neuem zu beginnen. Dieselbe Bedeutung hat die Befruchtung bei den Tieren. 


\section{Die Metamorphosenlehre und die Lehre von den Keimblättern.}

WolfF wird von GoEthe die Lehre von der Metamorphose der Pflanzen zugeschrieben, $d . h$. die Lehre, daß verschiedene Pflanzenteile, besonders Laub, Kelch-, Kronenblätter, Staubfäden und Pistille wesentlich Blätter darstellen. Diese Metamorphosenlehre ist den später entstandenen morphologischen Theorien entsprungen und konnte aus diesem Grunde nicht von WOLFF begründet worden sein. Daß die grünen Blätter, die Kelch- und Blumenblätter einander ähnlich sind, hat man vielleicht jederzeit gefühlt; tatsächlich finden sich bereits bei CAESALPIN Stellen, welche darauf hinweisen, daß er die genannten Gebilde für gleichartig angesehen hat. Auch WoLFF hat die Ähnlichkeit der verschiedenen Blattformen als selbstverständliche Tatsache hingenommen; ihm handelte es sich nur darum, aus der »wesentlichen "Kraft zu erklären, wie diese Gebilde entstehen; und weil sie morphologisch gleich sind, deshalb nahm er für sie eine der oben von uns erörterten ähnliche Entstehungsart an. WOLFFs »expansive Kraft «war übrigens wenig geeignet, die Verschiedenheit der Blattformen zu erklären, und verschleierte das Problem der Strukturähnlichkeit dieser Gebilde. WOLFF war jedoch kühn genug, seine Theorie auch auf die Tiere anzuwenden und zu behaupten, daß die "Keimblätter" auf wesentlich dieselbe Art wie die Pflanzenblätter entstehen und ihnen folglich ähnlich sind.

Die Zeitgenossen haben WOLFF wenig beachtet. HALLER nahm seine Abhandlung günstig auf, blieb aber gleichwohl seinem Evolutionismus auch weiterhin treu. BoNNET erwähnt WoLfF nur einmal in einer Anmerkung. Die Dunkelheit des Stils war - namentlich zu jener Zeit - nicht der letzte Grund seines Mißerfolgs; die wichtigste Ursache liegt in der Unfähigkeit der damaligen Forscher, die tieferen und selbständigeren Ansichten WoLFFs zu begreifen. Embryologische Forschungen gab es so gut wie nicht, für den Vitalismus waren nur die Mediziner eingenommen, während den Biologen selbst ein Buffon zu kühn war. In einer Zeit, in der Linné Triumphe feierte, konnte WoLFFs auf botanisches und zoologisches Material gegründete Theorie nicht auf Erfolg rechnen. Trotz dieser ungünstigen Verhältnisse ist die "Theorie von der Generation " in drei Auflagen (I759, I764, I774) erschienen.

Erst nachdem das Interesse für die Embryologie in Deutschland unter dem Einfluß der Naturphilosophie geweckt war und nachdem 
S. F. Meckel eine embryologische Abhandlung Wolffs, aus dem Lateinischen übersetzt und mit Anmerkungen versehen, neu herausgegeben hatte (18I2), fand die WolfFsche Theorie mehr Beachtung und Verständnis, das dann durch die Arbeiten BAERs wesentlich gefördert wurde.

Die WolfFsche Entwicklungslehre hat die Anfänge der Entwicklung und die Befruchtung berücksichtigt, ohne die Bedingungen derselben weiter bis zu den Eltern zurückzuverfolgen. Das Problem, warum die Kinder den Eltern, besonders warum sie beiden Eltern ähnlich sind, hat WoLFF durch seine Theorie nicht gelöst, wie er denn überhaupt außerstande war, das Formproblem in der Entwicklung $z u$ erklären.

Auch die Evolutionisten mußten vor dem Problem der Ähnlichkeit zwischen Kindern und Eltern und besonders vor dem der Bastardierungen ratlos stehen bleiben. BONNET kommt wieder und wieder auf die Erscheinungen der Kreuzung zu sprechen, ohne aber mehr als die flachste Erklärung derselben bieten zu können. Erwähnenswert ist, daß sich die Erkenntnis von der begrenzten Möglichkeit der Kreuzungen erst allmählich entwickelt hat. ARISTOTELES läßt ganz verschiedene Gattungen durch Kreuzung Nachkommen hervorbringen, und selbst LiNNḱ gab die Möglichkeit zu, daß die Arten durch Kreuzung der Gattungen untereinander entstanden seien. Exakte Versuche über die Kreuzungen hat Joseph GotTLIEB KölReuter, Professor in Karlsruhe (I733-I806), durchgeführt. Er zählte die Menge von Pollenkörnern, die zu einer vollständigen Befruchtung nötig sind, wies auf den Wind hin, auf die Erschütterung, auf die Insekten und die reizbaren Staubgefäße, als auf die für die Befruchtung nötigen Faktoren; auch kreuzte er verschiedene Pflanzenarten untereinander und erzielte auf diese Art eine Reihe von Bastarden. Seine Versuche wurden von Christian Konrad SprenGEL (I750-I8I6) fortgesetzt, welcher die natürlichen Kreuzungen, wie sie unter den Pflanzen vorzukommen pflegen, verfolgt hat. Er erkannte (1793), daß die Organe der Pflanzen, trotzdem diese überwiegend Zwitter sind, doch sehr oft auf die gekreuzte Befruchtung berechnet sind. Er drückt dies durch folgenden Satz aus:

Da sehr viele Blumen getrennten Geschlechts und wahrscheinlich ebensoviele Zwitterblumen Dichogamisten sind, so scheint die Natur es nicht haben zu wollen, daß irgendeine Blume durch ihren eigenen Staub befruchtet werden solle ${ }^{1}$ ).

1) Das neu entdeckte Geheimnis usw., S. 43 . 
Die Dichogamie, d. h. die Erscheinung, daß bei manchen Pflanzen das Pistill einer zwitterigen Blüte später reif wird als die Antheren, hat SPRENGEL selbst entdeckt; auch studierte er die Rolle der Insekten bei der Befruchtung der Pflanzen eingehender als KöLREUTER ${ }^{1}$ ).

1) Liter atur. Needham, Turb., New microscopical discoveries. London 1745 . Ders., Observations upon the generation, composition and decomposition of animal and vegetable substances. London I 749. - WoLFF, C. F., Theoria generationis. Halae 1759. - Über die Bildung des Darmkanals im befruchteten Hühnchen. Übersetzt von J. F. MEckel. Halle I812. - KöLReuter, J. G., Vorläufige Nachricht von einigen das Geschlecht der Pflanzen betreffenden Versuchen und Beobachtungen. Karlsruhe I76I-I766. - Sprengel, Chr. KonR., Das neu entdeckte Geheimnis der Natur in Bau und Befruchtung der Blumen. Berlin 1793. 


\section{Kapitel.}

\section{Linnés Methode.}

\section{Entstehung der Lehre vom Pflanzen- und Tiersystem.}

Die enzyklopädischen Werke Gesners und ALDROVANDIs und andere Schriften dieses Schlages sowie die medizinischen Zwecken dienenden Kräuterbücher haben das unmittelbar Praktische betont; deshalb waren sie jedem System, d. h. jedem Versuch, die Mannigfaltigkeit der Natur Vernunftgesetzen zu unterordnen, abhold. Doch hat die Notwendigkeit, einzelne Pflanzen und Tiere möglichst kurz und doch erschöpfend zu beschreiben, die Empiriker dazu geführt, allgemeine Bezeichnungen mit fester Bedeutung anzuwenden. Je weiter desto zahlreichere Pflanzen und Tiere wurden in die Bücher aufgenommen: zuerst interessierte man sich, unter dem Einfluß des Humanismus, vorwiegend nur für die von den klassischen Autoren beschriebenen Formen; später zog man auch neue Arten in die Beschreibung ein, ohne jedoch Ansprüche an Vollständigkeit zu erheben, denn immer noch hielt man die Organismenwelt für unendlich mannigfaltig und deshalb für unerschöpflich. Einzelne Reisende in fremden Ländern ${ }^{\mathbf{1}}$ ) gaben Schriften heraus, in denen sie auch neue, beachtenswerte Pflanzen und Tiere erwähnen. Die wachsende Menge der beschriebenen Organismen führte zu Definitionen, zur Schaffung neuer Namen, zur Angliederung des Neuen an das Bekannte nach bestimmten Prinzipien und förderte auf diese Weise den natürlichen Hang des menschlichen Geistes, die Gesetze der Vernunft auf die Naturerscheinungen konsequent anzuwenden, ein

1) Peter Belon, Les observations des plusieurs singularitez et choses mémorables trouvées en Grèce, Asie, Indée, Egypte, Arabie et autres pays estranges I553. Olaus Magnus, Historia de gentibus septentrionalibus. Roma I555. - Gonzalo FerNANDES DE OvIEDO, Historia general y natural de las Indias (= Amerika). Salamanca 1535. - Jos. DE AcostA O. J., Historia naturalis Indiarum (= Amer.). Sevilla I590. CH. DE L'Escluse (Clusius), Rariarum plantarum historia. Antwerp. I60I. - Ders., Exoticorum libri decem. Antwerp. I605. 
rationelles System der Organismen aufzustellen. Die Botaniker Jos. Pitton de Tournefort (I656-i708), Ant. L. Jussieu (i686 bis I738), BERNARD DE JUSSIEU (I699-I777) und der Botaniker und Zoologe John RAY (1628-I705), der letztere in Gemeinschaft mit FRANCIS WiLlUGHBY, haben diese aus praktischen Rücksichten sich ergebende Systematik am glücklichsten anzubahnen gewußt. TOURNEForT hat auf die Gattungen der Pflanzen als natürliche Gruppen hingewiesen, RAY hat die natürlichen Verwandtschaftsverhältnisse in ihren größeren Zügen erraten.

Neben den praktischen Bedürfnissen waren auch philosophische Rücksichten auf scharfe Definitionen und auf logische Bewältigung des Wissensschatzes für die Begründung des Systems entscheidend. Im Anschlusse an die aristotelische Logik hat CAESALPIN sein Pflanzensystem entwickelt und HARVEY die Tiere in den allgemeinsten Umrissen klassifiziert. In CAESALPINs Fußstapfen folgte der schon erwähnte J. Jungius, ferner RoB. Morison (I620-1683) und A. Q. Rivinus (1652-1725), der als erster den Versuch wagte, binäre Nomenklatur in die beschreibende Botanik einzuführen ${ }^{1}$ ).

\section{Linnés Methode.}

KARL VON LINNÉ(I707-I778) aus Rashult in Schweden, seit I74I Professor der Medizin und später der Botanik in Upsala, ist einer der genialsten Schulgelehrten, die es je gegeben hat. Sein Lebenslauf ist derjenige eines stillen, fleißigen, weltberühmten, pedantischen Gelehrten, ein Lebenslauf ohne besonderes Interesse und ohne beachtenswerte innere Beziehungen $\mathrm{zu}$ seiner in geradliniger Bahn fortschreitenden wissenschaftlichen Karriere. PARACELSUS', HELmonTs, SWAMmERdams Wissenschaft bildete einen integrierenden Teil

1) Literatur. JUng(IUS), JoACH., Doxoscopiae physicae minores 1662. - Ders., Isagoge phytoscopica 1678. - MORISON, RoB., Plantarum umbelliferarum distributio nova. Oxonii $1672 .-$ Rivin(US), Aug. QuIR., Introductio generalis in rem herbariam; 1690. - Tournefort, Jos. PITTON DE, Institutiones rei herbariae. I 700. - RAy, JoHN, Historia plantarum. 3 Vols. Londini 1686-1704. - Ders., Philosophical lettres. London I718. - Ders., Synopsis methodica animalium Quadrupedum et Serpenti generis etc. Londini 1693. - Ders., Synopsis methodica Avium et Piscium etc. Londini I713. - Ders., Historia Insectorum. Londini I710. - F. WILlughBY, Ornithologiae libri tres. Londini 1676. - Ders., De Historia Piscium libri quattuor. Oxonii 1686. Ders., Historia Insectorum. Londini I710. - Über die oben angef. Botaniker findet sich näheres in SAChS' Gesch. d. Botanik. Über J. RAY und Willughby vgl. EDW. Lankester, Memorials of John Ray. 2 Vols. London 1846 und Miall, L. C., The early Naturalists. Lond. I9I2. 
ihres Lebenskampfes; bei LinNé gestaltete sich das Leben zu einem bedeutungslosen Anhang seiner Bücher. Deshalb war dieser vom Staub der Gelehrsamkeit bedeckte Forscher dem weltweisen BuffoN und GoETHE widerwärtig; deshalb erstreckte sich sein Einfluß vor allem auf die Universitäten, deshalb liegt in der "Methode ", in konsequenter Anwendung der Kunstausdrücke sein Hauptverdienst. Auf der Upsalaer Hochschule lernte er wahrscheinlich die im Sinne des Aristotelismus, d. h. die nach strengen logischen Methoden vorgetragene Wissenschaft kennen und blieb dieser Richtung, ohne jemals irgendeine Spur von Zweifeln über deren Wert empfunden zu haben, sein Leben lang treu: niemals hat er etwas anderes liebgewonnen als die Systematik. Übrigens scheint er ein geborener Systematiker gewesen zu sein. Dieser Gedanke kommt einem unwillkürlich, wenn man seine Schriften ins Auge faßt. Es ist nicht auffallend, daß er seine großen, der Klassifikation der Organismen gewidmeten Werke systematisch bearbeitet hat, denn das gehört zur Sache; doch hat er eben alle seine Schriften nicht nur im großen systematisch angeordnet, sondern das System bis ins Kleinste, ja ins Unmögliche verfolgt. Bereits seine erste Arbeit über die intermittierenden Fieber ( 735 ) zeigt diesen Hang zum Systematisieren. Außer der I $1 / 2$ Seiten langen Einleitung ist dort alles in kleine und kleinste Absätze gegliedert, alles nach I. I. a. $\alpha$ durchgeführt und in gedrängtem Stil dargeboten. Seine "Philosophia botanica "- eine naturphilosophische Schrift - ist wegen der minutiös durchgeführten Klassifikation kaum zu lesen. Er führt dort nach der Einleitung die Literatur des Gegenstandes an, doch so, daß er zunächst den Botaniker im allgemeinen definiert und dann verschiedene Klassen der Pflanzenkenner nach festen Merkmalen unterscheidet:

Die Methodiker haben besonders die Einteilung und die darauf gegründete Benennung der Pflanzen bearbeitet; sie sind: Philosophen, Systematiker, Nomenklatoren.

Die Philosophen haben die botanische Wissenschaft durch logische Beweise (demonstrative) aus den Prinzipien des Verstandes in die Form der Wissenschaft zurückzuführen, wie: die Redner, Streiter, Physiologen, Lehrer.

Die Redner haben alles vorgeschlagen, was der Wissenschaft zur gelehrten Zierde gereicht, wie z. B. Hellwigs Botanices nobilitas.

Die Streiter (Eristici) haben in öffentlichen botanischen Schriften polemisiert.

Die Physiologen haben die Gesetze der Pflanzenwelt und das Mysterium des Geschlechts der Pflanzen entdeckt usw.

(Jeder Botaniker wird nun in dieser Weise charakterisiert und klassifiziert, z. B.:) Caesalpinus est fructista et primus verus systematicus, secundum 
corculi et receptaculi situm distribuens ${ }^{1}$ ); TOURNEFORTIUs est corollista secundum regulitatem et figuram cum duplici situ receptaculi floris ${ }^{2}$ ); MAGNolius est calycista cum fructicistis combinatus ${ }^{3}$ ).

Die Einteilung der Botanik nach den individuellen Tendenzen einzelner Forscher ist ganz ungewöhnlich, vom psychologischen Standpunkt jedoch berechtigter als es scheinen möchte; die Weiterführung derselben auf Grund einer einschlägigen Erfahrung würde zu einem interessanten 》natürlichen "System der Wissenschaft führen.

Wie weit Linné seine Klassifikationen getrieben hat, ist vielleicht am besten aus seinen Reden zu ersehen; sie sind nämlich ganz ebenso wie seine andern Schriften streng nach Klassifikationen und Definitionen angeordnet. Folgendermaßen hat er z. B. den schwedischen König und die Königin, als sie die Universität besuchten, begrüßt:

... Die Wissenschaften führen uns zur Ehrfurcht gegen Gott,

zum Gehorsam gegen den Magistrat, zur Liebe gegen andere.

Die Wissenschaften tragen uns die Fackel durch unser ganzes Leben voran. Sie lehren uns:

durch die Sprache, zu erzählen von den Experimenten anderer,

durch die Ökonomie, einen genügenden Vorrat der Dinge zu bereiten, durch die Geschichte, die Fehler der andern zu meiden -

(usw. noch elf solche Zeilen. Dann kommt:)

Welch eine Dunkelheit würde in unseren Ländern sein, wenn nur ein Teil der Wissenschaften in Vergessenheit geriete, wenn niemand im Königreiche sich daran versuchte,

$z u$ lösen ein schwieriges Problem, oder zu erklären dunkle Schriften, oder nach China treiben das Schiff, oder zu verfolgen den Strom des Flusses...

usw. noch acht solche Sprüche, denen sich eine neue Litanei anschließt, - und so geht es fort bis ans Ende der Rede. Andere Reden sind ebenfalls in dieser Art gehalten.

Man begreift, daß für einen in dieser Weise begabten Mann die systematische Biologie ein Gebiet war, auf dem er alles zu leisten vermochte, was zur Zeit geleistet werden konnte.

Linné hat unter "Methode "nur Klassifikation der durch die Natur unmittelbar gegebenen Objekte verstanden, während wir dem Worte einen wesentlich anderen Sinn geben; jedenfalls hat er dabei

1) Philos. bot. p. I 8 .

2) Ebenda, S. 23 .

3) Ebenda, S. 24. Diese an die Scholastik lebhaft erinnernden Definitionen sind schwer entsprechend $z u$ übersetzen. 
nicht die logischen (oder die praktischen) Forschungsmittel im Sinne gehabt: J. ST. Mills (induktive) Methode z. B. ist also toto genere von der LinNéschen "Methode "verschieden. Bereits der Vorläufer Linnés JoHn RAY hat in seiner Schrift "Methodus Plantarum ", welche aus Bestimmungstafeln der Pflanzenfamilien besteht, das Wort Methode in diesem enggefaßten, schulmäßigen Sinne genommen. LinNé war wesentlich Botaniker und auf diesem Gebiet nur Systematiker; zwar hat er auch durch die systematische Bearbeitung der Zoologie gewirkt, auch ein System der Mineralogie und ein System der menschlichen Krankheiten entworfen, doch stammen alle seine allgemeinen Ansichten aus dem Studium der Botanik. Er war kein Anatom und kein Physiologe; gleichwohl haben seine ausgedehnten literarischen Kenntnisse und sein Talent, die Merkmale einer Art oder Gattung richtig zu erfassen, es ihm ermöglicht, auch aus andern Wissenschaften weit mehr als das Mittelmäßige in seine Arbeiten aufzunehmen. Sein Leben lang hat er keine einzige biologisch wichtige Tatsache entdeckt, die experimentelle Methode war ihm fremd, und der Sinn für Vergleichungen ging ihm ab; neue Forschungswege (die Systematik ausgenommen) hat er nicht angebahnt; seine Größe liegt nur auf dem Gebiet des Definierens und Systematisierens. Die Tatsache, daß unter den fortwährend die experimentelle Wissenschaft betonenden und die Scholastik als einen längst überwundenen Standpunkt bespöttelnden Forschern des I8. Jahrhunderts plötzlich ein Gelehrter sich erhebt, der die Wissenschaft des AlBERTus MAGnus zu erneuern sich vornimmt und, was noch auffallender ist, einen allgemeinen Applaus erntet, erscheint auf den ersten Blick auffallend. Wir haben jedoch gesehen, daß mit der Scholastik, insofern diese einen Kultus der Logik und eine Hintansetzung der Natur bedeutet, nur die ältere Renaissance gründlich aufgeräumt hat. Seit LEONARDO und in erhöhtem Maße seit BACON, DESCARTES, HARvey wurde der scholastische Rationalismus von neuem in die Wissenschaft eingeführt. Von den Jesuiten, deren Macht im I7. Jahrhundert kulminiert hat, wurde die Scholastik eifrig gepflegt und in den Schulen den angehenden Gelehrten eingepflanzt. In Linné ist diese Betonung der Logik zum vollen Bewußtsein gelangt.

LiNné hat den mächtigsten Ansporn zu seiner Begründung des Pflanzensystems von CAESAlPIN, dem Erneuerer des Aristotelismus, empfangen; er hat ferner J. JungIUS und MORISON, die Anhänger CaEsalpins, studiert; sein Hauptverdienst, die Aufstellung des Artund Gattungsbegriffes, bedeutet eine Fortsetzung der aristotelisch- 
scholastischen Philosophie, in der die Begriffe der Art und der Gattung die allererste Rolle gespielt hatten. Seine Methode, den Inhalt des Gewußten weniger zu berücksichtigen als die logische Form, in der dasselbe vorgeführt wird, zeugt ebenfalls dafür, daß sich LinNé an den Aristotelikern herangebildet hat.

Vom Aristotelismus hat Linné die Betonung der Methode und die Unterscheidung der Art und Gattung übernommen; ARISTOTELES' (und CaEsalpins) Lehre von der Seele der Organismen, von der epigenetischen Entwicklung und ihre vergleichende Methode hat er nicht verstanden, sondern folgte den Anschauungen seiner rationalistischen Zeitgenossen: LEIBNIZens Grundsatz vom stetigen Stufengang der Wesen und von der Unfähigkeit der Natur, etwas Neues zu erschaffen, leiten auch LINNÉ bei der Aufstellung seiner Lehrsätze. Von den tiefsinnigen Aristotelikern unterscheidet sich ferner LiNNé durch das Bestreben, von seiner Wissenschaft alles Dunkle, nicht auf den ersten Schlag Verständliche fernzuhalten, dieselbe dem Auffassungsvermögen der hohen Welt anzupassen, wie es zu seiner Zeit, wo Könige und elegante Damen für die Wissenschaft Interesse zeigten, in der Mode war.

\section{Die Ansichten über die Sexualität.}

Linnés Pflanzensystem ist auf dem Unterschied, der sich aus der Anzahl und Form der Sexualorgane der Pflanzen, der Staubgefäße und der Pistille ergibt, begründet. Warum hat er eben diese Organe erwählt? Es ist nötig, an dieser Stelle das Problem der Sexualität zu berühren. Der Mann unterscheidet sich vom Weibe durch den Körperbau, durch die physiologischen und psychischen Leistungen; ebenso ist es bei den Tieren und Pflanzen. Wenn man die Eigenschaften des Männlichen zu einem Begriff zusammenfaßt und dem Begriff des Weiblichen gegenüberstellt, worin besteht der Gegensatz? Die Unterschiede des Männlichen und des Weiblichen lassen sich in mancher Hinsicht bis in die feinsten Äußerungen des Lebens verfolgen. Welchen Sinn hat diese tiefbegründete Polarität? Warum gibt es eben zwei Geschlechter, und nicht etwa drei oder vier?

Seit dem Altertum hat man über den Gegensatz der Geschlechter nachgedacht. Die Lehre des ARISTOTELEs haben wir angeführt. Wie er überhaupt im Gegensatz zwischen der dem Leben eingeprägten, nach ihrer Verwirklichung fortstrebenden Form und der Materie, in der sich das Leben abspielt, das Grundwesen der Natur erblickt, so versucht er auch den Geschlechtsunterschied auf diesen Gegen- 
satz zurückzuführen. Im Männchen ist nach ARISTOTELES das eigentliche Leben, das Formgebende, das Vorwärtsstrebende, im Weibchen das Material des Lebens vorherrschend. Erst bei den höheren Tieren kommt es aber zu dem Scheiden dieser beiden Prinzipien, indem jedes durch ein eigenes Individuum dargestellt wird; im Wesen der niederen Tiere und der Pflanzen fließen das männliche .und das weibliche Prinzip noch zu einer undifferenzierten Einheit zusammen.

Der Gedanke, daß nur die höheren Tiere geschlechtlich differenziert sind, hat sich unter den Gelehrten lange erhalten, und die volkstümliche Ansicht vom Geschlecht der Pflanzen und der niederen Tiere wurde als unwissenschaftlich verworfen. Bereits ARISTOTELES meinte die populären Vorstellungen vom Geschlecht der diözischen Pflanzen verwerfen zu müssen, und in den folgenden Zeiten findet man eine Erwähnung der Geschlechtsunterschiede der Pflanzen nur da, wo populäre Vorstellungen hineinspielen; so bezeichnet PLINIUS (wenn wir die Ansichten ThEOPHRASTs, eines Schülers des ARISTOTELES, übergehen) bei der Schilderung der Dattelpalme den Blütenstaub als Befruchtungsmittel; die Naturkundigen sollen erzählen, alle Bäume und Kräuter besäßen beiderlei Geschlecht.

HARvey, an den die neuzeitlichen Spekulationen über das Wesen des Geschlechts anschließen, hat ARISTOteles' Meinung von der Geschlechtslosigkeit der niederen Organismen wiederholt; auch die Befruchtung hat er aristotelisch gedeutet: der weibliche Uterus hat die passiv aufnehmende Vorstellungskraft, der Mann prägt ihm den Inhalt der Vorstellungen ein; wie das Gehirn die Umgebung erfaßt und ihr ähnliche Vorstellungen zeugt, so läßt sich der Uterus vom Manne beeinflussen und erschafft ein dem Vater ähnliches Kind.

Mit REDIs Bekämpfung der HaRveyschen Theorie und mit MALPIGHIS mechanistischem Evolutionismus beginnt die Zeit, in der man das Verständnis für die Erzeugung als Entstehung von etwas Neuem verlor. Mochte man die Einschachtelungstheorie im Sinne der Animalkulisten oder der Ovisten auffassen, immer war das Verständnis für die Bedeutung der Geschlechter a priori verschlossen. Wenn die ganze Nachkommenschaft im Weibe fertig eingeschlossen ist, wozu der Mann? Wenn sie in den Spermatozoen eingeschachtelt ist, wozu das Weib? Wenn in den Geschlechtsorganen, räumlich isoliert vom übrigen Körper, fertige Nachkommen wohnen, durch welches Spiel des Zufalls sind die anatomischen, physiologischen, psychischen Unterschiede zwischen dem Manne und dem Weibe zu erklären? 
Die Biologen des I7. Jahrhunderts haben solche Fragen nicht nur nicht gelöst, sondern nicht einmal geahnt. Man ließ sich nur in die Verfolgung des Befruchtungsvorganges ein, auf den das Problem des Geschlechtes verengt wurde. HARveY hat eine bestimmte Zeit nach der Begattung der Versuchstiere das Weibchen geöffnet und die Veränderungen an den Geschlechtsteilen untersucht. Derselben Methode folgten auch DE GraAF, VAllisnieri u. a. MALPIGHI versuchte, die Eier des Seidenwurms künstlich zu befruchten, aber ohne Erfolg. Swammerdam hat fast zur selben Zeit die Befruchtung der Froscheier außerhalb des Körpers direkt beobachten können, und Rösel V. ROSENHOF (I705-I759) bestätigte seine Beobachtung bei verschiedenen andern Amphibien (I750). Spallanzani führte diese Versuche weiter aus. Zu jener Zeit wurde auch der erste Fall der Zwittrigkeit (bei der Schnecke durch SwAmmERDAM) entdeckt, ohne daß man aber dieser Entdeckung eine neue Idee abzugewinnen vermocht hätte.

Die Bedeutung des Samens suchte VALLISNIERI chemisch zu erklären; mit demselben sollen in das Ei Säfte gelangen, welche den bisher ruhig im $\mathrm{Ei}$ schlafenden (präformierten) Organismus zum Wachstum anregen; alle Ovisten, auch Bonnet und Spallanzani, haben diese Theorie angenommen. RÉAUMUR schien auch diese Rolle des Samens bei der Befruchtung zu bedeutungsvoll zu sein; nach ihm hat die Befruchtung keinen anderen $Z_{\text {weck, als den Müttern }}$ die Ausscheidung derjenigen Keime zu erleichtern, die nicht zur Entwicklung bestimmt sind, damit die Mütter ihr Leben für die Nachkommenschaft, welche zu einer glücklicheren Zeit geboren werden soll, erhalten. LEEUWENHOEK, der Animalkulist, nahm dagegen an, daß je ein Spermatozoon in ein Ei eindringt und die Eisubstanz nur als Nährmaterial für sein Wachstum verwendet; an diese Auffassung haben sich dann die Animalkulisten gehalten.

An geschlechtliche Differenzierungen bei den Pflanzen haben die Gelehrten nicht geglaubt. MaLPIGHi hat zwar den Pflanzenkörper anatomisch untersucht, glaubte aber nicht durch sein Studium auf neue Begriffe gelangen zu können, suchte vielmehr die Ergebnisse seiner Arbeit den herrschenden Hypothesen anzupassen. Von den Staubgefäßen lehrte er, daß durch dieselben eine hypothetische, der Samenbildung hinderliche Substanz ausgeschieden werde. GREw, der sonst weniger glückliche Rivale MALPIGHIs, hat dagegen den Gedanken geäußert, daß in der Blüte die Geschlechtlichkeit der Pflanze zum Ausdruck kommt. Durch die Blumenblätter sollen 
gröbere Substanzen aus der Pflanze ausgeschieden werden (daher ihr Duft), während durch die Staubgefäße eine feinere Reinigung der Pflanze bewerkstelligt wird. Der in den Antheren eingeschlossene Pollen sei dem Samen der Tiere analog; auf die Geschlechtlichkeit soll nach GREw auch die Ähnlichkeit zwischen dem Griffel und der Narbe einerseits und dem Penis der Tiere anderseits hinweisen. Die Staubgefäße nehmen die Rolle der Hoden an.

RAY, auf den sich LinNé sonst stützt, war zwar von der Sexualität der Pflanzen nicht völlig überzeugt, doch neigt er zu der Annahme GREWs, deren Wahrscheinlichkeit er zugibt ${ }^{1}$ ).

Weniger gelehrte Beobachter waren der Annahme der Geschlechtlichkeit bei den Pflanzen geneigter. So AdAm ZaluzAnsky (I 592), der auf Grund der älteren Angaben die Behauptung aufstellt, daß einige Pflanzen Zwitter, andere getrennten Geschlechts sind; die ersteren haben die Fähigkeit, ohne Paarung zu zeugen, andere wieder, wie die Dattelpalme, sind männlich oder weiblich, und bei bei ihnen entsteht keine Frucht, wenn nicht der Staub von dem einen auf den anderen Baum übertragen wird. ZALUZANSKY unterscheidet auch richtig die geschlechtlich erzeugte Frucht vom ungeschlechtlichen Sproß2). Im Vaterlande der Dattelpalme war die Notwendigkeit der Befruchtung und folglich auch die Geschlechtlichkeit dieses diözischen Baumes seit altersher bekannt; diese und ähnliche andere Tatsachen haben wiederholt die Meinung gefördert, daß sich die Geschlechter auch bei den Pflanzen werden auffinden lassen. RUD. Jac. Camerarius (I665-I72I), Professor der Physik in Tübingen, hat durch eine Reihe von Versuchen diese Vermutung zur Gewißheit erhoben. Angeregt durch die Beobachtung an einem weiblichen Maulbeerbaum, welcher Früchte trug (allerdings taube Früchte), obwohl kein männlicher in der Nähe stand, stellte er Experimente mit verschiedenen diözischen Pflanzen an, indem er die weiblichen Blüten isoliert kultivierte oder bei monözischen die männlichen Blüten abschnitt. Auf diese Art überzeugte er sich, daß normale Samenbildung nur dann stattfindet, wenn der Inhalt der Antheren auf die weibliche Blüte gewirkt hat.

Im Pflanzenreiche findet keine Erzeugung durch Samen, dieses vollkommenste Geschenk der Natur, dieses allgemeine Mittel zur Erhaltung der Spezies, statt, wenn nicht vorher die Antheren die im Samen enthaltene junge Pflanze vorbereitet haben. Es scheint daher gerechtfertigt, jenen

1) Miali, The early Naturalists. S. I25.

2) Zalužanskx́, A. von, Methodus herbaria. I 592. 
" apices «(Antheren) einen edleren Namen und die Bedeutung von männlichen Geschlechtsorganen beizulegen, da ihre Kapseln Behälter sind, in denen der Same selbst, nämlich jenes Pulver, der subtilste Teil der Pflanze, sezerniert und gesammelt wird, um von hier aus später abgegeben zu werden. Ebenso leuchtet ein, da $\beta$ der Fruchtknoten mit seinem Griffel das weibliche Geschlechtsorgan der Pflanze darstellt ${ }^{1}$ ).

CAMERARIUS hat erkannt, daß einige Pflanzen getrenntes Geschlecht haben, die meisten dagegen zwittrig sind; er weist auf die Tatsache der zwittrigen Schnecken als auf einen analogen Fall hin.

Die Zeitgenossen des Camerarius wußten mit seinen Versuchen, die dem Evolutionismus widerstrebten, nichts anzufangen. Erst LINNÉ hat in ihnen ein geeignetes Mittel zur Entwicklung seines künstlichen Pflanzensystems gefunden. Durch CaEsalpin (den er gründlich studiert hat) war er auf den Geschlechtsunterschied der diözischen Pflanzen aufmerksam gemacht; CAMERARIUs brachte den experimentellen Nachweis dafür, daß alle Pflanzen geschlechtlich differenziert sind; die Geschlechter der Pflanzen lassen sich an den Staubgefäßen und Pistillen studieren, deren Form und Zahl großer Mannigfaltigkeit unterliegen. Weil nun im Sinne des Evolutionismus das Wesen der Geschlechter durch die anatomische Erscheinung der Geschlechtsteile (und nicht durch den einheitlichen Charakter der Männlichkeit bzw. der Weiblichkeit) gegeben ist, hat Linné den dogmatischen Grundsatz aufgestellt, daß die Sexualorgane für die Pflanze am wichtigsten sind, daß es keine andere organische Funktion gebe, für die von der Natur so konstante Apparate konstruiert wären als für die Fortpflanzung, und daß deshalb die Staubgefäße und das Pistill das geeignetste Mittel für die Einteilung der Pflanzenwelt liefern. Folgerichtig wollte LinNé auch das System der Tiere auf dem Bau ihrer Sexualorgane aufbauen, wurde jedoch durch die Rücksicht auf den Anstand - es war ja das I8. Jahrhundert, und die Zoologie mußte salonfähig bleiben - davon zurückgehalten ${ }^{2}$ ).

\section{Natürliches und künstliches System.}

Aristoteles war der erste Biologe, der auf ein biologisches System zugesteuert hat; als Philosoph, der im Naturgeschehen vernünftigen Sinn entdecken will, der an die Macht der Logik glaubt,

1) Camerarius, Rud. Jac., Opusculi botanici argumenti. Pragae 797 (von J. Ch. MikaN herausgegeben; die Originalabhandlungen sind als vorläufige Mitteilungen in den Ephemeriden der Leopoldina I69I-I694 enthalten). (Nach J. Sachs zitiert.)

2) Linnés Pflanzensystem ist zu bekannt, um hier angeführt werden zu müssen. 
mußte er ein System aufstellen und zwar ein natürliches System, denn nur ein solches ist mit der philosophischen Aufgabe der biologischen Wissenschaft verträglich, während die künstlichen Systeme entweder nur einen bewußt provisorischen Wert haben oder die Vernünftigkeit der Natur negieren. CAEsalPIN, der Erneuerer des Aristotelismus in der Botanik der Neuzeit, hat dem (natürlichen) Pflanzensystem eingehende Aufmerksamkeit gewidmet; er führt aus, daß die Einteilung der Pflanzen nach ihrem Wesen, d. h. nach der greifbaren Art, in der sich die Individualität jeder Pflanze offenbart, durchgeführt werden muß. Da er nun die Art der Lebensführung jeder einzelnen Pflanze (das Analogon desjenigen, was wir beim Menschen Charakter nennen) für ihr Wesen gehalten und die äußere Organisation für den bloßen Ausdruck der Lebensführung erklärt hat, suchte er die Pflanzen erstens nach der Art ihrer Ernährung und ihres Wachstums einzuteilen, die sich in der Form der Wurzel, des Keimes und des Stengels offenbaren, zweitens nach der Art der Vermehrung, d. h. nach der Form der Früchte. Diese beiden Einteilungsprinzipien entsprechen nämlich dem Charakter des Pflanzenlebens, der in »Ernährung《, 》Wachstum《 und "Vermehrung" besteht (aluntur, crescunt, gignunt sibi similia) ${ }^{\mathbf{1}}$ ).

Die Arbeit der philosophisch ungeschulten Enzyklopädisten hat ein anderes Pflanzensystem vorbereitet. Diese Schriftsteller pflegten einzelne Pflanzen abzubilden und nach den Abbildungen $\mathrm{zu}$ beschreiben; die starre äußere Form der Pflanze drängte sich dabei desto energischer in den Vordergrund, als man mit der Zeit nach getrockneten und in den Herbarien aufbewahrten Pflanzen ihre Charakteristiken aufzustellen lernte. Gleichzeitig suchten auch die Zoologen, mit Gesner und Aldrovandi an der Spitze, die Beschreibungen der Tiere den Abbildungen derselben anzupassen und folglich mehr die körperlichen Merkmale als die Eigentümlichkeiten der Lebensführung zu betonen. Diese neue Methode fand desto leichter Eingang, als die wachsende Menge der in die Bücher aufgenommenen Pflanzen- und Tierarten die Autoren ganz natürlich dazu führte, die Charakteristiken einzelner Typen so zu wählen, daß der Leser an der Hand derselben die beschriebene Tier- und Pflanzenart leicht erkenne. Dieses praktische Ziel wurde den theoretischen Bemühungen, das Wesen des Organismus durch eine Definition auszudrücken, vorangestellt.

1) Caesalpin, De Plantis. Kap. x. 
Bereits bei RAY streiten diese beiden Grundsätze mit einander um die Vorherrschaft. LINNÉ hat den Versuch gemacht, beiden Richtungen gerecht zu werden, führt aber nur die künstliche Einteilung der Pflanzen und Tiere durch. LinNé zeigte kein Verständnis mehr für das aristotelische Postulat, daß jede Definition das Wesen (die Idee) des definierten Objektes ausdrücken müsse, da ihm, einem Kind des rationalistischen Zeitalters, die aristotelische Lehre, daß jede Pflanze durch ihr Äußeres, durch ihre Entwicklung, durch ihre Lebensführung nur ihr einheitliches Wesen, ihre Seele im Raume und in der Zeit entfaltet, verschlossen blieb; unter einer Pflanze verstand LINNÉ bloß die Su m me ihrer materiellen Eigenschaften. Wenn er auch unter dem Eindruck CAESALPINs und noch mehr unter demjenigen der Evolutionisten die Aufstellung eines natürlichen Systems als die Aufgabe der Zukunft anerkennt, so faßt er die Natürlichkeit nicht mehr im aristotelischen Sinne; anstatt diesen Fortschritt von der Vertiefung der Pflanzenkenntnis zu erwarten, erhofft er denselben von der Entdeckung neuer Gattungen, durch die die noch vorhandenen Lücken im natürlichen System ausgefüllt werden sollen ${ }^{1}$ ).

Der Gedanke an ein natürliches System hängt bei LINNÉ mit seiner Auffassung des LEIBNIZschen Satzes "Natura non facit saltus « zusammen, den er als einen der ersten in seiner botanischen Philosophie (I75I) anführt. Auf diesen Grundsatz möchte er das natürliche System (natürliche Methode) aufgebaut wissen:

Die Fragmente der natürlichen Methode sind fleißig aufzusuchen. Dies ist das Erste und Letzte, was in der Botanik zu verlangen ist. Die Natur macht keine Sprünge ${ }^{2}$ ).

Wohl begreift Linné diesen Grundsatz besser als LeIBNiz und RAY: nicht daß sich die Pflanzen in eine aufsteigende Reihe zusammenstellen lassen, sondern die verschiedenen Arten sind mit verschiedenen andern durch ihre Eigenschaften wie die Knotenpunkte eines Netzes oder wie die Städte auf einer geographischen Karte verknüpft. "Alle Pflanzen zeigen die Verwandtschaft nach allen Seiten wie ein Territorium auf der geographischen Karte «3).

Nichtsdestoweniger bleibt diese Auffassung empiristisch und verkennt die Tatsache, daß jede Pflanze, jede natürliche Art, Gattung usw. reale Entitäten darstellt.

\footnotetext{
1) Philos. botanica. S. Ioo.

2) Ebenda, S. 27 .

3) Ebenda, S. 27 .
} 


\section{Begriff der Art.}

Die Unterscheidung des Art- vom Gattungsbegriffe scheint Plato in die wissenschaftliche Diskussion eingeführt $\mathrm{zu}$ haben. Aristoteles hat die beiden Begriffe auch auf Tier- und Pflanzengruppen angewendet, ohne jedoch deshalb unter einer Pflanzenart oder Gattung etwas wesentlich anderes $\mathrm{zu}$ verstehen, als wir unter den Arten der Farben, des Mehls, der Lebensführung verstehen. Jede natürliche Gruppe von beliebigen Wesenheiten heißt bei ARISTOTELES Art, und dieselbe Gruppe kann auch Gattung heißen, wenn sie in Gruppen niederer Ordnung zerfällt, die dann der »Gattung « gegenüber »Arten « darstellen.

In der Scholastik leben die Begriffe der Art und der Gattung in demselben Sinne weiter; bereits zu jener von der modernen so weit entfernten Zeit wütete Jahrhunderte hindurch der moderne Streit über das wahre Wesen dieser "Arten « und "Gattungen «. Am Anfange der scholastischen Periode formuliert den strittigen Punkt PORPHYRIUS $(232-30$ I):

Weil diese Worte "genus, species « für den Verstand eine bestimmte Bedeutung haben, so entsteht die Frage, ob das, was in die Definition des Genus eintritt, d. h. ob diese oder jene Gattung jenseits des Verstandes, in der Natur selbst eine von jeder anderen verschiedene Realität, eine wahre Entität darstellt. Ist die Art und die Gattung Realität (sive subsistant) oder nur Konzeption des Verstandes (sive in solis nudis intellectibus consistant)? Und PoRPHyrius fügt hinzu: denn diese Untersuchung ist eine der tiefsten und erfordert eine eingehende Analyse ${ }^{1}$ ).

Dieses Problem ist im dritten Jahrhundert $\mathrm{n}$. Chr. formuliert worden; heute, nach I 6 Jahrhunderten, besitzt es noch ungeschwächte Aktualität. Die Scholastiker traten in drei Lager auseinander: die Realisten erklärten die Arten für durch die Natur gegeben und über der Natur stehend, die Nominalisten degradierten die Arten $\mathrm{zu}$ bloßen Konstruktionen des denkenden Menschen, die Konzeptualisten nahmen eine Mittelstellung zwischen beiden Extremen ein und erklärten die Arten und Gattungen für durch die Natur gegeben, aber nicht für durch dieselbe erschaffen. Alle vorlinnéischen Biologen verstanden unter einer Art (oder einer Gattung) nur einen logischen Begriff, wie sie auch andere Begriffe, die heute konkrete Dinge bezeichnen (z. B. das »Ei «, die »Entwicklung «) nur abstrakt nahmen. Die vorlinnéischen Biologen würden die moderne Frage

1) Hervéau, Hist. de la scolast. I. S. 49. 
nach der Konstanz der Arten gar nicht verstanden haben, erstens weil uns erst (RAY und) LiNNÉ die Arten als Naturdinge kennen gelehrt hat, und zweitens weil man sich noch nicht die Konsequenzen der Tatsache klargemacht hat, daß jeder Organismus nur seinesgleichen zeugt und nur auf diesem Wege entstehen kann. Man war wohl fest davon überzeugt, daß einzelne Pflanzen und Tiere artkonstant sind, d. h. daß sie gewisse allgemeine Ideen ausdrücken; nichtsdestoweniger glaubte man, daß diese Pflanzen und Tiere spontan oder auch durch Umwandlung aus anderen Organismen entstehen können. ALBERT DER GROSSE war fest von der Unveränderlichkeit der organischen Formen überzeugt, doch hielt er sie etwa in demselben Sinne für konstant, wie wir die Kristallformen für gesetzmäßig halten: unter denselben Bedingungen sollen dieselben Formen entstehen - wohl aber auf verschiedenen Wegen. Deshalb unterscheidet ALBERT fünf Arten der Umwandlung einer Pflanze in eine andere ${ }^{\mathbf{1}}$ ).

I) Verwandlung der Samen z. B. des Weizens in Roggen und umgekehrt. Diese Verwandlung soll nach und nach (in 3 Jahren) erfolgen.

2) Aus der Fäulnis einer entsteht eine andere Pflanzenart. So sollen nach dem Fällen eines Eichen- und Buchenwaldes aus den Überresten Espen und Birken aufwachsen.

3) Einmal soll beobachtet worden sein, daß Eichenzweige in die Erde eingepflanzt zu Weinstöcken erwuchsen.

4) Aus dem Holz eines kranken Baumes entsteht sein Parasit.

5) Durch Pfropfen ${ }^{2}$ ).

Diese Metamorphosen geschehen jedoch nur innerhalb der Grenzen der gegebenen organischen Formen, die die ewig unwandelbaren Gesetze der organischen Gestaltung bestimmen. Alle Biologen der Neuzeit bis auf LINNÉ (und viele noch später) haben die von ALBERT erwähnten Umwandlungen für eine natürliche Erscheinung gehalten, obwohl seit dem Siege des Kartesianismus je weiter desto mehr dem Glauben an dieselben der Boden entzogen wurde. REDI erschütterte den Glauben an die spontane Entstehung der Organismen aus toter Erde, VALLISNIERI stellte die Behauptung auf, daß nicht einmal die Parasiten aus dem Körper ihrer Wirte entstehen können. Alle Evolutionisten verbreiteten die Lehre, daß jedes Individuum

1) Meyer, Gesch. d. Bot. IV. S. 63.

2) Noch RAy, der schon die Art zu definieren wußte, glaubte an solche Umwandlungen (Mrall, The early Naturalists. S. I25). 
aus einem Keim, einem Ei sich entwickeln muß, proklamierten den Grundsatz, daß nichts Neues auf der Welt entstehen kann, und gewöhnten die Gemüter an die Überzeugung, daß jedes Individuum und folglich auch jede Gruppe derselben seit der Erschaffung der Welt als solche unwandelbar besteht. So entstand die Lehre von der Konstanz der Arten, die später LINNÉ zur Last gelegt wurde, als eine Überwindung der falschen Umwandlungslehren der älteren Biologen; sie entstand ferner auf dem Boden der mechanistischen Philosophie, als Verneinung der schaffenden Kraft der Natur; klar und konsequent konnte sie erst dann formuliert werden, als LINNÉ die Art (im modernen Sinne) entdeckt hatte.

Indem LINNÉ das Vorhandensein der Arten in der Natur seiner Klassifikation zugrunde gelegt hat, erwuchs ihm die Aufgabe, diese Arten wissenschaftlich $\mathrm{zu}$ charakterisieren. RAY, dessen Fußstapfen LINNḱ gefolgt war, hatte sich bereits bemüht, die Arten der Pflanzen zu definieren. Wie die meisten Naturforscher, griff er nach physiologischen Charakteren und definiert als eine Art die Pflanze, die samenbeständig ist ${ }^{1}$ ). Auch LINNÉ blieb in der Theorie dieser physiologischen Charakteristik treu, praktisch wurde er jedoch durch sein Bemühen, leicht erkennbare Bestimmungsmerkmale für die Arten anzuführen, zur Auffassung der Art als eines Bündels von gewissen $\ddot{u}$ ßerlichkeiten verleitet, einer Auffassung, die vom Darwinismus übernommen wurde und bis auf den Tag herrschend ist.

Während ARISTOTELES, die Scholastiker und CAESALPIN nur Arten und Gattungen (oder noch die "höchsten Gattungen «) unterschieden, hat LiNNÉ auf Grund der Vorarbeiten der Enzyklopädisten noch Ordnungen und Klassen eingeführt. Die Arten und Gattungen sollen natürlich sein; die Ordnungen und Klassen sind zwar auch natürlich begründet; es ist aber nach LiNNÉ schwierig, sie zu erkennen, und so helfen wir uns durch künstlich gewählte Merkmale. Darum sind die Ordnungen und Klassen natürlich und künstlich.

Das Werk der Natur ist immer die Art; das der Kultur öfters die Varietät; das der Natur und Kunst (ars) die Klasse und Ordnung.

In der Auffassung des Begriffes der Art stand LinNé auf dem rationalistischen Standpunkt seiner Zeit. "Wir zählen so viele Arten ", definiert Linné die Spezies, vals verschiedene Formen am Anfange (in principio) ${ }^{2}$ ) geschaffen worden sind. " Dieser Satz ist nur eine

1) Miall, S. 125.

2) In den ersten Ausgaben der Phil. bot. stand sin initios. Auch diese kleine Änderung ist charakteristisch. 
andere Ausdrucksweise für die Behauptung: Der Artbegriff hat ein natürliches Substrat. Auf das Wort geschaffen darf man nicht besonderes Gewicht legen; zwar ist es möglich, den Satz auch nach der Auffassung der Bibel zu verstehen, daß im Anfang von jeder Art nur ein Paar geschaffen worden ist, und daß alle Individuen einer Art von diesem ursprünglichen Paar abstammen, aber diese Auffassung würde das Wesen jenes Satzes nicht treffen. Man beachte nur, daß LinNé die Gattung ähnlich wie die Art definiert:

Wir unterscheiden so viele Gattungen, als ähnlich gebaute Zeugungseinrichtungen von den verschiedenen natürlichen Arten hervorgebracht werden... Jede Gattung ist natürlich, von Anfang an (in principio) als solche geschaffen, und darf daher nicht nach Willkür und nach der Theorie eines jeden leichtfertig gespalten oder mit andern zusammengezogen werden.

Das Wort "geschaffen « hat den Sinn, daß die Regeln, nach denen die Arten einer Gattung gebildet sind, von allem Anfang an vorgeschrieben sind, daß die Gattungsmerkmale natürlich, nicht künstlich, nicht zufällig sind. Und ebendasselbe bedeutet der Satz, daß die Arten von Anfang an geschaffen worden sind; LINNÉ hätte auch behaupten können, daß der Kreis von Anfang an erschaffen sei, d. h. daß das Gesetz, nach dem der Kreis gebildet wird, aus der Natur der Dinge hervorgehe, daß es der Willkür nicht unterliege.

Für diese Auffassung spricht auch die Stelle, welche einige eifrige Darwinisten als auf die Transmutation der Arten bezüglich auffassen wollten, die Stelle nämlich, wo behauptet wird, daß anfangs nur je eine Spezies als Repräsentant einer jeden natürlichen Ordnung erschaffen worden ist, und daß durch Kreuzung dieser Spezies die heutigen Arten entstanden $\operatorname{sind}^{1}$ ).

I) Der Schöpfer hat am Anfange das medullare vegetabilische Wesen (sozusagen das weibliche Wesen der Pflanze) mit den konstitutiven Prinzipien des mannigfachen kortikalen Wesens versehen (d. h. mit Eigenschaften des männlichen Wesens), woraus so viele verschiedene Individuen entstanden sind, als es natürliche Ordnungen gibt.

2) Diese klassischen Pflanzen hat der Allmächtige untereinander gemischt; infolgedessen sind so viele Gattungen innerhalb der Ordnungen entstanden, als aus diesen Pflanzen entstanden sind.

3) Diese generischen Pflanzen hat die Natur gemischt, woraus so viele Spezies einer Gattung entstanden sind, als es deren heute gibt.

4) Diese Spezies hat der $Z$ ufall gemicht, woraus so viele Varietäten hervorgehen, als vorzukommen pflegen.

1) Genera plantarum, 4. Auf. I 764 . 
Der Sinn dieser Auseinandersetzung ist der, daß die Ordnungen und Gattungen metaphysischen Ursprungs sind, etwa wie die Ideen Piatos, die Spezies dagegen natürlichen Ursprungs, etwa in dem Sinne, wie der Salzkristall natürlichen Ursprungs ist (»natürlich « als Gegensatz gegen »zufällig «), während die Varietäten zufällig sind.

In der Einführung des Artbegriffes in die Biologie liegt Linnés unsterbliches Verdienst. Vor LINNé waren die Arten nur praktisch bekannt; erst seit LINNÉ ist die Bedeutung dieses Begriffes theoretisch fixiert. In diesem Sinne hat Linné die Arten in der Natur entdeckt. Mit der Entdeckung der Zellen verhält es sich nicht anders; auch die Zellen hat man vor Schleiden und Schwann gekannt, wie dem Namen so der Tatsache nach; daß sie aber ein Grundelement des organischen Körpers bilden, und nicht Quantitäten, sondern Qualitäten darstellen, haben erst jene Forscher erkannt.

LINNÉ hat die Wahrheit ausgesprochen, daß Arten existieren; als ein Kind seines Zeitalters konnte er sich die Existenz nicht anders als ein seit der Erschaffung der Welt unveränderliches Dasein vorstellen; das I9. Jahrhundert wird zu beweisen suchen, daß sich die Arten allmählich entwickelt haben, und wird wiederum diese These zu der Behauptung erweitern, daß die Arten als reale Wesen überhaupt nicht existieren: der Zukunft bleibt der Weg zur Erkenntnis offen, daß die Arten real und doch in der Zeit entstanden sein können.

\section{Binäre Nomenklatur.}

LINNÉ war viel daran gelegen, die Charakteristiken der einzelnen Arten und Gattungen möglichst kurz und präzis aufzustellen, und er brachte es darin zu großer Virtuosität, mitunter allerdings auf Kosten der Klarheit. Das Streben nach kurzer Ausdrucksweise hat ihn auch dazu geführt, die binäre Nomenklatur in die Biologie einzuführen. Bereits CASP. BAUHIN (I560-I624) hat den Versuch gemacht, ohne sich indes der Tragweite des Gedankens bewußt zu sein, je eine Gattung mit einem einzigen Namen zu versehen, während die Arten dann durch einen oder mehrere Namen charakterisiert wurden. Später sprach dann Rivinus (1652-I725) den Grundsatz aus, daß es am besten wäre, jede Pflanze mit zwei Namen zu bezeichnen, von denen der eine als Spezies-, der andere als Gattungsname in Betracht käme; er selbst hat es aber nicht versucht, diesen Gedanken systematisch durchzuführen. Dies tat crst Linsé: indem er in Gattungen und Arten Einheiten sah, die als solche durch die Natur 
gegeben sind, hat er den sachlichen Grund für die binäre Nomenklatur gefunden. Er hat sich erst versuchsweise zu ihr durcharbeiten müssen: zum erstenmal wendet er sie in der botanischen Schrift "Pan suedicus« (I749) an, durchgängig dann in "Species plantarum « (1753). LinNÉs binäre Nomenklatur hat sich allgemein eingebürgert, und zwar nicht nur die Methode, jeden Organismus mit zwei Namen (einem Gattungs- und einem Artnamen) zu benennen, sondern auch die konkreten von LiNNÉ den Organismen gegebenen Namen selbst. Die Überzeugung, daß es notwendig ist, jedem Organismus einen künstlichen Namen zu geben, der nur als eine Art Marke dient, indem er dem Organismus nur von außen her aufgeklebt wird, hat sich so eingebürgert, daß nur die Allerwenigsten an die Möglichkeit denken, es hafte etwas Gewaltsames, Unnatürliches, Pedantisches, höchstens Provisorisches dieser Klassifikation an. In der neuesten Zeit hat sich die künstliche Namengebung so eingelebt, daß jedermann mit der naivsten Sorglosigkeit jedes Pünktchen am Organismus, jede von dem Forscher auf künstlichem Wege ermittelte Lebensäußerung mit einem barbarischen Namen belegt, der zugestandenermaßen keinen inneren Sinn hat, sondern nur als praktisches, mnemotechnisches Hilfsmittel dienen soll. Ob diese sonderbaren Bezeichnungen praktisch sind, ob es auch ihre ungeheuere Anzahl immer ist, mag dahingestellt bleiben; jedenfalls verwandeln sie die Sprache in eine Art Esperanto, das aber leider nur den Eingeweihten verständlich — sein soll.

Es ist auch eine natürliche Sprache in der Wissenschaft möglich, es gibt auch natürliche Tier- und Pflanzennamen, zu denen sich die künstlichen Namen LiNNés ebenso verhalten, wie sein künstliches Pflanzensystem zu dem natürlichen. Natürliche Namen der wissenschaftlichen Objekte sind diejenigen, die sich aus der Natur der Objektes und aus dem Geiste der Sprache ergeben. In diesem Sinne sind die Volksnamen natürlicher als die wissenschaftlichen Bezeichnungen. Die natürlichsten Namen dagegen sind niemals zu entdecken: wir vermögen uns nur (durch Vertiefung des philosophischen und des biologischen Studiums) denselben je weiter desto mehr zu nähern.

Die Jetztwelt ist für solche Betrachtungen wenig vorbereitet; gewiß wird man aber einmal auch zu dem Versuch schreiten, LinNés Terminologie durch natürliche, philologisch, philosophisch und biologisch begründete Namen zu ersetzen. Indem LiNNḱ für die natürlichen Beziehungen der Tiere und Pflanzen, für ihre natürliche 
Erscheinungsform, für ihre volkstümlichen, sich natürlich ergebenden Namen so wenig Verständnis gezeigt hat, hat er am deutlichsten seine vom grünen Tisch aus entscheidende Gelehrtennatur geoffen$\left.\operatorname{bart}^{1}\right)$.

1) Literatur. LINNÉ, C. von, Systema naturae, sive regna tria naturae systematice proposita per classes, ordines, genera et species. Lugd. Batav. I735. (Diese erste Ausgabe des Werkes ist die kleinste und enthält nur I4 Seiten; jede spätere Auflage wurde vermehrt, so daß die I3. Auflage ro Bände enthält.) - Amoenitates academicae sive dissertationes variae physicae, medicae, botanicae antehac seorsim editae nunc collectae et auctae. 7 Vols. Holmiae, Lipsiae et Lugd. Batav. 749 bis I769. - Philosophia botanica, in qua explicantur fundamenta botanica cum definitionibus partium, exemplis terminorum, observationibus rariorum. Lugd. Batav. I 75 I. (Ich habe die 2. Aufl., Berolini I780, benutzt.) - Über Linné vgl. TH. M. FrIEs, Linne. Stockholm 1903. - C. von Linnés Bedeutung als Naturforscher und Arzt. Schwedische Akad. d. Wiss. Jena 1909. Die übrige Lit. ist in Mitt. Gesch. Mediz. I908, S. 27, und in W. Yunk, C. Linné und die Bibliographie, Berlin I907, angeführt. 


\section{Kapitel.}

\section{Buffon.}

\section{Charakteristik.}

Descartes und Leibniz mit ihren Nachfolgern haben das biologische Denken des I7. und zum großen Teil auch dasjenige des I8. Jahrhunderts beherrscht; ein flacher, poesieloser, dem frischen Leben entrückter Rationalismus und die Betonung der mechanistischen Weltanschauung gingen mit dem Verfall der Biologie (und dem allgemeinen Verfall des geistigen Lebens) Hand in Hand. LEIBNIZ versuchte zwar zum vergessenen Vitalismus zurückzukehren, blieb aber auf halbem Wege stehen; LinNé erneuerte die Herrschaft der aristotelischen Logik über die Biologie, der Inhalt der aristotelischen Lehre blieb ihm jedoch verschlossen; beide, LEIBNIZ wie LINNÉ, sind im Grunde der mechanistisch-rationalistischen Weltanschauung unterworfen geblieben. Mit BUFFon und seiner Epoche sollte ein weiterer Schritt nach dem Biologismus und somit eine neue und einflußreiche Auffassung des Lebens den Schauplatz betreten.

George Louis Leclerc, ComTe de Buffon (I707-i788), zu Montbard in der Nähe von Dijon als Sohn einer reichen Familie geboren, wurde von den Jesuiten erzogen, ist viel gereist und hat auf sich zuerst als Anhänger der englischen Wissenschaft, als Übersetzer des mechanisch-physiologischen Werkes von S. HALES, Vegetable Statics (I735) und der Fluxionen NEwTONs (I740) aufmerksam gemacht. Er wurde als Mechaniker und Mathematiker in die Akademie gewählt, und 7339 wurde er zum Intendanten des königlichen Gartens ernannt. Als solcher hat er sich entschlossen, eine große Enzyklopädie der beschreibenden Naturwissenschaften herauszugeben, obwohl er eigentlich kein Biologe war und für keinen solchen gehalten wurde ${ }^{1}$ ). Niemals hat er sich die wissenschaftlichen Me-

1) Vgl. Malesherbes' interessante Bemerkungen über Buffon, die Lotsy (Vorlesungen üb. Deszendenztheorien. I. S. 284) anführt. 
thoden im fachmännischen Sinne des Wortes angeeignet; andere haben die Beobachtungen und Versuche, wo solche nötig waren, für ihn gemacht: seine geologischen Kenntnisse schöpfte er aus STENo, WOODWARD und WHISTON; in der Anatomie hat DAUBENTON für ihn gearbeitet, T. NEEDHAM hat BuFFON der mikroskopischen Untersuchungen wegen $\mathrm{zu}$ sich eingeladen. BuFfons eigene Versuche (über das Wachstum der Wälder) und seine geologischen Beobachtungen haben nur den Wert einer allgemeinen Orientierung über das zu behandelnde Problem. Fachmann zu sein, war niemals Buffons Ideal; das Fachmännertum hat er gehaßt; durch sein außergewöhnliches Lob des Plinius' ${ }^{1}$ ) zeigt er, wohin seine Wissenschaft gezielt hat: er wollte als Weltmann, als Dilettant der Natur frei gegenüberstehen. Höher als Plinius schätzt Buffon nur ARIstoteles ein, und er zeigt für dessen Naturphilosophie ein angemesseneres Verständnis als seine Zeitgenossen; obwohl BUFFon selbst kein ausgesprochener Vitalist war, suchte er doch mit viel größerem Glück die biologische (innerhalb der Entwicklungstheorien die epigenetische) Auffassung der Phänomene mit dem Mechanismus zu verknüpfen als sein Vorläufer LEIBNiZ. Die ersten Bände der schön ausgestatteten Naturgeschichte erschienen I749, und bereits im nachfolgenden Jahr mußte eine zweite Auflage veranstaltet werden; I788, im Todesjahre Buffons, war das 3obändige Werk abgeschlossen. Geologie, Naturgeschichte der Säugetiere und der Vögel, sowie die Beschreibung der Mineralien werden darin behandelt; die Pflanzen und die niederen Tiere hat BUfFON nicht beachtet. Auch sonst ist BufFons Werk nichts weniger als homogen. Über die Pflanzenwelt schweigt es, bringt aber lange Ausführungen über das Wachstum der Bäume (T. IX); es enthält Buffons berühmte Rede über den Stil (T. X.), worauf statistische Tabellen den Menschen betreffend folgen; es enthält auch physikalische Untersuchungen über das Feuer (T. VIII.), ja. sogar über die Verbesserung der Kanone auf den Kriegsschiffen

1) .... in jeder Hinsicht ist Plinius groß; der Flug seiner Ideen, die Eleganz des Stils erheben noch seine tiefe Gelehrsamkeit; er wußte nicht nur alles, was man zu seiner Zeit wissen konnte, sondern er besaß im großen jene Beweglichkeit der Gedanken, die die Wissenschaft vermehrt; er besaß jene Feinheit der Reflexion, von der die Eleganz und der gute Geschmack abhängen, und er überträgt auf den Leser eine gewisse geistige Freiheit, eine Kühnheit im Denken, die wahren Keime der Philosophie.... Man beachte, was da eigentlich Buffon an Plinius lobt. Kein Fachmann würde die von Buffon hervorgehobenen Eigenschaften für besonders lobenswert erklären. 
(T. VIII.) u. ä. a. Überhaupt ist an dem Werk zu sehen, daß BUFFon sein Grundsatz, strenge Systeme zu verachten, von Herzen ging.

Buffons Werk bedeutet einen Todesstoß für den biologischen Kartesianismus und den Anfang einer neuen Epoche für die Lehre vom Leben; war es auch nicht BUFFoN allein, der diesen Umschwung verursacht hat (viel haben auch die Enzyklopädisten und die Führer der Aufklärung im allgemeinen beigetragen), jedenfalls steht er an der Spitze der Neuerer; an seine Schriften haben die Begründer der Wissenschaft des I9. Jahrhunderts angeknüpft. Wir wollen während der Darstellung der Theorien Buffons Gelegenheit suchen, auf die intellektuellen Bestrebungen seiner Zeitgenossen hinzuweisen.

\section{Locke und Condillac.}

Während auf dem Kontinente Descartes und LeIbniz um die Alleinherrschaft über die Biologie stritten, faßte in England die Philosophie John Lockes (I632-I704), des Zeitgenossen Leibnizens, festen Fuß. Auf die späteren biologischen Diskussionen hat LockEs Versuch, die Entstehung der Vorstellungen zu erklären, nachhaltig gewirkt. Locke bestreitet die Annahme Descartes', daß wir angeborene Grundprinzipien der Vernunft haben; dieselben sollen vielmehr durch Empfindungen in den Verstand gelangen. Der Verstand ist wie ein Stück reines Papier, das durch die Erfahrung, d. h. durch äußere (sensation) oder innere (reflexion) Empfindungen, von denen sich die ersteren auf äußere, die letzteren auf innere Vorgänge beziehen, beschrieben wird. Der Verstand nimmt die Eindrücke der Umgebung passiv auf (so kommen einfache Vorstellungen zustande) und kombiniert dieselben zu zusammengesetzten Vorstellungen. LOCKE klassifiziert die zusammengesetzten Vorstellungen, indem er sie in rationalistischer Art in Modi, Substanzen und Relationen scheidet. Empiristisch dagegen ist seine Annahme, daß der Verstand ursprünglich leer ist und sich erst durch die Einwirkung der Umgebung allmählich zu dem entwickelt, was er bei einem verständigen Menschen ist.

Die englische Wissenschaft stand $z u$ jener Zeit in Frankreich in hoher Ehre, und Locke hat auf die Franzosen einen mächtigen Einfluß ausgeübt, teils direkt - durch seine bald ins Französische übersetzten Schriften -, teils indirekt durch seinen Anhänger ABBÉ DE CONDILlaC (I7I5-I780), der unter anderem RoussEaUs genetische Methode beeinflußte. CONDILLAC hat DESCARTES' eingeborene 
Ideen eifrig bekämpft und Lockes Theorie, die von der Erfahrung unbefleckte Seele gleiche einer Tabula rasa, verteidigt. Es ist beachtenswert, wie er die Erfahrung "phylogenetisch «zu erklären versucht: er vergleicht die Seele mit einer lebendigen Statue, die zuerst ohne jede Erfahrung dasteht, die aber allmählich durch ein Sinnesorgan nach dem andern Erfahrungen über die Außenwelt sammelt; so wird die Tabula rasa allmählich beschrieben. In ähnlicher Weise stellt er in seiner Untersuchung über den Ursprung der menschlichen Kenntnisse (I777) die Theorie auf, daß die Sprache des Menschen sich allmählich entwickelt habe: wohl gibt er vorsichtig zu, daß Adam und Eva die Sprache von Gott gelernt haben, doch nimmt er weiter an, daß sich nach der Sintflut ein Kinderpaar verirrt haben mochte, das dann von selbst sprechen gelernt habe, indem es sich allmählich gewöhnte, mit gewissen Lauten einen bestimmten Sinn zu verbinden, - auf diesem Wege sei die Sprache entstanden.

Condillacs Methode, die Entstehung einer Tatsache dadurch zu erklären, daß man sie in (willkürliche) Elemente zerlegt, die dann wieder »allmählich « zusammengesetzt werden, mag noch so irrig sein, historisch bedeutete sie einen Widerspruch gegen den Evolutionismus der früheren Zeiten und ein schüchternes Zugeständnis, daß Neues in der Welt entstehen kann. CondILlaC hat zwar übersehen, daß die Entstehung (die Geschichte) der Erfahrung jedes einzelnen Menschen nur durch Beobachtung ermittelt werden könnte; indem er dieselbe erraten wollte, stand er noch im Banne des Rationalismus; seine Lehre dagegen, daß die Erfahrung allmählich entstehe und sich kristallisiere, war bereits dem Evolutionismus fremd. Seine Methode hat unter den Biologen bald Schule gemacht: Bonnet mußte sich gegen die Beschuldigung wehren, seine psychologischen Erörterungen seien Paraphrasen der Grundsätze Condillacs; RousSEAU bekennt in der Einleitung zu seiner epochalen, preisgekrönten Schrift über den Einfluß der Wissenschaften auf den Fortschritt der Zivilisation, daß ihm CoNDILLAC seine Ideen eingeflößt hat, und Buffon folgt derselben Methode wie Condillac in der Einleitung zu seiner Naturgeschichte.

CoNDILLAC hat auch eine Schrift biologischen Diskussionen gewidmet ${ }^{1}$ ), in der er DESCARTES' Behauptung zurückweist, die Tiere seien bloße Maschinen, und sich in einer bezeichnenden Weise gegen

1) Traité des animaux. Amsterdam $I 755$.

Rádl, Geschichte der biol. Theorien. I. 2. Aufl. 
die vor hundert Jahren durch Swammerdam in die Wissenschaft eingeführte und derselben verhängnisvolle Entomologie wendet 1 ):

$\mathrm{Zu}$ bemitleiden sind diejenigen, die nichts anderes tun als die In sekten beobachten: denn eine Fliege soll nicht im Kopfe des Naturforschers mehr Platz einnehmen als sie in der Natur einnimmt... So werdet ihr Gott als ganz den großen Dingen gewidmet sehen, das Weltall schaffend, .... unveränderlich und ewige Gesetze begründend; und ihr werdet euch in acht nehmen, sich ihn so vorzustellen, als ob er sich um die Republik der Fliegen sehr kümmern sollte oder aIs ob er mit der FaItung des FIügels eines Käfers beschäftigt wäre. Macht ihn euerem Bilde ähnlich und betrachtet ihn als einen großen Naturkundigen, der die Einzelheiten verachtet aus Furcht, daß ein Insekt $z u$ viel Platz in seinem Kopfe einnehmen könnte...

Durch diese vernüntige Kritik konnten sich alle Entomologen seit REDI, sowie die Pflanzensammler im Stile LinNés und überhaupt alle Gelehrten, deren Forschung die Fühlung mit praktischem Leben verloren hat, betroffen fühlen. Dieselbe beweist, daß eine neue, vom Staube der Gelehrsamkeit unabhängige Gedankenrichtung sich der Öffentlichkeit bemächtigt hat. VOLTAIRE und die Enzyklopädisten ${ }^{2}$ ) haben diese antiwissenschaftliche Gemütsstimmung, jeder in seiner Art, unterstützt, Rousseau hat sie auf die Spitze getrieben.

Condillacs Schrift über die Tiere ist der Polemik gegen Buffons Auffassung der Tierseele, die mit derjenigen des DESCARTES fast identisch war, gewidmet. Nach Condillac sind die Tiere psychisch dem Menschen ähnlich; sie fühlen, denken, schließen und sammeln Erfahrungen wie der $\mathrm{Mensch}^{3}$ ); die Stillung ihrer Bedürfnisse bedingt ihre Reaktionen.

Die Bedürfnisse wiederholen sich, und die Tätigkeit der Tiere erneuert sich so oft, da $B$ die Versuchsbewegungen am Körper und die Ungewißheit in der Seele aufhören: die Gewohnheiten sich zu bewegen und zu urteilen haben sich entwickelt. So rufen die Bedürfnisse einerseits eine Folge von Ideen, anderseits eine Folge von entsprechenden Bewegungen hervor ${ }^{4}$ )... Würden die Menschen gesondert von einander leben, würden sie wegen der Verschiedenheit des Ortes und des Klimas unter ungleichen Bedingungen

1) Traite des animaux. Amsterdam 1755. S. 64,65 .

2) Buffon stand abseits von den Enzyklopädisten.

3) Es sei nebenbei bemerkt, daß auch HuME, der berühmte Skeptiker, in analoger Weise wie Condillac über die Tiere geschrieben hat: sIch kenne keine sicherere Tatsache als es diejenige ist, daß die Tiere Gedanken und Vernunft haben wie die Menschen. Der Beweis dessen ist so evident, daß nicht einmal der dümmste und unwissendste Mensch sich darüber täuscht. " Huxley, Hume. Paris 1880. S. I42.

4) S. 79 . 
leben: daraus würde eine Verschiedenheit in ihren Bedürfnissen und folglich auch in ihrem Benehmen entstehen ${ }^{1}$ ).

Auf diese Weise hat Condillac Grundsätze formuliert, deren sich später LAMARCK, BuffoNs Schüler, für die Erklärung der Transformationen der Tiere bedienen sollte. LAMARCK konnte übrigens analoge Ideen auch bei BufFon selbst finden. In demjenigen Teile der Naturgeschichte Buffons, gegen den eben Condillacs Polemik gerichtet ist, stehen lange Ausführungen darüber, daß die Körper struktur keineswegs die Leistungen der Tiere beding ${ }^{2}$ ), denn wird das Tier von einem Objekt angezogen, so läuft es zu demselben, wenn es Füße hat; es würde aber nach demselben streben, sagt Buffon, auch wenn es keiner Lokomotion fähig wäre.

Es ist also die Einwirkung der Gegenstände auf die Sinne, die das Streben (le désir) erwecken, und dieses verursacht die Lokomotion ... Die natürlichen Bedürfnisse (les besoins naturels), z. B. das der Nahrungsaufnahme, stellen innere Bewegungen dar, deren Eindruck das Streben und die Begierde, ja die Nötigung hervorrufen; diese inneren Bewegungen werden also die äußeren Bewegungen der Tiere verursachen können ... ${ }^{3}$ )

Klingen diese Sätze nicht als der erste Anlauf zu der Theorie LAMARCKs, der ein ergebener Anhänger Buffons (und der Erzieher seines Sohnes) war?

\section{Natürliche Methode.}

Buffons Einleitung zu seiner Naturgeschichte ist von demselben Geiste getragen wie Condillacs Philosophie. Der Bekämpfung der Ausartungen des Gelehrtenwesens, als deren Typus Buffon Linnés Methode betrachtet, widmet er viele Seiten $\left.{ }^{4}\right)$. Die Gelehrten übertreiben, sagt er, die Methode, die nur ein Mittel zur Abkürzung der Arbeit und zum Behelf des Gedächtnisses ist; anstatt sich der proteusartigen Natur anzupassen, behandeln sie dieselbe nach künstlichen Regeln, wenden auf alle möglichen und unmöglichen Fälle dieselbe Methode an, sie zerstückeln die in sich einheitliche Natur,

1) Huxley, Hume. Paris I880. S. 9I.

2) T. V. S. $200 \mathrm{sq}$. Ich zitiere nach der Ausgabe in 160 (Aux deux Ponts); wo nur die Nummer des Bandes angeführt ist, bezieht sich das Zitat auf Hist. nat. générale.

3) Ebenda, S. 203 .

4) Buffon führt Linné ausdrücklich an und polemisiert gegen denselben heftig aber sachlich; Linné tat in seinen Schriften, als ob es keinen Buffon auf der Welt gäbe. Buffon polemisierte auch gegen Réaumur; dieser hat sich dadurch zu rächen gewußt, daß er einen Autor veranlaßt hat, eine anonyme Schmähschrift gegen Buffon (Lettres à un Americain) zu schreiben. (MIALL, The early Naturalists. S. 387 .) 
und indem sie die wissenschaftlichen Namen und Begriffe ins Unendliche vermehren, machen sie die wissenschaftliche Sprache schwieriger als die Wissenschaft selbst $^{\mathbf{1}}$ ).

Wäre es nicht einfacher, natürlicher, wahrhaftiger, den Esel Esel, die Katze Katze zu nennen, anstatt zu wollen, ohne zu wissen warum, daß der Esel ein Pferd, die Katze ein Luchs sei $\left.^{2}\right)$ ?

Eine allgemeine Methode der Wissenschaft ist nur eine neue Art vom Stein der $W_{\text {eisen }}^{3}$ ). Die Botaniker wählen willkürlich einen Bestandteil der Pflanze und erheben ihn zum spezifischen Merkmal derselben und verfallen so in die Pedanterie, über ein Ganzes aus einem Teil zu schließen. Dann gelangt man dahin, daß, um Bäume zu erkennen, man ein Mikroskop mit sich herumtragen müsse: die Größe des Baumes, seine äußere Form, sein Habitus, seine Blätter bedeuten für einen solchen Mann nichts; hat er die Staubfäden nicht gesehen, so hat er nichts gesehen $\left.{ }^{4}\right)$. Die Definitionen, seien sie noch so exakt, reichen niemals aus: ohne eine plastische Beschreibung ist keine wahre Wissenschaft möglich. BuFfoN drückt diesen Gedanken durch einen für seine Methode und für die Methode aller Realisten seit PLATO charakteristischen Grundsatz aus:

Nichts ist gut definiert, was nicht gut beschrieben ist: nun, um exakt beschreiben $z u$ können, muß man das zu beschreibende Objekt gesehen, wieder gesehen, geprüft haben, und alles dies ohne Voreingenommenheit, ohne jede Idee eines Systems ${ }^{5}$ ); ohne diese Bedingung fehlt der Beschreibung das Gepräge der Wahrheit...

In diesem Satz und in den Worten "voir presque sans dessein " (sich dem Eindruck völlig ergeben) liegt das Grundprinzip der Anschauungsweise Buffons und der Grund seiner Abneigung gegen den analytischen LINNḱ, der wiederum die These verteidigt hat:

Die Methode (= Klassifikation), die die Seele der Wissenschaft bildet, gibt auf den ersten BIick die unterscheidenden Merkmale jedes Geschöpfs; diese Merkmale verlangen einen Namen, mit Hilfe dessen alles rasch im Gedächtnis aufbewahrt wird, was man von dem zu bestimmenden

1) T. I. S. I3.

2) Ebenda, S. I7. Buffon spielt da auf Linnés lateinische binäre Nomenklatur an (Equus asinus, Felis catus).

3) S. I8.

4) S. 24 .

5) Man muß das Objekt naiv betrachten, sagt Buffon an einer anderen Stelle (représenter naïvement et nettement les choses), d. h., so wie es ein schlichter Mann und nicht so wie es ein Gelehrter betrachtet (S. 30). "Hinstarren auf die Nature hat Goethe diesen Gemütszustand, der auch der seinige war, genannt. 
Objekte weiß. Durch die Methode entsteht Ordnung im Plan der Natur; oline dieselbe erscheint alles konfus, da der menschliche Geist schwach ist.

Anstatt Merkmale aufzusuchen, Namen zu geben, künstliche Ordnung in die Natur einzuführen, suchte BufFon dem Leser plastische Bilder derselben vorzuführen und die Ordnung in der Natur zu erkennen. Deshalb hat er den Stil betont: le style c'est l'hommenicht nur Mensch im allgemeinen, sondern auch Naturforscher; "der Stil ist die Ordnung und Bewegung, die man seinen Gedanken verleiht «sagt Buffon Linné gegenüber ${ }^{1}$ ). Die Natur strebt nach geschlossenen Einheiten, geht überall planmäßig vor: durch den Stil muß man ihre Gesetzmäßigkeit nachzuahmen suchen ${ }^{2}$ ); man könnte Buffons Gedanken die extreme Fassung geben, daß der Stil die Natur selbst ist. LINNÉ suchte nach kürzesten Ausdrücken für seine Charakteristiken, BUFFoN nach den anschaulichsten, die das Wesen der Sache erschöpfen. Buffon bemühte sich, Tiere mit Worten zu malen - und deshalb hat sich aus seiner Naturgeschichte die Morphologie, die Lehre von der Form der Organismen entwickelt ${ }^{3}$ ). Als anschaulicher Denker hat BUfFon keine dogmatischen Wahrheiten gekannt, sondern, wie ihm alle Kritiker vorwerfen, hat er sich über dasselbe Thema auf verschiedenen Seiten seines Werkes verschieden ausgesprochen - aus demselben Grunde wie Plato, wie Paracelsus, wie Schopenhauer; die Worte dienten ihm nur als Mittel, die Natur zu malen, die, von verschiedenen Gesichtspunkten betrachtet, verschiedene Gestalten annimmt.

Bei den Gelehrten, namentlich bei den Deutschen, findet sich nach BufFoN zuviel überflüssige Gelehrsamkeit4); solche Schriftsteller scheinen vergessen zu haben, was sie eigentlich sagen wollen,

1) Discours sur le style. Hist. nat. X. S. 7 .

2) S. ro. Damit hängt Buffons Maxime zusammen: Das Ziel der Philosophie liegt nicht in der Erkenntnis des $\gg$ Warum , sondern in derjenigen des $\gg$ Wie

3) Folgende Worte Goethes seien als Beleg angeführt: "Buffon nimmt die äußere Welt, wie sie ist, wie ein unendlich mannigfaltiges Ganzes, dessen verschiedene Teile aneinander angepaßt sind und sich gegenseitig beeinflussen ... Geoffroy erinnert an Buffon in mehrerer Hinsicht. Dieser erkennt die große Synthese der empirischen Welt an, doch nutzt er alle Verschiedenheiten unter den Geschöpfen aus und hebt sie hervor. Jener nähert sich an die große Einheit, an die Abstraktion, die Buffon nur vermuten ließ...

4) In die erste Auflage seiner Naturgeschichte nahm Buffon die von seinem Mitarbeiter DAUBENTON verfaßte anatomische Analyse des Säugetierkörpers auf. Im richtigen Gefühl, daß diese zu abstrakte Abhandlung in sein Werk wenig passe, hat sie Buffon aus den späteren Auflagen fortgelassen. 
und »erzählen nur, was von anderen gesagt worden ist ${ }^{1}$ ); GOETHE, dessen Stellung zur Naturwissenschaft lebhaft an diejenige Buffons erinnert, hat sich zur Charakteristik der Schulweisheit fast derselben Worte bedient: »Es ist ihnen [den Gelehrten von Profession] selten um den lebendigen Begriff der Sache zu tun, sondern um das, was man davon gesagt hat. " Sollte diese Übereinstimmung beider Naturforscher nur durch analoge Gemütsverfassung derselben zu erklären sein? Sehr charakteristisch für den schulfeindlichen BUFFoN ist auch seine Warnung, daß man sich ja nicht in zu geringfügige Einzelheiten einlassen, oder daß man nicht auf die Beschreibung von Unwesentlichem Gewicht legen solle. Um Naturforscher zu sein, darf man Philosophie nicht vernachlässigen: nicht Formeln, nicht Wörterbücher, nicht symbolische Wörter und gelehrte Phrasen, sondern lebendige Wahrheit 2 )!

Nicht alle konkreten Belege, die Buffon für seinen Standpunkt ins Feld zieht, sind richtig; sein Standpunkt selbst jedoch ist in der Natur des Menschen tief begründet; die Tatsache, daß er mit einer solcherart freien Lehre auftreten konnte, veranschaulicht die bedeutende Höhe, die die Wissenschaft zu seiner Zeit erreicht hatte. Buffors Rede ist die Rede der Renaissancephilosophen, als diese die Scholastik bekämpft haben; Platos Polemik gegen die Sophisten, PARACELsus' Schmähungen der Doktoren, Pascals Angriffe gegen die Jesuiten, Schopenhauers Diatribe gegen die Philosophieprofessoren sind aus derselben herauszuhören.

Als ein Feind des Fachgelehrtentums hat BuFfoN ein System aufzustellen versucht, das dem Standpunkte eines schlichten, natürlichen Mannes am nächsten liegt. Lockes Methode kommt ihm dabei in den Sinn. Es sei vor allem nötig, führt er aus ${ }^{3}$ ), sich jeder vorgefaßten Meinung, jeder allgemeinen Idee $\mathrm{zu}$ entblößen, es sei nötig, alles zu vergessen. Ein Mann, der alle Erfahrungen von sich abschütteln könnte, würde, in ein von mannigfachen Tieren bewohntes Land ausgesetzt, anfangs alles nur wie in allgemeinen Umrissen sehen; später würde er zuerst lebende Materie von der leblosen zu unterscheiden lernen, dann die beseelte von der vegetativen; daraufhin würde er Landtiere von den Wasser- und den Lufttieren

1) S. 32. Die Gelehrten verhielten sich gegen Buffons Werk ablehnend; sein Kampf gegen das System erschien ihnen dilettantisch; sie wiesen auch auf zahlreiche Schnitzer, die sich Buffon unterlaufen ließ.

2) S. $5^{8}$.

3) I. S. 36 sq. 
scheiden; von den ersteren würde er die nützlichen eher als die übrigen erkennen und von diesen die Haustiere früher als die wilden. Auf diese Art wird er ein System aufstellen, in dem folgende Kategorien vorkommen: Mineralien, Pflanzen, Tiere; Land-, Luft-, Wassertiere (Säuger, Vögel, Fische); Haustiere, wilde Tiere usw. „Dieses System, das natürlichste von allen, ist dasjenige, das wir zu befolgen uns entschlossen haben ${ }^{\mathbf{1}}$ ). «

Über die Unmöglichkeit eines solchen Systems ist kein Wort zu verlieren ${ }^{2}$ ); jedenfalls ist aber Buffons Auffassung der Natürlichkeit auch eine mögliche Auffassung dieses Begriffes und eine historisch sehr bedeutsame: seit Plinius haben hunderte von Schriftstellern den Begriff des "Natürlichen « im Sinne des Angemessenen, Vereinbarten, Praktischen, Volkstümlichen verstanden. Buffons Negation des künstlichen Systems entspringt nebstdem der Abneigung des anschaulichen, künstlerisch veranlagten Denkers gegen die Vergewaltigung der unendlich plastischen Natur durch die scharfen Linien der Logik. Sein "System « hat sich nicht erhalten; daß aber die demselben zu Grunde liegende Idee einen Keim der Wahrheit enthielt, hat die Geschichte nachgewiesen: im Anschlusse an BuFfoN hat Cuvier (seit Aristoteles das erste Mal wieder) sein "natürliches «System der Tiere aufgestellt. Daß BufFon dem natürlichen, auf vergleichendes Studium der Organismen gegründeten System nicht abhold war, zeigt sein Lob des Pflanzensystems TourneforTs, des Vorläufers von LinNé.

Es wird erzählt von Rousseau, daß er, in Paris angelangt, die Wohnung Buffons aufgesucht und die Schwelle derselben ehrfurchtsvoll geküßt hat. An dieser sonderbaren Ehrbezeugung sind zum großen Teil die unnatürlichen, überspannten Manieren des I8. Jahrhunderts schuld; immerhin hatte Rousseau innere Gründe BuffoN hochzuschätzen. Die Betonung des Natürlichen (im Gegensatze zum Gesuchten und Künstlichen), die BuFFoN als der erste gepredigt hat, hat in Rousseau ihren Philosophen gefunden. Rousseaus Negation der Kultur, der Zivilisation, des Äußerlichen, des trockenen Rationalismus ist in ihren Keimen in Buffons Schriften enthalten; Buffons Gegensatz gegen Linné entspringt aus ähnlichen Beweg-

1) S. 38 .

2) Buffons Zeitgenosse Malesherbes hat schon Einwände erhoben; er hat richtig darauf hingewiesen, daß es nebst dem von Buffon bekämpften künstlichen auch ein natürliches System gibt, daß z. B. die Vögel, die Säuger, die Schmetterlinge natürliche Gruppen bilden (Lotsy, Vorles. üb. Deszendenz-Theor. r9og. S. 284). 
gründen wie RousSEAUs wohl tiefer und allgemeiner erfaßter Kampf gegen die Kultur seiner Zeit. Gewiß war Buffon selbst der überspannten Kultur übervoll; gewiß war seine öffentliche Stellung und seine Lebensführung, sein lächerlicher Größenwahn, sein unaufrichtiges Verhältnis zur Kirche der schlichten, durch die Kultur noch nicht verdorbenen Natur wenig angepaßt; nichtsdestoweniger war es BufFon, der die Losung nach der Rückkehr zur Natur als der erste gefördert hat. Rousseau hat selbst bis an den Hals in den durch die Kulturzustände jener Epoche bedingten Lastern gesteckt, und doch ist er der allseitig anerkannte Prophet des neuen, schlichten Lebens, des Naturlebens.

Der Ruf nach der Rückkehr zur Natur wandte sich nicht nur gegen die Sittenlosigkeit und gegen die politischen Mißstände des I7. und I8. Jahrhunderts; er bedeutete auch einen Protest gegen die überspannten Prärogativen des Verstandes (der analytischen Wissenschaft) dem praktischen Leben gegenüber, einen Protest gegen den Rationalismus der Intuition gegenüber, bedeutete den Kampf gegen die auf Tradition erbaute Wissenschaft und den Lobgesang der unabhängigen, von den starren Regeln der wissenschaftlichen Terminologie und der logischen Formeln befreiten Wissenschaft; als RousseaU die Wissenschaften mit Bann belegt hat, tat er dasselbe wie Plato in seiner Polemik gegen die Sophisten ${ }^{1}$ ): nicht jede Wissenschaft, sondern die verknöcherte, nur ein Scheinleben führende Wissenschaft wurde durch seine Kritik getroffen.

\section{Der Bruch mit der Religion.}

Seit dem Verfall der Renaissance war die Bedeutung der Religion in den Augen der Naturforscher, namentlich in katholischen Ländern, in stetigem Sinken begriffen. Man suchte wohl den Schein der Religiosität zu wahren, man schrieb auch viel über Gottes Allmacht und Weisheit, die sich in der Natur, im Bau und in den Leistungen der Tiere offenbart, im Herzen fühlte man jedoch kein religiöses Bedürfnis mehr. Bereits zu den Zeiten vaN HELMONTs nehmen sich seine innig gefühlten Gebete, mit denen er seine wissenschaftlichen Erörterungen durchflicht, als unzeitgemäß aus.

In der ersten Hälfte des I8. Jahrhunderts trat der religiöse Indifferentismus bei den Naturforschern deutlicher zutage. RÉAUMUR, LINNE, BONNET und teilweise auch HALLER sprechen zwar noch von

1) Rousseau soll Plato sehr geliebt haben. 
Gott, sie glauben gewiß an ihn und bewundern die Natur als sein Werk, doch der Glaube an ihn ist ihnen nicht mehr eine Sache des Herzens, sondern des Verstandes; sie operieren mit ihm wie mit einer wichtigen, ja sogar der wichtigsten Naturmacht, aber sie lieben ihn nicht, wenn man sich so ausdrücken darf.

Der dem Aufkommen ungesuchter Gefühle feindliche Rationalismus und die jesuitische Erziehung, die mehr auf äußeren Schein als auf innere Wahrhaftigkeit zielte, haben diese Abwendung von Gott unterstützt; die englische Philosophie hat derselben eine wissenschaftliche Begründung verliehen. Der Jesuitengeist spricht zu uns aus den bissigen, nur auf den Verstand berechneten Witzen VoLTAIREs; jesuitisch war auch BUFFONs unaufrichtiges wissenschaftliches Verhältnis zur Religion; die englische Philosophie, LOcKE, Hume und der englische Deismus bildeten die Grundlage, auf der Condillac, Buffon, Voltaire, MontesQuieu ihre Systeme errichtet haben.

BufFons Kollision mit den Theologen zeugt von dem Niedergang ihrer Macht und von der jesuitischen Art, wie man sich über solche Fälle hinwegzuhelfen wußte. BuFfoN hatte erfahren, daß seine Theorie der Erde, in der er seine geologischen Ansichten über den Ursprung der Kontinente durch allmähliche Senkung der Meeresoberfläche erklärt, auf Veranlassung der theologischen Fakultät der Zensur verfallen solle, als »Prinzipien und Maximen. enthaltend, welche nicht konform sind mit denen der Religion «(I75I). Auf diese Nachricht hin erklärte er sich sofort zu einer Satisfaktion bereit. Nachdem ihm von der theologischen Fakultät die Anstoß erregenden Stellen seiner Schrift bekannt gemacht waren, hat er es mit seinem wissenschaftlichen Gewissen als verträglich gefunden, folgende Erklärung abzugeben ${ }^{1}$ ):

Ich erkläre, daß ich nicht die Absicht gehabt habe, dem Text der Heiligen Schrift $\mathrm{zu}$ widersprechen, daß ich sehr fest an alles das glaube, was dort über die Schöpfung erzählt wird, wie in betreff der Zeiten, so bezüglich der Umstände des Geschehenen; und daß ich das, was in meinem Buche die Bildung der Erde betrifft, zurücknehme, und überhaupt alles das im allgemeinen, was der mosaischen Erzählung widersprechen könnte, indem ich meine Hypothese über die Bildung der Planeten nur als eine philosophische Supposition angeführt habe...

Die Fakultät begnügte sich mit dieser formalen Erklärung, und BuFFON konnte seine Theorien weiter predigen.

1) Hist nat. génér. I. p. 301 . 
Die Rationalisten haben eine scharfe Grenze zwischen Gott und der Natur gezogen. Gott hat nach ihnen die Natur erschaffen, in ihm liegt die bewegende Kraft, in ihm der Ursprung aller Veränderungen: die Natur an sich ist tot und unbeweglich. Zur Zeit der Aufklärung suchte man nun je weiter desto energischer Gott durch die »Natur « zu ersetzen.

Denis Diderot (I7I3-I784) hat zuerst (I746) die Organismen ${ }^{1}$ ) für Geschöpfe Gottes erklärt, welche durch ihr Dasein und ihre Zweckmäßigkeit Zeugnis geben von der Existenz des Schöpfers. Die erhabenen, gedankenreichen Auseinandersetzungen MALEBRANCHEs und DesCARTES' seien nicht so geeignet, den Materialismus zu erschüttern, als eine einzige Beobachtung MALPIGHIs, des großen Mikroskopikers. Bald nachher drückt sich DIDEROT jedoch viel skeptischer aus ${ }^{2}$ ). Das Eingreifen Gottes in den Gang der Natur anzunehmen, hieße den Knoten durch die Hand eines Wesens zerhauen lassen, nur um dadurch einen noch schwerer lösbaren Knoten zu erhalten. Dem Einwurf, daß die Vollkommenheit der heutigen Organismen einen intelligenten Schöpfer voraussetze, begegnet er mit der Frage, wer uns denn nachgewiesen habe, daß nicht einige der zuerst gebildeten Tiere ohne Kopf, andere ohne Beine, diese ohne Magen, jene ohne Herz gewesen seien. Man könne annehmen, daß diese Mißgeburten und fehlerhaften Verbindungen der Materie nach und nach verschwunden seien, und daß nur diejenigen sich behauptet hätten, die in Bau und Mechanismus keinen wesentlichen Widerspruch in sich trugen und fähig waren, durch sich selbst zu bestehen und sich fortzupflanzen. ,Von den Tieren könne man sich ins Weltall erheben und dort ebenso eine Unzahl verfehlter Gestirne annehmen. In seinen "Pensées sur l'interprétation de la nature « (I754) geht DI. DEROT kritisch und erweiternd auf die von MAUPERTUIS und BUFFON vertretene Hypothese ein, daß Pflanzen und Tiere aus belebter. kleinsten Teilchen zusammengesetzt seien. Die Natur scheine sich darin zu gefallen, so wiederholt er die herrschende Anschauung, den. selben Mechanismus in unendlich verschiedener Weise zu variierer und die Gattungen der Wesen nicht eher aufzugeben, als bis sie in der Individuen alle Möglichkeiten der Erscheinung erschöpft habe. Danı spinnt er den bereits von. MAUPERTUIS ausgesprochenen Gedanker über die Entwicklung der Arten weiter: Wie im Pflanzen- und Tier reich ein Wesen sozusagen anfängt, wächst, besteht, in Verfall gerä

1) Pensées philosophiques. Paris 1746.

2) Lettres sur les aveugles. I749. 
und vergeht, könnte es sich nicht etwa ebenso mit den Arten überhaupt verhalten? Wenn der religiöse Glaube uns nicht lehrte, daß die Tiere, so wie wir sie sehen, aus der Hand des Schöpfers hervorgegangen sind, und wenn der geringste Zweifel über ihren Anfang und ihr Ende erlaubt wäre, könnte nicht der seinen Vermutungen nachhängende Denker auf den Verdacht kommen, daß die Tierheit seit aller Ewigkeit ihre eigentümlichen Elemente unter und in der allgemeinen Masse des Stoffes gehabt habe; daß diese Elemente, weil die Möglichkeit dazu vorlag, sich vereinigten; daß das embryonale aus diesen Elementen hervorgegangene Wesen eine unendliche Reihe von Organisationen und Entwicklungen durchgemacht habe; daß nach und nach in ihm Bewegung, Sinnesempfindung, Vorstellungen, Gedanken, Überlegung, Gewissen, höhere Gefühle, Leidenschaften, Verständigungszeichen, Mienen, Töne, artikulierte Laute, eine Sprache, Gesetze, Wissenschaften, Kunst hervortraten; daß Millionen von Jahren zwischen jeder dieser Entwicklungsstufen vergingen, und daß vielleicht noch andere Entwicklungen folgen werden? DiDEROT schließt seine Pensées mit einem impertinenten Gebet:

Ich bitte dich, o Gott, um nichts in dieser Welt; denn der Lauf der Dinge ist durch sich selbst notwendig, wenn du nicht bist, oder durch deinen Befehl, wenn du bist. Ich weiß nicht, ob du bist; aber ich werde denken, als ob du in meine Seele sähest, und werde handeln, als ob ich vor dir stände.

BUFFon ist zwar weniger kühn als DiDERot, sucht aber ebenso die Macht Gottes durch diejenige der Natur (Nature mit großem Anfangsbuchstaben) zu ersetzen. Die Natur hat nach BuffoN die Organismen erschaffen ${ }^{1}$ ), die Natur verleiht den Organismen ihre Formen $^{2}$ ); das Tier ist das vollkommenste Werk der Natur, und der Mensch steht an der Spitze der Tiere ${ }^{3}$ ); der Mensch ist von der Natur mit allen zum Leben nötigen Organen versehen ${ }^{4}$ ) usw. Im allgemeinen drückt sich dagegen BUFFON vorsichtiger aus:

Die Natur vermag alles, nur nicht $z u$ erschaffen und zu vernichten, zwei Extreme, die sich Gott vorbehalten hat. Aber die Natur verdirbt, verändert, entwickelt, renoviert, produziert. Alles wurde also erschaffen, und noch nichts ist vernichtet worden. Die Natur schwebt zwischen diesen beiden Grenzen, ohne jemals die eine oder die andere zu erreichen.

Der Arzt DE LA MetTRIE (I709-I75I) ging in der Gegenüberstellung von Gott und Natur sehr weit. In einer Reihe von Schriften

1) T. III. S. 45 .

2) Ebenda, S. 40.

3) S. 6.

4) T. 4. S. II 3 . 
führt er die DescaRTESsche Lehre von der maschinellen Struktur des menschlichen Körpers konsequent durch, indem er zugleich die Überflüssigkeit einer spiritualistischen Seele im Körper behauptete. Seine Schriften zielen auf die Negation Gottes und der Seele und suchen Beweise dafür zu erbringen, so gut es eben geht. Ähnlich konsequent-materialistisch hat CABANIS (I757-I808) geschrieben; von ihm stammt die Auffassung, daß die Tätigkeit des Gehirns derjenigen des Magens durchaus ähnlich ist, mit dem einzigen Unterschiede, daß die Nahrungsmittel des ersteren Sinneseindrücke, seine Exkremente Gedanken sind.

\section{Entstehung der Organismen.}

Wenn Gott nicht mehr unmittelbar ins Weltgeschehen eingreift und wenn die Lehre der Erfahrungsphilosophen wahr ist, nach der die Organismen einmal entstanden sind, so muß man sich nach einer natürlichen Erklärung der Entstehung derselben umsehen. Die Versuche um eine solche häuften sich während der Aufklärung von Tag zu Tag; Buffons aus einer Verschmelzung der LEIBnizschen und der kartesianischen Ideen entstandener Versuch war einer der beachtenswertesten.

Die Tiere und Pflanzen, meint er, sind, namentlich durch ihre Nahrung, aufeinander angewiesen. Die Nahrung baut sich aus feinsten, lebendigen, überall in der Naturverbreiteten Partikelchen auf, aus diesen bilden sich die lebendigen Körper, ähnlich wie ein Kristall aus kleinsten Kriställchen zusammengesetzt ist. Diese Teilchen sind Pflanzen und Tieren gemeinsam - es besteht also nicht für jedes Tier eine besondere Art derselben (darin ist er DESCARTES gefolgt), und sie sind lebendig, organisiert und unzerstörbar (LEIBNIZ) ${ }^{\mathbf{1}}$ ). MAUPERTUIS hat bereits früher eine ähnliche Idee ausgeprochen: er erwähnt zunächst DESCARTES' mißlungenen Versuch, die Bildung der Tiere mechanisch zu erklären, verwirft dann die Evolutionstheorie, da sie nichts erkläre, und nimmt unsichtbare Körperchen an, welche die wesentlichen Eigenschaften der lebendigen Körper, wie Begehren, Abneigung, Gedächtnis, Gewohnheit usw., besitzen; diese Körperchen kristallisieren während der embryonalen Entwicklung zu einem neuen Organismus. Mangelt es bei der Entwicklung an einigen wesentlichen Partikelchen, so entstehen Monstra, und durch Umlagerung derselben könnten neue Arten gebildet werden, so daß

1) T. III. S. 29. 
auf diese Weise aus einem zufällig entstandenen Organismenpaar alle die verschiedenen lebenden Wesen hervorgegangen sein könnten.

Woher stammen aber die Form und die Strukturen eines lebendigen Wesens? fragte BuFFON. Von vitalistischen Theorien wußte er nichts oder wollte nichts wissen; immerhin mußte er zu einem verschleierten Universalvitalismus Zuflucht nehmen. Die Natur soll eine Tendenz zur Erschaffung des Lebens haben, die nur durch äußere Umstände gehemmt werden kann ${ }^{1}$ ), so daß eher die Ursachen des Todes und der Vernichtung als diejenigen des Lebens und dessen Entstehung zu suchen sind. Anstatt lebendige und leblose sollte man eher lebendige und tote Materie unterscheiden, denn das Leblose ist eigentlich das Abgestorbene, wie die Kalkschichten der Erdkruste nachweisen, die einmal aus lebendigen Tieren bestanden, und aus deren Trümmern das Gestein, der Sand und andere anorganische Materien später entstanden $\operatorname{sind}^{2}$ ).

Der allgemeine Drang der Natur nach dem Leben schlägt sich in einzelne Organismen nieder. Wie jeder Körper von der Gravitation beherrscht ist, so eignet den lebendigen Teilchen eine eigentümliche Kraft, "moule intérieure «(innere Form) genannt, die die organischen Partikelchen nötigt, sich $\mathrm{zu}$ bestimmten Strukturen zusammenzusetzen, in derselben Art, wie die Kristalle nach bestimmten Formgesetzen aufwachsen. Deutlicher hat sich BufFon über die innere Form nicht ausgesprochen; er versichert nur wiederholt, daß man darunter nicht nur die äußere Form, sondern alle inneren Beziehungen der Teile zu verstehen habe.

Über die Zeugung der Tiere, welche einen speziellen Fall ihrer Entstehung bildet, hat sich BUFFoN nach langen Diskussionen der Ansichten von LEEUWENHOEK, VALLISNIERI und vieler anderer folgende Theorie gebildet. Solange der Körper wächst, werden die durch die Nahrung aufgenommenen Partikelchen zum Aufbau des Körpers verwendet; nachdem das Wachstum aufgehört hat, sammeln sich die übrig bleibenden Partikelchen aus dem ganzen Körper in den Reproduktionsorganen, wo sie sich zu kleinen Tierchen - den Spermatozoen - zusammensetzen. Unrichtig sind nach Buffon die Ansichten derer, welche in den Ovarien der Säugetiere Eier auffinden wollten; vielmehr sind in deren Reproduktionsorganen kleine Samen-

1) T. III. S. 45 .

2) T. III. S. 45. LAmarck, Buffons Schüler, wird später nachzuweisen suchen, daß alles Gestein organischen Ursprunges ist. 
tierchen enthalten, und durch die Verbindung der männlichen und der weiblichen Tierchen entsteht der Embryo.

Wahrscheinlich bildet sich zuerst die Anlage der Generationsorgane; da sie bei Mann und Weib verschieden sind, und um dieselben verteilen sich dann die übrigen Teilchen nach derselben Ordnung, wie im entwickelten Organismus. Hiernach ist also die Evolutionstheorie unrichtig, richtig dagegen die mechanisch-epigenetische Theorie. Und doch sind im Embryo auch schon alle Teile des entwickelten Organismus enthalten, nur so eingewickelt, daß wir ihre künftige Form aus der Form des Embryo gar nicht erraten können.

Es folgt daraus, sagt Buffon, daß die Arten niemals auf dem Wege natürlichen Todes aussterben können; sondern »sie sind heute ebenso, wie sie vor 3000 Jahren waren; alle werden sich gleichbleiben, so lange sie nicht vernichtet sein werden durch den Willen des Schöpfers «. Die Überzeugung, daß nichts Neues auf der Welt entstehen kann, spricht deutlich zu uns aus diesem charakteristischen Satze.

BUfFon hat andere Denker zu analogen Hypothesen über die Entstehung der Organismen angeregt. DIDERoTs Theorie ist bereits angeführt worden; DIDEROT beruft sich ausdrücklich auf BUFFON als auf seinen Vorläufer. Bei LA MetTrIE gewinnt Buffons Idee einen noch prägnanteren Ausdruck. Woher kommen die Raupen und andere Insekten, fragt er und antwortet:

woher kommen sie, wenn nicht aus der Luft? Es gibt folglich in der Luft tierische und pflanzliche Keime und Samen; sie sind dort gewesen und werden dort immer vorhanden sein. Jedes Individuum zieht an sich diejenigen seiner Art oder die ihm passenden, wenn man nicht der Theorie Vorzug gibt, daß jene Samen die Körper aufsuchen, wo sie reifen, keimen, sich entwickeln können ${ }^{1}$ ).

Auf diese naive Art suchte man den Evolutionismus durch eine natürliche Erklärung des Lebens zu überwinden.

\section{Theorie der Erde.}

BUFFON ist der erste Naturforscher, der sich an eine großzügige Erdgeschichte gewagt hat. Er hat derselben die ersten zwei Bücher seiner Naturgeschichte gewidmet; ihre Originalität wurde oft hervorgehoben; die in denselben niedergelegten Ansichten waren es, die den Protest der Universität hervorriefen. Wohl konnte BuffoN

1) Système d'Epicure. Oeuvres de La Mettrie. Berlin I774. I. S. 23 I. 
auf eine lange Reihe Vorläufer, von den ehrwürdigen Schöpfungsgeschichten der klassischen Völker bis zu seinen Zeitgenossen hinweisen.

Wenn wir die Entwicklung der geologischen Theorien mit derjenigen der biologischen vergleichen, so überrascht uns die Wahrnehmung, daß man die Erde stets geschichtlich zu erklären versucht hat, während diese Erklärungsweise auf die organische Welt erst ziemlich spät angewendet wurde. Man könnte dabei sogar auf die Heilige Schrift hinweisen: nach ihr erhält die Erde ihre jetzige Beschaffenheit allmählich in sechs Tagen, während die Organismen plötzlich in die Erscheinung treten. Weder DESCARTES noch LEIBNIZ ist es eingefallen, über den Ursprung der Organismen nachzuforschen; über die Entstehung der Erde haben sie aber ausführliche Theorien entwickelt. Geologische Spekulationen haben den Biologen einen mächtigen Antrieb geboten, die genetische Methode auf ihr Gebiet anzuwenden: es sei nur an den bekannten Einfluß Lyelis auf DARWIN erinnert. Die Ursache liegt darin, daß der Organismus als ein Ganzes, als. eine natürlich gegebene Einheit begriffen wird; infolgedessen wurde als das Hauptproblem das Verhältn is der Teile zum Ganzen betrachtet, nicht ihre Entstehung. Wie man nicht nach der historischen Entstehung der Ellipse fragt, ebensowenig fragte man nach der historischen Entstehung eines Tieres. Die unregelmäßigen Berge und Täler der Erde dagegen, ihre vielfach sich krümmenden Flüsse, ihre so verschiedenartig gestalteten Küsten, alles das drängt nicht mit solcher Kraft zu der Auffassung der geologischen Verhältnisse der Erde als einer Einheit.

Die Versuche, eine geologische Theorie der Erde aufzustellen, wurden oft von den Scholastikern unternommen. Um von anderen Autoren $\mathrm{zu}$ schweigen, so findet man bereits in einer AvicenNA zugeschriebenen Schrift Behauptungen über die Versteinerungen der Pflanzen und Tiere, über a $11 \mathrm{mähliche} \mathrm{Entstehung} \mathrm{der} \mathrm{Berge}$ und Täler durch Erdbeben, durch die Erosion, und über die geologischen Folgen der Ebbe und Flut ${ }^{1}$ ). ALRERT DER Grosse entwickelte die Ideen dieser Schrift weiter. LEONARDO DA VINCI hat im Anschlusse an AlBert DE SAXE, einen Scholastiker und Schüler ALBERTs ${ }^{2}$ ), eine astronomisch-geologische Theorie von allmählichen Veränderungen der Erdkruste aufgestellt. LEONARDOs Ideen hat

1) De mineralibus. Vgl. P. DuHeM, Leonardo da Vinci II. S. $302 \mathrm{sq}$.

2) Ebenda, S. 334 . 
(nach DUHEM) vielleicht CARDANus wiederholt, von dem sie BERNARD PALISSY (I5IO-I 586) abgeschrieben haben soll.

Eine neue Theorie hat Nikolas STENo, der uns bereits bekannte Histologe und Bischof, aufgestellt ${ }^{1}$ ). Aus der Wahrnehmung der schichtenartigen Lagerung der Gesteine zog er den Schluß, daß, da jede neue Gesteinsschicht sich nur auf fester Unterlage habe bilden können, immer die untere Schicht schon fest gewesen sein müsse, ehe die nächstobere sich darauf niederschlug. Alle Schichten sind von zwei parallelen, ursprünglich horizontal gerichteten Ebenen eingeschlossen. Findet man geneigte oder senkrechte Schichten, so müssen diese entweder durch unterirdische Stöße oder durch Auswaschung und Zusammenbruch nachträglich aus ihrer Lage gebracht worden sein. Bei solchen Einbrüchen blieben einzelne Schichten horizontal, andere stellten sich schief oder senkrecht, und wieder andere krümmten sich im Bogen. Daraus kann man die Ungleichheiten der Erdoberfläche, die Entstehung von Bergen und Tälern, von Hochebenen und Niederungen erklären. Die Gebirge sind allmählich entstanden, haben also nicht schon am Anfang der Dinge existiert. Die geologische Geschichte von Toskana teilt STENo in sechs Perioden, die er in Übereinstimmung mit der Überlieferung der Heiligen Schrift zu bringen sucht. In der ersten Periode war Toskana wie die ganze übrige Erde mit Wasser bedeckt und setzte die primitiven, aus gleichartigem Material bestehenden versteinerungslosen Gesteinsschichten ab. In der zweiten liefen die Gewässer ab; die Erde wurde trocken und eben. Die dritte Periode war durch die Entstehung von Unebenheiten ausgezeichnet. Die in der vierten Periode eintretende Sintflut ließ auf den Bergen Sedimente und Versteinerungen zurück. Während der fünften Periode blieb die Erde mit ihren weit ausgedehnten Ebenen trocken; die Flüsse trugen große Mengen von Sedimenten ins Meer und erzeugten dadurch neues Land (z. B. das Nildelta). In der sechsten Periode endlich hat sich durch Wassererosion und Feuereinwirkung die Umwandlung der Ebenen in Täler und Berge vollzogen.

Nach DESCARTES (Principia philosophiae, I685) waren alle Sterne, Planeten und Trabanten ursprünglich glühende Sonnen, entstanden aus einer in wirbelnder Bewegung begriffenen Materie. Bei der Abkühlung umgab sich die Erde mit einer starren Rinde, unter der das Zentralfeuer fortbrannte; dieses ist die Ursache der vulkanischen Er-

1) De solido intra solidum contento. I669. 
scheinungen. Ähnliche Vorstellungen von der Entstehung der Erde hat auch LEIBNIZ (Protogaea, I693) entwickelt. Auch RAY hat eine Theorie der Erde aufgestellt. RAYs jüngerer Genosse MARTIN LISTER (I638-I7 I2) hat als der erste versucht, eine Karte der mineralogisch-geologischen Verhältnisse Englands (Yorkshires) wenigstens anzudeuten; um die Mitte des I8. Jahrhunderts haben mehrere englische und französische Autoren solche Karten entworfen ${ }^{1}$ ). LEIBNIZ schlug in seiner I749 (posthum) erschienenen "Protogaea sogar einen Namen für die neue mit der Analyse der Erdkruste sich befassende Wissenschaft, den Namen "natürliche Geographie " (geographia naturalis), vor.

Gegen das Ende des I7. Jahrhunderts wurden besonders in England Spekulationen über die Erdgeschichte und über ihren Zusammenhang mit der Sintflut beliebt. TH. BouRnET ${ }^{2}$ ) erklärte die Sintflut durch ein Zerklüften der ausgetrockneten Erde, die hierauf ins Meer sank und den Inseln und dem heutigen Festlande Ursprung gab. S. WOODWARD ${ }^{3}$ ) glaubte beweisen $\mathrm{zu}$ müssen, daß während der Sintflut aus den Tiefen der Erde Wasser hervorquoll, durch das das Festland aufgelöst worden sei; nur die Muschelschalen sind, ihrer organischen Kraft wegen, erhalten geblieben; daraufhin haben sich allmählich die Erdschichten niedergelegt: zu unterst liegen die schwersten, zu oberst die leichtesten Gesteinsmassen. W. WHiston ${ }^{4}$ ) verfolgte die Entwicklung der Erde in die Zeit vor der Sintflut. Aus dem Chaos soll sie sich entwickelt haben; zur Zeit des Diluviums hatte sie schon die jetzige Gestalt. Erst nach der Vertreibung der ersten Menschen aus dem Paradies soll die Erde begonnen haben sich um ihre Achse zu drehen. Die Sintflut soll am I8. November 2349 v. Chr. die Menschheit überrascht und die Erdoberfläche nach der von WOODWARD geschilderten Art verändert haben. Einmal wird die Erde durch das Feuer zu Grunde gehen ${ }^{5}$ ).

Mag dem heutigen an CUviER, LyeLL, DARwin herangebildeten Leser Buffons Theorie der Erde noch so naiv erscheinen, sie erhebt sich turmhoch über die Spekulationen seiner englischen Vorläufer. Neben einer souveränen Beherrschung der Geschichte des Problems verfügt BUFFON über ausgedehnte Erfahrungen über die

1) Miall, The early Naturalists. S. I33.

2) Telluris theoria sacra. Londini $168 \mathrm{I}$.

3) An essay towards the Natural History of the Earth. I695.

4) A new Theory of the Earth. Lond. I708.

5) Ich führe diese Theorien nach Buffon an.

Rádl, Geschichte der biol. Theorien. I. 2. Aufl. 
Lagerung der Schichten in Frankreich und weiß manche gute Tatsache über die geologischen Verhältnisse fremder Länder anzuführen. Tatsachen der Geographie, der Geologie, der Verbreitung der Tiere auf der Erde, Hypothesen über die Entstehung der Organismen werden als Beweismaterial für seine Ausführungen herangezogen.

BUfFON macht den ketzerischen Versuch, das Alter der Erde zu bestimmen (er schätzt dasselbe auf 65000 Jahre, eher mehr); er unterscheidet sechs (später sieben) Perioden der Erdentwicklung und gibt für jede Periode die Dauer in Jahren an. Die Erde hat sich aus der heißen Sonnenmasse entwickelt; wahrscheinlich wurde sie durch den Stoß eines Kometen von der Sonne abgeschnitten und in die jetzige Bahn geworfen. Dann wurde die Erde allmählich kälter, und das Meer bedeckte ihre ganze Oberfläche; darum finden sich Versteinerungen auf den höchsten Bergen. Die Tiere früherer Zeiten vermochten in viel größerer Wärme zu leben als heutzutage. Durch große Katastrophen bildeten sich tiefe Abgründe, in denen sich das Wasser sammelte, und so sank das Meer auf seine jetzige Höhe.

CUvier hat später diese Theorie übernommen und aus den sechs Perioden und den Katastrophen den Grundpfeiler seiner Geologie gebildet. Die heiße Sonnenmasse kommt auch bei Descartes vor; sie liegt auch der bekannten KANT-LAPLACEschen Theorie zu Grunde.

Kant, der fast zu derselben Zeit wie Buffon über seine astronomische Theorie der Erde nachdachte, war kühn genug, die Entstehung der Weltkörper mechanisch zu erklären: "Gebet mir Materie, " ruft er aus, »und ich will eine Welt daraus bauen $\left.{ }^{1}\right)$ ! "Vor der mechanischen Erklärung der Organismen schrak er jedoch zurück²). Bekanntlich war CUVIER noch zurückhaltender und ließ uns fast im Ungewissen darüber, wie er sich die Entstehung des Lebens vorgestellt hat. BufFoN ging konsequenter vor. Nach seiner Theorie hatte die junge Erde anfangs frische Bildungskraft und brachte infolgedessen viel größere Tiere als heute hervor. Die lebendigen organischen Moleküle, deren es auf der Welt eine endliche Anzahl gibt, haben sich durch die Einwirkung der Wärme auf die Materie, aus der die lebendigen Körper zusammengesetzt sind, gebildet (ces.

1) K. Fischer, J. Kant. 3. Auf. Heidelberg I889. I. S. I34.

2) Ebenda, S. 146 . 
molecules organiques, vivantes ont existé dès que les éléments d'une chaleur douce ont pu s'incorporer avec les substances qui composent les corps organisés) ${ }^{1}$ ). Die organischen Moleküle haben eine große Menge von Pflanzen, Schalentieren, Austern und Fischen produziert, welche durch Zeugung ihre Art fortgepflanzt haben. Zuerst waren die nördlichen, ehemals heißen Zirkumpolargegenden bewohnt, und dort sind zuerst Elefanten, Nashorne, Nilpferde und andere Tiere, die jetzt die äquatorialen Gegenden bewohnen, in großer Menge entstanden (nés) ${ }^{2}$ ). Die niederen Tiere sind vielleicht gleich am Äquator entstanden. Doch warum sind die Elefanten nur einmal im Norden geboren, und nicht später am Äquator (durch spontane Generation) entstanden? Die zuerst entstandenen Elefanten haben durch ihre kolossale Körpermasse (vielleicht waren sie noch größer als die heutigen $)^{3}$ ), eine große Menge der organischen Moleküle verbraucht, deshalb blieb für Indien und Afrika, wohin die Elefanten von Norden her eingewandert sind, nicht die nötige Menge von Molekülen für so große Formen übrig; in Amerika dagegen, in dessen heiße Gegenden keine großen Tiere von Norden her gekommen sind, wo also die organischen Moleküle noch nicht absorbiert waren, sind neue große Formen, wie das Tapir, entstanden. Auch die Pflanzen entstanden im Norden und wanderten allmählich nach Süden. Die meisten ausgestorbenen Tiere gehören nach BufFon Arten an, welche noch heute leben; doch ließ er bereits die Möglichkeit gelten, daß einige Arten ausgestorben sind.

Die Tatsache der geographischen Verbreitung der Tiere wurde auf diese Art das erstemal wissenschaftlich konstatiert und theoretisch ausgenutzt; dabei entwickelt BuFFON auch das erstemal die später viel diskutierte Hypothese von der Verschiedenheit der geologisch älteren Kontinente von den heutigen: die alte und die neue Welt sollten im Norden kontinuierlich zusammenhängen und erst nach der Entstehung der nördlichen Elefanten getrennt worden sein, worauf diese in Nordamerika ausgestorben sind; der Mythus von der Atlantis weist nach BuffoN auf das Vorhandensein von Festland auf heute vom Meer bedeckten Gebieten.

1) T. I2. S. 122. Lamarck ließ bekanntlich ebenfalls die Wärme die wichtigste Rolle bei der Entstehung der Organismen spielen.

2) Buffon beruft sich auf die im hohen Norden entdeckten Mammutknochen.

3) Ebenda, S. I 8 I. 


\section{Entstehung und Umwandlung der Arten.}

Buffon hat Linnés Prinzip der Klassifikation verworfen; es gebe, behauptet er, in der Natur keine Gattungen, keine Ordnungen und Klassen, sondern nur Individuen ${ }^{\mathbf{1}}$ ). Die Natur ist ungeheuer plastisch, schreitet über unmerkliche Nuancen von einer Erscheinung zur anderen, und jeder Versuch, scharfbegrenzte Organismengruppen zu unterscheiden, führt zur Vergewaltigung der Natur. LEIBNIz hat dieselbe These vertreten; BUFFon faßt sie jedoch plastischer, der Wirklichkeit angemessener auf, indem er dieselbe an die Formenund Lebensmannigfaltigkeit der Organismen anwendet und die Übergänge weder linear, noch flächenhaft, noch baumartig deutet; drei Raumdimensionen sind zu schematisch und genügen nicht zur vollen Erfassung der organischen Plastizität.

Die Arten, d. h. die konkreten Verwirklichungen der organischen Wesen sind nach BuFFon konstant, weil von innen aus, durch die "moule intérieure « bestimmt. BUFFON sagt ausdrücklich, daß die Anzahl der Organismenarten (durch ein Gesetz) begrenzt ist2); wenn sie unendlich ist, so entwickelt sich diese Unendlichkeit doch nur in bestimmten Grenzen ${ }^{3}$ ). Verfolgen wir z. B. die Konsequenzen dieser Behauptung Buffons ${ }^{4}$ ):

Würde plötzlich der größte Teil der Organismen vernichtet werden, so kämen neue Arten auf, weil sich die organischen Moleküle, die unzerstörbar und immer aktiv sind, zu neuen organischen Körpern verbinden würden; weil sie aber gänzlich von den inneren Formen (moules intérieurs) der vorhandenen Wesen absorbiert sind, können keine neuen Arten entstehen, wenigstens nicht in den ersten Klassen der Tiere, d. h. denjenigen der großen Tiere ${ }^{5}$ ).

BUFFON faßt die Tiere als vollkommen ausgeführte Kunstwerke auf: jedes Tier ist nach einem Prototyp modelliert, das verschiedene Variationen zuläßt; in seinem Wesen jedoch unwandelbar ist. Einen einheitlichen Plan sehen wir auch in größeren Gruppen der Tiere verwirklicht: der Körper des Pferdes, äußerlich von dem-

1) T. I. S. 43 .

2) T. IV. S. XXIX u. S. XXXV.

3) Nach Darwin und z. T. nach Lamarck gibt es auch unendlich viele mögliche Arten; da aber einzelne Arten durch äußere Bedingungen gegeben sind, ist in diesem Falle ihre Unendlichkeit unbegrenzt.

4) T. I2. S. 194 .

5) T. XII. S. I25. 
jenigen des Menschen verschieden, ist diesem wesentlich ähnlich gebaut, und noch bei den Vögeln und Fischen findet man denselben Plan befolgt; eine Idee spricht zu uns aus der Mannigfaltigkeit der Tierformen 1 ). Da BUFFon von solchem platonischen Standpunkte. die Natur betrachtete, konnte er unmöglich an unbegrenzte Variabilität der Tierformen glauben. Wenn er von Umwandlungen der Tiere spricht, so verläßt ihn dabei nicht die Überzeugung, daß dieStruktur des Tieres wesentlich unverändert bleibt. Wohl aber sind die angeführten Erörterungen BuFfons geeignet, auf die Morphologie, auf die Typenlehre CUviers und auf GEOFfROYs Lehre von der Einheit des Planes im Tierreich zu führen - auf die sie auch ge. führt haben.

An einigen Stellen spricht BuFfon von der Umwandlung (dégéné-. ration) einer organischen Form in eine andere, ohne aber auf diese Tatsache besonderes Gewicht zu legen; das Hervorsprossen der Tiere aus der Erde bildet für ihn jedenfalls fast die einzige Quelle für die Bildung neuer - auch der höchsten - Organismen. Doch spricht er von der Umwandlung der ursprünglich einen Art des Menschen in mehrere ${ }^{2}$ ), er nimmt an, daß die Neger durch die Einwirkung der Hitze und der Nahrung die schwarze Farbe bekommen haben ${ }^{3}$ ); er spekuliert auch über die Degeneration des Pferdes zum Esel, des Menschen zum Affen usw.

Ausgedehnte Betrachtungen über die Entstehung der jetzigen Organismenwelt aus einer anders beschaffenen, geologisch vorangehenden, sind bei BuFFoN desto weniger zu suchen, als er der erste war, dem überhaupt die Idee undeutlich aufkam, daß die jetzigen Organismen sich von den versteinerten unterscheiden. Von der Geschichte einer Tier- und Pflanzenform konnte vor Buffor keine Rede sein; wohl hat man aber über die Entstehung der Organismen und auch über den Ursprung der Versteinerungen spekuliert.

Die Nachfolger des ARIstoteles, welche der Erde die Möglichkeit des Lebens zuschrieben, haben ohne Bedenken die Tiere, namentlich die niederen, aus der Erde kristallisieren lassen. Einige derselben nahmen an, daß der Erde eine Kraft (vis plastica) eignet, die überall und aus jedem Material organisierte Körper hervorzubilden strebt; als Folge ihrer Tätigkeit haben sie die Versteinerungen

1) Quadrupèdes T. I. S. 55 sq.

2) T. V. S. 6.

3) Ebenda, S. I $28 \mathrm{sq}$. 
("pierres figurées «) betrachtet; so der engliche Entomologe MARTiN Lister (I638-I7II), der die fossilen Muscheln noch für Mineralien hielt; sie sind ihm »lapides sui generis ", den Tierformen durch eine uns unbekannte Ursache aufs Ungefähr hin nachgebildet, ohne jedoch deren Gestalt vollkommen zu erreichen. Die Meinung, daß die Versteinerungen niemals ein vollkommenes Leben geführt hätten, begründet LISTER dadurch, daß mehrere fossile Muschelschalen alle lebenden Formen an Größe überragen, daß sie auch im Inlande vorkommen, nur aus anorganischen Substanzen bestehen und oft unvollkommen ausgebildet sind ${ }^{\mathbf{1}}$ ). Ein anderer Engländer, ED. LHWyd (I699), äußerte in einem Briefe an RAY die Hypothese, daß die Versteinerungen durch Befruchtung der Gesteine mit dem Samen der Tiere entstehen: von lebenden oder vielleicht auch von bereits faulenden Tierüberresten sollen sich kleine Samenteilchen absondern, die dann von aufsteigenden Wasserdämpfen in die Luft geführt, mit dem Regenwasser in die Poren der Felsen und Berge eindringen, wo sie unter Benutzung der vorhandenen Materie ausgebrütet werden.

REDI war der erste, der diesen Wahn erschüttert hat; einen großen Teil seiner bekannten Schrift widmet er der Analyse der seit dem Altertum immer wieder auftauchenden Hypothese, daß die Organismen durch eine vitale der Erde innewohnende Kraft erschaffen worden sind, weist dieselbe zurück und stellt den Satz auf, daß Leben nur aus Leben entstehen könne, einen Satz, der die erste Voraussetzung der modernen Deszendenztheorien bildet; man erwehrt sich beim Lesen der Schrift REDIs tatsächlich kaum des Gedankens, daß REDI eigentlich eine Art Deszendenztheorie entwickelt. Nur vereinzelte Forscher traten für die Meinung ein, daß die Versteinerungen Überreste von Organismen bilden, die einmal die Erde belebt haben; zu diesen Forschern gehört von den neueren LEONARDO DA VINCI (I452-I5I3); ihm folgten ALESSANDRO DEgli Alessandri (I46I-I 523), FraCAstoro (I483-I 553), BERnH. PALISSY (I5IO-I590). Im Verlaufe des I7. Jahrhunderts traten solche Anschauungen immer häufiger hervor. Durch LEIBNIZ (I693), RAY (I693), WOODWARD (I695) und eine Reihe anderer Forscher erlangte die Erkenntnis vom organischen Ursprung der Versteinerungen allgemeinere Verbreitung, obwohl man diese Theorie in recht naive Umkleidung einzuhüllen pflegte. JoH. JAC. Scheuchzer

1) Miall, Early Naturalists. S. I34. 
(I672-I733) beschrieb z. B. die Versteinerungen zuerst (I702) als Naturspiele (naturae ludibria), später, unter dem Einfluß WooDWARDS, als organische Überreste. In der Schrift "Piscium querelae et vindiciae " (I708) läßt er die fossilen Fische darüber klagen, daß sie in der Sintflut untergegangen sind; und daß der Mensch sie jetzt nur für Naturspiele halten will. Gegen sein Lebensende meinte er das Glück gehabt zu haben, „das Beingerüst eines verruchten Menschenkindes, um dessen Sünde willen das Unglück über die Welt hereingebrochen sei «, zu entdecken; doch hat später CUvier nachgewiesen, daß dieser »homo diluvii testis « das Skelett eines Riesensalamanders war. WoODWARD war derselben Meinung: Gott habe diese Überreste des vorsintflutlichen Lebens auf uns kommen lassen, auf daß wir immer ein Denkmal seiner strafenden Hand vor den Augen hätten. Die Biologen des 18. Jahrhunderts haben wenig Interesse für die ausgestorbenen Tiere gezeigt. Noch BonneT tut ihrer in seinen dickleibigen Büchern kaum mit einem Wort Erwähnung, und Linné versteht unter Fossilien noch Gesteine, nicht Organismen ${ }^{1}$ ). Erst BuFfoN spendet ihnen ausgedehnte Aufmerksamkeit.

Die Möglichkeit, daß sich die Arten während der Erdentwicklung verändert haben, kam den älteren Philosophen höchstens unter der Annahme in den Sinn, daß aus ursprünglichen formlosen oder fast formlosen Anfängen die heutigen Tiere entstanden sind, etwa so wie es sich PASCAL vorgestellt haben mag, als er das Problem aufstellte:

Waren die beseelten Wesen am Anfang nur informe und unbestimmte Individuen, über deren definitive Beschaffenheit die Bedingungen, unter denen sie gelebt hatten, ursprünglich entschieden haben?

Eine ausführliche Untersuchung hat den Transformationen der Tiere DE MAILLET gewidmet, dessen Schrift fast gleichzeitig mit Buffons Theorie der Erde erschien.

Benoit DE MAILlet (I626-I738), ein Zeitgenosse Leibnizens und NEwTons, war lange Zeit französischer Generalkonsul in Ägypten. Seine Beobachtung der Wirkungen des Nilstromes auf die Bodenbeschaffenheit Ägyptens scheint ihm die Veranlassung zu seinen Theorien geboten $\mathrm{zu}$ haben. Die uns hier interessierende Schrift, ist I7 I 5 und I7I6 verfaßt, I735 gedruckt, jedoch erst I748

1) RÉAUMUR erwähnt die Versteinerungen der Muschelschalen. 
unter dem Pseudonym "Telliamed "(Anagramm von DE MAILlET) veröffentlicht ${ }^{1}$ ).

In der Einleitung führt DE MAILLET dem Leser einen indischen Philosophen Telliamed und einen französischen Missionar vor, die sich über die vorliegenden Fragen unterhalten. Telliamed will zu seinen Ansichten durch die Untersuchung der Natur gekommen sein. Er habe die Substanz der Erde anatomisch zerlegt und so ihre Bestandteile sowie ihre Verbindungen erkannt; dadurch sei er auf den wahren Ursprung der von uns bewohnten Weltkugel, wie und wodurch sie gebildet ist, geführt worden. Die eigentliche Abhandlung zerfällt in sechs Gespräche, von denen die drei ersten die geologische Entwicklung der Erde, die drei letzten die Entstehung der Organismen behandeln. Ursprünglich soll die Erde vollständig mit Wasser bedeckt gewesen sein, und erst allmählich habe sich die Wasserhülle vermindert, so daß Festland und Inseln emportauchen konnten. Eine allgemeine Sintflut sei ein Märchen, und die von Moses geschilderte Überschwemmung müsse als lokales Ereignis angesehen werden. Das vierte Gespräch beschäftigt sich vorzugsweise mit der Natur der Versteinerungen, für deren organischen Ursprung Telliamed mit Entschiedenheit eintritt. Alles Leben entsteht nach ihm im Meere. Als das Meer von seinen Ufern zurücktrat, gerieten einige Meerestiere auf das noch feuchte Land; ihre Lebensweise paßte sich der trockenen Luft an, und so sind Landtiere aus ihnen geworden. Ein Flugfisch gerät an das Ufer; infolge der Trockenheit zerfallen seine Schuppen in Fäserchen und werden zu Federn, und so wandelt sich der Fisch in einen Vogel um. Auch die Menschen lebten ursprünglich im Meere und gewöhnten sich erst allmählich (in den Polargegenden) an die Lebensweise auf trockenem Lande. Die Eskimos bilden die Übergangsstufe von den Meeres- zu den zivilisierten Menschen ${ }^{2}$ ).

DE MaIllets Schrift findet sich bei mehreren Autoren jener Epoche zitiert; einen nachhaltigen Einfluß scheint sie nicht ausgeübt zu haben. Die Theoretiker aus dem Ausgange des I8. Jahrhunderts knüpfen vielmehr an BUFFoN an; so CUVIER mit seinen

1) Buffons Théorie de la Terre erschien I749. - Die Schrift trägt den Titel: Telliamed, ou Entretiens d'un philosophe indien avec un missionnaire français sur la diminution de la mer. 2 Vols. 1755. Sie ist Cyrano de Bergerac, dessen treueren Nachabmer sich der Autor nennt, gewidmet.

2) Über de Maillet vgl. A. LANG, De Maillets Phantasien üb. die Umwandlung der Arten. Kosmos IIr. 1878. S. 258 sq. 
Katastrophentheorien, so auch LAMARCK mit seiner Negation der natürlichen Art und mit seiner Spekulation über die Entstehung des Lebens auf der Erde. -

Das 20. Jahrhundert besitzt kaum einen geeigneten Maßstab zur Beurteilung der wissenschaftlichen Leistung Buffons. Heute glaubt man nur an Spezialisten, höchstens an Nur-Naturforscher, an Experimentatoren, an Männer des Laboratoriums. Ein Adeliger, der des Vergnügens wegen die Wissenschaft pflegt, selbst kaum experimentell tätig ist und sich meistens an sekundäre Quellen stützt, würde heute gewiß von oben herab betrachtet werden. Man würde heutzutage auch wenig Verständnis für BufFons Theorienbau, für seine Verachtung der ins Einzelne gehenden Analyse, für seine anschauliche Darstellung zeigen. Seine Methode, die Dinge zu schauen und immer wieder zu schauen, gilt bei den Modernen für unexakt, denn man strebt nicht mehr nach neuen Anschauungen, sondern nach analytisch gewonnenen Bestandteilen und Ursachen der Erscheinungen. Buffons Naturgeschichte, vom modernen Standpunkt aus betrachtet, stellt ein populäres Werk dar, das nicht immer auf der Höhe der zeitgenössischen Wissenschaft stand und außer einer Menge von Hypothesen nichts Neues gebracht hat.

Und doch hat BufFons Werk auf die Nachwelt einen großartigen Einfluß ausgeübt. Vor BUFFoN verstand man unter Naturwissenschaft vorzüglich Mathematik und Physik; noch KANT war in dem Wahne begriffen, "daß in jeder besonderen Naturlehre nur so viele eigentliche Wissenschaft angetroffen werden könne, als darin Mathematik anzutreffen ist. " Mit BuffoN angefangen brach man mit dieser Hintanstellung der Biologie; sie wurde zwar nicht auf den Thron erhoben, von dem sie im Altertum und im Mittelalter alle übrigen Wissenschaften beherrscht hatte, wurde aber immerhin von nun an je weiter desto mehr als ein mit der Physik und der Mathematik gleichberechtigtes Glied betrachtet. BUFFON war kein Arzt mehr sondern Biologe, und seine Nachfolger Cuvier, Geoffroy, LAMARCK waren nicht einmal Physiker oder Mathematiker. Obwohl kein Fachmann, hat BuFFoN die Fachwissenschaft gefördert. VICQ D'AZYR, einer der ersten vergleichenden Anatomen, und CuviER, der bekannte Anatom, preisen ihn als ihren Vorläufer ${ }^{1}$ ); Cuvier schöpft aus ihm seine geologischen und paläontologischen Anschauungen;

1) Vor Buffon gab es (in der Neuzeit) nur deskriptive Anatomie des Menschen und der Tiere. 
LAMARCK entwickelt auf Grund der Ideen seines Meisters phylogenetische Spekulationen; PALLAS setzt die tiergeographischen Untersuchungen Buffons fort; GoEthe schöpft aus Buffons Auffassung der Naturwissenschaft die Anregung zu der seinigen. Der Widerwille gegen LinNé überlebte BUFFon, den Bekämpfer des Fachgelehrtentums: das 19. Jahrhundert suchte sich in seinem Kampfe gegen den LiNNÉschen Artbegriff und gegen die durch diesen Professor geförderte trockene Systematik auf den Weltmann Buffon zu stützen, indem man in ihm den Vorläufer der Phylogenie, des Ideals des I9. Jahrhunderts, entdeckt zu haben glaubte.

\section{Nach Buffon.}

BUfFoN ist I788 als einer der berühmtesten Männer der Zeit gestorben; fünf Jahre darauf verschied sein Sohn BufFonet als einer der Adeligen unter der Guillotine. Die theoretische Revolution, die die Aufklärer verbreitet hatten, wurde jetzt zur Revolution der Tat. Auch die Wissenschaften wurden vom Sturme der Epoche ergriffen; es wurden Konsequenzen gezogen aus Rousseaus Schwärmereien für die Natürlichkeit, aus dem Liebäugeln der Enzyklopädisten mit dem Materialismus, aus dem $\mathrm{Haß}$ gegen Institutionen, gegen die Akademie, gegen die Universität, gegen die theologische Zensur. Der Chemiker LAvorsien verschied auf dem Schafott, ob nur der politischen Fehler wegen? Er war einer der Repräsentanten der aristokratischen Wissenschaft, der einzigen, die sich vor der Revolution öffentlicher Anerkennung erfreut hatte; wir hören, daß gegen ihn nicht nur diejenigen gestimmt waren, die in ihm den königlichen Pächter gewisser Monopole erblickten, wir finden vielmehr, daß ihn auch Chemiker (FourCROY) und Physiker (MARAT) bekämpft haben. Die häßlichste Figur der Revolution, MARAT, war ein Naturforscher, ein Arzt, ein Physiker, ein Naturphilosoph, ein Anhänger DidEROTs 1 ). MARAT hat die Akademiker mit pöbelhaftem Haß verfolgt; LAvoIsIER

1) Marat hat insb. herausgegeben: A philosophical Essay in Man (psychologisch); Marat referiert da u. a. über Experimente, durch die er die Tätigkeit des Nervenfluidums ermitteln wollte. „Découvertes de M. Marat sur le feu, l'éléctricité et la lumière etc.く; in dieser Arbeit erörtert er Hypothesen, die später LAMARCK ergriffen hat. $\gg$ Découvertes sur la lumière (diese Schrift war in einigen Monaten vergriffen). »Recherches sur l'éléctricité e, wo er u. a. das elektrische Fluidum für das Prinzip der Vegetation erklärt (auch Lamarck hat eine analoge Hypothese vertreten). Lamarck soll sich auch ausdriicklich auf Marat als auf seinen Vorläufer berufen in $\gg$ Rech. sur les causes de principaux faits physiquese. t. I. app. S. 343-348. - Ich habe diese Angaben aus Cabank̀s, Marat inconnu, Paris ohne Jahreszahl, 2. Aufl, entnommen. 
war ihm als wissenschaftlicher Gegner, der seine Theorien nicht anerkennen wollte, zuwider. LAMARCK, der bekannte Biologe, verfolgte ebenfalls die Akademilker, LAvoisier und später CUvier, mit seinem Haß; als überzeugter Revolutionär griff er in seinen Schriften den ehemaligen König an und berief sich auf das französische Volk; die Verwandtschaft seiner Ideen mit denjenigen MARATs ist unverkennbar.

Das Interesse für die Wissenschaft war seit der Aufklärung rege; alle literarischen Anführer des geistigen Lebens suchten einen Standpunkt zu wissenschaftlichen Problemen einzunehmen; VoltarRE machte Witze über BuFfoNs Naturgeschichte und geologische Spekulationen, über MAUPERTUIs' und RÉAUMURs Vorschläge zur Verlängerung des Lebens u. a.; RoussEaU begründete botanische Ausflüge für eine kleine Gesellschaft seiner Anhänger (LAMARCK nahm an denselben teil); in den Salons debattierte man über NEwTONs Entdeckungen. Wohl haben sich an der Pflege der Wissenschaften nur aristokratische Kreise beteiligt - wer war jedoch zu jener Zeit kein Aristokrat? Versuchte doch auch ein MARAT als Aristokrat aufzutreten.

Die große Revolution war also auch eine wissenschaftliche Revolution. Als solche hat sie wenig Neues gezeitigt, sondern lebte nur von den Ideen Rousseaus, Buffons und von den Lehren der Aufklärer. Immerhin brachte sie einen frischen Idealismus, erweckte den Sinn für eine demokratische Wissenschaft und, indem sie auf die Wissenschaft (auf die Vernunft) alle ihre Hoffnungen setzte, bereitete sie dieser die Anerkennung vor, die ihr im I9. Jahrhundert zuteil wurde. Je mehr man sich in die revolutionären Ideen aus dem Ausgange des I8. Jahrhunderts vertieft, desto mehr befestigt sich in uns die Überzeugung, daß das 19. Jahrhundert, der wissenschaftliche Romantismus der Naturphilosophen wie der Darwinismus aus der hohen geistigen Spannung der großen Revolution seine Lebenskräfte geschöpft hat.

Der Umschwung des wissenschaftlichen Denkens kann aber durch keine noch so radikale Revolution hervorgerufen werden, sondern geschieht jederzeit allmählich. Allmählich haben sich die Gemüter von der Alleinherrschaft der Mathematik und der Physik abgewendet und der Biologie und verwandten Gebieten zugekehrt. Vor der Revolution hat die Pariser Akademie niemals einen Preis auf ein biologisches Problem ausgeschrieben ${ }^{1}$ ); nach der Revolution hat der

1) Blainville, Histoire etc. III. S. 369 . 
bekannte in der Akademie geführte Streit zwischen CuviER und GEOFFroy die ganze Öffentlichkeit interessiert. Die theoretisierenden Mediziner (Pinel, Broussais, Gall), die Biologen Cuvier, LAMARCK, Blainville wurden jetzt zu führenden Geistern. Buffons Ideen begannen jetzt zu reifen; aus ihnen und aus botanischer Systematik hat sich die neue biologische Wissenschaft, die Morphologie entwickelt. Zu gleicher Zeit begann auch der Ruhm der französischen Biologie zu sinken. CuviER brachte sie auf den Höhepunkt; unter der Führung Blainvilles, Milne Edwards' gelangte sie in die Hände von Epigonen, deren Nachfolger je weiter desto gedankenärmer waren. Inzwischen ist das deutsche Nationalbewußtsein erstarkt, und die deutsche Wissenschaft erwuchs bald zur gefährlichen Nebenbuhlerin für die französische: KANT hat die philosophischen Grundlagen für dieselbe gelegt, Goethe, der für Deutschland in vieler Hinsicht dasjenige bedeutet, was BUFFoN für Frankreich, hat das biologische Denken angeregt; in der Naturphilosophie erhob das junge Deutschland den Kopf, um in späteren Jahren aus den durch die Naturphilosophie geprägten Ideen sein wissenschaftliches Leben zu fristen. 


\section{Kapitel.}

\section{Französische Morphologie.}

\section{Entstehung der Morphologie.}

Die anorganischen Naturobjekte bestehen, die Organismen werden, entwickeln sich, streben nach einem Ziel. Die Biologen haben auch Jahrtausende lang unter Leben an erster Stelle Streben und Verwirklichung eines Charakters verstanden. Was den Leser der vor dem I8. Jahrhundert entstandenen biologischen Schriften am meisten überrascht, ist die Tatsache, daß deren Verfasser für die körperliche Erscheinung der Tiere und der Pflanzen meistens kein Verständnis zeigen. Es scheint, als ob sie die konkrete Form einer Pflanze, die Beschaffenheit ihrer Stengel, Laubblätter, Blüten usw. gar nicht gesehen hätten, denn unter Rose verstehen sie nur ein schönes, wohlriechendes Wesen, unter Nießwurz eine Kraft, die bestimmte Krankheiten heilt. Der Name "Hund " ruft ihnen ein bissiges oder wachsames Tier ins Gedächtnis, der Löwe stellt den Ausdruck der Tapferkeit, der Basilisk die Ausgeburt giftiger Boshaftigkeit dar; die Farbe, die Form des Schädels, die Struktur der Zähne existieren für die Biologen höchstens als Mittel, durch die jene Charakterzüge sich äußern können und die deshalb unwesentlich sind.

Diese physiologisch-psychologisch-ethische Auffassung der Organismenwelt besitzt eine Tiefe, für deren Verständnis unser Jahrhundert wenig angelegt ist; denn seit der Renaissance hat man sich je. weiter desto mehr gewöhnt, die Organismen je weiter desto materialistischer aufzufassen und in denselben vorzugsweise Körper zu sehen. Die Einführung der Holzschnitte in biologische Schriften am Anfange der Neuzeit hat gewiß viel dazu beigetragen, die Pflanzen und die Tiere eher als der unmittelbaren Sinneswahrnehmung zugängliche, relativ unveränderliche $\mathrm{Materien} \mathrm{als} \mathrm{bloß} \mathrm{dem}$ geistigen Auge faßbare Charaktere aufzufassen; die von den Kartesianern vertretene Maschinentheorie des Lebens, nach der 
die Leistungen bloße a priori erratbare Funktionen der Körpermaschine darstellen, hat diese Versinnlichung der Biologie ebenfalls gefördert. LinNés dogmatische Methode, die Pflanzen und Tiere als Aggregate von materiellen Merkmalen zu beschreiben, war geeignet, das Verständnis für die Lebewesen als harmonische Individualitäten ganz zu vernichten.

Buffon hat erkannt, daß Linnés Methode aus den Organismen das für dieselben am meisten Charakteristische, das Planmäßige, das im wahren Sinne des Wortes Organische verbannt; indem er die Organismen als plastische Naturwerke durch Worte zu malen unternommen hat, hat er sich der älteren Auffassung des Lebens als einer Qualität, einer harmonischen Einheit, genähert, ohne die neue Auffassungsweise der Tiere als wesentlich materieller Wesen zu verwerfen. In diesem Sinne sind die für Buffons Philosophie des Organischen charakteristischen Worte aus der wegen stilistischer Vorzüge gerühmten Schilderung des Esels zu verstehen:

Es gibt einen ursprünglichen und allgemeinen Plan, der sich sehr weit (in der Tierreihe) verfolgen läßt.. Bei der Erschaffung der Tiere wollte das höchste Wesen sich nur nach einer Idee richten und diese gleichzeitig in jeder Art variieren ... Und im Kapitel über die Affen schreibt Buffon: Dieser Plan, der unveränderlich in der ganzen Tierreihe, die vom Menschen zu den Affen, von diesen zu den Vierfüßlern, von diesen zu den Walfischen, zu den Vögeln, Fischen, Reptilien führt, befolgt wird, dieser Plan stellt, sage ich, vom Geist des Menschen gehörig erfaßt, das treue Modell der lebendigen Natur dar und den einfachsten und allgemeinsten Maßstab, mit dem sie gemessen werden kann.

Übrigens war es nicht BufFons Methode, diese formalistische Auffassungsweise der Tierwelt konsequent durchzuführen; ja im großen und ganzen betont auch BufFon, wie seine Vorläufer, die Leistungen der Tiere mehr als deren Struktureigenschaften. Immerhin führt seine Darstellungsmethode, die eine Vertiefung der LEIBNIZ-BONNETschen Lehre vom Stufengang der Wesen bedeutet, zur Begründung der Morphologie, einer Wissenschaft, die an den Tieren und Pflanzen an erster Stelle architektonische Eigenschaften der Körperteile studiert, einer Wissenschaft, die das biologische Denken am Ausgange des I8. und am Anfange des 19. Jahrhunderts beherrscht hat.

Es kann nicht erwartet werden, daß eine so natürliche Idee, wie es diejenige von der Einheit des Organisationsplanes der Tiere ist, von BUFFoN das erstemal in die Wissenschaft eingeführt worden wäre; dieselbe schlummerte im Gemüt der Naturforscher seit der 
ersten wissenschaftlichen Analyse der Organismen und wachte gelegentlich zu einem längeren oder kürzeren bewußten Leben auf, um jedoch bald wieder von den Systemen der Schuldogmatik eingeschläfert zu werden. In PLATOs Philosophie findet man mehrere Winke für die Lehre von der Einheit des Organisationsplanes; ARISTOTELES hat dieselbe fast zum System entwickelt; der hl. AUGUSTIN hat vielleicht an dieselbe bei der Aufstellung des Satzes »Natura appetit unitatem " gedacht; von den Aristotelikern CAESALPIN, HARvey, Severino wurde sie als eine Grundtatsache der Biologie betrachtet, und auch sonst fand sie Anhänger. Einen naiven Ausdruck dieser Idee bildet BeLONs Vergleich des Vogelskeletts ${ }^{1}$ ) mit demjenigen des Menschen (I555); NEwTON erklärt sich in seiner Optik als deren Anhänger durch die eindeutigen Worte: "Jene Uniformität, die in den Körpern der Tiere herrscht " und valle Teile nehmen fast bei allen Tieren eine analoge Lage ein ${ }^{2}{ }^{2}$ ). Bei LEIBNIZ haben wir darauf hingewiesen, daß seine Philosophie ebenfalls Keime der morphologischen Auffassung der Tierwelt enthält. LEIBNIZ hat viel über die Kontinuität der Naturwesen nachgedacht; "das Gesetz der Kontinuität fordert «, behauptet er, "daß, wenn die wesentlichen Bestimmungsstücke eines Wesens sich denen eines anderen nähern, auch alle sonstigen Eigenschaften des ersteren sich stetig denen des letzteren nähern müssen ${ }^{3}$ ) «.

Cuviers Gesetz von der Korrelation der organischen Eigenschaften ist nur der Fassung nach von diesem für die Philosophie LEIBNIZens charakteristischen Prinzipe verschieden. Während der letzten Jahrzehnte des I8. Jahrhunderts wurde diese Idee (vielleicht unter BUFFons Einfluß) vielfach ausgesprochen; so von HERDER in seinen Ideen zur Entwicklungsgeschichte der Menschheit (I784) und von dem Arzt Pinel (I793) und namentlich von Goethe ${ }^{4}$ ). Mit einer kurzen Schilderung der morphologischen Spekulationen aus dem Ende des 18. und dem Anfange des 19. Jahrhunderts wollen wir die Erörterungen des I. Bandes unserer Schrift abschließen, um im zweiten wiederum an dieselben anzuknüpfen.

1) Nach Js. Geoffroy, Vie d'É. Geoffroy. Paris 1847 . S. 142.

2) Ebenda, S. 143. (Uniformitas illa quae est in corporibus animalium. Similiter posita omnia in omnibus fere animalibus.)

3) Aus dem Briefe an Varignon (CASsierer, Leibnizens Hauptwerke. II. S. 77.)

4) Über Goethe, Herder und die Naturphilosophen wird im 2. Teil dieser Schrift gehandelt. 


\section{Die Entwicklung der botanischen Morphologie.}

Die Botaniker leiten die Lehre von der Pflanzenform von den Bemühungen BERNARD DE JUSSIEUs (I699-I776) ab, der, ohne etwas zu veröffentlichen, ein natürliches, nach anatomischen Verwandtschaften angeordnetes Pflanzensystem in der Katalogisierung der Pflanzen im botanischen Garten von Trianon eingeführt hat. Sein System ist später (1789) von seinem Neffen A. L. DE JUSSIEU (I748-I836) bekannt gemacht worden. Dieser unternahm den Versuch, die natürlichen Pflanzenfamilien (die sich bereits durch den äußeren Habitus als einheitliche Gruppen ergeben) durch bestimmte Merkmale zu charakterisieren und scharf voneinander $\mathrm{zu}$ unterscheiden. Er ging von der theoretischen Annahme einer Hierarchie der Merkmale aus, d. h. von der Voraussetzung, daß gewissen Merkmalen eine allgemeinere, umfassendere Geltung zukommt als anderen; diese Voraussetzung hat später bei CUviER eine wesentliche Rolle gespielt.

Michel AdANSon (1727-I806), ein exzentrischer Geist, hat in eigenartiger Weise die LinNésche Beschreibung der Pflanzen nach ihren Teilen mit morphologischer Auffassung zu verknüpfen gesucht. Er betrachtete einzelne Pflanzenorgane für sich und verfolgte deren Modifikationen bei verschiedenen Pflanzen; auf Grund der Modifikationen eines Organs klassifizierte er dann die Pflanzen, deren Verwandtschaftsbeziehungen hinsichtlich dieses Organs er feststellte. Dies führte er für jedes einzelne Organ durch und erhielt so eine Reihe von Systemen, die er miteinander verglich. In je mehr Systemen die Arten einander nahestehen, ein desto höherer Grad gegenseitiger Verwandtschaft ist ihnen zuzusprechen. So glaubte ADANSON zu einem System gelangen zu lsönnen, das rein natürliche Verwandtschaften zum Ausdruck bringt. Seine Theorien hat ADANSON in so dickleibigen Büchern veröffentlicht wie kaum je ein anderer, und noch dickere Bücher waren sein Ideal.

Am konsequentesten hat die morphologische Auffassung der Pflanzen Pyrame De Candolle (I778-I84I) durchgeführt.

De CANDOlle will das natürliche System auf der Kenntnis der Organe und ihrer Beziehungen zueinander aufbauen.

Bei der ganzen Pflanzenforschung, sagt er ${ }^{1}$ ), ist es ein Gegenstand

1) A.P. DE Candolles und K. Sprengels Grundzüge der wissenschaftl. Pflanzenkunde (worin die morphologischen Teile der »Théorie élémentaire DE CANDoLles wiedergegeben sind). S. 147 . 
von höchster Wichtigkeit, daß man über die wahre Bedeutung und Natur eines Organs im reinen sei, denn nur dann kann man sich einer richtigen Einsicht in den Haushalt der Gewächse rühmen.

Die Bedeutung eines Organs wird erstens an seiner Funktion erkannt; zweitens aber muß man seine Beziehungen zu anderen Organen ins Auge fassen:

es treten nämlich in unzähligen Fällen ähnliche Formen auf wie diejenigen, welche einer bestimmten Verrichtung dienen, doch werden sie nicht geübt, und die Natur scheint in solchen Fällen ebenso wie im Tierreich um der übereinstimmenden, symmetrischen Bildung willen oft völlig unnütze Formen hervorzubringen... Das alles sind Bildungen, die man sich nur aus dem Naturgesetz erklären kann ${ }^{1}$ ).

Unter der Symmetrie der Teile versteht DE CANDOLLE ihre relativen Stellungsverhältnisse. Jedesmal, wenn diese relativen Stellungsverhältnisse $\mathrm{nach}$ demselben Plane geregelt sind, bieten die Organismen unter sich eine Ort von Gesamtähnlichkeit dar, unabhängig von der Form der Organe im einzelnen. Für jede Pflanzenklasse muß man zunächst den Symmetrieplan kennen, und dessen Studium hat als Grundlage für jede Theorie der natürlichen Verwandtschaften zu gelten.

Um ein Organ morphologisch beurteilen zu können, muß man sowohl seine Symmetrie als auch sein Verhältnis zu anderen Organen oder zur ganzen Pflanze untersuchen. "Die Lage und Stellung der Teile ist der höchste Gesichtspunkt «²). Die absolute Lage und die relative Stellung verschiedener Organe zueinander sind zu unterscheiden; man muß nicht allein wissen, daß die Staubfäden auf dem Fruchtboden stehen (absolute Lage), sondern sich auch darüber klar werden, ob sie mit den Kronenblättern abwechseln oder, ihnen entgegengesetzt, vor ihnen stehen (relative Lage).

Die Begriffe der Symmetrie, des Verhältnisses der Organe zu einander, der absoluten und relativen Lage sind abstrakt morphologische Begriffe; DE CANDOLLE führt auch konkretere an, so die Gesichtspunkte, von denen aus man die wahre Natur eines Organs ermitteln kann. Er führt folgende Gesichtspunkte an:

I. Das Fehlschlagen der Organe. Die Natur solcher abortierter Organe erkennt man durch vergleichendes Studium, durch Verfolgung ihrer Entwicklung, durch Analogie, d. h. wenn eine Bil-

1) S. 148 .

2) S. 165 .

Radl, Geschichte der biol. Theorien. I. 2. Aufl. 
dung mehreren Familien gemeinsam ist, so werden wir, auch wo sie zu fehlen scheint, ihre Andeutung doch nicht verkennen.

2. Die Verwandlung und Ausartung der Teile. Es ist ein für die ganze Pflanzenwelt wichtiges Gesetz, daß aus jedem einzelnen Teil eines Gewächses sich jeder andere entwickeln kann, also daß die Wurzeln zu Stämmen und Zweigen, die letzteren wieder zu Wurzeln, die Blätter zu Blattstielen und umgekehrt usw. werden können.

3. Das Verwachsen von Organen. Gleichartige Organe sind darauf angelegt, nicht allein zusammenzuhängen, sondern auch zusammenzuschmelzen; so z. B., wenn bei den Umbelliferen jedesmal zwei Früchte verwachsen. Mehrere Gesetze der Verwachsung werden unterschieden: a) Die Wichtigkeit der Verwachsungen in den Befruchtungsteilen nimmt zu, je mehr dieser Vorgang mit Schwierigkeiten verbunden ist; denn je mehr Hindernisse zu überwinden sind, um so mächtiger muß die Ursache sein, welche sie beseitigt. b) Die Analogie der Teile erleichtert ihre Verschmelzung. c) Das Verwachsen ist um so wichtiger, je notwendiger es mit gewissen Änderungen in der allgemeinen Symmetrie verbunden ist.

Die Regeln über die Anwendbarkeit der Morphologie auf die Bestimmung der Verwandtschaftsverhältnisse schließt DE CANDollE. mit dem Ausspruch, die ganze Kunst der natürlichen Klassifikation bestehe darin, den Sy m metrieplan zu erkennen und von all den besprochenen Veränderungen desselben zu abstrahieren, ungefähr so, wie der Mineralog die Grundformen der Kristalle aus deren zahlreichen Ausbildungformen herauszufinden sucht.

Wie J. Sachs nachweist ${ }^{1}$ ), ist DE CANNOLLE den rein morphologischen Prinzipien in der Ausführung seines Systems jedoch nur bei der Bestimmung der kleineren Verwandtschaftskreise treu geblieben; bei der Aufstellung der größeren und größten Abteilungen des Pflanzenreichs hat er sich nach physiologischen Merkmalen gerichtet.

In ähnlicher, doch weniger theoretisierender Richtung als DE. CANDOLIE bearbeitete RoBERT BRown (I773-I858) die Morphologie der Pflanzen. BRowns Tätigkeit erschöpfte sich ${ }^{2}$ ) in kritisch-monographischer Bearbeitung der einzelnen Pflanzenfamilien auf Grund der vergleichenden Anatomie; eine Theorie der Klassifikation und

1) Gesch. d. Bot. S. I37 sq.

2) Ich übernehme dieses Urteil aus SAcHs. 
eine theoretische Darstellung der Morphologie hat er nicht dargeboten $^{1}$ ).

DE CANDOLle wurde eifrig von den deutschen Naturphilosophen studiert, bei denen morphologische Spekulationen im I9. Jahrhundert Zuflucht gefunden haben.

\section{Die Morphologie der Tiere vor Cuvier und Geoffroy.}

LUDWIG XIII. gründete auf Anregung seines Leibarztes GUY DE LA BROSSE I626 in Paris den seither berühmten botanischen Garten (Jardin de roi, später Jardin de plantes), der zuerst als pharmazeutische Schule verwendet werden sollte. Allmählich stieg die Bedeutung dieser Institution; ihr Ruhm wurde jedoch erst durch Buffon, ihren Leiter, begründet. Von LUdwiG XIV. wurde an dem Garten eine zu wissenschaftlichen Zwecken dienende Menagerie gegründet; die Zergliederung der dort verendeten Tiere lieferte das Material für anatomische Untersuchungen an den Wirbeltieren. Als solche Zergliederer ohne höhere theoretische Aspirationen taten sich namentlich Claude Perrault (I6I3-i688), Joseph Guichard Duverney (I648-I730), JEAN Georges Duverney (I69i-I759) u. a. hervor. Außerhalb Frankreichs haben zu jener Zeit, ebenfalls ohne höhere theoretische Gesichtspunkte zu verfolgen, insbesondere der berühmte Physiologe AlBRECHT von HALleR (I708-I777) in Deutschland, John Hunter (I728-i793) und EDw. Tyson (I650 bis I708) in England die Anatomie auf ähnliche Weise betrieben. Alex. Monro hat sogar ein "Essay on Comparative Anatomy " I 744 herausgegeben, ohne das Wesen dieser Wissenschaft erraten zu haben. Auch Louis J. M. DAuberTon (I 7 I6-I799), dem Mitarbeiter Buffons, war es nicht verliehen, sich in seiner Anatomie der Säugetiere zu einer selbständigen Auffassung der strukturellen Eigenschaften der Tiere aufzuschwingen.

Der erste Biologe nach BufFon, welcher darauf ausging, die Morphologie theoretisch zu erfassen, war FELIX VICG D'AzYR (I748 bis I794), Leibarzt der Königin Marie Antoinette, seit 1774 Professor

1) Literatur. AdANSON, M., Ordre universel de la nature, ou Méthode naturelle comprenant tous les êtres connus, leur qualités matérielles et leurs facultés spirituelles, suivant leur série naturelle, indiquée par l'ensemble de leurs rapports. 27 Vols. Paris 1749. - Jussieu, A. L., Genera plantarum. Paris 1789. - DE Cancolle, P., Théorie élémentaire de la botanique ou exposition des principes de la classification naturelle et de l'art d'écrire et d'étudier les végétaux. Paris $\mathbf{I}^{8} \mathrm{I}_{3}$. - - 
der Anatomie in Paris $^{1}$ ). In einer Reihe von anatomischen Arbeiten über Fische und Vögel, über die Analogie zwischen der Hand und dem Fuß, über das Gehirn usf. versuchte er seine Anschauungen zu verwerten. Theoretisch entwickelte er sie in seinem Vortrage über die Anatomie ${ }^{2}$ ). In dem letzteren lehrt er, daß die vergleichende Anatomie nicht nur die ähnlichen Organe verschiedener Tiere, sondern auch verschiedene analog gebaute Organe eines und desselben Tieres miteinander zu vergleichen hat. Die Organe des Körpers stehen in einem festen Zusammenhang: die äußeren, welche namentlich der Lokomotion dienen, und die inneren, die für die Ernährung, Empfindung, Fortpflanzung und für das Leben notwendig sind, entsprechen einander; die einen können keine wesentlichen Veränderungen erleiden, ohne daß die anderen daran teilnehmen ${ }^{3}$ ) ein Grundsatz, der später verallgemeinert und klar ausgedrückt als Korrelation der Formen bezeichnet wurde.

Der Gedanke eines Organisationsplanes, nach welchem die Tiere geformt sind, ist VICG D'AZYR nicht fremd. So findet sich in seiner Abhandlung zur Vergleichung der vorderen und hinteren Extremität des Menschen die Ansicht ausgesprochen, daß Hand und Fuß nach demselben Grundplane gebaut sind; das rudimentäre Schlüsselbein vieler Säugetiere sei aus dem für die Tiere geltenden einheitlichen Bauplan zu erklären, von dem die Natur nur ungern abweiche ${ }^{4}$ ).

Die Natur scheint allen Wesen zwei keineswegs kontradiktorische Charaktere eingeprägt zu haben: denjenigen der Konstanz des Typus und der Veränderlichkeit in den Modifikationen des letzteren, sagt er im Allgemeinen ${ }^{5}$ ).

Trotz solcher beachtenswerter Grundsätze und trotz gelungener konkreter Ausführungen blieb VICG D'AZYR wesentlich noch der physiologischen Auffassung der Tiere unterworfen; er stellt die physiologischen Prinzipien den morphologischen voran, und das rein Morphologische, das uns bei ihm begegnet, äußert sich noch wie unbewußt. Er beginnt seine Studie über das Wesen der Anatomie mit physiologischen Betrachtungen über die Lebenskraft, um zu den Funktionen des lebendigen Körpers überzugehen, die er in Stoffwechsel, Lokomotion und Sensibilität einteilt; er bezieht im speziellen

1) Ausführliches über ihn vgl. in der Einleitung zu seinen gesammelten Schriften und bei Blainville.

2) Discours sur l'anatomie. Euvres T. IV. S. I.

3) Ebenda, S. 22.

4) Ebenda, S. 26.

5) Cuvres IV. S. 3 I 5 . 
Teil die morphologischen Tatsachen fortwährend auf die Funktionen und behauptet sogar, daß wir die Anatomie (nur) deshalb kennen müssen, weil sie für das Verständnis der Funktion unentbehrlich ist ${ }^{\mathbf{1}}$. An einer Stelle sagt er, die Anatomie mache nur das Gerüst (squelette) der Wissenschaft aus, erst die Physiologie gewähre ihr die Beweglichkeit ${ }^{2}$ ). Seine Einteilung des Tierreichs ist physiologisch begründet. Er behauptet zwar, daß die Klassifikation auf Grund der morphologischen Eigenschaften durchgeführt werden müsse, tatsächlich basiert er sie jedoch auf das Vorhandensein des Darmkanals, der Atmungswerkzeuge, der lymphatischen Gefäße, der Genitalorgane, der Sinnesorgane, des Gehirns, der Knochen, wie überhaupt der physiologisch bestimmten Organe.

Peter CAMper (I722-I789), ein anderer Vorläufer der Morphologie, war nacheinander Professor der Philosophie, der Anatomie, der Chirurgie und Medizin an mehreren holländischen Universitäten. Seine schöngeistigen Arbeiten behandeln die verschiedensten Themata: praktische Medizin, Philosophie, Ästhetik, Anatomie u. a. CAMPER ist jener Anatome, der als Beleg dafür, daß in geschickten Händen auch ein anscheinend unbedeutendes Thema interessant werden kann, eine wissenschaftliche Abhandlung über die Form der Schuhe schrieb.

Wenn bei CAMPER von vergleichender Anatomie die Rede ist, so darf man dabei nicht an eine Wissenschaft denken, die durch Vergleichung der organischen Strukturen auf allgemeine Sätze führt. Er hat die Tiere anatomisch untersucht, das Bemerkenswerte hervorgehoben, doch nur gelegentlich und ohne bestimmte Absicht die Organe verglichen. Der Leser wird sich eine Vorstellung von seiner Auffassung der vergleichenden Anatomie aus dem Inhalt einer der besten seiner anatomischen Arbeiten, der Untersuchung des Baues vom Orang-Utan bilden, in der er nachweist, daß der Mensch und der Orang als verschiedene Arten zu gelten haben. Diese Arbeit ist I782 erschienen, also zu einer Zeit, wo man Arten, Gattungen usf. bereits gut zu unterscheiden wußte. So sehr hat man damals noch an die anatomische Ähnlichkeit zwischen dem Menschen und den höheren Affen geglaubt, daß CAMPERs Arbeit Aufsehen in der wissenschaftlichen Welt erregt hat. CAMPER zieht aus seiner Untersuchung folgende Schlüsse: 
Erstlich, daß der Orang sowohl in seiner Gestalt und Größe als auch im Gange sehr vom Menschen verschieden sei, - daß er weder sprechen und sitzen, noch auf dem Rücken liegen könne wie der Mensch -, viel weniger etwas anfassen, da sein Daumen viel zu kurz ist; zweitens, daß der Orang wirklich ein vierfüßiges Tier sei, welches.zwar mit einigen Affen, wie mit dem Gibbon und dem Pygmy des Tyson große Ähnlichkeit hat, doch von ihnen auch wieder in dem Stimmwerkzeug und im Knochenbau der Hände und anderer Teile sehr verschieden ist, und vornehmlich, daß er vom Pithecus nicht allein hinsichtlich des Stimmwerkzeugs, der Gestalt und der Eingeweide, sondern auch bezüglich der Knochen, insbesondere der Hände, erheblich abweiche. Der Orang-Utan von Borneo ist also ein Tier, welches zwar zum allgemeinen Geschlecht der Affen oder vierhändigen Tiere gehört, aber doch zugleich eine ganz besondere Art desselben ausmacht.

Vergleichend anatomisch ist auch die Vorlesung CAMPERs über die Analogie zwischen den Tieren und Pflanzen. Er hebt in diesem schöngeistigen Vortrage die Ähnlichkeit zwischen den Gefäßen, Drüsen und Sexualorganen der Pflanzen und jenen der Tiere hervor, weist auf die Spuren der Reizbarkeit bei den Pflanzen hin und erörtert die Möglichkeit, daß auch die Pflanzen ein diffuses Nervensystem haben. Eine Vorlesung widmete CAMPER auch den Analogien zwischen Menschen, Säugetieren, Vögeln und Fischen, doch zeichnet er diese Analogien nur in den allgemeinsten Umrissen. Mehrere seiner Abhandlungen beziehen sich auf die Physiognomie des Menschen, einer Forschungsrichtung, die um die Jahrhundertwende vielfach gepflegt wurde und der Morphologie nahesteht.

In Deutschland knüpften die Anatomen anfangs an LINNÉ an; unter seinem Einflusse stand AUG. JoH. GEORG CARL BATSCH (I76I bis I 802), von dem man rühmend hervorhebt, daß er vor CuviER die Wirbeltiere in eine Klasse ("Knochentiere «) zusammenfaßte; auch führte er zuerst zwischen die LINNÉschen Gruppen der Ordnung und der Gattung die »Familie« ein. Die späteren deutschen Autoren gehören der Periode der Naturphilosophie an. Die bedeutendsten unter ihnen waren IGNAZ DölLINGER (I770-I84I), KARL FRIEDR. BURDACH (I776-I847), FRIEDRICH TIEDEMANN (I78I-I860), LUDWig HEINRICH BOJANus (I776-I827), KarL Gustav Carus (I789 bis i 869), JoH. FrIEDR. MECKEL (I78I-I833), KARL ASMUND RUDOLPHI (I777-I832) und andere. Insgesamt taten sie sich mehr durch Herausgabe von Handbüchern, als durch Aufstellung eigener Theorien hervor ${ }^{1}$ ).

1) Literatur. Perrault, Cl., Description anatomique de divers animaux disséqués dans l'acad. roy. des sciences accompagnés de leur squelette et réprésentés, en figures gravées avec les observations faites en leur dissection. Paris 1682. - Duverney, J. G., 


\section{Georges Cuvier.}

\section{a) Morphologie.}

Georges (Leopold Christian Friedrich Dagobert) Cuvier ${ }^{1}$ ) (I769-I832) studierte seit I784 an der Karlsschule in Stuttgart Naturgeschichte und wurde dort mit dem Naturphilosophen KIELMEYER befreundet. Auf GEOfFroys Einladung kam er I794 nach Paris, wo er 1795 zum Professor der Naturgeschichte an den Zentralschulen erwannt wurde; später bekleidete er noch viele andere Ämter.

Cuvier hat versucht, Linnés gelehrte Methode, die in weltmännisch gesinntem Paris wenig Anhängerschaft fand, mit der Lehre Buffons zu versöhnen und ein morphologisch begründetes System der Tiere zu entwickeln. Alle morphologischen Untersuchungen CuvieRs sind von der Überzeugung getragen, daß Form und Funktion des Tieres eine in sich geschlossene Einheit darstellen, und daß alle Teile und Funktionen des Organismus

Traité de l'organe de l'ouie. Paris 1683. - CEuvres anotomiques. 2 Vols. Paris I76I. - Haller, A. von, Opera anatomici argumenti minora. 3 Vols. Lausanne I663-68. - Hunter, John, Observations on certain parts of the animal oeconomy. London I786. - Daubenton, L. J. M.; in Buffons Histoire naturelle, Ausgabe in 7 I Bänden, sind die ersten 19 von DaUBEnTon geschrieben. Paris 1752-I805. - VICG D'AzYR, F., Traité d'anatomie et de physiologie. Paris I786-89. - Discours sur l'anatomie. (Euvres. I805. T. 4.) - Mémoire sur les rapports qui se trouvent entre les usages et la structure de quatre extrémités dans l'homme et dans les quadrupèdes. (Ebenda). CEuvres, recueillies et publiées par J. L. Moreau. 6 Vols. Paris I805. - Camper, P., Natuurkundige verhandelingen over den Orang-Outang; en eenige andere aap-sorten; over den Rhinoceros, met den dubbelen horen, en over het Rendier. Amsterdam I782. - Discours sur le moyen de représenter d'une manière sûre les diverses passions qui se manifestent sur le visage, sur l'étonnante conformité qui existe entre les Quadrupèdes, les Oiseaux, les Poissons et l'Homme; et sur le beau physique; publié par A. G. Camper (Sohn). Utrecht I792. - CAMPer, Petr., Cuvres, qui ont pour objet l'histoire naturelle, la physiologie et l'anatomie comparée. 3 Vols. Paris I803. - Batsch, A. G. K., Versuch einer Anleitung zur Kenntnis und Geschichte der Tiere und Mineralien. Jena I788. - Einleitung zum Studium der allgem. Naturgeschichte. 3. Abtlg.: Tierreich, mit Zusätzen von L. F. Froriep. Weimar I806. - Döllinger, Joh. IGN. Jos., Über den Wert und die Bedeutung der vergleichenden Anatomie. Würzburg I8I4. BURdach, KARL FrIEDr., Die Physiologie als Erfahrungswissenschaft. Leipzig I832 bis I840. - Carus, C. G., Grundzüge der vergleichenden Anatomie und Physiologie. 3 Bände. Dresden 1828 . - Bojanus, Ludw. HeInr., Introductio in anatomiam comparatam. Vilnae 1815. - Anatome testudinis europaeae. Vilnae 1819. - TiedemanN, FrIEDR., Anatomie und Bildungsgeschichte des Gehirns im Fötus des Menschen, nebst einer vergleichenden Darstellung des Hirnbaues in den Tieren. Nürnberg 1816. Meckel, Joh. Friedr., System der vergl. Anatomie. 5 Teile. Halle I820-31. Rudolphi, Karl AsM., Beobachtungen aus der vergl. Anatomie. Berlin 1822.

1) Vgl. über Cuvier auch den 2. Teil dieser Schrift. 
nach einem Gesetz miteinander verbunden sind. Alle Organe und alle Funktionen im Körper stehen im Gleichgewicht; darunter ist nicht nur zu verstehen, daß der Körper nicht $\mathrm{f} u \mathrm{nkt}$ i on iere $\mathrm{n}$ kann, wenn ein Organ fehlt, sondern auch, daß das Nichtvorhandensein eines Körperteils die Planmäßigkeit der Form stört. CUviER bemerkt, daß die vergleichende Anatomie den mathematischen Wissenschaften sehr nahe stehe; der Vergleich der ersteren mit der Geometrie wäre wirklich nicht unzutreffend.

Die Vorstellung vom einheitlichen Bauplan der Tiere führt CUVIER auf seine Lehre von der Korrelation der For men zurück. Er begründet sie folgendermaßen ${ }^{\mathbf{1}}$ ):

Jedes Tier bildet ein einheitliches, in sich geschlossenes System, in dem alle Teile (erstens) aufeinander strukturell angewiesen sind und (zweitens) zu einer einheitlichen Gesamtleistung des Körpers nach gesetzmäßigem Verhältnis beitragen. Kein Teil kann sich verändern, ohne daß andere mit verändert würden, und so bestimmt jeder Teil alle übrigen.

a) Ist der Verdauungskanal eines Tieres für die Fleischnahrung eingerichtet, so müssen auch die Kauapparate dieses Tieres zum Zerschneiden des Fleisches, seine Bewegungsorgane zum Erhaschen der Beute angepaßt sein, dem Gehirn muß der Trieb innewohnen, auf die Beute zu lauern, u. ä. m. Es ist also möglich, aus der Kenntnis der Lebensweise eines Tieres Schlußfolgerungen auf seine Organisation zu ziehen. Würden wir ferner die Bezichungen zwischen dem Bau und der Tätigkeit der Organe vollständig kennen, so wäre uns möglich, aus der Kenntnis eines einzigen Organs das ganze Tier zu rekonstruieren; denn wir würden die Funktion dieses Organs, aus dieser die Lebensweise des Tieres, und daher auch die Funktionen sämtlicher anderer Organe erraten, aus denen man dann leichter auf ihren Bau zu schließen vermöchte.

b) Während man im angeführten Beispiel eines fleischfressenden Tieres von der Lebensweise leicht auf die Bauart schließen kann, ist dies in anderen Fällen unmöglich. Es kann z. B. nicht durch die Beziehung auf die Lebensweise erkannt werden, warum alle Wiederkäuer Zweihufer sein müssen oder daß nur diese Ordnung Hörner besitzen kann. Weil aber auch diese und ähnliche gegenseitige Beziehungen der Organe konstant sind, so müssen sie einen hinreichenden Grund haben, der aus der Erfahrung zu ermitteln ist.

1) Anatomie comparée. T. I. S. 38. 
Durch die Erfahrung stellen wir Erfahrungsgesetze auf, welche fast die Gewißheit der rationellen Gesetze gewinnen, wenn sie auf einer oft genug wiederholten Beobachtung aufgebaut sind, so daß jeder, der die Spur eines gut gespaltenen Hufes sieht, daraus schließen kann, das Tier, dem ein so gebauter Fuß gehört, sei ein Wiederkäuer; und dieser Schluß ist so bestimmt, wie jeder andere in der Naturgeschichte oder in der Moral.

c) Durch die Tatsache, daß bestimmte Eigenschaften der Tiere stets mit anderen Eigenschaften zugleich vorkommen (WiederkäuerZweihufer), ist die Bedeutung dieser Beziehungen noch nicht erschöpft. Das Gebiß der behuften nicht wiederkäuenden Tiere ist durchgängig vollkommener als das der Wiederkäuer; aber auch im Bau ihres Fußes zeigt sich eine größere Vollkommenheit, sei es, daß sie mehrere Finger besitzen, sei es, daß sie mehrere freie Knochen im Mittelfuß oder in der Fußwurzel haben, oder alle diese Charaktere zusammen besitzen. Wir dürfen aber nicht nur schließen, daß immer ein komplizierter gebauter Fuß auch ein vollständigeres Gebiß nach sich zieht, sondern auch, daß, wenn ein Wiederkäuer im Gebiß von anderen $Z$ weihufern etwas abweicht, auch der Bau seines Fußes abweichend ist, wie es z. B. bei dem Kamel der Fall ist, das nicht nur (zum Unterschied von anderen Zweihufern) obere Schneidezähne und Eckzähne, sondern auch einen anders gebauten Fuß als andere Wiederkäuer besitzt.

Die Grenzen zwischen morphologischer und physiologischer Korrelation sind von CUviER nicht so scharf gezogen worden, wie es hier geschehen ist. Besonders in der Praxis hat er die physiologische (funktionelle) Korrelation gegenüber der morphologischen gar zu oft in den Vordergrund gerückt. So bestimmt er zu klassifikatorischen Zwecken (die Klassifikation soll bei ihm morphologisch sein) rein funktionelle Korrelationen zwischen der Atmung und der Blutzirkulation, daß nämlich Tiere mit einem Herzen durch lokalisierte Organe (Kiemen, Lunge) atmen, Tiere ohne Herz mit Tracheen u. ä.

Die Tatsache, daß Cuvier den Gedanken nicht durchgeführt hat, den morphologischen Korrelationen eine selbständige Stellung gegenüber den funktionellen zu sichern, zeigt, wie sehr er noch von der physiologischen Betrachtungsweise des Organismus beherrscht wurde. Wir werden sehen, daß dies auch in anderer Hinsicht bei ihm zutrifft.

Die Lehre von den Korrelationen führt auf den Begriff der istatischen "Zweckmäßigkeit (nach der Terminologie von H. DRIESCH). Die Einheit, zu der die Teile des Organismus verknüpft sind, ist der Zweck des Organismus. Die Organe stehen ferner zu den Funk- 
tionen des Organismus in Beziehung; infolgedessen sind diese Funktionen der Zweck der Organe. Endlich steht der Organismus in einem bestimmten Verhältnis zu seiner Umgebung (loi des conditions d'existence); und in dieser Hinsicht sind sein Bau und seine Funktion wiederum zweckmäßig, eben diesen Bedingungen angepaßt.

Die Lehre von der Einheit im Bauplan und von den Korrelationen dient CUvier zur Grundlage des Tiersystems. Jede Tierart ist nach ihm einem besonderen Plane gemäß gebaut, etwa so, wie jede regelmäßige Figur einem Plan, einem Gesetz entspricht, demzufolge sie eben regelmäßig ist. Dieser Plan ändert sich von einer Art zur anderen. Ebenso wie die Individuen einer Art haben auch alle Arten einer Gattung einen gemeinsamen Plan, d. h. etwas Gemeinsames und Gesetzmäßiges in ihrer Struktur, und gleicherweise auch die Gattungen einer Ordnung und die Ordnungen einer Klasse. In der Ausführung dieser Grundsätze ist CUvIER weniger konsequent; er berücksichtigt in concreto die Anzahl und die relative Lage der Organe und nicht der morphologisch definierten Elemente; unter ähnlichem Bauplan versteht er die Tatsache, daß die Zahl und die spezielle Ausbildung der Organe variieren, aber dieselbe Stellung zueinander beibehalten. CUVIER hat ohne eingehendere Untersuchung seine Lehre auf die These gegründet, daß die Organe elementare morphologische Einheiten sind. Ein Organ ist aber etwas Physiologisches, etwas, das durch die Funktion, deren Organ es eben ist, bedingt wird. Die Hand z. B., als ein Werlkzeug, dessen sich der Körper bedient, ist ein Organ; die vordere Extremität dagegen, die nur einen strukturellen Plan für verschiedenartige Werkzeuge, als wie für die Hand, für den Vorderfuß, für den Flügel darstellt, ist als ein morphologischer Bestandteil aufzufassen. Als CuviER seine Baupläne durch die relative Lage der Organe bestimmt sein ließ, hat er sie eben dadurch nach wesentlich physiologischen Merkmalen charakterisiert: der Begriff der relativen Lage ist morphologisch, der Begriff des Organs dagegen physiologisch.

Daraus erklärt sich, daß die höchsten Gruppen Cuviens in der Theorie physiologisch begründet sind.

CUVIER verließ sich auf den apriori festgestellten Grundsatz, daß der Körperbau im großen und ganzen von den funktionell bedeutsamsten Organen beherrscht wird, und zog aus diesem Grundsatz die Folgerung, daß rotblütige Tiere mehr dem Menschen ähnlich sind als diejenigen, die kein rotes Blut besitzen, 
denn da alle Körperteile direkt oder indirekt aus dem Blut entstehen, muß in der Beschaffenheit des Blutes der wichtigste Grund für die Unterschiede zwischen jenen Teilen gesucht werden. Daher haben die weißblütigen Tiere nur dasjenige mit den rotblütigen gemeinsam, was für den Begriff des Tieres als eines solchen wesentlich ist, während die Reihe der rotblütigen Tiere nur Modifikationen eines und desselben Planes darstellt, dessen wesentlichsten Grundzüge unverändert bleiben ${ }^{1}$ ).

Nach der Beschaffenheit der Oxydation des Blutes will Cuvier auch die Wirbeltiere einteilen ${ }^{2}$ ), während er die weißblütigen Tiere eher nur negativ bestimmen wollte (da ihnen gewisse Eigenschaften fehlen sollen); er möchte sie nur der Reihe nach durchnehmen und auf die stufenweise Vereinfachung ihrer Organisation hinweisen. In seinem großen Werke "Règne animal «(I8I7) teilt CuvieR die Tiere nicht mehr nach der Blutbeschaffenheit ein, ohne jedoch den physiologischen Standpunkt verlassen zu haben. Als den Grund der Klassifikation nimmt er jetzt in erster Reihe die Organe, welche der Empfindlichkeit und der Bewegung dienen (Gehirn, Sinnesorgane, Muskeln, Knochen), welche erstens für die Tiere als solche wesentlich sind und zweitens auch den Grad der Animalität eines jeden Tieres angeben sollen. An zweiter Stelle wollte er das Herz und die Organe des Kreislaufes im allgemeinen berücksichtigen,

die eine Art Zentrum für die vegetativen Funktionen bilden, wie das Gehirn und das Rückenmark als Zentren für die animalen Funktionen dienen $\left.{ }^{3}\right)$.

So hat Cuvier, obwohl ein Morphologe, die Einteilung des Tierreiches nach physiologischen Merkmalen durchzuführen gesucht. Etwa weil eine konsequent morphologische Einteilung nicht durchzuführen ist, oder weil sie nicht natürlich wäre? Cuvier hat über diese Frage nicht nachgedacht, wie es überhaupt nicht seine Sache war, die letzten Konsequenzen aus seinen Thesen zu ziehen. Cuviers Grundlage der Klassifikation ist nur um einen Grad natürlicher als diejenige LINNÉs; jedenfalls hat weder Cuvier noch jemand nach ihm den Nachweis geführt, daß Cuviers klassifikatorische Prinzipien auf das natürlichste System führen müssen.

CUVIER begründet seine Typenlehre nur empirisch, nicht rationell; er konnte keinen allgemeinen Grund dafür anführen, warum ẻben die Verschiedenheit im Bau des Nervensystems die Veränderung des

1) Tableau élémentaire de l'hist. nat. des animaux. Paris an VI. (I798).

2) Ibid., S. 86.

3) Règne animal. S. 55 . 
Grundplans verursacht, und warum etwa die Variationen im Bau der Atmungsorgane auf einen und denselben Grundplan zurücligeführt werden dürfen. Er konnte nur empirisch nachweisen, daß die als verschiedene Typen aufgefaßten Tierformen in Wirklichkeit sehr voneinander verschieden sind. So erscheint die Morphologie CuvIERs auch in diesem Punkt als eine Organanatomie und nicht als eine reine Formenlehre.

Vom Begriffe der Einheit des Bauplans ging Cuvier logisch ganz folgerichtig zu dem der Subordination der Charaktere über, den er (dem Beispiele des jüngeren Jussieu folgend, der diesen Begriff in die botanische Morphologie vor CUvier einführte) zur Grundlage der Systematik gemacht hat.

Die Bedeutung der verschiedenen Teile eines Organismus ist nach diesem Prinzip von ungleichem Werte, $d$. h. der eine Teil ist für die Einheit der Form und Funktion wesentlicher als ein anderer. Nach ihrer morphologischen und funktionellen Bedeutung zusammengestellt, würden die Teile des Organismus eine Hierarchie bilden, welche sich für klassifikatorische Zwecke am besten verwerten läßt.

Als weniger bedeutend sind diejenigen Merkmale der Tiere aufzufassen, die nur engeren Kreisen der Tierformen angehören; je allgemeiner ein Merkmal in der Tierreihe vorkommt, desto höher steht es in der Hierarchie der Teile. Auch die Korrelationen zwischen einzelnen Merkmalen sind von verschiedenem Werte. Vergleichen. wir - sagt Cuvier - z. B. die Korrelation zwischen der Bezahnung und anderen Körpereigenschaften mit derjenigen zwischen dem Bau der Wirbel und anderen Organen, so erscheinen die letzteren als. von viel radikalerer Natur zu sein, denn die Variationen in der Ausbildung der Zähne sind mit solchen Veränderungen im Bau der Tiere verbunden, die zur Aufstellung nur der Arten, Gattungen oder kleinerer Gruppen führen, während an das Vorhandensein des. Rückenmarks alle Eigenschaften gebunden sind, welche das Wirbeltier den Wirbellosen gegenüber charakterisieren. Der morphologische Verband zwischen dem Rückenmark und den übrigen Körpereigenschaften ist so fest, daß er von der Variation der übrigen Körperteile kaum betroffen wird; das Gebiß kann innerhalb weitester Grenzen. variieren, ohne daß das Rückenmark dadurch stark beeinflußt wird; das Gebiß kann auch vollständig fehlen (bei den Walen z. B.), aber das Rückenmark bleibt unverändert; wenn aber umgekehrt das Rückenmark in seiner Ausbildung variiert, so sind damit sehr starke Veränderungen im Gebiß (zwischen den einzelnen Wirbeltierklassen). 
verbunden; fehlt das Rückenmark, so ist der Körperbau so radikal verändert, daß an ein Gebiß gar nicht gedacht werden kann (wirbellose Tiere). Es gibt also Korrelationen engerer und allgemeinerer Art: je allgemeiner eine Korrelation ist, desto größeren klassifikatorischen Wert hat sie; der Wert der Korrelation ist also ein Maß für die systematische Wichtigkeit einer Eigenschaft.

Nur durch vergleichendes Studium (und durch das Experiment) gelangt man zur Erkenntnis der Wichtigkeit eines. Körperteils; natürlich wird man morphologische und physiologische Bedeutung der Teile begrifflich voneinander unterscheiden müssen. CUviER hat weder das eine noch das andere getan, und ist wieder in der physiologischen Auffassung der Organismen stecken geblieben. Wie oben bemerkt, gilt ihm als höchstes Organ das Nervensystem, weil es die Individualität des Tieres sozusagen in sich konzentriert; an die zweite Stelle setzt er die Zirkulations- und Atmungsorgane, in denen das materielle Leben sich zeigt; den dritten Rang in jener Subordination nehmen die Verdauungsorgane ein, die zur Erhaltung des materiellen Lebens bestimmt sind - lauter physiologische Merkmale.

Im speziellen hat Cuvier die Säugetiere, Vögel, Reptilien und Fische LINNÉs zusammengefaßt und aus ihnen den Wirbeltiertypus gebildet, von dem er die Typen der Weichtiere, der Gliedertiere und der Strahlentiere oder Zoophyten unterscheidet. Die Typen teilt er in Klassen, diese in Ordnungen, Gattungen, Arten.

\section{b) Palaeontologie und Geologie.}

CUVIER war einer der eifrigsten und einflußreichsten Förderer der Lehre von ausgestorbenen Tieren. BUFFON hat als erster die Fossilien wissenschaftlich in ausgedehntem Maße verwertet; die Idee, daß die Versteinerungen Formen darstellen, die von den heute lebenden verschieden sind, schwebte jedoch BuFfon nur undeutlich vor Augen. PALlAS und CAMPER sprachen bestimmt die Überzeugung aus, daß einige Tierarten durch die allgemeine Katastrophe zugrunde gegangen sind. Erst Cuvier brachte auf Grund reichhaltigen Materials den Satz zur allgemeinen Geltung, daß die Versteinerungen aus Zeiten herrühren, in denen eine von der heutigen verschiedene Tierwelt unsere Erde bevölkerte, und daß die lebendige Natur auf der Erde mehrmals ihren Charakter geändert hat, eine Entdeckung, durch die eine Geschichte des Lebens auf der Erde erst möglich gemacht worden ist. CUviER wies nach, daß die 
erhaltenen Überreste des vorweltlichen Elefanten einer anderen als der bekannten Spezies angehören, und erbrachte später den gleichen Nachweis für das Rhinozeros, den Bären, den Hirsch und andere fossile Tiere. Endlich legte er in seinen "Umwälzungen " auf Grund sehr genauer geographischer und historischer Untersuchungen die allgemeinen Gründe für seine Überzeugung dar, nach der es überhaupt unwahrscheinlich ist, da $\beta$ die ausgestorbenen und versteinerten Tiere noch heute irgendwo lebend anzutreffen seien. Doch sei die Umkehrung dieser Behauptung nicht in gleicher Weise zutreffend: Cuvier läßt die Möglichkeit $\mathbf{1}$ ) offen, daß die jetzt lebenden Arten in früheren Epochen gewisse Erdstriche bevölkert haben; dort wurden sie von der Katastrophe fast total vernichtet, und die übrig gebliebenen sind in der nächsten Epoche nach anderen Wohnorten ausgewandert.

In mehreren Kapiteln der »Umwälzungen « analysiert CUVIER altertümliche Zeichnungen und Sagen, verbessert unrichtige Hypothesen durch eigenes Studium der alten handschriftlichen Denkmäler, wobei er in außergewöhnlichem Grade philologischen und historischen Scharfsinn entwickelt. Auch die Meinung Lamarcks will er nicht gelten lassen, daß die jetzt vorhandenen Rassen nur Veränderungen jener früheren seien, die man in fossilem Zustande vorfindet: Abänderungen, welche, durch örtliche Umstände und verändertes Klima veranlaßt, durch die lange Folge der Jahre bis zur äußersten Abweichung gediehen sein könnten. Er betont vielmehr dieser Auffassung gegenüber die scharfe Umgrenzung der im wilden Zustande lebenden Arten.

Cuvier hat den originellen Schritt getan, die fossilen Tiere zur Bestimmung der geologischen Epochen zu verwerten; er war davon durchdrungen,

daß man nur den Fossilien die Entstehung der Theorien von der Erde verdankt: ohne sie hätte man kaum daran gedacht, daß es während der Bildung der Erde aufeinander folgende Epochen und eine Reihe verschiedener Vorgänge gegeben hat. Nur die Fossilien geben die Gewißheit, daß die Erde nicht immer dieselbe Hülle trug, indem sie uns den Schluß nah legen, da $\beta$ sie erst auf der Oberfläche gelebt haben müssen, bevor sie in den Tiefen begraben wurden.

Über die Geschichte des organischen Lebens hat CuvIER folgende von Buffon stark beeinflußte Theorie entwickeit: Nicht immer hat Leben auf der Erde existiert. In den ersten Zeiten, die durch das

1) S. II6. 
Vorhandensein von Granit, Gneis, Marmor und der primitiven Schiefer (dieser altertümlichen Fundamente der jetzigen Erdoberfläche) charakterisiert sind, war kein lebendiges Wesen auf der Erde vorhanden. In der nachfolgenden Periode (Übergangsgebirge) haben die Zoophyten, Mollusken, Krustazeen und Fische die Meere bevölkert. Daran schloß sich eine Epoche, in der die ersten Reichtümer der Pflanzen das Antlitz der Erde schmückten. Die nächste Zeitperiode ist durch das Auftreten unzähliger Fische gekennzeichnet, unter denen zum erstenmal auch Reptilien erscheinen, die in der folgenden Zeit einen großen Reichtum von Formen entwickeln. Danach erst kamen Säugetiere zum Vorschein, die zuerst das Meer, später auch das trockene Land bewohnt haben; namentlich ist auf. der Erde zuerst eine Menge von Huftieren, aber auch Raubtiere, Nagetiere, Vögel erschienen. Diese Tierwelt ist ganz oder fast ganz vernichtet und vom Meere überflutet worden, und auf den Steppen, auf denen die ältesten Huftiere sich ihre Nahrung gesucht hatten, lebten nun Walfische, Delphine und andere Meertiere. Das Meer trat wieder zurück, und es kam die Periode der Mammuts, Nashorne, Mastodons, Nilpferde, der Huf- und Renntiere. Auch diese Tierwelt ging zugrunde, um der jetzt vorhandenen Platz zu machen.

In der Geschichte der Organismen gab es hiernach eine Reihe von Veränderungen der Tierwelt, die mit einem stetigen Fortschritt der Organisation verbunden waren.

CUVIER veröffentlichte über die von ihm gesammelten Versteinerungen zunächst kürzere Berichte, die er dann, mit einer theoretischen Einleitung versehen, unter dem Titel »Recherches sur les ossements fossiles de Quadrupèdes etc. (I8I2) herausgab. Die zahlreichen Auflagen dieses fachwissenschaftlichen Werkes geben von der ihm gezollten großen Anerkennung beredtes Zeugnis. Die Einleitung ist später auch als selbständiges Werk unter dem Titel "Discours sur les Révolutions de la surface du globe « (in sechs Auflagen) erschienen.

In diesem "Discours « versucht CuviER als erster auf Grund der vergleichend-anatomischen Untersuchung der Fossilien ${ }^{1}$ ) die Grenze der Zeit zu überschreiten, welche dem Menschengeschlecht gesetzt ist, und die Geschichte der Erde zu entschleiern. Er könne noch keine aus einem Prinzip abgeleitete Theorie der Erdgeschichte

1) Buffon hat dagegen seine Einteilung der sPerioden $<$ welche die Erdentwicklung aufweist, nur geologisch begründet. 
bieten, sagt er, doch werde das gewiß einmal möglich sein $\left.{ }^{\mathbf{1}}\right)$ : "warum sollte die Naturgeschichte nicht auch einmal ihren NEWTON erhalten? «

Die Oberfläche der Erde wurde im Laufe der Zeit durch heftige Revolutionen und Katastrophen (von denen schon Buffon zu erzählen wußte) verheert, wie man am besten an den mächtigen Gesteinsschichten marinen Ursprungs sieht, welche die ursprünglichen Ebenen und Gebirge bedeckten. Die höheren aus geneigten oder senkrechten mächtigen Gesteinslagen bestehenden Gebirge sprechen am deutlichsten von der kolossalen Macht jener Umwälzungen. Die meisten Gesteinsschichten sind mit fossilen Überresten der verschiedensten Meeresbewohner durchsetzt. Die.Kräfte, welche diese Veränderungen verursacht haben, müssen ungeheuer gewesen sein; die jetzt wahrnehmbaren Wirkungen von Eis und Schnee, von fließenden Gewässern, von der Meëresbrandung, von den Vulkanen und von astronomischen Einflüssen reichen nicht aus, um die Gestaltungen der Erdschichten, noch auch den gegenwärtigen Zustand zu erklären.

Der Mensch ist nach Cuviers Annahme erst nach der letzten Katastrophe entstanden. Nach den Anschwemmungen großer Flüsse (Nil, Rhein, Po, Arno), dem Fortschreiten der Dünen, dem Anwachsen der Torfmoore und nach den historischen Überlieferungen der Völker (die Cuvier mit philologischer Gründlichkeit erörtert), berechnet er die Zeit seit der letzten Katastrophe auf etwa 5000 bis 6000 Jahre.

Daß die Voraussetzungen, auf denen diese "Philosophie der Geschichte «konstruiert worden ist, mit der Zeit ihre Beweiskraft eingebüßt haben, ist nichts Überraschendes. Als man später CUviERs Theorie der Erde zu bekämpfen für nötig fand, hat man vergessen, daß Cuvier (nebst BuffoN) der erste Mann war, der eine solche Theorie in großem Maßstabe aufzustellen wagte, und daß die späteren Systeme nur durch seine Theorie ermöglicht wurden. CUvier hat die Geschichte der Organismenwelt entdeckt; erst durch ihn sind verschiedene Deutungen derselben ermöglicht worden.

\section{c) Cuviers Logik.}

CUVIER unterscheidet mathematische, Natur- und moralische Wissenschaften; zu den ersteren rechnet er die der exakten Messung

1) Einleitung, S. 3. (Ich zitiere nach der deutschen Übersetzung von NöGGERATH. Bonn I830. 5. Aufl.) 
und des exakten Kalkuls fähigen Wissenschaften (Mathematik und theoretische Physik), zu den Naturwissenschaften alle anderen mit Ausnahme der Geisteswissenschaften, welche die dritte Klasse bilden.

Für die mathematischen Wissenschaften genügt eine einzige exakt ermittelte Tatsache, um exakte Folgerungen aus derselben entwickeln $\mathrm{zu}$ können, und sie bleiben innerhalb dieses Kalkuls exakt. Die Gewißheit der Naturwissenschaften ist weniger exakt, gründet sich lediglich auf die Zusammenfassung von Tatsachen; darum bleibt sie immer nur approximativ, wenn sie freilich auch jede beliebige Grenze der Richtigkeit erreichen kann. Demnach sind Thesen der Naturwissenschaften nur von relativem Wert.

Nur die physikalische Analyse des Stoßes ergibt reine Beziehungen zwischen der Ursache und der Wirkung; in jedem anderen Falle bleibt nichts anderes übrig, vals einzelne Tatsachen zu sammeln und allgemeine Begriffe zu suchen, die eine möglichst große Gruppe der Tatsachen zusammenfassen $\|^{1}$ ). Z war gibt es Theorien, wie die der Gravitation, welche ein weites Tatsachengebiet beherrschen, doch kennt auch in diesem Falle die Naturwissenschaft nur angenäherte Fakta; unsere Theorien sind nur Formeln, die eine große Anzahl der Tatsachen umfassen;

und es folgt ganz notwendig, daß das kleinste gut beobachtete Faktum beachtet werden muß, wenn es neu ist, da es unsere bestakkreditierten Theorien modifizieren könnte; denn auch die einfachste Beobachtung ist geeignet, die genialsten Systeme umzustürzen und die Augen zu öffnen für eine große Reihe von Enţdeckungen, von denen uns der Schleier der überkommenen Formeln trennte 2 ).

Diese Darstellung des Verhältnisses zwischen den Tatsachen und den Theorien ist unrichtig und pflegt, in der Praxis ausgeführt, zu Tatsachenkrämerei zu führen; immerhin wurde in diesem Falle zum erstenmal die für das I9. Jahrhundert charakteristische Auffassung der wissenschaftlichen Methode formuliert.

CUVIER gehört seiner wissenschaftlichen Richtung nach der Periode der im I8. Jahrhundert herrschenden rationalistischen Auffassung der Natur an. Man vergegenwärtige sich seine Hochachtung der ver gleichendèn Methode dem Experiment gegenüber, die, ohne darauf zu achten, daß in der Natur Neues entstehe, nur das Vorhandene vergleicht, um es einheitlich mit dem Verstande begreifen zu

1) S. 2.

2) S. 3 .

Rádl, Geschichte der biol. Theorien. I. 2. Aufl. 
können. Dieser Standpunkt verhinderte ihn auch, die embryonale Entwicklung der Tiere als stufenweise Genese von neuen Organen zu würdigen; er hielt noch an der Evolutionstheorie fest.

Aus dem Unvermögen, die schaffende Kraft der Natur zu erfassen, ist CUVIERs Abneigung gegen die in seiner Zeit hervortretenden phylogenetischen Versuche zu begreifen. Die Hypothese DE. MAILIETs über die historische Entwicklung der Tierwelt erklärt er als »die vielleicht oberflächlichste und unfruchtbarste Idee von allen; die er schon abzuweisen hatte « 1 ). Er-könne sich, so behauptet er, nicht mit den Vorstellungen derer befreunden, welche den Organismus wie ein Stück Teig oder Ton ansehen, das sich in der Hand. formen läßt. Darum zeigte er auch so wenig Verständnis für die LAMARCKsche Theorie.

Der damals schon stark hervortretenden Neigung zu ursächlicher Auffassung der Natur stand Cuvier fremd gegenüber. Trotzdem lassen sich in seinen Lehren Elemente einer solchen Auffassung aufzeigen. Mit seiner Kataklysmentheorie hat er einen Schritt in der angedeuteten Richtung getan: er behandelt darin die Geschichte der Tierwelt, die Entstehung der einen und das Vergehen der anderen; und muß doch auch nach den Ursachen dieser Veränderungen fragen, obwohl er sie für unbekannt, ja für fast unerkennbar, erklärt. Auch in seiner Definition der Art macht sich: die genetische Auffassung geltend. Die Art ist nach ihm die Gesamtheit der Individuen, welche eins vom andern oder von gemeinschaftlichen Eltern abstammen, und solcher, die eine Ähnlichkeit wie jene untereinander aufweisen. Den morphologischen Vergleichungspunkt, die Ähnlichkeit, bringt er erst an zweiter Stelle und beschränkt ihn noch durch den Hinweis auf den morphologischen Unterschied der Hundevarietäten; der genetische Gesichtspunkt, die Herkunft von gemeinsamen Eltern, ist. für ihn entscheidend.

Mehrere Autoren haben CUVIER vorgeworfen, daß er die LAMARCKsche genetische Theorie in seiner. Geschichte der Fortschritte der Naturwissenschaften. nicht anführe. Man hat ihm auch ganz ungerechtfertigterweise nachgesagt, daß er die genetischen Spekulationen totgeschwiegen. habe. Aber CuviER spricht doch über die Arbeit LAMARcks: er sagt ${ }^{2}$ ) im Text ganz allgemein, daß die, welche die Theorien über die Entwicklung der Erde entworfen haben, mehr

1) Anat. comp. I. p. IOI.

2) Histoire du progrès etc. I. p. 89 . 
spekulative Geister, kühne Betrachter als philosophische Forscher waren, und führt dann in der dazugehörigen Anmerkung auch LAMARCK als einen solchen Autor an. Man darf nur nicht vergessen; daß zu Cuviers Zeit die Paläontologie mehr zur Geologie als zur Zoologie gerechnet wurde. Die anatomischen (morphologischen) Theorien sind von CUVIER eingehend berücksichtigt worden; ausführlich geht er auf die morphologischen Spekulationen der SERRES, Geoffroy, Audouin, ja sogar Okens; ferner auf die Phantasien. über die Irritabilität ein. Es trifft auch nicht $z u$, daß er die genetische Theorie GEOFFroys totgeschwiegen habe: in seinem Streite mit Geoffroy handelt sichs ja nicht um den Gegensatz zwischen genetischer und rationalistischer Auffassung der Tierwelt; beide waren Rationalisten und nur verschiedener Ansicht über die spezielle Aufgabe der Morphologie. In dieser Hinsicht sei auf das, was weiterhin über GEOFFROY gesagt wird, insbesondere auch auf dessen Schule hingewiesen, die ihre Theorien zwar im Gegensatz zu CUvier aufstellte, trotzdem aber ganz innerhalb der Morphologie und gegenüber der Phylogenie abweisend geblieben ist.

Cuvier war durch seine empiristische Denkweise gegen die Extreme gesichert, in welche die begeisterten Anhänger LEIBNIZens verfallen sind. Er faßte den Satz mnatura non facit saltus « richtiger als andere auf, indem er ihn.wohl für die Reihen der einzelnen Organe, nicht aber für den Organismus als Ganzes gelten ließ. Er folgte LEIBNIZ in der Anerkennung eines Organisationsplanes, doch beschränkte er sie durch seine Annahme von vier verschiedenen Plänen und blieb dadurch vor manchen Irrtümern bewahrt, von denen sich der weniger behutsame GEOFFROY ST.-HILAIRE nicht frei gehalten hat.

Die Geologen werfen Cuvier vor ${ }^{\mathbf{1}}$ ), dåß er bei Aufstellung seiner Theorie der Erdrevolutionen mit den Leistungen seiner Zeitgenossen auf geologischem Gebiete nicht genügend vertraut gewesen sei. Seine Anschauungen über den Bau der Gebirge erheben sich nach von ZitTels Behauptung kaum über diejenigen Buffons, Pallas' und Saussures. Neu soll nur die Annahme mehrerer Revolutionen und ihres plötzlichen Eintretens sein. Dies mag seine Richtigkeit haben; es sei jedoch nicht vergessen, daß Cuvier die Erdgeschichte als Paläontologe (als Biologe) und nicht als Geologe s. str. studiert

1) A. v. ZitTel, Geschichte der Geologie und Paläontologie. München u. Leipzig I899. S. 199. 
hat. LyELL hat später dadurch über Cuvien triumphiert, daß er Cuviers Paläontologie beiseite schob und auf die dynamische Geologie den größten Nachdruck legte.

Die vergleichende Anatomie hat Cuvier auf einen Höhepunkt gebracht, den sie weder zuvor noch nachher wieder in der Zoologie eingenommen hat; seine anerkannte Führerschaft auf diesem Gebiete ist erst durch DARWIN, der ja einer neuen Philosophie Geltung verschaffte, ganz in den Hintergrund gedrängt worden (das, was seit DARWIN "vergleichende Anatomie "genannt wird, ist keine Morphologie im Sinne Cuviers). Es sollte aber auch nicht unbeachtet bleiben, daß GEOFFroy einen ebenso großen, wenn nicht größeren Einfluß geübt hat als CUVIER. Letzterer ist zwar berühmter als GEOFFROy, sein äußerer Ruhm ist jedoch zum guten Teil von der gleichen Art wie die Anerkennung und Wertschätzung, deren sich die Gelehrten des I8. Jahrhunderts zu erfreuen hatten.

Einzelne darwinistische Enthusiasten haben CuviERs Stellung in der Geschichte der Wissenschaften und seine Bedeutung sehr ungünstig beurteilt, wesentlich darum, weil sie andere Forscher, insbesondere LAMARCK, in den Vordergrund zu rücken beabsichtigten. Cuvier Mangel an philosophischen Ideen vorzuwerfen und ihm gegenüber die philosophische Tiefe LAMARCKs zu betonen, ist unstatthaft; kein Mann von selbständigem Urteil, der die »Umwälzungen ", die einleitenden Kapitel zur »Geschichte der Fortschritte der Wissenschaften " oder die Einleitung des Werkes "Règne animal «lauter Darlegungen, aus denen sich Cuviers Auffassung von der Stellung der Biologie zu den übrigen Wissenschaften und von ihrer Methode klar ergibt - in Betracht zieht, wird wagen dürfen, diesen klassischen Ausführungen LAMARCKs Phantastereien an die Seite zu stellen, mag er sonst der genetischen Naturbetrachtung noch so freundlich gegenüberstehen $\mathbf{1}$ ).

1) Literatur. Die wichtigsten Schriften Cuviers sind: Mémoires pour servir à l'histoire et à l'anatomie des Mollusques. Paris i8r 7. - Tableau élémentaire de l'histoire naturelle des animaux. Paris 1798 . - Le Règne animal distrubué d'après son organisation. 4 Vols. Paris ISI7. - Leçons d'anatomie comparée recueillies et publiées sous les yeux de G. Cuvier par C. DumériL, chef des travaux anatomiques de l'école de médicine de Paris. 5 Vols. Paris $1800-1805$. - Recherches sur les ossements fossiles de Quadrupèdes etc. 4 Vols. Paris I8I2. - Discours sur les revolutions de la surface du globe. Paris ISI5. - Rapport historique sur les progrès des sciences physiques depuis 1789. Paris 18 ro. 


\section{Geoffroy St. Hilaire.}

Étienne Geoffroy St. Hilaire (I772-i844) entstammte einer Familie, die der Wissenschaft bereits eine Reihe von Forschern gegeben hatte. ÉtIENNE GEOfFRoY ist der berühmteste derselben. Ursprünglich Mineraloge und Schüler sowie Freund HauYs, des Schöpfers der Kristallographie (der Morphologie der Mineralien), begann Geoffroy später die Anatomie der Wirbeltiere zu studieren, nachdem er in seinem 2r. Jahre Professor der Zoologie geworden war. Obwohl ein überzeugter Demokrat und Republikaner, suchte GEOFFROY seine aristokratisch gesinnten Freunde aus den Kreisen der Naturforscher vor der Gefahr der Guillotine zu retten, was ihm in einigen Fällen auch gelang. Mit seinem Widerpart CuviER war er anfangs befreundet; später hat die Verschiedenheit ihrer theoretischen Überzeugungen die Freundschaft gelöst. Seiner biologischen Richtung nach war GEOFFroy vergleichender Anatom; die vergleichende Anatomie faßte er als selbständige Wissenschaft auf und stellte sie nicht in den Dienst der Systematik wie Cuvier. Geofrroy war ein sehr produktiver Biologe, doch wiederholt er sich in seinen Schriften oft.

Als Grundprinzip der Morphologie betrachtet Geoffroy den Gedanken des Bauplans der Tiere, d. h. er nimmt an, daß jede Tierform eine in sich geschlossene Einheit bilde, deren einzelne Teile gesetzmäßig miteinander verknüpft sind, so daß sie sich gegenseitig, wie die Kristallflächen, bestimmen. Man wird in seine Auffassung leicht eindringen, wenn man sie mit den Evolutionstheorien der vorangehenden Epoche vergleicht, mit deren Grundgedanken sie übereinstimmt. Wie BonNeT gelehrt hatte, daß alle Formen, welche das Tier während seiner embryonalen Entwicklung durchläuft, im Grunde eine und dieselbe Form sind, und daß sich die einzelnen Embryonalzustände nur durch ungleichmäßiges Wachstum der gleichen Elemente voneinander unterscheiden, so behauptet Geoffroy, daß alle entwickelten Formen, der Mensch, der Löwe, das Insekt, das Infusor, ihrem Wesen nach eine und dieselbe Form sind, die ebenfalls nur durch ungleiches Wachstum der Elemente die Mannigfaltigkeit des organischen Reiches hervorbringt.

GeOfFroy verteidigt z. B. folgende These:

[Diese Tatsachen] ... haben mich zur Überzeugung geführt, daß die Keime für alle Organe, die man z. B. bei verschiedenen Familien der Lungenatmer beobachten kann, bei allen Tierarten überhaupt exi- 
stieren, und daß die Ursache der endlosen Variabilität der Formen ... und der großen Anzahl von halb unterdrückten oder gänzlich obliterierten Organen in der verhältnismäßig stärkeren Entwickelung einzelner Organe gesucht werden muß, die sich immer nur auf Kosten der benachbarten Organe entwickeln ${ }^{1}$.

An einer anderen Stelle behauptet GEOFFroy:

Folglich resultieren alle Formen in jeder Tierklasse, mögen sie noch so sehr variieren, im Grunde a us Organen, die allen gemeinsam sind; die Natur will keine neuen erschaffen. Es rühren also alle noch so wesentlichen Unterschiede zwischen den Familien einer Klasse nur von einer anderen Anordnung, Komplikation, Modifikation ders e Ib en Org a n e ${ }^{2}$ ).

GEOFFroy hat niemals bestimmte Grenzen angegeben, innerhalb deren die Einheit des Planes gelten soll. Enthalten nur die Säugetiere oder nur die Wirbeltiere dieselben Körperbestandteile wie der Mensch? GEOFFroy will ausdrücklich auch die Weichtiere, die Insekten und die Krustazeen seiner Regel unterordnen. Es wäre dann konsequent, auch von einer Amöbe anzunehmen, daß sie Augen, Ohrmuscheln, Nägel, Haare, Muschelschalen, Insektenfühler und alle übrigen im Tierreich vorkommenden Körperteile besitzt; GEOFFROY wagt nicht diese Konsequenz zu ziehen, erstens, weil er sich nur gelegentlich mit den Wirbellosen befaßt hat, und zweitens, weil zu seiner Zeit die innere Organisation der einfachsten Tiere unbekannt war. Hat doch noch in den dreißiger Jahren des I9. Jahrhunderts EHRENBERG im Körper der Infusorien die kompliziertesten an die Wirbeltiere erinnernden Organe entdecken wollen! Um von seinem Grundsatz aus, daß es wesentlich nur ein Tier auf der Welt gibt, zur tatsächlichen Mannigfaltigkeit der Formen gelangen zu können, hat GEOFFROY eine Reihe von morphologischen Gesetzen aufgestellt, die er in folgender Weise begründet.

Die Materialien der Organisation ordnen sich untereinander, um ein Organ aufzubauen, wie die Häuser sich aneinanderreihen, um eine Stadt zu bilden. Solch eine Stadt wird, wie man es in Paris getan hat, in mehrere Munizipaldistrikte eingeteilt: so werden auch die organischen Materialien nicht willkürlich, sondern immer durch irgendeine Notwendigkeit der Lage verteilt. Diese Notwendigkeit, welche die sich berührenden Elemente zwingt, die Folgen einer reziproken Anpassung (convenance) anzunehmen, stellt

1) Exposition d'un plan d'expériences I80o. (Ich zitiere nach Isidore Geoffroy, Vie de Ét. Geoffroy. S. I37. - Geoffroy war sich nicht bewußt, daß seine Lehre nur eine Erneuerung der Einschachtelungstheorien bedeutet, und hat diese bekämpft. Isidore Geoff. Vie. S. ${ }_{3} 8$.

2) Is. Geoff. Vie. S. 135 . 
dasjenige dar, was ich unter elektiver Verwandtschaft der organischen Elemente verstehe (affinité élective des éléments organiques.) ${ }^{1}$ ).

Als einen speziellen Fall dieser Struktureinheit jedes Individuums betrachtet GEOFFROY das Gesetz, welches wir Gesetz der Erhaltung der Masse nennen könnten, und das von ihm als Gesetz des Gleichgewichts der Organe (balancement des organes) bezeichnet wird. Nach demselben

erlangt kein normaler oder pathologischer Körperteil jemals eine übermäßige Entwicklung (prospérité), ohne daß ein anderer in seinem System oder in seinen Beziehungen zu jenem in demselben Verhältnis an der Entwicklung einbüßt.

Die erwähnten Gesetze betreffen jedes Individuum für sich. Über die gegenseitigen morphologischen Beziehungen der Arten und Gattungen hat GEoffroy den Satz von analogen Teilen formuliert (théorie des analogues). Dieses, nach Geoffroys Ansicht schon von ARISTOTELES erkannte "Gesetz " nimmt GEOFFroy in seiner weitesten Fassung und behauptet nicht nur, daß sich die Form der Organe im ganzen genommen bei (allen) Tieren analog finden lasse, sondern auch, daß die konstitutiven Teile jedes Organs bei den vergleichbaren Formen identisch sind.

Die Vermutung, zu der uns diese Wahrheit führt, d.h. die Ahnung, daß wir immer in jeder Familie alle organischen Materialien finden werden, welche wir in einer anderen beobachten, ist das, was ich im Laufe meiner Arbeit mit dem Namen Theorie der Analoga bezeichnet habe-2).

GEOFFROY behauptet zwar, dieses 》Gesetz « a posteriori ermittelt zu haben, der zitierte Satz beweist jedoch zur Genüge, daß er es als a priori gültig ansieht. Er identifiziert z. B. den Bauchschild der Schildkröten mit dem Brustbein der Säuger. Nun besteht jener Bauchschild regelmäßig aus neun Knochen:

der Schluß, den man daraus ziehen kann, besagt, daß jedes Sternum, wenn seine Entwicklung kein Hindernis hemmt, aus neun elementaren Teilen zusammengesetzt ist.

In ähnlicher Weise beschreibt GeOFFRoy zuerst alle Knochen am Schädel der Knochenfische und sucht dann nachzuweisen, daß jeder derselben bei allen anderen Wirbeltieren vorhanden ist.

Das Gesetz der Analoga hat GEOFFroy durch ein anderes ebenso kühnes Gesetz vervollständigt, durch das Prinzip des Zusammen-

1) Monstros. humaines. Introduct. p. 23.

2) Phil. anat. p. XXXII. 
hangs (principe des connexions), das dem Begriffe der Analogie angeblich erst konkreten Sinn verleihen soll. Man habe - sagt GEOFFROY - bis daher über die Analogie der Formen gestritten, ohne zu bedenken, daß die Unterschiede der Form von einem Tiere zum anderen sehr schwankend, nicht greifbar sind. Er fasse also die Analogie so auf, daß bei analogen Teilen die konstitutiven Elemente die gleiche räumliche Anordnung haben. „Ein Organ wird eher verändert, atrophisch, vernichtet, als versetzt $\left.{ }^{(1} \mathbf{1}\right)$. Folglich bestehe die Ähnlichkeit zweier Formen einmal in der Identität ihrer konstitutiven Teile und dann darin, daß die letzteren in beiden dieselbe gegenseitige Lage einnehmen.

Wenn alle Tiere dieselben Bestandteile, d. h. dieselben Knochen, Muskeln, Sinnesorgane usw. und in derselben Anzahl besitzen, und wenn bei allen diese Bestandteile dieselbe relative Lage einnehmen, so folgt, daß es nur ein Tier auf der Welt gibt, und daß die Mannigfaltigkeit der Formen nur durch (quantitative) Verkümmerung einzelner Bestandteile hervorgebracht wird: es gibt dann keine qualitativen Unterschiede zwischen den Organismen. Die Mechanisten seit DESCARTES und namentlich die Evolutionisten haben diese Schlußfolgerung vertreten; GEOFFROY erklärte sich zwar für den Vitalismus und protestierte gegen die Identifizierung seiner Theorie mit dem evolutionistischen Systeme BonneTs, aber vergeblich: die dogmatische Fassung der Lehre von der Einheit des Planes stellt ihn in eine Reihe mit den Biologen des I7. und I8. Jahrhunderts.

Auf Grund der angeführten Gesetze versuchte GEOFFroy auch Analogien zwischen den Insekten und den Wirbeltieren zu entdecken. Die verschiedenen Ordnungen der Insekten meint er auf verschiedene Ordnungen der Wirbeltiere zurückführen zu können; in einer Anmerkung erklärt er, wie er sich diese Zurückführung vorstellt: wie bei der Bienenlarve die Nahrung dafür bestimmend ist, ob sich aus ihr eine Arbeiterin oder eine Königin entwickelt, so hängt es auch von unbekannten Ursachen $a b$, ob sich ein Keim zu einem Wirbeltier oder zu einer Fliege entwickelt;

und diese Idee habe ich vor Augen, sagt er, wenn ich gestehe, daß ich die fundamentale Organisation der Krustazeen beispielsweise eher in den Organen der Vögel erkennen kann als in denen der Fische, welche ihnen näher stehen. Es war mehr Identität in den bewirkenden Ursachen bei Vögeln und Krustazeen, so daß, wenn man bei letzteren das oben zitierte Beispiel der Bienen nachahmen und sie durch kräftigere (plus effective)

1) Phil. anat., p. XXX. 
Nahrung auf eine höhere Entwicklungsstufe bringen könnte, nicht Fische, sondern Vögel daraus entstehen würden. Man lasse umgekehrte Bedingungen zu und nehme an, daß das Krustentier eine Verminderung seiner ernährenden Tätigkeit erleide, so wird es auf ein niedrigeres Stadium der organischen Entwicklung herabsinken; es wird aus ihm kein durch Tracheen atmendes Insekt werden, sondern eines jener sechsfüßigen Insekten, welche sich durch die Einfachheit ihrer Atmungsorgane auszeichnen. Ich bitte übrigens, alles dies nicht buchstäblich zu nehmen, ich wollte nur meinem Gedanken durch eine Fiktion eine erklärende Form geben ${ }^{1}$ ).

Nachdem Geoffroy den Leser auf diese Art in seine Auffassungsweise eingeführt hat, behauptet er, daß die Insekten den Embryonen (foetus) der Wirbeltiere ähnlich sind. Ihre Wirbel sind bis auf die Körperoberfläche erweitert (bei der Schildkröte ist die Erweiterung bereits angebahnt); "daraus ist zu folgern, daß die Insekten Wirbeltiere sind $\left\langle^{2}\right)$, woraus wieder eine noch allgemeinere Schlußfolgerung folgt: "Jedes Tier wohnt innerhalb oder außerhalb seiner Wirbelsäule $\left.\ll^{3}\right)$ - die Insekten innerhalb, die Wirbeltiere außerhalb derselben. Geoffroy geht dann auf das Spezielle ein und sucht für jedes Körperelement der Wirbeltiere ein Analogon bei den Insekten: den Kopf der Insekten homologisiert er mit den Gesichtsknochen, die Insektenflügel haben ihr Analogon (Homologon) in der Schwimmblase der Fische; und so kommt er endlich dazu, folgende Klassifikation der Tiere zu entwerfen:

Wirbeltiere

\begin{tabular}{|c|c|c|}
\hline $\begin{array}{r}\text { Höhere } \\
\text { (hauts }\end{array}$ & $\begin{array}{l}\text { Wirbeltiere } \\
\text { vertébrés) }\end{array}$ & $\begin{array}{l}\text { Hautwirbeltiere } \\
\text { (dermovertébrés) } \\
\quad=\text { Insekten. }\end{array}$ \\
\hline
\end{tabular}

Wirbellose

Weichtiere Strahltiere.

Diese Einteilung ist nicht konsequent genug: den Prinzipien GEOFFroys zufolge sollten auch seine Wirbellosen eigentlich Wirbeltiere sein. Tatsächlich hat er später diese Korrektur vorgenommen und auch in den Zephalopoden die Wirbeltiernatur zu entdecken gesucht. Noch einmal (1822) ist er auf die Analogie der Arthropoden mit den Wirbeltieren zurückgekommen und hat im einzelnen mancherlei an seinen Ansichten geändert; in der Hauptsache ist er ihnen aber treu geblieben.

Die Auseinandersetzungen Geoffroys sind nicht nur deshalb bemerkenswert, weil sie an die Spekulationen der deutschen Natur-

1) OKens Isis 4 , I820 I. S. 456, wo die Abhandlung abgedruckt ist.

2) Ebenda, S. 457 .

3) Ebenda, S. 457 . 
philosophen erinnern - OKEN hat sie in seine Isis aufgenommen sondern auch darum, weil sie die rein morphologische Betrachtungsweise GEOFfroys deutlich wiedergeben. Seine Ansichten sind unrichtig, phantastisch, dogmatisch und haben vielleicht noch andere Fehler, aber sie sind rein morphologisch gedacht: keine Spur von einem Gedanken an die Leistungen der Körperteile, keine Spur eines genetischen (embryologischen, phylogenetischen) Gedankens ist in ihnen enthalten.

GEOFFROY schreckt nicht vor der Annahme zurück, daß die Gehörknöchelchen keine physiologische Rolle haben, und behauptet morphologisch folgerichtig, sie stellten eine rudimentäre Überflüssigkeit (une sorte de superflu resté rudimentaire) dar, die bei den Fischen vollständig entwickelt (er homologisierte den Kiemendeckel mit denselben), bei den höheren Wirbeltieren aber nur infolge der Einheit der Struktur vorhanden und rudimentär sind. CUvIER hat über diese Art der Schlußfolgerung den Kopf geschüttelt; er faßte die Morphologie nicht so konsequent auf, und deshalb mußte ihm ein funktionsloses Organ bedenklich erscheinen.

GEOFFROY verwirft die Erklärung der Körperteile aus den Funktionen derselben, denn das Organ stellt für ihn das primär Gegebene, das aus der Funktion nicht erraten werden kann:

Bleiben wir bei der Beschreibung dessen, was gegeben ist; sprechen wir über die Funktionen nicht, bevor wir sie gesehen oder bevor wir gesucht hätten, durch welche Organe sie hervorgebracht werden. Ein jedes Wesen kam aus den Händen des Schöpfers mit gegebenen materiellen Bedingungen; es leistet soviel, als ihm von Anfang an zu leisten verliehen wurde; es verwendet seine Organe ihrer Leistungsfähigkeit gemäß1).

Auch diese Idee, die organisch aus GeOffroys Naturphilosophie hervorwächst, beweist, daß dieser Morphologe mit Unrecht in eine Reihe mit LAMARCK gestellt wird, der gerade umgekehrt die Funktion als die primäre Eigenschaft der Organismen betont hat.

Morphologische Betrachtungen haben Geoffroy zum Studium der Mißbildungen der Tiere (der Teratologie) geführt. Vor der morphologischen Periode der Biologie hat man auch hie und da Monstrositäten beachtet, jedoch ohne zu einer irgendwie bestimmten Ansicht über dieselben zu gelangen. Theoretisch haben sich mit der Frage der Mißbildungen die Evolutionisten befaßt, weil das Vorkommen dieser Unregelmäßigkeit wesentliches Hemmnis für ihre

1) Is. Geoffroy a. a. O. S. 34I. - Die in diesem Satze ausgesprochenen Grundsätze stehen an einem der Lamarckschen Lehre entgegengesetzten Pole. 
Spekulationen über die Ewigkeit eines jeden Individuums bildete. Ihre teratologischen Anschauungen wurden früher erwähnt.

BUfFON war der erste, welcher die Monstrositäten klassifizierte. Er unterschied drei Klassen derselben, nämlich durch Exzeß, durch Mangel, durch Umkehrung oder fehlerhafte Stellung der Teile verursachte Mißbildungen. Eine viel gründlichere Untersuchung hat ihnen GEOFfroy gewidmet. Zwar hat er den Monstrositäten den Charakter der Abnormitäten nicht völlig abgesprochen, er betrachtete sie aber insofern als natürliche Erscheinungen, als er nachweisen konnte, daß das von der Norm abweichende an denselben nicht ganz regellos vorkommt, daß gewisse Arten derselben wiederzukehren pflegen, und daß überhaupt in allen ein gesetzmäßiger morphologischer Zusammenhang erscheint. Konsequenterweise versuchte er, die Mißbildungen ganz wie normale Formen zu klassifizieren, und teilte sie in Ordnungen, Familien, Gattungen und Arten ein. Mit seinem Versuche, durch die Teratologie (der Name stammt von $\mathrm{ihm}$ ) die vergleichende Anatomie zu erweitern und zu vertiefen, erinnert GEOFFROY an W. Roux, der durch künstliche Eingriffe in die Entwicklung die Embryologie gefördert hat. Faßt man hierbei ins Auge, wie trotz der Analogie zwischen den diesbezüglichen Bestrebungen beider Forscher die Problemstellung (Morphologie Entwicklungsgeschichte) und ihre Lösung (dort Klassifikation, hier Experiment) ausgefallen ist, so wird man den Unterschied zwischen der damaligen morphologischen und der heutigen genetischen Forschungsrichtung leicht innewerden.

GEOFFROY nimmt auch für die Mißbildungen die (normale) Grundform der tierischen Körper an, die nur durch quantitative Disproportionen einzelner Teile zur Monstrosität wird; so findet er, daß die sog. kopflosen Embryonen doch Rudimente einer knöchernen Gehirnkapsel besitzen, daß die Hasenscharte in der Auflösung der Artikulation der Intermaxillarknochen untereinander oder der Artikulation zwischen diesen und den Maxillen besteht usf., überhaupt, daß die Monstrositäten nur quantitative, nicht qualitative Abnormitäten darstellen.

Geoffroy St.-Hilaire hat sich auch über die Umwandlung der Formen konkrete Vorstellungen zu bilden gesucht. So veröffentlichte er I795 eine vergleichend-anatomische Untersuchung über die Krokodile, in der er zunächst deren systematische Beziehungen behandelt, dann aber auch fossile Formen derselben - aus diesen bildet er zwei Gattungen: Teleosaurus und Steneosaurus - in den Kreis seiner Be- 
trachtungen zieht. Daran schließt er die Theorie, daß die jetzigen Krokodile durch eine ununterbrochene Reihe von Veränderungen aus jenen vorweltlichen entstanden seien; als Ursache der Veränderungen bezeichnet er die Wirkungen der veränderten Atmosphäre, welche die Atmungsorgane und dadurch auch alle übrigen Organe beeinflußt haben ${ }^{1}$ ). In einer spätern Arbeit (I 829) über denselben Gegenstand spinnt er seine Theorie weiter. Er führt an, daß die ausgestorbenen und die jetzt vorhandenen Krokodile ohneSchwierigkeit in dasselbe System passen und nur eine spezielle Modifikation des gleichen Wirbeltiertypus darstellen. Auf Grund dieser Auffassung werde man, wie er hofft, später einmal, wenn die zoologischen und geologischen Kenntnisse hinreichend erweitert sein würden, eine Chronologie der Tiere aufstellen können. GEOffroy hat auch den Versuch gemacht (I8I9), durch künstliche Eingriffe in die Entwicklung der Vogeleier bestimmte Monstrositäten zu erzielen, was ihm bis zu gewissen Grenzen auch gelang; dieselben sollten die Art angeben, in welcher sich die Tiere auch in der Natur umwandeln können.

In einer anderen Abhandlung (I83I) beschäftigt sich GEOFFroY nochmals mit der Frage, wie die Umgebung auf die Tiere wirke:

Jedes Jahr, schreibt er²), bemerken wir die Erscheinung, daß die Organisation sich verändert, um aus den organischen Bedingungen einer Tierklasse in die einer anderen überzugehen; so die Organisation der Frösche. Ein Batrachier ist anfangs ein Fisch, der Kaulquappe heißt, dann ein Reptil, welches Frosch genannt wird ... So können wir erkennen, wie diese merkwürdige Metamorphose vor sich geht; und in dieser beachtenswerten Tatsache verwirklicht sich das, was wir oben als Hypothese aufgestellt haben: die Umänderung (transformation) aus einer organischen Stufe in eine Stufe, die unmittelbar höher steht.

Aus dieser und aus anderen Stellen in Geoffroys Schriften ergibt sich, daß er an sprungweise Veränderungen der Tiere gedacht hat; und diese Annahme stimmt auch mit seinem morphologischen Standpunkt überein. Er hat ausdrücklich den kontinuierlichen Stufen-

1) Recherches sur l'organisation de Gavials; sur leurs affinités naturelles; desquelles résulte la nécessité d'une autre distribution générique, Gavialis, Teleosaurus et Steneosaurus; et sur cette question, si les Gavials etc. \& 1825. - Cuvier begleitet sein Referat über diese Arbeit mit folgender impertinenten Bemerkung, die auch für die Jetztzeit noch aktuell sein dürfte: >Gewiß müssen die Geologen wie die Physiologen die Resultate, die er aus jenen Untersuchungen ableitet, gleich $z \mathfrak{u}$ erfahren wünschen; die embryologischen wie die geologischen Theorien haben gleiches Interesse daran: namentlich die Geologie wird in einer ihrer wichtigsten Grundlagen wesentlich alteriert werden, wenn es gelingt, auch nur eine Spezies zu verändern.

2) Mém. sur l'influence du monde ambiant pour modifier les formes animales. I831. 
gang der Wesen, der bei LAMARCK und bei den Darwinisten die wichtigste Rolle spielt, bekämpft:

Die Natur kennt keine ununterbrochenen Reihen, noch eine einzige, in einer Richtung sich entwickelnde Kette ${ }^{1}$ ).

Geoffroy ST.-HILAIRE hat durch seine Theorien namentlich in Frankreich Einfluß gewonnen. Durch seine Bemühungen ist das Studium der Monstrositäten zu einer Blüte gelangt, wie sie sich weder vor noch nach ihm gezeigt hat; man braucht nur die Berichte der Pariser Akademie aus den zwanziger und dreißiger Jahren des 19. Jahrhunderts durchzublättern, um sich von der Fülle solcher Einzelforschungen zu überzeugen.

Der Erfolg des sonst viel berühmten Empirikers Cuvier blieb in seiner Wirkung doch mehr äußerlich und fruchtete kaum etwas anderes, als daß Cuviers Spekulationen fortan nicht mehr als solche, sondern für Tatsachen ausgegeben wurden. Die besten und bekanntesten Morphologen waren Anhänger GEOFFroys, obwohl selbstverständlich nicht zu bestreiten ist, daß auch CuviER sie beeinflußt hat. Die Bestrebungen Latreilles und Audouins, die Segmentation der Insekten auf einen Grundplan zurückzuführen und diesen mit dem Grundplan der Wirbeltiere zu homologisieren, knüpfen direkt an Geoffroys Phantasien an. Auch die morphologischen Arbeiten Savignys über die Homologien der Mundteile der Insekten müssen auf die spekulativen Bestrebungen Geoffroys, der Savignys Freund war, zurückgeführt werden.

GEOFFROY ist der Repräsentant der französischen Naturphilosophie, wenn wir unter Naturphilosophie die Spekulationen über die Natur begreifen, die in Deutschland seit KANT in den Vordergrund traten. Naturphilosophisch ist an GEOFFroy die Unbestimmtheit seiner "Gesetze «, die der wissenschaftlich scharfen Fassung entbehren, und die morphologische (vergleichende) Richtung, die ja auch für die deutschen Naturphilosophen charakteristisch ist. Daß GEOFFROY den deutschen Naturphilosophen sehr nahestehe, erkannte auch CUVIER und wies - allerdings nur indirekt - in den Referaten über seine Forschungen darauf hin. GEoffroy fand gegen seine Zusammenstellung mit den Naturphilosophen nichts Wesentliches einzuwenden und wollte sich nur darin von ihnen unterscheiden, daß er seine »Gesetze « aus der Erfahrung ableite, während

1) Js. Geoffroy, S. I2I; vgl. auch S. I3I, wo sich Geoffroy direkt gegen Bonnets Stufengangtheorie wendet. 
sie die ihrigen a priori aufstellten ${ }^{1}$ ). OKen bot die wissenschaftlichen der französischen Akademie vorgelegten Arbeiten GEOFFroYs den Lesern seiner »Isis "nochmals dar und betonte ihren naturphilosophischen Geist. So bemerkt er zu der Abhandlung über die Organisation der Insekten ${ }^{2}$ ), GEOFFROY sei der erste Franzose, der in die vergleichende Anatomie die Naturphilosophie eingeführt habe, die geeignet sei, die Bedeutung der Organe durch Vergleichung mit anderen Teilen desselben oder eines anderen Organismus klarzustellen.

Von den deutschen Naturphilosophen unterscheidet sich GEOFFROY auch dadurch, daß er nicht von fachphilosophischen Gesichtspunkten ausging, daß KANT, SchELLING usw. für ihn nicht vorhanden waren, und daß er seine vergleichende Methode nur auf die Morphologie, nicht auf andere Gebiete der Biologie oder auf andere Wissenschaften angewendet hat. Der wichtigste Unterschied zwischen ihm und den deutschen Naturphilosophen ist jedoch der, daß ihm der Begriff des Strebens fehlte, der von den letzteren fortwährend betont wird. Bei den Naturphilosophen strebt die Natur, bestimmte Formen anzunehmen, sie such t von einer Form zu einer anderen überzugehen; dadurch wurde in die Morphologie ein dynamisches Element eingeführt, das anfangs lediglich mit ihr verknüpft, später aber immer schärfer hervorgehoben wurde, bis es endlich der Bedeutung der Morphologie wesentlichen Abbruch tat und zur physiologischen Auffassung der Tierwelt geführt hat. Dieser Standpunkt blieb GEOFFroy fremd: er betrachtet die organischen Formen wie geometrische Figuren.

\section{Cuvier und Geoffroy.}

Cuviers Begründung der Morphologie war weniger konsequent, im Grunde jedoch mit derjenigen Geoffroys identisch. Beide Forscher erwuchsen aus dem rationalistischen Zeitalter und konnten sich nur mit Mühe in die Tatsache hineinleben, daß die Natur in fortwährender Strömung begriffen ist, fortwährend Neues, noch nie Dagewesenes schafft und das Alte vernichtet. Beide waren im. höchsten Grade von Buffons biologischen Lehren über die Organismen als Kunstwerke der Natur abhängig. Weder dem einen noch dem anderen ist die Möglichkeit eingefallen (die uns Modernen je weiter desto klarer vor die Augen tritt), daß die organischen Bestandteile des Körpers erst durch mühsame Analyse und Vergleichung.

1) Fragments sur la nature. Courtins Encyclop. moderne I 829.

2) Isis, I820. I. S. $552 \mathrm{ff}$. 
eventuell auch durch Experimente gesucht werden müssen, sondern beide waren dem Wahne ergeben, daß als Elemente des Körpers einzelne räumlich begrenzte Materien; wie einzelne Knochen oder Muskeln oder einzelne Organe aufzufassen wären, während in der Tat z. B. die Kreuzungsversuche auf Elemente führen, als deren Beispiel das männliche Geschlecht, die rote Farbe, der Albinismus, die Scheckigkeit, Verdoppelung gewisser Teile usf. angeführt werden können. Die dogmatische Auffassung der Organisation haben GEOFEROY und CUVIER von. ihren Vorläufern übernommen; die gemeinsame Überlieferung suchte jedoch jeder in einer anderen Richtung weiterzuentwickeln. GEOFFROY zeigt wenig Verständnis für die Klassifikation, für Beschreibungen einzelner Arten und Gat.tungen; dem philosophischen Geiste Bonnets und Buffons treu, interessiert er sich vorzugsweise um Ideen; das Tierreich bietet ihm nur geeignetes Material, um sich zu allgemeinen Theoremen aufschwingen zu können. Enthusiastisch, voraussetzungslos, folgt er seinen Idealen ohne Hintergedanken, leider auch ohne genügende logische Kontrolle und ohne tiefere philosophische Vorbildung. Er verwickelt sich in Widersprüche, gelangt zu unmöglichen Schlußfolgerungen, sein wissenschaftlicher. Gesichtskreis ist nicht breit genug, er verliert Herrschaft über die Ideen, die in ihm leben; er ist jedoch $\mathrm{zu}$ aufrichtig, um die Mängel seiner Lehre verschleiern zu. können. CUVIER dagegen weiß sich und seine Wissenschaft zu beherrschen; er bleibt mit seinen Schlußfolgerungen rechtzeitig stehen, um sich vor dem Leser nicht bloßzustellen; er fürchtet sich vor den Kompromissen nicht, ist gewandt in der Polemik; weiß die Arbeit anderer zu schätzen und sich dienstbar zu machen: Als Forscher sucht CuviER, der halb Weltmann, halb Gelehrter war, Linnés "Methode " (= Klassifikation) mit Buffons Darstellungs" kunst zu. vereinigen; er begründet ein Syste m der Tiere; wie LinNé, aber ein. natürliches, um auch. BuFfon gerecht zu werden.

GeOfFroy ist mit Cuvier anfangs befreundet gewesen; später gingen sie auseinander und gerieten schließlich in eine öffentlich geführte Polemik, die mit allgemeinem Interesse verfolgt wurde. Sie stritten um die Hauptthese der morphologischen Spekulationen GEOFfroys: ob die Strukturen der Organismen nur quantitative Modifikationen einer und derselben Grundform darstellen, oder ob qualitative Unterschiede unter denselben angenommen werden müssen.

Bei der Durchblätterung der von CuvieR in der Akademie er- 
statteten Referate über die Fortschritte der Naturwissenschaft findet man, daß er gleich von Anfang an GEoffroys Spekulationen mit auffallend kalter, unaufrichtiger Objektivität behandelt, und der Gegensatz erweiterte sich je länger je mehr, bis er I830 zum offenen Bruche wurde. Es wurde der Akademie damals eine Abhandlung von MEyRauX und LAURENCET vorgelegt, in der diese jungen Schüler GEOFFroYs eine wesentliche Ähnlichkeit zwischen dem Bau der Wirbeltiere und der Zephalopoden gefunden zu haben behaupteten; danach sollten sich beide Typen aufeinander zurückführen lassen, wenn man den Zephalopodenkörper als ein in der Mitte seiner Länge nach dem Rücken zurückgebogenes Wirbeltier betrachtet, bei dem Becken und Füße an den Kopf zu liegen kämen. Die Zephalopoden würden sich nach dieser Auffassung (auf ihren Armen schreitend) ebenso bewegen wie Gaukler, welche ihre Schultern und ihren Kopf nach hinten krümmen, um gleichzeitig auf Händen und Füßen gehen zu können. Die Autoren meinten durch ihre Annahme die zwischen den Wirbeltieren und den Mollusken vorhandene Lücke ausgefüllt zu haben. GEOFFroy beurteilte diese phantastische aber im Geiste seiner Philosophie getragene Hypothese nicht ungünstig, während Cuvier an derselben Anstoß fand. Es kam zu öffentlicher Disputation um die Frage, was man unter der Ähnlichkeit des Planes und der Struktur zu verstehen habe, und ob die Analogie des Planes auch über die Grenzen einzelner Typen hinausreiche und alle Tiere umfasse, ob die Einheit des Planes als Einheit der Struktur, wie Cuvier behauptete, oder als Identität der konstitutiven Teile, wie Geoffroy lehrte, zu deuten sei.

Cuvier hatte mit der Überwindung seines Gegners leichte Arbeit; denn Geoffroys Ansicht, daß die Form aller Tiere materiell dieselbe und nur der Größe der einzelnen Elemente nach verschieden sei, war zu absurd. Wer wird denn bei den Weichtieren die fünffingerige Hand, bei einer Biene das Rückgrat, beim Regenwurm die Gehörknöchelchen suchen wollen? So mußte denn GEOFFroy im Verlaufe des Streites immer weiter von seiner Auffassung zurückweichen und konnte seinen Rückzug nur durch allgemeine Redensarten zu verschleiern suchen ${ }^{1}$ ).

1) Man verstehe folgende Bemerkung eines Geoffroy nicht ungünstigen Zeitgenossen jenes Streites: »In der Form sprach also alles gegen Geoffroy St. Hilaire, und doch hat sich die Öffentlichkeit mit ihrem bewunderungswürdigen Verständnis für die Wahrheit nicht geirrt. Vom ersten Tage der Debatte an wünschte ein jeder, daß die Anschauungen Geoffroys sich bewahrheiten; man begriff allgemein, daß der Menschengeist auf der Schwelle einer neuen Wahrheit steht. (Isid. Geoffroy, Vie, S. 379.) 
CUVIER behielt im Streite mit GEOFFROY recht; er hat nicht nur äußerlich, sondern auch tatsächlich gesiegt. Wie ihm überhaupt ein feiner Sinn für die richtige Beurteilung des Tatsächlichen eigen war, so hat er sich auch in Sachen der Morphologie nicht in Einseitigkeiten verloren wie sein Gegner. Deshalb wurde ihm leicht, auf Grund des Tatsachenmaterials $z u$ beweisen, daß es qualitative Unterschiede zwischen den einzelnen Typen gibt, und daß die Annahme bloß einer organischen Grundform zu Unmöglichkeiten führen muß.

Es ist leicht zu verstehen, daß auch GEOFFroy trotz der Unhaltbarkeit seines Standpunktes zahlreiche Anhänger fand. Denn seine Stellungnahme berührt noch heute sympathisch: er hat ja gewagt, die vergleichende Anatomie, die es mit materiellen Teilen, mit Organen als Einheiten des Körpers, zu tun hat, in ihre Konsequenzen zu verfolgen, und hat diese Konsequenzen tapfer verteidigt. CUviER und GEOFFROY gingen beide von der unrichtigen Voraussetzung aus, daß es Aufgabe der Morphologie sei, den Körper in Organe zu analysieren und diese dann miteinander zu vergleichen. Bei einer derartigen Annahme kann der Begriff der Einheit der Organisation allerdings keinen anderen Sinn haben als den der Gleichheit der Anzahl dieser Organe, der materiellen Elemente. Cuvier nahm solche Gleichheit für den Bereich der einzelnen Typen in Anspruch, und das war ebenso unzutreffend wie GEOFRroys Theorie, die allen Typen dieselben Organe zuschreibt. Ersterer hat aber seine Behauptung nicht auf die Spitze getrieben, sich vielmehr von der richtigen Erkenntnis leiten lassen, daß auch die gegenseitigen Beziehungen (die formalen Korrelationen) der Teile des Organismus beachtet werden müssen, während der letztere, mehr konsequent als praktisch, nur Massenkorrelation, keine Formkorrelation gelten lassen wollte.

An das Problem der Einheit der organischen Grundform schlossen sich während der Diskussion noch andere Fragen an; so die Frage nach dem Wert der Klassifikation, nach der Unveränderlichkeit der Arten, nach den Zweckursachen und der Aufeinanderfolge der Tierformen auf der Erde ${ }^{1}$ ). Die nachfolgenden

1) Diese Probleme zählt Js. Geoffroy auf; da später ein besonderer Nachdruck darauf gelegt wurde, daß sich der Streit um die allmähliche Entstehung der Tierwelt gedreht haben soll, so sei noch das Referat eines Zeitgenossen, von NiCARD (einem Biographen Blainvilles) angeführt: „Blainville - hat sich begnïgt, jene Probleme klar zu formulieren, die die Einheit des Planes, das Gleichgewicht der Organe, die Theorie der analogen Teile betreffen, Fragen, iiber die ehedem so heftig in der Akademie zwischen G. Cuvier und É. Geoffroy St. Hilaire diskutiert worden ist, und über die ein 
Generationen haben den Streit im darwinistischen Sinne zu deuten versucht ${ }^{1}$ ).

\section{Die Schule Cuviers.}

Cuvier, ein in seinem Vaterlande äußerst einflußreicher Mann, hat in seiner nächsten Umgebung keine besonders bedeutende Schule zu gründen vermocht; als Morphologe hat der idealreiche GEOFFroY die Jugend stärker angezogen. Als CuvieRs Anhänger hat sich der Geologe ÉLIE DE BEAUMONT, der über die Katastrophen spekulierte, hervorgetan; der experimentelle Physiologe P. Flourens, der berühmte Gegner Galls und der Begründer der physiologischen Analyse der Gehirnfunktionen, gehörte ebenfalls zum Kreise der Verehrer CUviers; die morphologischen Traditionen der Schule Cuviers hat H. D. Blainville vertreten, der jedoch noch bei Lebzeiten Cuviers mit demselben (aus persönlichen Ursachen) gebrochen hat und seinen Meister seitdem in gehässiger und sachlich wenig begründeter Weise anzugreifen für nötig fand ${ }^{2}$ ). H. MILNE EDwARDS (der ältere) suchte Cuviers Auffassung der Naturwissenschaft mit derjenigen GEOFFroys und LAMARCKs zu versöhnen. Von nicht französischen Gelehrten ließen sich die Paläontologen L. AGAssiz und C. VoGT, sowie der deutsche Morphologe J. SPIX in höherem Grade von CUviER beeinflussen. Comres positivistische Methode scheint auch zum Teil von Cuviers Methodologie abhängig zu sein.

\section{Die Schule Geoffroys.}

J. V. Audouin bemühte sich aus Geoffroys Gesetz von der Analogie der Teile allerlei Folgerungen über den Bau der Arthro-

vollständiges Schweigen nach dem Tode jener zwei Antagonisten zu herrschen scheint.< (Vie de Blainville, S. 133.) Lamarck wird an dieser Stelle gar nicht erwähnt. Schon Is. Geofrroy klagt darüber, daß die Pointe jenes Streites von seinen Zeitgenossen falsch verstanden wird (Is. Geoffroy, Vie de Ét. Geoffroy, S. 262. 1847).

1) Literatur. Geoffroy St. Hilaire, Ét., Philosophie anatomique. 2 Vols. Paris 1818. (Der zweite Band handelt ausschließlich von den menschlichen Monstrositäten.) - Des Insectes, sur leur organisation, sur un squelette chez eux. Paris 1820. - Sur une colonne vertébrale dans les Insectes. Paris 1820. - Mémoire sur la génération des animaux à bourse et le développement de leur foetus. Paris 1824. Recherches sur l'organisation des Gavials .... et sur cette question, si les gavials aujourd'hui répandus dans les parties orientales de l'Asie, descendent par la voie non interrompue de génération, des Gavials antediluviens .... Paris 1825. - Sur le principe de l'unité de composition organique. Paris 1828 . - Is. Geoffroy, Vie, travaux et doctrine scientifique d'É. Geoffroy St. Hilaire. Paris-Straßbourg 1847.

2) Blainville wirft Cuvier Atheismus, literarischen Diebstahl u. ä. vor. 
poden abzuleiten. Er glaubte nachweisen zu können, daß sich dieselben Körperteile der Lage und Anzahl nach bei allen Arthropoden wiederfinden; so erklärt er beispielsweise die Unterschiede zwischen den Insekten und den Krustazeen aus Verwachsung, Teilung und ungleichem Wachstum der gemeinsamen Elemente. Ferner versuchte er zwischen den Teilen des Insektenkörpers nach Lage, Form und Anzahl ähnliche Beziehungen aufzuzeigen, wie sie zwischen einzelnen Knochen des Wirbeltierkörpers angenommen werden. Den Kopf der Insekten hat Audouin in drei Segmente geteilt und diese dann auch bei anderen Arthropoden vermutet; von ihm stammt die Einteilung in Prothorax, Meso- und Metathorax und die dementsprechende Benennung, sowie die Bezeichnungen Sternum, Episternum, Epimerit usw. Eine ähnliche Richtung wie er verfolgte P. A. LATREILLE in seinen vergleichendanatomischen Studien. Auch LatreIlle bemühte sich, die Wirbellosen auf den Wirbeltierplan zurückzuführen, oder, in modernerer Terminologie, den Übergang zwischen den Wirbeltieren und den Wirbellosen aufzufinden; er erklärt z. B. die kurzschwänzigen Krebse für Fische, deren Kiemendeckel sich in den Thorax umgewandelt und der Hinterkörper in deutliche Segmente gegliedert hat. Auch der berühmte Physiker AMPÈRE teilte GEOfFroys Lehre von der Einheit des Organisationsplanes mit $\mathbf{1}$ ).

Einen interessanten Versuch zur Deutung der Lehre von der Einheit des Organisationsplanes hat der Physiologe und Morphologe ANT. DuGìs (I797-I838) gemacht.

Bei der Analyse der Ansichten Cuviers wurde bemerkt, daß seine Richtung sich von der Physiologie insofern nicht $\mathrm{zu}$ emanzipieren vermocht hat, als er die Morphologie auf die Kenntnis der Organe gründete, welche, wenigstens in der angenommenen Auffassung, wesentlich physiologische Einheiten darstellen, und nur nebenbei auf die richtige Grundlage der Morphologie, nämlich das Verhältnis der Teile, hinwies. Geoffroy faßte die Morphologie konsequenter auf, machte sich jedoch das Verständnis für die vergleichende Formenlehre durch die Annahme, daß bei allen Tieren materiell dieselben Teile vorhanden seien, unmöglich. DUGìs hat beide Standpunkte $z u$ einem einzigen, logisch unanfechtbaren vereinigt. Er behauptet nämlich, daß alle Tiere irgendein morphologisches Element gemeinsam haben müssen, und dieses Element sucht er nun

1) Is. Geoffroy, Vie etc. S. $25^{\circ}$. 
zutreffenderweise durch strukturelle Analyse des Tierkörpers nachzuweisen. Er ging von der morphologischen Untersuchung ALFR. MoQUiN-TANDONS (I827) aus, welcher nachgewiesen hatte, daß einzelne Segmente der Hirudineen einander strukturell ähnlich sind, und daß jedes von ihnen eine physiologische und morphologische Einheit bildet und deshalb als ein Organismus betrachtet werden kann; diesen Organismus nannte MoQUIN-TANDON "Zoonit《. Nach seiner Auffassung bildet bei den Artikulaten jedes Segment oder vielmehr jede (laterale) Hälfte eines solchen ein elementares lebendiges Wesen, ein Zoonit, d. h. eine Einheit von Organen, die ein mehr oder weniger in sich abgeschlossenes Leben zu führen imstande sind; jedes Zoonit hängt freilich organisch mit angrenzenden Elementarorganismen (Zooniten) mehr oder weniger zusammen und ist mit diesen zu einer höheren Einheit verbunden. Analog sind die Kolonien der Polypen oder die Knospen und Äste der Bäume gebaut.

Diesen Gedanken erweitert Dugìs über die Grenzen der Artikulaten und Ringelwürmer hinaus, und will ihn auf das ganze Tierreich anwenden. Der Körper der einfachsten Wesen 》Monadaires « nach DuGìs) besteht entweder nur aus einem Zoonit, oder deren mehrere vereinigen sich $z u$ einem Aggregat. Bei den Radiaten CuviERs stehen vier oder fünf Zoonite in einem Kreise; die Artikulaten weisen eine Reihe von Zooniten auf, die dann bei ihren höchsten Individuen bereits $z u$ verschmelzen anfangen, wie es der Thorax der Insekten zeigt. Die Zusammensetzung der Wirbeltiere aus Zooniten ist durch die Segmentation ihrer Wirbelsäule angedeutet.

Nach Dugìs' Meinung kann auf diese Weise der gute Kern gerettet werden, der in dem GEOFFroyschen Gesetz der Einheit des Tierplanes liegt, ohne daß man zu den Unbestimmtheiten gelangt, in die sich Geoffroy verlor. Anstatt der Einheit des Bauplanes müsse die Zusammensetzung der Organismen aus denselben Elementen, eben den Zooniten, angenommen werden. Indem diese Zoonite sich verschiedenartig gruppieren und ein harmonisches Ganze bilden, bauen sie die höheren und höchsten Typen auf. Die Form und die Leistungen jedes Elementarorganismus oder Zoonites ist bis zu gewissem Grade variabel; das Zoonit kann auch ganz unterdrückt werden. DuGìs homologisiert z. B. den Oberkiefer der Wirbeltiere mit den Mandibeln der Arthropoden, ihren Unterkiefer mit den Maxillen, die fünf Finger des Menschen mit den fünf Thorakalfüßen der Krustazeen.

Alle von DuGìs aufgestellten Homologien anzuführen, hätte 
wenig Zwveck; die erwähnten Beispiele werden genügen. Ich übergehe auch seine Klassifikation der Tiere, in der er, dem Beispiele DE Blainvilles folgend, zwischen die Typen und Klassen Cuviers noch Unterklassen als besondere Gruppen einführte, wie er denn auch sonst in der Klassifikation Neuerungen einzubürgern versuchte; sie haben aber keinen Anklang gefunden.

DUĠ̀S' morphologischer Standpunkt tritt in seiner Definition der Art zutage ${ }^{1}$ ).

Die Art ist, sagt er, nicht eine Gruppe von Individuen (wie BuffoN und Cuvier gelehrt haben), sondern eine Gruppe von bestimmten Charakteren; es ist dies ein idealer Form-, Organisations- und Lebenstypus, auf den man alle Individuen zurückführen kann, welche einander sehr ähnlich sind und sich durch dieselben Formen fortpflanzen. Auf ähnliche Weise bestimmt man »den idealen Typus «der Gattung und der Familie.

Die Unabhängigkeit der morphologischen Spekulationen DUGìs' von der Physiologie ist um so interessanter, als er zugleich Physiolog war und die erste "vergleichende Physiologie «herausgab. In dieser ist er den vitalistischen Theorien der Montpellierschen Schule gefolgt. Enthält das Buch auch nur wenig Neues, so ist es doch noch heute für die vergleichenden Physiologen lesenswert, die aus der Schrift erfahren können, daß ihre Wissenschaft nicht erst seit gestern da ist, sondern bereits am Anfang des 19. Jahrhunderts auf allgemeinen und soliden Grundlagen aufgebaut war.

An GEOfFroys morphologische Lehren knüpfte auch ÉT. RÉNAULD Aug. Serres seine embryologischen Spekulationen an. GEOffroy hat wiederholt die Idee vertreten, daß niedere Tiere ihrer Struktur nach mit den Embryonen der höheren Formen identisch sind. SERRES hat diese Lehre zu einem System entwickelt. Zu diesem Zweck verfolgte er die ersten Anfänge der Ossifikation in menschlichen und tierischen Embryonen und leitete dann allgemeine Regeln über die Ossifikation daraus ab. Es sind dies die folgenden:

I. Gesetz der Symmetrie, nach welchem die Ossifikation des Skeletts von den lateralen Teilen gegen die Symmetrieebene hin fortschreitet; so verknöchern die Rippen früher als die Wirbel, und auch die in der Symmetrieebene liegenden Teile, z. B. die Wirbel und das Sternum, werden zuerst doppelt angelegt.

2. Gesetz der Verbindung; nach diesem entstehen alle Löcher in den Knochen dadurch, daß zuerst freie Knochenanlagen

1) Physiol. comparée I. S. I 3 ff. 
um sie herum verwachsen sind; so z. B. erkannte SERRES, daß die transversalen Apophysen der Halswirbel aus Verwachsung mit den rudimentären Rippen hervorgegangen sind.

3. Gesetz der Perforation; danach bestehen auch die längeren Knochenkanäle, z. B. die halbzirkelförmigen Kanäle, ursprünglich aus mehreren selbständigen Knochenstücken.

4. und 5. Alle Gelenkhöcker sind aus selbständigen Ossifikationszentren entstanden.

Das erste Gesetz hat SERRES später auch auf andere anatomische Körperelemente angewendet und auf diesem Wege die evolutionistische Theorie in der Embryologie durch die epigenetische zu ersetzen versucht. Er bemerkt, daß die ersten Anfänge des Blutgefäßsystems sich peripherisch anlegen, daß der Darmkanal ebenfalls doppelseitig angelegt wird (er beruft sich auf C. F. WOLFF), und daß überhaupt alle Organe von der Peripherie aus gegen die Symmetrieebene hin entstehen, nicht von dieser nach der Peripherie zu, wie die Evolutionisten anzunehmen genötigt sind. Weiter behauptet er, daß jedes Organ während der embryonalen Entwicklung eine Reihe von verschiedenen Formen durchläuft, und zwar eine desto längere, je komplizierter es gebaut ist.

Die rationalistische Ansicht, daß nichts Neues entstehen könne, und der Einfluß sowohl der evolutionistischen Theorien wie der Lehre Geoffroys von der Einheit des Planes machten es SERREs unmöglich, die Epigenesis konsequent durchzuführen: so verfällt er auf den unglücklichen Ausweg, anzunehmen, daß die verschiedenen Tierformen nur verschiedene Embryonalzustände einer und derselben Form sind, welche durch irgendeine Ursache in ihrer Weiterentwicklung gehemmt worden sind. Er glaubt, daß die Weichtiere mit den ersten Entwicklungsstadien des Menschen zu vergleichen seien, daß der Regenwurm während seiner Entwicklung zuerst einen Polypen, dann einen Bandwurm darstelle. Die Organentwicklung des vollkommensten Wesens stellt also ein Bild der ganzen vergleichenden Anatomie vor; das Tierreich ist eine Kette immer vollkommener werdender Embryonen, bzw. alle Tiere sind nur ein und dasselbe Tier, lediglich verschieden entwickelt.

Wie nahe diese Ideen mit denen Geoffroys verwandt sind, ist leicht einzusehen. Später gaben sich H. Milne-Edwards und E. V. BAER viel Mühe, die Unrichtigkeit dieser Lehre nachzuweisen; von HAECKEL wurde sie wieder erneuert.

Während der ersten Hälfte des I9. Jahrhunderts schlug die ver- 
gleichende Anatomie zwei Wege ein: die eine Richtung blieb der reinen Morphologie Geoffroys und DE CANDOlles treu und fand in R. Owen, A. Braun, Schimper u. a. sehr bedeutende Vertreter; die andere Richtung wurde unter der Einwirkung des wiederaufblühenden Vitalismus und der physiologisierenden deutschen Naturphilosophie zur physiologischen Anatomie, die dann vom Darwinismus übernommen ist und bis auf den heutigen Tag unter dem Namen "vergleichende Anatomie « getrieben wird. Dies zu erörtern, wird jedoch Aufgabe der späteren Abschnitte sein ${ }^{1}$ ).

1) Literatur. Audouin, J. N., Recherches anatomiques sur le thorax des animaux articulés et celui des Insectes hexapodes en particulier. Paris I821. - LATREILle, PIERre ANDrÉ, De la formation des ailes des Insectes et de l'organisation extérieure de ces animaux, comparée, en divers points, avec celle des Arachnides et des Crustacées. Paris I820. - Dugk̀s, ANT., Mémoires sur la conformité organique dans l'échelle animale. Montpellier I832. - Ders., Traité de physiologie comparée de l'homme et des animaux. 3 Vols. Paris 1838 -39. - Serres, Ér. RÉnauld A., Recherches d'anatomie transcendante sur les lois de l'organogénésie appliquée à l'anatomie pathologique. Paris 1827 . 


\section{NAMENREGISTER.}

Acosta I. de $25 \mathrm{I}$.

Adans on M. 304 .

Agrippa C. 94 .

A Ibert d. Groß über Arist. I8; Neuerer 19; u. Augustin 20, 2I; auf d. Universit. 22 ; üb.Artproblem 264 ; üb.Erdgeschichte 287 .

Albinus 235 .

Aldrovandi u. Plinius 15 ; Entw. des Hühnchens I34; Ornithologie 145.

Alessandro 294.

Amerbach 60.

Andry N. 162; Animalkulist 180 .

Aris toteles Universalvitalist I47, $\mathrm{I}_{48}$; ïb. Muskelkraft I57; u. Redi I64; Tiersystem 3; Lehren 6-r 4; u. Scholastik 20; u. Renaissance 27-28; u. Leonardo II2; Studium des A. erneuert I2I; $u$. Caesalpin I22; u. Wotton I44; u. Leibniz 220; üb. Kreuzung 249; u. Linné 256 ; üb. Sexualität $256-257$; üb. Artproblem 263; u. Buffon 27I; u. Morphologie 303 .

Aselli G. I34.

Audo o in u. Cuvier 323; u. Geoffroy 333 ; Lehre $338-339$.

Augustin 17, r9; u. Morphologie 303. Avicenna u. Paracelsus 68; üb. Versteinerungen 287 .

B a con F. üb. Biologie I53; u. Paracelsus I84.

Baer 249, 342 .

Baglivi G. I58; Empirismus 162.

Barthez P. Vitalist 2I3-2I4.

Bartholin Th. I07, 134 .

Bartholomäus Anglicus 143 .

Bartscherer A. 92.
Batsch I. G. 310.

Bauhin C. I 45, 267.

B ea umont 338 .

Belon P. 25I; u. Morphologie 303.

Benedetto A. ro8.

Bernard de Chartes 18.

Bessarion 28.

Bichat F. 2I4-2I8.

Blainville 300 ; u. Cuvier $33^{8}, 34 \mathrm{I}$.

Böhme J. Paracelsist 184 .

Boerhaave $235,236,237,238$.

Bojanus C. 3 ro.

Bombast W. 30 .

B on net Ch. I 72, 227; Lehren 228-235;

u. Maupertuis 24I; u. Wolff 248 ; üb. Befruchtung 258; u. Condillac 273 ; u. Geoffroy 325 .

B ordeu Th. Vitalist 2 I 3 .

Borelli $157-158$.

Boruttau IIx.

Bourguet 180 .

Bourignon A. de 169.

Bournet Th. 289.

Boyle 163 .

B raun A. 343 .

Broussais 217,300 .

B rown R. 306.

Browning 187 .

Brunfels 145 .

Bruno Gi. Vitalist I49; geg. Scholastik 28, 29, I20; Mikrokosmos 8o; uib. $\mathrm{Pa}$ racelsus ${ }^{2} 8_{3}$.

$\mathrm{Buffon}$ u. Plinius $\mathrm{x} 6$; Realist 73, 235; Epigenesis 24I; Lehren 270-300; u. Morphol. 302, 307, 3I7, 323; üb. Mißbildungen $33 \mathrm{I}$.

B uffonet 298 .

Burdach 3 ro.

$\mathrm{Butler} \mathrm{Ch}$. I75. 
Cabanis 217,283 .

Caesalpin geg. Galilei $122, \mathbf{x} 26 ; u$. Linné I26; Blutkreislauf ı 28, I30; Metamorphosenlehre 248; u. Linné 255, 260; u. Morphol. 303.

Camerarius 259.

Campanella 29, I20, I49.

Camper P. 309-310, 3 I 7 .

Cardanus $149,288$.

Carus C. G. 3 Io.

Clusius Ch. 25 I.

Coiter V. 107; Embryologe 135 .

Colombo R. Io7; Blutkreislauf I30.

Comenius $186,189$.

Comte 2 I 7 .

Condillac 272-275.

Croce B. II 4 .

Cudworth 226.

Cusanus 28; Vitalist I49; u. Leonardo I08; Mikrokosmos 80.

Cuvier I8I ; Evolutionist 24I; u. Buffon 279, 290, 297; Typenlehre 293; u. Scheuchzer 295; u. Lamarck 299; Lehren 3 II-324; u. Geoffroy $334-338$.

Dalenpatius 180.

Dante 26.

Darwin Ch. 163 ; u. Cuvier 324.

Daubenton 27I; Morphol. 307.

Decandolle P. 304.

Demokrit 12.

Descartes u. Biologie $154-157$; u. Leibniz 220; u. Locke 272, 282, 284; Erdgeschichte 288, 290.

Diderot $282-283,298$.

Dodonaeus 145 .

Döllinger 3 Io.

Driesch 3 I 3 .

Dugès 339 .

Duhem P. 2I, IIO.

Duverney Georg 307.

Duverney Guich. 307 .

Er a m us v. Rotterd. u. Paracelsus 47, 48; Skeptiker 94.

Erastus u. Parac. $48-50,183$; üb. Hexen 69; Nominalist 72.

Eustachi ro7.
Fabricius ab Aquap. I07; u. Harvey 130; Embryologe 135 .

Fallopio ro7.

Ficinus M. 28, 72.

Flourens 338 .

Fludd R. I84.

Fracastoro 294 .

Frisch L. 175 .

Frobenius 39.

Fuchs L. 145 .

F üg er S. 33, 34 .

Furcroy 298.

Galen u. Hippokrates 3; u. Plato 6; Lehren I6-I7; u. Scholastik 20; u. Paracelsus 68; u. Vesal ı05; u. Leonardo I08; üb. Sexualität I4I; Universalvitalist 147 ; Körpermaschine 152.

Galenis mus I6-I7; Wesen des G. 99; während d. Renaissance I 5 I-I 52 .

Galilei I20, I2I; u. Caesalpin I26; Mechanist $152-\mathrm{I} 53$.

Gall 300.

Gautier I 8 r.

G e offroy Ét. Evolutionist 24I ; u. Buffon 293; u. Cuvier 3 I I, 323, 324, 334 bis 338 ; Lehren 325-334.

Ge sner u. Plinius I5; Lehren I44- $_{4} 45$. Gliss on F. Lehren $14 \mathrm{I}-\mathrm{I} 43,238$.

Go e the Realist 73; u. Paracelsus 92, 93, I 86; u. Wolff 248; u. Buffon 278, 298, 300 ; Morpholog 303.

Graaf R. I40, I4I, I 78, 258.

Grew N. Theologie 163; Anatomie 167 ; Sexualität 258 .

Haeckel 342 .

Hales S. 270.

Haller u. Bonnet 233; Lehren 235-240;

u. Wolff 248 ; u. Morphologie 307.

$\mathrm{H}$ arts oeker N. I80; Vitalist 213 .

Harvey W. u. Redi I63; u. Swammerdam I70; Lehre I26-I4I; üb. Sexualität 257; Morphologie 303 .

Ha uy 325 .

Helm ont F. M. I85, 202-203.

Helmont J. B. I 87-203; u. Rosenkreuzer I86; u. Stahl 2 I I. 
Herder u. Leibniz 227, 234; Stufengang d. Wesen 303.

Hip pokrates $2-4 ; 68$.

Hoffmann F. 158 .

Hooke R. Pflanzenzellen $167,235$.

Hunter J. 307.

Huser J. I83.

Jansen C. I 89 .

Jesuiten gegründet I2O; u. Helmont I89-19r; u. Buffon 28I.

Jungius J. 126, 185; u. Linné 255.

Jussieu A. L. 252 ; Morphol. 304.

Jussieu B. 236, 252; Morphol. 304 .

Kant 217; u. Leibniz 227; u. Buffon 290; über Biologie 297, 300, 334 .

Keppler J. 29, I20; Platoniker I47; kein Biologe 149.

$\mathrm{Kielmeyer}$ F. 227.

$\mathrm{Kircher}$ A. 163 .

Ko is che Schule 3 .

Kolumbus 29.

Kölreuter J. 249.

Kon rad v. Meggenberg 143 .

Kopernikus 29, 12 I.

$\mathrm{K}$ oy ter $=$ Coiter.

Lamarck 234; u. Condillac 274, 297; u. Buffon 298; u. Marat 299; u. Cuvier $318,322,324$.

Lamettrie de 217, 239; Lehre 283-284; Entstehung d. Organismen 286.

Latreille 333,339 .

Laurencet 336 .

Lavo isier u. Bichat 216 ; u. Revolution 298.

Le Clerc r79.

Le e u w en hoek Lehre 173 ; Animalkulist I80, 258.

Leibniz Mikrokosmos 80; u. Helmont 202; Rosenkreuzer 185; Lehre 220 bis 227; u. Linné 262, 289; uib. Versteinerungen 294; üb. Morphologie 303 .

Leonardo da V. 29; Lehre 107-II8, I2I; Mechanist 150-I5I; üb. Erdgeschichte 287 ; üb. Versteinerungen 294 .
Lhwy d E. 294.

Lichtenberg 17 .

Linné Stufengang 234, 237; Lehre 251 bis 269; u. Buffon 275-280; u. Morphologie 302 ; u. Cuvier 3 II, 315.

L ister M. 289; üb. Versteinerungen 294. Lobelius 145 .

Locke's Lehre 272-275; u. Buffon 278. Lu the r u. Paracelsus 48 .

Lyell u. Cuvier 324 .

Ly o net I72, 175 .

Maillet B. 295-296; u. Cuvier 322.

Malebranche üb. Tierseele 155,282 .

Malpighi M. I34; Lehre I65-I68; u.

Harvey 140; Mechanist 178, 257, 282. Marat Naturforscher 298, 299.

Marc Antonio della Torre ro8, Iro.

Martin del Rio I9I.

Mattioli P. 145.

Ma up ertuis Epigenesis 24I ; üb. Lebenskeime 282, 284, 299.

Meckel J. F. 249, 320.

Mendel u. Paracelsus 87 .

Merian $\mathbf{1 7 2 .}$

Meyraux 336 .

Michelangelo ro8.

Mill J. S. 255.

Milne Edwards u. Cuvier 338; gegen

Praeformation 342.

Monro A. 307.

Montpellier-sche Hochschule 23;

Vitalismus v. M. 213 .

Mo quin-Tand on 340 .

More 226.

Morison R. 252, 255 .

Mundinu sehre ror; u. Leonardo ro8.

Needham C. 241.

Need ham T. I77; Epigenetiker 24I, 27 I. Newton 303 .

Nietzsche 95 .

Oken 234; u. Cuvier 323; u. Geoffroy 330,334 .

Olaus M. 25 I.

Oporinus 56 . 
Oviedo $25 \mathrm{I}$.

Owen R. 343 .

Pacchioni A. $15^{8}$.

$\mathrm{Pal}$ issy B. 288, 294.

Pallas P. S. 234; u. Buffon 298, 317 , 323.

Paracelsisten $182-203$.

Paracelsus 29; Lehre 30-98, I2I, I49; u. Helmont 202, 277.

Parisanus gegen Harvey 133 .

Pascal u. Swammerdam 169, I70; Pessimist 185,278 ; üb. Entst. d. Tiere 295.

Perrault C. 307.

Petrarca u. Wisschenschaft 26.

Pico della M. 28.

Pinel Ph. 214, 2I5, 300; Stufengang 303.

Plato Lehre 4-6; u. Scholastik 20; u. Bruno 28; u. Renaissance 28; u. Parac. 68; üb. d. Sinn d. Wörter 72, So ; Universalvitalist $147, \mathrm{I}_{4} 8$; ìb. Arten 263; u. Buffon 277; u. Morphologie 303.

Plinius Lehren 14-I6; im Mittelalter 25; ïber Sexualität 257; u. Buffon 27 .

Plotin 28, 72, 80 .

Pollajuolo A. Io8.

Pomponatius 72.

Porphyrius üb. Artproblem 263.

Pythagoräer 8o.

Ray Theologie I63; u. Jungius 126; System 252, 255; Sexualität 259, 262; Artproblem 265; uiber Erdgeschichte 289, 294.

Ré a umur I72; Lehre I73-I75; Thermometer 235, 258, 299.

Redi F. Lehren I63-I64; Mechanist I78; Ursprung d. Würmer I79, 257;

u. Condillac 274; u. Darwin 294.

Rembrandt 105.

Rivinus A. Q. 252, 267.

Robinet 227; Lehre 234.

Rondellet G. Io7.

Rösel v. Rosenhof I75, $25^{8}$.
Rousseau u. Paracelsus 66, 93; u. Condillac 273; u. Buffon 279; Botaniker 299.

Roux W. 33I.

Rudolphi K. A. 310.

Sachs üb. Haller 237; üb. Decandolle 306.

Saussure u. Cuvier 323.

Savigny u. Geoffroy 333 .

Schelling Realist 72; u. Geoffroy 334. Scheuchzer J. Theologie $6_{3}$; Versteinerungen 295.

Schiller üb. Haller 236.

Schimper 343 .

Schopenhauer Realist 73, 95, 277.

Serres É. u. Cuvier 323; Lehre 34I.

Serres O. I75.

Severin P. I84.

Severino I49; Lehre II8-II9; u. Morphologie 303 .

Sokrates 4, 95.

Spallanzani 172 , I 75 ; Lehre I76-I77;

u. Bonnet 233; u. Needham 242.

Sprengel Ch. üb. Kreuzung 249 bis 250.

Stahl u. Helmont 203, 204; Lehre 204 bis 218 ; u. Leibniz 225.

Steno N. Histologie I57; u. Swammerdam I68, I69, 27 г; üb. Erdgeschichte 288.

S w a m merd a m J. Lehre I68-I 72; Mechanist I78, 258; u. Condillac 274.

Sylvius F. 204.

Sylvius J. I03.

Telesius I20, I49; auf d. Index I2I. Theophrast 30 .

Thevenot 168 .

Thomas a Kempis 188.

Thomas de Cantimpré 25, I43.

Tiedemann 3 ro.

Tintoretto 32 .

Tissot 239 .

Tournefort 252 .

Trembley I72, 175 .

Trithemius 33 .

Tyson 307. 
Unzer 213.

Valisnieri u. Redi I64; Lehre 178 bis I 79, 258,264 .

Vasari 108.

Vendelinus 39.

Verocchio 107, I09.

Vesal Körpermaschine I52; u. Plato 6, 29; Lehre I03-IO7; üb.d.Kopf IOO, I 2 I.

Vicq d'Azyr u. Buffon 297; Lehre 307 bis 309 .

Vincent de Beauvais 25.

Voltaire 274, 28I; u. Buffon 299.
Weismann 88, I75.

Whiston 27I; Erdgeschichte 289.

Whytt 2I 3 .

Will is F. Lehre I58-I6o; u. Harvey 134 Willughby 252 .

Wolff C. F. u. Leibniz 227; Lehre $24 \hat{3}$ bis 250 ; u. Serres 342 .

Wolff Chr. 243 .

Woodward 27I; Erdgeschichte 289, 294 Wotton I44.

Zalužanský 259.

Zittel 323 . 


\section{SACHREGISTER.}

Aberglaube bei Paracelsus 7I.

Analogien in d. Natur 224; n. Needham $242 ;$ n. Camper $310 ; n$. Geoffroy 327,336 .

Anatomie n. Aristoteles 9; im Mittelalter 99-I03.; währ. d. Renaissance IO2 bis I03; n. Glisson I42; n. Bacon I54; n. Willis $158-159 ; n$. Malpighi $165 ; n$. Helmont 200; n. Stahl 208; n. Leibniz 224 ; n. Wolff 246 ; n. Buffon 275 ; im I9. Jh. 343 .

Animalkulisten $177-I 8 I$.

Animismus 209.

A rch e u s n. Paracelsus $89 ;$ n. Helmont I 97. Artproblem nach Aristoteles 9; $n$. Caesalpin $125 ; n$. Linné $263-267 ; n$. Buffon 292; n. Maillet 296; n. Geoffroy $33 \mathrm{I}$ bis 332 .

Arzt Wesen des A.es 8o.

Atmung n. Galen I29.

Aura seminalis 177 .

Befruchtung n. Arist. II; n. Spallanzani 176 ; n. d. Animalkulisten I8I; n. Wolff $247,258$.

Bestiarius 25.

B ew e gung n. Aristoteles Io; n. Stahl 2 Io. Biologie n. Harvey I33; n. Stahl 206 bis 208 ; n. Buffon 297.

Blas n. Helmont 196 .

Blutkreislauf n. Aristoteles IO, I28; n. Hippokrates I28; n. Caesalpin I28; n. Galen I28-I29; n. Colombo I30; kapillarer 165 .

Chemie n. Hippokrates 3 ; n. Aristoteles 9; n. Paracelsus 84; n. Helmont 202. Chirurgie n. Paracelsus 83 .

Darwinismus u. Redi 164.
Ei Wesen des -es 137-I39.

Einheit d. Planes n. Cuvier 3I4; n. Geoffroy 326.

Einschachtelungsthe orie (= Praeformationstheorie) I 79.

Energetik b. Hippokrates 3 .

Entomologie Aufschwung der E. I68; ihr Verfall 274.

Entstehung d. Organismen n. Aristoteles I2; n. Harvey I38; n. Leibniz 222; n. Buffon 290, 292-298; n. Cuvier 318.

Entwicklung (embryonale) n. Aristoteles IO; n. Demokrit I2; n. Caesalpin I23; n. Galen I $34 ; n$. Harwey $136-137$; n. Paracelsus 88 ; n. Stahl 2I2; n. Malpighi I65; n. Leibniz 22I; n. Bonnet 229 bis 230 ; n. Haller 240; n. Needham u. Wolff 242,$244 ; n$. Serres $34 \mathrm{I}-342$.

Enzyklopaedisten I43-I46.

Epigenesis n. Malpighi r66; n. Arist. I I n. Harvey I 36; n. Helmont 20I; Wesen der 24I-250.

Erblichkeit n. Paracelsus $87,200$.

Erdgeschichte n. Leibniz 222-223; n. Buffon 286-29I.

Erfahrung n. Paracelsus $38,65-68$; n. Locke 272 .

Ernährung n. Caesalpinı25; n. Helmont I95; n. Stahl 2 II.

Evolution $=$ Präformation.

Fäulnis n. Parac. 86.

Ferment n. Helmont 196.

Fortpflanzung der Blattläuse 228.

Galenismus 99-Ioo; erneuert I62.

Gase n. Helmont 199.

Gattung vgl. Art.

Gehirn n. Aristot. Io.

Geist n. Parac. 89.

Generation spontane n. Redi $164 ; n$. Arist. I2; n. Harvey I38; n. Spallanzani 177. 
Geographische Verbr. d. Tiere 29I. Geologie n. Leibniz 222; n. Buffon 286 bis 29I; n. Cuvier $317-323$.

$\mathrm{Geschlechts} \mathrm{unterschiede} \mathrm{n.} \mathrm{Arist.} 12 ; \mathrm{n}$. Harvey I4I ; Lehre v. d. G.-U.256-26o. Gewebelehre n. Aristot. 9; n. Glisson I42; n. Bichat 216-2I7; n. Haller 240. Gott bei Paracelsus 80 ; n. Helmont I 89 ; n. Galen I6; n. Diderot 282-283; n. Buffon 283 ; n. Lamettrie 283 .

Herz n. Arist. Io; n. Harvey 126-1 32 . Hexenwahn n. Paracels. u. Erastus 69 bis 70; n. Helmont 192.

Humanismus u. Scholastik 26; Wesen des H. 27; n. Paracelsus 45 .

Humoraltheorie 3 .

Iatromechanik $157-158$.

Ic hthyotheologie 163 .

Ideen n. Helmont Ig8.

Insektotheologie 163 .

Intelligenzen in den Sternen ${ }_{4} 48$.

Intuition u. Logik n. Helmont 192, I93; n. Stahl 209, 210.

Irritabilität n. Glisson I43; n. Haller 238.

Katastrophen theorie $\mathrm{n}$. Bonnet $23 \mathrm{I} ; \mathrm{n}$. F. Helmont 203; n. Buffon 290; n. Cuvier $319-320$.

Klassifikation $=$ System.

Kontinuitätsprinzip n. Leibniz 224.

Konzeptualismus $26_{3}$.

Korrelation n. Paracelsus 75 ; n. Cuvier $303,312-314$.

Kosmos 147 .

Kraft n. Leonardo I $50 ; n$. Descartes 194 ; n. Helmont 194.

Krankheit n. Helmont I98, 200; n. Paracelsus 8I.

Kreuzung n. Bonnet 23I; Lehren v. d. K. $249-250$.

Laienwissenschaft im Mittelalter 23. Leben, Wesen des Ls. I 40; n. Helmont I95; latentes L. 200; n. Paracelsus 85 bis 87 ; n. Stahl 210,2 I .
Lebensgeister n. Leonardo I 5 I $n$. Descartes 155 ; n. Willis I 59; Wesen d. L. I 28 ; n. Helmont 199.

Lebenskräfte 215 .

Leber Bedtg. der L. I29.

Makro- u. Mikrokosmos n. Paracelsus 75 sq; n. Helmont 194; b. Leonardo I 50. Materie n. Paracels. 84.

Mechanismus u. Biol. I58, I66-I67, I 70; bei Harvey I32; -us n. Stahl 205, 206; bei Leibniz 220, 225 ; n. Wolff 246 bis 247 .

Mercurius n. Paracels. 84 .

Metamorphosenlehren. Swammerdam I 70; n. Harvey I36; n. Wolff 248.

Methode Wesen d. M. bei Linné 254; n. Buffon 275-2So; u. Cuvier 320-322. Mikroskopie n. Malpighi $165 ;$ n. Hooke I65; n. Leeuwenhoek 165.

MiBbildungen n. d. Evolutionisten I8I; n. d. Morphologen $33 \mathrm{I}$.

Mittelleben 200.

Monaden 223-224.

Morphologie n. Jungius I26; n. Leibniz 227; n. Buffon 293; Entsthg. der M. 301-313; botanische 304-307; n. Cuvier $31 \mathrm{I}-\mathrm{I} 7$; n. Geoffroy 325-334. Muskelzuckung I57.

Natur n. Aristoteles $148 ; n$. Paracelsus 83 ; u. Kultur 35 ; n. Helmont I89-I9I; n. Rousseau $279 ; \mathrm{n}$. Buffon 283 .

Naturphilosophie 300; französische 333.

Natürlichkeit n. Paracelsus $72 ; n$. Helmont 192; n. Linné 261; n. Buffon 279; n. Rousseau 279; n. Cuvier 315.

Neuplatonismus gegen die Biologie I49; b. d. Paracelsisten I 83 .

Nomenklatur binäre $267-269$; $n$. Buffon 276.

Nominalismus 263 .

Organe animale u. vegetative $2 \mathrm{I}_{4}$.

Organismen n. Stahl 205-206; Entstehung der O. $284-286$.

Ovisten $177-\mathrm{I} 8 \mathrm{I}$. 
Paläontol ogie n. Leibniz 222; n. Buffon 293 ; n. Cuvier $317-324$.

Phylogenie n. Leibniz 227; n. Bonnet 23I; n. Robinet 234.

Physiologie n. Arist. ro; Begriindung d. P. 235 ; n. Haller 238.

Physiologus 25.

Pietismus n. Helmont $187-r 89$.

Platonismus 4.

Pneuma n. Hippokr. 3 ; n. Aristot. Io.

Positivismus Entstehung des P. 217.

Praeformation $n$. Malpighi $r 66 ; n$.

Swammerdam I70-I72; n. Réaumur I 74; n. Aristot. I I ; n. Spallanzani I 76; Wesen der P. I7 8 ; n. Leibniz 22I; n. Geoffroy 325-326.

Protoplast $\mathbf{4} 4$.

Realismus b. Paracelsus 72; b. Helmont I92; in d. Scholastik 263; b. Buffon276.

Reflexe 213 .

Reformation I2r.

Regeneration n. Réaumur $\mathbf{r} 75 ; \mathrm{n}$. Bonnet 228, 23 r.

Religion u. Wissenschaft 2So; n. Swammerdam r69; n. Caesalpin $126 ; n$. d. Renaissance I 2 I.

Renaissance Wesen d. R. 162, 26 bis IIg.

Revolutionen d. Erde 231.

Rosenkreuzer $185-$ I 86 .

Sachkenntnis u. logisches Wissen 9I. Sal n. Paracels. 84 .

Salernitaner Schule 23; Anatomie der S. S. Ioo.

Same n. Caesalpin I24; Begriff des Ss. I39; n. Helmont I96; n. Paracelsus 86. Scholastik I7-22; Methode d. S. I56; n. Paracelsus 43 ; üb. Artproblem 263 . Seele n. Leonardo 150 ; $n$. Willis 159 ;

n. Descartes $155 ;$ n. Malebranche 155 ; n. Aristot. 8 ; n. Caesalpin I23; n. Stahl 208-210, 226; n. Hartsoeker 213; n. Condillac 274 .

Sensibilität 238 .

Spermatozoen n. Leeuwenhoek I73; n. d. Animalkulisten I80; n. Spallanzani I 77 ; n, Leibniz 222; n. Vallisnieri 258. Spiritus $=$ Lebensgeister.

Sprache Ursprung d. 273.

Stufengang d. Wesen n. Bonnet 228;

n. Robinet 234 .

Subordination d. Charaktere 316.

Sulphur n. Paracelsus 84.

Sympathie d. Dinge 77 .

System n. Hippokrates 3; n. Aristot. 8;

d. Pflanzen n. Caesalpin I24-125, 26r;

n. Swammerdam I72; n. Helmont 20I;

n. Paracelsus 90 ; n. Haller 237 ; n. Linné $260-262 ; \mathrm{n}$. Buffon $278-279 ; \mathrm{n}$. Cuvier 3I4-3I ; n. Geoffroy 329 .

Teratologie $330-33$ I.

Theologie u. Biologie 163 .

Tiere, Bedtg. d. niederen T. nach Redi I65; n. Swammerdam I 7o, I 7 ; n. Condillac 274.

Typenlehre 3 I $4-3$ I 7 .

Universalvitalismus 147.

Universitäten Wesen d. U. 22; n. Paracelsus $35 ; \mathrm{n}$. Helmont $189-191$.

Ursache n. Aristot. 7; n. Helmont 195; n. Paracels. 75 .

V erdauung n. Arist. 10; n. Réaumur I 74. Versteinerungen n. Leibniz 223.

Vitalismus n. Aristot. 13 ; n. Stahl 205; in Montpellier 213;n. Bichat 214-218; n. Leibniz 220, 225 .

Wahrheit n. Helmont 193; n. Parac. u. Plato I44.

Weltanschaung biologische 147 .

Welts eele I 49.

Wörter Sinn der W. 72.

Würmer parasitische W. I62, I64, I79.

Zellen n. Hooke I67; n. Wolff 247 bis 248.

Zeugung n. Aristot. Io, II; nach Stahl $212 ;$ n. Buffon 285 . 
Druck von Breitkopf \& Härtel in Leipzig. 





UNIVERSITY OF ILLINOIS-URBAaNA
||||||||||||||||||||||||||||||||||||||||||||||||||||||||||||| 